Portland State University

PDXScholar

$1-1-1975$

\title{
Charles E. Borden: his formulation and testing of archaeological hypotheses
}

Ellen Wallace Robinson

Portland State University

Follow this and additional works at: https://pdxscholar.library.pdx.edu/open_access_etds Let us know how access to this document benefits you.

\section{Recommended Citation}

Robinson, Ellen Wallace, "Charles E. Borden: his formulation and testing of archaeological hypotheses" (1975). Dissertations and Theses. Paper 856.

https://doi.org/10.15760/etd.856

This Thesis is brought to you for free and open access. It has been accepted for inclusion in Dissertations and Theses by an authorized administrator of PDXScholar. Please contact us if we can make this document more accessible: pdxscholar@pdx.edu. 
CHARLES E. BORDEN:

HIS FORMULATION AND TESTING OF ARCHAEOLOGICAL HYPOTHESES

by

ELLEN WALLACE ROBINSON

A thesis submitted in partial fulfillment of the requirements for the degree of

MASTER O' ARTS

in

ANTHROPOLOGY

Portland State University

1975 
TO THE OFFICE OF GRADUATE STUDIES AND RESEARCH:

The members of the Committee approve the thesis of

Ellen Wallace Robinson presented July 13, 1974.
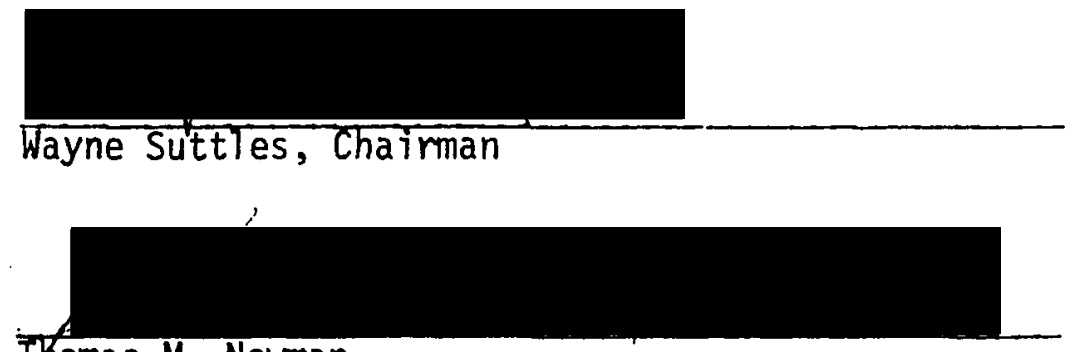

Thomas M. Newman

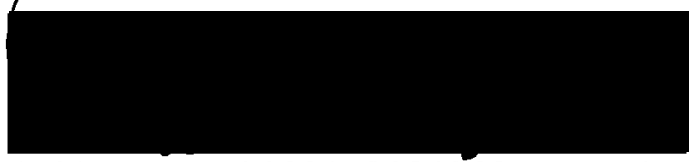

Marc R. Feldesman

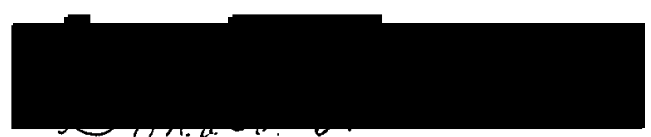

Donald Robert Moor

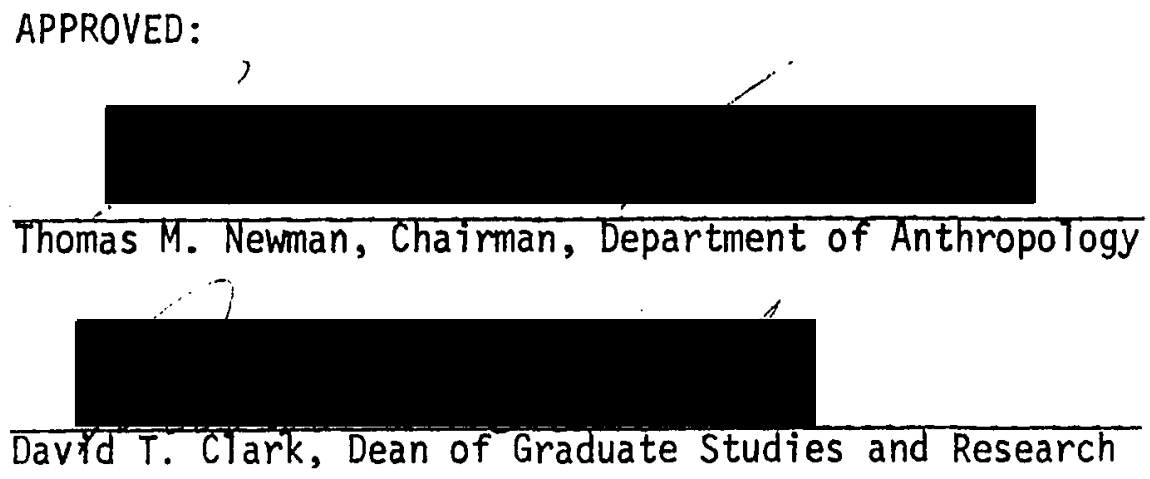


AN ABSTRACT OF THE THESIS OF EIlen Wallace Robinson for the Master of Arts in Anthropology presented July 13, 1974.

Title: Charles E. Borden: His Formulation and Testing of Archaeological Hypotheses.

Analysis of Borden's papers, including unpublished (to 1975), to discover logic used to formulate and test hypotheses. Available data and explanatory patterns shown. Work characterized as search for Northwest Coast chronology with three periods: Early. Evidence from stratigraphy, geology, historical linguistics, ethnographies, study of spatial distribution of similar artifacts. Middle. Application of C-14 dating to test and correct earlier hypotheses. Recent. Sequences of hypotheses to explain complex, puzzling phenomena involving many basic sciences. Papers shown to be series of retroductions, moving from puzzling phenomina to hypotheses from which the phenomena would follow as a matter of course. 


\section{ACKNOWLEDGEMENTS}

I wish to thank all those who helped me in writing this thesis. Each member of the Anthropology Department of Portland State University accepted me as fellow-scholar, and taught me with joy and with the discipline of high expectation.

Wayne Suttles opened the conceptual world of Anthropology for me and anchored my studies with his demands for good scholarship. Charles Borden offered any help he could give, and he has given it in full measure. He studied this thesis in outline and in the first draft. At his home and at the Archaeology Laboratory of the University of British Columbia, he has laid the evidence in my hands. I have had full access to all of his unpublished material. Borden, Suttles, and I have had extended discussions about the ideas in Borden's publications, and in works still to be published. I treasure their friendship and confidence. I thank them for their help in correcting mistakes in earlier drafts of this thesis. Those that remain will be my own.

For the opportunity, the time, and the energy to devote to these studies, I thank my family and friends. They will recognize the parts they played. At each critical moment, someone heiped: with funds to visit Dr. Borden, to enroll for another term at school, and to continue with this research; with aid in keeping my household running smoothly; with goods and services to exchange for Jo Stiles' loving typing of this document. To Victor Murdock, who has proof-read all the versions of this thesis, I owe a special debt. I am deeply grateful to all of my teachers, friends, and family. It is a goodly company. 


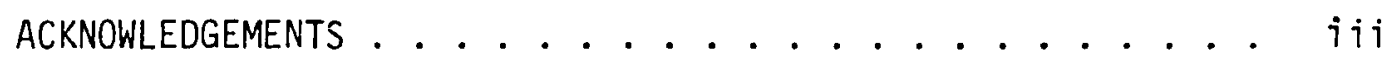

LIST OF TABLES . . . . . . . . . . . . . . . . . . $\quad x \times V$

LIST OF FIGURES . . . . . . . . . . . . . . . . . . xxvi

PART I. FORMULATING AND TESTING HYPOTHESES

CHAPTER

I INTRODUCTION . . . . . . . . . . . . . . . . . 1

I. PURPOSE ......................... 1

Retroduction

Uses of Hypotheses

Testing Hypotheses

Disconfirming Instances

II. ORDER OF ANALYSIS . . . . . . . . . . 8

Chapters Introducing Each Period

Common Themes

Supplying Implicit Premises

Levels of Abstraction

Changing Problems

II PURPOSES, PROCEDURES, AND DEFINITIONS . . . . . 12

I. PURPOSE OF ARCHAEOLOGY . . . . . . . . . 12

To Readers of an Historical Journal

To Indians of the Pacific Northwest

II. EXCAVATION PROCEDURES AND LABORATORY WORK . . 14

III. DEFINITIONS . . . . . . . . . . . . . . 15

IV. CLASSIFICATION ............ 15

V. RELATION OF DATA TO HYPOTHESES . . . . . . . 16

VI. PROBLEMS .......................... 17 
PAGE

PART II. EARLY PERIOD

CHAPTER

III THE LOGIC OF THE PERIOD . . . . . . . . . . . 19

I. CHARACTERISTICS .............. 19

Anomalies

Variety of Hypotheses

Chronology and the Age Area Hypothes is

Solutions to the Problem of Circularity

Linguistic Evidence as Basic Data

II. OUTLINES OF PAPERS . . . . . . . . . . . .

1950a Preliminary Report on Archaeological

Investigations in the Fraser Delta Region (Chapter IV)

1950b Notes on the Prehistory of the Southern North-west Coast (Chapter V)

1957 a Facts and Problems of Northwest Coast

Prehistory (Chapter VI)

1951b Fraser River Delta Archaeological

Findings (Chapter VII)

1951c Review of M. W. Smith: Archaeology of the Columbia Fraser Region (Chapter VIII)

1951d Review of A. King: Cattle Point (Chapter IX)

1952a An Archaeological Reconnaissance of Tweedsmuir Park, B.C. (Chapter X)

1952b Results of Archaeological Investigations in Central British Columbia (Chapter XI)

1954 A Scottsbluff-Eden Point from British Columbia (Chapter XII)

1954a Some Aspects of Prehistoric CoastalInterior Relations in the Pacific Northwest (Chapter XIII)

1954b Distribution, Culture, and Origin of

the Indigenous Population of British Columbia (Chapter XIV)

IV 1950a PRELIMINARY REPORT.............. . . . 33

I. SOURCES OF EVIDENCE . . . . . . . . . 33

II. HYPOTHESES . . . . . . . . . . . . . . 35

Hypotheses to Establish a Time Sequence Hypotheses Relating Sites to Each Other and to Other Areas 
PAGE

CHAPTER

V T T950b NOTES ON THE PRE-HISTORY... . . . . . . 43

I. INTRODUCTION ................. 43

II. HYPOTHESES . . . . . . . . . . . . 44

1. Evidence and Hypotheses for Two Cultures

2. Hypotheses of Coastal and Interior Orientation

3. Hypotheses Identifying Later Inhabitants

4. Hypothesis Relating to Age of Site

IIi. CONCLUSION . . . . . . . . . . . 49

VI 1951a FACTS AND PROBLEMS OF... . . . . . . . 50

I. THEORETICAL BACKGROUND .......... 50

Kroeber's Hypotheses

Drucker's Hypotheses

II. BORDEN'S HYPOTHESES . . . . . . . . . . 52

Locarno Beach/Marpole Sequence Test

Interior/Eskimoid Trait Hypotheses

General Sequence Hypotheses and Tests

III. SITE ASSEMBLAGES CORRELATED WITH GENERA!.

SEQUENCE .................

Stselax

Marpole/Point Grey/Whalen II

Whaten I

Locarno Beach I and II

Summary of Site Analyses

IV. CULTURE STAGES .............. 65

Comparison with de Laguna's Stages

Correlation with Coast Salish Presence

V. AGE OF SITES .............. 66 
CHAPTER

VI. SPREAD OF ESKIMOID TRADITION . . . . . . .

A1ternate Hypotheses

Arguments for Preferred Hypothes is

Subsequent Treatment of the Preceding Argument

VII. CATTLE POINT . . . . . . . . . .

An Instance of the Kroeber Hypotheses

An Instance of the Borden Hypotheses

VIII. CONCLUSION . . . . . . . . . . . . 71

VII 1951b FRASER RIVER ARCHAEOLOGICAL FINDINGS . . . . 73

VIII 1951C REVIEW OF M. W. SMITH... . . . . . . 75

IX 1951d REVIEW OF ARDEN KING: CÄTILE POINT... . . 76

X 1952a AN ARCHAEOLOGICAL RECONNAISSANCE... . . . 78

I. SURVEY EVIDENCE AND HYPOTHESES . . . . . . . 78

Background Information

Survey Procedure and General Results

Artifacts

II. HYPOTHESES FOR TESTING . . . . . . . . . 86

Tentative Nature of the Hypotheses

Argument for Cultural or Traditional Basis of Raw Material Preferences

Argument for Two Cultural Traditions

Argument for Relative Age of the Two Traditions

Types of Evidence Too Fragmentary to Sucygest Hypotheses

III. HYPOTHESES RELATING TO LINGUISTIC AND OTHER

DATA . . . . . . . . . . . . .

Linguistic Hypotheses

Hypotheses on Peopling of the New World

XI 1952b RESULTS OF ARCHAEOLOGICAL INVESTIGATIONS... • 
PAGE

CHAPTER

1. CHINLAC VILLAGE ............. . . 93

Ethnographic Information

Habitations

Artifacts

Presupposition of an Accurate Sample

Features Suggesting Wood Use

Food and Diet

Ornamentation and Trade

Dating

II. TWEEDSMUIR PARK, NATALKUZ LAKE . . . . . . 103

Background

Dating and Trade

Habitations

Rhyolite Tool Industry

III. SUMMARY INTERPRETATIONS . . . . . . . . 113

Chinlac/Natalkuz Distinction

Comparison of Natalkuz with Other Assem-

blages

Comparison with $H$. I. Smith Sites

Implications of Habitation Types

Possible Relationships of Carrier and

Natalkuz Lake Cultures

Alternate Hypotheses for Culture Change

in the Interior

Possible Suggestions Identifying Natalkuz

Lake Inhabitants

XII A SCOTTSBLUFF-EDEN POINT FROM BRITISH COLUMBIA . .

XIII 1954a SOME ASPECTS OF PREHISTORIC COASTAL-

INTERIOR RELATIONS... .......... . 124

I. BACKGROUND ................... 124

Age-Area Hypothes is

Recapitulation of 1957 Position

II. CALDWELL'S POSITION . . . . . . . . 130

III. BORDEN'S RESPONSE TO CALLWELL'S EVIDENCE

AND INTERPRETATIONS ............ 130 
CHAPTER

\author{
Use of Verne Ray's Evidence \\ Use of H. I. Smith's Evidence \\ Critique of Smith Controversy \\ My Alternative View of H. I. Smith \\ The Nature of Caldwell's Survey \\ Review of Borden's Response \\ IV. RE-EXAMINATION OF 1951 POSITION . . . . . \\ Stone Chipping Industry \\ Barbed Harpoons \\ Stone Sculpture \\ Woodworking Complex \\ V. CONCLUSION ....................... 149 \\ XIV 1954b DISTRIBUTION, CULTURE, AND ORIGIN... . . 151 \\ I. FORMULATING HYPOTHESES . . . . . . . . 151 \\ II. LIMITS OF SIGNIFICANCE . . . . . . . . . 153 \\ III. I.ANGUAGE DISTRIBUTION . . . . . . . . . 154 \\ Diversity \\ Location of Linguistic Stocks \\ Population Size \\ IV. CULTURES . . . . . . . . . . . . . 158 \\ Basis of Division \\ Coastal Culture \\ Interior Culture \\ Interpretation of Interior Relationships \\ with Other Areas \\ V. ORIGINS ....................... 163 \\ General Hypotheses on Peopling the New \\ World \\ Hypotheses from Physical Anthropology \\ Hypotheses from Linguistics
}

PART III. MIDDLE PERIOD

XV THE LOGIC OF THE PERIOD ............ 172 
PAGE

CHAPTER

I. CHARACTERISTICS .............

Basis in New Technology

Consequences

Chronology and Faunal Analys is

Three Papers of Interest

Anomalies

II. OUTLINES OF PAPERS . . . . . . . . . . .

1955 An Ancient Coast Village in Southern British Columbia (Chapter XVI)

1956 Results of Two Archaeological Surveys in the East Kootenay Region of British

Columbia (Chapter XVII)

1957 Notes and News (Chapter XVIII)

1959 a Notes and News (Chapter XIX)

$1959 \mathrm{~b}$ Notes and News (Chapter XX)

1960a DjRi3, An Early Site in the Fraser

Canyon, British Columbia (Chapter XXI)

1960 b Notes and News (Chapter XXII)

1960C Notes and News (Chapter XXIII)

1960d Notes and News (Chapter XXIV)

196la Notes and News (Chapter XXV)

1962 a West Coast Crossties with Alaska

(Chapter XXVI)

1961b Fraser River Archaeological Proj-

ect Progress Report (Chapter XXVII)

$1961 \mathrm{c}$ Notes and NewS (Chapter XXVIII)

$1962 b$ Review of L. S. Cressman: Cultural Se-

quence at The Dalles, Oregon (Chapter XXIX)

1962 c Notes and News (Chapter XXX)

1963 Review of Ruth Gruhn: The Archaeology

of Wilson Butte Cave... (Chapter XXXI)

XVI 1955 AN ANCIENT COAST INDIAN VILLAGE.......

I. BACKGROUND ...................... 189

Aims of the Paper

Argument by Ethnographic Analogy

II. AGE OF THE SITE . . . . . . . . . . . .

Dating the Early Occupation of this

Midden Site

Dating the Abandoning of this Midden Site 
CHAPTER

III. RECONSTRUCTION OF FOOD HABITS . . . . . . .

Efficient Exploitation of Resources

Women's Role

Fish-Based Economy

Land Mammal Hunting

Fowling

Plant Food

IV. OTHER ASPECTS OF MARPOLE CULTURE . . . . .

Tools

Quality of Workmanship

Artistic Expression

V. RELATION OF MARPOLE TO OTHER DELTA CULTURES .

XVII 1956 RESULTS OF TWO ARCHAEOLOGICAL SURVEYS

IN THE EAST KOOTENAY REGION... . . . . . . 202

I. NATURE OF PAPER . . . . . . . . . . 202

Levels of Hypotheses

Nature of Survey

Tests Proposed

Relationship to Other Borden Publications

Survey Area

Resources of Area

II. TIME LEVELS . . . . . . . . . . . . 205

Recent Arrivals

Early Man

III. THE SURVEY AREAS . . . . . . . . . . 208

Distribution of Sites

Kootenay Valley Sites

Northern Survey Area Sites

IV. ARTIFACTS . . . . . . . . . 272

Sample Size

Information Presented

Hypotheses with Some Supporting Evidence

V. CONCLUSIONS 
CHAPTER

$$
\begin{aligned}
& \text { Problem of Kutenai/Shuswap Distinction } \\
& \text { Test Sites and the Hypotheses Relating } \\
& \text { to Them } \\
& \text { Negative Evidence Prior to Kutenai/Shuswap } \\
& \text { Occupation }
\end{aligned}
$$

XVIII 1957 NOTES AND NEWS, BRITISH COLUMBIA . . . . . 228

XIX 1959a NOTES AND NEWS, NORTHWEST . . . . . . . . 229

XX 1959b NOTES AND NEWS, NORTHWEST . . . . . . . . 231

I. RADIOCARBON DATING RELIABILITY . . . . . 231

II. NEW EVIDENCE AND PROBLEMS . . . . . . . . 232

XXI 1960a DjRi 3, AN EARLY SITE IN THE FRASER

CANYON ................. 233

I. FRASER DELTA BACKGROUND . . . . . . . . 234

\begin{tabular}{l} 
II. LOCATION AND ETHNOGRAPHIC BACKGROUND OF \\
SITE DJRi $3 . .$. \\
\hline
\end{tabular}

Great Age

Location

Ethnographic Information

III. GEOLOGICAL DEPOSIT AND GEOLOGICAL ANALYSIS. . 236

Earlier Interpretation

Mathews' Analysis

IV. RADIOCARBON EVIDENCE . . . . . . . . . 240

Limiting Conditions

Dating Sample

Confirmation of Geological Hypothesis

V. ARTIFACTS ...............

Early Horizon

Later Horizon

VI. HIGHER LEVELS OF DjRi 3 AND OTHER SITES . . .

Higher Levels

Ethnographic Evidence of Pit House Sites 
CHAPTER

VII. HYPOTHESES RELATING DjRi 3 TO OTHER

SITES AND CONCERNING NORTHWEST COAST

CULTURE .................

Tentative Nature of Hypotheses

Hypotheses Relating to Big-Game Hunting

Tradition

Hypotheses of Lind Coulee/DjRi 3 Relationship

Ecological Hypotheses Leading to Lind

Coulee Test

Salmon-Base Hypotheses

Test of Five Mile Rapids/DjRi 3 Hypothesis

Salmon Area Hypothes is

Origins and Development of Northwest Coast

Culture

Relation to One Kroeber Hypothes is

Fraser Delta Local Cultural Development Hypothes is

Wider Relationships

XXII I960b NOTES AND NEWS, NORTHWEST . . . . . .

XXIII 1960C NOTES AND NEWS, NORTHWEST . . . . . . 259

XXIV 1960d NOTES AND NEWS, NORTHWEST . . . . . . 261

XXV 1961a NOTES AND NEWS, NORTHWEST . . . . . . 262

XXVI 1962a WEST COAST CROSSTIES WITH ALASKA . . . . 264

I. INTRODUCTION . . . . . . . . . . . . 264

II. EARLY DRUCKER AND BORDEN HYPOTHESES . . . . . 265

Early Evidence and Its Use

Value of Testable Hypotheses

Misuse of Evidence

III. EVIDENCE FROM COLUMBIA AND FRASER AREAS

TO SUPPORT AN ALTERNATIVE HYPOTHESIS . . . 268

Fraser Canyon

Columbia River

Hypotheses of Local Adaptation and Development

Fraser Delta Area 
IV. COMPARISON OF ESKIMO AND NORTHWEST COAST TRAITS . . . . . . . . . . . .

Borden's Hypothes is

Marpole: Earliest Known Fully Developed Northwest Coast Phase

Traits Thought to Have Been of Eskimoid Origin

Ground STate

Alternative Hypotheses for Origin of Northwest Coast Slate Industry

Preferred Hypothesis of Origin of Slate Industry

Problem of Route of Influence

Microblade Complex

Earlier Eskimo Homeland

V. SUMMARY HYPOTHESES ..............

Protracted Intercontinental Exchange

!inguistic Correlations

Archaeological Testing

Work to be Done

XXVII 1961b FRASER RIVER ARCHAEOLOGICAL PROJECT,

PROGRESS REPORT ................

XXVIII 1961C NOTES AND NEWS, NORTHWEST . . . . . . . 302

XXIX 1962b REVIEW OF L. S. CRESSMAN... : CULTURAL

SEQUENCES AT THE DALLES, OREGON . . . . . . 304

I. EVIDENCE FROM THE REPORT . . . . . . . . 304

II . IMPORTANCE TO BORDEN OF REPORT'S CLASSIFICATION SYSTEM .......... 305

XXX 1962C NOTES AND NEWS, NORTHWEST . . . . . . . 309

I. EARLY HORIZON ARTIFACTS . . . . . . . 309

II. FOSSILIZED SALMON BONES . . . . . . . 309

Evidence

Subsequent Developments

III. RECENT CULTURAL ZONE . . . . . . . . .

Evidence

Subsequent Developments 
XXXI 1963 REVIEW OF RUTH GRUHN: THE ARCHAEOLOGY

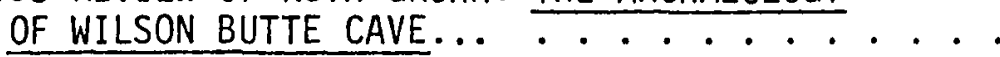

PART III. RECENT PERIOD

XXXII RECENT PERIOD PAPERS . . . . . . . . . . . 315

I. CHARACTERISTICS ........... . . 375

II. OUTLINES OF PAPERS . . . . . . . . . . . 320

1965 Radiocarbon and Geological Dating of the Lower Fraser Canyon Archaeological

Sequence (Chapter XXXIII)

1968a Prehistory of the Lower Mainland (Chapter XXXIV)

1968b A Late Pleistocene Pebble Tool

Industry... (Chapter XXXV)

1969a Excavations at 01d Musqueam 1967-

68 (Chapter XXXVI)

1969b The Skagit River Atlat1: A Reappraisal (Chapter XXXVII)

1969c Early Population Movements from Asia into Western North America (Chapn ter XXXVIII)

1969d Discussion of Papers Presented During the Symposium... (Chapter XXXIX)

1970 Culture History of the Fraser-Delta Region: An Outline (Chapter XL)

1972 New Radiocarbon Dates From the Yale Area of the Lower Fraser River Canyon, British Columbia (Chapter XLI)

1970 and 1973 Unpublished Papers (Chapter XLII)

XXXIII 1965 RADIOCARBON AND GEOLOGICAL DATING OF THE LOWER FRASER CANYON ARCHAEOLOGICAL SEQUENCE • . 333

I. BACKGROUND ............... . . 333

Illustrations

Basic Argument

Amount of Evidence

The Sites 
II. MILLIKEN AND ESILAO VILLAGE SITES . . . . .

Milliken Phase

Mazama Phase

Eayem Phase

Baldwin Phase

More Recent Phases: Skamel, Emery and Esilao

III. SOUTH YALE SITE..............

Background

Terrace Description

Artifact Distribution

Artifact Description

Cobble Tool and Pebble Tool Designation

Manufacture Technique

Contrast with Earliest, Milliken Phase, at Milliken Site

Hypotheses Determining Earliest Time the Terraces Could Be Inhabited

Glaciation Evidence and Hypotheses

Terrace Cutting Hypotheses

Correlations of Water Levels at South Yale and Milliken Sites

Rate of Terrace Cutting

Summary of Time of Terrace Cutting

Correlation of Artifact Evidence with Previous Hypotheses

Problem of Terrace I Artifacts

Hypotheses on Pasika-Milliken Relationships

XXXIV 1968a PREHISTORY OF THE LOWER MAINLAND . . . . . 362

I. BACKGROUND . . . . . . . . . . . . . 362

II. RECENT LIMITS OF PREHISTORY . . . . . . . 363

Sumas Evidence

Postglacial Period

III. GEOLOGICAL AND CLIMATIC CONDITIONS . . .

Earliest Possible Post Cordilleran Occupation

Deposition of South Yale Terraces 
PAGE

CHAPTER

IV. PASIKA PHASE ca. $10,500-9000$ B.C. . . . . . 366

Definition of "Phase"

Artifacts and their Distribution

Artifact Deposition

Types of Artifacts

Discussion

Relation to Other cultures

Eventual Fate of the Makers of Pebble Tools

V. MILLIKEN PHASE ca. 7500-6000 B.C. . . . . . 371

Possible Pasika-Milliken Relationships

Milliken Technology

Salmon-Based Economy

Climatic Correlations

VI. THE MAZAMA PHASE ca. 6000-4500 B.C. . . . . 374

VII. EAYEM PHASE ca. 3500-1500 B.C. . . . . . . 374

VIII. BALDWIN PHASE ca. 1000-350 B.C. . . . . . 376

Hypotheses on Cultural Richness

Artifacts and their Use

Discussion

Stone Abrading

Uiscussion of Woodworking Complex

Microblades

Ornaments

Sculpture

IX. SKAMEL PHASE ca. 350 B.C. -200 A.D. . . . . 383

Evidence

Discussion

X. DELTA SITES AND GEOLOGICAL CONDITIONS . . . 385

XI. LOCARNO BEACH PHASE ca. 1000-100 B.C. . . . 386

Dating

As semblage

Food Quest

Preservation of Artifacts

Woodworking

Seasonal Occupation of a More Northeriy or Is Iand Culture 
XII. MARPOLE PHASE ca. 450 B.C. -500 A.D. ..... 389

Typical Northwest Coast Culture

Salmon Base

Comparisons with Locarno Beach and Eayem Phases

Woodworking, Canoes, and Habitations

Artistic Endeavors

Comparison with Baldwin Phase

XIII. WHALEN II PHASE Ca. A.D. 350-750 . . . . . 393

Discussion

Distinctive Features

Fusion of Traits

XIV. INTERVENING PERIOD . . . . . . . . . 395

XV. STSELAX PHASE ca. A.D. 1250-1808 . . . . . . 396

Cultural Stability

Fusion of Traits

Changes in Artistic Expression and Burial

Customs

XVI. EMERY PHASE ca. A.D. 200-1200 . . . . . 398

Definition of Culture

Assemblage and Hypotheses

Discussion

XVII. ESILAO PHASE ca. A.D. 1200-1808 ....... 400

Components

Village Site and Pit House Description

Problem

Discussion

As semblage

Ground Slate and Fish Processing

Woodworking

Weaving

Smoking and Ornaments

Length of Stalo Occupation: A Problem

Ethnographic Conclusion

XXXV 1968b A LATE PLEISTOCENE PEBBLE TOOL INDUSTRY... . 408 
I. BACKGROUND MATERIAL FOR THIS PAPER ..... 408

1965 Publication

1966 Geologist's Analysis

Consequences of Mathews' Position for Borden's Analys is

Borden's Interpretation

General Chart and Illustration

II. PASIKA ASSEMBLAGE . . . . . . . . .

New Terraces

Summary Hypotheses

Slate Tools

Pebble Core Tools

Basis of Classification

Class ification of Core Tools

Flake Tools

Uses of Artifacts

Uniformity of Pasika Technology

Contrast with Milliken Technology

Examples and Problems of Other Pebble

Tool As semblages

Discussion

III. DATING THE PASIKA COMPLEX . . . . . . .

Arguments by Analogy

Argument from Milliken Correlation

Hypotheses Correlating Time of Terrace

Cutting and Age of Artifacts

other Cultural Relationships

XXXVI 1969a EXCAVATIONS AT OLD MUSQUEAM 1967-68 . . . 443

XXXVII 1969b THE SKAGIT RIVER ATLATL: A REAPPRAISAL . . . 445

I. PROBLEM . . . . . . . . . . . . . . 445

Position of Taylor and Caldwell

Borden's Position

II. DESCRIPTION OF THE ATLATL . . . . . . . . 447

Illustrations

Raw Material

Form and Function 
CHAPTER

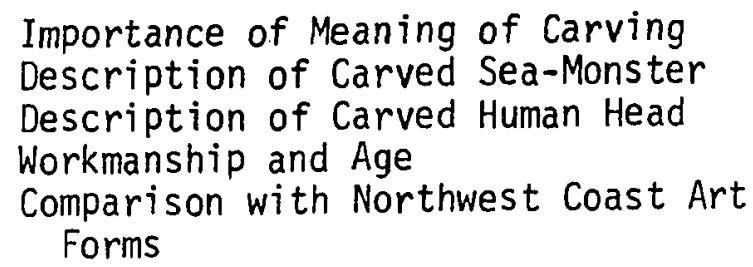

III. NORTHWEST COAST MOTIFS . . . . . . .

Whales

Serpents and Snakes

"Lightning Snakes" and the Sisiutl

Description of the Sisiut]

Significance of the Sisiutl in Mythology

IV. POSSIBLE AGE OF THE ATLATL . . . . . . .

Evidence That It Is Not Recent

Other Northwest Coast Atlatis

Comparison of Skagit River and Locarno Beach Atlatls

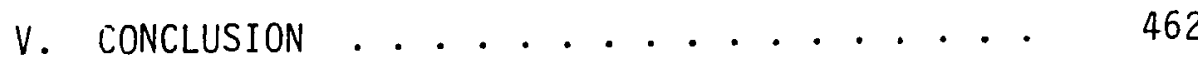

XXXVIII 1969C EARLY POPULATION MOVEMENTS FROM ASIA INTO WESTERN NORTH AMERICA............ 463

I. GEOLOGICAL AND CLIMATIC BACKGROUND . . . . 465

Bering Landbridge and Southern Dispersion Routes

Description of the Intermontane Corridor

Glaciation

II. EARLY BOREAL CULTURAL TRADITION . . . . . .

Review of Earlier Writings

Presently Known and Dated Microblade

Sites, 1969

Hypotheses for Time and Route of New World

Microblade Introduction

Correlation with Deglaciation

Intermontane Route

Early Boreal Cultural Tradition

Summary Hypotheses

Discussion 
III. HYPOTHESES CONCERNING PROTO-ATHAPASCANS ...

Discussion

General hypotheses

Relationships with Early New World

Populations

Discussion of Milliken Site

Diffusion of Early Boreal Tradition

Summary Hypotheses

IV. PROTOWESTERN CULTURAL TRADITION . . . . . . 480

Early Remains west of the Rockies

Western Assemblage

Milliken Prase Assemblage

Other Protowestern Sites

San Dieguito Test Hypotheses

Muller-Beck Migration Route Hypotheses

Borden Migration Route Hypotheses

V. PEBBLE TOOL TRADITION ........... 486

Widespread Occurrences

Pasika Complex

Hypotheses of Early Connections

VI. CONCLUSIONS ........................ 489

Early Boreal/Proto-Athapascan Summary

Summary of Migration Route Hypotheses

Protowestern Summary

Problem of Archaeological Testing

XXXIX 1969d A DISCUSSION OF PAPERS... . . . . . . . 494

I. BACKGROUND . . . . . . . . . . . . 494

II. PORTIONS OF MITCHELL'S PAPER . . . . . . 496

Two Models

Instances of Dislocation Model

Instances of Continuity Mode 1

Rules of the Models

Questions Asked by Each Model

Statement of Intent

Acceptable Evidence 
III. BORDEN'S DISCUSSION OF MITCHELL'S PAPER . . . 501

Survey Results

Defense of Dislocation Illustration

Evidence for Continuity and Dislocation

Danger of Choosing a Model

IV. PORTIONS OF MACDONALD'S PAPER . . . . . . 504

Previous Evidence and Theories on Coast

Tsimshian Prehistory

MacDonald's Evidence to the Contrary

Co-Tradition Model

V. BORDEN'S DISCUSSION OF MACDONALD'S PAPER . . 508

Co-Tradition Model

Comparison of Tsimshian/Marpole Assemblages

Relationship with Fraser Delta Discontinuity

Hypotheses Relating to Ethnographic Linguistic Distribution

Hypotheses on Coast Tsimshian Homeland

Locarno Beach Relationships

VI. RESPONSE OF MITCHELL AND MACDONALD . . . . . 515

Nitchell's Response

MacDonald's Response

VII. RESPONSE TO QUESTIONS ........... 519

MacDonald on Changes in Rate of Population Growth

Borden on Evidence of Early Limits of Population and on Adaptation Rate

Concluding Questions

Discussion

XL 1970 CULTURE HISTORY OF THE FRASER-DELTA REGION:

AN OUTLINE . . . . . . . . . . . . . 524

I. INTRODUCTION AND BACKGROUND MATERIAL . . . . 524

IJ. LOCARNO BEACH PHASE ca. 800-200 B.C. . . . . 528 
III. MARPOLE PHASE ca. 400 B.C. - A.D. 450 . . . . 534

Marpole Assemblage Description

Comparison of This Hypothesis With Sim-

ilar Hypotheses in Borden's Writings

Marpole Assemblage Description, Continued

Interrelationships of Marpole and Other Areas and Phases

IV. WHALEN II PHASE ca. A.D. 350-800 . . . . . . 544

V. PRE-STSELAX PHASE ............. . 548

VI. STSELAX PHASE ca. A.D. 1250-1808 . . . . . . . 548

XLI 1972 NEW RADIOCARBON DATES FROM THE SOUTH YALE

AREA... ................ . 556

I. INTRODUCTION AND BACKGROUND ......... . 556

II. BORDEN'S CANYON SEQUENCE . . . . . . . . 558

III. EVIDENCE FROM PINECREST AND SQUEAH LAKES . . • 558

IV. INTERPRETATIONS . . . . . . . . . 560

XLII RECENT UNPUBLISHED PAPERS . . . . . . . . . . 563

I. INTRODUCTION . . . . . . . . . . 563

II. 1970 PAPER . . . . . . . . . . . . . 564

Mosan Linguistic Argument

Microblade Evidence and Glaciological

Evidence

Recent Research on Dated Components

Interpretation and Discussion

The Penutian Question

The Athapascans

III. 1973 PAPER . . . . . . . . . . . 571

PART IV. CONCLUSION

XLIII SUMMARY ............... 574 
CHAPTER

I. EVIDENCE .............. 575

Ancillary Sciences

Physical Anthropology

Ethnographic Evidence

Historical Linguistics

Questions

II. MODELS . . . . . . . . . . . 578

Meaning and Use of Models

Mitche11's Criteria for the Discontinuity Model

Data and Hypotheses

III. PRESUPPOSITIONS . . . . . . . . . 583

Early Period

Middle Period

Recent Period

Presuppositions Common to A11 Periods

Problems in Identifying Presuppositions

IV. RETRODUCTION . . . . . . . . . . . 589

BIBLIOGRAPHY . . . . . . . . . . . . . . 593 


\section{LIST OF TABLES}

TABLE

PAGE

I Estimates of the Indigenous Population of

British Columbia (Borden 1954b:189) .... 189

II Classification of Core Tools (Borden 1968b:58

Table I) ............... 420

II Classification of Flake Tools (Borden 1968b:59

Table II) ............... 421 


\section{LIST OF FIGURES}

FIGURE

1. Main sites investigated by Borden [Map] . . . . 3

2. Artifacts typical of Whalen II (Borden 1970:

106 Figure 32) . . . . . . . . . . . 34

3. Artifacts typical of Locarno Beach (1970:100

Figure 30) . . . . . . . . . . 54

4. Artifacts typical of Marpole (1970:102 Figure 31). 55

5. Location of Natalkuz Lake and Chinlac Village

Sites [Map] . . . . . . . . . . . . 79

6. Lower Fraser Canyon region (1968b:56 Figure 1) . 412

7. Geoarchaeological chronology of the lower Fraser

Canyon region (1968b:57 Figure 2) ..... 413

8. Classification of core tools (1968b:60 Figure 3) . 419

9. River terraces at South Yale, B.C. profile on

left bank of Fraser River (1968b:65 Figure 6) . 434

10. Skagit River atlat1, 1eft and right views (1969b:

14 ff Figures 1 and 2) .......... 448

11. Totem figure, atlatl hook, and bone knives (1969b:

$14 \mathrm{ff}$ Figures 7,8,9, and 10) ...... 449

12. Fraser Delta sequence (1970:96 Figure 29) . . . 527

13. Artifacts typical of Stselax phase (1970:108

Figure 33) ........... . . 550

14. Major archaeological traditions in western North

America (Borden $1973 \mathrm{~ms}$. ) . . . . . . . 565

15. Borden's primary theoretical concerns: relative

emphases of main papers [chart]... . . . Back

Pocket 
CHAPTER I

INTRODUCTION

The published works of Charles E. Borden from 1950 to 1973 represent one of the longest sequences of archaeological work in British Columbia. Publications of his former students, and their students, comprise the bulk of the remaining work in the Province. Archaeological evidence and theory in this part of the Northwest Coast culture area come to the student under the dominant influence of this one scholar and teacher (Fig. 1).

\section{PURPOSE}

My purpose in this thes is is to explore the problems facing Borden, the evidence as he saw it, and the hypotheses by which he attempted to explain their significance and connection. By identifying some of the anomalies, ambiguities, or problems, we can identify Borden's reasoning that is used in formulating his hypotheses. By examining his hypotheses and the tests he proposes for them, we can see by what patterns he organizes his evidence. In colloquial terms, we can see how his arguments "hang together". More than that, however, we can see the general pattern by which Borden makes all of the data meaningful.

Retroduction

The formulation and testing of hypotheses may be viewed as one extended process suggesting explanations from which surprising or puzzling observations wouid foillow as a matter of course (Hanson 1958). Such an 


\section{PART I}

\section{FORMULATING AND TESTING HYPOTHESES}




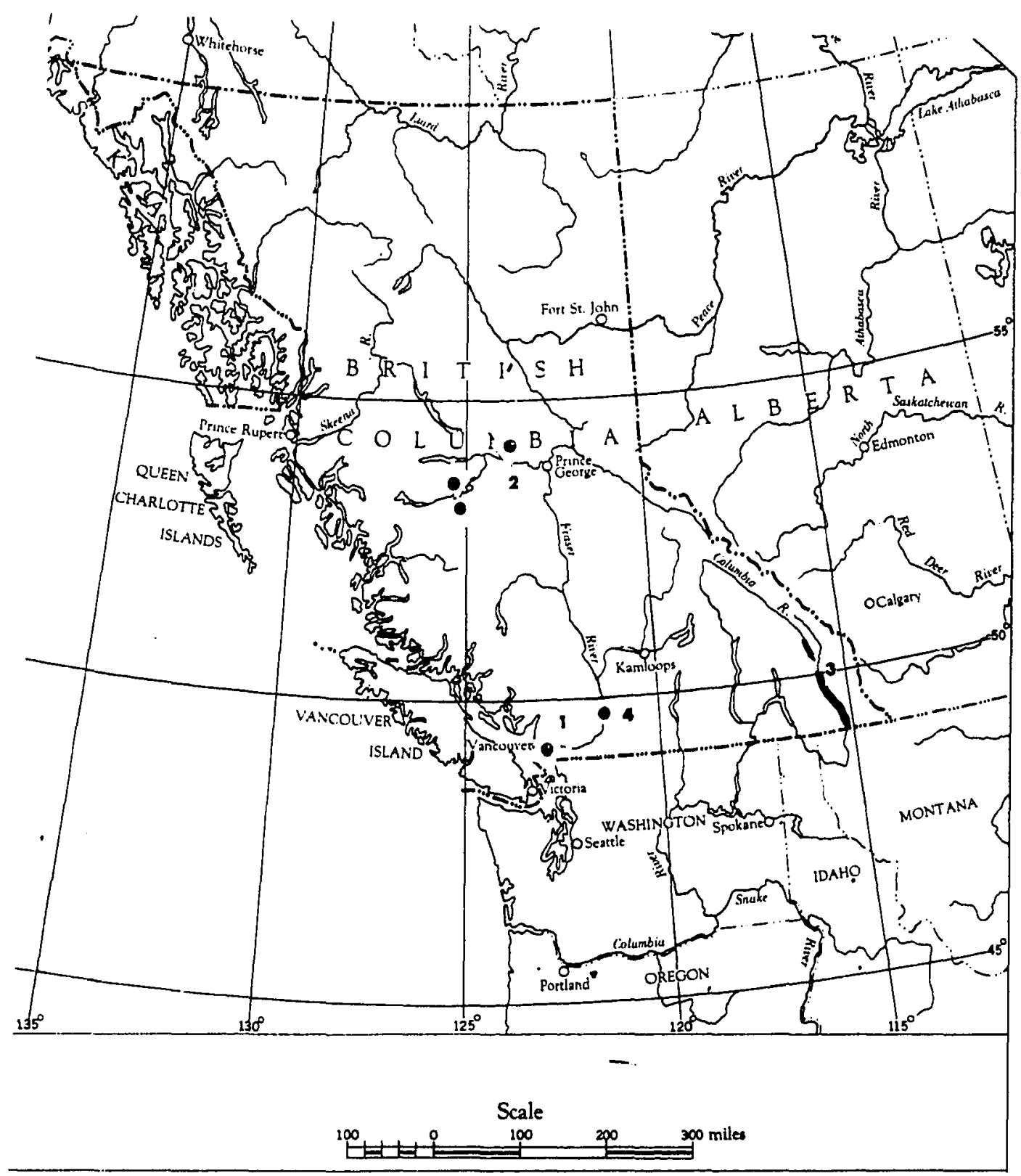

$\div \cdot$

1 Fraser Delta Sites

2 Natalkuz Lake, Chinlac Village Sites

3 Kootenay Survey Sites

4 Fraser Canyon Sites

Figure 1. Main sites investigated by Borden 
explanation is not a summary of statistical regularities.

A hypothesis to be regarded as a natural law must be a general proposition which can be thought to explain its instances; if the reason for believing the general proposition is solely direct knowledge of the truth of its instances, it will be felt to be a poor sort of explanation of these instances [Braithwaite 1953:302].

We may distinguish the logic of discovery (retroduction), from the logic of testing (hypothetico deduction and induction). Retroduction (or abduction) was distinguished from deduction and induction by Aristotle, but was not iritensively investigated until the 1930's by Charles Senders Peirce. In Patterns of Discovery, Norwood Russell Hanson uses the history of physics as the lens through which to study retroduction as a form of inference:

The form of the inference is this:

1. Some surprising phenomenon $P$ is observed.

2. P would be explicable as a matter of course if $\mathrm{H}[\mathrm{Hy}$ pothesis] were true.

3. Hence there is reason to think that $H$ is true....

The $H^{\prime} s$ here did not result from any actuarial or statistical processing of increasingly large numbers of the P's. Nor were they just 'thought of', the $P^{\prime}$ 's being deducible from them.

Perceiving the pattern in phenomena is central to their being 'explicable as a matter of course' [Hanson 86, 87, my emphasis].

Hypotheses are pattern statements to explain detail statements.

To correct an observation is to question a detail statement; to correct an hypothesis is to pull away the pattern.

Hanson describes the moment and direction of discovery.

The critical moment comes when the physicist perceives that one might reason about the data in such and such a way. One might explain this welter of phenomena $P$, throw it all into an intelligible pattern, by supposing $H$ to obtain. But $P$ controls $H$, not vice versa. The reasoning is from data to hypotheses and theories, not the reverse....

[Writing of Galileo as an example of this:] Suffice it to say 
that he always tries to exp?ain his original data by fashioning general hypotheses and theories 'in their image'. His hypotheses are never inductive summaries of his data; nor does he actively doubt them until he can deduce new observation statements which experiments confirm [1958: 88, 89 my emphasis].

This movement from data to theory is emphasized in all of Borden's work. Borden speaks repeatedly of the theory based on "known evidence", of the importance of preserving archaeological sites so that the evidence will not be lost forever. He writes of the facts "speaking for themselves", which they do not do, since they are perceived as facts only within some theoretical framework. Borden's emphasis is correct however. The hypothesis must be formulated from the phenomena, or as Hanson says, "in their image".

Uses of Hypotheses

Hanson suggests (pp. 99-100), that any one hypothesis is actual1y used in a number of ways. Some of Borden's hypotheses are used in each of these ways; some predominantly in one or another of them. (Glottochronology, a linguistic hypothesis of which Borden makes use, has been used in each of these five ways.) Ways hypotheses can be used are:

1. As a definition. When Borden assigns a certain collection of artifacts to a particular phase, he is stating an hypothes is with this emphasis.

2. As so sure that the opposite is psychologically inconceivable. When Borden is sure that inhabitants of the South Yale terraces would surely have borrowed the more complex technology of the nearby Milliken site if they had lived at the same time, he is formulating an hypothesis of this second sort.

3. As in \#2, yet only one of alternative hypotheses. A7though it 
may be impossible to imagine an hypothes is to be false, a different concept may be substituted, yet the earlier hypothes is may still organize the complex evidence in a logical and consistent manner. Borden's hypotheses relating the languages spoken by early people with the remains of their material culture are possibly of this third type.

4. As a simple summary of phenomena such that other phenomena can readily disprove it. Most of Borden's hypotheses about the direction of influence and traditions are of the fourth type. Radiocarbon dating evidence readily reversed the hypotheses developed before the sites were dated.

5. As not true or false statements at all, but as rules, techniques, conventions, or systems of notation. Classification of artifacts, the techniques of dating and of excavation are usually seen in this way. Most of the illustrations of one use of an hypothesis could be re-stated to illustrate other uses, however.

Testing Hypotheses

If hypotheses can be seen in so many ways, how can they be conformed or disconfirmed? Salmon, using "hypothesis" in the sense of the third, fourth and fifth usages, says this about testing hypotheses: ...a statement is functioning as a hypothesis if it is taken as a premise, in order that its logical consequences can be examined and comp red with facts that can be ascertained by observation. When the comparison is favorable, that is, when a consequence of the hypothes is turns out to be true, it is a confirmatory instance of the hypothesis. When a consequence turns out to be false, it is a disconfirmatory instance of the hypothesis. A hypothesis is confirmed if it is adequately supported by inductive evidence. There are degrees of confirmation; a hypothesis may be highly confirmed, moderately confirmed, or 
slightly confirmed by a confirmatory instance. A given confirmatory instance may add considerable support or only slight support to a hypothesis.... [Salmon 1963:77].

In developing a correct form by which an hypothes is is tested, Salmon makes use of a concept that is the subject of keen debate among logicians. It is the concept of prior probability. Although the status of this concept is in question, it refers to a familiar idea. Some hypotheses seem more credible than others quite aside from the argument at hand. Three examples may illustrate this:

1. A statistical summary may approximate a regular sequence, line, or curve. An hypothesis that expresses that regularity seems more credible, or has a higher prior probability, than an hypothesis that exactly describes the statistical summary.

2. The hypothes is that warts disappear when rubbed with an onion has negligible prior probability, even if we were to observe a confirmatory instance, because we see this hypothesis along with a body of knowledge about the nature of onions and of warts.

3. Hypotheses, particularly in the social sciences, which oversimplify a complex situation have negligible prior probability. For instance, research to find a cause or an effect presume a world of chain-link simplicity in which there are no "bachelor events", only an endless line of father-and-son sequences.

Utilizing this concept of prior probability, Salmon develops a schema, or form, which is inductively correct for the confirmation of hypotheses.

[Premises ]

[1] The hypothesis has a nonnegligible prior probability. 
[2] If the hypothesis is true, then the observational prediction is true.

[3] The observational prediction is true.

[4] No other hypothesis is strongly confirmed by the truth of this observational prediction; that is, other hypotheses for which the same observational prediction is a confirming instance have lower prior probabilities.

[Conclusion]

[5] The hypothesis is true [SaImon 1963:85-86].

\section{Disconfirming Instances}

As Hanson noted in discussing Galileo, disconfirming instances do not lead directly to changing the hypothesis unless it is the crucial instance. In most cases, crucial instances are very difficult to find, and are very late in being discovered or isolated by a scientist. Usually, evidence can support more than one hypothesis, can be seen as part of more than one conceptual pattern. Disconfirming instances may be the result of technological error, mistakes in computation, mistaken presuppositions that are not recognized, or other methodological problems. There are so many places to check when a disconfirming instance is found, that the pattern itself is often the last thing doubted, especially if it has proved to be useful in organizing a vast array of different phenomena. Hanson's account of Kepler's retroduction leading to the hypothesis of the elliptical orbit of Mars shows this process repeatedly (pp. 72-85). Borden's reasoning about the South Yale terraces shows it also. (See Chapter XXXII for the outline of these papers).

\section{ORDER OF ANALYSIS}

My function is to analyze Borden's work in order to show its logical structure. His papers divide quite nicely into three time periods. The early works before radiocarbon dates were available share certain 
characteristics. The middle period papers contain a few landmark radiocarbon dates, and supply answers to early questions. In the recent years, the problem is too much evidence, with a great complexity where things had seemed quite simple.

Chapters Introducing Each Period

In the chapters that introduce these periods, I have listed the anomalies, the surprising phenomena that Borden observes and attempts to explain. For each period, I have discussed the different range of evidence, the different problems which characterize it, and Borden's instruments and methods of research or discovery. I have also outlined the evidence, problems, and methods of each of the papers in that section. The chart inside the back cover is a further guide to some of the interlocking hypotheses and evidence as they appear through all of the papers.

Common Themes

Common themes run through all of the periods. Borden's first and consistent question is about chronology. When was the evidence deposited? Everything else is dependent upon that. Another common thread is the search for the identity of the people who left the archaeological evidence; not only does he ask where they came from, but who they were in their language affiliation.

Given the complex culture of the Northwest loast of North America, with its salmon-based economy, dense population, complex social structure, and its patch-work of language affiliations, Borden seeks to trace back to the earliest times the paths by which they came, and the "cultural baggage" they brought with them. He has always been confident 
that the prehistory would be as complex as the ethnographic present. Supplying Implicit Premises

Within the analysis of each paper, I have attempted to stand in Borden's place, to supply implicit premises or missing steps so as to complete a valid argument. By this procedure, it is possible to clarify which strands of evidence and hypotheses are validly linked, so that as disconfirming instances are found, the logically related hypotheses may be identified. Salmon states the consequence of retaining invalid arguments within the analysis:

If we reconstruct the argument so that it becomes fallacious, then the argument is indefensible. If we make it valid by introducing a less plausible premise, then we can go on to investigate more fully the truth or falsity of the premise. A fallacious argument cannot turn out to be valid, but an implausible premise may actually be true. In adopting this procedure, we give the argument all possible benefit of the doubt $[1963: 29-30]$.

For examples of arguments in which I have supplied implicit premises, see 1951a (Chapter VI) for Borden's hypotheses on tools and too1 use in the Whaten I assemblage, and 1954a (Chapter XII) for the extended argument on the age of the woodworking industry. Arguments from the middle period include, from 1955 (Chapter XVI), the basic ethnographic analogy argument, and from 1960a (Chapter XXI), the argument in which Borden concludes that DjRi3 is a salmon fishing site, on the basis of the presence of cherry pits. Probably the most complex argument in these papers concerns the South Yale terraces. My expansion of Borden's argument on the deposition of artifacts in the terraces is in the 1968b paper (Chapter XXXV). Levels of Abstraction

In each of these time periods, Borden's hypotheses vary widely 
in levels of abstraction. Some are closely empirical and descriptive. Among these are hypotheses on probable use of artifacts as evidenced by wear patterns, and hypotheses on stratification and classification of sites. More abstract hypotheses inciude theories of methodology, as in classifying artifacts. Among the most abstract hypotheses are theories on the use of models and hypotheses, and on the nature of culture change.

In identifying these as different levels, the problem of moving significantly between these levels is illustrated. For instance, before radiocarbon dating, if assemblages were sorted by harpoon type, the Locarno Beach assemblage appeared more recent than the Marpole assemblage. If they were grouped by interior or northern traits, Locarno Beach appeared to pre-date Marpole. Determining the basis of classification or grouping made the difference in interpretation, and became the basis of other hypotheses on culture influence and change. After radiocarbon dating, the phases were sorted within a probable time range or chronology.

\section{Changing Problems}

The problems of interpreting culture change from preserved remains of material culture still persist. Even the reasonable limits of meaning that can be attached to the evidence changes. As the amount and type of evidence changes and as technology changes, new questions can be asked with hope of significant answers. New anomalies call for new hypotheses in the science of archaeology: "...the science of predicting man's prehistoric past" (Carlson 1970:7). 


\section{CHAPTER II}

PURPOSES, PROCEDURES, AND DEFINITIONS

Borden's statements of archaeological purpose, method, definitions, classification, and evaluations of hypotheses and models are scattered within his published papers. These are expressed over the whole span of his first twenty-three years of publication. I have chosen a few quotations which seem to be appropriate as a basis for my analysis.

\section{PURPOSE OF ARCHAEOLOGY}

\section{To Readers of an Historical Journal}

The objectives of archaeology have changed greatly since the early part of the century. To-day they are no longer confined to the mere recovery of skeletal remains and artifacts. The modern archaeologist digs in order to recover as complete a picture as possible of the life and culture of ancient peoples at the various periods of their history. He tries to follow their migrations and attempts to determine the nature of their relationships with other groups. In order to realize these objectives, he employs, both in the field and in the laboratory, techniques which are as precise as those of other exact sciences $[1950 \mathrm{~b}: 241]$.

\section{To Indians of the Pacific Northwest}

...I would like to comment briefly on the nature of archaeological remains, the aims of modern prehistoric research and the state of such research in British Columbia.

The collecting and scientific disposal of refuse is a comparatively new practice and indeed one which as yet has not been introduced everywhere. In many places all over the world, garbage and all sorts of domestic and other refuse are still dumped and allowed to accumulate in the immediate vicinity of human homes and settlements. In some localities this has been going on for a long time.

If future archaeologists were to investigate such dumps they could by careful examination of the food remains, implements, and other articles that were dug up, learn a great deal about 
the food habits, manufactures, art, trade and many other activIties of the people who had discarded these items. Moreover, if the excavations were made systematically so that the finds could be arranged in chronological order and in their proper association, the scientists would be able to trace at least some of the changes in fashion, practices, and customs that had taken place in the varlous periods during which the deposit was laid down. If the settlement is no longer inhabited and it is possible to dig into the remains of former dwellings, then one may also learn much about house construction and the interior arrangement and furnishings of these habitations.

Middens too are essentially heaps of refuse and other occupational debris that have accumulated at village and camp sites. Such heaps, some of them very ancient, are found in many parts of the world, especially along the seashore. The Northwest Coast is no exception. The coastal waters, which teem with a great variety of food animals, supported in former times a large Indian population. The estuaries of rivers, the shores of many bays and sounds are dotted with the remains of Indian camp and village sites, and middens are invariably found at such places. Some are small, others are of great extent, depending on the number of people who lived there and on the length of time the site was occupied. In certain areas they extend literally for miles along the shore, some of them attaining a depth of fifteen feet and more. A number have been occupied in historic times, and still others must have been abandoned centuries ago, for enormous cedars, Douglas firs, and other coniferous trees grow directly on the midden deposits.

Compared to investigators in many other areas, the archaeologist working on the Northwest Coast is at a disadvantage. In some arctic regions, for instance, objects as delicate as feathers are preserved for many centuries in deposits that are frozen for the greater part of the year. Again, in the Southwest of this continent the arid climate preserves wood, textiles, and similar perishable matter almost indefinitely. By contrast, the warm, moist climate of the Pacific Coast promotes rapid decay of perishable matter, including, of course, wood, cedar bark, plant and animal fiber. Anyone who knows how important wood and cedar bark were in the life of all Northwest Coast Indians must realize that the greater part of Indian manufactures are not preserved in the middens of this region. What we do find are those artifacts which are made of decayresisting materials, such as stone, bone, antler, and shell. It is chiefly from such imperishable remains that the Northwest Coast archaeologist must try to plece together the long and, no doubt, complicated history of the Indian peoples who inhabited this area in early times.

The aims of modern archaeology are not limited to the mere collecting of specimens for display in the exhibition cases of museums. The archaeologist digs in order to learn as much as possible about the culture and life of prehistoric times. He 
seeks to trace the cultural development of ancient peoples, he tries to determine their origin, to follow their migrations, to note their conflicts and peaceful contacts with other groups. These aims can be realized only by precise and systematic excavations and by keeping accurate and extensive written and photographic records of all finds and features that may enrich our knowledge of the past.

Each midden can be likened to a chronfcle which, when carefully deciphered, will yield a historical account of events in the proper order of time. Most middens are stratified, that is, they are built up in layers. The individual layers or strata can be compared to the separate pages of the chronicle; the lowest stratum will relate the beginning, and the topmost the end of this particular chapter in the history. Since, however, the middens are not all of the same age it is obvious that the most ancient middens will tell us about the earliest and the more recent about the later periods of the long prehistory of this area. $[1955: 9,10]$.

\section{EXCAVATION PROCEDURES AND LABORATORY WORK}

Borden describes the procedures of the excavation in 1949 at

Whaten Farm.

Before the excavation proper began, the students were busy with alidade, plane-table, and stadia rod, surveying, fixing datum points and benchmarks, and preparing contour maps of the site.. Thereupon the area to be excavated was carefully staked out and its location recorded on the contour map. In excavating, only small implements were used--pointed mason trowels and dust-pans, and, for even finer work, grapefruit-knives, spoons, dentist's tools, whisk-brooms, and soft-hair brushes. Shovels came into play only during clean-up operations. All excavated material was screened and closely scrutinized. Every find, upon discovery, immediately recelved an identification number and its location was measured three-dimensionally with reference to datum point and benchmark. One artifact recordsheet, the size of standard typewriter-paper, was devoted to each find for the recording of these and other data. Associated material, such as food remains, detritus of manufacture, charcoal, samples of ash and of other midden material from the various strata, was collected in special bags and its origin recorded. After the excavation of every 4-foot level was completed, scale drawings of the stratification as it appeared on the trench-faces were made on graph paper. In addition to copious fleld-notes, nearly 350 photographs were taken of the 
work in progress, of special features, such as rock-filled fire-pits, burials, and so forth. In this fashion a trench 80 feet long, 5 feet wide, and 12 feet deep was excavated during the nine weeks of the field-trip.

The reward for all this care in the field came later in the laboratory when, after the original position of each find had been precisely plotted on the profile drawings, the artifacts were laid out on a large table in their proper association and sequence. Although not one of the artifacts was very spectacular by itself, as the finds lay spread out in this fashion they began to tell the story of two interesting chapters in the pre-history of this area [1950b:242].

\section{DEFINITIONS}

Borden quotes definitions for "phase" and "culture", two basic terms used in archaeology.

The concept "phase", as employed by archaeologists, denotes "an archaeological unit possessing traits sufficiently characteristic to distinguish it from all other units similarly conceived, whether of the same or other cultures or civilizations spatially limited to the order of magnitude of a locality or region and chronologically limited to a relatively brief interval of time" (Willey and Phillips, 1958:22) [Borden 1968a:25].

Numerous anthropological studies have shown that a culture "is a very composite phenomenon, in which elements from widely different sources and of greatly different ages gather together, not into an accidental and incoherent conglomerate, but into a harmonious, working organism" (Birket-Smith, 1929, 222) [Borden 1968a:22].

\section{CLASSIFICATION}

Borden attempts to classify artifacts according to their "business edge" (1956:95; 1968b:55-59, 61) if no earlier classification has been done. However, he does not make up new classifications if others have already done so. This is the clearest account of his reasoning on the use of classification in comparative studies: 
Among artifacts made of non-perishable materials chipped projectile points, if present, are probably the most suitable for comparative studies in a non-ceramic area. Stone projectile points often occur in considerable numbers, and they are highly subject to stylistic and other variations in time and from region to region. To facilitate comparative studies a classificatory system applicable over a wide area is essential. Unfortunately, archaeologists in the Pacific Northwest have not yet worked out a classification which is generally acceptable. Comparative studies in this area are becoming increasingly difficult because individual workers continue to devise their own schemes and to use terminology which frem quently is vague in meaning. Rather than add to the confusion through the Introduction of another system, I have used the one devised by Thomas Wilson and elaborated by Gifford, Schenck, Strong, Collier and others (...Strong 1935 is the specific model followed here).

Although this classification has obvious defects, it is practicable, and the symbols it employs have at least some meaning. In order to avoid misunderstanding, it is often advisable to present with the classification brief descriptions of the various types represented in an area and particularly of subtypes not included in earlier applications of the scheme. This is the procedure used here. In addition, each type is illustrated by one or several examples on Plate $V$ in the sequence of the descriptions. Dimensions and, where a series of specimens is available, range in size may also be inferred from the illustrations. The table on p. 89 shows the distribution of the various types in the two survey areas [Borden 1956:86].

\section{RELATION OF DATA TO HYPOTHESES}

On the relation of data to hypotheses, Borden spoke in response

to papers presented by other archaeologists:

...Mitchell quotes from some of my papers written some 20 years ago in those ancient B.C. -14 days. I shall not defend what I wrote then beyond stating that interpretations were based on then available data. I still think that some of the interpretations were correct, although new data have made new interpretations necessary in other instances. A reading of my pubIications will reveal that I am neither a 'dislocationist' nor committed to a 'continuity model.' I prefer to let the evidence speak for itself.

In a recently published paper on the prehistory of the lower 
mainland of British Columbia, I was able to trace cultural development in the Fraser Canyon through five phases, from late in the 8th millennium B.C. to the second century B.C. without any marked break, only gradual changes in the style of artifacts, and cultural accretion attributable to vigorous local growth, at times stimulated by outside influences. But eventually, there was a break--the discontinuity between the Baldwin phase on the one hand and the ensuing Skamel phase on the other--is sudden and complete, and I cannot account for it in any other way than by inferring that the Skamel phase assemblage marks the appearance of a new population in the canyon region. A few centuries later, a similarly sharp break is discernible in the Fraser Delta, and I believe probably for similar reasons. At least that is what the data seem to tell me and certainly not because I am an adherent of this or that operational mode1 [1969d:255-256, my emphasis].

\section{PROBLEMS}

Borden writes, beginning in his earliest papers, of the difficulty of the work to be done by archaeologists in accomplishing their in-

\section{terpretations:}

Systematic excavations have just begun. It will take much time and effort before a clear understanding of pre-historic events in this area can be gained [1950b:246].

Prehistory is a field where truth is not easily and quickly come upon. We greatly appreciate the co-operation of all those who send in specimens, report the location of sites, or assist us in any way which will advance the knowledge of the prehistory of British Columbia [1954b:196]. 
PART II

EARLY PERIOD 
CHAPTER III

THE LOGIC OF THE PERIOD

\section{CHARACTERISTICS}

The early papers contain evidence from Borden's first excavations on the coast (Chapters IV-VI), and in the interior (Chapters X-XII), and general interpretations about British Columbia prehistory (Chapter XIV).

\section{Anomalies}

The anomalies or surprising phenomena that Borden faces are these:

1. Assemblages at Locarno Beach and Marpole appear to be about the same age, but are very different. Did one precede the other? Which was earlier? What does their difference mean?

2. There is much sculpture and ornamentation at Marpole, but none in the same area ethnographically. What made the change?

3. Whaling practices along the Northwest Coast and Alaska follow an uneven geographical distribution. What does this mean prehistorically about the whaling tradition?

4. The use of ground slate, and the use of chipping techniques is uneven and varied. What does this mean?

5. Ethnographically, the linguistic distribution of language families is extraordinarily complex. What does this mean as to the history of the people now living in these areas?

6. Each site investigated seems to be unique. What kinds of 
similarities can organize this complexity?

Variety of Hypotheses

The early papers 117 ustrate how many different reasonable explanations Borden proposed. With a limited amount of evidence accumulated, he was free to sort it out in a variety of ways, according to a variety of classifying characteristics. This lack of constraint emphasizes the ambiguity of archaeological evidence. Borden eagerly anticipated radiocarbon dates to anchor his data, and to eliminate some of the possible hypotheses. One function of these early papers is to suggest alternative, reasonable patterns of order, with questions chosen to best utilize the new radiocarbon dating.

Chronology and the Age Area Hypothesis

Borden's primary concern was to establich a chronology. After an archaeologist establishes a temporal order tying separate components into a sequence, then we may ask questions of influence, environment, and innovation.

However, in order to establish a temporal order before radiocarbon dating, the sequence of questions is reversed. The usual distribution of artifacts, and the expected geographic spread over time, are used to suggest a time relationship. The age-area hypothesis is described in detail in Chapter XIII. Borden argues from the ethnographically known use of tools to suggest the environmental orientation (and perhaps the history) of the makers and users of the tools found archaeologically. Solutions to the Problem of Circularity

Borden faces a probiem of logic to avoid a circular argument. If spatial distribution is used to argue for a temporal relationship, that temporal relationship cannot then be used to "explain" the spatial one. 
Stratified Sites. Borden uses two particularly important lines of reasoning in these early papers to avoid this circularity. The first is based on evidence from stratified sites, which provides a relative sequence between assemblages. Borden finds this at Whalen Farm (see 1950b, Chapter V), with an abrupt change in artifacts and in midden food remains. If either of these components is similar to other sites, he has a further link in establishing a time sequence independent of typological reasoning.

Linguistic Evidence. The second line of reasoning is based on linguistic evidence. Borden uses the relationships between the languages to check the conclusions derived from this other evidence. (Occasionally, as in Chapter XIV, he combines evidence from physical anthropology with linguistic evidence. Since the evidence in 1954 was also based on the age-area hypothesis, it does not solve the logical problem of arguing in a circle.)

The linglistic evidence often appears toward the end of Borden's papers. He first utilizes the stratigraphic evidence from each component; then he discusses the geographic distribution of similar traits, complexes, or assemblages. Utilizing ethnographic examples, Borden correlates tool use, tool material and style, with known temporal and spatial distribution. These correlations are stated in one or more hypotheses. He usually suggests tests that would confirm them. Then, using evidence from historical linguistics, Borden checks his conclusions, and suggests which language group may have been connected with the sites and times. Because both the linguistic evidence and reasoning are derived independently from Borden's other arguments, it cannot be circular. 
Problems of Linguistic Evidence. The linguistic argument may suffer from another problem, however. People who speak a common or a related language may not use common or related tools. Borden follows Boas in this (1954b, Chapter XIV). Race, language, and culture are known to vary independently. However, in order to provide the most reasonable hypotheses for testing, Borden consistently assumes that languages and cultural remains may be viewed as covariant. Borden chooses to examine the complex 1inguistic pattern of the Northwest Coast in addition to the archaeological evidence. In the absence of radiocarbon dating, he uses the historical linguistic evidence as another relative time-scale. I think that Borden's background in the study of German language and culture enable him to rely on linguistic scholarship and evidence as readily as on archaeological evidence. Linguistic Evidence as Basic Data

Linguistic evidence was important to Borden in its own right, in addition to its use as a check on archaeological theory. If the archaeologist is to trace the prehistory of ethnographically known peoples, then the varied distribution of the linguistic families would need to be explained and traced. If patterns of movement and exchange are suggested by hypotheses, then accumulating evidence can be arranged within each pattern. The evidence may fit the pattern, or anomolies may be seen. The evidence will not be contradictory or confirmatory except in the framework of suggested patterns of explanation. These early papers form such a framework for later archaeological and linguistic research on the Northwest Coast. 


\section{OUTLINES OF PAPERS}

1950a Prel iminary Report on Archaeological Investigations in the Fraser Del ta Reyion (Chapter IV)

A. Evidence:

1. Five dry, she11 midden sites (bone material preserved; little wood)

2. Assemblages from these sites.

3. Samples taken for radiocarbon dating.

B. Purpose:

1. To suggest a time sequence, organizing the evidence in a systematic way.

2. To suggest possible relationships for further archaeological study.

C. Steps in Retroduction: and testing:

1. Define the basic archaeological units from midden composition and stratigraphy, and associated cultural materials.

2. Calculate minimum age of deposit from characteristic of surface Tayers.

3. Calculate maximum age by charuuteristics of basal deposits.

4. Arrange 7 units on a tentative, relative time scale.

5. Chart changes in harpoon form with this sequence.

6. Suggest test for hypothesis that the harpoons change in a developmental sequence.

7. Suggest further relationships between sites on basis of similar artifacts.

8. Suggest "interior" or "northern" traits similar to those of 
delta artifacts.

9. Suggest population movement as explanation of some changes found stratigraphically at Whalen Farm. 
1950b Notes on the Prehistory of the Southern North-west Coast (Chapter V)

A. Evidence:

1. Same as Chapter IV, but concentrated on Whalen Farm site.

2. Linguistic evidence from Swadesh.

B. Purpose: to discuss Whalen Farm site with a general audience stressing site preservation, interdisciplinary scholarship needed, and the methods and aims of archaeologists.

C. Steps in Retroduction: and testing:

1. Assume accuracy of Swadesh in historical linguistics.

2. Assume that abrupt change in assemblage means a new culture.

3. Analyze food resources utilized, tool types, technology, and materials from which tools were made.

4. Ask four questions; suggest hypotheses

a. How many cultures are found at the site? (Two)

b. What is their orientation? (First, coast 31 ; second, interior).

c. Who lived there? (The second may have been Salish).

d. When was the site occupied? (Up to 250 years ago; no earliest date). 
1951 a Facts and Problems of Northwest Coast Prehistory (Chapter VI)

A. Evidence:

1. Archaeologically, nearly the same as Chapters IV and V.

2. Ethnographic data on whaling practices.

3. Drucker's trait distribution studies.

4. King's Cattle Point site siudy.

B. Purpose: To examine two alternative hypotheses on Northwest Coast prehistory.

1. Northwest Coast culture had been considered the result of an ancient interior culture adapting to a coastal environment: Kroeber, Boas, H. I. Smith.

2. If the Northwest Coast is divided as Drucker suggests: North, Central and South, then North and South are more oriented to the interior, the Central more oriented to the North, suggesting that the Central, northern orientation may be the oldest occupation.

C. Steps in Retroduction and testing:

1. Determine which characteristics seem to be oldest, most complex, using ethnographic whaling studies.

2. Re-order the seven Fraser delta units studied in Chapter IV, with the northern elements considered oldest, (i.e. Nootkan), interior elements considered youngest.

3. Argue from archaeologically recovered tools to the earlier presence of the thing they do most efficiently.

4. Compare sculptures of Marpole, Locarno Beach, with Kwakiutl, Nootka traditions. 
5. Generalize the changes into three stages.

6. Compare these with stages suggested for the more northern areas by de Laguna.

7. Suggest tests on spread of Eskimo tradition, specifically the harpoon.

8. Show that evidence from Cattle Point can support either hypothesis.

1951b Fraser River Delta Archaeological Findings (Chapter VII)

Summary article correlating harpoons, slate grinding and woodworking tools in Fraser delta sites.

1951c Review of M. W. Smith: Archaeology of the Columbia Fraser Region (Chapter VIII)

Book review critical of Marian Smith's scholarship.

1951d Review of A. King: Cattle Point (Chapter IX)

Book review of Arden King's Cattle Point study. This shows the way King's evidence fits Kroeber's hypothesis. (This was written at the same time as Chapter VI, which shows that an alternative hypothes is is also possible.) 
1952a An Archaeological Reconnaissance of Tweedsmuir Park, B.C. (Chap$\operatorname{ter} x)$

A. Evidence:

1. Geographic and ecological information of the Tweedsmuir Park area.

2. Ethnographic information, prehistoric tradition and historic accounts .

3. Results of survey concerning sites, uses of sites, and locations

4. Surface collected artifacts, ordered by

a. tool type.

b. raw material.

c. manufacturing technique.

d. geographic distribution.

5. Linguistic information.

B. Purpose: to present to a general museum audience

1. The urgency of archaeological salvage.

2. Hypotheses organizing present evidence.

3. Hypotheses for further research.

C. Steps in Retroduction:and testing:

1. Order hypotheses according to projectile point raw material, suggesting two traditions in the area.

2. Correlate this hypothesis with linguistic data.

3. Formulate hypotheses about the peopling of the New World. 
$1952 \mathrm{~b}$ Results of Archaeological Investigations in Central British Columbia (Chapter XI)

A. Evidence:

1. Evidence from other archaeologists in the area.

2. Evidence from Chapter $X$.

3. Earlier Borden excavations at Chinlac Village (Carrier).

a. Habitation forms and features.

b. Assemblages.

c. Food remains.

d. Dating.

4. Natalkuz Lake excavations (problems of securing evidence).
a. Habitation forms (unique).
b. Assemblages.
c. Trade evidence.

B. Purpose:

1. Outline content and relationship of interior sites.

2. Outline extra-areal relationships.

C. Steps in Retroduction and testing:

1. Use base line of historic Carrier assemblage at Chinlac.

2. Contrast non-historic site (Natalkuz Lake) for habitation styles, tools, confirming survey hypothesis of two cultures.

3. Compare similarities and differences among all known sites.

4. Interpret semi-subterranean house distribution.

5. Explain Natalkuz Lake assemblage as representing an earlier people than Carrier.

6. Describe a long history of movement of people in the area, not 
always peaceful.

7. Suggest Natalkuz may have been early Salish, perhaps not.

1954 A Scottsbluff-Eden Point from British Columbia (Chapter XII)

\section{A. Evidence:}

1. One point, probably from Windermere area.

2. Description of the Rocky Mountain Trench.

B. Purpose: to suggest that this area is of potential importance as an early migration route for Early Man sites.

C. Retroduction: to be tested by a survey in 1954 . 
$1954 a$ Some Aspects of Prehistoric Coastal-Interior Relations in the

\section{Pacific Northwest (Chapter XIII)}

A. Evidence:

1. Same as earlier papers.

2. Borden's evidence from interior sites as needed.

3. Caldwell's evidence from a survey in the interior.

4. Known geographic distribution of various artifacts.

5. First Radiocarbon date, from Locarno Beach.

B. Purpose: to re-examine his 1957 (Chapter VI) position, and to defend it in response to a criticism and alternate hypothesis suggested by Caldwell.

C. Steps in Retroduction and testing:

1. Organize evidence by spatial distribution in absence of dating.

2. Recapitulate 1951 position, with stages of development.

3. State Caldwell's position to the contrary.

4. Reject each of Caldwell's arguments.

5. Re-examine 1951 position with age-area hypothesis. 
1954b Distribution, Culture, and Origin of the Indigenous Population of British Columbia (Chapter XIV)

A. Evidence (specifically stated as very 7 imited)

1. Ethnographic evidence of culture of the Northwest Coast, primarily divided according to Coast/Interior location.

2. Demographic information on indigenous population.

3. Historical linguistic evidence of diverse and complex language relationships and distribution.

4. Archaeological assemblages, and relative dates in the area.

5. Physical comparison of indigenous population with residents of Mongolia (Physical Anthropology).

6. Radiocarbon dates in the New World.

B. Purpose: to investigate the relationships between language and culture ethnographically, and to suggest hypotheses for the origin of language groups suggested by archaeological investigations and linguistic evidence, for further testing.

C. Steps in Retroduction and testing:

1. Use age-area hypothesis.

2. Correlate historical Linguistics/physical anthropology.

3. Assume Interior/Coast is a significant division, thus looking for an either/or source for these groups.

4. Develop detailed hypotheses for each linguistic group based on Methods 1-3. 


\section{CHAPTER IV}

\section{0a PRELIMINARY REPORT...}

This is Borden's first publication, and was written for an archaeological audience. It appears in the first issue of Anthropology in British Columbia. In response to Drucker's plea for systematic investigation in the area (Drucker 1943:128), Borden summarizes the evidence that is available to the student in 1950. He attempts to order the sites temporally, using the only systematically, thoroughly excavated sites, those at Locarno Beach and Whalen Farm, for key sequential evidence (Fig. 2).

\section{SOURCES OF EVIDENCE}

The evidence at Borden's command consisted of material from five sites in the Fraser Delta. These were 1) surface finds at Musqueam, 2) Locarno Beach systematic excavations which stopped when a bulldozer destroyed the site, 3) excavations at Point Grey and 4) Whalen Farm, and 5) unstratified results from the Marpole (Eburne) site in the writings of Harlan I. Smith supplemented by an excavation by Borden. With no vertical distribution in Smith's material, Marpole yielded little knowledge of culture history. Borden's excavation there showed modern disturbance down to a depth of four or five feet and the only undisturbed layer to be of three and a half feet maximum depth with the top strata clearly missing. Smith reported a maximum depth of nine feet for this site (H. I. Smith 1903:139). Borden notes evidence in his work that 


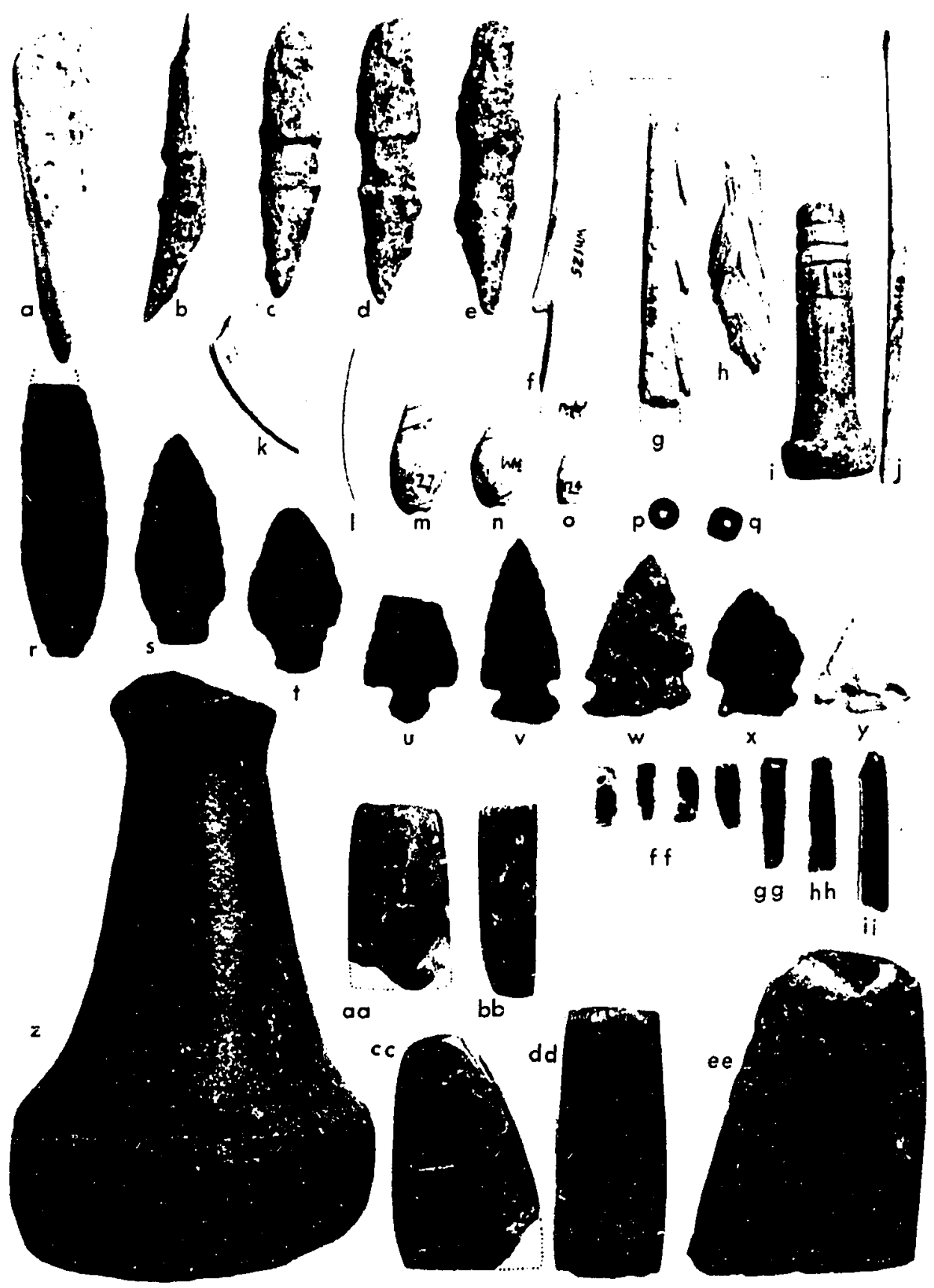

Figure 2. Artifacts typical of Whaten II (Borden 1970:106 (Figure 32). 
this midden represents a cultural sequence.

Perhaps the most significant discovery so far was the complete absence of ground slate projectile points in the undisturbed strata excavated by us. Chipped points on the other hand were frequent. Since $H$. I. Smith reports ground slate points as being 'more than half as numerous as the chipped points' (H. I. Smith, 1903, p.144) at this stte, the absence of ground slate points in our deposits may indicate that such points were not used in the early period of occupation [Borden 1950a:18].

Borden gives general site descriptions, locations, and lists of artifacts that are "...limited in the main to those traits which will best reveal culture change and differences and similarities existing between different sites" (1950a:13). "Until age determinations by the C 14 method can be made, all chronological considerations will have to remain tentative" (1950a:21). Having thus made explicit a future source of more certain evidence, he presents three groups of hypotheses which form the basis of this first paper.

\section{HYPOTHESES}

\section{Hypotheses to Establish a Time Sequence}

The first group of hypotheses divides the five sites into periods or cultures, derived from evidence of the stratigraphy of midden composition and cultural material. In this way he defines his basic archaeological units. The second group relates the relative ages of these sites by surface layer minimums, and the third group of hypotheses concerns relative site ages from evidence of the basal deposits. In the absence of other dating procedures, these two groups of hypotheses give relative maximum and minimum ages of these units.

After charting the cultures on the basis of minimum surface age, Borden charts with a summary of the first three groups of hypotheses the 
distribution of harpoon types related to these cultures (p.22).

Harpoon type

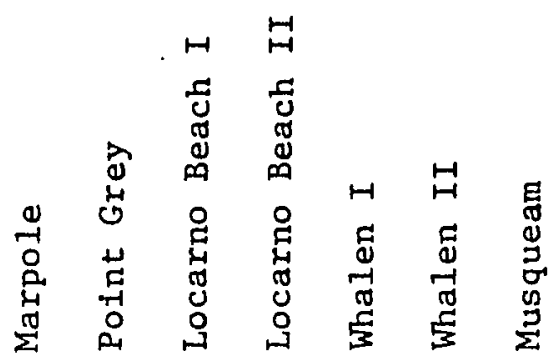

Barbed w. tang... $\mathrm{x} \quad \mathrm{x}$

One-piece toggles $\quad$ ? $\mathrm{x} \quad \mathrm{x}$ ? $\mathrm{x}$

Two-piece toggles $\quad x \quad x \quad x$

Figure 2. Correlation of sites with harpoon types.

From this evidence, Borden moves to a higher level of abstraction in his next hypothesis. He proposes that the harpoon development was temporally sequential from one type to the next, and is correlated to the ages of the cultures. Finally, he suggests a test for one aspect of this harpoon developmental hypothesis. The question marks in the preceding chart indicate the expected occurrences if the hypothes is is correct. The "x?" at Whalen I sumbolizes the test hypothesis. Locarno Beach I no longer exists for testing, therefore only a "?" appears in the chart.

The argument leading to the test hypothesis may be condensed into this form:

1. If the sequence of harpoon development is from barbed harpoon to one-piece toggles to two-piece toggles, and

2. If Whalen I, the earlier culture at the Whalen Farm site, is a later phase of Locarno Beach II, with common emphasis on state grinding and many other traits, it may be an instance 
of the local development of two-piece from one-piece toggles. ...we may have here evidence that the two-plece toggle was developed by a group [Whalen I] who originally [Locarno II] employed one-plece toggles with opposed lateral spurs" [p.22].

3. If the Whalen Farm site, with two distinct cultures, one underlying the other, represents the transition from the older cultures :

a. Marpole, and Point Grey, with barbed harpoons and

b. Locarno Beach I (no harpoons found) and Locarno Beach II, with one-piece toggles,

to the newest cultures:

c. The site at Musqueam where surface finds and

d. Ethnographic evidence confirms the two-piece toggle as the most recent form,

4. Then, the Whalen I and Whalen II harpoons can be a confirmatory or disconfirmatory instance of the sequence.

5. The evidence at Whaten II consists of a single one-piece toggle head, and numerous two-piece heads.

6. No one-piece harpoon heads were found at Wha? en I. Borden suggests this test:

7. If Whalen II represents the end of a transitional phase in the evolution of toggles on the coast, and

8. Since the inventory on Whalen I is still incomplete,

9. "... it is still possible that we may yet find more one-plece than two-piece heads in the oldest deposits at this site" [1950a:23].

10. A find of this nature would be a confirmatory instance of the 
developmental hypothesis 1 , and the Whalen transitional hypotheses 2 and 3.

\section{Hypotheses Relating Sites to Each Other and to Other Areas}

The rest of the hypotheses in this paper are based on evidence at the sites that suggest correlations between the sites, between these sites and other areas, and possible sources of origin or influence. None are built consistently to a test as in the previous series of arguments. In this they are characteristic of a science with fragmentary data. They are set out as possible 1and-marks for the scientist in further investigation.

They are the most tentative in probability, and yet need to be listed explicitly even though their basis is admittedly sketchy evidence, because many of them recur as hypotheses intermittently throughout the rest of the Borden papers. One group of hypotheses presupposes the knowledge and validity of traits of interior, coastal, or northern origin. These presuppositions will be made explicit and finally examined in the 1951a, 1954a, and the 1962a papers.

Marpole and Point Grey. Marpole and Point Grey are shown to have a large list of traits in common with few dissimilarities, and the hypothesis follows that they be treated as in reality one culture. Borden supplies auxiliary hypotheses to account for the differences:

[Hypothesis of seasonal use of Point Grey:] Point Grey in all probability was occupied only seasonally. Marpole is by far the richer of the two components, chiefly due to the presence here of a greater number of interior traits [1950a: 23].

The next group of hypotheses concerns "...a small seated steatite figurine, holding a bowl-like container..." (p.23), found at Marpole, 
similar to others described by H. I. Smith. The hypothesis is that this represents "...the same supernatural being, who among the Kwakiutl is known as Tso'noqoa...often represented on wooden dishes, houseposts and masks..." (p.23), with citations from Boas for the ethnographic material. This hypothesized identity is the subject of two, more abstract and wider reaching, hypotheses.

[1 Hypothesis of carving tradition:]

It thus becomes possible to draw a direct line from early prehistoric stone carving in the Fraser-Columbia basin to the modern wood carving of the Kwakiutl,

[2 Hypothesis of mythical tradition:] and to trace the tradition of the child-devouring giantess back into an early period [p.23].

Later in the paper Borden reemphasizes this hypothesis, adding that these artistic-ceremonial elements are lacking in the historic Salish horizon, but "...passed over into Kwakiutl culture, where they flourished until modern times" (p.25).

Locarno Beach and the North. Locarno Beach, in the next hypothesis, is in sharp contrast to Marpole and Point Grey. "From earliest times we notice here strong ties with the far north..." (p.23). Note that this hypothesis states strong similarities, but makes no statement of origin, or direction of influence.

Marpole and Locarno Beach. The next two hypotheses relate the cultures to their environmental adaptations. "...we sense at Locarno Beach the existence of a culture which has a more genuine maritime character" (p.23). And again Borden contrasts this with Marpole, which "... gives the impression of an interior culture pattern adapted to 1ife on the coast..." (p.23). These hypotheses depend on interpretations of 
tool uses and trait origins.

While still contrasting Locarno Beach with Marpole, the next pair of hypotheses depend on a different presupposition. The presence, at Marpole, and the absence, at Locarno Beach, of

...the three concomitants characteristic of the highly developed wood-working industry of later t1mes: numerous large splitting wedges of antler, heavy pounding hammers (hand mauls,...) to drive these wedges, and many small and large blades of serpentine and nephrite for planing adzes [pp.23-24],

are instances of a general presupposition that is implicit in many arguments: From the presence or absence of a tool, we may infer, with caution, the presence or absence of what that tool can make. Thus there is indirect evidence for plank houses of the modern Coast Salish type, and for dug-out canoes in the Marpole artifacts, but for the Locarno Beach occupants,

...we may suspect that...[they] hunted their sea lions and other sea mammals with skin covered boats and that they lived in houses different from the large plank houses of the modern Coast Salish ... [p.24].

The contrasts between these two ancient cultures led to a general hypothesis, stated in a variety of ways in this paper, and echoed in later ones. Before these next, more abstract hypotheses are proposed, Borden underlines that they are even more tentative than the previous ones:

[The caution:]

With the limlted data at our disposal it is difficult to trace correctly the events and developments which occurred in this area in the early past, and future evidence may necessitate extensive revision in the present interpretation of the data.

[Hypothesis of two eariy traditions:]

But we seem to recognize two main cultural currents which, beginning at an early time, met and mingled in the Fraser Delta region, one coming from the far north down the coast, and another broader current from the interior plateau [p.24].

[Hypothes is restated:] 
At an early period two important focl of autonomous cultures became established near the mouth of the Fraser, one of northern stamp at Locarno Beach, and six miles away at Marpole another which bears the imprint of strong influence from the interior $[p .25]$.

Evidence of interior traits at Locarno Beach and of northern traits at Marpole may support the hypothesis that these cultures were coeval. The alternate hypothesis, that they were not at the same time, is supported by the fact that the superior wood working tools were not adopted at Locarno Beach, nor the superior toggling harpoons at Marpole. Note here an implicit presupposition probably of this sort: that since cultures are adaptive, the most efficient tool will be used, if it is available. Which of the alternative hypotheses will prove correct is not yet known.

Whatever the time relationship of the Marpole and Locarno Beach sites, Borden stresses that Locarno Beach is part of a coastal continuity which, at various times and places, was interrupted by intrusive interior groups. Thus he writes that Locarno Beach

...exhibits so strikingly the impact of that vigorous cultural current which at one time flowed from the Far North south along the coast until it was choked of $f$ by intrusive tribes from the northern interior [p.26].

Whaten II. The next hypotheses treat the Whalen II culture. If the Marpole-Point Grey culture was contemporary with Locarno Beach, and if Whalen I is a later phase of Locarno Beach, there is a period of development or continuity with these two foci of cultures. Borden hypothesizes discontinuity with the beginning culture of Whalen II.

Whalen I was eventually overwhelmed by a fairly recent wave of probably migration borne interior elements [p.25].

Whalen II, though interpreted as marking the beginning of a new culture or people in the Delta, is characterized as a synthesis of 
Locarno Beach and Marpole traits.

It is in Whalen II that we note the synthesis of the advanced wood working complex with the technique of harpooning fish and sea mammals with toggle heads $[p .25]$.

The lack of ground slate at whalen II is the important exception to this synthesis, since it is the predominant stone industry at Musqueam and in ethnographic evidence of the area. Therefore, this intermediate time with chipping rather than slate grinding leads Borden to the last hypothesis.

But, even at that time [Whalen II] the ground slate industry must have been fully entrenched among other groups of this region...[p.25]. 
CHAPTER V

1950b NOTES ON THE PRE-HISTORY...

Published in the British Columbia Historical Quarterly, this paper is directed to readers knowledgeable in history, but not necessarily in prehistory. Borden writes about the 1949 excavations at Whalen Farm, carried out jointly by students from the University of Washington and the University of British Columbia. It includes an account of the purposes and some of the field and laboratory procedures of the archaeologist. Portions of these are included in the second chapter of this thesis. I detect no new evidence since the 1950a paper. Instead, it is an enlarged account of one site, intended for a different audience.

\section{INTRODUCTION}

Borden explains the excavating procedures. Only small implements were used. Artifacts were recorded in three-dimensional association upon discovery. Stratification drawings were made at each four foot leve1, supplemented with field notes and photographs. Associated materials from the strata were collected and their origin recorded.

In this fashion a trench 80 feet long, 5 feet wide, and 12 feet deep was excavated during the nine weeks of the fleld trip.

The reward for all this care in the fleld came later in the laboratory when, after the original position of each find had been precisely plotted on the profile drawings, the artafacts were laid out on a large table in their proper association and sequence. Although not one of the artifacts was very spectacular by itself, as the finds lay spread out in this fashion they began to tell the story of two interesting chapters in the pre-history of this area [Borden 1950b:242]. 
The final sentence in this quotation contains an idea central to Borden's approach to his work:

...as the finds lay spread out in this fashion they began to tell the story...

This emphasis on the finds in proper association telling the story will be re-stated in the 1969d paper, and a personal communication, in 1973. Borden still insists that the data speak for themselves. I will discuss another aspect of the data-hypothesis relationship at the end of the analysis of this 1950b paper.

\section{HYPOTHESES}

The hypotheses in this paper are related to four questions about this site:

1. Are there one or more cultures found here? Most of the paper is supporting evidence for the hypothesis that the site represents a succession of two very distinct cultures.

2. How does the orientation of these cultures differ? The second group of hypotheses interprets the orientation of these cultures, the earlier oriented to the coast, the later with strong ties to the interior.

3. Who were the inhabitants of the site? The third group of hypotheses introduces linguistic evidence which Borden relates to the Whalen II people.

4. When was the site used? Borden proposes one limited hypothesis on dating.

1. Evidence and Hypotheses for Two Cultures 
Evidence for the first two questions comes from a comparison of cultural material from the site levels.

The collection contained two distinct assemblages of artifacts; that is, it represented a sequence of two different Indian cultures... The transition from one to the other is quite abrupt, with a distinct dividing line between the two groups [Borden $1950 \mathrm{~b}: 243]$.

This is the basic hypothesis answering the first question. It depends upon this implicit hypothesis: If we have distinct assemblages, with no evidence of developmental transition, then we may infer distinct cultures.

It is necessary to summarize some of Borden's evidence that supports this first hypothesis, so that his answer to the second question is placed in context. Although both groups (we may speak of two groups since two assemblages mean two cultures), rely mainly on sea food, they used different tools in their work, and their diet shifted away from major use of bay mussels to use of several varieties of clams.

Early groups used tools made of raw materials which were of local origin: bone, slate and shell of the giant-mussel (Mytilus californianus). The later groups used no slate, mussel shell only rarely, but made important tools of nephrite, serpentine and obsidian that come from the Interior.

The early groups used projectile points which were too large and heavy for arrows, but

...must have tipped spears or lances. The very few chipped or flaked points... had a simple leaf shape [Borden 1950b:243].

The later groups used small projectile points, which were chipped for arrow heads,

...of types and shapes such as have been found at archaeolog-

ical sites in the Interior of Washington [Borden 1950b:243]. 
Early groups used cutting tools of ground slate and giant-mussel shel1.

The later Indians used small razor-sharp obsidian blades, which seem to have been hafted by lashing them into an open groove of a handle made of antler [Borden 1950b:243].

Celts were rare, and of soft material in early deposits, but numerous, and of hard tough material later on. All the heavy-duty wood-working tools are present in the later culture, but absent in the earlier one.

The presence of this configuration of wood-working tools in the upper horizon suggests, therefore, that the later occupants of the Whalen site had a well-developed wood-working industry, and that they probably lived in large plank houses of the historic Coast Salish type. Conversely, the absence in the lower horizon of all three of these heavy-duty tools may indicate that woodworking was not highly developed among the earlier occupants, and that they lived in houses of a different type [Borden 1950b: 244].

In addition to differences in tools, Borden describes a difference in burial customs:

...there is one difference which may be significant: the earlier Indians buried their dead facing west, and the later group buried their dead facing east [Borden 1950b:244].

\section{Hypotheses of Coastal and Interior Orientation}

Borden answers the second question of this paper with two tentative hypotheses:

[Hypothesis of early coastal people:]

While the evidence which was gathered last summer at this site cannot as yet be regarded as conclusive [in other words, what follows are hypotheses], the data that were obtained strongly suggest that an early group of Indians who had lived at this site for a considerable time, and whose entire orientation was evidently coastal by long tradition,

(Hypothesis of later Interior people:] was eventually overwhelmed by intrusive Indians whose culture exhibits strong ties with the Interior [Borden 1950b:245].

The material, form, and function of tools as Borden has analyzed 
them suggest these hypotheses. Burial practices may also be a confirming instance. The evidence and hypotheses concerning the first two questions are early examples of the way Borden formulates hypotheses. He proposes no specific tests in this work, as he does in the archaeological publications that immediately precede and follow this.

\section{Hypotheses Identifying Later Inhabitants}

The third question is posed in this manner:

Who were these Invaders and where did they come from? The science of comparative linguistics suggests a plausible answer. [Borden 1950b:245].

Following Swadesh (1949:161-173), Borden presents an extended group of hypotheses. Some are qualified by phrases such as "it appears that", others by the word "must". I interpret the tentatively worded portions as the antecedents or premises, and the more definite statements as consequences or conclusions. Thus the schema is: If the conditions were as they appear, then it must be the case that... Since the conclusions become the subject of further investigation in the inductive process, they also serve as hypotheses in spite of the wording which seems to express certainty. With this interpretation, the inductive, or probable nature of the argument is clarified. To take one seemingly definite statement out of this argument as "Borden's position" is to break the hypothetical nature of the relationship and to essentially misquote his intent and method.

This is Borden's argument:

It appears that at an early period extensive dislocations among the Indian groups of the North-west were caused by repeated waves of migration of Athabaskan-speaking peoples sweeping from northern regions southward along the Coast and through the Interior. After the turmoll had ceased, many Indian groups occupled terri- 
tory quite different from what they had held before the invasions started. Some groups held more than they possessed previously; others were squeezed into areas far smaller than they originally occupied.

Great unrest was caused among the Sallsh. It appears that Salish-speaking groups were jostled out of positions in the Interior of Washington and migrated toward the Coast, where they adapted themselves to a new 1ife. They did not necessarily settle for long periods in one place after arrival on the Coast, but of ten may have been hustled along to more distant places by new groups coming from the Interior. It must have been during this time of unrest, which may have lasted for several centuries, that the North-west Coast of Washington, the San Juan Islands, the East Coast of Vancouver Island, and the opposite Mainland were settled by the ancestors of the Salish groups inhabiting this area to-day. It must be the remains of these intrusive Salish and of their descendants which we find in the upper levels of many of the middens along our Southern Coast [Borden 1950b:245].

The next question is not even attempted, because of lack of data:

But who were the Indians who ceded this territory to the invading Salish? This question cannot, as yet, be answered with any degree of probability. Their culture seems to have been characterized by an absence or paucity of Interior traits, by the grinding of slate for knives, daggers, lance and arrow points, and by the presence of toggling harpoon-heads. These and other traits suggest that this culture derived its main stimulus from the Far North rather than from the East [Borden 1950b:245-246].

Here is the stimulus-from-the-North hypothesis, which we saw in the first paper, and which will recur, and be clarified, and amended in papers to follow.

\section{Hypothes is Relating to Age of Site}

The final question, of the age of the site, is answered in this 7 imited way:

The age of the Douglas fir-trees on the enormous shell mound on the Whalen farm indicates that the final events in the last chapter of this chronicle took place about two and a half centurles ago. We have, as yet, no clue as to the time of the earliest events at this site [Borden 1950b:246]. 
III. CONCLUSION

Borden concludes the paper with a statement, not of archaeological tests, but of needs in many disciplines as well as in archaeology to solve the problems:

Systematic excavations have fust begun. It will take much t1me and effort before a clear understanding of pre-historic events in this area can be gained. But by patient investigation and with the assistance of scientists in other fields, with the help of Individuals and groups outside of the two cooperating universitfes, we shall gradually approach this goal [Borden 1950b:246].

This concluding statement, together with his use of linguistic hypotheses, begin another aspect of Borden's formulation and testing of hypotheses: he will continue to use a heterogeneous body of evidence throughout his papers. Here we see the ethnographic/linguistic distribution and comparative or historical linguistics employed in formulating hypotheses.

This is a more important and wider expression of his statement tnat the artifacts in proper association tell the story. It places that seeming simplistic statement in a more thoroughly scientific context. Borden begins to ask that all the data be placed in proper association, and in later papers he states this explicitly. This is the self-corrective aspect of the scientific method. It is from this heterogeneous material that richly predictive hypotheses can be formulated. 
CHAPTER VI

1951 a FACTS AND PROBLEMS OF...

I. THEORETICAL BACKGROUND

Borden's second paper in Anthropology in British Columbia uses largely the same evidence from the Fraser Delta sites as in the 1950 papers. He organizes the evidence in a consciously theoretical way, to see which hypotheses on Northwest Coast prehistory may tend to be confirmed or disconfirmed.

He states first the theories of Kroeber with evidence from earlier conclusions of H. I. Smith and Boas, and second the theories of Philip Drucker. Borden analyzes Arden King's work at Cattle Point as a possible instance of either of these two alternative hypotheses. Borden draws extensively on ethnographic evidence of whaling practices in the Nootka, Koniag, Bering Strait, and Northwest Alaska areas as he finds it in Heizer (1943), and Lantis (1938). Borden also depends on Drucker's trait distribution lists

...which were based on Northwest Coast material scattered throughout numerous collections and on the finds that were recovered during his archeological survey of Coast Tsimshian and Kwakiutl territories [Borden 1951a:36].

Borden's paper begins with a summary interpretation of Smith and Boas. This leads to a statement of the first alternative hypothesis considered in this paper.

Kroeber's Hypotheses 
[First general statement of hypothesis:]

...the theory arose that the Northwest Coast culture was to be regarded as a specialization from an ancient interior cultural base.

[Introduction to Kroeber's formulation of this hypothesis:]

This theory gained wide acceptance and was well summarized by A. L. Kroeber not so very long ago when he suggested

[Kroeber's formulation of the first hypothesis:]

'that the Northwest Coast culture was originally a river or river-mouth culture, later a beach culture, and only finally and in part a seagoing one. This means,' he continued,

[Kroeber's test hypothesis:]

'that the recent hinterland cultures of the Columbia-Fraser drainage (Plateau) and of the Intermountain Athabascans evident$1 y$ provide approximate illustrations of an early stage of Northwest Coast culture.' (Kroeber, 1939, p.28)

[Second aspect of Kroeber hypothesis:]

Along with Boas and others Kroeber noted the evident importance of Asiatic influences in the evolution of the coastal culture pattern (Ibid., p.28; Kroeber, 1923). [Borden 1951a:36].

Arden King interprets his Cattle Point data as an instance of the Kroeber hypothesis. Borden notes that later in this paper he will use King's data to support a second hypothesis proposed by Philip Drucker.

\section{Drucker's Hypotheses}

Borden analyzes Drucker's work as three related ideas:

1. From his distribution studies, Drucker divided the coast into Northern, Central, and Southern aspects, and noted that the parallels between the North and the South were due largely to the interior traits that they shared.

2. The Central area had fewest interior traits, therefore may be the oldest culture area on the coast. 
Drucker's test hypothesis proposes that the ethnographic example of earliest arrivals on the coast would be the Kwakiutl.

Borden's test hypothesis proposes that the Nootkans are this ethnographic example, on the basis of their more sea-going orientation and their strong ties with northern whaling practices.

3. Drucker "...considered the possibility that the components exhibiting many interfor traits may have been preceded by an earlier 'purely coastal' culture" (Borden 1951a:37).

\section{BORDEN'S HYPOTHESES}

The preliminary statement of the hypothesis of this paper relates to this third part of the Drucker hypothesis. After reviewing ethnographic evidence of historic population movements, Borden proposes:

We may discern here perhaps the last ripples of those great and gradual population shifts which brought Interior Indians to the coast, and there is an increasing body of evidence suggesting that not only Tanaina, Eyak, and Tlingit, but other Indian groups as well encountered people of Eskimo stock or at least of Eskimoid culture on their arrival in the coastal area [Borden 1951a:38].

After arguments supporting his hypothesis that the Nootkan was the earliest culture on the coast, Borden returns to the hypothes is of an early coastal component.

Recent archeological findings in the Fraser Delta region fit in well with evidence adduced from other sources that a strongly Eskimoid culture forms an early--and perhaps the earliest--culture stratum along the coast, at least as far south as the Gulf of Georgla region [Borden 1951a:44].

\section{Locarno Beach/Marpole Sequence Test}

Corollary and test of this is a repositioning of the Locarno Beach phase in the Delta sequence: 
If the five Delta sites are arranged according to the apparent minimum age of their surface layers we obtain the following sequence:

$500+$ years

Locarno Beach, Marpole, and Point Grey, the first probably being the oldest

$200+$ years

Whalen Farm

Late prehistoric to historic

Stselax Village at Musqueam

[Borden 1951a:44].

One 1950a hypothesis had proposed that if the harpoon development were temporally sequential from barbed to one-piece toggles to two-piece toggles, then Locarno Beach would probably be found to be more recent than Marpole. In the present paper, Borden organizes the same data with reference to hypotheses on the Northwest Coast cultural development. If Locarno Beach is found to be earlier than Marpole, this might be an instance confirming Drucker's last stated hypothesis. If, on the contrary, Marpole is earlier, this might be an instance confirming the Kroeber hypothesis. Thus the phrase "...the first [Locarno Beach] probably being the oldest..." is a test of the Drucker hypothesis.

\section{Interior/Eskimoid Trait Hypotheses}

The formulation and testing of Drucker's hypothesis depends on the age of the traits in the Delta, the Interior and the north, and on the accuracy of Drucker's identification of those archaeologically observable traits as of Eskimoid or of Interior origin. Borden's wording clarifies both the importance and the tentative nature of this classification. Since these traits are the subject of this and the 1954a and 1964a papers, they are illustrated in figures 3 and 4 on the following pages. I will quote Borden's lists in full: 


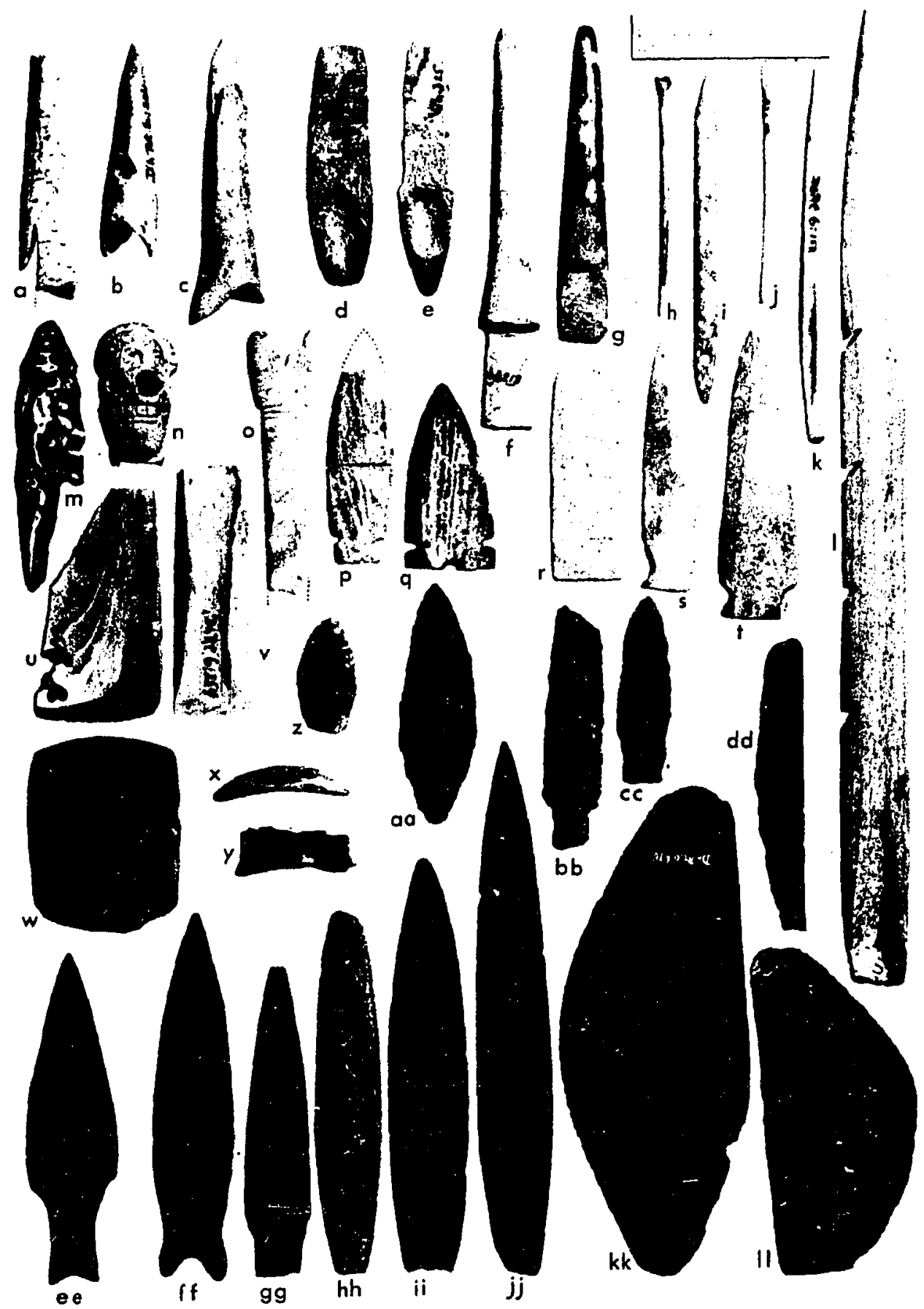

Figure 3. Artifacts typical of Locarno Beach (1970:100 Figure 30). 


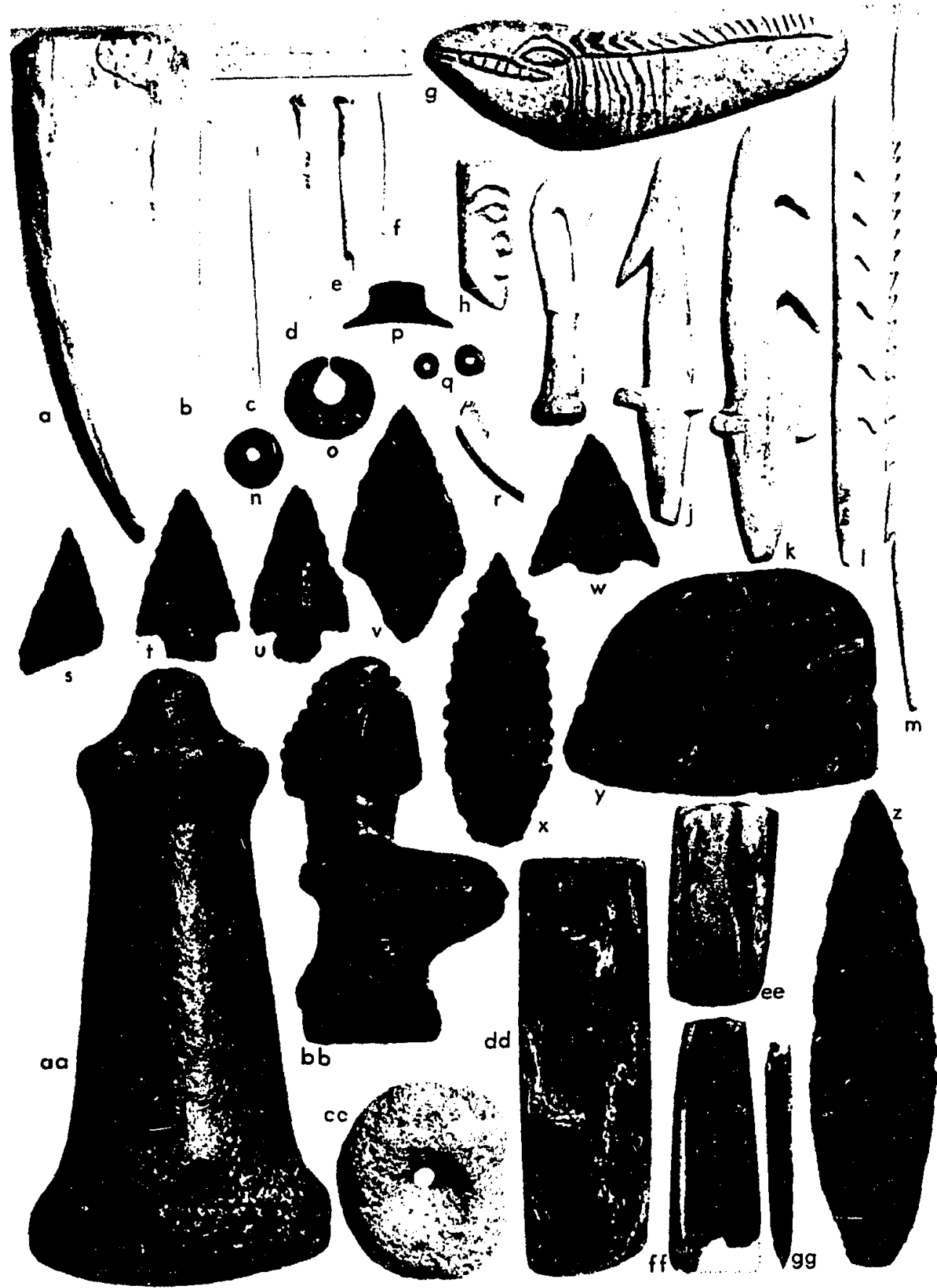

Figure 4. Artifacts typical of Marpole (1970:102 Figure 31). 


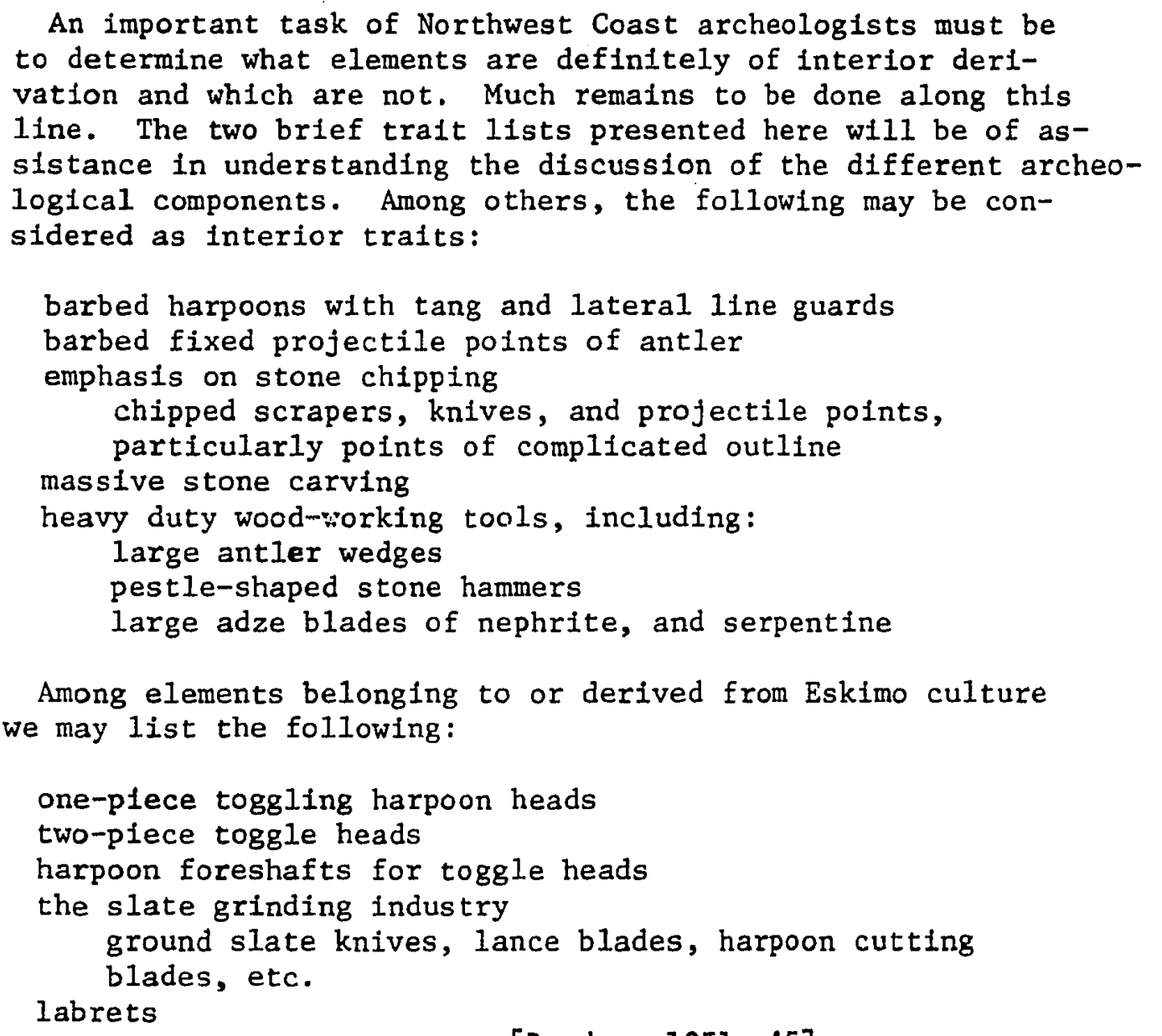$$
\text { [Borden, 1951a:45] }
$$

General Sequence Hypotheses and Tests

The arguments up to this point in the paper may be summarized in this way:

If the traits listed above are in fact traits of Interior or of Eskimoid origin, and if the cultures that have been longest on the coast do in fact have the fewest Interior traits, then we may order the Delta assemblages sequentially from oldest to most recent according to presence or absence of their Interior and Eskimoid traits.

If such ordering is contrary to stratigraphic or other age evidence, it might constitute a disconfirmatory instance of Drucker's hy- 
pothesis. If such a sequence seems in accord with present evidence, it might be a confirmatory instance of it.

Confirmatory instances of the Kroeber hypothesis, on the other hand, would show that cultures which have been found to be longest on the coast would have many Interior traits, and would approximate the ethnographic Plateau culture. Both Kroeber and Drucker are predicting something about man's prehistoric past. Borden continues the paper by examining these predictions about this early sequence on the Northwest Coast using the evidence from the Fraser Delta sites, and the Interior/ Eskimoid division of traits. The interpretation of Delta evidence becomes a test case of these two major positions.

\section{SITE ASSEMBLAGES CORRELATED WITH GENERAL SEQUENCE}

\section{Stselax}

Using the surface layer minimum division (page of my analysis of this paper), Borden reviews the artifact evidence first from the site with an historic horizon, Stselax village at Musqueam. In this assemblage are interior elements of the full woodworking complex, and early coastal elements of slate grinding with the complete absence of stone chipping, and fishing with two-piece toggling harpoons which "...may be regarded as descended from early Eskimoid toggling harpoons" (Borden $19512: 45)$

Marpole/Point Grey/Whalen II

Marpole, Point Grey, and the upper horizon at Whalen Farm (Whalen II) appear to belong to an intermediate period and show interior cultures in a state of transition [Borden 1951a:45]. 
Borden's ordering on the basis of Interior/Eskimoid traits places Whalen II in this category for the first time. The differences between Marpole-Point Grey and Whalen II fit with the Drucker-Borden time sequence hypothesis.

Marpole/Point Grey Assemblages. At Marpole and Point Grey, thin slate knives and, rarely and late, ground projectile points are "among the archeologically detectable signs indicating that... their occupants ...were being subjected to the influence of another culture already established on the coast..." (1951a:46). Every item on the interior trait list is found in the Marpole, Point Grey assemblages. "A11 of these and numerous other elements are patently of interior origin" (1951a:46).

The Problem of Certainty in the Hypothes is Above. This last line is important in the analysis of Borden's formulation and testing of hypotheses. He begins this paper explicitly stating its theoretical, hypothetical nature, and continues with the statement that the problem of the origin of traits still needs to have further archeological study. Then he states that the Marpole, Point Grey assemblages are clearly, openiy, "patently" of interior origin. This need not be seen as a cat-. egorical statement of fact. It is only consistent with the whole of Borden's work as a statement indicating the high degree of probability or certainty that Borden would attach to this origin of these traits. His defense of this high probability, and his examination of proposed evidence to the contrary is detailed in the 1954 paper, "Some Aspects of Prehistoric Coastal-Interior Relations in the Pacific Northwest". He re-examines the material again in a 1961 symposium paper (1962a), with new evidence, and with different conclusions. 
Whalen II. Continuing with the site analysis, Borden notes that the Whalen II assemblage contains the wood-working complex, and much stone chipping but with some types unlike Marpole. Whalen II people retained their interior chipped knives rather than the earlier coastal slate knives, but unlike Marpole inhabitants, they adopted the two-piece toggling harpoon, "... which had been developed on the coast prior to their arrival [at Whalen I]" (Borden 1951a:46). Both the interior chipped knives and the interior barbed harpoons disappeared "... in the fully developed southern Northwest Coast culture...", (1951a:46) and their coastal equivalents remained.

Whalen I

Whalen I, underlying this modified interior culture, is quite different. Borden sums up the evidence that this site, the only clearly stratified site with contrasting cultures in the Delta, is an instance, or test, tending to confirm Drucker's hypothesis of "...an early, distinctly coastal component underlying a culture of modifled Plateau type" (1951a:47).

Too1/Product Argument. I have expanded the first argument dealing with the different pattern of Whalen I as follows:

[Negative evidence:]

[1] Most remarkable is the apparent absence in this earlier culture of all heavy-duty wood-working tools [1951a:46].

[General tool-task relationship hypothesis]

[2 In the absence of alternative tools for a particular task or product, the absence of tools indicates a task was not done, or a product was not made.]

[Hypothesis on probability of product based on tool efficiency:] 
[3 The increased efficiency of a tool makes more probable the implied product that it is designed to make; the decreased efficiency of a tool makes less probable that implied product.]

[Conclusion:]

[4] This implies, of course, the absence, as well, of all those things that can be manufactured [a) only, or b) only efficiently] with such implements,

[a] including plank houses

[b] and dug-out canoes [1951a:46].

The insertion of "only" in step three seems to be logically necessary. A 1973 personal communication with Borden on this hypothes is suggested the importance of efficient tools. Thus I added the "oniy efficiently" to his statement. It accurately clarifies his position at the later date and what possibly was his position in 1951. Because it may have been his intent, the additional general hypothesis, \#3, is necessary in order to reach the conclusion, \#4 above.

Discussion of Borden's Usage. Borden introduced this discussion of differences between the Whaten II and Whalen I culture pattern with a phrase of the sort far more significant than a casual reading might suggest. It is the sort of phrase that comes to alert the student of Borden's writing to examine the passage very closely. Of all the differences, "most remarkable" is the absence of the wood-working complex. Sometimes Borden will say "...Surprisingly..." or "Significantly,...", and the careful reader will search for the relationship that these markers denote. While making my analysis, I have noted "Why?" by many of these judgments. Sometimes the answers were within the text of the paper, and sometimes the answers were clarified in papers later in the published sequence.

If this statement were part of a full site report, the phrase 
"Most remarkable" would appear in context as part of the summary or conclusion of a large body of evidence and sub-hypotheses. Borden's full body of argument is not completed in 1973. Borden's short papers function as summaries of this un-published, even un-written body of evidence and reasoning. Upon questioning him, I find this background material readily in his mind, and often at hand among un-published papers. In the absence of Borden's complete material, it is well to look at all the evidence within these papers to expand an enigmatic but significant phrase of this sort.

Analysis of Emphasis on Presence or Absence of Wood-Working Tools. Why is the lack of the wood-working complex the most remarkable difference between Whalen I and Whalen II? The first reason, clearly documented in this passage, is the consequence of the line of reasoning which leads to the conclusion that dug-out canoes were absent, in relation to the conclusion of the line of reasoning that immediately follows it. Borden intends the close connection of these arguments. He proceeds from the end of one argument to the beginning of the next in this way:

[Conclusion of previous argument:]

[4] This Implies...the absence of all those things that can be manufactured with such implements, including plank houses and dug-out canoes.

[Conclusion from evidence following and 1950b:243:]

And yet [my emphasis], these early coast-dwellers were seamammal hunters [1951 a:46].

Borden continues with evidence: "They were the earliest users of two-piece toggles we have yet encountered" (1951a:46). Sea-mammal bones were also found in the deposit (Borden 1950a:243). Both direct and indirect evidence indicates sea-mammal hunting. 
The next premise is implied:

Sea-mammals of the types represented cannot be hunted except from a boat.

Borden finishes this argument by proposing an alternate boat type. It is part of the discussion of the Locarno Beach material, but will be seen to fit just as properiy at this point of the argument.

Again, as in whalen I, heavy-duty wood-working tools are absent and we must suspect that these people pursued these sea-mammals in skin-covered boats and that their dwellings were different from the plank-houses of the later perlods [1951a:47].

The absence of wood-working tools at Whalen I is "most remarkable" first for the relationship between these two lines of evidence, which together support an hypothesis of an early culture which used skin-covered boats, in contrast to the culture outstanding for its use of wood resources, the culture which continued from early times to the present.

The wood-working complex, from the interior trait list, is in contrast to the coastal orientation of sea-marmal hunting, skin-boat using peoples. Both of these aspects at Whalen I have parallels in other Eskimoid cultures. To find the lack of complete, efficient wood utilization underlying and therefore earlier than, Whalen II with its full components of the wood-working industry is the test or crucial instance of the third section of the Drucker hypothesis. This is probably Borden's second, and more complete meaning when he calls the absence of this component "most remarkable".

Whalen I as Eskimoid. To complete this interpretation of Whalen I, Borden goes over other traits in the assemblage, all in accord with an Eskimoid culture list. The few chipped points are of simple leaf 
shape. The slate ground implements include thin knives and lance heads. The bone points are ground with facets in the same manner as slate. Giant mussel shell was made into projectile points, knives, and scrapers. This use of almost entirely local material in manufacture is evidence supporting Borden's interpretation of Whalen I. This interpretation has three aspects:

[1] ...this culture in general gives the impression of a coastwise orfentation

[2] of long standing.

[3 It] . .bears little resemblance to the intrusive Indian cultures... [1951a:46-47].

Borden's evidence and reasoning leading to the conclusion that whalen II is intrusive was in 1950b, and in my analysis $p$.

\section{Locarno Beach I and II}

Closely related to Whalen $I$ and probably antedating 1 t 1 s the material from Locarno Beach I and II. If the Whalen I culture already bears little resemblance to the intrusive Indian cultures, there can be no doubt that at Locarno Beach we are face to face with a culture of pronounced Eskimoid pattern [1951a: 47].

The only item on the Eskimoid trait list that was not found in the interrupted work at Locarno Beach is the two-piece toggling harpoon. The argument of harpoon development in the 1950a paper results in the conclusion repeated above that Locarno Beach I and II antedate Whalen I. It is the ground slate knives that exhibit much variety in this site.

Ground slate knives are numerous and occur in a variety of forms ....Most of them are rather heavy implements with a thick back and with a straight or curving cutting edge. Quite a number are typical ulos. Small narrow blades like the Eskimo men's knives are also present [1951a:47].

The ornamental objects from Locarno Beach are interpreted as relating to coastal or more northern culture. (The deletions indicated below 
are references to illustrations in the paper.)

Carefully made lenticular stone beads and medial labrets of lignite...were among the ornaments used. Among the finds is a small figurine carved of antler, wearing a cone-shaped hat and a labret in the lower lip.... The figurine apparently was originally fitted to the top of a staff. [This was identified as an atlatl hook before 1959, see the 1969b paper on the subject.] Another clue to the ceremonial life of these people is provided by a small, carefully made replica of a human skull which was found lying near a human femur bone.... [This association is new information in this paper.] We cannot help but think of rituals among the Koniag, Nootka, and Kwakiutl in which similar objects played an important part [1951a:47].

In the 1950a paper, Borden had suggested connections between Marpole and Kwakiutl culture; this reference to Koniag, Nootka, and Kwakiutl is not explicitly worked out in that way. "We cannot help but think..." expresses a similarity that is not tied into a neat hypothesis, but probably serves to indicate evidence that Borden thinks interpretations by later researchers might profitably include.

Summary of Site Analyses

Analysis of the Locarno Beach site concludes this review. Each section of this analysis implicitly depends on the following logical relationship:

IF: we class these sites by Interior/Eskimoid traits

THEN: ....some particular conclusions are reached.... In this case, the consequent clause could read:

IF: we class these sites by Interior/Eskimoid categories,

THEN: Locarno Beach I and II are distinctly in the Eskimoid class. Borden has given us a hypothetical sequence of the Delta sites. He begins with an interpretation of site assemblages, which are at a relatively low level of abstraction. He compares these with trait lists 
organized to show place of origin, which, particularly with dating techniques used in 1951, are of a much higher level of abstraction.

\section{CULTURE STAGES}

Borden moves to a still higher level of abstraction in the next group of hypotheses. He generalizes the sequence into stages of culture history. He suggests in this argument that data from the Delta sites ...seem to indicate three main stages in the culture history of this area. They may be arranged tentatively in the following sequence:

1. Early Period--Eskimoid cultures

(a) Locarno Beach I and II

(b) Whalen I

2. Intermediate Period--Interior cultures in a state of transition

(a) Marpole-Point Grey-Locarno Beach III

(b) Whalen II

3. Late Period--Developed southern aspect of Northwest Coast culture Steelax Village at Musqueam and other Delta sites with historic and late pre-historic horizons. [1951a:47-48].

In each of the jerious, the sites marked (b) are interpreted to be temporally later than the sites marked (a).

\section{Comparison with de Laguna's Stages}

Borden compares this sequence with de Laguna's 1947 stages for the same area. He notes that her early stage, an "'ancient substratum of culture corresponding to Kachemak Bay I' (de Laguna, 1947, p. 12)" (Borden 1951a:48), could be interpreted to mean either that the early southern Northwest Coast is of the same age as Kachemak Bay I, or that it is "... an early martitime culture of Eskimoid stamp..." (Borden 1951a:48).

\section{Correlation with Coast Sal ish Presence}


His comments on de Laguna's Intermediate stage clarify Borden's hypothesis on the Coast Salish as he held it in 1951, and are evidence for the temporal sequence within the stages.

De Laguna's "Intermediate stage of culture represented by the Coast Salish sites excavated by H. I. Smith," would be more acceptable if it read (and this is probably what is implied) "excavated by H. I. Smith in present Coast Salish territory." Not all of Smith's sites necessarfly represent early phases of Coast Salish culture. My own inclination would be to place the "movement of Interior Salish tribes to the coast" Into the late phases of the Intermediate rather than frito the third or Late period [Borden 1951a:48].

The late phase of the Intermediate is Whalen II, so that here as in the $1950 \mathrm{~b}$ paper, we have Borden's hypothesis that this is the earliest known Delta site of early Coast Salish culture.

\section{AGE OF SITES}

He continues with a note of caution, and then an estimate of the age of the earliest sites. In 1950a, he spoke of the sterile underlying material at Locarno Beach and Marpoie being perhaps evidence that these cultures flourished before the coastal forest reached its present climax. Borden's 1951 age estimate in this passage was daringly early for its time.

Finally, it is hazardous to assign dates to these periods without Carbon 14 tests. It is probable, however, that the earl1est remains recovered in this region to date are not older than 1500-2000 years [Borden 1951a:48].

\section{SPREAD OF ESKIMOID TRADITION}

Borden proposes alternative hypotheses about the way "...the ear1y Eskimold culture spread to this region..." (1957a:48), and a type of test site suggested for his tentative choice between these alternatives. 


\section{Alternate Hypotheses}

My expansion of Borden's argument follows.

Either early Eskimoid culture "...developed locally under the influence of early northern maritime cultures..." (1951a:48) or early Eskimoid culture "...arrived here nearly fully developed" (1951a:48).

Confirmation procedures depend on a paraliel alternative. Archaeological evidence will either show gradual development or sudden change in stratified sites.

1. The first alternative in the archaelogical record of gradual development, would be an instance confirming the first alternative hypothesis. Its form would be: If a local population, which had arrived from whatever source earlier than Locarno Beach time had received direct or stimulus diffusion from the north and had locally modified these traits, then we will find instances of gradual change in these artifact assemblages of Eskimoid type.

2. The second alternative in the archaeological record, of sudden change, particularly with many varieties of a new trait or complex, would be an instance confirming the second alternative hypothesis. Its form would be: If Eskimoid cultural development with its variations, is found elsewhere and earlier, and if recent (Locarno Beach time) migration or strong diffusion brought these traits to the area at its climax stage, then we will find instances of sudden change in these artifact assemblages of Eskimoid type.

3. "The material from Locarno Beach I is too scanty to enable us 
to discern with certainty..." (1951a:48) between the hypotheses suggesting local development and suggesting arrival from el sewhere.

4. "There are Indications favoring the latter possibility" (1951a: 48).

\section{Arguments for Preferred Hypothes is}

Borden's argument for statement $\# 4$ from the 1950 publications runs thus:

a. There were two types of one-piece toggles found at Locarno Beach II.

b. If Locarno Beach I \& II are a developmental sequence, and

c. If the development of harpoons begins with fewer, simpler forms,

d. Then we would expect to find some kind of harpoon, probably one-piece, at Locarno Beach I.

e. We have only scanty remains from Locarno Beach I.

f. There were no harpoon points found at Locarno Beach I.

g. The Locarno Beach I and II site was completely obliterated.

h. It is possible that there were one-piece toggles used by Locarno Beach I people. (Borden 1950a:22, table 2, see the "?" at this place on the chart.)

i. Evidence a-d would tend to confirm the second hypothes is, as indicated in $\# 4$.

$j$. Evidence $e-h$ would limit the certainty of this evidence, due to small sample size, and the impossibility of future work at that site. 
k. Early deposits may be very hard to find.

5. "The answer to this and other questions can be supplied only by future work" (1957a:48).

\section{Subsequent Treatment of the Preceding Argument}

The student will find Borden retaining the division of Locarno Beach into two phases through his 1954 papers. This division, which is the basis of the foregoing argument, is abandoned by the next paper on the Delta sites, "West Coast Crossties...", presented in 1961. Due to small sample size in the early period, and significant similarities in artifacts common to both periods, the division was dropped. (Borden, pers. comm., 1973). From that time to the present Borden treats Locarno Beach as a single phase.

To bring the reader up to date, excavations in progress at Musqueam to be continued in 1974, a water-logged site rich in perishables, includes a Locarno Beach component which will answer many of the questions waiting since 1950 and 1951 but there seems to be no sign of two sub-phases at that site (Borden, pers. comm., 1973). The argument above is therefore one that seems in 1973 to be a short strand in the work of Borden, not in the current theoretical literature of the area.

\section{CATTLE POINT}

Borden next examines the Cattle Point material to see if the assemblages when ordered according to interior/Eskimoid traits make up a confirmatory or disconfirmatory instance of the Drucker-Borden thesis.

\section{An Instance of the Kroeber Hypotheses}


King had interpreted his material as an instance of the Kroeber hypothesis, "...a continuous evolution from a simple culture pattern depending chiefly on mainland resources to a full blown maritime economy" (Borden, 1951a:48). Borden summarizes King's interpretation in this way:

On the basis of the physical and cultural stratigraphy, King proposes a sequence of four culture phases which he terms Island, Developmental, Maritime, and Late. The Island phase, according to King, represents a culture pattern adapted to mainland resources, a hunting and gathering economy with some fishing. The Developmental phase sees the beginning of an adaptation to the utilization of sea resources which reaches its full height in the Maritime phase and continues in the Late phase (King, 1950, pp. 12,79ff) [Borden 1957a:36].

\section{An Instance of the Borden Hypotheses}

Borden's reinterpretation begins with the negative evidence in the earliest deposits of this seasonal site. My expansion of Borden's argument follows:

1. [IsTand and Developmental phases] "early cultural phases" (1951 a: 48-49).

a. Because this is a seasonal site, these are annual deposits

b. "The lowermost annual deposits apparently were very shallow..." (1951a:48)

c. "...the early cultural phases are poorly documented by artifacts,..." (1951a:48-49)

d. "...those made of bone and antler being especially rare" (1957a:48).

[Evidence "My own experience indicates":]

[1)] ...bone and antler will rapidly deteriorate and disappear in a short time if they are left on or near the surface [2)] but these materials will keep much longer and in many instances indefinitely if they are covered from the start with refuse or other material. 
[Specific instance of general statement $d$. 1) above:] [e. Since early deposits at Cattle Point were shallow, with conditions as in d. 1), J

[Conclusion from $c, d, e:]$

[f] It is unwise to infer too readily from the absence or paucity of implements made of such materials that they were not present originally [1951a:49].

2. Developmental Phase

a. Artifacts present and found include the following

1) one-piece Eskimoid toggling harpoons

2) two-piece toggles

3) ground slate knives and projectile points

b. Artifacts absent include heavy-duty wood-working tools

c. Classification according to Eskimoid/interior traits:

1) artifacts 1), 2), and 3) under $2 a$ above are of the Eskimoid list.

2) absence of $2 b$ is indication that an important plateauInterior element is lacking.

[Conclusion-hypothes is:]

[d. ...the suspicion seems fustified that a culture of Eskimoid pattern similar to that of Locarno Beach and Whalen I existed in the San Juan Islands as well.

[Conclusion-hypothesis:]

[3] It seems to me that it is not until after this early phase that a culture of modified Plateau type comparable to Whalen II appears at Cattle Point.

[Summary Hypothesis:]

[4] Thus, although the culture sequences at this site cannot be exactly equated with those of the Fraser Delta region, indications are, at least, that the developments in the two areas were similar [1957a:49].

\section{CONCLUSION}

Borden concludes this paper with a summary of his hypothesis, and 
suggestions of work that could lead to confirmatory or disconfirmatory instances. On the basis of evidence from Harlan I. Smith's excavations, the hypothesis or "...conclusion that the culture of this area was to be regarded essentially as a specialization from an originally interior culture base was perfectly justified..." (1951a:49).

Although we know as yet tantalizingly little of the early Eskimoid coast culture, enough evidence has come in to suggest that the current views regarding the earliest culture stage on the Northwest Coast may have to be revised, and that the nature of the subsequent development should be conceived not so much as a gradual specialization of an early interior culture base to the conditions of a new coastal environment, but as a welding and blending of an early interior culture [Marpole] with an early maritime culture [Locarno Beach] and of later stages of interior culture [Whalen II] with coastal cultures that had evolved under the direct impact of Eskimo culture [1951a:49].

To confirm or disconfirm this, Borden suggests work similar to the studies on Nootkan and Eskimo whaling practices. If the Borden position is correct, not only the Nootkan culture will show this influence. The test would be stated in the following form:

If the Borden hypothesis is correct, then

Similar evidence of Eskimo influence, although probably less strong, must be detectable in the historic and prehistoric cultures of other coast Indians [1951a:50].

Borden looks at the pre-history of the Northwest Coast as a developmental process, and asks that "...awareness on the part of ethnologists, linguists, and archeologists of the possibility of direct or indirect contact with Eskimo culture..." (1957a:50), may lead to new discoveries and understanding of the process. Borden spells out the areas where tests may be expected. From such diverse areas, heterogeneous evidence leads to much greater probability of the confirmatory instances. 
CHAPTER VII

\section{1b FRASER RIVER ARCHAEOLOGICAL FINDINGS}

Borden's one column summary in American Antiquity documents this statement of the opening of the article:

Our findings to date indicate that the archaeology of the Fraser delta region is far more complicated than Harlan I. Smith or even Philip Drucker anticipated. Every major site investigated so far has a distinctive character. At some of them culture sequences are clearly apparent [Borden 1951b:263].

Borden re-states the three classes of harpoon types, but his hypothesis that they are diagnostic elements is not the same as in 1950 when he arranged the sites by age according to the sequence of types, i.e., barbed, then one-piece, then two-piece toggle heads.

Two-piece toggles are present at sites with historic (Musqueam) and proto-historic (Whalen) horizons, but conspicuously absent at sites where very old (500+years) coniferous trees grow on the deposits (P. Grey, Marpole, and probably Locarno Beach) [1951b:263].

This much is the same as the 1950 hypothesis. Now Borden correlates the early toggling harpoon with the slate-grinding industry:

The one-piece (Locarno Beach II) and early two-piece (Whalen I) toggles appear to be part of a culture pattern in which the grinding of slate (for knives, arrow and lance heads) was of major importance; chipping is reduced to a minor role. Heavyduty woodworking tools are significantly absent. Sea-mammal hunting with toggle heads, ground slate projectile points, ulolike slate knives, elliptical medial labrets, and other elements suggest a culture which closely resembled early far northern cultures [1951b:263].

Borden's wording of the hypothes is in the preceding paragraph is cautious and tentative: "...suggest a culture which closely resembled early northern cultures". Except for the word "early", Borden could have 
accepted this statement of his position at any time since 1951 .

Borden next deals with "...implements suggesting the existence of an advanced woodworking industry (plank houses, dugout canoes, wood carving, etc.)" (1951b:263).

The advanced woodworking complex seems to have evolved among groups that had strong ties with the interior plateau [1951b: 263].

Again Borden does not postulate origin of elements, but words his hypothesis cautiously. He then correlates the woodworking complex with harpoon types and other elements:

At Marpole (because of inadequate work the situation is not clear here) and at Pt. Grey woodworking seems to be associated with the use of barbed harpoons with tang. In Whalen II woodworking implements appear together with two-piece toggles. Emphasis on chipping and complete lack of ground slate in whalen II may suggest recent arrival of this group from the interior. At Musqueam and other sites with historic horizons woodworking, fishing and sea-mammal hunting with two-piece toggles and the slate grinding industry are found together, forming characteristic components of the historic culture pattern of most of the Gulf of Georgia Salish groups [1951b:263]. 
1951C REVIEW OF M. W. SMITH...

Borden's other two published titles in 1951 are book reviews in American Antiquity. The review of Marian W. Smith's 1950 publication has little of interest in relation to Borden's own hypotheses. Indirectly, however, we can see the standards of scholarship by which he expects archaeological works to be judged. He is critical of Smith's classification of cultures into Early Bone, Late Bone and Eastern Stone, Coastal Stone after the division of Reagan's 1917 work, which Borden regards as misleading in the light of recent excavations in the area.

His most serious comment shows that her classification and data are suspect. Borden cites Smith's error in classifying "Eburne" as an example of Coastal Stone culture and "Marpole" as a major site of Early Bone, because "...'Eburne' and 'Marpole' are two names for the same site" (1951c:279). Finally, Borden cautions that Smith's speculation on areal relationships may be premature, and he suggests that the primary need is for more systematic excavations. 
CHAPTER IX

\section{7d REVIEW OF ARDEN KING: CATTLE POINT...}

Borden's American Antiquity review of King's monograph emphasizes that this "...is the first detailed report of a systematically excavated site on the Pacific Northwest Coast" (1957d:279). This is the evidence to support Borden's comment in his Smith book review that speculation needs to wait on systematic work. Up to 1951, Borden had not published detailed reports on his excavations. The student sees in this review what Borden considers important in such a work, and compares this with Borden's 1956 survey report. For instance, Borden's theories of classification are implicit in his criticisms of King's artifact classification, and in his evaluation of this area of archaeological work in 1951. Borden's discussion reveals his knowledge of artifact use, particularly of harpoons and other sea hunting and fishing artifacts.

Borden's comments on the theoretical aspect of King's work are as follows :

Arden King has built a convincing case for his main thesis, namely, that the Cattle Point deposits indicate a gradual development from a simple culture pattern based largely on land resources to an economy which efficiently exploited the rich resources of the sea. Only future investigations will tell, however, whether the contrast between the individual periods is as marked as it appears, or whether some of the present gaps in the trait lists of the Island and Developmental phases will eventually be filled when a more complete record of the early culture has been obtained [1951d:281].

This paragraph seems to indicate Borden's agreement with King's (and Kroeber's), thesis. The only reservations are expressions of changes 
that may come with future research erasing the discreteness of the stages by filling gaps in the traits missing at this site. Because Borden's "Facts and Problems...", published in this same year, presents his alternative interpretation of King's data, I wondered if this review had been written earlier than "Facts and .iublems...". Dr. Borden has informed me (pers. comm., November, 1973), that he was working on both papers at the same time. Since not everything could be put in the book review, Borden limited the comments to those that affirm the logic of King's case. King's data do support the Kroeber hypothesis. In "Facts and Problems...", Borden develops the thesis that the King data also support the Drucker-Borden hypothesis. In summary, this review does not represent any change in Borden's 1951 position. 
CHAPTER $X$

1952a AN ARCHEOLOGICAL RECONNAISSANCE...

In the two papers published in 1952, Borden describes the survey of archaeological sites in the north and central interior of British Columbia, and the subsequent excavations of several of these sites. The map of the following page, Figure 5, shows the area reported in these papers. The present paper appeared in Museum and Art Notes, which was the publication of the Art, Historical and Scientific Association, was sixty years old with this April, 1952 edition. It contains articles on anthropological, geological, paleontological, and historical subjects.

Borden describes the survey area, and the urgency and nature of the survey process. The first part of the paper presents the evidence of artifacts and other archaeological features observed in the survey area. The hypotheses in this part of the paper organize and relate this evidence. Finally, Borden formulates an extended series of hypotheses related to this evidence, to be tested by further investigation.

In the fall of 1952, a power reservoir would begin to flood the survey area, which would be covered by the following year. Archaeological evidence would have to be recovered before that time.

\section{SURVEY EVIDENCE AND HYPOTHESES}

Background Information 


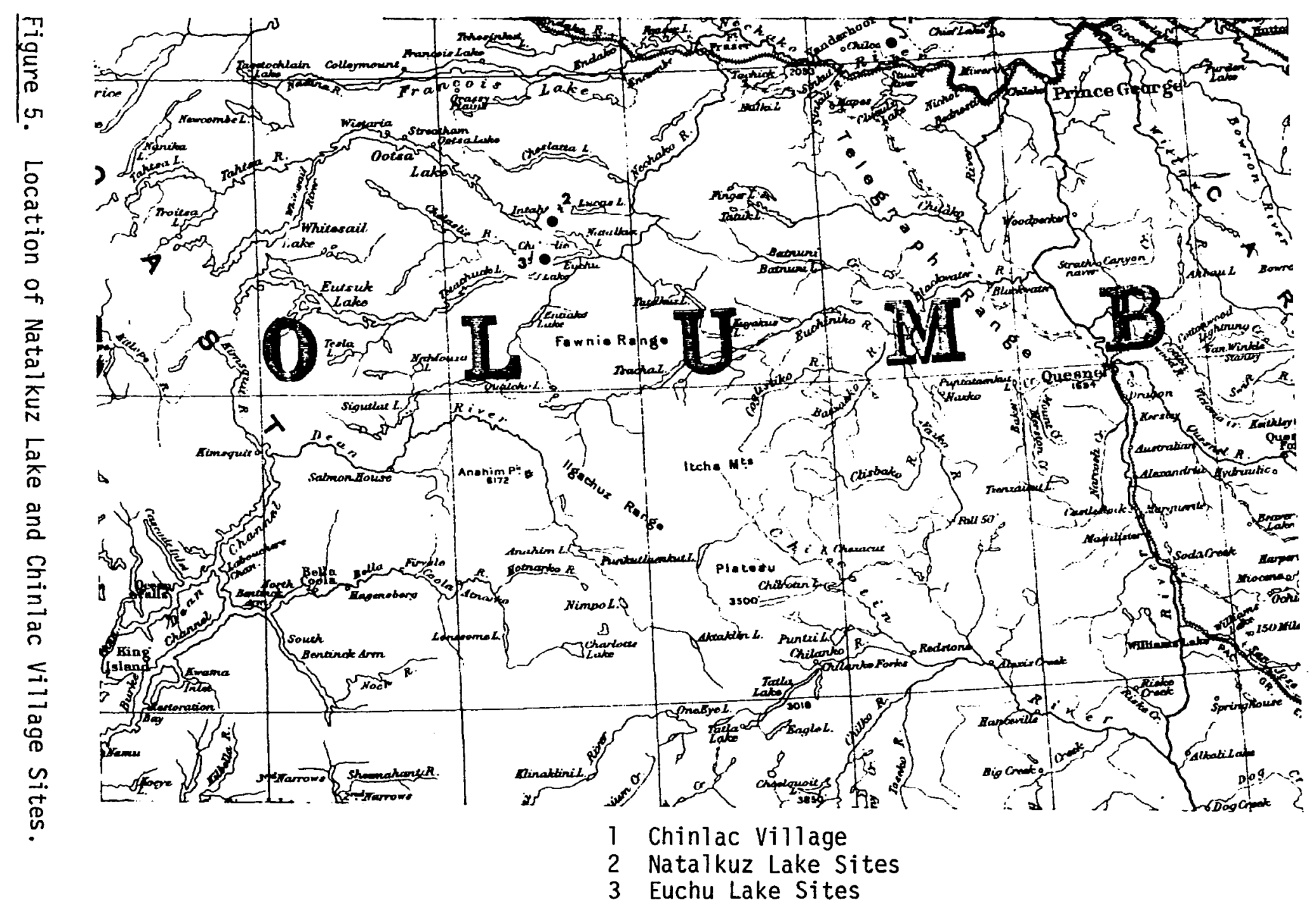


The interior plateau of northern and central British Columbia is archeologically one of the least known regions of North America.... The projected flooding of 300 square miles of archeologically unexplored lake and river margins constituted a major threat to our knowledge of the prehistory and cultural development of the Pacific Northwest and of other parts of North America [Borden 1952a:9].

Geography. The survey area extended from the eastern edge of the Coast Range nearly 120 miles east "...into the hilly country of the interior plateau" (1952a:9). It is a territory of lakes and rivers "... drained by the Nechako River, which empties into the Fraser at Prince George" (p.g). Borden distinguishes three sub-areas:

1. The lakes and rivers within or just east of the Coast Range,

2. Central lakes, and

3. Eastern rivers and lakes, including Natalkuz and Euchu.

Resources. Borden's brief description of the resources of the area is as follows:

Much of the shoreline of the various bodies of water is lined with forest, which is preponderantly coniferous in the westernmost part, while in addition to conifers some species of deciduous trees, such as quaking aspen and cottonwood, are conspicuous in the central and eastern portions. Berries of various kinds grow in great profusion at many places.

There is a considerable variety of game. Mountain goats and caribou graze on the slopes above timberline, while black bear, mule deer, and moose inhabit the lower forested areas. Grouse occur in considerable numbers, and many of the swamps abound in water fowl. The lakes and streams are well stocked with trout, whitefish, and suckers. It is important to note, however, that moose were not observed in this area until just prior to the First World War, and that salmon, the basic food staple of most of the Indian groups in coastal and intertor British Columbia, are completely lacking in all these waters [1952a:9].

Climate. Borden infers from the evidence of heavy snow in the western sub-area, and the absence of the snowshoe prior to the nineteenth 
century, as follows:

... [These] suggest that in pre-contact times the Indians [Hypotheses:]

[1] used the western portion of this area only during the warm season and

[2] that they spent the winters in falrly permanent quarters somewhere in the eastern half,

[Evidence:]

where conditions in winter are less severe [1952a:9-10].

Ethnographic Information. Ethnographic hypotheses are considered

next:

Very little is known about the people who ranged over this vast tract in early historic days. According to information gathered during the past summer by Mr. Wilson Duff,

[1] the Cheslatta, a subtribe of the Athapascan-speaking Carrier Indians, included in their territory all of the land that is to be flooded.

[Evidence:]

Their known villages were concentrated in the eastern area around Cheslatta Lake, which is just outside and northeast of the territory under consideration.

[2] The Cheslatta are said to have made annual trips to the Tahtsa, Whitesail and Eutsuk areas to hunt mountain goat, bear and caribou, and to gather berries.

[3] Some of them, according to reports, made occasional trips west over the Coast Range to fish for salmon in the headwaters of the Kimsquit River.

[4] Others went north to join other Carrier groups in the salmon Eishing on Fraser Lake [1952a:10].

Borden then gives evidence, from the historic period, of trade routes between the Cheslatta and the Kwakiutl and Bella Coola groups on the coast.

[5] According to informants the Cheslatta took furs and skins to trade for oolachan grease and White Man's goods.

[6] It is probable but not certain that such trading went on even in precontact times [1952a:10]. 
Finally, Borden suggests the interior groups having significant relationships with the Cheslatta:

[7] The Cheslatta must also have had frequent contacts with the neighbouring Carrier subtribes, with the Bulkley River people, with the groups on Fraser Lake and Stony Creek, and with the Algatcho to the south.

[8] It is probable, too, that they traded with another Athapascan-speaking people, the Chilcotins, in whose territory is located the Anahim Peak, the sole source of obsidian for many Interior Indians.

[Evidence of most recent Cheslatta history:]

After the Cheslatta were nearly wiped out by a smallpox epIdemic in 1838 the Bulkley River Carrier took over much of the former hunting territory of thelr ill-fated neighbours [1952a:10].

\section{Survey Procedure and General Results}

Borden and two others, "...Mr. Alan Bryan, an advanced anthropology student at the University of Washington, and...Mr. Robert Steiner, an expert photographer and graduate of the University of British Columbia" (p.10), surveyed by boat and car, under difficult weather, water, and road conditions.

In the course of the reconnalssance more than 400 miles of lake and river margins were examined. Our party put ashore nearly 600 times to investigate likely-looking areas. Sites that were located were charted on maps and pin-pointed on airphotos. Copious data were assembled on the nature of sites, on habitations, cache pits, sweat-houses and other features. Numerous photographs were taken, and many artifacts, samples of raw materials, and food remains were collected [1952a:10].

Summary of Sites. This is Borden's summary oi the results:

The reconnaissance resulted in the discovery of a total of 130 sites. More than half of these were small camps, only briefly, although in many instances probably repeatedly occupied for hunting, fishing, berry-picking, or the gathering of bark and of pinetree cambium. Such sites were usually present in sheltered bays or coves, especially if a marsh or 
swamp with good hunting prospects was near at hand [1952a: 10].

Twenty-five sites were cache, or storage sites, some of them on small islands in the lakes. Evidence of habitation forms shows two types probably had been used:

We discovered thirty-six circular pits of semi-subterranean houses ranging in diameter from twelve to twenty-six feet. The majority measured less than nineteen feet across, only five were nineteen feet in diameter or larger. [Note in the 1952b paper, the data relating to size after one of these habitations was excavated.] The depth was between two and three feet plus a varying amount of fill. Usually these house pits occur singly, rarely in pairs or in groups of three. Only at one site did we find a small village community. At two localities we were able to discern the faint outlines of rectangular houses. At one old village site there were eight of these houses arranged in a line behind the beach with the narrow end of the structures facing the water [1952a:12].

Distribution of Sites. Borden notes the distribution of these habitation sites, with "...only sixteen small camps in the westernmost..." (p.12) sub-area.

[1] This area [west sub-area] apparently was not intensively utilized in prehistoric times [p.12].

This first habitation hypothesis, and several of the following ones, logically depend on the assumption that the sites discovered represent a fair statistical sample of total sites in the area. The central lakes did not appear to have many sites:

[Evidence:]

Huge Ootsa Lake with more than one hundred miles of shore line yielded only the rather small total of forty-two sites.

[Hypotheses:]

[2] Most of these were temporary hunting and fishing camps.

[3] Nearly all the remainder were cache pit sites.

[4] Only two localities were discovered on Ootsa Lake where the evidence suggested more than very temporary occupation. 
[Evidence:]

These were two house-sites on the north shore of the lake with two circular house pits at one site and three at the other [1952a:12].

Borden then discusses the eastern sub-area where they found "... unexpected archeological richness..." (p.12).

[5] The survey in this portion of the park disclosed much evidence of [what is interpreted as] more permanent and intensive occupation.

[Evidence:]

On Euchu Lake, for instance, no fewer than sixteen sites were concentrated in an area of less than two square miles. It was only in this eastern portion that midden accumulations of measurable depth were encountered.

Twenty sites with circular and two with rectangular houses are located on the shores of the eastern lakes. It was on the north shore of Euchu Lake that we found evidence suggesting the former existence here of two small village communities, one consisting of circular pit houses, the other of rectangular dwellings [1952a:12].

\section{Artifacts}

Distribution. Borden then turns to a summary of artifact evidence. First, he gives the geographic distribution of this evidence:

The western and central portions of Tweedsmuir Park were marked by a paucity of artifacts, although chipping detritus --the waste product in the manufacture of stone implements-was present at most camps. At one site on Natulkuz Lake in particular, we found a great abundance of stone flakes and artifacts along 720 yards of lake shore [1952a:12].

Natulkuz Lake/General Survey Area Contrasts. The evidence from this last Natalkuz Lake site is examined in four ways. Borden contrasts the artifacts found there with the artifacts found generally throughout the survey area according to

1. Their tool types, 
2. Their raw materials,

3. Their manufacture techniques and

4. Their geographic distribution.

The whole survey area, including the Natalkuz Lake site, contained scrapers, knives and projectile points, usually made

...of basalt and obsidian, more rarely of quartz, chalcedony, and fasper. Although implements and chipping debris of such materials are not absent at this Natalkuz Lake site, by far the most common raw material is a buff to reddish rhyolite [1952a:12].

Borden does not attempt to classify these rhyolite tools by type except in a general way:

As a rule, these artifacts are of Indefinite outline and indeterminate usage. Many of them could have been employed for cutting, scraping, or chopping. No projectile points were found at this site [1952a:12].

The manufacturing techniques contrast in this way:

The rhyolite tools...differ from the others not only in type, but also in their ruder manufacture. To be sure, some of the basalt and obsidian implements are simple flake tools, made with a great economy of effort, but a combination of percussion and pressure flaking techniques is applied to most artifacts of these materials. The usually larger rhyolite tools, on the other hand, appear to be made exclusively by percussion chipping, the implements having been hewn into shape by detaching fairly large flakes with no or very little secondary chipping [1952a:12].

The limited geographic distribution of these rhyolite tools is not caused by scarcity of the material.

Obsidian...had to be imported. Rhyolite, it is significant to note, is a suitable raw material which is available in many parts of the park area. But aside from a few isolated rhyolite flakes at sites not far to the east and west of the Natalkuz Lake site, the only other localities where we found evidence of this rude rhyolite industry were on the southern shore of the Lake, directly opposite the type site and again six miles slightly southwest of here on the north shore of Euchu Lake [1952a:13]. 


\section{HYPOTHESES FOR TESTING}

With this evidence before us, Borden formulates an extended series of hypotheses for future testing in this area.

\section{Tentative Nature of the Hypotheses}

He begins with a caution about the problem of such preliminary theories:

It is impossible to offer at this stage of our investigations an adequate interpretation of the evidence presented by the various stone tools that were collected. The task is made even more difficult because of the paucity of reliable comparative material from central British Columbia [1952a:14].

[Hypotheses:]

[1] It seems...that small chipped points with lateral notches ...were very common among Carrier Indians in late prehistoric times...

[Evidence for this probability comes from preliminary work at Chinlac village, occupied just before and after contact times.]

[2] It is perhaps significant, too, that simple leaf-shaped points, a few of which were found in Tweedsmuir Park...did not occur at Chinlac. [In other words, this form is diagnostic.]

[3] They [leaf-shaped points] may belong to an earlier period.

[Confirming evidence:]

Points of such simple outline seem to antedate more complicated forms in other parts of British Columbia [1952a:14].

Argument for Cultural or Traditional Basis of Raw Material Preferences

Borden proceeds with evidence and hypotheses related to the only projectile point made of rhyolite, found in the central sub-area. It is made with "...expertly controlled ripple flaking..." (p.14), which is evidence that

[4] ...rhyolite was a raw material eminently suitable for fine pressure flaking [1952a:14]. 
I am supplying the implied reasoning leading to hypothes is \#8 below:

5. Therefore raw material is not the limiting factor in either the manufacturing method or the artifact types at the Natalkuz site.

Evidence:

In this area rhyolite is widely available, and basalt and obsidian (particularly the latter) are harder to obtain.

6. If choice of raw material for projectile points depended on availability of raw material only, then the raw material of the artifacts would be found to be in the same mathematical ratio as the raw materials themselves.

Argument:

We can deny the consequent of the above, \#6, hypothesis from the evidence above it. (In other words, the evidence proves it false.) We can then prove that the antecedent of the hypothesis is false. 7. The variables that Borden considers in the choosing of raw materials for artifacts are:

a. The suitability of the raw material for the needed tool

b. The materials available

c. The individual person's preference

d. The group's preference or custom

Summary: Because of the geographically "...widespread preference..." (p.14) for the rarer materials, Borden has eliminated variable c. as well as a. and b. above. He supposes a cultural, group-derived value in the preference he has observed, and infer- 
red, from his survey observation. He therefore concludes with

this hypothesis:

[8] There must be certain, as yet unknown, cultural reasons for the widespread preference for basalt and obsidian despite the greater availability of rhyolite [1952a:14].

\section{Argument for Two Cultural Traditions}

The presence of this finely worked artifact is then used as evidence for the next argument and series of hypotheses:

[Evidence:]

On the other hand, [looking at the fine manufacturing technique, rather than the projectile point: raw material ratio as above] the skillful flaking of this rhyolite point further serves to set off the crude chipping technique evidenced by the numerous rhyolite tools recovered at the three sites on Natalkuz and Euchu Lakes [1952a:14].

Borden states the hypothesis of two lithic industries, and the four differences by which he classifies or distinguishes them:

There seems to be, thus, good evidence for

[Hypothes is:]

[9] the existence in this area of at least two distinct 1ithic industries

differing not only in

[a] material,

[b] techniques of manufacture, and

[c] types of implements, but also in

[d] distribution [1952a:14].

\section{Argument for Relative Age of the Two Traditions}

Borden then gives much more abstract hypotheses concerning the groups using these two 1ithic industries:

[10] Most of the implements of the more widespread industry were probably left behind by the Cheslatta and other Carrier groups who still ranged over this entire area in recent times.

[Evidence:]

[a] On the other hand, the restricted distribution of the ruder stone industry, and 
[b] its concentration at sites oriented nearly north and south from each other,

[11] hints that these implements may be the remains of a different

[12] and possibly more ancient group of people,

[13] who may have passed through this territory along an old migration route.

[Qualification:]

This interpretation of the evidence must, of course, be regarded as tentative. The data on hand pose important problems which urgently demand fuller investigation [1952a:14].

This needed investigation has been one of Borden's concerns ever since this paper.

Types of Evidence Too Fragmentary to Suggest Hypotheses

The next section gives the evidence of habitation types and shell remains relating to this proposed research:

Virtually nothing is known of house types in Carrier territory in prehistoric times, and even the information of Carrier houses in the post-contact period is vague and contradictory. The occurrence on Euchu Lake of two villages, each with a different house type, is therefore of great interest. Excavations that must be made at these villages should produce not only information on the structures themselves, but also other important data that will throw light on the culture history of this area [1952a:14].

This, and the evidence below is fully developed in the second, 1952b, paper about this area. Neither area of research is expressed in the present paper in terms of hypotheses, but both are fully developed

as a series of hypotheses in the second paper.

The discovery of a worked fragment of the shell of Mytilus californianis, a saltwater mollusc, at a prehistoric site on Euchu Lake raises the further hope that through intensive investigations here we may learn something about early contact between coast and interior Indians of this area, another important problem about which nothing is known at present [1952 a: 14$]$. 
III. HYPOTHESES RELATING TO LINGUISTIC AND OTHER DATA

Borden's final group of hypotheses deals with population movements, at the highest level of abstraction of any hypotheses in this paper.

\section{Linguistic Hypotheses}

[14] The ramifications of some of the data may be more farreaching than is apparent now. [In other words, the evidence and hypotheses above are instances relating to the hypotheses below:]

[Hypotheses from linguistic evidence:]

[15] We only need recall that the Athapascan-speaking groups of Washington, Oregon and northern California in all likelihood passed through the intermontane plateau of British Columbia

[16] and that the Nicola, Chilcotin and Carrier of the area are linguistically more closely related to the distant Navaho and Apache of the Southwest than to some of their nearer relatives to the north.

[17] Movements of Athapascan-speaking peoples southward may have been preceded by those of other groups.

[Alternate hypothesis to 17 above:]

[18] On the other hand, it is entirely possible that some of the ethnic groups now living in British Columbia entered this area from the south by way of the interior plateau [1952 a: 14$]$.

Recent 1 inguistic work by Krauss would tend to disconfirm hypothes is \#16 above (Suttles, pers. comm., 1974). The strands of argument in these last five hypotheses are to be found among Borden's writings up to the 1973 paper:

Hypotheses on Peopling of the New World

Borden concludes with these general New World hypotheses as related to Canadian sites: 
It is not generally realized that in Canada lie buried the clues to many of the problems connected with the early peopling of the New World,

[19] for the ancestors of all the Indian tribes now residing south of Canada, in North as well as in South America, once lived on and passed through Canadian territory.

[Tentative nature of present knowledge:]

Archeology has barely scratched the surface in Canada, and we do not know precisely where we shall find the early remains of the ancestors of these numerous peoples.

[20] Many now doubt lie buried in the Yukon

[21] and in the hills and on the plains east of the Rocky Mountains.

[22] It is very probable also that others will be found in the plateau area of interior British Columbia [1952a: 14-15].

The formulation of these or similar hypotheses changes with increased and complex evidence. Testing them at geographically and temporally varied sites, tends to increase (or decrease), their probability.

By 1953 the important sites on Natalkuz and Euchu lakes will be flooded. Only a single summer remains in which intensive emergency investigations can be carried on in the threatened area $[1952 \mathrm{a}: 15]$.

We can read in the next paper of this subsequent investigation. 
CHAPTER XI

1952b RESULTS OF ARCHAEOLOGICAL INVESTIGATIONS...

Borden's introduction to this paper, published in Anthropology in British Columbia, contains almost the same geographical and ecological information about the area that he wrote in the preceding, 1952a, paper. The history of archaeological work is the same as the previous account with two additions in the present paper. First, Borden tells about the only other Irterior archaeological investigations in British Columbia, by Harlan I. Smith in 1899 and 1900. These were farther south, in Thompson Indian territory, "... around the confluence of the Thompson and Fraser Rivers, and along the valley of the Thompson River between Spences Bridge and Kamloops..." (7952b:31). Second, he reports on an excavation at Chinlac village, which is outside the area of Tweedsmuir Park, about eighty miles east and slightly north of the Natalkuz Lake site.

In August, 1950, we began the excavation of a rectangular house at Chinlac village, a long-abandoned Carrier Indian settlement near the junction of the Stuart and Nechako Rivers. Excavation of this house was resumed and completed in June, 1952 [1952b:31].

The summary of investigations reported in this paper continues in this way:

...intensive salvage operations were conducted in July, August, and September of ...[1952] at a selected few of these sites on Doisa, Natalkuz, and Euchu Lakes, and near the mouth of the Tetachuk River [1952b:31].

Work in this area had financial support from the University of 
British Columbia, the Provincial Government, and the Aluminum Company of Canada Ltd, whose power reservoir flooded the Tweedsmuir Park area.

The balance of this paper deals with three concerns.

1. The evidence and interpretations of the Chinlac village investigation.

2. The excavation at Natalkuz Lake, comparing this assemblage and the features at this site with Chinlac village material.

3. Possible implications of this research.

\section{CHINLAC VILLAGE}

\section{Ethnographic Information}

Borden gives ethnographic evidence about the people who lived in this village.

The former inhabitants of Chinlac constituted one of the two branches of the Tano'tenne, a Carrier sub-tribe, whose other branch was the people of Leitli, a village at the confluence of the Nechako and Fraser Rivers in the present vicinity of Prince George (Morice, 1895, p.25) [Borden 1952b:32].

Morice (1904:14ff.) described the abandoning of the site "...after most of its inhabitants were massacred by a band of raiding Chilcotin Indians" (Borden 1952b:34).

\section{Habitations}

\section{Surface Features.}

Before it was overtaken by disaster..., the village of Chinlac must have presented an impressive sight. Still visible are the shallow depressions of ten large rectangular houses, arranged in an extended row along the brow of the high, steep bank of the Stuart River. The size of the depressions varies somewhat, but the average dimensions are approximately 25 by 40 feet. One of the narrow ends of the houses faced the river [Borden 1952b:32]. 
Excavation. Excavations of one of these houses revealed evidence that the roof had been supported by two large posts midway between the narrow ends of the house, and two smaller ones midway along the 40 foot length of the building.

[Habitation hypotheses:]

[1] The original posts appear to have supported a long single ridge-pole, consisting of two spars placed end to end, with the smaller ends by-passing each other in the middle of the house.

[Evidence:]

A layer of decayed vegetable matter, soil, and rocks, overlying the deposits of the house-floor,

[2] suggests that the gabled roof was covered with bark and sod,

[3] and that it probably sloped from the ridge-pole all the way to the ground.

[Evidence:";

The excavation, however, did not disclose a discernible pattern of slanting post-holes or depressions which might have held the butts of rafters, but numerous small irregularly spaced post-holes ran along both sides of the house.

[4] The pusts in these holes could not have constituted a wall because the distances between them are too great.

[5] Some of these posts, however, may have held in place low lateral supports of two or three horizontal logs on which the rafter butts could have rested.

[Ethnographic confirmation:]

A structural arrangement of this sort, which suggests an incipient side-wall, was apparently used occasionally by the Chilcotin Indiéns (Lane, 1952).

[6] The narrow ends of the house seem to have been braced by a number of slanting posts propped against them from the outside.

[7] Several other groups of holes next to the dwelling may have held the pcles of raised caches and drying-racks.

[Evidence:]

The most prominent feature in the interior of the excavated house 
was a thick broad bed of ash extending for 35 feet along the middle of the long axis of the structure.

[8] Apparently there were six individual hearths arranged close together in three opposite pairs [1952b:32].

The Argument. These hypotheses are at a very low level of abstraction, being closely tied to the material evidence of post-holes, and so forth. For a parallel treatment of artifacts by Borden, see his 1956 paper reporting another Interior British Columbia investigation. In that later paper, he begins with use-marks on the artifacts in making tool-type classifications.

\section{Artifacts}

The Argument. In this paper, he interprets the evidence from artifacts found at the site in a more general way, mentioning the types of tools, usually without the evidence for their classification. Therefore, these hypotheses are mostly at a middle level of abstraction.

Stone Industry.

[Evidence pertaining to chipped stone artifacts, Statistical importance:]

Chipped stone implements constitute the largest proportion of the more than 1,500 artifacts that were recovered...

[Raw material order of frequency:]

The raw materials for stone tools in the order of their importance were basalt, obsidian, quartz, and coarser igneous rocks.

[Size and method of manufacture:]

With few exceptions, the chipped implements are sma11, of ten diminutive, and most of them are finished by pressure flaking.

[Artifact hypotheses:]

[1] They include [what are interpreted to be] end and side scrapers, projectile points of various types, knives, drills, and numerous unworked irregular flakes that were used for scraping and cutting operations.

[At a higher leve] of abstraction:] 
[2] The thrifty use of such flakes, which many other groups would discard as waste, seems to have been a common trait among the Carrier Indians.

[Evidence pertaining to ground-stone artifacts,

Statistical importance:]

The technique of grinding stone was employed only sparingly.

[3] It seems to have been used chiefly for finishing adze blades, whose shape had been roughly blocked out by battering and chipping....

[4] Abrasive stones and whetstones, which are so numerous on the North-west Coast, are therefore quite rare in this part of the Interior.

[5] Some of the abrasive stones that did occur no doubt were also used for abrading bone, antler, and wood.

[See the expanded argument leading to this hypothesis following hypothes is \#8, below.]

[6] Of interest is the occurrence at ChInlac of rectangular grooved arrow-shaft smoothers....

[Evidence pertaining to bone and ant]er artifacts, Statistical importance, order altered:]

...only few implements of these materials were recovered, and those were usually in poor condition.

[7] Although work in bone and antler must have been an important industry among the Carrier Indians,...

[8] Artifacts of these materials include [what are interpreted to be] awls, small slender pointed objects, a small projectile point, and one oval bone pendant with a circular hole in the centre, possibly for an inset.... [Borden 1952b: 32].

Argument Pertaining to Bone and Antler Use. Logically, hypothes is

\#8. I would re-order and expand Borden's argument in this way:

a. The awls and other bone and antler artifacts show marks of manufacture by abrading.

b. The paucity and poor condition of artifacts of these raw materials probably indicate that many others have disinte- 
grated since they were deposited.

c. We have ethnographic evidence of wood artifacts made by abrading being used by these people.

d. Wood artifacts disintegrate even more rapidly than bone and antler.

e. (Hypothesis \#4) Therefore, since stone worked by abrading is rare in the area,

f. (Hypothesis \#5) "Some of the abrasive stones that did occur no doubt were also used for abrading bone, antler, and $\operatorname{wood}^{\prime \prime}(p .33)$.

Steps $c$. and $d$. seem to be logically necessary even in the face of abundant evidence of birch-bark, below. To return to Borden's artifact hypotheses:

Birch Bark.

[Evidence pertaining to birch-bark,

Statistical importance:]

Among the most abundant remains at Chinlac were cut pieces of birch-bark,

[9] most of these obviously detritus from the manufacture of birch-bark containers

[10] and possibly of canoes.

[Evidence of 'use-marks':]

Some of the bark fragments had series of stitching holes. Also recovered were numerous small birch-bark rolls, often charred at one or both ends.

[11] It is probable that these,... were used as torches...

[Ethnographic confirmation, order altered:]

...like similar rolls recovered by H. I. Smith in Thompson territory near Lytton,...(1899, p.160f.) [Borden 1952b:33].

Scrapers. In presenting evidence and hypotheses about scrapers, Borden so abbreviates his reasoning that even by changing the sequence 
of his statements, I cannot follow the pattern of his reasoning as I have above. I have therefore added some of the implicit steps in reaching the hypothesis \#13, as follows:

[Evidence pertaining to scrapers, Statistical importance:]

[There is a] ...great frequency of scrapers

[12. Scrapers are primarily used in hide preparation]

[13] The importance of dressing and tanning skins for clothing and other purposes is [thus] indicated by the great frequency of scrapers.

[Evidence of size:]

Most of these are of small size, but a few are quite large.

[14] Some of the larger scrapers, especially those provided with a tang, were no doubt hafted to a long handle....

[Ethnographic citations:]

(cf. Morice, 1895, p. 50f.; Jenness, 1934, p. 39, illustration) [Borden 1952b:33].

\section{Presupposition of an Accurate Sample}

In each artifact category, Borden bases hypotheses on the relative frequency of each type. Implicit in this whole section, then, is the presupposition that his collected sample represents a fair statistical sample of the artifacts used by those who lived at this site. This is also basic to my expansion of Borden's argument leading to the fifth hypothesis, concerning irregularities in the sample due to poor artifact preservation.

Features Suggesting Wood Use

Various archaeological features and remains in and around this excavated house lead to hypotheses about the wood utilized, and the foods secured, prepared, stored, and disposed of. Borden first examines ev- 
idence of wood use:

[Evidence: ]

The large semi-circular clearing behind the village, which is only slowly being reinvaded by the surrounding pine forest, and the paucity of old deadfall within a wide radius from the village are evidence of

[1] extensive wood utilization for construction purposes and fuel.

[2] It may also indicate a fairly long occupation of the site, perhaps extending over a period of a century or more.

[Evidence: ]

The occurrence of charcoal at the bottom of some post-holes hints at

[3] the practice of felling trees by building a fire around the base of the trunk [1952b:33].

\section{Food and Diet}

From evidence of food remains, Borden begins his interpretation

of the diet and food quest of these people:

[4] The Carrier seem to have been in the habit of burning food refuse in their hearths,

[Evidence for \#4 above:]

for the ash in the house was filled with thousands of small

fragments of calcined bone.

[5] The food remains emphasize [or lend weight to our interpretation of] the importance of small game, such as squirrels, porcupines, beavers, and birds.

[6] However, deer and black bear were hunted [and eaten] as well.

[Evidence:]

The bones of fish, including those of salmon, also occurred.

[Implicit hypothesis:]

[7. Salmon and other fish were eaten.]

[Evidence:]

Large accumulations of cracked and crackled rocks 
[8] tell of [or are interpreted as indicating] the use of heated stones in cooking food in bark containers [1952b:33].

The wording of two of these hypotheses reflects Borden's concern that the evidence tells the story, as he said in the 1950b paper. Here he has said, "These food remains emphasize...", and "Large accumulations of... rocks tell of the use...". The wording does not reflect the human element of choice in formulating even very low abstraction hypotheses. To continue with his food quest hypotheses:

[Evidence:]

The numerous small projectile points

[9] indicate the importance of the bow and arrow in the food quest.

\section{[Evidence:]}

Deep rectangular excavations in the direct path of old game trails are evidence that

[10] larger game was also taken in pitfalls.

[Evidence:]

The presence of clusters of stunted nettles at the site, away from their natural habitat, suggests that

[11] the stalks of these were taken to the village to work the fibre into lines and nets for fishing.

[Ethnographic evidence:]

From the information of one informant, we may infer that

[12] Some of the small stone scrapers were used in removing the cortex from nettle-stems.

[Evidence:]

The country all about Chinlac abounds in berries of various species,

[13] and these must have formed an important part of the diet.

[Ethnographic evidence:]

According to informants, berries were mashed and bolled down to the consistency of a thick paste which was then spread over slat-frames and placed over shallow rectangular pits for drying. 
[14] Rectangular pits which may have served this purpose are found near the village.

[15] Food was stored not only on raised caches, but also in circular pits having the shape of inverted cones.

[Evidence of \#15 above:]

A typical food-cellar of this kind is from 5 to 6 feet in diameter and from 3 to 4 feet deep. Many hundreds of such storage-pits are located on two sandy ridges behind the village and along the opposite bank of the river [1952b:33].

\section{Ornamentation and Trade}

Ornamentation is sometimes a distinguishing feature of a culture. It also can be a clue to trade between peoples. Borden next deals with both of these subjects, and uses these hypotheses to evaluate ethnographic evidence concerning the age of this village site. Thus he derives one set of hypotheses from the other. Finally, Borden notes the use to which these Chinlac data can be put.

Ornamentation.

[Evidence pertaining to ornaments, Statistical importance:]

Conspicuous by their rarity are ornaments.

[Hypotheses:]

[1] It is possible that some of these were of a perishable nature

[2] and that others were destroyed during cremation of the dead.

[3] but still their paucity is striking, particularly if we consider their importance farther to the south.

[Confirmatory evidence of \#3 above:]

In the Upper Columbia region of Washington, for instance, beads, pendants, and other ornaments constituted nearly 90 per cent of the artifacts recovered by the Columbia Basin Archaeological Survey (Collier et al., 1942, p.57). By contrast, ornaments make up less than 1 per cent of the artifacts recovered at Chinlac [1952b:33].

Borden's hypotheses above might be re-written thus: Even with 
factors of poor preservation, and purposeful destruction of artifacts, the contrast with similar cultures in similar conditions indicates that the difference in ratio of ornamental artifacts found, reflects a real difference in the ratio of ornamental artifacts used by these two peopres.

Trade. These ornaments at Chinlac, "with the possible exception of one bone pendant...are of foreign origin" (p.33). This first evidence of trade is followed by several others.

The nearest known source of obsidian, a frequently utilized raw material at Chinlac, is the Anahim Peak region, about 120 miles to the south-west of the village [p.33].

4. Chinlac inhabitants traded directly or indirectly with Anahim Peak Indians is the implied hypothesis.

Borden's stress on distance seems to be somewhat uneven. In the preceding argument, he emphasizes 120 miles as a long distance. On the other hand, the distance from Chinlac Village to Natalkuz Lake ( 80 miles in the direction of Anahim Peak), is not mentioned at all. In the absence of that information, and with no map of the two sites, I had falsely assumed that Chinlac Village and the Natalkuz Lake sites were quite close to each other.

Dentalia and a Chinese coin tentatively dated at about 1125 A.D., are cited as evidence for:

[5] trade with the Coast.

[6] It is probable that the few other trade goods also found their way to Chinlac from the Coast. Among them are porcelain and glass beads, copper foil rolled into tubular beads..., a strike-a-1ight, and other articles and pieces of iron [1952b: 33-34]. 
I assume that these two coast trade hypotheses rest upon implicit ethnographic evidence of fur trade routes through this area. The fur trade is evidence in the dating hypotheses that follow:

\section{Dating}

[Ethnographic evidence:]

According to information obtained by Morice (1904, pp. 14ff.), Chinlac was abandoned after most of its inhabitants were massacred by a band of raiding Chilcotin Indians.

[Ethnographic hypothesis:]

[7] He estimates that the attack occurred about 1745 .

[Borden alternative hypothesis:]

[8] But the presence of contact goods suggests that the village was abandoned nearer the end of the eighteenth century; i.e., after the fur trade had become well established on the Coast $[p .34]$.

Borden then uses this last hypothesis as the basis for those following:

With the historic horizon thus well established, [9] there can be no doubt that the Chinlac material represents Carrier Indian culture during late prehistoric times and at the period of early contact.

[10] As such it 1s of great value for comparative purposes and in gaining some perspective for other archaeological remains in Central British Columbia [p.34].

\section{TWEEDSMUIR PARK, NATALKUZ LAKE}

\section{Background}

The ethnographic evidence is almost identical to that presented in the 1952a publication. The new piece of evidence has to do with the known Cheslatta villages, which were on Cheslatta Lake, outside and north-east of the area of the survey.

Unfortunately, the level of this rather inaccessible lake 
was raised in the summer of 1952 by a reservoir created by

the International Fisheries Commission before archaeological investigations could be conducted there [1952b:34].

Borden discusses the orientation of these sites, the evidence of their dating and trade, habitations, and the rhyolite tool industry from Natalkuz Lake:

Most of the sites along the lakes and rivers of Tweedsmuir Park are hunting, fishing, berry-picking, and cambiumgathering camps without indications of permanent habitations. Sites are often located at the head or outlet of lakes, near marshes or game crossings, in sheltered bays or coves with sandy beaches, and near headlands affording a sweeping view of the lake. Most sites are found on the north shore of the lakes,

[1] indicating that southern exposure was a desirable feature [1952b:34].

\section{Dating and Trade}

Dating.

[Negative evidence:]

Complete absence of contact goods in any of the sites investigated in 1952

[2] suggests that the deposits were laid down in prehistoric times.

[3] Favourite sites seem to have been repeatedly occupied over a period of many years.

[4] However, we need not assume very great antiquity for these remains,

[Evidence for \#4 above:]

which in nearly every respect resemble those of Chinlac.

[5] We may safely assume that they were left behind by the Cheslatta,

[6] and that this group had a culture, as one might expect, very similar to that of their close relatives and near neighbors at Chinlac village [1952b:34].

The geographic relationships of these "near neighbors" are clar- 
ified on the map, Figure 5. Occupants of Chinlac Village were a Carrier speaking people. The Cheslatta are a sub-tribe of the Carrier, formerly using all of the Tweedsmuir Park area, as well as the Cheslatta Lake area north-east of it.

Discussion of the Argument. This series of abbreviated arguments will be testable by carbon 14 dating, but in the meantime, Borden shows the historic horizon is probably more recent than these sites, and notes that logically this does not have to mean that the sites are very old. Evidence that they are similar to the Chinlac cuiture which does fall within the historic period, and ethnographic information about the ways of the Cheslatta, materially support the fourth, fifth and sixth hypotheses. This is a summary paper. In full reports, Borden expands with further evidence the support of this type of hypothesis. In such a report, Borden would, for instance, give the stratigraphic evidence for repeated, interrupted occupation of the sites.

Trade. Borden continues with evidence and hypotheses concerning trade practices of these Cheslatta people, in contrast to Chinlac residents.

[7] One difference, however, ts worthy of mention [i.e., cuiturally significant].

[Interpretation/Hypothesis based on negative evidence:]

[8] At Chinlac no evidence was recovered which would indicate trade with the coast in prehistoric times.

[Evidence:]

[a] Dentalia do not appear to have arrived earlier than trade beads, copper foil, iron, etc.

[b] At two sites on Euchu Lake, however, in deposits containing Carrier Indian material, artifacts made of the shell of the large mussel Mytilus californianus were encountered.

[c] The tough shell of this marine mollusc was an import- 
ant raw material on the Coast, where it was worked into knives, scrapers, harpoon cutting blades, etc.

[d] Since modern trade goods were completely lacking in

the Euchu Lake sites, where the objects of mussel shell

were recovered,

[9] these implements are good evidence for trade between the Cheslatta and Coast Indians at least in late prehistoric times [1952b:35].

This series of hypotheses illustrates a typical argument in Borden's work. If the previous hypotheses are true, and the evidence is interpreted correctly, the succeeding hypotheses are valid, and probably true.

\section{Habitations}

Borden now describes and interprets the evidence of the habitation forms found in Tweedsmuir Park. He introduces the discussion with this sentence: "Cultural manffestations different from those a1ready mentioned aiso occur in Tweedsmuir Park" (p.35). In the 1952a survey report, Borden stressed the presence of both rectangular and circular house forms in this area. I find no specific reference to the rectangular house forms, outside of Chinlac, in this paper, but it may be implied in the word "also" in the above phrase, [house forms] "...different from [Chinlac forms] also occur..."

\section{$1952 a$ Euchu Lake Test Hypothesis. On page 14 of the $1952 a$ pa-}

per, Borden had stated:

The occurrence on Euchu Lake of two villages, each with a different house type [rectangular and circular], is therefore of great interest. Excavations that must be made at these villages should produce not only information on the structures themselves, but also other important data that will throw light on the culture history of this area [1952 $\mathrm{a}:$ : 14]. 
This expected information was not found at this site, however:

The two cultures [recent Carrier and older Natalkuz culture] were not so clearly separated here as at the Natalkuz Lake house-site, a circumstance which may be attributed to two causes: to the shallowness of these Euchu Lake deposits, and to the fact that they were washed by waves when the lake was at high level [1952b:37].

New Natalkuz Lake Test Site. Therefore, we find in this paper that Borden is developing habitation hypotheses on the basis of the Natalkuz Lake site rather than the Euchu Lake site as he had anticipated in his survey report.

Distribution. I will quote his recapitulation of the distribution of habitation sites:

Cultural manifestations different from those already mentioned also occur in Tweedsmuir Park. Among these are the remains of circular earth lodges, which are scattered along the shores of Ootsa, Intata, Natal.kuz, and Euchu Lakes, the greatest concentration being in the eastern part of the park, particularly on the north shore of Euchu Lake near the mouth of Chelaslie River. Usually these house-pits occur singly or in pairs, rarely in groups of three or more. The diameter of these pits, measured from the crest of the rim, varies between 12 and 27 feet, a considerable number being of small size [1952b:35].

Problems. Borden tells of problems in research on Plateau habitations. This functions to warn us that although hypotheses with a wide scope of significance will be derived from this evidence, they will be very tentative or of low probability, since the evidence is, statistically, scanty in proportion to possible instances, and may not be taken as a fair sample of that total.

Data on structural details are difficult to recover from the ruins of circular lodges in the Plateau, and the results of efforts to gather such information in Washington and Oregon have been discouraging (cf. among others Osborne et al., 1952, p.363, and Shtner, 1952, pp.349,351). To a 
large extent our experience parallels that of investigations in the southern part of the Plateau. Although nine housepits were investigated, only one ylelded information on construction and design [p.35].

The Natalkuz Unique Form. This one informative site is near the head of Natalkuz Lake. In the first, 1952a, paper about this area, Borden described the rhyolite artifacts that were distinctive to this and several other sites. The habitation he calls "somewhat unexpected" (p.35). "So far, this form is unique..." (p.39). This is what was expected, and what was unexpectedly found:

Although the surface manifestations before excavation ind 1cated a house with a diameter of approximately 18 feet, measured in the usual way from the crest of the lip, the charred butts of what appeared to be rafter-beams and side-rafters were found buried in the sandy soil of the site between 16 and 18 feet from the centre of the house,

[1] indicating a diameter of about 34 feet for the structure $[1952 b: 35]$.

As he continues the description of the roof structure, Borden retains the pattern of very general summary-evidence/hypothes is that he has been following in this paper:

[Evidence:]

Our findings suggest that

[2] there were four main rafters oriented approximately north-south and east-west.

[3] Each of these appears to have been braced by two siderafters

[4] which evidently were joined to the main rafters at 45degree angles.

[5] The main rafters must have been supported also by struts, [Absence of evidence:] although no convincing evidence for the former existence of such timbers could be found.

[Evidence:]

The butts of some of the side-rafters rested on roughly circular foundations of chipping detritus and small rocks. Measurements which could be taken on the substantial butts of two 
of the main rafters indicate

[6] that these must have emerged from the ground at angles of 37 and 38 degrees.

[Evidence:]

With a diameter of about 34 feet, these measurements suggest

[7] a height of approximately 10 or 11 feet from the ground to the truncated apex of the structure [1952b:35].

Borden specifies that some of these are "discerned" and some are "inferable", in giving ethnographic confirmatory instances of this roof structure:

In these discernible and inferable details, the pattern of the roof construction seems to conform closely to that reported by Teit for the Thompson and other Interior Salish groups to the south and south-east (1900, pp.192-195; 1906, pp.212-213; 1909, p.492) [Borden 1952b:35].

This much was expected. The rest was not. Borden presents ethnographic evidence of the usual sub-structure, and the evidence from the site:

[Ethnographic evidence:]

Among the groups in the plateau that have been studied by ethnographers, the common practice seems to have been to excavate the entire interior area of a pit house from the centre to very near where the rafters meet the ground.

[Archaeological evidence:]

The builders of the lodge on Natalkuz Lake, however, dug only a large oblong central hearth-pit, while the remainder of the house-floor was left nearly on a level with the surrounding surface. The pit, whose long axis was oriented roughly east to west, measured about 7 by 10 feet at the rim and 6 by 9 feet at the bottom, so that the sides were quite steep. The original 3-foot depth of the pit had been subsequently reduced to about 2 feet by refilling the bottom of the excavation with a layer of fine brown sand, containing numerous flakes, and a second layer of coarse sand and gravel. Although a cluster of charred pine-cones was found at the very bottom of the pit, the first discernible fires rested on the strat:um of coarse sand and gravel. The ash layers in the two hearths did not have the form of lenses, but were de- 
pressed at the centre and turned rather sharply upward at the edges [1952b:35-36].

Manner of Collapse. Borden interprets the manner in which the collapsed lodge resulted in a rim of smaller diameter than the original:

[Evidence:]

As stated parlier, before excavation the house-pit measured about 18 feet in diameter.

[8] It would seem that when the roof of this lodge disintegrated, most of the debris and dirt covering dropped onto the occupation sheif and accumulated in a ring around the hearth-pit, about midway between the latter and the circle of features which we could not but interpret as the buttends of rafters.

[Work to be done:]

Complete excavations of other houses in this area will have to be made to see whether they yield similar data.

[9] For the time being, there is good reason to suspect that at least many of the smaller house-pits in this area are actually merely the hearth-pits of larger structures similar to the one at Natalkuz Lake.

[10] The larger pits, on the other hand, may be the remains of earth lodges that conform more closely to the types that were described by Teit and others [1952b:36].

As far as Borden knows in 1974, this habitation form is still unique (pers. com., June 1974).

\section{Rhyolite Tool Industry}

Borden turns from the habitation form at Natalkuz to a description and interpretation of the tools found there. He compares the Natalkuz assemblage with the Chinlac assemblage, specifically contrasting projectile point types, use of lamellar flakes (microblades), cores, and their geographic distribution in the Tweedsmuir Park area. 
Confirmation of 1950a Hypothesis. Borden begins with a review of the earlier survey hypotheses, that the rhyolite (now identified as altered rhyolite tuff) tool concentrations "...were different in type, material, and in manufacture from those of the late Carrier Indians" (p.36). Still referring to the earlier paper, he says that this evidence "... seemed to suggest a prolonged occupation of this part of the lake-shore by a group with a culture different from that of the recent Cheslatta" (p.36).

[1] Results of our work at the Natalkuz Lake house-site tend to confirm this earlier impression [1952b:36].

With this general hypothesis that the testing of the earlier series of hypotheses had resulted in confirmation, Borden begins the more detailed exposition of the findings:

Contrast to Late Carrier Assemblages.

[Stratigraphic evidence:]

The excavation revealed numerous Carrier implements in and just under the turf which covered the site, while the actual house deposits in the heart-pit and on the broad habitation shelf around it yielded artifacts that were different in type, materfal, and in manufacture from those of the late Carrier Indians.

[Evidence of raw material:]

Rhyolite was by far the most important material, whereas basalt and obsidian, the favoured materials among the Carrier, were rarely used.

[Evidence of tool types and manufacture:]

Most abundant among the earlier artifacts were crudely chipped knives, many of them of large size...

large boulder chip scrapers also occurred. [See 1956 tool descriptions of these tools, pp. 92-93, and their importance in discussions of the Pasika phase in 1965 and following years.]

Percussion chipping seems to have been the favoured technique,

[New evidence:] 
although some blades and points exhibited careful workmanship.

[Evidence of detritus:]

The builders and occupants of this house also showed a disregard for all chipping detritus,

[2] carelessly discarding many large flakes

[3] that certainly would have been used by the thrifty Carrier Indians who more recently camped at this site [1952b:

36].

In the survey of the area, no projectile points had been associated with the Natalkuz culture. In the course of excavation, some were found. This is Borden's comparison:

There is a striking contrast in projectile-point types. Carrier points are generally small, sometimes minute in size, and abound in the following forms...:--

Unstemmed, triangular, straight base, side notches.

Unstemmed, triangular, concave base, side notches.

Parallel sided stem, square shoulders.

Parallel sided stem, sloping or no shoulders.

Miniature points.

Not many points were recovered from the Natalkuz Lake house deposits, but those that did occur were much larger than the normal Carrier points. They include the following types...:--

Laurel-leaf-shaped, pointed at both ends.

Laurel-leaf-shaped, pointed at one end, convex base.

Laurel-leaf-shaped, pointed at one end, straight base.

Expanding stem, produced by diagonal corner notches, broad concave base [1952b:36].

The investigation of recent Carrier sites did not disclose 1amel-

lar flakes (microblades).

Of interest also was the occurrence in the Natalkuz Lake house of numerous lamellar flakes, which had been struck from prepared cores. One polyhedral core was recovered from the hearth deposits in the centre of the house... Small lamellar flakes were made of obsidian..., larger blades of rhyolite....A few of these implements exhibited secondary chipping, but the majority were not retouched $[1952 b: 37]$. 
Assemblages Correlated with Distribution. Borden corroborates

his $1952 a$ distribution analys is of these contrasting cultures.

While recent Carrier material was found scattered all over the surveyed parts of Tweedsmuir Park, evidence of the earlier culture was confined to a limited area. Its main manifestations were at the head of Natalkuz Lake. Secondary concentrations were discovered about 6 miles to the southwest at two small nearly adjacent sites on the north shore of Euchu Lake.... Typical Carrier implements were also found at these sites $[1952 \mathrm{~b}: 37]$.

In the preceding and following sections of the paper, Borden's work logically depends on his interpretation of a "Carrier assemblage" as distinct from a "Natalkuz Lake assemblage".

\section{SUMMARY INTERPRETATIONS}

Borden begins by again warning us of the necessarily tentative nature of this endeavor to assign meaning to this body of information. This is "...the first systematic archaeological work in the vast Central Interior of British Columbia" (p.37).

The full significance of our findings, therefore, will become apparent only after further intensive research in this area. In summing up the results, we may consider briefly a few of the possible implications and attendant problems [1952b:37].

These implications and problems are organized in this way:

1. The basic Chinlac/Natalkuz division hypotheses.

2. Comparison of Natalkuz artifacts, the lamellar flakes and projectile points with Fraser Delta and other assemblages outside this area.

3. Comparison of the assemblages from this survey with those from Harlan I. Smith's investigations. 
4. The implications of habitation types as known ethnographically and archaeologically.

5. Two al ternative hypotheses relating the Carrier and $\mathrm{Na}-$ talkuz Lake cultures, with supporting evidence and hypotheses for the one he regards as more probable.

6. Alternative hypotheses for culture change in the Interior.

7. Identification of Natalkuz Lake inhabitants.

\section{Chinlac/Natalkuz Distinction}

The basic Chinlac/Carrier hypotheses lay the groundwork for all the rest. The order is altered:

[1] The material collected at...Chinlac... [which represents] many of the archaeological manifestations of historic and late prehistoric Carrier Indian culture,... has already proved of value in recognizing the late Carrier Indian deposits at many sites in Tweedsmuir Park.

[Stratigraphic evidence of age relationship:]

[2] It has been possible to establish that the Natalkuz Lake culture underlies recent Carrier Indian material.

[Evidence summary:]

The contrast between the two complexes is very sharp,

[3] and, for the present at least, it is difficult to envisage the earlier as ancestral to the later culture of this area [1952b:37].

Comparison of Natalkuz with Other Assemblages

Lamellar Flakes (Microblades). Lamellar flakes (microblades), which are next examined in detai1, formed one of the bases of Borden's theories of movements of peoples in the New World, and will appear in many of his later papers.

[4] Of potentially far-reaching significance is the presence of lamellar flakes in the Natalkuz Lake culture. 
[Evidence:]

The diagnostic value of these blades in Central British Columbia is demonstrated by the fact that not a single lame1lar flake was found among thousands of flakes and chipped artifacts from Chinlac and other typical Carrier sites.

[Evidence of geographic distribution of artifact:]

The technique of fashioning prismatic flakes represents one of the more ancient cultural links between the 0ld and the New Worlds (Nelson, 1937, pp.268-272). Lamellar flakes are widely distributed in the far northern portions of North America from the Aleutian Islands to Greenland. There are also scattered occurrences thousands of miles farther south in various parts of the United States and as far south as Mexico and other parts of Middle America (Nelson, 1937, p. 270; de Laguna 1947, pp.171-172; Laugh11n, 1951, pp.52-55). The discovery of such blades in Central British Columbia begins to bridge the wide distributional gap between the far northern and southern areas.

[Evidence of time range of this artifact:]

Lamellar flakes have been found in North America under conditions suggesting considerable antiquity (Giddings, 1951, pp.193-202). In some areas, however, the technique of fashioning them has survived into recent times (Rainey, 1939, p.388; Barnes, 1947, pp.625-626).

[Evidence to date Natalkuz:]

As yet we have no notion of the age of the specimens from the Natalkuz Lake house, but charcoal samples collected from the hearth in which a polyhedral core was found offer an excellent opportunity for radiocarbon dating of these blades and of the associated culture.

[Evidence including the hypotheses from Fraser Delta sites:] Lamellar blades similar to the microlithic specimens from Natalkuz Lake have recently been discovered in the Fraser Delta region. They occurred in the upper horizon of the Whalen Farm site (Borden, 1950, p.20). This deposit (Whalen II) overlies an earlier culture of more distinctly maritime character (Whalen I). Whalen II st111 antedates the period of the fully developed North-west Coast culture, and the artifactual assemblage exhibits complexes of Interior traits, while [i.e. Which] at a later time disappear on the coast. Chief among these is a still flourishing stone-chipping industry with types of projectile points which also occur in the Southern Plateau. The lamellar blades in the Whalen II deposit are obviously part of the same chipping tradition. Nelson refers in passing to the alleged occurrence of polyhedral cores in Oregon (1937, p.270). It is curious that netther such cores nor lamellar flakes have been reported 
in any of the accounts of the numerous archaeological investigations of recent years in Washington and Oregon.

[5] At any rate, the now demonstrated presence of lame1lar blades farther north in the Plateau further emphasizes the affillation of the Whalen II material with the Interior $[1952 b: 37-38]$.

Projectile Points. Projectile points do not follow the same relationship as Borden hypothesizes in \#5, above.

[Negative evidence:]

None of the Whalen II projectile points bears any particular resemblance to those of the Natalkuz Lake culture.

[6] But at certain other Fraser Delta sites, also antedating the recent period, points similar to the Natalkuz Lake point types occur. [Marpole phase sites, (Borden pers. com., 1974)].

[Theoretical limitations of work:]

Until field work produces data on the intervening areas, the possible significance of this parallelism will remain obscure [1952b:38].

Comparison with H. I. Smith Sites

Now Borden compares his Interior assemblages with those of the south Interior:

[7] It is necessary to mention at least in passing that there is little similarity between the Natalkuz Lake culture and the material which H. I. Smith recovered around Lytton and in the Thompson River valley.

[8] Most of Smith's material seems quite late.

[Theoretical limitations of work:] Early Interior Salish sites in British Columbia have yet to be discovered and investigated [1952b:38].

\section{Implications of Habitation Types}

The next problem concerns habitation forms. First Borden gives ethnographic evidence and hypotheses, and relates these to his archae- 
ological evidence.

In recent times, the "...Carrier culture was rapidly changing... under the influence of neighbouring groups" (p.38). Jenness, (1934:

364) describes the coast plank house diffusing eastward.

Some of the Lower Carrier, on the other hand, were adopting as their winter dwelling the circular semi-subterranean earth lodge, which came to them from the south either directly from the adjacent Shuswap or indirectly by way of the Chilcotin, their Athapaskan neighbours (Morice, 1895, p.191; Ray, 1939, p.134). [Borden 1952b:38].

What is the distribution of these subterranean dwellings?

[9] Waterman gave as the distribution of earth-covered pit dwellings in the historic period the Interior area, adjacent to the coastal region, extending southward from the mouth of Stikine River in Alaska and approaching the coast again near San Francisco Bay (1921, p.19).

[10] This somewhat sweeping statement needs amending. [a] In the first place, the territory of the Tsetsaut should not be included because, as Waterman himself admits, their habitations were not really pit dwellings. [b] Secondly, only part of the territory of the Carrier should be included since only some of the Lower Carrier had adopted these habitations and evidently just recently.

[11] The assumption that not only the Carrier but also the Chilcotin borrowed the circular pit dwelling from their Salish neighbours (Morice, 1895, p.191) seems plausible.

[12] Indications are that the subterranean earth lodge was not one of the original house forms among the Athapaskan peoples of Northern North America.

[13] Consequently, in the not too remote past the territory of the Shuswap or of some other Salish group probably marked the northern Interior limits of circular pit dwellings [1952b:38].

Hypothes is \#13 above will be a basis of a number of theories in Borden's 1956 report on investigations in the Kootenay area relating to Kutenai/Shuswap relationships. Borden notes a consequence of this last series of hypotheses: 
Other problems arise from the distribution of house types in this part of the Interior.

[11 repeated] If the circular earth lodge is a recent importation among the Carrier, we may well wonder who built the numerous earth lodges whose remains we discovered in Tweedsmuir Park and near-by areas.

[14] Some of them may have been bullt by recent Carrier Indians,

[Evidence to the contrary:]

a1though the artifactual material of none of the lodges investigated was of a kind which would definitely link it with recent Carrier culture [1952b:39].

Now Borden speculates about the Natalkuz habitation:

The Natalkuz Lake house presents a special problem. [Implicit definition of 'tyfe' or 'form':]

So far, this form is unique, and remains of similar habitations will have to be discovered before it can be accepted as a definite type.

[15] If it can be established as a distinct type, its interior plan, with the large central pit surrounded by a broad habitation shelf, would raise intriguing possibilities of a historic connection with plank houses of similar interior arrangement on the Northern North-west Coast (see, e.g., Krause, 1885, p.127).

[Waterman hypothesis:]

[16] It would also lend further support to Waterman's theory that the Coast and Interior dwellings of the Pacific North-west are genetically related (1921, pp.30-34) [Borden 1952b:39].

\section{Possible Relationships of Carrier and Natalkuz Lake Cultures}

In the light of all this, Borden re-considers the alternate theories of the relationship between the Carrier and Natalkuz Lake cultures:

Whatever data may be produced by future work, or whether or not our present interpretation of the remains is correct in all details, the Natalkuz Lake dwelling is a form of circular pit house. In view of the fact that the cultural remains it contained are so dissimilar to recent Carrter material, we may consider two alternate hypotheses:-- 
[17] (1) The Natalkuz Lake culture is ancestral to that of the historic Carrier.

[18] If so, we would have to allow considerable time for an intervening period of development, and, consequently,

[19] circular pit lodges, at least a variety thereof, would be much older among the Carrier than one might assume from the ethnographic evidence.

[3, repeated:] (2) The Carrier are an intrusive people. The Natalkuz Lake house and the associated artifactual material are the remains of an earlier group who occupied this territory prior to the arrival of the Carrier $[1952 b: 39]$.

Borden judges the latter of these two to be more plausible, and gives the evidence which will support this choice.

[Confirmatory ethnographic evidence:]

Jenness states categorically that the "Tahltan, Sekani, and... the Carrier...were immigrants from the Mackenzie basin" (1934, p.91).

[Confirmatory linguistic evidence:]

The region of our particular concern is near the present boundary between two major linguistic stocks--Athapaskan and Salishan.

[20] This boundary has probably been in a fluid state for a long time

[21] and has moved southward rather than in the opposite direction in recent centuries [1952b:39].

\section{Alternate Hypotheses for Culture Change in the Interior}

How have these cultural changes proceeded? Borden up to 1973

and 1974 is still considering this question, seeking new evidence for hypotheses about it.

[Ethnographic hypothesis:]

[22] The impression has been created that warfare in the Northern Plateau was always on a minor scale, that war parties were usually small and that, even when large, their activities were motivated by the desire for personal gain rather than by group interest (Ray, 1939, pp.37-40). 
[Significance of problem:]

This question has an important bearing on the probable course of prehistoric events in this region.

[23] It is possible that a state of near equilibrium existed in this area at the beginning of the historic period. [Thus limiting Ray's hypothesis in time.]

[24] However, the distribution of ethnic groups argues that such comparative tranquility did not prevail at all times.

[Evidence:]

Obviously, the various ethnic groups did not originate in those localities where they happened to be at the time of discovery.

[25] At some earlier period their ancestors must have moved into those particular areas.

[26] If the land was sparsely settled, as certainly much of it was, migrations into new areas may have proceeded peacefully enough.

[27, modification of 24:] But it is hard to imagine that all population shifts in this part of the Plateau took place without sharp conflicts, and that aggressors never attacked with intent to move their entire group into a desirable area which was already occupied [1952b:39].

\section{Possible Suggestions Identifying Natalkuz Lake Inhabitants}

Thus Borden takes almost complete exception to Ray's hypothes is,

\#22 above. This will be noted in his vigorous verbs below:

[Hypotheses primarily from linguistic evidence:]

[28] There is abundant evidence that Athapaskan peoples have exerted southward pressure over a prolonged period.

[29] That they must have repeatedly invaded alien territory en masse and fought their way south through the Plateau is evidenced by the presence of isolated groups of Athapaskans in Southern British Columbia, Washington, Oregon, and Northern California.

[30] Among the last Athapaskan groups to have wrested territory from the Interior Salish are probably the Chilcotin.

[31] Linguistic and other evidence suggest that they moved 
southward not so very long ago, driving the lillooet before them and cutting the Bella Colla off from both the Lillooet and the Shuswap (Swadesh, 1949, pp.165-166) [Borden 1952b:39].

[Hypotheses resulting from numbers 28 to 31 above:]

[32] There is, thus, a strong probability that Salish people at an earlier time lived farther north than they did at the beginning of the historic period,

[Test hypothesis:]

[33] and it is reasonable, therefore, to expect to find the cultural remains of such Salish ancestors at least in the southern marginal areas of present Athapaskan territory.

[34] It is not likely that the Natalkuz Lake culture is early Carrier or Chilcotin.

[35] Whether it is early Salish [instance of \#33]

[36] or whether these remains were left behind by an entirely different people,

[Work to be done:]

these are questions which can be answered with certainty only after further extensive field work in various parts of the Northern Plateau [1952b:40]. 


\section{A SCOTTSBLUFF-EDEN POINT FROM BRITISH COLUMBIA}

This short paper published in Anthropology in British Columbia describes a chipped stone point of a type which is associated with Big Game Hunter traditions, one of the early New World cultures. Thought to be from the Windermere area, this point at the Provincial Museum of British Columbia had been collected by Basil G. Hamilton along with other "...historical, ethnological, and archeological specimens from the East Kootenay region of British Columbia" (Duff and Borden 1954: 33).

The last two paragraphs of the paper, based on the hypothesis that this point was in fact found in the Windermere area, are important since Borden's description of the Rocky Mountain Trench, a geological feature of the plateau, emphasizes the possible significance of this area in the early peopling of the New World. Both 1952 papers contain mention of the plateau as a migration route. In 1956, Borden writes again of this Trench, and in 1962 and 1969, develops arguments for an important expansion route west of the Rockies. He continues to stress this "intermontane corridor" route up to 1973 and 1974.

I have designated the hypotheses by numbering them:

Lake Windermere in which vicinity the point apparently originated, is located about 200 miles north of the southern end of the Rocky Mountain Trench, that spectacular steep-sided valley which extends for some 1,100 miles in a continuous, nearly straight line from the Liard River valley in Yukon Territory through British Columbia to Flathead Lake, Mont. (Robinson, 1953, p.37). Little is known as yet regarding the 
delineation and movement of glacial features in the Far West during terminal and post-Pleistocene times,

[1] but the Rocky Mountain Trench is jelieved to have been generally free of ice as early as the last or Valders advance (ca. 9000 B.C.) of the Wisconsin glaciation (Quimby, 1954, p.321).

[2] This long valley thus looms as a potential migration route for paleo-Indians (Robinson, 1953, p.37; Quimby, 1954, p.319).

[Confirmatory archaeological evidence:]

It is of interest to note in this connection that the Mac Haffie site, an Early Man site near Helena, Mont., which has yielded a succession of Folsom, Scottsbluff, and late types (Forbis and Sperry, 1952, pp.127-133; Sellards, 1952, p.132) is situated not far from the southern end of the Rocky Mountain Trench. More recently R. S. MacNeish (1954, pp.248-249) has reported the occurrence of points resembling Scottsbluff on a high beach at the west end of Maxhamish Lake. This small lake near the Liard River in North-eastern British Columbia is about 150 miles east of the Rocky Mountain Trench.

[General test hypothesis:]

[3] There is, therefore, a strong possibility of the occurrence of Early Man sites along the length of this immense natural highway.

[Specific test hypothesis:]

[4] As part of its summer programme for 1954 the University of British Columbia is planning to conduct a survey of a section of this likely migration route in the Kootenay region of South-eastern British Columbia [Duff and Borden 1954:34]. 
CHAPTER XII I

\section{4a SOME ASPECTS OF PREHISTORIC COASTAL-INTERIOR RELATIONS...}

In this paper published in Anthropology in British Columbia, Borden responds to criticisms of his 1951 position regarding classification of the Interior origin of certain traits found in delta assemblages. Three aspects of this paper are of special interest in showing Borden's logic as he criticizes Caldwell's work. The first is Borden's caution that disproofs based on surface collections have limited validity. The second two are found in Borden's discussion of harpoons, and other perishable bone or antler artifacts. He uses the argument called by logicians reductio ad absurdum. Then he comments on the limited usefulness of this sort of negative evidence in archaeology.

\section{BACKGROUND}

Borden has done considerable archaeological work between the 1951 papers and this one, but this evidence is not specifically spelled out. Only as it relates to the re-examination of his 1951 position on the Interior origin of certain traits does he bring in new data. Age-Area Hypothesis

Much of Borden's argument rests on the presupposition of the Wissler-Kroeber age-area hypothesis. For instance, when Borden can show widespread distribution of a trait in the Interior, and restricted distribution on the coast, he concludes that the trait probably 0- 
riginated in the Interior.

The most concise account of this thesis is in Kroeber's 1931 paper "The Culture-area and Age-area Concepts of Clark Wissler". It is a chapter of a book Methods in Social Science (Rice:1931). As he himself notes, Kroeber is one of the very few anthropologists to use this as a serious methodology, citing his own book Anthropology, 1923. A series of quotations from Kroeber's paper will best describe this method:

The age-area concept... [is a] method of inferring at least the relative time sequences of stages of culture-trait or culture-complex developments from the more or less concentrically zonal distribution of phases of such developments ... [Kroeber 1931:254].

Wissler deals with this in three books, (1922, 1923 and 1926):

In this last work, (Wissler:1926) the concept is systematicalIy developed by wissler, analogous to its use in the biological sciences, but, as in the case of his forerunners, apparently as the result of independent empirical findings. Essentially, this concept implies that of the culture center as a locus of superior productivity. This center, normally maintaining itself for some time, tends inevitably to radiate culture content or forms to a surrounding zone, which in turn imparts the contribution to a more peripheral belt, while the center, in the interim, is likely to have advanced to subsequent phases of development which normally obliterate more or less the earlier ones. These earlier phases, however, are likely to survive, with greater or less modification, in the marginal zone which they have only recently reached. In principle, a distinction must be made between cases in which the time sequence is independently known through history, inscriptions, or cultural stratigraphy (in biology through paleontologica? evidence resting ultimately on stratigraphy), and is in agreement with the observed recent space distribution; and cases in which the time sequence is unknown and becomes the goal of investigation, being in that case merely deduced from the space distribution. In anthropology, at least a number of seemingly clear-cut instances of the first type were established before Wissler's venture to set up the principle as a generally valid one and employ it for the finding of the time factor in cases lacking time data. A still 
further logical step, though apparently an inevitable one, is the inference that the present center of culmination is a) so the presumptive locus of origin. In short, there are three elements involved: related phases of a culture trait or complex or culture whole; the spatial or geographical distribution of these; and the time consumed in the accomplishment of the distribution of the phases. When all three elements are known and correlate approximately, there can be no reasonable doubt as to the story of what happened. When the time factor is sought instead of given, the result is no more than an inference; and since the known factors are usually either complex or variable, and difficult of exact measurement, judgments are likely to differ as to the degree of validity of the findings [Kroeber 1931:254-255].

Kroeber notes that "The age-area method is accepted in principle by

Kroeber, but employed more cautious7y" (Kroeber 1937:257).

The difference between Wissler and the English diffusionist and the German Kulturkrejs schools, which also aim to supply history for historically undocumented periods and areas, lies in the fact that these make their explanations in terms of a single or few origins, respectively, in place of an indefinite number of variable centers. The limitation of factors yields a simplified scheme, but almost inevitably involves an arbitrary or subjective choosing of the original centers. It is characteristic that discussion of the views of these two schools has revolved not so much about the validity of determination of the asserted centers as to whether the facts of culture can be made to fit the schemes of derivation from them. By comparison, Wissler is inductive. The culture ares dealt with are in their nature empirical, and the age-area method, provided it is critically used, is an inductive device [Kroeber 1931:260].

Two further passages express Kroeber's cautions in using this method.

As to the age-area principle, the analogy to recognized biological method gives support to the essential soundness and the utility of this concept, the more so as its anthropological use was empirically and independently arrived at, not borrowed from the life-sciences. Interest in this method will vary directly with the ultimate objective of study; and when historical interest is slight, distrust of the method will be pronounced. It is in its nature merely a method of inference, supplementary to the direct evidence of documentary history and archaeological superposition; but, as such, it is warranted when it is desired to push beyond the confined limits of this sort of evidence. The age-area principle may never be applied mechanically; culture is too com- 
plexly irregular, the resultant of too many factors, to be approached without care, accuracy, and discrimination [Kroeber $1931: 263]$.

The relations of distributional facts assembled by Wissler do seem on the whole to substantiate his claim that migration was culturally a rather unimportant factor in pre-Columbian America. But it did occur; and his own Euro-American area show that it may at times be of fundamental importance. This is true, similarly, with respect to all other factors that may cut across the operation of normal diffusion and the age-area principle. The danger lies in utilizing the latter too exclusively.... He [Wissler] has done enough with the age-area concept to show that it is not a mere instrument of speculation but a legitimate means of inferential reconstruction when other data fail. That it must be critically handled goes without saying. The age-area principle cannot be applied as between diverse and unrelated elements of culture. Wissler has made this clear. Much of the criticism leveled at the method rests on failure to understand this fact; which also holds in biology. No one would infer respective age of birds and snails from their distribution; but within the limits of a group such as an order, and especially within the genus, the method is constantly being used and apparently with fair reliability [Kroeber 1931:264].

Borden's 1954a paper contains his most complete published exposition of his position on the origin, movement, and development of the woodworking industry. It also contains the first radio-carbon date for any of Borden's sites. The subject matter and approach of this paper justify classification of it with the early works of Borden.

Recapitulation of 1951 Position

Borden begins with a recapitulation of the thesis of his 1951 a paper. It is faithful to the original in every way. I interpret some of the expressions in this section as evidence of a more mature presentation than he made in the earlier papers. The first instance is his use of the concept "corollary" in this sentence:

A corollary to the assumption that North-west Coast culture was derived from an ancient Interior culture base had to be 
that the earliest coastal cultures should still exhibit a marked Interior cast without advanced adjustments to their new environment [1954a:24].

In the next paragraph Borden carefully cites Harlan Smith and Drucker as sources of his 1951 a "...1ist of traits which appeared to be of Interior derivation" (1954a:26). The phrase "appeared to be" is consistent with Borden's 1951a statement that further work on clarifying the origin of traits needed to be done, and it is much less likely to be misunderstood than the phrase from that same earlier paper that certain traits are "patently" of Interior origin.

Locarno Beach/Whalen I. Borden's summary of his 1951 position includes statements about the early horizons at Locarno Beach (I and II), and Whalen Farm (I). After the corollary quoted above, Borden writes:

However, contrary to expectations, our investigations in the
Fraser Delta revealed, in addition to cultural assemblages
similar to those which Harlan Smith had discovered at the turn
of the century, and on which the theories of the time were
largely based, other assemblages that were evidently both old-
er and strikingly different in content [1954a:26].

Borden then lists the artifacts from Locarno Beach I and II and Whalen I which he had listed in his 1951 paper as Eskimoid traits:

...a whole cluster of elements quite evidently not derived from the Interior but suggesting rather

[1] an advanced adjustment to a maritime environment and [2] a strong affiliation with ancient Pacific Eskino cultures in Alaska [1954a:26].

The evidence for the hypothesis that these are "...evidentiy... older..." than the sites which support the Kroeber hypothesis is stratigraphic in the case of Whalen I. In the case of Locarno Beach, the hypothesis is based on the presupposition that cultures with interior 
traits not fully adapted to a maritime environment will be found to be more recent than those with a maritime orientation, the Drucker third hypothesis from Borden 1957a.

Radiocarbon Evidence. Borden in 1954 has no Marpole/Point Grey dates to test this presupposition, but he has one for this maritime culture. It is not only evidence new in this paper, but a new kind of evidence that Borden has been anticipating since 1950:

It is this culture [Locarno Beach] for which we now have the $C$ 14 date of $2430( \pm 163)$ years [1954a:26].

Interpretation of this Evidence. The sample which yielded this date was taken from zone I at the Locarno Beach site, but not at the bottom of that lowest zone, so that Borden dates this phase from before $2430 \pm 163$ years ago (pers. com., 1973). At the end of this paper, Borden briefly interprets this new datum.

Culture Periods. Borden continues his hypothes is of 1957 and 1954 in this way:

The archeological evidence from the Fraser Delta seemed to suggest three periods of cultural development for this part of the Pacific Coast:--

(1) An early period with a well-developed maritime or "Eskimoid" culture which presumably had spread down the coast from the north.

(2) An intermediate period marked by the arrival of Interior groups, adjusting to a coastal environment, adopting and modifying elements of the earIy maritime culture, and initiating the great woodworking industry of the Coast.

(3) A late period in which the southern aspect of North-west Coast culture achieved 1ts historic form through the final repatterning and integration of elements derived from the early Interior and Coast cultures [1954a:26].

Development. Borden completes his position summary with his basic hypothesis on the development of this area: It is conceived as 
...a welding and blending of early Interior culture with an early maritime culture already present on the Coast and of later stages of Interior culture with Coast cultures that had evolved under the direct impact of the early maritime culture [1954a:27].

\section{CALDWELL'S POSITION}

Borden next states the position taken by Warren $W$. Caldwell in a report printed in the same publication with this paper. Caldwell's Plateau archaeological survey failed to reveal some of the elements that Borden had classified as of Interior origin. Those elements that were found, had little archaeological depth and so Caldwell "... regards them as late importations" (Borden 1954a:27).

Caldwell maintains that "temporally the situation is similar elsewhere in the Plateau," and he quotes with approval an early statement by Harlan I. Smith to the effect that the peoples of the Coast and of the Interior developed on distinct lines, and that points of resemblance are due to later contact (Smith, 1900, p.433) [Borden, 1954a:27].

Caldwell finds confirmation from a second independent source. It is Verne Ray who emphasized "'...unidirectional diffusion up the major rivers to the Plateau' (Ray, 1939, p.147)" (Borden 1954a:27). Caldwell asks for a re-examination of current theory in the light of his survey and these concurring views.

\section{BORDEN'S RESPONSE TO CALDWELL'S EVIDENCE AND INTERPRETATIONS}

The rest of this paper is Borden's reply. It is in two sections. In the first, Borden responds to Caldwell's paper, both to the concurring authorities and to Caldwell's archarological survey and in- 
terpretation. In the second section Borden re-examines the evidence and reasoning supporting his own hypothesis of the Interior derivation of each of the traits in question.

\title{
Use of Verne Ray's Evidence
}

Borden's comments on Caldwell's use of Verne Ray's evidence are these:

\begin{abstract}
Although there is abundant evidence of a strong culture flow from the Coast to the Interior in late prehistoric and protohistoric times, it is hazardous to conclude from such evidence that there was no movement of culture in the opposite direction at earlier periods [1954a:27].
\end{abstract}

Borden is saying that Ray's hypothes is neither confirms or disconfirms Caldwell's hypothesis. To infer from present culture movement the absence of different past culture movement is a non sequitur. It does not foliow.

\section{Use of H. I. Smith's Evidence}

In regard to Harlan Smith's position, Borden then notes that in later works Smith had changed his earlier position from that which Caldwell had cited,

... and concluded not only that the Interior had influenced cultural developments on the Coast, but also that Interior groups had migrated to the coastal region, bringing the art of stone chipping and other Interior elements with them. (Smith, 1903, p.190f.; 1907, p.439.) [Borden 1954a:27].

\section{Critique of Smith Controversy}

This exchange between Borden and Caldwell would have been stronger if it had been extended so that the student could be aware of the evidence that contributed to this change in Smith's position. As it 
stands, Borden can only caution against use of Smith as an authority to either position. It may not necessarily follow that hypotheses published later in a man's writings are more correct than hypotheses published earlier.

\section{My Alternative View of $H$. I. Smith}

In fact, from an analysis (Robinson, n.d.) of Smith's Jesup Expedition papers (1899, 1900, 1903, 1907, and Smith and Fowke 1901), I conclude that Smith's earlier trade and influence hypotheses for coastal/interior similarities are better founded than his later migration hypothesis. Logically, and in fact, Smith bases his migration hypothesis $(1903,1907)$ on cephalic measurements and interpretations by Franz Boas. Smith is saying...

If Boas is right in interpreting these remains as two populations, one originating in the interior (the broad head type), the other originating on the coast (the narrow head type), then I [Smith], must suppose that co-incident culture changes in the archaeological data are most simply explained as coming with that interior population....Recent considerations of the data (Mitche11 1971; Cybulski n.d.) show, and even Boas' subsequent work on the cephalic index (1912, 1913) probably confirms that Boas' interpretation (Boas in Teit 1900:387-390; Boas in Smith 1903:189) is either incorrect or inconclusive. In Smith's later papers, where he accepts the migration hypothesis, he presents hypotheses for diffusion or "influence" and trade sufficient to interpret all the evidence, including the Eburne sku11s. It renders the migration theory unnecessary in Smith's own 
terms.

In the event that other evidence is discovered of movements of genetically related populations, whether it be blood types, skeletal evidence or other, then Smith's migration hypothesis must again be considered.

It is interesting to note that Borden does not follow Smith in using evidence of the Eburne skulls. It is not from the evidence of physical anthropology that Borden derives his migration hypotheses. Borden uses linguistic diversity as his best evidence. This is presented most fully in his $1954 \mathrm{~b}$ paper. Smith is thus dealing with biological populations, Borden with linguistic populations. These may very well be different populations, as Borden states in the opening of his 1954b paper.

\section{The Nature of Caldwell's Survey}

Borden then turns to Caldwell's survey and to the implications of the evidence derived from it. Borden makes a general introductory statement before he turns to the evidence concerning each trait in question. This is his entire introductory statement:

\footnotetext{
Since Caldwell's doubts as to the correctness of my interpretations of cultural developments on the Coast were aroused chiefly by his failure to find in the survey area the series of elements suggested as derived from the Interior, or, when he did find them, is inclined to regard them as late importations from the Coast, we have to consider the evidence in some detail.

Germane to the evaluation of Caldwell's own findings are certain particulars on the survey which he was good enough to supply at my request. The survey of this considerable area was conducted in less than ten weeks by a party varying between one and three persons. No excavations were made, except "very sma1l-scale tests at several sites" to deter-
} 
mine the nature of the fill matrix. The number of artifacts collected (evidently all surface material) reached a total of some sixty items. The discussion and concluslons are based on these and "several hundred" artifacts in "Pothunter' and casual local collections." To be sure, negative evidence, if well founded, may constitute valuable data. In this instance, however, it would seem that some of Caldwell's negative findings are likely to be due to the nature of his survey, and that they do not necessarily reflect the true cultural situation [1954a: 27].

\section{Review of Borden's Response}

In short, Borden concludes that from Caldwell's sketchy work, conclusions about origins or areal relationships simply cannot be drawn. Caldwell's position may be summarized in this form:

1. Caldwell's hypothesis:

Movement of culture and/or of people in the area in question was from the coast to the Interior.

2. Orthodox hypothesis, supported by Kroeber, amended and supported by Drucker, and by Borden:

Movement of culture and/or of people in the area in question was from the Interior to the coast.

3. Caldwell's corollary:

If Caldwell's hypothes is is confirmed, the orthodox hypothesis is disconfirmed and needs to be re-examined.

4. Caldwell's confirming instances:

a. If elements thought by orthodox theories to be derived from the Interior and brought to or diffused to the Coast are in fact found to be more recent in the Interior than on the coast, this could confirm the Cald- 
well hypothesis, and disconfirm the orthodox hypothesis.

b. If these archaeological conditions hold, they support Ray's position of unidirectional diffusion up the major rivers.

c. If Smith is right, then similarities between coast and Interior are due to late contact.

Borden has replied:

In response to point $\mathrm{a}$ :

Caldwell's survey methods could not provide evidence to lead to the conclusion that these traits are not derived from the Interior.

In response to point $b$ :

There is no logical connection between Ray's position and the archaeological data.

In response to point $c$ :

"If Smith is right" cannot have clear meaning, since Smith took an opposing position at a later time in his writing.

Borden does not argue from these three replies that the consequence of each conditional phrase of the three Caldwell points is therefore false. If he did, the argument would be an instance of the fallacy of denying the antecedent. There may be other, true conditions, leading to the same conclusion; it still might be the case that these traits are not of Interior origin.

\section{RE-EXAMINATION OF 1951 POSITION}

The logical alternative is to re-examine the evidence for the 
Interior derivation of each of the traits in question. Borden examines each of the four elements in turn.

\section{Stone Chipping Industry}

First he discusses the stone chipping industry. A knowledge of this industry may be especially significant to the archaeologist working in this area.

In the absence of potsherds, which in other areas provide convenient clues regarding cultural relations in time and space, in the Pacific Northwest we shall have to look for other indicators from which to extract similar information. Despite certain difficulties, significant information may be derived from the changes in type, style, manufacturing techniques, and materials of chipped stone artifacts, as well as from the relative importance of such implements in the economy of individual groups at different times and places [1954a:28].

Borden discusses the basis of his hypothesis:

My contention that certain Fraser Delta assemblages are markedly Intericr in character is based in considerable part on the strong emphasis in these particular cultures on stone chipping for projectile-points, knives, scrapers, etc., as well as on typological similarities existing between Coast and Interior specimens [1954a:28].

The time dimension is significant. Interior cultures have always included stone chipping as a major industry. The Coast cultures are not uniform throughout time in this respect. In the early maritime cultures, "...stone chipping is [numerically] completely overshadowed by the slate grinding industry" (1954a:28). The chipped artifacts that have been recovered from this culture "...are essentially dissimilar to types occurring in the Interior" (1954a:28). Borden thus has no reason in either statistical frequency or typological similarity to link this early culture to the Interior. 
It is only in the assemblages of the intermediate period during which, I believe, there occurred population shifts from the Interior to the Coast, that stone chipping becomes important [1954a:28].

Here Borden finds not only numerical importance, but typological similarity. He proposes a test as more evidence becomes available:

There are many chipped artifact types of this intermediate coastal period which can be duplicated in the Interior. Indications are that eventually it will be possible to show that the sequence of types is similar in certain coastal and inland regions [1954a:28].

The most recent coastal culture shows almost none of this chipping industry.

By the beginning of the late period, when North-west Coast culture was fully developed, the art of stone chipping had declined into insignificance [1954a:28].

This change of stone working on the Coast is the basis of two further hypotheses. First, the rise in the proportion and number of chipped stone artifacts in the intermediate period coincides with Borden's hypothesized population shifts from the Interior to the coast. Second, the subsequent decline and disappearance of stone chipping is perhaps due to the environmental differences between the Interior and the Coast which made the Interior derived industry less adaptively useful than the slate industry which had been established earlier on the coast.

I would suggest that land hunting, for which chipped points were primarily used in the Interior, became unimportant on the Coast, and that the bow and arrow was found to be ineffective for taking sea-mammals. Furthermore, chlpped stone knives were replaced on the Coast by knives of ground slate, which were taken over from the early martitime culture. Finally, skin clothing, which had been indispensable in the Interior, proved to be impractical in the moist coastal climate. The disappearance of chipped stone scrapers is, therefore, probably indicative of the reduced importance on the Coast of working skins [1954a:28]. 
Until further work gives evidence of other relationships, Borden finds

his hypotheses to be internally consistent.

\section{Barbed Harpoons}

The second element examined is the barbed harpoon with tang and

lateral line guard.

Mr. Caldwell reports finding no evidence of barbed harpoons with tang and lateral line guards or of barbed fixed projectile-points of antler in the survey area and evidently infers that such artifacts were not used. It should be noted, however, that $\mathrm{Mr}$. Caldwell does not report finding any archeological evidence either of other antler and bone tools, such as awls, bodkins, needles, punches, flakers, knives, chisels, digging-stick handles, unbarbed arrow and lance points, fish-hooks, beaming-tools, sap-scrapers, beads, and so forth. It would, of course, be reckless to conclude from the negative evidence of this survey that all of these items were also lacking in the survey area [1954a:28].

This is the argument reductio ad absurdum.

Negative Evidence. Borden continues to examine preservation prob-

lems related to this negative evidence:

I know from personal experience in the Northern Plateau that repeated freezing and thawing of bone and antler artifacts which were left on the surface or in the frequently shallow deposits of Interior sites promotes their rapid decay and disappearance. Failure to find implements of such organic materials in the course of a site survey cannot, therefore, be taken as reliable evidence that they were not present originally. Information from Interior sites where implements of perishable materials were well covered, and hence preserved, is, therefore, of special importance and should not be overlooked [1954a:28].

Distribution in the Interior. Borden next reviews the known instances of these artifacts found in the Interior.

Excavations of burials in the Upper Columbia region, some of them--judging from the absence of contact goods--of preEuropean date, have yielded numerous bone and antler artifacts, included the disputed harpoons with tang and lateral line guard (Collier et al., 1942, pp.52, 53, 79; cf. Plate IX,1). Evidence from other parts of the Interior is still 
scanty, but Drucker reports the presence of such harpoons on the Upper Skeena in the territory of the Interfor-dwelling Gitksan (Drucker, 1943, 126), and a sma11 specimen of this type is among the items in a collection from a site on the Lower Columbia near Portland, Ore. [1954a:28-29].

Borden does not give the number of artifacts from the Upper Columbia. Some question may be raised about classifying the Gitksan artifact as representing Interior cultures. If it is so regarded, Borden's 1ist contains seven Interior harpoons in addition to those from the Upper Columbia sites. One of these is the Gitksan harpoon from Drucker's list, one from the Portland area, four from Lytton, and one from WilTiams Lake.

Barbed harpoons with tang and lateral line guards appear in the early part of the intermediate period together with numerous stone artifacts. Moreover, they seem to be confined to the deposits of this period (Marpole-Point Grey-01d Musqueam) [Borten 1954a:29].

Borden concludes that this is an instance of the general age-area hypothesis:

The far-flung distribution of this harpoon type in the Interior and the evidently restricted distribution on the Coast point to an Interior origin [1954a:29].

Discussion. I questioned Dr. Borden about this in 1973. Drucker's reference that Borden sites (1943:120) lists tanged harpoons found at these sites:

Eburne (Marpole)

North Saanich

Strait of Georgia (general)

Interior Tsimshian (Gitksan)
35

4

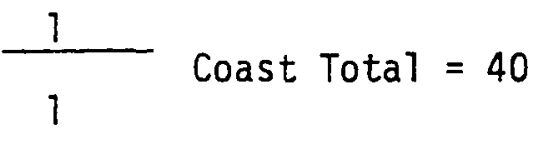

I asked whether the 40:7+ ratio was less significant evidence of origin than the geographic distribution. Borden answered that he still 
felt this particular evidence supported the conclusion of Interior origin. Since Borden's first training and experience in archaeology was in Germany, I asked if he was influenced by Graebner, Foy and Schmidt of the Kulturkreis school. He replied that he was not; but that the four anthropologists who had most influenced him were Kroeber, Drucker, Willey and Phillips. In the early days of archaeology in the Northwest Coast area, Borden's reasoning is an instance of Kroeber's description:

...the age-area concept... is not a mere instrument of speculation but a legitimate means of inferential reconstruction when other data fail [Kroeber 1931:264].

Distribution in Coastal Sites. Borden completes his examination of harpoon types with a review of harpoons found in coastal sites and relates these to the Interior in much the same way that he considered the stone chipping and grinding industries. With only one radiocarbon date, he cannot confirm or disconfirm the relative ages of Locarno Beach, Marpole and the Whalen Farm sites. The arguments for the relative ages of Locarno Beach and the Whalen Farm cultures are still based on the same reasoning found in his first paper, 1950a. This next argument presupposes that Borden's hypothesis of harpoon development has led him to the correct sequence of cultures.

In the Fraser Delta only one-piece toggling harpoons have been found in the deposits of the early maritime period (Locarno Beach II). Barbed harpoon with tang and lateral Iine guards appear in the early part of the intermediate period together with numerous stone artifacts. Moreover, they seem to be confined to the deposits of this period (Marpole-Point Grey-0ld Musqueam). [01d Musqueam is a designation new with this paper, and no lists of artifacts seem published about it up to this 1954 date.] Even though this Interior harpoon type was modified on the Coast to render it more suitable 
for sea-mammal hunting, it was replaced later in the intermediate perlod (Whalen II) by the more efficient composite toggling harpoons, which seem to have been developed from the one-piece toggles late in the early marltime period (Whalen I). Composite toggling harpoons of various types were standard equipment along the southern North-west Coast for sea-mammal hunting and fishing until the twentieth century, and toggle types for harpooning fish diffused far into the Interior along with other elements of the developed North-west Coast culture [1954a:29].

Borden expands his argument about modified barbed harpoons in his 1970 discussion of the Marpole and Stselax phases. Borden's evidence and reasoned sequence do not lead to the conclusion that the tanged, barbed harpoons from recent Interior deposits had come from recent coastal cultures. "On the contrary, such harpoons appear to be survivals from an early Interior culture base" (1954a:29).

\section{Stone Sculpture}

Borden turns to the third element, stone sculpture, and summarizes Caldwell's position:

Mr. Caldwell found no evidence for stone carving in the survey area. He considers the distribution of this art restricted in the Interior, its manifestations late and coastally oriented [1954a:29].

Each point is countered in turn.

Statistical Considerations. First, on the basis of a survey collection of sixty artifacts supplemented by several hundred items from casual collections, it is not statistically improbable to find no carvings .

It is not particularly surprising that a rather hurried survey should fail to encounter examples of stone sculpture. They are generally rare in the entire area of their distribution, the frequency of their occurrence--although variable from place to place--being in the order of one carving to many hundred other artifacts [1954a:29]. 
Borden gives evidence of the existence of such carvings.

I should mention, however, that on a recent trip into the Interior I noted the occurrence of zoomorphic stone carving on vessels and pestles in the Okanagan, i.e., in the area surveyed by Caldwel1 [1954a:29].

Distribution in the Interior. Borden discusses the extent of stone carving in reply to Caldwell's second contention, that the Interior distribution is restricted. In this brief examination of the evidence, Borden clearly uses the Wissler-Kroeber concepts of culture area, culture center and age-area.

The known distribution of stone carving in the Interior is very wide. It extends from the Humboldt Basin in Nevada north through Oregon and Washington to Shuswap territory in British Columbia (Smith, 1900, p.431; Strong et al., 1930, pp.106-1.10; Drucker, 1943, pp.127-128). Important elements suggest a genetic relationship of this entire carving complex, but a study of subject-matter and stylistic features reveals two main divistons: (1) A southern group, comprising the sculpture of the Columbia River valley, and (2) a northern group encompassing the Fraser River-Puget Sound area (Wingert, 1952, p.11). The Columbia River province can again be subdivided into three main regional centres which extend from the Yakima Valley and the Middle Columbia area around Vantage to Sauvies Island in the Lower Columbia near Portland, Ore. (Wingert, 1952, p.12). The western limits of this southern province evidently do not extend to the coast proper [1954a:29].

Borden's conclusions rest on this distribution and on the quality of this art form:

The distribution of this carving appears to be strictly inland, and it certainly strains one's credulity that this widespread and impressive complex should have been inspired by late influences from the North-west Coast. The certainty of conception and masterful technical execution of many of these sculptures strongly suggest that this art has a long tradition behind $i t$, and that its inception is to be sought in the Interior rather than on the Coast [1954a:29].

Borden looks at the Upper Columbia, Okanogan and Fraser evidence. Duff's paper on the subject of stone sculpture in British Co- 
lumbia was being written at this time, so Borden mentions only a few particulars.

Distribution in the North and on the Coast. The northern 1 imits of carving seems to be present Shuswap territory, but a recently discovered carving from Fraser Lake, Central British Columbia may be the first evidence of a more northerly distribution.

Farther south in the Fraser drainage region, some of the main centres of stone carving occur along the lower reaches of the river between Yale and Mission City. However, by contrast with the southern province, this northern stone sculpture is not confined to the Interior, but extends to the mouth of the Fraser and fans out from there some distance north and south along the coast of the Mainland and leaps the Strait of Georgia to include the opposite coast of Vancouver Island approximately between Comox and Victoria [1954a:30].

No doubt Borden would today omit the active verbs in this description and refer to stone carving within the limits of present Coast Salish territory. His conclusion logically depends on the existence of the culture centers up the river near Yale, and the general age-area hypothesis:

Despite the inclusion of this limited salt-water area in the northern province of this art, it seems easier to account for its presence on the Coast by assuming a spread of the culture with which it was associated down-river to the Coast than to assume the reverse, particularly if we consider the immense total distribution of the stone-carving complex in the Interior [1954a:30].

Borden discusses coastal occurrences of stone sculpture with restraint and qualifications. He is suspicious of conclusion derived from any but systematic excavations.

Few specimens of stone sculpture have been recovered in the course of systematic excavations. In the Fraser Delta and adjacent areas it seems to belong in the early intermediate phase, being associated here with emphasis on stone 
chipping, numerous barbed points of antler, barbed harpoons with tang and lateral line guards, and other elements of restricted distribution on the Coast and of probable Interfor origin.

Along with harpoons, certain types of chipped implements, and other elements of this culture, stone carving seems to be confined to the early intermediate period (Marpole-Point Grey-0ld Musqueam). There is as yet no evidence for its occurrence in later deposits of the Fraser Delta area [1954a: $30]$.

Cautions. Borden then examines what conclusions might be drawn if stone carving is discovered in more recent delta deposits, and if it is not, the possible reasons for its absence. Excavation of stone carving in those deposits would not necessarily be a disconfirming instance of Borden's thesis of Interior origin. (Excavations in sites where perishables have been preserved can test Borden's second hypothes is of a late wood carving tradition).

Yet it should not be surprising to encounter carved stone objects occasionally in recent sites, for evidently recent Indian groups did not hesitate to utilize ancient carved stone vessels, etc., if they happened to find them near their habitation sites. Teit reports this practice for the Upper Lillooet (Teit, 1906, p.204), and Duff gives similar information for the Upper Stalo Indians (Duff, 1952, p.61). Perhaps the art of stone carving persisted longer in some areas than in others. Its disappearance on the southern North-west Coast may have been a consequence of the increasing importance in later times of wood as a medium for manufactures and artistic expression [1954a:30].

\section{Woodworking Complex}

The student of Borden's thought follows the most complete and detailed argument of Borden's theories of the woodworking complex, the fourth element under discussion, in the next passage of this paper. He first designates the traits that he organizes in this way, and he distinguishes them from similar elements found in the early 
maritime culture by differences in sizes, raw material, and limits of use of these two groups of implements.

As a final group of traits of probable Interior derivation, I listed large antler wedges, pestle-shaped stone hammers, and large adze-blades of nephrite and serpentine. This triad of heavy-duty tools constitutes the basis for the woodworking industry of the southern North-west Coast. Occasional medium-sized antler wedges and small adze-blades, or rather chisels, of materials available on the Coast, such as bone, shell, slate, and very rarely of tougher stone, do occur in the deposits of the early maritime period. Such implements were adequate for carving bone and antler and for working wood on a small scale, but were inadequate for large manufactures. Heavy-duty tools are required for splitting planks from cedar logs, for dressing large house-posts, and in the manufacture of dugout canoes [1954a:30-31].

First Known Appearance. Borden's first statement of the hypothesis of the Interior origin of the woodworking complex illustrates the inductive aspect of the age-area hypothesis. He generalizes or looks for significance from a collection of different sorts of traits present or absent in a series of cultures:

It certainly seems significant that according to present evidence the implements necessary for woodworking on a large scale first appear on the Coast together with elements discussed earlier as of probable Interior origin [1954a:31].

Argument for Age of Woodworking Industry. Borden introduced his discussion of the time dimension of the woodworking industries of the Interior and Coast with a reply to Caldwell's statement that "...'for Borden's purposes, a well-developed woodworking complex of long standing would have to be present in the Interior at least 500 years ago"" (Borden 1954a:31). I have supplied the implicit steps in Borden's argument which follow:

From his first radiocarbon date, Borden places all these Delta cultures prior to 500 B.P.: 
[1] It is quite certain that the woodworking industry had its beginning on the Coast much earlier than 500 years ago [1954a:31].

Definition of origin:

2. Therefore, if the woodworking industry was fully developed when it reached the Coast from the Interior area of origin, the woodworking complex would have to be even older in the Interior.

Statement of alternative patterns of possible cultural development:

3. The woodworking industry could have either been fully or partly developed in the Interior at this early time.

[Hypothes is of preferred alternative:]

[4 Therefore]... we need not assume that it arrived on the Coast fully developed [1954a:31].

[Archaeologica] and ethnographic evidence:]

[5 The Interior woodworking industry is not "fully developed" in the Coast sense even in historic times, ]...although adzes, wedges, and hammers were used for felling and trimming branches off small trees, for splitting timber, for readying posts and rafters for earth lodges, etc. [1954a: 37 .

Definition of the unit under study:

6. Variables of a woodworking industry include both the wood, and the tools to work it.

Hypothes is to be tested with datable Interior excavations:

7. The Interior had heavier, larger tools than the coast

at a comparable time, but was not comparably timbered.

Archaeological and ethnographic evidence:

8. The coast had abundant, easily worked red cedar.

[Hypothesis from 6 to 8 above:]

[9] I would suggest that it was the meeting of an ideal medium, like the straight-splitting, easily worked wood of the red cedar, with suitable implements which gave rise to the great woodworking industry of the Coast [1954a:31].

Subsequent Discussion. In discussing this argument with me in

1973, Borden touched on both the raw materials and the tools used. He suggested the analogy of Athenian marble as an instance of another such ideal medium. Returning to the Fraser Delta area, he said: 
The distinction between the pestle-shaped stone hammer at Marpole and the hammerstone at Locarno Beach is one of efficiency. When you think of the size and construction of plank houses, efficiency is important. [pers. com., 1973].

Raw Materials. Borden continues to consider evidence of Interior origin of the three woodworking tools. The raw material for efficient adze blades seems to be of Interior origin.

Tough, fine-grained stones suitable for efficient adzeblades are rare or absent on most parts of the Coast, but do occur in fair abundance in some regions of the Interior, for instance, near the confluence of the Thompson and Fraser Rivers [1954a:31].

Borden suggests two hypotheses, the first relating to the migration borne arrival of the tough stone adze blades on the Coast, the second relating to the continuing trade in this article.

It is likely that adze-blades of such stones were originally brought to the Coast from such regions, and that subsequently, when woodworking began to flourish in the coastal area, they became valuable items of trade and constituted an important incentive for maintaining contacts with the Interior $[1954 a: 31]$.

Relative Sizes of Adze Blades. Borden's next concern is the difference in sizes of adze blades in Coastal and Interior sites:

It is interesting to note that very large adze-blades are rarely found on the Coast, but are falrly numerous in some Interior centres, where they were probably made for export $[1954 a: 31]$.

Possible Implications. I have noted that Borden's phrase "it is interesting" has come to alert me to items that he probably regards with special theoretical import. I considered three possible interpretations of this difference in size distribution. First, usefulness of various sizes might be different in the two areas, either because the wooden material or the end product was different. Second, the 
source of the raw material in the Interior might make larger artifacts more economical to use there, both in manufacture and in transport, than on the Coast. Third, the difference might be accounted for by a statistical variation in the archaeological process itself. Thus, perhaps quarry or workshop sites in the Interior have been compared to use sites on the Coast. Each of these may be considered in relation to the hypothesis of the Interior origin of the woodworking complex. For instance, in relation to the second possibility above, perhaps the larger adze blades if broken in use would be used as raw material to make smaller blades, particularly on the coast, where the stone was rare, and so remains of large blades would not be found, but would be related as raw material to the smaller ones that were found. Borden also introduces a time dimension to this variation in size:

If large adze-blades are late in the Upper Columbia and Okanogan regions, as indeed they seem to be, it is more likely that they were brought in from such Interior centres than from the Coast $[1954 a: 31]$.

The statistical variation between Interior and Coastal instances of the large blades seems not to be a disconfirming instance of Borden's position.

Antler Wedges. Borden's evidence for the Interior origin of large antler wedges also confirms his consideration of these three different tools as one group. Ethnographic evidence supports this latter hypothesis, but Borden gives an early archaeological instance as well:

The main reason for including large antler wedges among the elements of Interior origin is that they first appear together with numerous adze-blades and large hand-mauls [1954a:31]. 
While it does not confirm a dated instance to support origin, confirming Interior presence,

It is of interest to note, however, that such wedges were the only objects of antler observed by Caldwell in the area of his survey $[1954 a: 31]$.

In contrast to earlier interpretations by Harlan I. Smith, Borden does not stress that wooden wedges that may have been used would not have been preserved in these sites. It is possible that space limitations in these short publications is sufficient explanation for this omission.

Hand-mauls. Borden's treatment of the third element is as follows:

The pestle-shaped stone hammer or hand-maul of the Pacific Northwest is almost certainly the Interior pestle or foodpounder specialized for woodworking, i.e., for the specific purpose of driving wedges, straight-adzes, etc. Whether this speclalization occurred in the Interior or on the Coast is not yet known, but it is certainly suggestive that the whole series of transitional forms from the cylindrical food-pounder to the fully developed woodworking hammer with strikinghead, tapering shaft, hand-flange, and nipple top is found only in the Interior [1954a:31].

In the absence of dated evidence, Borden utilizes another aspect of the age-area hypothesis. At the culture center, within the area of origin, a trait or aspect of culture will have it's longest series of developmental stages.

\section{CONCLUSION.}

Borden calls more detailed reconstruction of Interior/Coastal relationships futile until dated, excavated work has proceeded in the Interior. In the meantime, he finds no sufficient reason to abandon 
his earlier interpretation.

The archeological evidence and present ethnic distribution attest strong earlier cultural movements outward from the Interior to the Coast. Our outline of prehistoric events has received additional support through the carbon 14 date of $2430 \pm 163$ years for the early maritime culture. This date leaves ample time for the postulated welding and blending of the early Coast and Interior complexes which eventually resulted in the historic North-west Coast culture pattern [1954a:31].

Certainly the carbon 14 date cannot disconfirm Borden's position. The 1954b paper deals in detail with the ethnic distributions to which Borden refers. 


\section{CHAPTER XIV}

1954b DISTRIBUTION, CULTURE, AND ORIGIN...

\section{FORMULATING HYPOTHESES}

Borden's purpose is to use the evidence of the distribution and culture, including language, of the indigenous population of British Columbia to guide him in formulating hypotheses about their origin, so that these hypotheses may be tested archaeologically. It was published in Transactions 7 th B.C. Natural Resources Conference. I have quoted extensively from this paper since it is not available in most libraries, and is the earliest paper dealing at length with linguistic evidence, functioning as the base line for comparison with later evidence and hypotheses. Borden's conclusion should be kept in mind from the outset:

...I should stress that this sketch of the origin and pre-history of the British Columbia Indians is to a large extent based on Inferences and confectures and that these theorles must be tested by extensive archaeological research (Borden 1954b:195].

Retroduction, as a logical process, does not guarantee success in finding an explanation of evidence. After Kepler had seen the pattern of planetary motion, any student could check it out, "But no one but Kepler could have written the first 367 pages of De Motibus Stellae Martis" (Hanson: 199). Salmon regards discovery of hypotheses as "...the most difficult part of creative scientific work..." (p. 66). Cohen and Nage1 in discussing the scientific method say:

The ability to formulate problems whose solutions may also help 
solve other problems is a rare gift, requiring extraordinary genius.... The number of hypotheses which may occur to an inquirer is without limit, and is a function of the character of his imagination [Cohen and Nage1 1934:392, 393].

Borden's 1954b paper presents an extended series of hypotheses of this fruitful sort. It was presented before a gathering devoted to consideration of natural resources of British Columbia. The panel on the people of British Columbia as a resource in themselves, which was opened with Borden's paper, was introduced by Professor V. C. Brink, agronomist of the University of British Columbia. In this introduction, Brink said,

To the end then that future generations will not say of us 'our calculations outran our conceptions' I commend to you the pane] on 'The People of B.C. [Resources Transactions 1954:186].

The quoted phrase in that statement of purpose comes from Shelley's $A$ Defence of Poetry. I propose that the scientist hypothesizes as the poet images, particularly in the early stages of a scientific inquiry. Shelley writes:

We want [lack] the creative faculty to imagine that which we know. We want the generous impulse to act that which we imagine; we want the poetry of life: our calculations have outrun conception; we have eaten more than we can digest. The cultivation of those sciences which have enlarged the Empire of man over the external world, has, for want of the poetical faculty, proportionately circumscribed those of the internal world; and man, having enslaved the elements, remains himself a slave [as quoted in Evans 1968:340].

Thus the creative hypothesis embodies the elements that we know in order that we can imagine them. It is fruitful of action in testing the hypotheses we imagine. It creates a possible ordering of the world in question so that we can grasp it. It allows us to digest, as well as eat; in other words we can more easily see all the implications of the 
undigested 'elements' that had been obscure.

Shelley asks that the poetic faculty cultivate the Empire of the internal world so that man will no longer remain a slave. Man, this internal world, was then a topic of this conference. My position is that this poetic faculty is the faculty of the scientist who conjectures and infers far ahead of the evidence so that man may know, and know himself.

In a letter to me in 1973 , Dr. Borden wrote of his papers:

If you do discover a consistent streak running through them I trust it will be my endeavor always to search out the truth. In doing so I have never hesitated to hypothesize and sometimes I may have pushed the data pretty hard, but I have always tried to resist falling in love with my hypotheses.... I was probably already on the right track in my $1954 \mathrm{~b}$ paper. Eventually I will elaborate this further for you [pers, com., 1973].

Further elaboration of the ideas from this paper are found in the 1969d paper, Chapter XXXIX, and in the unpublished papers discussed in Chapter XLII of this thesis. The reader may enjoy finding threads from this 1954b paper following throughout Borden's search. I came back to this paper with excitement and delight as I studied the pertinent evidence from later publications. All the hypotheses are not confirmed. Some are disconfirmed, but the fruitfulness of the hypotheses, based on such slim evidence, has been a source of wonder to me, and also to $\mathrm{Dr}$. Borden.

\section{LIMITS OF SIGNIFICANCE}

Borden begins with a statement on the limitations of the significance of language groups in studying ethnic relationships:

Although there is of ten no correlation between language and 
race or ethnic affillation the terms denoting linguistic stocks are usually applied to American Indian groups speaking languages belonging to one of these stocks. In the absence of more fitting appelations we have to follow this practice [1954b:186].

\section{LANGUAGE DISTRIBUTION}

Even though the language/race correlation often does not hold, Borden hopes to get clues from the language distribution:

The distribution of the linguistic stocks in British Columbia is important because of its bearing on the origin and culture history of the different Indian peoples [1954b: 186].

\section{Diversity}

This is Borden's evidence concerning the linguistic stocks:

A notion of the ethnic diversity of British Columbia's indigenous population may be gained by comparing the number of linguistic stocks in this province with the total number in Canada. The aboriginal languages of this country are usually classified into twelve distinct stocks:

1. Haida

2. Tsimshian

3. Wakashan

4. Salishan

5. Kootenayan
8. Siouan

9. Algonkian

10. Iroquoian

11. Beothukan

12. Eskimoan

All except the last five of these linguistic familles are represented in British Columbia, and no languages of the first five are spoken anywhere else in Canada [1954b:186].

This linguistic diversity is evidence for Borden of a long and complex history in this area. The archaeological problem as he sees it is to account for this diversity known in ethnographic times through any culturally significant traces of differences or similarities in archaeological remains. 
Location of Linguistic Stocks

Borden's classification of these language stocks reflects his hypothes is that Interior/Coastal divisions are significant of the culture and the origins of these peoples.

According to their distribution, the linguistic stocks in this province may be divided into three groups:

A. Stocks Confined to Coastal Areas-1. Wakashan. 2. Haida.

B. Stocks Distributed over Coastal and Interfor Regions-1. Tsimshian. 2. Salishan.

C. Stocks Restricted to the Interior-1. Athapascan. 2. Kootenayan. 3. Tlingit. [1954b:186-187].

Borden describes in more detail the locations of these linguistic groups, and indicates the language families within these seven British Columbia stocks. Of coastal stocks, the Haida is not subgrouped; the Wakashan is divided "... into two main groups differing in languages and details of culture: (a) Nootka; (b) Kwakiut1" (1954b:187). Of the stock "straddling" the two areas, Borden includes this information:

Tsimshian is the most important of three divisions of the Tsimshian language family and that which gives it its name ... [They live north of the Kwakiut]] between and along the estuaries of the Skeen[a] and Nass rivers. However, about half of the Tsimshian were inland or up-river people, whose villages were scattered especially along the skeena river and its tributaries....

Salishan-speaking peoples accounted for nearly half of the indigenous populations of British Columbia. A little more than half their number were living in coastal areas [1954b:187].

Borden does not name the divisions of the Coast Salish language stock except for the Bella Coola, who are isolated in the midst of Kwakiutl territory. He does not mention the Tillamook, Oregon's isolated southern branch. 
The Salishan-speaking peoples of British Columbia's southern interior nearly equalled in number the combined total of all other inland tribes of the province.... Five divisions are recognized among the Interior Salish of British Columbia. The Shuswap, the northernmost division, occupied more than half of the entire territory. The other four, the Lake, Okanagan, Thompson, and Lillooet are arranged in this order from east to west... [in the south] [1954b:188].

of the three stocks found only in the Interior, the Athapascans are found over the widest area, about two-thirds of the province, in the north and center. They controlled about one-third of Canada's territory, and are important in much of North America. Their most southern group in British Columbia, the Chilcotin,

...separates the Interior Salish from the Bella Coola and the Kwakiutl on the coast.

A small group of Athapascan-speaking Indians used to exist, surrounded by Salish Indians, in the valleys of the Nicola and Similkameen rivers. During the early nineteenth century, this Athapascan outpost was completely absorbed by the surrounding Salish groups [1954b:188].

The Kootenayan speakers in the southeast also extend into Montana and Idaho. Most of the Tlingits live in Alaska, almost entirely in the southeastern coastal area.

However, several small bands speaking Tlingit dialects inhabit the extreme northwest corner of the province. They appear to have been originally Athapascan speaking Indians who in the post-contact period adopted Tlingit speech through contact and intermarriage with the coastal people [1954b: 189].

In later papers when Borden no longer depends exclusively on the Interior/Coastal division, he no longer faces the problems of labeling Tsimshian or Tlingit as one or the other.

Borden in this sketch has included evidence of change in the 7 inguistic affiliation of groups in various geographic locations. The 
student can expect him to appreciate the complex past of these peoples and to suggest hypotheses that reflect it.

\section{Population Size}

How many Indians are we talking about? Borden answers in a table, introduced in this way:

British Columbia has not only a greater diversity of Indian peoples, but its population density was also higher than that of any other region in Canada. Precise population figures are rarely available, but careful estimates add up to about 235,000 for the entire country. Nearly one-third of these lived in British Columbia alone.

The accompanying table presents estimates of the size of the separate Indian groups in British Columbia at about 1775 and 1925 respectively. The disastrous effect of the advent of Europeans on the Indians of this province is reflected in the drop of the native population from about 75,000 to 22,000 after a century and a half of white contact.

\section{TABLE I}

ESTIMATES OF THE INDIGENOUS POPULATIONS

OF BRITISH COLIMBIA

$$
\text { Group }
$$

1775

Coast

Nootka..................... 6,000

Haida............... 8,400

Tsimshian........... 3,500

Gulf of Georgia Salish...15,000

Bella Coola (Salish).... 2,000

Interior Salish.........

Athapascan.............

Kootenay.............

Interior Tlingit........

\section{Interior}

1925

1,500

2,000

650

3,448

4,000

300

6,000

2,901

500

200 (?)

0 (?)

$$
\overline{40,900} \quad \overline{33,500}
$$

Totals............ $\quad 74,400$

21,499

(*) The table is based on estimates cited in A. L. Kroeber, "Cultural and Natural Areas of Native North America," and Diamond Jenness, "The Indians of Canada." [Borden 1954b:189]. 


\section{CULTURES}

Borden's sketch of the cultures within British Columbia stresses the common patterns rather than the "...traits which give each of the many Individual cultures its particular stamp" (1954b:189).

The economy of the different groups was fundamentally similar. None practiced agriculture or the raising of live stock. The only domestic animal was the dog. Their entire economy was based on hunting, fishing, and the gathering of plant and animal foods. But important differences arose in consequence of regional variations in the type and abundance of food resources. Economically and culturally British Columbia can be roughly divided into two main areas: (1) The Coast and (2) The Interior [1954b:189].

Basis of Division

Here is the theoretical basis for Borden's Interior/Coastal classification: the type and abundance of food resources. Within the Interior he will make a further division on this same basis. What does the land and the water have to supply; what is the climate? This environmental factor is a limiting but not I think, a determining factor for Borden, and led him and will lead him in later papers to look not only at what was available, but at the resources actually utilized, and in what proportions.

\section{Coastal Culture}

Borden describes the "...mild climate and teeming supply-of marine foods..." (1954b:190) of the beach dwelling coastal peoples.

The maritime food resources included fish (halibut, cod, oolachan, herring, and, above all, five species of salmon), sea-mammals (the Nootka even hunted the large whales), waterfowl, and shellfish. Even plant food, in the form of edible sea weeds was taken from the sea. Land mammals were comparatively unimportant, but berries and roots gathered 
by the women close to the shore formed an important supplement to the diet.... But not all of the foods were obtainable close to the village site. Hence, from the spring to the fall, the members of each community followed a regular annual cycle of movements to specific localities where they stayed for varying periods in order to obtain particular foods. A large supply of fish, clams, berries, and other victuals were especially prepared and stored for winter use [1954b:190].

Borden then describes the winter life on the coast:

It was in the winter months that the members of each communith congregated in the village for a season of festivity. This was the time of potlatches, of ceremonial dances, singing and dramatic performances. The comparative leisure which the coast peoples enjoyed during the winter also favored the remarkable developments of arts and crafts for which the Northwest Coast cultures are justly famous. Perhaps the greatest achievements were attained in woodworking, which are all the more astonishing since they were accomplished with tools of bone, antler, and stone. The early explorers and travellers marvelled at the long rows of huge cedar plank houses which were typical of the winter villages, and at the masterfully designed dug-out canoes [1954b:190].

Borden's hypothes is of culture change and development on the coast stresses the importance of the canoe. It remains an important

theme in his thought up to the present publications (1973).

The large, sea-worthy canoes not only amplified intercourse within local areas, but they also made possible visits and trade between widely separated groups. In addition, however, they facilitated surprise attacks and were, therefore, an important factor in the warfare which seems to have been ever-present along the coast. Nevertheless, the frequency of these various contacts favoured the diffusion of culture traits and complexes and promoted the rapid growth and proliferation of culture which was particularly in evidence in the northern half of the coastal region [1954b: $190]$.

Borden touches only briefly on the differences in the complex social organization on the Coast, with the northern groups divided into exogamic clans, reckoning descent in the female line; within the 
Kwakiutl groups are both this form in the north, and bilateral descent in the south. Clans were not part of the Nootkan or Salish structure, but they had a stratified society, in comon with all the Coast. High rank, acquired by heritage and wealth dominated the common and slave classes below. The display and prestige in giving away this wealth was common to the whole coast, but less strong in the south.

\section{Interior Culture}

The Interior generally was different:

On the whole, existence in the interior was more difficult than on the coast. Winters were long and severe. Much time and energy had to be expended In coping with the adversities of the environment and in the quest for food. Shortage of food and even starvation were a more imminent possibility than on the coast. Although bark canoes could be used along lakes and on navigable stretches of river, travel was largely on foot, and goods and personal belongings had to be carried. In winter, travel was often difficult or even dangerous. While there was a good deal of intercourse between groups nevertheless contacts were less frequent than in the coast region [1954b:191].

On the basis of this evidence, Borden finds the difference in population density and culture simplicity a reasonable consequence.

It is not surprising, therefore that the population density drops off sharply as one proceeds from the coast to the interior, and that the cultures were simpler and lacked the extravagant aspects of the cultures on the coast [1954b: $191]$.

The interior peoples are divided by resources available to them:

Groups living in the drainage basins of rivers emptying into the Pacific were able to share in some measure in the rich food resources of the sea through the annual runs of salmon that ascended the streams to reach their spawning grounds. As on the coast, many of these fish were preserved for consumption in winter [1954b:191]. 
A11 interior groups, unlike coastal groups, depended on land mammal hunting.

Among the game animals were moose, deer, caribou, bear, and smaller species like beaver, porcupine, rabbits and squirrels. The Kootenay and some of the neighboring Salish groups even crossed the mountains annually to hunt buffalo. Many species of birds were also taken, and, as on the coast, the women added to the diet by gathering berries and digging up edible roots. The Sekani and Kaska, who roamed through the northeastern parts of the province lived almost entirely by hunting since no fish, comparable to the big salmon runs of the rivers draining the Pacific slope, ascended the MacKenzie and its tributaries [1954b:191].

Borden's ethnographic information includes clothing and habitation patterns. With these data of food, clothing and habitation as base line or the most recent link in the history and pre-history of these people, the archaeologist can search for the preceding steps or links leading backward in time to the original peopling of this region and of the New World. Borden's knowledge of the ethnographic present is important evidence in his hypothes is formulation and testing.

While only a modicum of clothing was worn by the Coast Indians--except on ceremonial occasions--the severer climate in the interior made different types of dress and habitations necessary. Tunics, leggings, and moccasins of buckskin were worn by all, and robes of fur provided protection against extreme cold.

The characteristic winter dwelling of nearly all the Interior Salish, as well as of the Chilcotin and some of the southern Carrier, was the circular semi-subterranean house, from twenty to forty feet in diameter, and with entrance by means of a $\log$ ladder through an opening in the apex of the conical sod-covered roof. The chief advantage of this earth-lodge was its warmth even in the rigours of the most severe winters.

Most of the Carrier and other northern Athapascan groups built rectangular structures, some of which showed strong coastal influence, while others were more like simple or 
double leantos. The Kootenay, like the Plains tribes east of the Rockies, used the tipi throughout the year, either covered with buffalo hides or rush mats [1954b:191-192].

Rather than the rank, class and wealth emphasis of the Coast, social equality is the pattern of the Interior. Emphasis among the Interior Salish

...is on pacifism instead of on warfare, although war-1ikeness could be engendered by aggressive neighbours. The Chilcotin were aggressive and caused much unrest. The Kootenay tribes, as in many other aspects of their culture, follow Plains culture also in the pattern of their warfare [1954b:192].

\section{Interpretation of Interior Relationships with Other Areas}

The next section of Borden's description logically depends on Borden's interpretation of the Interior as home of an early population influenced by other peoples around them. He notes that the Sekani, Chilcotin and Carrier probably moved into the area rather recently, but, although he does not deal with his presupposition direct1y in this passage, it is plain that he does not think the Interior Salish, for instance, were intrusive from the coast. One of the important aspects of an analysis of Borden's work is to note these presuppositions and see supporting or disconfirming evidence as it appears through the course of his papers. For instance, note Borden's phrase "the original cultures" [in the Interior], below:

Several subareas of interior culture are apparent. The coast with its abundance and cultural richness held a great attraction for interfor groups, and all along the western fringe of the interior, the original cultures were changed profoundly through sustained contact with the coast dwellers. In the southeastern part of the province, on the other hand, Plains culture is strongly in evidence, and only in the more central parts of the southern plateau are extra-areal influences less strongly felt [1954b:192]. 
This description of the Interior as influenced along its eastern and western borders by Plains and Coast cultures includes the impression that in the southern central part where these influences were not felt, a culture of some long standing existed, and might profitably be studied by archaeological techniques with strong chance of finding preceding stages in its developmerit. In contrast to this picture, Borden gives instances of complexities that make the archaeologist's task very difficult. He describes the adaptiveness of the Athapascans.

Like Athapascan peoples in other parts of this continent, the Athapascan groups of this province exhibited great cultural adaptiveness. The culture of some of the western Carrier, for instance, was modelled closely after that of their Tsimshian neighbours, although there is every reason to believe that in the not too distant past they ranged as nomadic hunters in small bands through the northern interior like their close kin, the Sekani, in historic times [1954b:192].

How can these people be traced archaeologically if they adapt to, and adopt the ways of those around them? There is no doubt that Borden appreciates the complexity of studying the early origins of these peoples, and that he regards all hypotheses in this reconstruction as tentative. It is characteristic of Borden that he first shows the scope of the problem, but then orders the available data even if the results have a very low range of probability. He thinks that such speculation clarifies the problems of research. In later papers, 1962a: 9, and 1965:5, he will make this position explicit.

\section{ORIGINS}

The rest of this paper is an extended series of hypotheses on 
the origins of New World peoples, particularly in British Columbia. Borden begins with general hypotheses on the peopling of the New World. Second, he adds hypotheses derived from physical anthropology, and third he uses hypotheses from linguists as the basis of his own reconstructions. I have numbered these three groups of hypotheses consecutively, to indicate that they are essentially one series.

General Hypotheses on Peopling the New World

Under the general hypothesis that the New World was populated from Asia by way of Bering Strait, Borden gives three sub-hypotheses:

[1] These early immigrants to the New World were nomadic hunters travelling in small bands and their "mf.grations" were determined by the movements of the game animals on which their existence depended. They were not travelling toward a definite goal or even in any definite direction [1954b: 193].

2. The earliest dated remains (in 1954), 8,000 B.C. for the New World and perhaps 8,000 B.B. for British Columbia do not represent the earliest inhabitants:

The first immigrants to the New World arrived at a much earlier date, certainly well before the end of the last glaciation [1954b:193].

[3] The peopling of North and South America was a gradual process which extended over thousands of years [1954b:193].

\section{Hypotheses from Physical Anthropology}

Borden cites studies in physical anthropology as the source of evidence of variation in physical characteristics of indigenous New World populations, and the geographic distribution of that variation. The hypotheses include two general theories, and a possible corollary suggested by Borden.

[1] Some physical anthropologists believe that American In- 
dian populations descended from the earliest arrivals in the New World resemble present Mongolian Inhabitants of northeastern Asia the least, while the descendents of the latest immigrants resemble them the most [1954b:193].

[2] Furthermore, it has been suggested that the descendents of the earliest groups are likely to be found farthest from their original point of entry, while those of the late-comers will still be located in or near that general vicinity [1954 b:193].

Borden gives population information for his area of interest:

The three major groups in northwestern North America nearest Bering Strait today are the Eskimo, the Athapascan and the Salish. We do not know the precise sequence of their arrival, but it is generally assumed that the Athapascan were the last to enter North America [1954b:193].

(Borden has noted a change to this wording on his copy of this paper, so that he would have this last sentence read, "...but it is assumed by some that the Athapascan..."). Borden then gives his corollary to the two general theories, all three clearly instances of the age-area thesis.

[3] Since the bulk of the Salish are at present farthest removed from buring Strait the sequence may have been (1) Salish, (2) Eskimo, (3) Athapascan [1954b:193].

\section{Hypotheses from Linguistics}

Borden now begins the last sequence of theories, adding evidence and hypotheses from linguistics. In the next passage is Borden's statement of the problem of the complex "splinter groups" and what seems to me to be an accurate interpretation of Sapir's and Greenberg's hypotheses on two larger linguistic groupings:

But what about the splinter groups, the Tlingit, the llaida, the Tsimshian, and the Wakashan? Perhaps comparative linguistics can help to unravel this apparently complex situation. The great linguist Edward Sapir pointed out long ago similarities existing on the one hand between Haida, Tlingit 
and Athapascan and on the other between Wakashan, Chemakuan (a language stock in the State of Washington) and Salishan. Although much comparative work remains to be done some authorities regard it as certain that Athapascan-Tlingit--Haida constitute one single linguistic stock and Salishan--Chemakuan--Wakashan another (Greenberg, 1953, p.283). Although, as I have indicated before, there is of ten no correlation between language, race and culture, linguistic relationships nevertheless may of fer important clues regarding early historic connections and events [1954b:193-194].

Borden proceeds to use these clues, having again stated how tentative his hypotheses are. As I list these hypotheses, I will divide some into sections. In this way, I can note the succeeding publication and evidence that relate to different aspects of Borden's theories.

Salishan-Chemakuan-Wakashan. In respect first to the Salishan, Chemakuan, Wakashan grouping, Borden's hypotheses are as follows:

Thus, if Wakashan, Chemakuan, and Salishan are indeed related it seems plausible to assume that

[1] some thousands of years ago the ancestors of the groups speaking these languages were not so scattered as they are now

[see 1973 for confirmatory instances]

[2] and that these ancestors lived farther north in Alaska and the Yukon [1954b:194].

[see 1973 for confirmatory hypotheses]

From [1] and [2] Borden moves to Wakashan hypotheses:

This assumption raises the intriguing possibllity that [3] some of the Wakashans, especially the ancestors of the Nootka, at an early time had found their way to the coast

[see 1969d: $502 ; 1973$ for confirmatory instances]

[4] and developed their remarkable maritime culture while they were living in the proximity of ancient Eskimo groups located somewhere on the Pacific Coast of Alaska. 
[5] With the development of boats capable of navigating the coastal waters Wakashans may have spread this early maritime culture southward along the Northwest Coast, for we believe to detect evidence of it in some of the earliest cultural deposits of the Fraser Delta and of nearby coastal areas [1954b:194].

[see 1973 for confirmatory instances]

Athapascan-Tlingit-Haida. From [1] and [2] Borden develops his theories about the Athapascan, Haida and Tlingit, as related to the earlier Salish and Wakashan peoples (from physical anthropological corolTary [3] above).

Again, if, as it seems, the Haida and Tlingit languages are related to Athapascan we may assume that when the late-arriving Athapascan peoples were expanding,

[6] some of them either followed or crowded the Early Salish southward into the interior of British Columbia,

[see the final chapter of this thesis for a further discussion of the early Salish movements in the Interior thought plausible by Borden, pers. com., 1973.]

[7] while a few groups, especially the ancestors of the Haida and Tlingit, filtered through river valleys, such as the Stikine and Skeena, to the coast

[8] where they either displaced or,

[9] more likely, mingled with the (Wakashan?) maritime population already present, at the same time adopting much of their coastal culture [1954b:194].

Tsimshian. Borden now takes up another linguistic group entire-

7y: the Tsimshian. He gives three al ternative hypotheses:

The origin of the Tsimshian is obscure.

[10] They may be late arrivals from Asia,

[11] but it is also possible that they migrated northward

from an earlier southern habitat.

[see 1969d, Chapter XXXIX and discussion of the unpublished papers, Chapter XLII concerning the site at Namu.] 
Their language bears no evident relation to other Canadian languages, but 1 tis genetic relation to the Penutian languages of California has been suggested. [Borden has noted an insert "Oregon and" before "Cal ifornia" in his corrected copy of this paper.]

[12] It is probable that the Tsimshian came to their present location from the interior.

[see 1969d:513 for disconfirmatory evidence, and discussion relating to the evidence that Borden cites below:]

Not only are half of them still inland people, but Tsimshian traditions consistently take an interfor origin for granted, and one of their legends relates the migration from the interior down the Skeena River to the coast in considerable detail [1954b:194].

Borden summarizes the twelve preceding hypotheses in this way:

I would suggest that the mingling of the early maritime culture with the culture groups arriving from the interior eventually produced the classical Northwest Coast culture. However, important elements of the early coast culture evidently were not incorporated in the new synthesis.

The arrival of Haida, Tlingit, and Tsimshian on the coast naturally disrupted the cultural connection which had existed at an earlier time between the southern British Columbia coast and the Pacific coast of Alaska. Striking evidence for an earlier cultural condinuum between the northern and southern areas is provided by the Nootka, whose historic culture still exhibited a long series of significant parallels with Eskimo cultures, which are totally absent in the long stretch of coast now separating the Nootka from the nearest Eskimo (Borden, 1951) [1954b:194-195].

Kwakiut1. Borden next discusses the Kwakiutl branch of the Wakashan linguistic family:

The culture of the Kwakiutl was strongly influenced by the culture of their northern neighbours although

[13] formerly it probably bore a greater resemblance to Nootka culture.

Yet Kwakfutl culture lacks most of the elements which the Nootka share with the Eskimo. It may be an indication that [14] they [the Kwakiut7] lived fairly far south on the coast even at an earlier period [1954b:195]. 
[note Borden's references from 1950 on, to parallels between Marpole and ethnographic Kwakiuti cultures].

Salishan Theory and Archaeological Testing. Borden returns to consideration of the Salish peoples:

Excavations in the Fraser Delta have shown that the early maritime culture is overlaid there by the cultural deposits of

[15] people who must have come from the interior.

[see Borden 1950 up to the present]

[16] At least some of these later remains must have been left by the ancestors of the present Coast Salish [1954b: 195].

Borden suggests several hypotheses for Salish movements. Any one or combination may be confirmed without disconfirming the others:

We do not know as yet what brought the Salish to the coast. [17] It may have been merely the lure of abundant food resources and of a mild climate.

But there is reason to believe that

[18] the movements of Athapascan groups southward through the Plateau are at least partly responsible for srme of the population shifts.

[19] Similar dislocations seem to have occurred farther north, when the Chilcotin drove their wedge deep into Salish territory. This spearhead cut the Bella Coola off from their interior kin and may have pushed the Lillooet into their present location [1954b:195].

Borden discusses archaeological confirmation relating to these hypotheses:

To date, our archaeological. Investigations in centra1 British Columbia have not revealed any considerable time depth for Athapascan remains. On the contrary, on Natalkuz Lake in Tweedsmuir Park, in present Carrier Indian territory, we found recent Carrier Indian artifacts overlying the remains of an earlier and totally different culture [1954b:195].

Borden then proposes one test for a part of his thinking: Whether these earlier implements were left behind by an an- 
cient Salish group is still uncertain, but if our theory is correct that the Salish moved south through the northern interior of British Columbia

[20] we should expect to find their earlier remains in the areas to the north of their present habitat [1954b:195].

Borden concludes this paper stressing its tentative nature as I quoted early in this section of the thesis. He asks that these be subjected to extensive archaeological testing, and that sites not be destroyed.

Prehistory is a field where truth is not easily and quickly come upon. We greatly appreciate the co-operation of all those who send in specimens, report the location of sites, or assist us in any way which will advance the knowledge of the prehistory of British Columbia [1954b:196]. 
PART III

MIDOLE PERIOD

Reproduced with permission of the copyright owner. Further reproduction prohibited without permission. 
CHAPTER XV

THE LOGIC OF THE PERIOD

\section{CHARACTERISTICS}

Two items in this section (1960d Chapter XXIV; 1961a Chapter XXV) tell of a Provincial law protecting archaeological sites. Borden played an important part in this legislation, and in its active implementation.

Basis in New Technology

The middle period papers present several facets of archaeological theory and practice. They are based on the fact that from 1955 to 1963, evidence from radiocarbon dating was accumulating rapidly from many sites. The "Notes and News" in American Antiquity illustrate the regularity with which important data appeared.

\section{Consequences}

The first consequence of this dating evidence is that Borden now argues from the date to the assemblage and its interpretation. The period covered by Chapter XVI, a study of the Iife of the early occupants of the Marpole site, is fixed by a radiocarbon date. The discovery of the Milliken site in the Fraser Canyon is reported together with a series of radiocarbon dates.

The second consequence of radiocarbon dating is the testing and formulation of hypotheses concerning sites that are geographically wide spread. Borden compares the early Fraser Canyon assemblages with other early assemblages at Lind Coulee and Five Mile Rapids (1960a, Chapter 
$X X I)$. He re-structures the northern-influence theories from his early period to fit a new time/space gradient. Borden illustrates his theories with maps showing radiocarbon dates of similar assemblages (see 1962a, Chapter XXVI).

A third consequence results from this early and primary use of radiocarbon dates. Instances of probable error in these dates are not easily detectable at first. Thus Borden now regards one of the Marpole dates (first cited in 1959b, Chapter XX; 1ast cited in 1962a, Chapter XXVI) $2900 \pm 170$ B.P. as in error, a "bad date". Likewise, he no longer trusts his use of Siberian data in the 1962a paper, since the cited Soviet chronology now seems based on single or 1 imited radiocarbon samples from most sites (see Chapter XLII). In summary, the interpretation of radiocarbon data was sometimes incorrect during this period.

Fourth, many full archaeological reports became available during this period. Borden's 1956 paper of the East Kootenay Survey (Chapter XVII) is one. The Cressman and Gruhn publications which Borden reviews (1962b, Chapter XXIX; 1963, Chapter XXXI) are others. With these studies, including full statistical reports of the assemblages, other archaeologists can check their own work for similarities and differences. The self-correcting aspect of archaeology as a science begins with this step. Borden's concern that a consistent pattern of archaeological classification be followed (1956, Chapter XVII and 1962b, Chapter XXIX), is based on this prerequisite for self-correcting theories.

Fifth, different hypotheses or approaches to archaeological work can be tested. Thus, Ruth Gruin's paper reflects the environmental archaeologist's questions about the fit between the culture and the specific environment as both change through time. Questions about these 
changes simply couldn't be answered before radiocarbon dating, or other absolute dating techniques, provided the framework.

Chronology and Faunal Analysis

While new questions are being asked and answered, Borden's interest remains centered on the details of a space/time chronology, depending on others to use the statistical techniques of the environmental archaeologist, for instance. 1961c, Chapter XXVII "Notes and News" i1lustrates another aspect of Borden's research in which he depended on other specialists, in this case for faunal analysis of his material. This analysis was, tragically, never completed.

Three Papers of Interest

There are three particularly interesting theoretical papers in this section. The 1962a (Chapter XXVI) West Coast Crossties... is Borden's major re-assessment of all the evidence found in his early period. The 1960a DjRi3... (Chapter XXI) paper is an extended series of hypotheses based on two very brief visits to the Fraser Canyon site. These two papers show most of the aspects typical of this period.

The 1956 Survey of the East Kootenay area (Chapter XVII), is one of the most complex theoretical papers, because it, alone of al1 of Borden's published works, is a complete archaeological report. It therefore contains evidence and hypotheses at every level of generality or abstraction. There are no gaps in the logic as Borden moves from one level of argument to the next. Anomalies

Some of the anomalies that Borden perceives for this period are the same as those for the early period. The new ones are connected with 
unexpected, surprising, radiocarbon dates:

1. Northwest Coast dates earlier than Alaskan dates lead Borden to an explanation which completely reverses his early theories of the direction of influence.

2. Early Fraser Canyon dates allow Borden to explain the delta cultures within a pattern of local cultural development (1960a, Chapter XXI).

The old interior/coastal dichotomy has lost its explanatory value. Borden has new, better evidence. He argues from the data, from the phenomena, to formulate hypotheses which can best explain them. 
II. OUTLINES OF PAPERS

\section{An Ancient Coast Village in Southern British Columbia (Chapter XVI)}

A. Evidence:

1. Past archaeological work at Marpole (Eburne).

2. Recent (endangered) archaeological evidence.
a. vegetal and faunal remains.
b. tools
c. industries.
d. habitations.

3. First radiocarbon date from Marpole.

4. Ethnographic information.

B. Purpose:

1. To explain to Indian readers the purpose of archaeology.

2. To reconstruct the life of the people who formerly inhabited what is now called the Marpole site.

C. Steps in Retroduction and testing:

1. Correlate old and recent work to get a span of occupation time around the radiocarbon date.

2. Use ethnographic analogy to organize the assemblage as if it were used recently,--to show tool uses in the past, women's work, etc.

3. Examine and contrast workmanship and techniques with other sites and times.

4. Suggest an hypothesis of different origins and histories of Marpole and Locarno Beach. 
1956 Results of Two Archaeological Surveys in the East Kootenay Region of British Columbia (Chapter XVII)

A. Evidence:

1. Kootenay survey plans and results in general distribution and character of sites.

2. Artifacts and their statistics, description, illustration.

3. Ethnographic information, conflicting in some details.

4. Geographic, ecological information.

B. Purpose:

1. To present a full archaeological report of two surveys in southern interior British Columbia.

2. To test hypotheses mentioned in Scottsbluff paper about Early Man.

3. To suggest further hypotheses for testing.

4. To suggest places and ways of testing them.

c. Steps in Retroduction and testing:

1. Correlate distribution of habitation remains (using ethnographic information, for spatial references), with projectile type distribution and frequency.

2. Suggest meaning of habitation remains.

3. Propose patination as a further test of Hypotheses $\# 2$.

4. Suggest further testing of Shuswap/Kutenai origins, relationships, and time depths. 


\section{Notes and News (Châpter XVIII)}

A. Evidence:

1. Survey in Gulf Islands to look for "Early Maritime" [Locarno Beach] evidence...

2. First account of Milliken site up the Fraser Canyon, a deeply stratified site.

3. First account of a pit house site in the same area.

B. Purpose: To give new Northwest Coast information and interpretation to archaeological readers.

C. Steps in Retroduction and testing:

1. Designate Locarno Beach as "Early Maritime" rather than "Eskimoid". This is from radiocarbon dates, see next paper.

2. Use basic archaeological procedures, stratigraphic studies, site surveys. 


\section{9a Notes and News (Chapter XIX)}

A. Evidence:

1. Pender Island Canal site (similar to Locarno Beach, Whalen I?).

2. New dates (not specifically given) from Alaska and Northwest Coast.

3. Radiocarbon date at Stselax Village, on Musqueam Reserve $[1290$ \pm 130 S. 20].

4. Large excavations at Stselax Village 300 artifacts, etc., details of house construction.

B. Purpose: to give newest evidence and interpretation to archaeoiogists.

C. Steps in Retroduction and testing:

1. Correlate dates of separate assemblages, as in \#2 above, (current views on Northwest Coast and Alaska may have to be revised as anomalies are perceived).

2. Correlate radiocarbon date, \#3 evidence above, with stratigraphy. 
1959b Notes and News (Chapter XX)

A. Evidence:

1. Radiocarbon date at DjRi3, Fraser Canyon $8130 \pm 310$ B.P.

2. Radiocarbon date at Marpole $2900 \pm 170$ B.P. (The bad date).

B. Purpose: to give new evidence and interpretations to archaeologists.

C. Steps in Retroduction and testing: Carbon-14 techniques.

(The Marpole date was the first sample dated by a new method.

Borden questioned it, and as further dates came in, he abandoned

it as one of the statistically predictable incorrect dates). 
1960a DjRi3, An Early Site in the Fraser Canyon, British Columbia (Chapter $X X I)$

A. Evidence:

1. Survey-based stratigraphy.

2. Geologist's interpretation.

3. One radiocarbon date.

4. A few artifacts.

5. Ethnographic information.

6. Archaeological work at Lind Coulee.

7. Archaeological work at Five Mile Rapids.

8. Vegetal remains (cherry pits).

B. Purpose: to formulate hypotheses on the basis of a brief survey.

1. The nature of the site.

2. The length of its occupation, seasonality, etc.

3. Its relation to this Fraser area and other areas in North America.

C. Steps in Retroduction and Testing:

1. Correlate archaeological stratigraphy, geological evidence, and radiocarbon evidence for the age of the site.

2. Describe artifacts by level, from earlier of two at DjRi3 to later ones in nearby sites, which are dated ethnographically.

3. Compare with Lind Coulee, Big Game Hunting site (no expected connection).

4. Synthesize \#5, \#2, and \#8, indicating saimon use.

5. Propose Five Mile Rapids comparison as test of early salmon area hypothesis. 
6. State hypothesis that origin of salmon industry may not be northern.

7. Apply Kroeber adaptive hypothesis to pre-adaptive seal hunting \#7.

8. Organize Fraser delta sequence as local cultural development.

9. Suggest direction of influence from Northwest Coast to Alaska.

1960b Notes and News (Chapter XXII)

A. Evidence from DjRi3

1. An earlier cultural deposit, with charcoal sample taken.

2. Stratigraphic: three recent levels separated by massive gravels.

B. Purpose: to inform archaeologists of new evidence and interpretations.

C. Retroduction and testing: comparison with other assemblages; (\#3 uppermost layer like neither Marpole nor Stalo). 
1960c Notes and News (Chapter XXIII)

A. Evidence from DjRi3, DjRil, pit house site.

1. 167 artifacts from 8150 B.P. horizon.

2. New radiocarbon date $7350 \pm 150$ B.P. next level, little assemblage difference.

3. Volcanic ash layer.

4. Slate knives at DjRil.

5. Knives dated $2270 \pm 100$ B.P.

B. Purpose: to inform archaeologists of new evidence and interpretations.

C. Steps in Retroduction and testing:

1. Correlate radiocarbon dates and artifacts.

2. Suggest volcanic ash, \#3, may be Glacier Peak eruption, 6700 B.P.

3. Correlate sites typologically, pending further dating.

1960d Notes and News (Chapter XXIV)

Antiquities Act to be introduced to protect archaeological sites in British Columbia. 
1961a Notes and News (Chapter XXV)

A. Evidence:

1. Passage of Archaeological Antiquities Act.

2. From DjRi3, 6000 stone artifacts.

3. Stratigraphic evidence.

4. Sculptured objects to be radiocarbon dated.

5. 500 artifacts from $8150 \pm 310$ B.P. level.

6. Additional artifacts from $7350 \pm 150$ B.P. level also.

7. Artifacts at a deeper level; also charcoal for dating, cherry pits, stake holes.

B. Purpose: to inform archaeologists of new evidence and interpretations.

C. Retroduction and testing: standard archaeological procedures. 
1962a West Coast Crossties with Alaska (Chapter XXVI)

A. Evidence:

1. Radiocarbon dates from the Northwestern New World (Note this is the last time Borden uses the bad Marpole date).

2. Assemblages in the 01d and New World with assemblages similar to the dated sites.

B. Purpose:

1. To revise earlier hypotheses suggesting chronologies relating the Northwest Coast and Alaska.

2. To revise hypotheses of influence dependent upon \#1.

3. To suggest linguistic correlations to these new hypotheses.

4. To suggest new archaeological tests.

c. Steps in Retroduction and testing:

1. Assume diffusion, rather than innovation, and put these dated sites on a time line to calculate the rate and route of diffusion, or migration, or whatever.

2. Use linguistic evidence as an additional test.

3. Correlate assemblages in Fraser Delta and Canyon with the Columbia River (Five Mile Rapids).

4. Correlate dated Marpole assemblage, its influence, and antecedents.

5. List dated assemblages containing ground slate, to determine their origin, route and rate of diffusion.

6. Suggest hypotheses from dated microblade assemblages and compare with \#5 above. 
1961 braser River Archaeological Project Progress Report (Chapter XXVII)

A. Evidence:

1. Dates from Fraser Canyon site DjRi3.

2. Artifacts, photographs.

3. Geological features, photographs, drawings.

4. Sample size by zones.

5. Oldest date $9000 \pm 150$ years B.P.

6. Geological evidence downstream.

B. Purpose: to summarize evidence from $D j R i 3$ to date.

C. Steps in Retroduction and testing:

1. Put the artifacts into order by zones correlating items above.

2. Interpret deposition and character of matrix.

3. Correlate with glacial deposits and times.

\section{1c Notes and News (Chapter XXVII)}

A. Evidence:

1. Radiocarbon dates given in previous chapter.

2. Drake's faunal analysis (not in usable form) 
1962b Review of L. S. Cressman: Cultural Sequence at The Dalles, Oregon (Chapter XXIX)

A. Evidence:

1. Cressman's dates.

2. Cressman's interpretations.

3. Cressman's classification of artifacts.

B. Purpose: to review Cressman's Five Mile Rapids publication.

C. Steps in Retroduction and testing:

1. Report what seems to be important, both to Cressman and Borden.

2. Discuss \#3 above, pointing out that unusual definitions and usages prevent Borden from utilizing this information in comparing it to DjRi3

1962C Notes and News (Chapter XXX)

A. Evidence:

1. From DjRi3 a few additional artifacts from early horizon.

2. From DjRi3 test pit to depth of 46 feet (no cultural evidence).

3. From nearby deposit, fossilized salmon bones, no date [even in 1974].

4. From DjRi3 stratigraphic evidence: top deposits contain pendants and zoomorphic carving below ground slate knives.

5. From DjRi5 Esileu: a few contact goods.

B. Purpose: to summarize evidence for archaeologists.

C. Retroduction and testing: use standard archaeological procedures. 
1963 Review of Ruth Gruhn: The Archaeology of Wilson Butte Cave...

\section{(Chapter XXXI)}

A. Evidence:

1. Gruhn's theoretical framework: environmental archaeology.

2. Gruhn's evidence: dates; fauna, flora; climatic change; artifact change correlated with climatic change.

3. Comparisons with other areas.

B. Purpose: In book review to give evidence and comments on report of Wi1son Butte Cave site investigated by Ruth Gruhn.

C. Steps in Retroduction and testing:

1. Review evidence.

2. Comment (favorably) on methods, procedures, and finished product.

3. Point out anomalies, offer new Borden hypotheses.

a. on time of climatic shifts (Altithermal beginning) in relation to archaeological evidence

b. the numbers of water fow 1 remains during increasing drought 
CHAPTER XVI

1955 AN ANCIENT COAST INDIAN VILLAGE...

\section{BACKGROUND}

\section{Aims of the Paper}

Extensive introductory sections of this paper are quoted in Chapter II of this thesis. Writing for Indian Time, Borden relates to a contemporary Indian audience the life of the ancient Indians on the lower Fraser as it is suggested by material from one midden. His account answers questions that people ask about their ancestors: How were their ways different from and how were they the same as ours? What changed, and how did these changes happen? How do older ways compare with the customs that Simon Fraser, Boas, and other writers reported? In short, what is our history, our past?

Borden has included explanations of the aims of archaeology. He tells what middens are and were, the procedures, problems and history of Northwest Coast archaeological work, and of the Marpole midden in particular. This paper was written at the close of a sumer's excavation at Marpole (formerly called Eburne), when destruction of the site was threatened. He tells of public appeals for funds and labor to extend the digging season. At the end of the paper, he calls for legislation to protect endangered sites.

Argument by Ethnographic Analogy

Against this background of urgency, he interprets the early re- 
sults of the excavation. Most often he is using ethnographic analogies. This is unwritten, yet easity grasped, particularly to his contemporary Indian readers. He assumes cultural continuity from the time of his Marpole culture up to the ethnographic present, unless there is evidence otherwise. A sample of the way Borden's argument moves from artifact to interpretation follows:

Slate knives in large numbers of a certain shape and workmanship are found in the midden. Therefore: "These knives were probably made and used chiefly by women to eviscerate fish and to cut them up for drying and smoking" (1955:16).

If this abbreviated argument were expanded, it would be logically necessary to insert at least these two steps between the statement of artifact presence, and the interpretive conclusion, thus:

[1] Slate knives in large numbers of a certain shape and workmanship are found in the midden.

[2 We now observe, or others have observed, Indian women of historic times making and using comparably shaped tools to eviscerate fish and to cut them up for drying and smoking.]

[3 We may assume that artifacts used in the present were used similarly in the past.]

Therefore: "These knives were probably made and used chiefly by women to eviscerate fish and to cut them up for drying and smokIng" (1955:16).

The third step above is the hypothesis of ethnographic analogy, and it is the conclusion of a further argument. Supporting evidence for this conclusion increases the probability that it is true, but 
never makes it certain. In this case, evidence of the following type would have to be supplied:

Other inter-related aspects of historic Indian culture include artifacts and faunal remains which are similar to artifacts and faunal remains at this site, such as sinker stones, harpoons, spears and house remains.

To use the ethnographic analogy, the archaeologist depends first on accurate and complete ethnographic information, and, second, on the presumption of continuity in the way artifacts were used unless there is evidence of a significant number of related changes in the assemblage.

This paper deals with the Marpole site in four general aspects. Borden discusses the age of the site, reconstructs the food habits of the inhabitants, considers the significance of other tools, ornaments or habitation remains, and places Marpole in context with other Delta cultures.

\section{AGE OF THE SITE}

\section{Dating the Early Occupation of this Midden Site}

In dating the culture represented by this site, Borden uses two sorts of evidence. One of these is radio-carbon dating.

One of the charcoal samples which we collected in the summer of 1954 was taken from the lowest ten inches of the midden overlying the subsoil [1955:15].

The age was determined to be $1950 \pm 125$ years ago, which Borden interprets as follows:

These results indicate that the ancient Indian village at 
Marpole was in existence at, and most likely even before the time of Christ [1955:15].

Since the charcoal was not from the very base of the midden, and since the sample was from the extreme end of the midden, rather than the deepest part which by 1954 had been destroyed, it seems likely that this sample would not represent the earliest date for the Marpole culture.

\section{Dating the Abandoning of this Midden Site}

In the absence of charcoal samples near the midden surface in this much damaged site, Borden relies on evidence he has used since his first papers. Observations by Hill-Tout and Harlan I. Smith tell of "...a magnificent stand of ancient forest" (Borden 1955:14), on this site. In addition to repeating Hill-Tout's calculations from tree rings, which indicate "...trees started to grow on the site around 1200 A.D." (Borden 1955:14), Borden gives new evidence for interpretation on the growth on middens:

\footnotetext{
From observations at coast village sites that have been abandoned for about a century it appears that coniferous trees, such as Douglas fir, cedar and hemlock, do not become established on recent shell middens until certain internal changes in the midden-mass have taken place. How much time must elapse before such trees will grow on them is not known, but it may be two centuries or more [1955: 14].
}

Borden then arrives at his hypothesis of the last use of the Marpole site:

When we consider further that the large trees whose age Hi11-Tout was able to determine were probably not the first that became established on this midden--Harlan Smith describes gigantic trees that had died and fallen--it seems virtually certain that the old settlement was abandoned some time prior to 1000 A.D. [1955:14]. 
Borden has thus concluded that the Marpole culture flourished for about a thousand years from 2000 to 1000 years ago.

\section{RECONSTRUCTION OF FOOD HABITS}

In an important respect, the site at Marpole was different two thousand years ago. Borden describes the way he thinks it was:

At that period the Marpole region was quite different in appearance. From studies of the rate of growth of the Fraser delta, we may conclude that the mouth of the river was still to the east of the site and that Sea Island and the bottom-land in front of the gravel ridge on which the v11lage was located had not yet formed. In other words, the inhabitants of the settlement were looking out over the salt water of the Gulf of Georgia [1955:15].

\section{Efficient Exploitation of Resources}

With this environmental hypothesis as a foundation, Borden begins the reconstruction of the food habits of the Marpole inhabitants. On the first two pages of the analysis of the paper, I have an instance of his basic method of analysis and comparison with recent shore-dwelling Indians. The next hypothesis, that the Marpole Indians exploited their food resources efficiently, could not be gained from midden analysis alone. Evidence of un-utilized resources, not brought to the site, would have to be sought in other places by other means. Aga in here, therefore, Borden's thesis rests on a comparison of recent resources and utilization, and evidence of similarity from the midden. In so far as they were similar, he may logically say that, like recent coast Indians, the Marpole inhabitants used their resources efficiently.

The maritime environment of the village offered a rich va- 
riety of food resources, and Indications are that the inhabItants exploited them efficiently. We have learned much about the food quest of this early group by a careful analysis of the food remains. On the whole, the food habits seem to have been similar to those of recent Indians in this area, although there are some interesting differences in equipment [1955:15].

\section{Women's Role}

Borden assumes that the mussels were gathered at the site, and

that the women's role had been the same 2000 years ago:

Even a casual examination of the midden material at Marpole reveals that it consists chiefly of the broken shells of millions of mussels. The shells of various clams and cockles also occur, but their numbers are far less. At the time when the salt water of the Gulf was still. washing the base of the gravel ridge on which the village was located, it must have been possible at low tide to gather the mussels from the rocks that lined the shore in the immediate vicinity of the settlement. I never cease to marvel at the enormous heaps of shellfish remains that are present at virtually all of our coastal village sites, and when one recalls that it was the women who gathered the mussels and cockles and dug the clams, hauled them to the village and prepared them for their families, one begins to realize that these shell middens are veritable monuments to the ceaseless toil of Indian women over the centuries $[1955: 15]$.

\section{Fish-Based Economy}

After this personal tribute to the Northwest Coast Indian women, Borden continues with another important hypothesis:

There is every reason to believe that in those ancient days as in more recent times, fish was the staff of life and formed the economic basts on which the well-being of coastal communities depended [1955:16].

Fish Remains. This hypothesis is based on the fish remains in the midden, and on the implements for catching them.

A somewhat closer study of the midden material shows that among the broken mussel shells are the bones and other re- 
mains of countless thousands of fish, chief among them salmon, then flounders, codfish, sturgeon and some smaller species [1955:16].

Fishing Gear. Borden pieces together the evidence for early fishing techniques. Fishing spears probably were used.

Many of the points with a single row of barbs, carved of antler, probably armed fish spears. The bevel at the butt of some of these points suggests that two of them are lashed fork-like as prongs to the end of a shaft [1955:16].

Barbed harpoons are distinctive of the Marpole middens. "Large fish may have been taken with some of the smaller barbed harpoons" (1955: 16). This is not a site at which we would expect to find remains of fish traps or weirs, but Borden says they were probably used. From the presence of many sinker stones and "flat rectangular bone pieces, cut from the shoulder blades of deer and elk... [which probabiy] served as net gauges to assure that the mesh was of uniform size" (1955:16), Borden concludes the Marpole inhabitants used nets in fishing.

We may be certain...that some species were caught in nets suspended in the water from floats and held vertically by means of perforated pebbles tied to the lower edge of the net $[1955: 16]$.

Borden knows of recent use of nettle fiber nets, and adds:

Nets and lines were perhaps made of threads spun from nettle fiber. Thick stands of tall nettles still grow at the western end of the site [1955:76].

I have noted a question about the implication of nettles "still" being found at the site. This begs the question of the plant's presence at the earlier time. In the absence of plant remains, it would have been as strong a statement to say the plants grow widely in the area and locally, and were recently used for these purposes.

The preparation of these fish involved slate knives, "...prob- 
ably made and used chlefly by women to eviscerate fish and to cut them up for drying and smoking" (1955:16). The large proportion of this artifact to the others in the Marpole midden reflects the use of this site for salmon preparation.

Among the most frequently encountered tools in the Marpole midden are knives ground of slate. The majority are rectangular or oval in shape with a curving cutting edge. As a rule, they are very thin, so thin in fact that they fracture easily. To date we have found well over 1,200 slate knives, most of them broken or knife fragments [1955:16].

Just as Borden was confident of his interpretation of perforated pebbles as sinker stones, he is also sure that the large barbed harpoons were used for sea mammal hunting:

The occurrence of the bones of seals and porpoises in the midden indicates that these sea-mammals were hunted occasionally, no doubt, with some of the larger barbed harpoons of antlex which were recovered [1955:16].

A more accurate statement would word these interpretations as hypotheses with high probability.

Land Mammal Hunting

Borden states the next hypothes is quite distinctly:

Of far greater importance [than sea-mammal hunting], however, was the hunting of land mammals [1955:16].

The evidence he gives for this generalization includes the relative frequency of the faunal remains, and the presence of tools that Borden believes were used to hunt land mammals.

Among the remains of such game animals, those of elk are most frequent. The bones of deer, black bear, mountaingoat, beaver and various small fur-bearing carnivores also occur....the occurrence of numerous projectile points chipped of stone and varying considerably in size and shape indicate that spears and the bow and arrow were frequently employed in the hunt [1955:16]. 
Borden then notes that this stone chipping is interesting because in later deposits in this area this industry is not found.

Fowling

The next food resource of importance is significant in Borden's theories up to the 1973 paper.

The inhabitants of the Marpole settlement were expert fowlers as is vividly demonstrated by the great frequency of bird bones among the food remains. These bones have not yet been identified, but most of them seem to be from various species of ducks, geese and other water fowl which still abound in the Fraser delta region [1955:17].

In later papers, Borden will link the bone net gauges with the netting of fowl as well as of fish. The preceding passage also shows that Borden was aware of the need for faunal analys is of the material he was collecting.

\section{Plant Food}

In addition to mussels, fish, sea-mammals, land mammals and birds, plant foods were important.

Before turning to the manufactures of these early coast dwellers, I should mention that in addition to food of animal origin, no doubt much plant food such as berrles, young shoots, roots and bulbs, was also utilized, although little positive evidence is to be found in the Marpole midden. It is great interest, however, that we did recover from some of the hearths the charred bulbs of a small species of 1ily [1955:17].

\section{OTHER ASPECTS OF MARPOLE CULTURE}

In this section of Borden's interpretation he discusses manufactures, habitations, art and ornamentation from the Marpole settlement. 
$\underline{\text { Tools }}$

Tools are grouped into those for grinding, for woodworking, and for piercing, such as awls and needles.

Grinding Tools. Grinding tools are of major importance. In the following paragraph, Borden combines evidence and interpretation in order to place the artifacts in their original cultural setting.

\begin{abstract}
Abrasive techniques were of great importance in many manufactures of this group, and it is small wonder, therefore, that abrasive stones and whetstones in a graded series ranging from coarsely-grained sandstones to soft siltstone are extremely numerous in this midden, second in frequency only to the slate knives. Many implements of stone, bone or antler were ground into shape and given a high polish. Furthermore, because sharp knives, adzes and so forth were required in numerous every day operations a keen cutting edge had to be maintained on all such tools by frequent whetting and honing [1955:17].
\end{abstract}

Woodworking Tools and House Construction. "Among the most significant data we have collected were those on woodworking and house construction" (1955:17). Borden has important new evidence to support his hypotheses of a heavy woodworking industry among Marpole inhabitants.

He reviews the evidence of the three heavy woodworking tools, now found at the same level as the dated charcoal sample. This dating and the evidence of house remains leads Borden to two hypotheses:

[1] There is, thus, a strong probability that Northwest Coast woodworking was well-advanced as long as 2,000 years ago.

[2] ...this woodworking may have already included long plank houses of the historic Nootka-Coast Salish type...[1955:17].

Although part of the house site had been destroyed so that the total house length could not be determined, Borden gives the dimensions of the portion that was excavated:

This portion included a rectangular area with postholes, that must have contained massive houseposts, $21^{\prime}$ (east to west) by 
ca. $30^{\prime}$ (north to south) apart. There was unmistakable evidence that the broad hearth area running east to west through the centre (i.e. the long axis) of the dwelling extended farther in both directions [1955:17].

Piercing Tools. Another major tool category is piercing implements such as awls and needles. Borden proposes two hypotheses on their use:

1 Some [aw]s] served no doubt for piercing soft material such as buckskin.

2 Others were probably used by the women in the manufacture of baskets [1955:18].

Quality of Workmanship

Borden mentions the high relative frequency of these and other implements and objects, their varied shapes and sizes, and careful details of workmanship.

Clearly evident in nearly all the objects that have been found at Marpole is a pride in workmanship, a delight in giving the implements a beauty of form and finish which goes beyond mere utilitarian requirements. Numerous trinkets in the shell heap also tell of a fondness for personal ornament. Among these are shell and bone beads, pendants fashioned from animal teeth or carved of antler, and thin broad rectangular bone gorgets, embellished with geometric or representative designs [1955:18].

\section{Artistic Expression}

Borden gives further evidence of the artistic work from the Marpole site. His interpretation clearly reflects his abiding response to this assemblage. Borden sees this culture in strong contrast to the succession of later sites characterized by little ornamentation in their assemblages, which he sees related to the historic Coast Salish people.

Certain objects that have been found in the midden reveal 
the urge to give artistic expression to the things these anclent coast dwellers saw around them or to the things which lived in the world of their imagination. A few of the fairly frequent stone vessels, which may have served as mortars for grinding pigment, are made so as to represent entire animals. We also recovered two harpoons engraved on both faces with the head of some sea monster, possibly the sea-serpent. The human form is rarely represented. But, we did find one pendant carved in the shape of a human head with a mask-like face. We also have in our collection from Marpole a small seated figurine, holding a bowl-like container.

The numerous wood-working tools suitable for carving make it fairly certain that wood rather than bone, antler and stone, was the chief medium of artistic expression. But, unfortunately, objects of art in this and other similarly perishable materials have not been preserved [1955:18].

Thus Borden concludes this section of the paper with a last hypothesis on the importance of wood in artistic endeavors. This will be testable at current [1974] excavations on the Musqueam reserve.

\section{RELATION OF MARPOLE TO OTHER DELTA CULTURES}

How is Marpole related to other sites and other cultures? Borden gives summary hypotheses about Marpole, Locarno Beach and their different origins, about the more recent cultures and the complex history of the area.

First is the Marpole summary:

The remains in the Marpole midden are representative of a cultural period which had its beginning approximately at the time of Christ, but which almost certainly had come to an end before 1000 A.D. [1955:18-19].

Second, there is evidence of earlier peoples:

One of the earlier sites is the one at Locarno Beach for which we have a radiocarbon-date of $2430 \pm 165$ years before the present. The implements and art at Locarno Beach show this culture to be quite different from that at Marpole...[1955:19].

From this difference in artifact assemblage, Borden derives his 
hypothes is of difference in origin:

...suggesting that the two cultures had different origins and histories before they met in this area [1955:19].

The more recent sites, not yet dated with radiocarbon tests, are the subject of the next hypothesis:

More recent deposits contain cultural complexes which seem to be largely a blend of elements derived from

[1] the two earlier cultures

[2] with traits that may have come to the Fraser delta area

from other regions in later times [1955:19].

Finally, Borden predicts that future work will produce evidence

filling in a complex rather than a simple cultural history:

There is much we have to learn before we shall know the full course of events which transpired here in the past. But we have gathered enough information to predict with certainty that the story will be long, complex, and fascinating--provided, of course, that competent archaeologists will have the opportunity to investigate important sites before they are destroyed [1955:19]. 
CHAPTER XVII

\section{RESULTS OF TWO ARCHAEOLOGICAL SURVEYS IN THE EAST KOOTENAY REGION...}

\section{NATURE OF PAPER}

This is the earliest technical, statistical archaeological paper published by Charles E. Borden appearing in Research Studies, State College of Washington.

Levels of Hypotheses

In this work are hypotheses at every level of abstraction. Dozens are at the lowest level. These, based on the use-marks on artifacts, propose the task for which the artifacts were intended and used. At a higher level are theories of classification or ordering of these artifacts. Even more abstract are theories of population movements based on statistically varied artifact assemblages.

\section{Nature of Survey}

Borden explicitly states the purpose, limits, and appropriate questions that can be asked within the scope of this site survey. The student can compare Borden's own publication with the standards and criticisms he stated in his review of the Arden King Cattle Point report, (1957d) and in "Some Aspects...", (1954a) his criticism of the methods and published interpretations by Warren W. Caldwell of Caldwell's survey in the Okanagan and Similkameen Valleys. 


\section{Tests Proposed}

For my purposes, studying the formulation and testing of hypotheses in Borden's papers, this is a rich paper at every level. Not on$1 y$ are hypotheses proposed at all levels, with Borden's own methods clearly laid out for examination, but tests are proposed in a tight and systematic manner. He makes wide and detailed use of ethnographic and linguistic evidence and theory as he orders his archaeological evidence and theories. Then he carries out or proposes further archaeological tests for the linguistic and ethnographic hypotheses.

In this paper Borden reviews the theories of Robinson and Quimby on the Rocky Mountain Trench which he and Duff reported in their 1954 paper. He will later deal with the more general area, the "intermontane corridor", within which the trench is one feature, and will call attention to this route in every paper concerned with peopling the New World.

\section{Relationship to Other Borden Publications}

When I first read Borden's papers, I proposed to confine my research to his theories pertaining to the prehistory of the Coast Salish. At that time I set this paper aside, not thinking it pertinent to my research. When the written analyses were completed and organized so that the relationships between the succeeding hypotheses were outlined, I showed the result to Dr. Borden. In the course of our review, he mentioned that I had left out the 1956 paper. "When you have read my [1973] Khabarovsk paper, I think you'11 see that the 1956 paper is important." In the meantime I had completely accepted Borden's insistence that the Coast Salish hypotheses were not separable from the rest 
of Northwest Coast prehistory. After reading the Khabarovsk paper, I returned to the 1956 publication, and found it was central in Borden's views on Salish prehistory, as well as an important link in the formulation and testing of many other strands of his work. Because the process of analyzing this paper was done out of sequence, I was continually reminded of the close knit fabric of Borden's thought. In writing it for the thesis, I have retained the comments that reflect this understanding.

\section{Survey Area}

Borden's introduction explains the urgency of the survey because of proposed dam construction. It was a three week survey, with three volunteer assistants (Roy Carlson, James Baldwin, Harvey Borden, with Mrs. Carlson as cook). The survey was in two areas on or near the Kootenay river. The southern area extended from the Canadian-U.S. border north to Bull River. Fifty miles north of this is the Windermere Lake, Columbia Lake survey area just to the west of the Kootenay river.

\section{Resources of Area}

Borden begins his account with a description of the resources of the Kootenay country. It reveals his presupposition, not explicitly stated here, that a favorable habitat will attract inhabitants, and thus the corollary that such a place will have a history of inhabitants, or if not, questions may appropriately be asked about causes of their absence.

In his "Ethnography of the Kutenai," Turney-High describes 
the Kootenay country in considerable detail and refers to it as "probably the most favorable part of the Plateau for Indian life... an area of both rugged and gentle mountains, well watered, beautifully forested, and well stocked with game and fish" (Turney-High 1941:23). Curiously enough, despite these environmental advantages, the two aboriginal groups in this region are reported to be relatively recent arrivals, and there is as yet no information on earlier inhabitants [Borden $1956: 73-74)$.

\section{TIME LEVELS}

Borden's questions will pertain to three general time levels. First, he will discuss the "relatively recent arrivals" in this area. Second, he will ask about the "earlier inhabitants", and third, he will ask about evidence in this area for Early Man in the New World.

Recent Arrivals

Borden gives the ethno-historic background first and then the hypotheses to which archaeological investigations may provide illuminating data.

Salish-Speaking Shuswap. One of the two recent arrivals is the Kinbasket branch of the Salish-speaking Shuswap. A leader among the North Thompson group of Shuswap, named Kenpesket with "...fifty or sixty of his friends moved permanently into the Columbia valley around 1840" (1956:74) after many years of coming to the area on annual hunting trips. According to Teit and Turney-High, in this movement "... they were trespassing on the range of the Kutenai Indians..." (Borden 1956:74). The Kutenai resisted at first, seeking support from the Stony Indians from the Rocky Mountains, who seasonally came to the Columbia River here to fish and gather berries.

Kutenai. The other, somewhat less recent arrivals are the Kut- 
enai. Those in the survey area were termed Upper Kutenai, as residents of the upper, and eastern area of the river, near the Rocky Mountains. Borden describes the resources used by these people.

The game animal of chief economic Importance to the Upper Kutenai was the buffalo. Three times a year, in midJune, September, and January, they went in force over the mountains to hunt bison on the Plains in order to replenish their supplies of pemican, bone grease, and hides. In the intervening periods, the Upper Kutenai exploited the food resources of secondary economic importance which were available on their home grounds. The men hunted deer, elk, caribou, and birds, and fished in the Kootenay River and its tributaries, while the women engaged in their seasonal activities of gathering bitterroot and picking berries. Salmon, too, although they do not ascend the Kootenay River, had some importance in the economy of the Upper Kutenai. The main fishing spots for salmon appear to have been in the Columbia River near the outlet of Windermere Lake, where the recently intrusive Kinbaskets were esconced [1956:74-75].

Four Hypotheses of Kutenai Homeland. With this ethnographic in-

formation as background, Borden presents the problem of the history of these people.

Opinions differ on whether they came from the west or the east. The question is important because linked with it is the problem whether the Kutenai a few centuries ago were a Plateau people or whether in earlier periods they were nomadic hunters on the Plains [1956:75].

The first alternative comes from linguistic study by Morris

Swadesh.

Since, according to Swadesh, the Salish, displaced eastward, pushed the Kutenai into their present territory (Swadesh $1949: 161)$. This theory, which implies an earlier, more westerly habitat for the Kutenai, should be thoroughly tested [Borden 1956:75].

The second alternative theories "...supported by historic and ethnographic evidence, suggest a recent Plains origin" (1956:75). David Thompson, explorer of the early nineteenth century, wrote that 
the Kutenai were driven across the mountains from the western Plains where they had "..full possession of hunting grounds..." (Borden 1956:75). Thompson's editor, Tyrell, specifies that it was the Blackfeet who forced them west after they got firearms. Diamond Jenness, accepting Thompson's evidence,

...finds this assumption corroborated by Kutenai traditions and the strong Plains character of their culture (Jenness 1955: 358-359) [Borden 1956:75-76].

Borden cites Chamberlairi, ethnographer from 1891, and Turney-High from 1941 supporting this tradition of eastern origin.

The third alternative, cited from Baker, quotes Carling Malouf's view that the Kutenai were on both sides of the Rockies. Borden notes that this is supported for recent times, but he looks for an either/or answer:

...It still leaves wide open the problem whether the earlier home of this people was east or west of the divide [1956:76].

Verne Ray's 1939 theories on Plateau culture relations to the Plain culture include the Kutenai, and are a fourth theory that Borden presents for possible archaeological testing. Ray includes the Kutenai in this general statement:

"The tribes with most typical Plains political structure are also those with the heaviest veneer of Plains culture in general, yet obviously quite superficial and recently borrowed" (Ray:13) and, "A11 elements of Plains culture to be found in the Plateau...are intimately bound up with the horse complex" (Ibid:14) [Borden 1956:77].

Borden cites Turney-High's evidence that the Kutenai hunted bison before they had horses.

Systematic archaeological investigations on both sides of the Rockies may well produce data that could illuminate this problem and that of Kutenal origins [1956:77]. 
Aims of Survey. Borden then says the primary aim of the 1954 sur-

vey

...was to help prepare the way for future research of this kind by determining the nature of the archaeological resources in the areas indicated [1956:77].

Two kinds of data were expected:

[1] We expected to find, above all, evidence of the activities of secondary economic importance to the Upper Kutenai.

[2] There also seemed to be an excellent opportunity of testing the possibility of differentiating between the archaeological assemblage of these people and that of the Kinbaskets, i.e., of two distinct ethnic groups whose ranges were known to overlap [1956:77].

\section{Early Man}

Just as the evidence of the resources led Borden to the preceding hypothesis, the evidence of the terrain led him to the next one. I will give Borden's entire description concerning Early Man and the Rocky Mountain Trench:

Finally, there was a possibility of finding evidence of Early Man in the region. The two survey areas lie in the Rocky Mountain Trench. This remarkable steep-sided valley; which runs along the western base of the Rockies for some 1,100 miles from Yukon Territory through British Columbia to Flathead Lake, Montana, has been mentioned in recent articles as one of the possible routes by which Early Man spread south to various parts of this continent (Robinson 1953:37; Quimby $1954: 319)$. The possibility that cultural remains of early hunters might be encountered here had been strengthened earlier in the year by the discovery of a Scottsbluff-Eden point which was said to have been found in the Windermere Lake district (Duff and Borden 1953-54:33-34) [Borden 1956: 77-78].

\section{THE SURVEY AREAS}

Having presented the ethnographic background, and archaeological approaches to the problems, Borden tells about each survey area. There 
are a few hypotheses in this section. The survey located fifty-four sites, distributed in this way:

\section{Distribution of Sites}

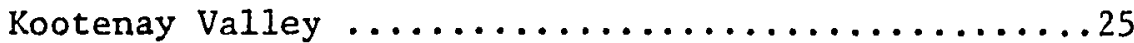

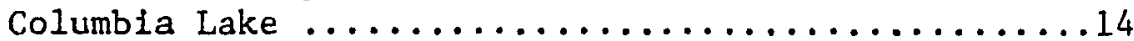

Columbia River between Columbia Lake and

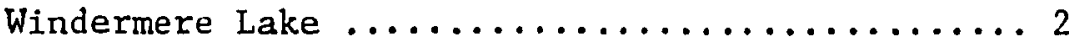

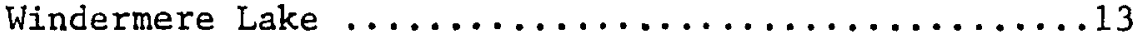

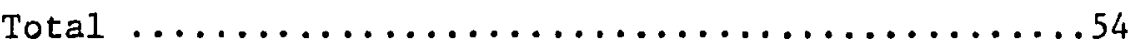

[1956:78]

Kootenay Valley Sites

The Kootenay valley sites are all within thirty miles of the International Boundary, but Borden's hypotheses at a middle level of abstraction, caution against mis-interpreting this as evidence of intensive utilization.

Small Sites. His hypotheses to the contrary begins with this evidence:

Most of the sites are small, some indicated merely by firecracked rocks and a little chipping detritus, others yielding in addition small quantities of artifacts.

[1] No doubt many sites are temporary hunting camps

[2] or merely strategic locations where hunters could lie in wait for the approach of game.

[At a higher level of abstraction:]

[3] An important factor in the choice of sites obviously was that they afforded a sweeping view over the meadows and marshes in the river valley,

[Evidence:]

for nearly all of the sites were located along the edge of the flrst terrace above the flood plain and on top of razorback ridges and 1solated hillocks along the valley margin. Such sites were concentrated particularly where the valley widens to receive tributary streams...[1956:78-79]. 
Large Sites. Borden mentions three large sites located by the survey. One was at the edge of Waldo, a small town on the east bank of the Kootenay. He describes the surface evidence, and the results from two test pits there. Those test pits "...produced cultural material down to a depth of 22 inches..." (1956:79). The next hypotheses relate to this site and another large one, nearly a mile in length, across the river.

[4] The site [across the river] was not test-pitted, but it is probable that in places it will have a depth at least comparable to that of the Waldo site.

[5] The part of the Kootenay valley between Waldo and the mouth of the Elk River was evidently the most intensively used portion of the southern survey area [1956:80].

The fourth hypothesis is at a low level of abstraction. From the surface evidence similarities and proximity of the two large sites, Borden concludes that the second site will have comparable depth. The fifth hypothesis is slightly more removed from the data, and with a lower probability, since it is based not only on sites that were found, but on the presupposition that these represent a true sample of what was there, even though the survey was generally restricted to the area that would be covered by dammed up water.

No Evidence of Depression from Habitations. Borden notes a lack of archaeological evidence to confirm an ethno-historical hypothesis:

At no site in this southern area did we find any depression of a sort that might have indicated the former existence there of a Plateau-type long hoise such as the Upper Kutenai are supposed to have used once (Turney-High 1941:61ff.) [Borden 1956:80].

Neither were there any instances of "...circular pits of former earth lodges" (1956:80). 
Northern Survey Area Sites

The first group of hypotheses concerning the northern survey area are of a higher level of abstraction. Borden interprets archaeological data as evidence that the population represented two cultural backgrounds .

[6] The comparatively large number of sites in this northern area is no doubt attributable to its jolnt utilization by the Kutenai and Shuswap [1956:80].

Although Borden has supplied us with ethnographic evidence of these two groups, he writes as follows:

[7] Even if we had no information of the presence here of the Kinbaskets, the archaeological evidence would lead us to suspect that some group other than the Kutenai, and most likely some Salish people, had also lived in the area [1956: $80]$.

Borden reports that the usual ethno-historical hypothesis of the Shuswap range is as follows:

The southern limit of the Shuswap range in this region is usually drawn north of or across the northern part of Windermere Lake [1956:81].

Earth Lodges. He then gives the first archaeological criterion for the distinction of the Salish,

[8] If earth lodges are an indication the Shuswap wintered at least as far south as we have found house-p1ts [1956:81],

and a consequent revision of the earlier hypothes is:

[9] and the limit of their range should, therefore, be extended southward to include all of Columbia Lake [1956:81].

Borden gives evidence of the location and distribution of these housepits and this summary:

Indeed, the ruins of such pit houses, which were the characteristic dwelling of most interior Salish groups, are the most prominent archaeological features in this northern area $[1956: 81]$. 
Hunting, Burial, and Pictographic Sites. Borden interprets other data as ordered in three other types of sites: hunting, burial, and pictographic. These hypotheses, with some supporting data are as follows:

[10] Many of the sites in the Windermere-Columbia lakes area were hunting camps, usually near small streams or draws. A few extended for about a hundred feet or more along the lake shore. Some sites with wave-cut banks revealed occupational deposits up to six inches thick...

[11] A burial ground, probably belonging to the Shuswap, used to exist on the east shore of Windermere Lake...

Pictographs in reddish-brown pigment are present at the base of a sheer cliff behind Site EbPw $I$ near the head of Columbia Lake.

[12] Several series of heavy vertical lines depict perhaps members of a war or hunting party. Anatomical detalls are not clearly indicated, but some of the men carry large bows in front of them... These bowmen and apparently the others are facing southward. About twenty individuals can be discerned in the longest series [1956:81].

\section{ARTIFACTS}

The next, and Tongest, section of Borden's report is an analys is and interpretation of the artifacts recovered during the survey.

\section{Sample Size}

His introduction gives the sample size and the qualification Borden places on this evidence.

We collected nearly 600 artifacts in the two survey areas, most of them on the surface. Twenty-five specimens were obtained from private collectors in the Columbia-Windermere lakes region. The following sections contain descriptions of the various classes and types of artifacts that were recovered in the course of the investigations. Our collection, of course, cannot be regarded as a complete inventory of the archaeological materlals occurring in the East Kootenays, but 
in view of the absence of published information on the archaeology of this area these descriptive sections may at least provide a basis for further study [1956:82].

\section{Information Presented}

In the tables which accompany each artifact category, Borden gives the artifact catalogue number, its dimensions, raw material, and if illustrated, the plate number. Plate identification is also organized on pages 102-104 at the end of the report, making it easy to relate the written text, tables, plates and plate explanation. I have numbered all artifact hypotheses consecutively, while distinguishing them by subject matter and level of abstraction.

\section{Hypotheses with Some Supporting Evidence}

The first five hypotheses are based on evidence of raw material and/or use-marks in distinguishing between or identifying possible artifact classifications. They are at a low level of abstraction.

Stone mauls grooved for hafting. Investigators working in the Plateau have found it difficult to distinguish grooved stones that were used as sinkers from those that were hafted and used as hammer or maul heads (cf. Smith 1899:141-142; Strong et al. 1930:110-111; Collier et al. 1942:74).

[1] Included as mauls here are only those implements which were carefully shaped from tough, fine-grained rock and provided with a transverse groove. These tools show battering on two opposite striking surfaces, and the groove is smoothed or polished from hafting....

Handmauls and/or pestles. It is not always easy to differentiate between pestles and handmauls (Strong et al.:94, 100: Collier et al.:69).

[2] The slender pieces without a noticeably bulbous base were probably chiefly used as pestles.

[3] However, some of the implements with an enlarged head, which are generally classed as mauls, could be, and quite 
likely were, also used as pestles or food pounders.

[4] The three implements collected by us probably served such a dual purpose....

Hammerstones. Four stones vere collected whose natural shape is unmodified except through use in some hammering or pounding operation.... The second...implement...in addition to being battered at both ends, is pitted over much of its surface, particularly toward the center.

[5] This pitting may be due to the stone's having been used also as an anvil [1956:82-83].

Borden's next hypothesis is of a middle level of abstraction, generalizing on the relative frequency of an artifact type.

[6] The paucity of grinding and whetstones in the survey areas emphasizes the relative unimportance of abrasive techniques in the manufactures of the inhabitants [1956: 84].

Borden's evidence consists of one Kootenay site slab, and two fragments that are specimens whose smooth face "...may be due to use as an abrasive" (1956:84).

7. Twelve specimens "...were probably used as line sinkers" (1956: 84). Borden divides these into two groups, notched and grooved. They are also distinct in that the notched specimens are much smaller.

The next hypothesis functions in a similar way to number 6 above. Of the nine notched pebble sinkers, only one was from the north survey area.

[8] Indications are that they were used more frequently in the Kootenay valley than in the northern survey area [1956: 84].

The next three hypotheses are at a low level of abstraction. Borden stays very close to the artifact, and suggests the use of the specimens as evidenced by wear markings. 
One is a river cobble... One face is pitted and scored, the markings being concentrated in two areas about $3 \mathrm{~cm}$. apart.

[9] It is likely that this stone was used as a chipping anvil. Three other stones evidently were used for a different purpose.

All three are oval river cobbles, having one face scored with numerous straight, very thin, often parallel lines, frequently running completeiy across the utilized face.

[10] The markings suggest that the stones were used as supports for some cutting operation.

The scored face of one of these artifacts has a very high polish,

[11] suggesting that it was also employed as a smoothing or polishing tool [1956:85].

Borden begins his discussion of chipped projectile points with a middle level summary of the relative frequency of this artifact, and its significance:

Chipped projectile points.

[12] The Importance of aboriginal hunting in the East Kootenays is attested by the presence of numerous chipped projectile points.

Eighteen per cent of the artifacts recovered belong in this category. Of the one hundred and eight entire and fragmentary points in the collection ninety are suitable for study. Fifty are from the Kootenay valley and forty from the Columbia-Windermere lakes region [1956:85-86].

Borden's discussion of projectile point classification which forlows this summary is presented in this thesis in Chapter II. In summary, he tells of his decision to use a classification system already used so that comparative areal studies can be done.

The two basic hypotheses are these, presented in reverse order to Borden's, and moving from a middle to a high level of abstraction:

Stone projectile points often occur in considerable numbers, and 
[13] They are highly subject to stylistic and other varlations in time and from region to region.

[14] Among artifacts made of non-perishable materials chipped profectile points, if present, are probably the most suitable for comparative studies in a non-ceramic area [1956:86].

Borden uses the Thomas Wilson classification as used by Strong

in 1935. His procedure in its use is worth quoting:

In order to avold misunderstanding, it is often advisable to present with the classification brief descriptions of the various types represented in an area and particularly of subtypes not included in earlier applications of the scheme. This is the procedure used here. In addition, each type is illustrated by one or several examples on Plate $V$ in the sequence of the descriptions. Dimensions and, where a series of specimens is available, range in size may also be inferred from the illustrations. The table on p. 89 shows the distribution of the various types in the two survey areas [1956:86].

This method makes Borden's data available in the most useful form to other archaeologists. This is his purpose "...in view of the absence of published information on the archaeology of this area...[to] provide a basis for further study" (1956:82).

The raw material summary is also important for comparative studies in the Plateau:

The preferred raw material for projectile points in both areas is chert in a variety of shades grading from nearly white to black, but predominantiy gray. Other materials which were occasionally used are shale, argillite, jasper, quartzite and crystalline quartz. Obsidian and glassy basalt, so prominent in some parts of the Plateau, are consplcuously absent [1956: $86]$.

Borden interprets the distribution table in the conclusion of the paper. I will follow his organization of the hypotheses concerning projectile points in this respect.

The classification Large Scraper-knives, organizes a group of 
tools which have become very important to Borden and to his readers.

A series of nineteen artifacts, somewhat difficult to classify as to type and function, are rather heavy tools, made by detaching a large chip from a stone slab or river cobble. Quartzite seems to be the preferred raw material for these implements.

Nine of these tools are boulder chips of irregular outline without evidence of deliberate shaping. They can be recognized as artifacts only because one or more of the originally sharp edges are blunted through use....

Five implements are oblong or ovate in outline, this form being predetermined by the selection of a suitable boulder from which the tool flake is to be detached. One face of these implements is that of the boulder or slab from which they were struck. The original shape of the chips is left essentially unchanged, the edge being only slightly trimmed in places by chipping from one, rarely from both faces [1956:92].

These will be known as cobble or pebble tools in later publications about Fraser canyon excavations, particularly the Pasika complex. One presupposition or implicit hypothesis in the preceding description is that the shapes of boulders were selected for a task. My evidence is Borden's phrase "...the selection of a suitable boulder..." To me, "suitable" implies "for a purpose", whether general, "for flaking" or more specifically, "for what the flake was to accomplish".

The next group of these tools is what he later came to call "cortex spall tools", when classifying the Pasika assemblage:

Three other ovate tools of coarse-grained quartzite show vestiges of the original surface of the stone from which they were detached only at the rather thick back, from which the two faces gradually converge toward a long curving edge deliberately shaped by careful chipping from both faces [1956:93].

Borden suggests hypotheses on the use of these tools:

All three of the above implements have been used laterally and two also at one of the narrow ends. In one specimen..., the main wear is at one of these ends, and the adjacent area 
on one face shows a glossy polish of the raised portions.

[15] It is likely that at least this tool and also the three ovate tools exhibiting similar wear, described in the previous paragraph, were hafted at the end of a long stick and used for scraping skins in the manner described by H. I. Smith (1899:146-147; see also Teit 1900:185, Fig. 127; Collier et al. 1942:33).

[16] Such scrapers evidently were widely used in the interior Plateau and very likely elsewhere.

[17] The other implements which show wear only or mainly on one side were probably used in the hand as knives and/ or scrapers [1956:93].

Borden continues at this low level of interpretation as in hypotheses 15 and 17 above, in identifying the use of the choppers below. They also are of the chopper-chopping tool tradition that has become important in later theories of early population movements.

[18] Four artifacts collected in the Kootenay valley may have been employed as choppers....

The largest chopper... is of even thickness throughout so that the two broad faces are parallel planes.

[19] The faces are smoothed and polished as though this chopper had been used also as a support for other work [1956:93].

Borden divides the small chipped scrapers into end scrapers and side scrapers. There is a wide variety in this group, and he suggests a methodological possibility for the future:

[20] It is possible that further subdivision of this general type could be made when larger series are examined and that local speclalizations would become apparent [1956:94].

Side scrapers also may be further divided in the future. Borden gives evidence of the variety and basis of further classification.

The business edge, which may vary between 2 and $6 \mathrm{~cm}$. In length, is usually slightly convex, sometimes straight and in a few instances concave. 
[21] These and other variations suggest a variety of speclalized uses for these tools

[22] and may eventually make further subdivisions necessary [1956:95].

Here we see the implicit basis of Borden's classification: from a study of the "business edge", we may search for the tool's use or purpose, and therefore classify it as it really was used or really was intended when made, rather than according to a category arising from the classifier's perhaps extraneous perceptions and conceptions.

The next hypothesis points to other basic but implied assumptions.

[23] The importance of these implements should not be underrated. Seventy side scrapers were recovered in the Kootenay River valley..., while the sites on the shores of Columbia and Windermere lakes yielded thirty-six.... Statistically, at least these implements rank in importance with projectile points [1956:95].

I interpret this to mean that statistically at least, and really, in al1 probability, these are important tools. The assumptions again, are first, that the artifacts of the collection are a fair sample, and second, that this classification of the archaeologist represents a real classification by the people who made and used the artifacts.

Two hypotheses compare two gravers with other types of this tool. This I classify as middle level abstraction.

[24] Th1s implement from Columbia Lake resembles certain types of Old World gravers based on parallel-sided blades....

[25] The other graver... is similar to gravers occurring in the Dalles-Deschutes and Upper Columbia regions...[1956:95].

A final low level hypothesis completes this section on artifacts. One of the four artifacts which "...appear to be drills" (1956:96), [26] ...is probably a drill point intended for hafting in a handle; it is not provided with a hand grip [1956:96]. 
v. CONCLUSIONS

\section{Problem of Kutenai/Shuswap Distinction}

Borden's conclusions first consider the problem of distinguishing between Kutenai and Salish assemblages. He begins with a statistical study and interpretation of the projectile points. The first series of hypotheses deals with the distribution and significance of small side-notched points. The second series adds to this another dimension, --the possible age grading of these through examination of patination of these artifacts. I have numbered the two series consecutively to indicate that they are logically related.

Statistical Study and Interpretation of Projectile Points. Borden begins at a high level of abstraction, and then works back to less abstract, more concrete hypotheses.

A study of the projectile points in our collection makes it reasonably certain that

[1] the Kutenal who hunted deer and other game in the Kootenay valley and along the lakes to the north had a marked predilection for points with expanding stem, either merely shouldered or provided with very short stubby barbs.

[Evidence:]

[a] A scrutiny of the table on p. 89 reveals that such points predominate in the Kootenay valley.

[b] While they are also present in the Columbia-Windermere lakes area, they are there outnumbered by small unstemmed triangular points with side notches.

[c] Percentagewise the distribution is as follows: KOOTENAY VALLEY COLUMBIA-WINDERMERE LAKES

Points with expanding stem ............... $82 \%$ (41 out of 50 ) $25 \%$ (10 out of 40 ) Small side-notched points...........2\% (1 out of 50$) \quad 50 \%(20$ out of 40$)$ other types ..........16\% ( 8 out of 50 ) $25 \%$ (10 out of 40 ) [Borden 1956:97]. 
Borden then moves to the abstract level again, followed by his evidence. This time he deals with Shuswap assemblage characteristics.

[2] The dominance of the small side-notched points in the northern area may plausibly be attributed to the presence there of the Kinbaskets.

[Evidence:]

[a] Similar points are very common in Salish territory farther west in the Canadian Plateau.

[b] The assumption that the Kinbaskets are the authors of these points is further supported by the remains along the lake shores of the circular earth lodges, the characteristic winter dwellings of the Shuswap.

[c] The main distribution of side-notched points in the East Kootenay region appears to be coextensive with that of house-pits.

[Test:]

While these results must be regarded as tentative, it is probable that the distinctiveness of Kutenai and Kinbasket assemblages, suggested by these surface finds, will be corroborated and amplified by systematic excavations.

[Ethno-historic correlation:]

The present archaeological data are on the whole in agreement with ethno-historical information, except that the Shuswap, as already pointed out, had evidently extended their range a good deal farther south than had been previously realized $[1956: 97]$.

Patination and Age Grading. Borden discusses patination, which

varies in the artifacts from the survey areas. First, he notes the $1 \mathrm{im}-$

itations of reliability when using patination for age classification.

Patina, as is well-known, cannot be regarded as a consistently reliable criterion for the relative age of stone implements, since time is not the only variable factor in the process of patination. Among others are the susceptibility of the raw material to patination, exposure to atmospheric influences, and the chemical composition of the matrix [1956:98].

Within certain limits, some information may be suggestive, however: 
Still, if examination of a series of artifacts from one site or even from different sites in the same general area reveals absence of patina in some and greatly varying degrees of patination in others,

[3] it is very difficult to escape the conclusion that such manifestations are indicative of age differences [1956:98].

Borden gives the evidence:

If we examine--with the proper mental reservations--the projectile points in our collection for patination some probably significant facts become apparent. Thus, all the small side-notched points have a completely fresh appearance. The same is true of many points with expanding stem, while, by contrast other SC [expanding stemmed] points are patinated to a varying degree.

[4] It is tempting to attribute the fresh appearance of the side-notched points to the reportedly recent immigration of the Shuswap to this region.

[5] On the other hand, the graded series of SC points from completely unpatinated to heavily encrusted specimens... may indicate a considerably greater time depth for points with expanding stem in this region.

[Work for the future:]

Whether Kutenai Indians were the originators of all or even of most of these points is again a question to which systematic investigations may eventually provide an answer [1956: 98].

Hypothetical Nature of Classification. The underlying presupposition which technically makes all use of classified artifacts hypothetical, is that the classifier ordered the artifacts in the same way as the early users, or in such a way that the statistics group together the entities that appeared together in reality in the earlier time. If side-notching or expanding stems were not significant, then no conclusions can be drawn except by chance. All artifact classifications, then, may be read:

IF: such and such attribute is a real basis of ordering these artifacts, 
THEN: we may conclude that these classifications can be compared to reach the following conclusions. Such presuppositions are rarely testable. Only when alternative classifications have been examined, or the consequences of using them lead to conclusions that conflict with each other, or with a substantial body of coherent theory, are these presumed classifications seriously re-examined.

Tentative Comparisons with Neighboring Areas. In concluding this argument, Borden reviews the scanty evidence available from neighboring areas and cautions against weighing the results too heavily:

Comparative studies with immediately adjacent areas are not very meaningful at this stage because of the nearly total lack of published information on the archaeology of neighboring regions [1956:98].

He reports a possible confirmation from archaeological material

to information derived from ethnographic sources:

Shiner illustrates a series of twenty-one projectile points found during salvage work in the Albent Falls Reservoir in northern Idaho about twenty-five miles west of Pend Oreille Lake (Shiner 1953:Plate at end of report). All seven points with expanding stem in the top row and the third from the right in the bottom row represent types which are common in Upper Kutenai territory of British Columbia. This is of some interest since

[6] Kutenai are said to have been among the diverse Indian groups who hunted and collected in this area, which was not permanently inhabited by any one group (Ibid:11) [Borden 1956:98-99].

In a similar comparison with projectile points from a site in the eastern foothills of the Rockies, Borden notes that of the eighteen projectile points illustrated

...twelve of the points with expanding stem closely resemble SC types from the Kootenay valley. 
[Either 7] This similarity is not particularly surprising, since the site in question appears to be located in the very country which the Kutenai must have frequented during their bison hunts.

[or 8] On the other hand, it is possible that other tribes in the western Plains were using such points and that the similarity is merely another indication of the close and perhaps ancient ties of the Kutenai with groups east of the Rockies [1956:99].

Test Sites and the Hypotheses Relating to Them

Thus Borden cautions that this is not a crucial test of either hypothesis \#7 or \#8 above. He gives an extended series of test sites, and the alternative hypotheses to which each might apply. I have numbered these consecutively.

General test needs.

[T] The ethno-historical evidence pointing to an eastern provenience of the Kutenai must be tested by systematic investigations at important sites on both sides of the divide.

[Evidence that two sites found during this survey might be such "important sites":]

Indications are that the part of the Kootenay River valley between Waldo and the mouth of the Elk River was an intensively used area in British Columbia.

[2] Excavations at sites DhPt 9 and 10 no doubt could furnish significant information.

[Ethno-historic hypothesis:]

[3] Since Turney-High assumes that the Tobacco Plains band was the original Kutenai group from which the other bands in the Plateau split off (Turney-High 1941:15), it is imperative to carry out extensive excavations also in the Tobacco Plains area.

[Evidence relating to this site:]

Neither Turney-High nor Shiner attempts to indicate the precise location of the main settlement of the Tobacco Plains group. An informant on the Grasmere Indian Reserve in British Columbia intimated that the village used to be located a short distance south of the border. River Basin Surveys site 24-LN-8 could be the site in question. It was, says the report, 
the only site in the reservoir where flakes of stone appeared in any quantity. More artifacts were found on the surface there than at any other location. The site is on a flat terrace and has a sandy deposit averaging three feet in depth. The owners of the property reported that over fifty projectile points had been found there in recent years (Shiner 1950:p.7).

From the sketch map it appears that site $24-\mathrm{LN}-8$ is located on the east bank of the Kootenay River, about six miles south of the border, which would place it at the mouth of the Tobacco River.

[4] In view of Turney-High's reconstruction of Kutenaf prehistory, site 24-LN-8 looms as of exceptional importance, since it might well be the oldest Kutenal site west of the Rocky Mountains [1956:99-100].

Tests of Kutenai Origin. Borden turns again to the need for archaeological tests of the alternative hypotheses of Kutenai origin.

[5] Although the theory of the Plains origin of the Kutenai is attractive and appears to be supported by considerable evIdence, much of this evidence is circumstantial and may turn out to be spurious.

[6] The possibility that the Kutenai are a Plateau people of long standing must be kept in mind.

[7] Swadesh may be correct in assuming that they had been forced out of an earlier, more westerly habitat [1956:100].

Borden next proposes an hypothes is of his own, new to this pa-

per. It is, as he points out, derived from conclusions suggested by

the results of this survey:

[8] A further distinct possibility is that the Kutenai moved into their present territory from the north along the Rocky Mountain trench. Some of the most heavily patinated projectile points, which seem to be of Kutenai type, come from the Columbia-Windermere lakes region. Shuswap pressure on these people may extend back into a more remote time than is apparent from Teit's account [1956:100].

\section{Negative Evidence Prior to Kutenai/Shuswap Occupation}

Two aims of the survey had been, first, to look for evidence of 
populations before the Shuswap and Kutenai, and, second, to look for evidence of Early Man.

In this connection I must report that we were unable to find any definite indications of pre-Kutenai occupation of the East Kootenay region or any evidence in support of the postulated passage of groups of Early Man through the territory. To be sure, a few isolated artifacts, like the heavy quartzite ovate from the Kootenay valley..., seem to be unlike other implements in the area in type and stoneworking technique, but on the whole we did not encounter any surface manifestations which could not be explained in terms of either Kutenai or Shuswap occupation [1956:100].

Borden concludes that the survey has been significant.

The resources are surprisingly rich and varied, and the problems are challenging and important enough to merit systematic and intensive investigation [1956:100]. 


\section{CHAPTER XVIII}

\section{NOTES AND NEWS, BRITISH COLUMBIA}

The American Antiquity section called "Notes and News" provides a concise source of published evidence of Borden's archaeological activities. The following three chapters are from three issues of this publication. In them we read for the first time about early investigation of a site near Yale in the Fraser Canyon, DJRi3, also named the Milliken site after the man who discovered it. This site and nearby pit-house sites are important to Borden's hypotheses both because of their long occupation, and because of their location between the coastal and Interior sites al ready discussed. In these papers, Borden also includes evidence from the Fraser delta and adjacent areas.

Borden reports conducting a survey with Jim Baldwin on the lower Fraser and some Gulf Islands. A few sites are expected to be significant:

It is hoped that one of the results of the Gulf Islands survey will be the discovery of sites which may add to the knowledge of the Early Maritime culture [Locarno Beach] which is known at present only from 2 Fraser delta sites, both of which have been obliterated since they were first investigated [Borden 1957:325].

Note the change in Borden's language that refers to Locarno Beach. In "Facts and Problems..." (1957a:47), he used the term "Eskimoid". In "Some Aspects..." (1954a:26), Borden calls this "...well-developed maritime or "Eskimoid'". Here in 1957 Borden calls Locarno Beach "Early Maritime". One reason for this change is first stated in the follow- 
ing paper (1959a), hypothesis 2.

Now he begins the story of the Milliken site:

Some time ago, A. C. Milliken, a resident of Yale, reported the discovery of an old site a few miles north of Yale, exposed by work on the Canadian National Railroad right of way.

[Hypotheses:]

[1] Results of a brief preliminary investigation suggest that the site has indeed a long history.

[Evidence:]

The rallway cut reveals at least 6 distinct occupation hortzons, separated by thick strata of sand and gravel, some of the latter cemented into solid rock. The lowest occupation level is 16 feet below the present surface. The next oldest, at a depth of 12 feet, yielded numerous chips and a considerable amount of charcoal.

[2] The uppermost deposit, from 2 to 3 feet in thickness, contains the cultural remains of the recent Upper Stalo Indians.

[3] The sands and gravels underlying the recent deposit were presumably laid down by the Fraser, whose present high-water level is some 40 feet below the lowest alluvial stratum of the site.

Geological studies of the site are planned for the fall. [1957:325].

Then Borden discusses the other newly surveyed canyon sites:

Further indications of long human occupation were found at other sites along the river between Yale and Hope. At the large pit-house village site at Hope it was determined that the cultural deposit extends uninterruptedly down to a maximum depth of at least 7 feet. The artifact content of many of these Fraser River sites is high

[4] and Intensive work in this region promises to shed light on the history of wood working and related problems [1957: 325]. 
CHAPTER XIX

1959a NOTES AND NEWS, NORTHWEST

Borden reports on a Gulf Islands site perhaps related to the Locarno Beach phase:

During August, 1958, Michael Kew of the Provincial Museum and student assistant John Sendey continued exploratory investigations at the Pender Island Canal site. Further evidence was discovered

[1] suggesting a relationship between the early phase of this site and the Locarno Beach-Whalen I complex, for which Borden has radiocarbon dates of around 500 B. C. More extensive excavations at this site are planned [Borden assembler 1959a:452].

In the next hypothesis we see the reason for Borden's change in the name of the culture stage or phase for which Locarno Beach is the type site. The 'Eskimoid' designation (1951a) was based on the presupposition that the maritime traits found in northern, Eskimo, sites, were earlier than those same traits found in southern, Locarno Beach, sites. This is the way Borden refers to the problem in relation to 1958 data:

No major field work was undertaken by the University of British Columbia in the summer of 1958. Borden was on leave of absence, preparing a monograph [later published as 1968a], on the Fraser delta sequence and its implications.

[2] If available radiocarbon dates for Alaska and southern British Columbia are correct, current views on early interrelations between the Northwest Coast and Alaska will need to be revised.

[Problem:]

Much depends on the relative antiquity of the separate phases In the northern and southern centers, and completion of Borden's study will have to await the results of further radio- 
carbon measurements [Borden 1959a:452].

The change from 'Eskimoid' to 'Maritime' culture, and this tentative statement, hypothes is 2, foreshadow the conclusion of Borden's 1960 paper, and his "Crossties..." paper (1962a), in which he pub1 ishes the results of these "...further radiocarbon measurements", and his revised interpretation of early Eskimo-Northwest Coast relationships.

Borden next gives information about the Stselax Village site, with a date that formed the base line of developed Coast Salish culture:

In October, 1958, Borden resumed excavations at [S]tselax, a recent Coast Salish village near the University of British Columbia campus. Work here continued throughout the winter. Through the cooperation of the Indian Agency and the Charles family of the Musqueam Indian band, the University has been able to lease for archaeological investigations in the next four years the last of the large old Indian houses of $[S]$ tselax village.

[Hypothes is:]

[3] Radiocarbon analysis suggests A. D. 1300 for the beginning of the settlement.

[Artifact sample size and types of other evidence:] To date more than 3000 artifacts have been recovered at this site in addition to valuable data on food resources, manufacturing techniques, and house construction [1959a: 452].

The third hypothesis above is based on a radiocarbon date of A.D. $1290 \pm 130$ (S. 20) (Borden pers. com., 1973). 
CHAPTER XX

1959b NOTES AND NEWS, NORTHWEST

\section{RADIOCARBON DATING RELIABILITY}

Borden gives two new radiocarbon dates. In addition to their archaeological significance, they illustrate the ambiguity in designating information "evidence" as different from "hypothesis". Neither Borden nor I can be sure that any one piece of evidence is "good evidence" or "hard evidence", or on the contrary, that it is "bad evidence". I mean by this that as soon as a datum is interpreted, and we say, "This ' $x$ ' is evidence of ' $y$ '", we have already grouped, ordered, or classified it according to some perception or hypothesis. This applies to evidence interpreted at a low level of abstraction, such as identification of the use of an artifact by its wear pattern. It applies at least as much to radiocarbon dating, which is formulated or expressed within a time range, and with a certain stated probability.

Errors in carefully interpreted radiocarbon dates range between one in twenty and one in three (Polach and Golson 1966:22). Only within a larger body of evidence can these statistically predictable errors be located. In 1973, Borden sees no reason to doubt the reliability of the Fraser Canyon date published in this paper, but he calls the Marpole date "...a bad date, which should not be used" (Borden pers. com.). For more than ten years he has judged it to be in error, 
not using it after his "Crossties" paper (1962a). Whereas in the 1959 paper Borden presents radiocarbon "evidence" of two dates, now in 1974, we label the one "evidence" while we would label the other "hypothesis".

\section{NEW EVIDENCE AND PROBLEMS}

Borden's statement of his latest evidence and the problems that he is about to investigate is as follows:

\begin{abstract}
Under the direction of C. E. Borden, the University of British Columbia will begin systematic excavations at Site DjRi: 3 in the Fraser Canyon. Preliminary investigations at this deep site have revealed a series of intermittent occupations separated by sterile sands and gravels. In conjunction with this project, site surveys will be conducted along the lower course of the Fraser in an effort to locate sites which may yield information on the gap of some 5000 years that exists at present between the earliest occupation at site $\mathrm{DjRi}: 3$ ( $8130 \pm 310$ B.P.) and Marpole $(2900 \pm 170$ B.P.), the earliest known settlement at the mouth of the river [Borden assembler 1959b:146].
\end{abstract}

The next paper reports in more detail this preliminary survey at $D j R i: 3$, and belongs to the same general time period of investigation that is summarized above. Both deal with evidence and interpretations before systematic excavation began. 
CHAPTER XXI

\section{0a DjRi 3, AN EARLY SITE \\ IN THE FRASER CANYON}

Published in a Bulletin of the National Museum of Canada, Contributions to Anthropology, this is the next paper in the sequence of Borden's writings although its publication date seems to place it later. In the paper, he speaks of "The only projectile point (DjRi 3:36) recovered to date (spring 1958)...". This sequence is corroborated by internal evidence in the papers preceding and following it and was confirmed by Borden (pers. com., 1973).

Presenting the evidence obtained during two brief visits to the site, Borden proposes a series of hypotheses about the nature of the site and its relationships to other sites of similar antiquity. He examines various applicable theories, such as the salmon area hypothesis, the riverine adaptation hypothes is, and predicts what sorts of assemblages or evidence he expects to find at the site during systematic investigation. This paper contains evidence, hypotheses and tests which can be traced through his succeeding papers. It is particularly interesting to study this paper as an instance of hypothesis formulation based on a small amount of data from preliminary investigations.

These are the topics that Borden considers in this paper:

1. Fraser delta dates, and questions about antecedents of these cultures.

2. DjRi 3, a much earlier site, its location and ethnographic 
background.

3. The geological deposit, with a geologist's analysis.

4. Radiocarbon evidence confirming the geological hypothesis.

5. Description and illustration of artifacts from two occupation levels.

6. Other higher and inaccessible occupation levels and nearby pit house sites yet to be studied.

7. Hypotheses about this site and its relation to other sites and to the theoretical problems that excavation may test or clarify.

\section{FRASER DELTA BACKGROUND}

Fraser delta excavations and six radiocarbon dates

...have made it possible to work out a fairly detailed cultural sequence in the delta region for the last 3,000 years (Borden n.d.) [Borden 1960:101].

The cited Borden manuscript is the paper mentioned in the second "Notes and News" for 1959. In framing the two-fold problem of interpreting that sequence, Borden asks what were the "stages" that led up to the Fraser delta material, and where did those stages develop.

The stages which preceded the initial phases of this sequence are not yet known, nor do we have any clear notion where such earlier developments may have taken place [1960:101].

Borden will organize his evidence in terms of this question, presupposing that there are such developmental stages.

\section{LOCATION AND ETHNOGRAPHIC BACKGROUND OF SITE DjRi 3}

About 100 miles upriver there is evidence that one site represents 
a much earlier time period, and may answer some of the developmental questions.

Great Age

In 1957 Borden first formulated the hypothesis of great age for this site, supposing it to have "a long history" (Borden 1957:325, hypothesis I have numbered []]). This is the hypothesis he re-states, tests, and supports in the present paper.

\section{Location}

A 1956 survey of about 30 miles of the Fraser river from five miles north of Yale down river to about nine miles southwest of Hope located many sites.

This stretch of the river is entirely within the territory of the Tait, the easternmost group of the Stalo Indians, who constitute one of the mainland divisions of the Coast Salish [1960:101].

\section{Ethnographic Information}

Both the 1956 survey and the present paper make use of ethnographic evidence:

In his excellent ethnography of the Upper Stalo, Duff (1952: 30-34) lists and describes the location of twenty-three sites in Tait territory that were known to his informants. Most of these were visited and examined in 1956. In addition, a series of previously unrecorded sites was located.

[Hypothesis, parallel to Hypothes is 1, 1957:]

[1] Indications of long human occupation were found at some localities near Hope and Yale.

The region immediately north of Yale holds particular interest. Here the valley of the Fraser River, which is navigable up to Yale, narrows abruptly to form a deep, steepsided canyon. The turbulent river, forcing its way through this narrow channel, presents a formidable obstacle to the 
various species of salmon as they ascend the Fraser in their annual runs. "Fighting their way up the canyon, hugging the banks to utilize every backwater and eddy, these flsh were easily caught in dip-nets, and drew thousands of Indians to the banks of the river to reap the harvest. The weather, warm, dry, with a constant up-river breeze, was ideal for drying the fish. This fortunate array of circumstances gave the Upper stalo a storehouse of food unexcelled by that of any other Indian tribe" (Duff, 1952:62).

[Duff ethnographic hypothesis:]

It would be difficult, states Duff, (ibid., 14) to over-emphasize the "importance in Stalo economy and prehistory" of the 5 miles of canyon above Yale [Borden 1960:101].

Salmon Hypothesis. Then Borden anticipates his major hypothes is

of this paper in this sentence:

Interestingly, the earliest known evidence of human occupation in western Canada comes from site DjRi 3, situated in this 5-mile stretch of the Fraser Canyon [1960:101].

The implicit argument, based on Duff's hypothesis, is this:

IF: the exceptional salmon fishing-preserving conditions are what make these five miles of supreme importance to the Stalo economy,

THEN: evidence of exceptionally early occupation within that five miles may indicate that the same salmon fishing-preserving conditions applied at that earlier time.

Caution About Stalo. Borden cautions against the further, and unnecessary, assumption that it was the genetic or linguistic ancestors of the Stalo whose artifacts are found in the early deposits:

The ancestors of the Stalo, of course, were not necessarily the first Indians to be attracted to this region [1960:101].

\section{GEOLOGICAL DEPOSIT AND}

GEOLOGICAL ANALYSIS

Earlier Interpretation 
In discussing the stratigraphy of the site, Borden first reviews his earlier interpretation and then presents a revised hypothesis in an extended section written by geologist William H. Mathews.

This is Borden's review:

Site DjRi 3 is located on the east bank of the Fraser, a few hundred yards north of the mouth of Siwash Creek. Here a large pit was excavated by bulldozer into the hillside east of the CNR right-of-way. The nearly vertical south face of this pit reveals a deposit of stratified sands and gravels more than twenty feet in depth, the massive geological strata being interlaced by a series of occupational layers containing charcoal, chipping detritus, and artifacts.

[Hypothesis, \#3 in 1957 analysis, repeated and expanded:] A preliminary examination suggested that the thick sand deposits in which the earliest occupation horizon was embedded and possibly some of the later geological strata were lafd down by the Fraser at a period when the high-water level of the river was at least forty feet higher than it is today (Borden 1957:325) [Borden 1960:106].

Borden introduces the Mathews material in this way:

Because of this suggestion of considerable antiquity, I persuaded Dr. William H. Mathews of the Department of Geology, University of British Columbia, to visit the site with me in the spring of 1957 and to make a study of its geological history. Dr. Mathews very kindly has granted permission to present here the results of his examination [1960: 106].

\section{Mathews' Analys is}

I insert in brackets identification headings in the argument and add implicit assumptions:

[Evidence and hypotheses of the underlying and surrounding formation:]

[Genera]-summary hypothesis:]

Site DjRi 3 lies in sands and gravels occupying a rock-rimmed embayment low on the east wall of the Fraser Canyon.

[Evidence for embayment hypothesis above, and specific hypothesis below:]

The recess, though now partly concealed by the growth of talus and alluvial fans, is clearly cut off on the north by rock, 
[Negative consequence of evidence:] and could not have been created by any through-going reach of the Fraser River;

[A1 ternate hypothesis of embayment formation:] instead it seems to have been excavated by glacial action

[Hypothes is of embayment related to the Fraser River:] and merely occupied by a back eddy at a high-water stage of the river.

[Absence of additiona] evidence for embayment formation hypotheses:]

Glacial deposits, if present within the recess, are now concealed by younger deposits [Mathews in Borden 1960:106].

Mathews continues with a discussion of the fill material in three divisions:

[1 Sand layer]

[Hypothes is of geological significance:]

The most significant geological horizon within the unconsolidated beds of this pocket is a layer of sand in which the lowest artifacts have been found.

[Genera] description of this layer:]

This sand layer maintains a thickness of about $2 \frac{1}{2}$ feet over an area of at least 70 feet by 70 feet and is nearly horizontal.

[General statement of similar known sand depositions:] No similar occurrence of sand of such extend and thickness is known to be forming today except below high-water level in the Fraser River

[or, every case of this sand formation is a case of formation below high-water level.]

[Statement that this constitutes sufficient evidence:] and for this reason

[and presuming that every case in the present is like every case in the past,]

[Hypothesis of sand formation:]

the sand layer is regarded as a former river bar

[Hypothesis on general time frame:] dating back to the time when flood levels reached this height, some 50 feet above normal high water of today.

[Evidence of relation between artifact age and sand layer age:] 
Significantly [for dating purposes], the cultural horizon lies within the sand layer,

[Re-emphasis on definition of 'within':]

in part covered by younger undisturbed and sterile sand,

[If it is true that 1) the deeper in the site a layer is, the older it is, and 2) that objects in the same, undisturbed layer of a site are of the same age,]

[Hypothesis of artifact age:]

hence the artifacts, too, date back to this higher stage of the Fraser River.

[Limits of reliable interpretation of age:]

How long a time was required for the river to deepen its channel to the extent indicated by the lowering of the highwater marks, cannot reliably be judged,

[General age hypothesis:]

but it is likely to represent a considerable fraction of postglacial time [Mathews in Borden 1960:106].

[2 Geological features underlying sand layer:]

[Evidence of underlying features:]

The beds upon which the sand layer rests include in one place up to six feet of sandy silt, in another at least a foot of dirty angular gravel. At two points the sand abuts against bedrock and contains numerous fragments of it, one a boulder about five feet in diameter.

[Statement of insufficient data for formulating hypotheses:] The material underlying the sand is, however, not well exposed and mutual relationships are uncertain.

[3 Geological features above the sand layer:]

[Evidence:]

The sand layer is covered by angular, poorly sorted gravel with bedding dipping westerly at about $5^{\circ}$, parallel to the upper surface.

[Hypothesis of formulation of gravel layer:]

The gravels are the outermost part of an alluvial fan built by a sma 11, unnamed, intermittent stream flowing off the hillside to the east.

[Evidence and hypothesis:]

$A$ few sand layers interbedded in the westernmost part of the fan deposit may conceivably be high-water sands laid down by the Fraser River,

[Evidence for alternate, preferred hypothesis:] 
but their very limited extent and thickness permits an alternative suggestion

[Alternate hypothesis of interbedded sand layer formation:] that they have been deposited by the same stream responsible for the associated gravels [Mathews in Borden 1960:107].

\section{RADIOCARBON EVIDENCE}

\section{Limiting Conditions}

Borden begins his description of the evidence from the early horizon, and the limiting conditions under which he collected this evidence:

During the two rather brief visits to site DjRt 3, no extensive excavation could be undertaken, but by clearing away sloughed-off material from the base of the south face of the pit it was possible to expose a narrow shelf of undisturbed sand in which a portion of the early occupational horizon was embedded.

[Stratum description:]

This stratum, which is stained a greyish black, attains in places a thickness of about one foot

[Types of evidence:]

and contains numerous small bits of charcoal, an abundance of chipping detritus, and a fair concentration of flaked artifacts [1960:107].

\section{Dating Sample}

While Borden was preparing the charcoal sample for dating, he recognized charred seeds, identified as probably wild cherry, Prunus demissa (1960:117; Borden pers. com., 1973). He introduces this evidence late in this paper, along with his interpretations of its significance.

\section{Confirmation of Geological Hypothes is}


Borden presents the next evidence as a test confirming Mathews' general age hypothesis for the early cultural horizon:

Sufficient charcoal to make up a sample was collected and submitted to $\mathrm{Dr}$. K. J. McCallum, University of Saskatchewan, for radiocarbon measurement.

[Test of Mathews' genera] age hypothesis:]

The results, indicating an age of $8150 \pm 310$ years for this culture stratum, support the geological evidence of considerable antiquity.

[Borden re-statement of age hypothesis:]

The earliest occupation of this site thus appears to fall within the last centuries of the seventh millennium $B$. C. [1960:107].

\section{ARTIFACTS}

Early Horizon

Borden presents evidence of artifacts recovered from the early horizon:

The stone implements recovered from this stratum to date include (1) flake tools of irregular shape; (2) purposefully formed scrapers; (3) one projectile point; (4) a cobble chopper, and (5) a flat oval disc [1960:107].

Borden does not give the sample size of the first two categories. In his descriptions, he gives the dimensions, raw material and manufacturing technique for them, and plates illustrating three "flake tools of irregular shape", and two "purposefully formed scrapers". The irregular flake tools

...are small thin flakes, which are unworked except for slight retouching by pressure along one or several edges ....All are fashioned of argilitite, which in two instances is cherty [1960:107].

The scrapers, which are ...carefully made tools are based on good-sized primary 
flakes struck from an argillite core....using both percussion and pressure [techniques in manufacture]... [Borden 1960:112].

Borden now deals with the single examples that he recovered of three artifact types. He found one chipped projectile point, with its tip missing. It is illustrated in the paper.

In outline the point is a narrow leaf-shape with the base convex and the sides nearly parallel for about one half of the total length. One face is quite flat. The reverse has a marked median ridge so that the cross-section resembles an isosceles triangle. The point is made of hornfels, a raw material which does not chip readily with a neat conchoidal fracture. The rather crude workmanship of the specimen may be, in part, attributed to this fact. Percussion chipping seems to have been used primarily with some secondary retouching by pressure along the edges. High spots along the ridge and one edge are smoothed down somewhat by grinding, especially near the base [Borden 1960:112].

A parenthetical note states that this is a classic Lerma point.

The pebble chopper is described and illustrated.

This is a core tool made by percussion flaking. The crude edge and bevel were produced by striking off large chips from one face of an oval river pebble of cherty argillite.

[Hypothesis:]

This artifact is probably merely the butt of an originally longer implement which was shortened by repeated sharpening through the removal of additional chips when the edge became blunted [1960:112].

Borden notes that larger choppers like this one are common in the disturbed material at the site, which would tend to confirm rather than disconfirm his hypothesis.

Borden discusses the next object and supports the hypothesis

that it is an artifact.

[Description of artifact:]

An oval disc of mica chlorite schist, measuring $132 \mathrm{~mm}$ by $103 \mathrm{~mm}$ by $15 \mathrm{~mm}$,

[Evidence of association with artifacts:] 
was found associated with artifacts and detritus in the early culture stratum.

[Contrast between sand matrix and culture horizon:]

Since apparently all the stone material where the disc was found [was not like other areas of the sand matrix that lacked a cultural component]

[Hypothesis of human introduction:]

[then the only variable, the human agent, suggests that any stone article] was introduced into the fine sand of this stratum by human agency,

[Hypothesis of human purpose as a necessary conc]usion of previous hypothesis:]

this specimen evidently was also brought to camp for some purpose.

[Negative or ambiguous evidence:]

It is not obviously modified, but the edges are smoothed, possibly by rubbing or scraping.

[Evidence of analogous objects and their purpose:]

Discoidal scrapers of slate are common in some of the more recent sites in the nearby coastal region [1960:113].

\section{Later Horizon}

Borden now reviews the evidence of the next higher cultural stratum. Borden had originally thought that the sands and gravels of this level were laid down by the Fraser (Borden 1957:325). Mathews prefers the hypothesis that they were deposited by an intermittent stream entering the Fraser at this point (Mathews in Borden 1960:107).

[Stratigraphic evidence:]

Approximately two feet of sterile sand and gravel separate the deepest culture stratum from the next one above 1 .

[Evidence and its deposition:]

Charcoal, numerous chips, and two artifacts were protruding from this next oldest horizon.

[Test which will relate to the alternate Borden/Mathews hypotheses:]

The age is not yet known, but a charcoal sample has been submitted for radiocarbon dating [Borden 1960:113]. 
The two artifacts are described and illustrated. One is a short knife of basalt modified by pressure flaking. The other is a "...ready made tool..." (p.113), modified only by use, which Borden interprets as serving "... a variety of purposes" (P.113). These are 1) as a rubbing stone for rubbing and grinding, 2) as a hammerstone, and 3) as an anvil stone.

\section{HIGHER LEVELS OF DjRi 3}

AND OTHER SITES

Borden could not reach above this level. This is his summary of what was in sight:

\section{Higher Leve]s}

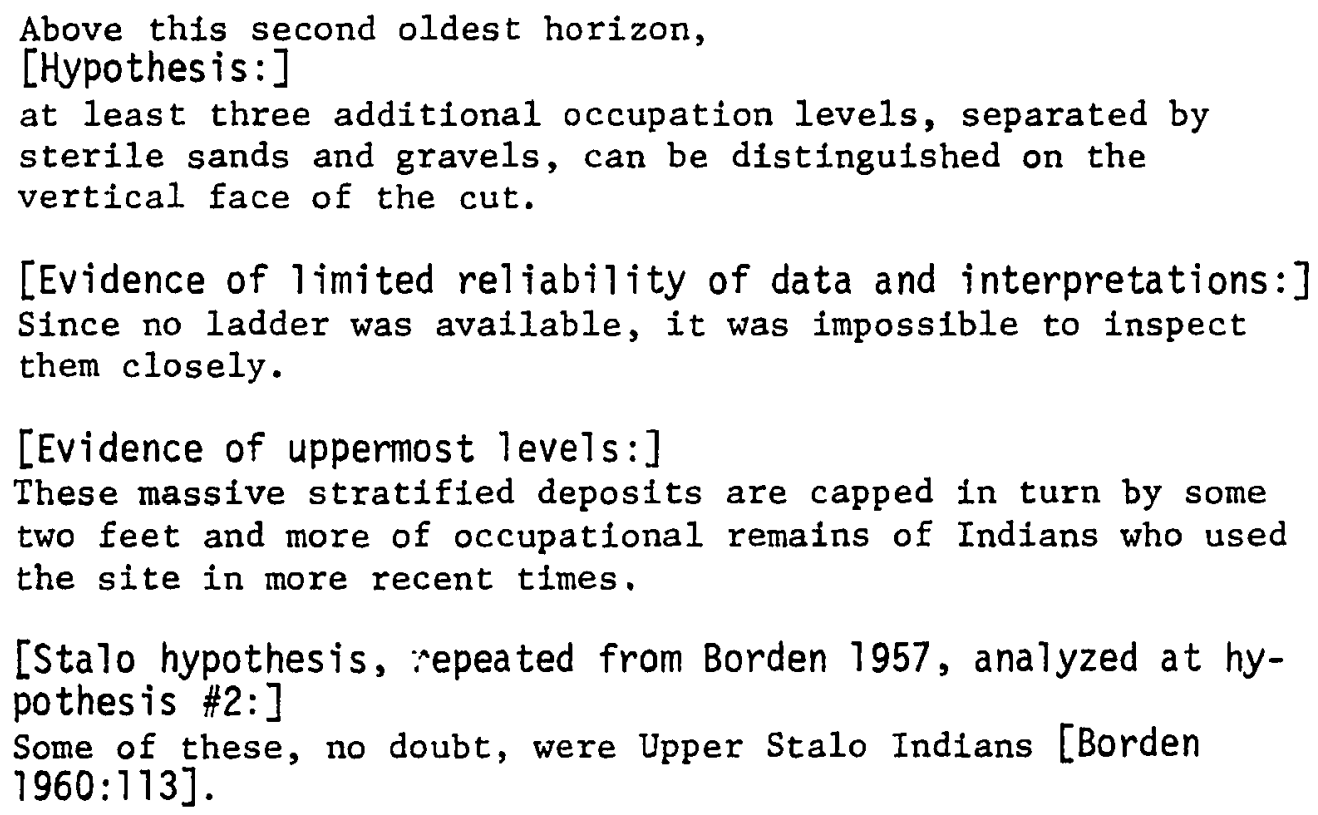

[Sta10 hypothesis, iepeated from Borden 1957, analyzed at hypothes is \#2:]

Some of these, no doubt, were Upper Stalo Indians [Borden 1960:113].

\section{Ethnographic Evidence of Pit House Sites}

Borden now presents additional ethnographic evidence which can function to confirm the Stalo occupation hypothesis above, and to con- 
firm the Stalo occupation hypothesis above, and to confirm the hypothesis below, that $\mathrm{DjRi} 3$ and nearby sites together have evidence of 8,000 years of human occupation. In this quotation are references to the Tait place-names which Borden later used to designate two sites and phases, Esilao and Eayem.

An old Tait village, called Esile'u is situated at the mouth of Siwash Creek, a few hundred yards away. "Today," notes Duff (1952:30-31), "the location of the old winter village is marked by four house-pits...There were many fishing-places along this part of the river, part of which is now set aside as I.R. 21." On the west bank of the Fraser, directly across from site DjRi 3, are the remains of another pit-house village of the Tait. Its name, i'y means "lucky place" for catching salmon (Duff, 1952:30-3I).

[Hypothesis:]

Excavations at site $\operatorname{DjRi} 3$ and others in the immediate vicinity promise to yield a more or less continuous record of human occupancy embracing more than 8,000 years [Borden 1960: 113].

\section{HYPOTHESES RELATING DjRi 3 TO OTHER SITES} AND CONCERNING NORTHWEST COAST CULTURE

Borden now uses the evidence he has presented from geological, ethnographic, and archaeological sources and first suggests hypotheses relating this site to other areas, then second suggests more general hypotheses based on the first series, relating to the origin and development of Northwest Coast culture.

\section{Tentative Nature of Hypotheses}

I interpret his first sentences as disclaiming high prior probability for these hypotheses. As I explained in the introduction to this thesis, theories that "fit" a large body of diverse evidence and 
theory have high prior probability, when compared to theories that are contrary to such existing theory, or as in this case, where such a large body of diverse evidence and theory does not yet exist. This is Borden's short statement:

At the present state of research, comparative studies of only the most tentative sort can be made. The sample from the early occupation level at DjRi 3 is as yet small, and data on other early Indian cultures in the area are still few [1960:116].

\section{Hypotheses Relating to Big-Game Hunting Tradition}

Borden first looks at DjRi 3 evidence in relation to the Osborne hypothesis that ecological changes caused a northern movement of early big-game hunters. I have expanded the Borden argument, and inserted before his final hypothesis on this subject, two alternative hypotheses that are not in Borden, but that express alternatives that I regard to be as important to explore as the two he mentions:

[Evidence for comparison:] Sporadic occurrences of Scottsbluff, Plainview, and even earlier point types [or points found in earlier sites] in southern British Columbia and Washington have been reported in recent years (Duff and Borden, 1953-54; Osborne 1956).

[Evidence needed to weigh alternate hypotheses below:] Until such projectile heads are found in situ and in association with other materials, it will be impossible to say

[Hypothesis of intrusive origin:] whether they are intrusive--perhaps transported by wounded animals--

[Osborne hypothesis:] or whether they indicate, as Osborne suggests, movements into the Pacific Northwest of early big-game hunters from the Southwest and the Plains as ecological zones shifted in terminal and post-Pleistocene times [Borden 1960:116].

[My added stimulus-diffusion hypothesis:] 
[or whether the manufacture was learned from neighboring southern and/or eastern peoples]

[My added 'or other' culture change hypothesis:]

[or other alternative or combinations of mechanisms of culture change may explain the archaeological phenomena.]

[Conciuding hypothes is from negative evidence, 1958:] Whatever the solution to this problem, there is no apparent reason [at this time] to link such manifestations with the early occupation in the Fraser Canyon [Borden 1960:116].

My second added hypothesis is important because it explicitly recognizes that any listed alternative hypotheses do not exhaust the possible hypotheses, and perhaps do not divide those possibilities in an accurate way.

\section{Hypotheses of Lind CouTee/DjRi 3 Relationship}

The next area compared to DjRi 3 is represented by the Lind Coulee site. First Borden discusses the age of the sites and compares the artifacts, then he predicts that future work will show these areas to be different because of their different ecological/economic/cultural base:

[General DjRi 3-Lind Coulee hypothesis, negative formulation:] Nor are there indications of close affinity between the ear$1 y$ horizon at DjRi 3 and the Lind Coulee site, excavated by Daughtery (1956),

[Evidence of temporal proximity:]

although the $C 14$ dates of $8150 \pm 310$ and $8700 \pm 400$ years for these sites show them to be nearly [or perhaps] contemporary.

[Artifact similarity:]

To be sure, the irregular flake tools from DjRi 3 bear some resemblance to the irregular thin flake side scrapers and knives from Lind Coulee,

[Evidence of authority:]

but as Daugherty $(1956: 239,244)$ rightly points out,

[Daugherty (\& Borden) statement of ambiguous evidence:]

these artifacts are so little specialized that they lack 
sufficient diagnostic value for cultural comparisons.

[Hypotheses of possible diagnostic artifacts:]

The purposefully formed scrapers at DJRi 3 may eventually offer a better basis for comparative study, when more become available. The same is true of profectile points [1960:116].

Borden finds that the one DjRi 3 projectile point is as long as

the smallest Lind Coulee point,

...but in all other respects--outline, cross-section, workmanship--there is no similarity between the Fraser Canyon and Lind Coulee specimens [1960:116].

Ecological Hypotheses Leading to Lind Coulee Test

Now Borden states his DjRi 3-Lind Coulee hypothesis more explicitly, and then states subsidiary hypotheses and supporting evidence:

[DjRi 3-Lind Coulee hypothesis, affirmative formulation for testing:]

Differences between the two cultures will probably become more marked as knowledge of the early occupation at DjRi 3 accumulates.

[Hypothesis of ecological cause of previous hypothesis, expanded:]

Sharp contrasts in the ecology of the two site areas must have produced markedly different economic and cultural specializations.

[Evidence of ecologica] hypothesis above, Bison-Lind Coulee evidence:]

Thus, bison, which were the chief game animal at Lind Coulee,

[Bison-negative evidence at DjRi 3:]

did not roam the mountainous southwestern part of the Brit-

ish Columbia mainland in post-glacial times.

[Evidence and hypotheses of food base at DjRi 3:]

Although identifiable faunal remains have not yet been recovered from the Fraser Canyon site, the early occupants, no doubt, hunted the game mammals and birds of their habitat [1960:116].

In other words, in the absence of archaeological evidence, since 
all known peoples of the time in question, and in the present, peoples with similar cultural complexity, hunted the game mammals and birds of their habitat, we may conclude, or hypothesize that the occupants of this site did the same. Now Borden moves to his crucial hypothesis:

\section{Salmon-Base Hypotheses}

[General Salmon-Fraser Canyon hypothesis:]

Circumstantial evidence, however, permits us to infer with reasonable certainty that salmon, which was the main food resource in recent times, also was of primary importance in much earlier periods [1960:116].

Evidence. Borden next presents his additional DjRi 3 evidence to support this salmon-base hypothes is:

[Periodic use hypothesis:]

The early canyon site, evidently was occupied only during certain times of the year.

[Hypothesis interpreting stratigraphic evidence,--corollary of Mathews' sand-formation hypothesis:]

The camping area, as suggested by stratigraphic evidence, was subject to periodic inundation [Borden 1960:116].

The phrase "camping area" might be interpreted as smuggling in the concept af periodic or short term occupation, seeming to beg the question being argued. The same information without this problem can be stated thus: the stratigraphy of the cultural horizon suggests the site was subject to periodic inundation. Borden's argument continues in this way:

[Hypothesis of historic analogy:] and, if the present behavior of the river can be taken as a guide,

[Hypothesis on period of high-water:] ...periodic inundation [occurred]...probably from the middle of May to the end of July. The crest of the flood stage is usually reached in early June. 
[Evidence of authority:]

Information supplied through the courtesy of Professor E. S. Pretious, Director, Fraser River Mode1, University of British Columbia.

[General statement that evidence at hand is in fact evidence of period of site occupation:]

other evidence makes it possible to infer when the site was occupied.

[Evidence of charred cherry pits, Evidence that pits are present:]

Among the charcoal collected from the early level were charred fragments of wild cherry pits. According to Dr. T. M. C. Taylor of the Department of Biology and Botany, University of British Columbia, the species would almost certainly be Prunus demissa, which is still flourishing in the river valleys of the Coast and Cascade ranges.

[Evidence of present season of this cherry:]

The fleshy, edible fruits of this tree mature in August and September.

[Implicit hypothes is of site occupation:]

[The site was occupied at some time within August and September.]

[Ethnographic evidence:]

Significantly, this is precisely the time of year when the main runs of spring and sockeye salmon fight their way up the canyon (Duff, 1952:62), the fish being in their prime as they pass the location of the site [Borden 1960:116-117].

Argument. To expand the steps in reasoning at this point, I interpret Borden's terse "Significantly" as a link in this argument:

Premises: 1) If the site were occupied during August and September, (cherry-pit hypothesis p.117); 2) and if salmon runs are timed today as they were then, (salmon-run hypothesis p.117); and 3) if the occupants of the site secured the food available in their habitat, (generalized form of hunting-fowling hypothesis, p.116);

Conclusion: Then we may "...infer with reasonable certainty that salmon, which was the main food resource in recent times, also was of 
primary importance in much earlier periods" (p.116).

Test of Five Mile Rapids/DjRi 3 Hypothesis

Borden then presents an hypothesis parallel to his testable formulation of the DjRi 3-Lind Coulee hypothesis:

[DjRi 3-Five Mile Rapids hypothesis, formulated for testing:] These data point to the probability that excavations at site DJRi 3 will uncover evidence of an early occupation similar in character to that of the Five Mile Rapids site on the Oregon side of the Columbia River immediately east of the Cascade Mountains.

[Ecological and dating evidence from Five Mile Rapids:] Here Cressman (1956) reports the occurrence of tremendous numbers of salmon vertebrae in levels dated by radiocarbon as having been occupied from 7,000 to 9,000 years ago.

[Borden's general hypothesis on Northwest salmon fishing:] This important discovery, combined with the indirect evidence from the Fraser Canyon site, leaves no doubt that salmon fishing was well established more than eight millennia ago in the Paciflc Northwest when Early Lithic hunters were still stalking big game in other parts of the continent [1960:117].

\section{Salmon Area Hypothes is}

Borden further generalizes on this hypothesis, referring to the Salmon Area, one of the eight food areas into which Wissler divided the New World (1917:chapter 1). The culture areas that Wissler distinguished within the Salmon Area were North Pacific Coast, and the Plateau (1917:chapter 14). The ethnographer looks to the archaeologist to provide the time dimension to this basic areal subsistence pattern. It is this time dimension that Borden refers to:

[Sa?mon Area age hypothesis:]

The Salmon Area as one of the major food areas of the New World had [by 9,000 B.P.] begun to take shape [Borden 1960: 117].

Origins and Development of Northwest Coast Culture 
With this hypothesis of major significance proposed and supported, Borden turns to how this relates to the origin and development of Northwest Coast culture. He begins with a general statement that this new evidence is important. Note that his use of the term "demonstrated" is probably parallel to his earlier usage when he says that from "circumstantial evidence... [we] infer..." (p.116), al though "demonstrated" carries a connotation of greater certainty than "infer". Until the early DjRi 3 date, the earliest occupation for which Borden discovered evidence was in the first thousand years B. C. With the new early date, and the hypotheses proposed thus far, Borden relates the new state of knowledge to problems of origin and development in this area:

[Borden's statement of significance of Salmon Area age hypothesis:]

The demonstrated presence in the early post-Pleistocene period of Indian sites along the lower course of the two major salmon streams of the Pacific slope has an important bearing on hypotheses regarding the origin and development of Northwest Coast culture.

[Hypothesis based on geographical barriers:]

The rugged and shredded coastline of southeastern Alaska and British Columbia precludes the possibility of population movements on foot from the north via the coast.

[Lack of evidence for alternate north coastal migration hypothes is:]

Since we cannot assume either [in the absence of direct evidence, and in the absence of even indirect evidence for boat building] the existence at such a remote period of boats capable of navigating the rough coastal waters,

[Two implied hypotheses to account for other options:] [Unti] such evidence of boat-building at the early time, or within the 5,000 year gap, is found, or significant indirect evidence of northern coastal origians, ]

[and in the absence of early evidence from the coast or from coastal valleys to the south of the Fraser Delta,]

[Hypothesis, by process of elimination, of migration routes 
followed by early occupants of DjRi 3 and Five Mile Rapids sites:]

we must conclude [that the most probable hypothesis is] that the early Indians who occupled the Five Mile Rapids and Fraser Canyon sites came to these localities via interfor routes and, to be sure, not necessarily from the north [Borden 1960: $117]$.

This last phrase, "...not necessarily from the north", recalls

a 1952 Borden hypothesis, long before he had evidence of this long history of settlement in British Columbia:

On the other hand, it is entirely possible that some of the ethnic groups now living in British Columbia entered this area from the south by way of the interior plateau [Borden 1952a:14].

Excavation and interpretation of DjRi 3 material may test this earlier hypothesis, repeated here in 1960.

Relation to One Kroeber Hypothesis

Borden next relates his evidence and hypotheses to one of Kroeber's hypotheses. In his early works, Borden had stated and examined this hypothesis in relation to his Fraser Delta material (1951a:36; 1954a:26). Here Borden interprets the evidence from the Fraser and Columbia as instances confirming the Kroeber position:

[Borden hypothesis that evidence at the two Salmon Area sites support Kroeber's hypothesis:]

The findings at these sites lend support to Kroeber's hypothesis $(1923$; 1939).

[Kroeber hypothesis:]

which views the several areal patterns of Northwest Coast culture as having come into being when groups of interior Indians made their way down the river valleys to the Pacific seaboard, gradually modifying their economy from the exploitation of inland to coastal and marine resources.

[Cressman's "pre-adaptation" hypothesis an instance of kroeber:] A striking illustration of such ecological adjustments is provided by the presence in the early levels at Five Mile 
Rapids of seal bones. "This," comments Cressman (1956:6)

"Is of considerable significance, for it shows that these

Indians had developed the art and habit of taking marine animals, in addition to fish, for food. Adaptation to a seacoast economy could mean more of the same and not a complete change" [Borden 1960:117].

Borden views Cressman's seal bone evidence as "a striking illustration" of Kroeber's position. It seems to me that the evidence at Five Mile Rapids does not preclude the possibility that the seals were hunted by coastal Indians who were moving in to the Interior, and utilizing marine and coastal resources along the river. Neither does it preclude stimulus diffusion of hunting skills without population movement. If early evidence is found of coastal occupation, the first of my alternatives would be strengthened. The second alternative does not depend on additional evidence, in order to be considered likely. In other words, with the evidence available here, Cressman's evidence may be a confirming instance, but it is not a crucial test of the Kroeber hypothesis.

\section{Fraser Delta Local Cultural Development Hypothes is}

With the $8750 \pm 310$ B.P. date for the early occupation of DjRi 3 and with the Kroeber hypothesis as the theoretical frame of reference, Borden has evidence to deal with his Fraser delta material in a completely different way, in terms of local cultural evolution. The Kroeber hypothesis is evident in Borden's introduction to new radiocarbon dates from the Fraser delta:

[Borden's hypothesis that Fraser delta patterns are an instance of Kroeber hypothesis:] Advanced stages of adaptation to the coastal environment, with the basic patterns of Northwest Coast culture well blocked out, have been revealed by excavations in the ear- 
liest known sites of the Fraser delta region (Borden, 1950; 1951; n.d.)

[Evidence from radiocarbon analysis:]

[Note this is the date he later came to consider wrong:]

A new $\mathrm{Cl} 4$ date of $2900 \pm 170$ years for the Marpole site

["Good dates":]

and the dates of $2430 \pm 163$ years and $2450 \pm 160$ years for

Locarno Beach and Whalen I, respectively,

[General time-culture stage hypothesis:]

suggest that these stages have been reached early in the

first millennium B.C.,

[Implied archaeological assumption of gradual change:

Since development is in small gradual stages,]

[Hypothesis of mechanism of culture change:]

[advanced stages of adaptation can be interpreted as]

hinting at a considerable period of prior development

[Borden 1960:117].

\section{Wider ReTationships}

In his concluding section, Borden relates $D j R i 3$ to wider areas

of Northwest Coast culture.

[Summary of one area of time and distances yet unexplored:] A gap of more than 5,000 years separates these ancient maritime cultures of the Gulf of Georgia from the period of the early occupation in the Fraser Canyon, a hundred miles inland [1960:117-118].

[General hypothesis predicting result at DjRi 3:]

Excavations at site $\operatorname{DjRi} 3$ and at other sites along the lower course of the river may be expected to fill part of this gap

[Local cultural evolution hypothesis:]

and to disclose intermediate stages in local cultural evolution.

[Hypothesis of stimulus diffusion:]

While influences from other areas no doubt stimulated this process,

[Negative hypothesis on early Eskimo-Aleut culture center:] recent suggestions regarding the controlling part that the maritime cultures of the Eskimo-Aleut are said to have played in the emergence and rise of Northwest Coast culture (Drucker, 1955; Chard, 1956) must be taken with caution. 
[Preliminary hypothes is on Northwest Coast as early culture center, expanded from 1959a assembler:452, analyzed as hypothesis 2:]

The initial phases of Northwest Coast culture evidently ran their course at a much earlier time than suspected,

[Paucity of needed evidence:]

and little is known as yet about the problem of early

Eskimo-Indian relationships.

[Ethnographic evidence:]

In recent centuries the main culture flow was obviously

from the Northwest Coast to the Eskimo.

[Northwest Coast culture center hypothesis, re-stated:]

It will not be surprising to find that the Northwest Coast was also the more important centre of cultural elaboration and diffusion in much earlier periods [1960:118].

Borden prepares to re-order his theories, as we will read in "Crossties...". 


\section{CHAPTER XXII}

\section{0b NOTES AND NEWS, NORTHWEST}

The following four chapters are from four issues of American Antiquity with information about current archaeological research in the northwest assembled by Borden, include evidence and interpretation from his Fraser Canyon exiavations along with other items of importance.

Borden begins his account in this way:

A field party, directed by Charles $E$. Borden, the University of British Columbia, carried out excavations at site DjRi 3

in the Fraser Canyon. This deeply stratified site has an early occupation horizon radiocarbon-dated at 6193 B.C. \pm 310 years [1960a:442].

The radiocarbon date wi11 later appear as $6200 \pm 310$ B. C. after the radiocarbon dates were corrected to be reckoned from 1950. Borden has been calling this level the early horizon, but here he says an early horizon, because:

A test pit, a short distance from the main trench, yielded some evidence hinting at an even earlier occupation some 5 feet below the dated horizon. A charcoal sample, but no indubitable cultural material, has been obtained to date from this deeper stratum [1960a:442].

This hypothesis of a possible earlier occupation will be tested with further excavation.

Borden writes of the levels above the early dated level:

[Hypothesis of cultural levels:]

Three subsequent cultural levels, separated by massive gravel deposits, have been distinguished.

[Disconfirmation of Stalo upper horizon hypothesis:]

The uppermost horizon is exceptionally rich. Contrary to 
earlier assumption [Borden 1957:325, hypothes is 2; repeated in 1960:113], the cultural remains in this horizon are probably not characteristic of the Upper Stalo of recent centuries,

[Additional work to verify disconfirmation hypothesis:] although, to be sure, the late archaeological manifestations of these local Indians are as yet little known.

[Implicitly, evidence of late manifestations of these 10cal Indians will be dissimilar to this top horizon and confirm the new hypothesis, or be similar and disconfirm the new hypothesis.]

[Tentative or partia] nature of evidence:]

At any rate [until such investigations are made], despite marked differences [with the Marpole phase],

[Hypothesis of upper DjRi 3 horizon-Marpole similarity:] the closest affinity of the uppermost occupation level of site DJRi 3 appears to be with the Marpole phase at the mouth of the river,

["Bad" date again:]

which has a radiocarbon date of 950 B.C. [1960a:442].

With this new evidence, Borden does not frame his hypothesis on

the similarity in terms of migration, but in terms of cultural exchange:

[Hypothesis:]

Comparative studies, supported by additional dates should shed light on early cultural exchange between upriver and downriver groups [p.442].

Borden does not give us evidence from the early horizon:

At the time of writing, some 290 square feet of the 8150 year old horizon had been exposed, but excavation of this level was just beginning [1960a:442]. 
CHAPTER XXIII

1960c NOTES AND NEWS, NORTHWEST

Borden presents evidence and hypotheses from three levels of

DjRi 3:

During the latter part of the summer of 1959, the University of British Columbia field party in the Fraser Canyon excavated the 8150 B.P. horizon of site DjRi 3, which had just been exposted at the time when the last "Notes and News" copy was submitted.

[Evidence, including sample size, from 8150 B.P. horizon:] Heavy cobble choppers and numerous irregular flake scrapers dominate the assemblage of 167 artifacts recovered from this horizon. Well-made end-, side- and spokeshave scrapers and chipped knives also occur. Projectile points are relatively rare. Two complete specimens have a single shoulder or slight inset rather high up on one side. One leaf-shaped point with a broken tip has a rounded base. Charred pits of a wild cherry, tentatively identified as Prunus demissa, were found throughout the early occupation level.

[Hypothesis comparing the 8150 B.P. horizon with level above it:]

There appears to be little cultural difference between this and the next oldest culture stratum of the site,

[Radiocarbon evidence:]

for which K. J. McCallum, University of Saskatchewan, has just reported an age of $7350 \pm 150$ years.

[Stratigraphic, volcanic evidence:]

Massive deposits of stream-laid gravel and a layer of volcanic ash,

[Glacier Peak hypothesis:]

evidently from the Glacier Peak eruption, overlie this later occupation.

[Evidence dating one Glacier Peak eruption:]

The last eruption of this volcano has been dated at 6700 B.P.

[Hypothesis of age of next higher occupation level:] 
The next cultural horizon at the site is probably much more recent.

[Evidence-hypothesis for above hypothesis:]

Well-made ground slate knives are already present

[Hypothesis suggesting relation to nearby, newly dated site:] and there is a possibility that this occupation is more or less contemporary with a cultural horlzon at Site DjRi 1 near Hope,

[Evidence from DiRi 1:]

In which fragments of simflar knives were found next to a hearth that has fust been dated by McCallum at $2270 \pm 100$ B.P. [Borden 1960b:628].

Borden's use of "already" above, probably refers to other sites, later in time, in which ground slate is present. 
CHAPTER XXIV

\section{0d NOTES AND NEWS, NORTHWEST}

One paragraph from this issue is worth quoting in ful1:

It appears that an event of great consequence to the archaeology of British Columbia is about to occur. At the opening meeting of the 1960 session of the Provincial Legislature it was announced that an Antiquity Act would be introduced. Details have not yet been made public, but, if the act will make adequate provision for salvage archaeology, it would mean the attainment of an objective toward which we have been working for many years [1960c:149]. 


\section{CHAPTER XXV}

\section{1a NOTES AND NEWS, NORTHWEST}

Borden reports the consequences of the legislative action anticipated in the previous paper.

At Its last session, the British Columbia Legislature passed an Act for the Protection of Archaeological and Historical Sites, which, it is hoped, will help prevent the recurrence of such archaeological atrocities as were committed at the Chase burial ground [where most of the area was destroyed by indiscriminate digging after the site was discovered]. It is now illegal and punishable by fines, imprisonment, or both to excavate or knowingly alter an archaeological site in British Columbia, unless authorized to do so by a Government permit issued under the Act. In view of proposed largescale power developments on the Columbia and in other river basins of the Province, Section 10 of the new law is especially significant. It provides "for adequate investigation, recording, and salvage" of archaeological remains whenever sites are "threatened with destruction by reason of commercial, Industrial, or other activity." British Columbia is the first province in Canada to have such an act. Wilson Duff, Provincial Anthropologist, and Borden have been appointed to the Advisory Board which was set up to assist in the administration of the new law [1961a:585].

Borden's summary of the Canyon excavations includes new evidence:

[Sample size through summer 1960:]

To date the site has yielded some 6000 stone artifacts.

[Genera] statement of evidence from upper deposit:] Most of these come from a massive deposit of sandy loam which in places extends from the surface to a depth of 6 feet. Among the artifacts from this rich horizon are steatite carvings of animals and of the human figure.

[Sculpture-ground slate sequence hypothesis:]

Stratigraphic evidence suggests that the earliest sculptures at the site antedate the introduction of ground slate knives which at a nearby locality are known to be present 2300 years ago $(S-62)$. 
[Dating to be obtained:]

Radiocarbon analysis of charcoal found in association with an animal carving at the bottom of the sandy loam should give an approximate initial date for the complex [1961a: $584]$.

The two earlier levels, already dated, were further excavated:

Important additions were made to the assemblages of earlier occupation levels, previously assigned radiocarbon ages $7350 \pm 150$ B.P. (S-61) and $8150 \pm 310$ B.P. $(S-47)$.

[Sample size from earlier level:]

Around 500 artifacts, in addition to large quantities of waste flakes, have been recovered from the latter.

[Evidence of chipped points:]

Chipped points in these levels are predominantly leaf shaped, pointed at both ends and vary in length from $5.5 \mathrm{~cm}$. to more than $17 \mathrm{~cm}$.

[Hypothesis of uses:]

They could have served either as projectile points or endblades for knives [1967a:584].

Borden confirms the hypothes is stated in 1960a, of an earlier occupation level at the site:

[Confirming test hypothesis:]

During the final days of the field season, an even earlier occupation level was reached at a depth of 25 feet below the surface.

[Evidence to support preceding hypothes is test:]

Detritus, black ash, charred pits of a wild cherry, stake holes, and five artifacts, including a chipped point, were encountered in this earliest culture stratum.

[Dating to be obtained:]

A charcoal sample has been submitted for dating [1961a:584]. 
CHAPTER XXVI

\section{2a WEST COAST CROSSTIES \\ WITH ALASKA}

\section{INTRODUCTION}

This paper was presented at a symposium "Organized by the late great Louis Giddings,...[and] was held in 1960 at Yale University as part of the annual SAA meeting" (Borden pers. com., 1973). It appears in Prehistoric Cultural Relations between the Arctic and Temperate Zones of North America, a Technical Paper of the Arctic Institute of North America. All of the papers in this publication re-examine old hypotheses in the light of dates from radiocarbon analysis, and suggest new hypotheses in line with this new body of evidence.

Borden's paper, the last major publication in his middle period, considers many theories first proposed in his earliest works, and is a major summing-up and re-evaluation with the best evidence available in 1960. Because it is a major theoretical paper, Borden particularly regrets his use of the bad Marpole date as good evidence. That date places the Marpole phase earlier than the Locarno Beach phase. When this date is discarded, the Locarno Beach material will again be interpreted as early maritime, but not as Eskimoid (Borden 1970:99).

In writing to me about his use of hypotheses, Borden said, "... when new data seemed to make it necessary I have been ready to abandon previously held views and even to reverse myself (cf. 1962 West coast 
Crossties...). This is an ongoing process" (pers. com., 1973).

Borden begins by presenting the old hypotheses explaining the similarities between Alaska and the West Coast, and his own place among those holding the old hypotheses. Next he gives new evidence from the Fraser and Columbia that will have to be accommodated in any hypotheses. Then he asks if there is evidence to support the hypothes is that Eskimos laid the foundation for these more southerly cultures, and answers that there is no such evidence. He supports his negative hypothesis by examining evidence related to the various traits found in common between Alaska and the West Coast. Both ground slate and microblade complexes are examined to see if there is a time gradient in their occurrences so that a geographic directional spread may be hypothesized. Then Borden proposes that evidence supports the interior diffusion route as an important link in "...a protracted intercontinental cultural exchange... in the millennia before Eskimos occupied Bering strait..." (1962a:17). He concludes with a series of hypotheses relating to early movements of peoples and linguistic groups on the Northwest coast, and their possible relations with the Eskimo and Aleut.

\section{EARLY DRUCKER AND BORDEN HYPOTHESES}

\section{Early Evidence and Its Use}

Borden begins with a general statement of the types of evidence that led to early hypotheses:

It is common knowledge that numerous crossties exist between the Northwest Coast and Alaska. These links encompass not only many individual traits and complexes of minor 
importance, but also culture patterns of basic socio-economic significance. Some of the correspondences are so extensive and of such esoteric nature as to suggest sustained early contacts between certain groups of Northwest Coast Indians and Eskimos (de Laguna, 1934, p. 218; Co11ins, 1937, pp. 271-2; 1940, pp. 576-7; Lantis, 1938;

Helzer, 1943, p. 448; 1956, pp. 10-11; Borden, 1950, pp. 22-6; 1951, pp. 37-40; 1954; p. 26; Drucker, 1955) [Borden 1962a:9].

Then Borden includes himself among those who held the early hypotheses, almost without question:

For some of us who have grappled with the problems of cultura1 development in northwestern North American it has been almost axiomatic in the past to attribute any aspect concerned with the efficient exploiting of maritime resources to Eskimo influence [1962a:9].

Specifically, Borden ordered his evidence in two different ways because of the Maritime/Eskimo origin hypotheses:

[1] Thus, the present writer was persuaded to assign the loaded term "Eskimoid" to the Locarno Beach Phase of the Fraser delta region because the sites in question included such items as toggling harpoons, harpoon foreshafts, ulus, men's knives and projectile points of ground slate, labrets, and other elements often regarded as typically Eskimo (P1s. 2-5; Borden, 1950, pp. 15-17, 20; 1951, pp. 45-7; 1954, p. 26).

[2] On the other hand, the suggestion that certain types of barbed antler harpoons and fixed points characteristic of the Marpole Phase had been introduced from the adjacent interior (P. 2; Borden, 1951, p. 45; 1954, pp. 26-31) was dismissed as nothing more than "carrying coals to Newcastle" [1962a:9].

In sum, this is the evidence that was "considered sufficient" to support the hypotheses:

The occurrence of similar devices in Aleut and Pacific Eskimo centers was considered sufficient to settle the question of origin (Osborne et a1., 1956, pp. 119, 121) [Borden 1962a:9].

Value of Testable Hypotheses 
The next section is doubly important to note for the purpose of this thesis. Borden discusses Drucker's hypotheses as instances of proper procedure for archaeological testing.

Drucker, one of the most astute students of Northwest Coast culture, has rendered a service by giving this tendency to attribute existing parallels to Eskimo influence its most extreme expression in an hypothesis which lends itself to archaeological testing [1962a:9].

These are the aspects of the Drucker hypothesis as Borden presents them:

[Early sub-arctic culture base hypothesis:]

He proposes: "that the distinctive basic patterns of the Northwest Coast culture, from Yakutat Bay to northwest Ca1ifornia were derived from the same subarctic fishing-andsea-hunting base of the coasts of Bering Sea and southwest Alaska that gave rise to the various Eskimo and Aleut cultures."

[Eskimo-Aleut economic base hypothesis:]

Eskimo-Aleut, according to Drucker, did not only provide the economic basis for the subsequent development of the various reglonal variants of Northwest Coast culture,

[Drucker's trait and complex origin hypothesis:] but were also the donors of a long list of traits and complexes.

[Asiatic influence transmission hypothesis:]

Recalling the well-known indications of Asiatic influence on the Northwest Coast, Drucker asserts, moreover, that "any northeast Asiatic concepts, whether of major or minor significance in Northwest Coast culture growth, must have been transmitted to the Northwest Coast peoples by EskimoAleut..."

[Testable time-sequence hypothesis:]

"These Asiatic influences", he emphasizes, "could not have been transmitted prior to the development of Eskimo-Aleut Culture in southwest Alaska and the Bering Sea region" (Drucker, 1955, pp. 61, 64) [Borden 1962a:9-10].

\section{Misuse of Evidence}

Now Borden states the importance of weighing carefully the prob- 
ability of the evidence on which hypotheses are based, and is critical of himself in this passage:

Those who embraced this thesis with all too great alacrity should have taken note of Drucker's (1955, p. 59) own awareness that his interpretation was based mainly

[1] on recent ethnographic distributions and

[2] that it lacked the controls defined by archaeological sequences and relationships [1962a:10].

\section{EVIDENCE FROM COLUMBIA AND FRASER AREAS}

TO SUPPORT AN ALTERNATIVE HYPOTHESIS

With the old hypotheses no longer regarded as axiomatic, but now considered tentative, Borden examines evidence from the Fraser and Columbia which will relate to origins of those traits held in common with northern areas.

\section{Fraser Canyon}

He begins with a summary of evidence from $\operatorname{DjRi} 3$ in the Fraser Canyon. The site now shows five occupations. The top level dates from near the beginning of the "Christian era". Below this and below volcanic ash of the 4800 B.C. Glacier Peak eruption is a cultural deposit "... with a C-14 date of 5391 B.C." (p.10). Then under massive gravels is a layer dated at 6193 B.C.

Five feet below this level, evidence of a st1ll earlier occupation was found. This earliest horizon has not yet been dated, [Hypothes is of age:] but its antiquity probably exceeds 9,000 years, an age which would place it in the eighth millennium B.C. [1962a:10].

Artifact types from the earliest levels are mentioned:

The stone industry from the early levels includes heavy cobble choppers, numerous scrapers of different types, knives, 
including crescentic forms, and leaf-shaped points, some of which have a single shoulder or inset, rather high on one edge, reminiscent of Sandia forms.... These too may have been knives rather than projectile points [1962a:10].

Then Borden presents the cherry-pit evidence and in a tentative manner presents his salmon-base hypothesis:

The earliest two levels also yielded charred pits of a wild cherry (Prunus demissa),

[Hypothesis:]

This edible fruit evidently was gathered in considerable quantities and consumed at the site.

[Negative evidence:]

Unfortunately, soil conditions are such that no artifacts of organic materials nor any faunal remains survive. It is, therefore, not immediately apparent what brought the Indians to this site.

[Ethnographic evidence:]

Opportunities for hunting, particularly of large animals would have been poor, but to this day, this turbulent stretch of the river is famed among Indians as the best place for catching salmon (Duff, 1952, p. 62).

[Hypothesis and evidence:]

A hint that it was also anadromous fishes which attracted Indians to this locality in remote periods is provided by the pits of the wild cherry. This fruit matures in the months of August and September, the very time when the biggest salmon runs ascend the river [1962a:10].

The next evidence is new with this paper, supporting an hypothes is of early relationships with Oregon resources:

Among the stone detritus of the level dated at 6193 B.C. was a chip of transparent obsidian. While opaque and translucent obsidian occurs in British Columbia, the nearest natural occurrence of such clear volcanic glass is in Oregon.

[Hypothesis:]

Very likely, therefore, the early occupants of the Fraser Canyon had connections in that direction [1962a:10-11].

\section{Columbia River}

Borden now introduces Cressman's work as a support for the riv- 
erine adaptation hypothesis:

And it is to the Columbia River that we now must turn our attention, where Cressman's important discoveries at The Dalles provide the most significant evidence for an early riverine adaptation in the Northwest (Cressman et al., 1960). From cultural levels which, according to $\mathrm{C}-14$ analysis, are contemporary with, and in part earlier than, our early levels on the Fraser, Cressman's students recovered more than 200,000 salmon vertebrae,

[Hypothesis of salmon-base:]

leaving no doubt that these fish were the major food staple of the local Indian inhabitants.

[Evidence of sea]s:]

of more than passing interest is the occasional presence of seal bones.

[Hypothesis on seals:]

These sea mammals evidently were taken as they followed the salmon runs upriver,

[Hypothes is on 01d-World-New World paralle1:]

an interesting New World parallel to similar practices of inland-dwelling Upper Paleolithic groups of western Europe (Clark, 1952, pp. 72-3).

[Evidence of fowling:]

While the hunting of land mammals seems to have been unimportant, the early Columbia River Indians killed great numbers of birds with bolas.

[Evidence of antier industry:]

Associated with the food remains is a flourishing elk antler industry. Antler and bone were sectioned and worked into artifacts with true burins of several types.

[Hypothes is of old World paralle1:]

Interestingly, the techniques employed are virtually identical to those of the nearly contemporary site at Starr Carr, England (Clark et al., 1954, chap.5), emphasizing the early distribution around the world of such manufacturing methods.

[Evidence of other artifacts at The Dalles:]

Among the devices produced of antler at The Dalles were the spurs for throwing boards and small unilaterally barbed points, Identified by Cressman as harpoons. [In Borden's review of Cressman, 1962b, he takes issue with this identification.] 
[Hypothesis of riverine adaptation, repeated:] Obviously, these Indians were well-equipped for exploiting riverine resources [1962a:11].

\section{Hypotheses of Local Adaptation and Development}

Now Borden presents and recommends Cressman's hypotheses of origin and development of riverine adaptation in North America:

Noting that his findings are earlier by several thousand years than evidence of similar ecological adaptation elsewhere in North America,

[Cressman hypotheses:]

Cressman rightly suggests the possibility that

[1] on this continent such patterns were first evolved in the Pacific Northwest,

[2] and that in the following millennia they were carried into northern regions by Indians moving through the interior of Washington and British Columbia [Borden 1962a:11].

Borden refers to MacNeish's theory (Borden pers. com., 1973), of further population movements, but tempers these with another mechanism of culture change:

[Cressman's thesis re-stated:]

While such northward population movements of hunter-fishers very likely occurred

[MacNeish hypothesis:]

--paralleling the northward drift of big game hunters farther to the east--

[Borden's local development hypothesis:] we must not ignore the possibility that the potentialities inherent in the new way of life were further developed not far from where they had originated.

[Kroeber's general riverine adaptation hypothesis:] The adaptation to riverine resources is a natural step toward successful existence at the river mouth and eventually on the sea shore.

[Kroeber's Gulf of Georgia hypothesis:] Kroeber (1939, p.30) long ago called attention to the (iulf of Georgia region as a potentially important area for the 
inftial stages in the development of Northwest Coast culture. Dismissing the coastal environment near the estuary of the Columbia as unfavorable, Kroeber pointed to the mouth of the Fraser as the most logical and ideal locality where the early transformation might have occurred [Borden 1962a: 11].

\section{Fraser Delta Area}

Now Borden examines geological evidence concerning the Gulf of Georgia at the time when DjRi 3 and The Dalles sites were first occupied.

\footnotetext{
[Evidence:]

[1] It is significant in this context that 8,000 to 9,000 years ago the lower valley of the Fraser was still depressed from the last and recently terminated local glaciation and that a long inlet extended from the Gulf of Georgia to the vicinity of Hope ( $\mathrm{Dr}$. J. E. Armstrong, Geological Survey of Canada, personal communication).
}

[2] Thus, the Indians who fished in the Fraser Canyon at that time were little more than twenty miles from the mouth of the river and salt water.

[Borden time hypothesis on marine adaptation:] The stage for experimenting with maritime resources was set even then. Perhaps such experiments had already begun [1962a: $11]$.

The next section of this paper is Borden's solution to the problem of the bad Marpole date which he accepted at this time, and which indicated that the Marpole phase was earlier than, as well as contemporary with, the Locarno Beach Phase. He could not accept this new date and regard the marine orientation of Locarno Beach as evidence of an early maritime people interrupted by a people with major interior elements. Even though the evidence of the early Marpole date is no longer accepted, this is a passage that shows how Borden deals with evidence contrary to his previous position. He considers this quest- 
ion: If maritime experiments began 9,000 years ago near the mouth of the Fraser, what other evidence do we have from this region?

A time span of some 4,000 years intervenes between the last of the early occupational horizons of the Fraser Canyon site and the sites investigated to date one hundred miles to the west near the present mouth of the river.

[Cultural development hypothesis:]

A tremendous cultural development, of which we know as yet nothing, had taken place meanwhile...[1962a:12].

There are two early contrasting cultures that are known from Fraser

delta sites. How do they compare in maritime orientation and in time depth?

[Hypothes is of Northwest Coast culture pattern time depth:]

These delta cultures of the first millennium B.C. loom up before us with the Northwest Coast culture patterns well blocked out; maritime orientation, highly developed woodworking, large villages with commodious houses along the shore, and so forth.

[Marpole Phase evidence and hypothesis:]

These features are particularly apparent in the sites of the Marpole Phase, which has a series of $\mathrm{C}-14$ dates ranging from 943 B. C. to A. D. 179. Although additional C-14 analyses are necessary to determine the approximate beginnings of this phase,

[Time hypothesis on Marpole origins:]

it seems probable that its characteristic features were in existence by $1000 \mathrm{~B}$. C. and possibly earlier.

[Locarno Beach evidence and hypotheses:]

A culture variant [my emphasis.], the Locarno Beach Phase,

[Locarno Beach culture center hypothesis:]

whose main centers may have been on the Gulf Islands, is so far known only from two sites on the outermost fringe [my emphasis] of the delta region. The radiocarbon dates of $476 \mathrm{~B}$. C. and $493 \mathrm{~B}$. C. suggest that it was roughly contemporary with the Marpole Phase.

[Negative evidence:]

Evidence of woodworking on a large scale--which is so prominent at the sites of the Marpole culture--is so far lacking from the Locarno Beach Phase. 
[Locarno Beach maritime hypothesis:]

on the other hand, the latter seems even more strongly oriented toward the sea [1962a:12].

Borden's Locarno Beach hypothes is now envisions a maritime center off-shore from the delta, with its "variant" adaptations reflecting this more maritime setting. The delta sites then, represent the outer ring of settlements, on the "outermost fringe" of the delta portion of the mainland. Borden will repeat and expand this last possibility in his 1970 paper.

\section{COMPARISON OF ESKIMO AND NORTHWEST COAST TRAITS}

Borden's Hypothesis

Borden now re-states Drucker's test hypothesis and examines the evidence which relates to it:

Must we assume now [Drucker's hypothesis:] that these cultures came into being only after the Eskimos had laid the foundation?

[Borden's hypothesis to the contrary:]

There is no evidence to support such an hypothesis [1962a: 12].

This is the first statement of the main hypothesis Borden presents in this paper. Whatever the source of Northwest Coast culture, it is not from an Eskimo foundation. He now examines Northwest Coast culture and the evidence supporting Eskimoid places of origin and other places of development.

\section{Marpole: Earliest Known Fully Developed Northwest Coast Phase}

First, if Marpole sites represent "we11 blocked out" Northwest 
Coast culture patterns, antecedents of these traits can be traced to support or examine Borden's new position.

Marpole Artifacts Developed Locally. [Borden's summary hypothesis on cultural development antecedent to Marpole:]

The culture of the Marpole Phase is firmly rooted in local tradition.

[Evidence summary:]

Links with the ancient riverine cultures of the Columbia and the Fraser are obvious.

[Evidence of specific trait similarities:]

[1] Exploitation of the rich fish resources, which started more than 7,000 years earlier, is still the economic basis, [2] supplemented by fowling [as at The Dalles] and some hunting of land animals.

[Evidence of differences from up-river sites:]

But in addition shellfish is extensively eaten,

[Evidence of developmental link:]

and numerous harpoons... as well as the bones of seal, sea lion, and porpoise, attest to the importance of sea mammal hunting. Some marine game, it is of interest to recall, was already taken in the Early Period at The Dalles [1962a: 12].

Among harpoons, the composite, or toggling, varieties have been

important in Borden's hypotheses from his earliest paper. Here he deals

with them only negatively:

The problem concerning the origin of toggling harpoons deserves a more detailed treatment than is possible here. At any rate, there is no compelling reason to assume that Esk1mos were the donors of these devices [1962a:12].

Barbed points are found preserved in some interior sites.

[Hypothesis:]

The barbed antler harpoons and fixed points very likely were evolved from early interfor prototypes.

[Hypothesis that some affirmative evidence is missing:] Accidents of preservation have probably obscured the importance among interior groups of barbed projectiles of organic materials in remote periods. 
[Evidence of early interior bone point presence:]

It is noteworthy, for instance, that even the bison hunters of the Lind Coulee site in eastern Washington used barbed bone points nearly 9,000 years ago (Daugherty, 1956, pp. 253-5, Figs. 25, 3 and 26, 5).

[Evidence of antler wedges as a local development:] Again, certain antler wedges of the Marpole Phase, which play a prominent role in the flourishing woodworking industry of this coastal culture, are almost indistinguishable from similar artifacts of the Early Period at The Dalles.

[Evidence of stone chipping resemblances:]

Finally, though there are many new forms, even the chipping industry of the Marpole Phase still shows marked affinities with the ancient up-river types [1962a:12].

Artistic Traits from the South. Borden now turns to traits not known locally, but from other areas. First he suggests there are artistic and decorative items at Marpole similar to items found to the sou i. In his summary statement, Borden does not speak of population movements, and probably he is referring to stimulus diffusion:

[Hypothesis of variety of mechanisms of culture change:] Aside from indications of vigorous local growth there is striking evidence of later cultural impulses from other areas.

[Stone-working origin hypothesis:]

Stone vessels, mortars, and the pestle-shaped stone hammer-so important in the woodworking of the coast--probably were developed from prototypes derived from the Great Basin-Lower Columbia region, where similar artifacts have great time depth (Cressman, 1956, pp. 419-20, 464; Cressman et al., 1960).

[Evidence of similarity, but negative chronological evidence:] Though few will question the genetic relationship between the impressive sculpture of the Lower Fraser-Gulf of Georgia region and that of the Lower Columbia, we still lack sufficient chronological data to permit us to indicate the origin of this artistic activity.

[Hypothesis of southern origin:]

It may have been in the south.

[A] ternate northern hypothesis, with evidence:] 
On the other hand, considerable antiquity for the beginnings of this art in the more northerly of the two regions is suggested by the fact that carving in stone, antler, and bone reached an early climax in the Fraser delta during the first millennium B.C...

[Hypothesis of "ancient tradition" of art:]

The famed art of the classic Northwest Coast is, obviously, rooted in this ancient tradition (Drucker, 1943, pp. 127-8; Borden, 1950, pp. 19, 25; Wingert, 1952, pp. 9-11; Duff, 1956a, pp. 94-115 [Borden 1962a:12-13].

Having summarized a long and extensive artistic tradition on the Northwest Coast, even without good chronological evidence for origins, Borden relates this to known, dated Eskimo sites:

[Negative hypothesis of Eskimo origin of artistic tradition:] It is likewise evident that these anclent artistic manifestations of the southern Northwest Coast are too early and too developed to have been stimulated by any known Eskimo culture.

[Test hypothesis of artistic influence from Northwest Coast to the Eskimo:]

Future studies may determine whether palpable influences were exerted in the opposite direction.

[Evidence for hypothesis above:]

Some years ago, Collins (1937, p. 291) called attention to certain similarities between old Bering Sea art and that at prehistoric sites in British Columbia and Washington [1962a: 13].

Instance of Indian to Eskimo Influence. The use of labrets may be an instance of Indian to Eskimo influence. Borden suggests a southern origin of this trait:

[Hypothesis on labret influence pattern:] Eskimo-Aleut very likely adopted the practice of wearing lip ornaments from early Northwest Coast Indians (Borden n.d.a.) [1962a:13].

Influences from Middle America. Labrets are found in Marpole and Locarno Beach sites, and an ear spool was found at Locarno Beach.

[Hypothesis of use:] 
It seems that ear spools were also worn in the Gulf of Georgia region during the first millennium B.C.

\section{[Evidence:]}

A broken ear spool carved in white marble was recovered from the Locarno Beach site (cf. also Duff, 1956a, p. 131, P1. 4, B; 1956b, p. 5, Fig. $3 \mathrm{~F}, 8)$ [1962a:13].

On the basis of a small amount of evidence from the Locarno Beach Phase, Borden draws a general conclusion. The lack of other sites of this Phase has made tests of these hypotheses impossible, and under1ines the importance of the 1972-1974 excavations of a waterlogged site at Musqueam which has both Marpole and Locarno Beach components.

[Labret-ear spool origin diffusion hypothesis:]

Labrets and ear spools may hint at cultural stimuli originating in Nuclear America [1962a:13].

Note that Borden does not say that these traits came with people from Middle America moving north.

\section{Traits Thought to Have Been of Eskimoid Origin}

Borden now turns to other artifacts from the Marpole Phase, the southern locus of the crossties he is examining, and from Locarno Beach, which have been considered to be of Eskimoid origin. Borden first hypothesizes that they originated neither locally nor in the south. These artifacts include ground slate implements, stone saws, "neatly cut and polished nephrite adzes" (p. 13), bone whistles, beaver tooth knives or gouges, and fish effigies. All but the effigies and beaver tooth tools are also elements of the Locarno Beach Phase. Borden asks again:

Could Eskimos have been the donors of this cluster of elements? Since ulus, men's knives, harpoon blades, and the like of ground slate are commonly regarded as "typical" EskImo artifacts, it seems appropriate to review briefly the 
evidence concerning the slate industry. A more detailed

study is in preparation, Borden (n.d.b) [1962a:13].

Ground Slate

Ground Slate in the Fraser Delta. The first step in Borden's review of evidence is to look at the early Fraser delta occurrence of ground slate:

Ground slates had a tremendous vogue in the Lower FraserGulf of Georgia region in the first millennium B.C. Just how important a part they played in the economic life of these people may be inferred from the fact that more than 3,000 out of a total of some 8,000 artifacts recovered from the Marpole site alone were of ground slate. Relatively, they were even more important in the Locarno Beach Phase.

[Note that this next section would be revised when the eariy Marpole date is discarded:]

While chipped artifacts are still fairly common at Marpole, the flourishing ground slate industry in whalen $I$ and at Locarno Beach had reduced chipping to an insignificant role.

[Evidence from Locarno Beach sites:]

Among the ground slates at the latter site are a wide variety of implements: typical ulus of various outlines, single-edged end blades, double-edged knives, saws, and numerous projectile points of different form and size, but especially large dart heads, ground to an hexagonal crosssection....

[Hypothes is of use:]

Along with three types of toggling harpoons, the large slate projectiles appear to have been used in sea mammal hunting [1962a:13].

[Hypothesis of time for development:]

A considerable number of centuries must be allowed from the time of introduction of this slate industry to the middle of the first millennium B.C., when it had gained such dominance [pp. 13-14].

[Stratigraphic evidence:]

Since, moreover, the C-14 samples which yielded the dates of 476 B.C. for Locarno Beach and 493 B.C. for Whalen I originated well above the bottom of their respective deposits, 
[Time of origin hypothesis:]

we may reasonably assume that the beginnings of the industry in the Gulf of Georgia extend well back into the second m11lennium B.C. [1962a:14].

Ground Slate in Eskimo Sites. The second step in this examination is to look at the evidence from Eskimo sites. He cites Ritchie (1951a) in a statement that eastern Archaic slates are earlier than Eskimo examples. Then Borden looks at Eskimo sites beginning with those nearest the Northwest Coast, and proceeding northward. His first series of statements and dates refers to the earliest occurrences at each site, either stratigraphically or chronologically.

[Evidence from Cook Inlet:]

At Cook Inlet, in the deposits of the Kachemak Bay I period, dated at 748 B.C., de Laguna found five ground slate artifacts in an assemblage otherwise dominated by chipped implements (Rainey and Ralph, 1959, p.371; de Laguna, 1934, p.69).

[Borden's hypothesis interpreting these data but also based on Kachemak Bay III evidence below:]

Artifacts of rubbed slate, evidently, were just coming in.

[Evidence farther north:]

Farther north, a few fragments of roughly ground or scratched slate blades in the Choris assemblage, dated 677 and 688 B.C., and very similar to isolated specimens in the Norton culture (Giddings, 1957, p.126; Rainey and Ralph, 1959, p.370).

[Borden's hypothesis from evidence above and from presupposition that time gradient represents spread of common idea:] suggest that slate grinding was spreading to Eskimos inhabiting the Seward Peninsula area in the seventh century B.C. $[1962 \mathrm{a}: 14]$.

Now Borden looks at dated assemblages lacking ground slate artifacts. Note that he does not preclude the possibility that this manufacturing method was an option. He just says it was not accepted and used:

[Summary negative time hypothesis:] But many centuries were to pass before slate grinding really took hold. 
[Evidence of sites with no slate grinding:]

Artifacts of ground slate are not present in Paleo-Aleut sites either before or after the beginning of the Christian era (Laughlin and Marsh, 1951, p.82). Also the Iplutak Eskimos had not adopted implements of rubbed slate at around A.D. 300 and later (Larson and Rainey, 1948; Rainey and Ralph, 1959, p.370) [Borden 1962a:14].

The next evidence of the Eskimo slate industry dates the cul-

tures in which slate grinding. is statistically important. Borden considers four different sites in the Eskimo-Aleut area.

[1] Although in the Okvik stage of the 01d Bering Sea sequence slate grinding is well established, chipping is still the more important industry (Collins, 1937, p.334).

[Conflicting evidence in dating this stage:] Originally dated at 300 B.C. (Collins, 1953b, p.1970), more recent analyses by means of the reportedly more reliable carbon dioxide gas counting technique on a series of eight old Bering Sea samples, including two from Okvik levels, have produced dates ranging from the third to the seventh century A.D. (Rainey and Ralph, 1959, p.369).

[2] At Cook Inlet again, the region nearest the Northwest Coast, ground slates begin to dominate the scene during the Kachemak Bay III period, which has a C-14 date of A.D. 589 (de Laguna, 1934, p.69; Rainey and Ra1ph, 1959, p.368).

[3] At Bering Strait this state of affairs is not reached until a few centuries later, i.e., in the Punuk period around A.D. 1000 (Collins, 1937, p.334; Rainey and Ralph, 1959, p.373).

[4, Hypothesis on sequence:]

The last of the Eskimos to adopt ground slates seem to have been the Aleut.

[4, Evidence:]

At Chaluka on Umnak Island, such implements appear in only the most recent Aleut strata (Laughiln, 1952, p.32) [Borden $1962 \mathrm{a}: 14 \mathrm{~J}$.

General Conclusion Denying Eskimo Origin of Ground Slate Industry.

The time gradient derived from absence, presence, and abundance of this type of artifact, leads Borden to these hypotheses:

This review is sufficient to demonstrate that 
[Hypothesis denying Eskimo origin of Northwest Coast slate industry: ]

The ground slate industry which flourished in the Gulf of Georgia in the first millennium B.C. could not possibly have been derived from Eskimo culture in Alaska [1962a:14].

I would want to add, "... if presently known sites are representative of all Eskimo sites". Then Borden states a positive hypothesis of the direction of diffusion:

On the contrary, the distribution of rubbed slate artifacts in space and time can be interpreted as indicating a diffusion of the industry from the Northwest Coast to the Eskimo [1962a:14].

Time for Diffusion of Ground Slate. Another sort of generalization can be made from the dates of these sites. In addition to the question "Did the Eskimos derive the slate industry from the Indians of the Northwest Coast?" we may ask "How long did it take from the introduction of this new technique until it finally became well estabTished?" Two sites give us this information.

We may pause here briefly to note the time which elapsed from the approximate date of introduction of slate grinding among Eskimo groups in Alaska to the time when artifacts of rubbed slate greatly outnumber those made by chipping.

[1] In Cook Inlet, the C-14 dates indicate an interval of some 1,350 years (Kachemak Bay I to III: 750 B.C.-A.D. 600).

[2] Farther north, near Bering Strait, it required approxImately 1,700 years (Choris to Punuk; 690 B.C.-A.D. 1000) [1962a: 14].

After stating that evidence from these two sites does not permit us to generalize with confidence, Borden notes that this time span does not disconfirm his hypothesis that in the Fraser delta the slate industry took a long time to develop:

Though such evidence must be used with caution, 
[Hypothes is:]

these time lapses tend to support the assumption that the beginnings of the ground slate industry of the Gulf of

Georgia region extend well back into the second millennium and perhaps to as early as around 2000 B.C. [1962a:15].

\section{Alternative Hypotheses for Origin of Northwest Coast Slate Industry}

Now the problem is pushed back farther in time: From what source did this industry come to the southern Northwest Coast. Borden presents two alternative hypotheses. It is interesting to note that evidence is lacking in each case, but that Borden nevertheless prefers one above the other. Not until a later part of the argument can we indirectly discover the reasons for Borden's position.

The origins of the early slate industry on the southern Northwest Coast are still uncertain.

[Hypothesis of origin in eastern North America:] For the time being, any suggestion that the slate grinding of the west was sparked by the well-known and perhaps older manifestations in the east of the continent

[Conditions for supporting or testing this hypothesis:] must remain in abeyance until we have more definite indications of transcontinental connections at the proper time.

[Preferred hypothesis of Asiatic origin to sites on both sides of the New World:]

A more likely possibility at present is that the slate grinding in both the east and the west was initiated by common influences from Asia.

[Lack of necessary evidence:]

To be sure, to date, no evidence has been uncovered in support of Gjessing's (1944, p.21-5, Fig.7) postulated broad belt of slate-grinding peoples who, he belleved, were concentrated across the boreal areas of Eurasia and North America.

[Evidence in Asia that Borden interprets as confirmation:] Nevertheless, we cannot ignore the fact that slate grinding was once an important industry in certain parts of Asia and of sufficient antiquity to have stimulated similar practices in North America [1962a:15]. 
Next Borden reviews evidence of the slate industry in Siberia. This is how he introduces it:

Few areas of Asla have been so well studied by archaeologists as the Lake Baikal-Upper Lena reglon, where Okladnikov (cf. bibliographies in Chard, $1958 \mathrm{a}$ and Tolstoy, $1958 \mathrm{a}, \mathrm{b}$ ) has developed a long cultural sequence. Though there is some disagreement concerning certain details and on the dating of this sequence (Chard, 1958a:Gimbutas, 1959), on the whole it has found general acceptance. The differences in interpretation do not materially affect the present argument [1962a: 15].

Problem of Siberian Evidence. If these dates and this sequence are in fact correct, it is important evidence and part of it supports Borden's preference for a common Asiatic origin to all New World artifacts of this type. After having read 0kladnikov, I regard this section of Borden's argument with great caution. Borden's statement above, that Okladnikov's sequence "...on the whole... has found general acceptance", is reminiscent of "almost axiomatic" (1962a:9) acceptance of Drucker's hypotheses which Borden rejects in this paper. Borden, in 1973, also cautions against hasty acceptance of Siberian data. In 1960, however, transiations were not sufficient to indicate the evidence on which the Siberian hypotheses were based. Klein (1971), and Chard (1969), have stressed that until radiocarbon dating is based on more than one sample, the conclusions from the evidence will be extremely tentative. However, Borden's 1960 use of Okladnikov was justified on the basis of evidence available at that time.

Siberian Evidence and Hypotheses. This is Borden's argument derived from this material:

[Evidence of earliest rubbed slate:]

Implements of rubbed slate first appear in the, as yet, poorly represented Khin'skaya stage tentatively dated by Okladnikov as of the fifth millennium B. C. 
[Khina artifact resemblance to Marpole:]

Among the most distinctive artifacts of the Khina complex are long, slender, parallel-sided hexagonally ground slate points--of which virtually exact duplicates occur in sites of the Marpole Phase of the Fraser delta...--and some shorter leaf-shaped polished slate implements of lenticular crosssection (Okladnikov, 1950, Figs. 9, A and 15; Chard, 1958a, p.7; Michael, 1958, p.37; Tolstoy, 1958a, p.398).

[Negative evidence of slate points:]

Slate points are not specifically mentioned in the English summaries of Soviet research for the later Neolithic periods of the Batkal sequence,

[Baikal evidence of ground knives:]

but sub-rectangular knives of ground shale or slate are typical of the Batkal from Isakovo (4000-3000 B.C.) through the Serovo (3000-2500 B.C.) and Kitoi (2500-1700 B.C.) periods (Chard, 1956, p.407; Tolstoy, 1958a, pp.400, 410; Michael, 1958, pp.46-7, Fig. 23) [Borden 1962a:75].

Now Borden examines evidence for the sequence in types of slate

and nephrite that were used:

While a rather soft slate was used in the Khin'skaya stage the Isakovo people began to use a harder cherty slate and, in the absence of suitable flint, even used this material for adze blades which were first blocked out by percussion chipping and then ground (Michael, 1958, pp.40-2).

[Evidence of similarity to Locarno Beach:]

Ground adze blades of the same material, we may note in passing, are found in the Locarno Beach Phase of the Fraser delta....

[Sequence from hard slate to nephrite:]

Also in use in the Kitoi period, the last in the pre-metal sequence, slate was superseded by this superfor material. The ground knives and adzes of dark grey cherty slate, so numerous in the preceding periods, become very rare, and pollshed adzes and knives, including end blades, of green nephrite take their place. Toward the end of the Kotoi, i.e. circa 1700 B.C., slate artifacts disappear altogether (Michael, 1958, pp.61-3). However, a concomitant of the new technology in nephrite was the development in Kitoi times of stone cutting with slate saws having smoothed beveled edges (Michae1, 1958, pp.62-3; Tolstoy, 1958a, p.402).

[Evidence of similarity to Fraser delta artifacts:] Similar slate saws were used during the Marpole and Locarno 
Beach phases ( $P 1.4, k$ ) in the manufacture of chisels and adze blades (P1.6, note especially groove in $P 1.6, i$ ) [Borden 1962a:15-16].

Comparison with Marpole Assemblage. Borden turns to the other Marpole artifacts similar to Siberian ones. Note that if the Siberian material were not older, or if some of it were not older, this next section might be changed to read: It is possible to add these features common to Asia, eastern New World and Fraser delta sites, which appear late or not at all in Eskimo sites.

[Hypothesis of influence of "Siberian Neolithic":]

In addition to the ground slates, which include projectiles, knives, adze blades, and saws, other traits in the Fraser delta assemblages of the first millennium B.C. suggest influences of the Siberian Neolithic.

[Instances of artifact types:]

Among these are the previously mentioned neatly sawed and polished adze blades of nephrite, bone whistles..., beaver tooth knives or gouges..., and stone fish effigies, perforated for suspension from the middle of the back....All of these are prominent features in one or several of the periods of the Baikalian Neolithic (Okladnikov, 1950; Chard, 1958a; Michae1, 1958, Tolstoy, 1958a,b) [Borden 1962a:16].

\section{Preferred Hypothes is of Origin of Slate Industry}

Now Borden gives the reason which must be the basis for his reluctance to derive ground slates from an eastern Archaic source:

[Similarity to eastern Archaic assemblages:]

Together with ground slates, they also appear to be characteristic of certain Archaic complexes in eastern North America (Ritchie, 1944; 1951b; Tolstoy, 1958b; pp.66,67, Table 1) [1962a:16].

With such a distribution of this whole assemblage, it is a simpler thesis to suppose a common origin, in Asia, for these New World occurrences. When secure dating is obtainable, the thesis can be tested. Borden now combines these data and one piece of negative evi- 
idence to argue against Drucker's test hypothesis:

[Test of Drucker hypothesis:]

Significantly, not only ground slates, but also these other traits of probable Asiatic origin are either absent or later in Eskimo sites than on the southern Northwest Coast, a situation which obviously cannot be reconciled with a major premise of Drucker's hypothesis, namely,

[Re-statement of Drucker's hypothesis:] that such Asiatic influences could have been transmitted only by Eskimo-Aleut and not until their culture had been established on the shores of Bering Sea and southwest Alaska [1962a: 16].

\section{Problem of Route of Influence}

Borden moves to answer the question, "How can traits or other influences move from Asia to various parts of the New World in a way that by-passes the Eskimo sites?"

[Statement that there is sufficient evidence for route of influence to be studied:]

Although we are not yet in a position to demonstrate the actual routes of diffusion of the above elements, the state of research has advanced sufficiently now so that it is possible to show at least by means of one complex how Northwest Coast Indians could be affected by stimuli emanating from Asia without Eskimos acting as intermediaries [1962a:16].

\section{Microblade Complex}

After examining this second complex, Borden will reason by analogy that a similar route may well be followed by other traits or complexes. This complex second is the microblade and core industry. Borden begins with the evidence from the Fraser delta, then from Alaska, merely stating that the complex had been introduced from Asia. Since it is not found in Pacific Eskimo sites, Borden traces its occurrence and the time gradient from dated sites, to see if he can tell the route by which this Asiatic complex spread. 
One of the more interesting crossties of the southern Northwest Coast with Alaska is the microblade and core complex which begins to appear in the Fraser delta region in the early centuries of the Christian era.

[Evidence of microblades in dated Fraser sites:] Expertly made microblades of obsidian were first discovered here in 1949 in the upper horizon of the Whalen Farm site (p.7,a; Borden 1950, pp.20,24; 1952, p.37). Whalen II has a C-14 date of A.D. 377. A few microblades and part of the Marpole site, several feet above a C-14 sample dated at A.D. 179. Since their discovery in 1949, polyhedral cores and blades have been found at eight widely distributed sites in the Gulf of Georgia region (P. $7, i, j$; Borden, field notes; Carlson, n.d.; J. Sendey, personal communication).

[Negative evidence:]

How long this complex persisted here has not yet been established. We only know that microblades are no longer present in the developed Coast Salish Phase, which, according to C-14 analysis, began around A.D. 1300 [1962a:16].

In his 1970 paper Borden adds another piece of evidence from the developed Coast Salish Phase at Stselax: a bone implement with microblades carved on its side. Borden's statement about Asiatic influence is as follows:

There is general agreement, based on convincing evidence, that the microblade technology and associated practices were introduced into the New World from Asia [1962a:16].

The northern New World evidence is stated this way:

This specialized industry, which forms a prominent component of the pre-Eskimo Denbigh Flint complex, seems to make its appearance in sites of the Bering Stralt region at some time during the fourth millennium B.C., although age estimates as well as the results of $C-14$ analyses differ widely (Giddings, 1951; 1955; Rainey and Ralph, 1959, p.373; Wormington, 1957, p.212). From Bering Strait the general spread of microblades across North America has been traced in several recent summaries (MacNeish, 1959b; Taylor, 1959b; Griffin, 1960, p.809) [Borden 1962a:16].

Now Borden re-states the Drucker hypothesis, and compares what would confirm it with the evidence at hand: 
If, In accordance with Drucker's hypothesis, the microblade industry of the Gulf of Georgia was transmitted to the Northwest Coast via Eskimo cultures, we should expect to find indications of it on the Pacific coast of Alaska. Significant$1 y$, although this technology spread to the Aleutian Islands, where Paleo-Aleut seem to have employed it for more than a millennium (Laughlin and Marsh, 1954, p.38),

[Disconfirming negative evidence:] polyhedral cores and microblades have not been reported from any site in the Pacific Eskimo area (de Laguna, 1934; 1947, pp.171-2; 1956; Oswalt, 1955b; Heizer 1956) [Borden 1962a: 16-17].

Diffusion Route. Borden presents his hypothesis of the route of diffusion:

[Diffusion route hypothesis:]

On present evidence, we must conclude that this Asiatic complex spread to the Gulf of Georgia via interior routes [p.17].

In the paper is a map, Plate 8 , of microblade sites, and dates of the dated sites. These dated sites range from the Bering Sea aTong the Arctic coast from west to east, then south in time sequence earliest to latest as follows:
1. Trail Creek
later than 4000 B.C.
[Bering Sea
2. Denbigh Flint earlier than 3000 B.C.
[Bering Sea
3. New Mountains
3000 B.C. sites
4. Chaluka
1000 B.C. [Aleutian I.,
5. Natalkuz Lake
500 B.C. sub-Arctic site]
6. Whalen II
A.D. 300
[Interior
[Fraser delta]
[1962a: on plate 8]

Borden cites other authors who have described Yukon microblade sites:

Microblades and cores have been traced up the Yukon and Tanana rivers into the Yukon Territory of Canada (Nelson, 1937; Rainey, 1939; 1953, p.44; Johnson, 1946a; MacNe1sh, 1960, pp.2, 16-23) [Borden 1962a:17]. 
From the citations published before radiocarbon dating, it is clear that Borden does not mean that all of these authors traced a correlated sequence of movement through space and time. His meaning may be re-stated: Microblades and cores have been found in sites along the Yukon and Tanana rivers in both ATaska and the Yukon Territory of Canada. This usage suggesting movement of this complex is apparently limited to dated sites, since in the next section Borden indicates that the route can be traced farther to the south with this time factor known.

It is now possible also to follow the diffusion into and through the intermontane region of British Columbia, down the Fraser drainage to the southern Northwest Coast [1962a: $17]$.

The evidence for the interior and coastal British Columbia sites is as follows:

Fieldwork in Tweedsmuir Park in the central interior of British Columbia produced cores and bladelets at several sites (P1.7, b, c; Borden, 1952, P.37 (P1.II). They have also been found a short distance to the northeast near Fraser Lake, again at several sites in the Vanderhoof area..., and then farther south near Adams Lake..., and finally at two sites in the Fraser Canyon $(\mathrm{P} 1.7, \mathrm{~h})$, especially in the top level of site DJRi 3, excavated in 1959. The last two sites are only a relatively short distance from whalen Farm at the mouth of the river, the site from which the first bladelets on the Pacific coast were recovered [Borden 1962a:17].

Without dating of Washington sites, Borden introduces the next step as an hypothesis:

Microblade technology seems also to have spread to the interfor of Washington, where lamelles and cores have been found recently at three sites (Butler, 1958; Gallagher, 1959, p.16, P1. I, 6,7; Osborne, n.d.) Earlier Nelson (1937, p.270) had called attention to the occurrence of polyhedral cores in Oregon and Montana [1962a:17].

The radiocarbon evidence from Natalkuz Lake is a crucial link in 
Now Borden writes about intercontinental exchange, not just oneway passage of culture traits:

[Hypothesis of prolonged intercontinental exchange:]

Data accumulating from both the old and New World make it increasingly evident that a protracted intercontinental cultural exchange

[Time depth hypothesis:]

was in progress in the millennia before Eskimos occupled Bering Strait (Tolstoy, 1958 a, b; Chard, 1958a; Griffin, 1960) [Borden 1962a:17-18].

\section{Earlier Eskimo Homeland}

Where were the Eskimos at this earlier time? Borden suggests another testable hypothesis:

At this period, prior to their expansion, and possibly before their culture had attained its distinctive character, the ancestors of the later Eskimos may have inhabited a region--perhaps in southwestern Alaska--some distance away from the main diffusion routes into the New World [1962a: 18].

Note Borden's use of the words "expansion" and "diffusion route" in this passage. These are alternative concepts to "migration" used in some of his earlier works.

Two areas of evidence seem to "fit" if these two theories hold:

Granting this and the possibility of diffusion via the interior,

[1] we have a plausible explanation for the seemingly anomalous situation that Asiatic influences become effective on the Northwest Coast either without leaving a trace of their passage in Eskimo sites or that they appear later in Eskimo centers than in the south--evidently after having made the long detour over the Northwest Coast.

[2] Moreover, we may have here a clue as to whence some of the important stimuli came that contributed to the efflorescence and expansion of Eskimo culture [1962a:18].

Subsequent evidence may tend to confirm Borden's theories of interior diffusion routes and early Eskimo habitation in southwestern Alaska. 
his argument:

Charred pine cones associated with lamellar flakes and a fluted core at a site near the head of Natalkuz Lake in central British Columbia have been dated at 461 B.C.

[General time gradient diffusion hypothesis:]

On combining this date with the dates at Bering Strait and at the mouth of the Fraser we obtain a time gradient running from north to south of roughly 3,000 years for the diffusion of this microlithic complex from the port of entry into the New World to the Gulf of Georgia (P1. 8) [1962a:17].

Generalized Hypothesis. Borden underlines the importance of the intermontane route in the next passage, which is an extended series of hypotheses to be tested:

[Interior route hypothesis:]

The interior, as this study strikingly demonstrates, is a potentially important diffusion route that must be reckoned with.

[Re-emphasized, as contrary to the other theories:] This point would not have to be stressed especially, if it were not for the fact that this possibility is frequently ignored or even specifically denied (Drucker, 1955; Osborne et a1., 1956, p.122).

[Hypothesis of interior as route of other traits:] Although we are not yet in a position to demonstrate 1 , other Asiatic traits and complexes both of a material and non-material sort could have and, seemingly, did travel similar routes to the Northwest Coast, not necessarily all by way of the Fraser, but also via other river valleys and passes that lead from the interior to the seaboard.

[Hypothes is of flexible time gradient rate:] Moreover, we need not postulate as much time for their passage as was required for the microblade complex [1962a:17].

Borden's first publications about this intermontane route were in $1952 \mathrm{a}, \mathrm{b}$, and in 1954 . This route will be important in his theories up to 1973 .

\section{SUMMARY HYPOTHESES}

\section{Protracted Intercontinental Exchange}


If new evidence does not confirm them, new theories must be suggested that can account for or "fit with" the evidence that Borden has outlined above.

\section{Linguistic Correlations}

Borden concludes this paper with a series of hypotheses concerning the history of some of the early peoples of North America and their linguistic groupings, bringing into his theories from archaeological evidence, the evidence from historical linguistics. First he summarizes his position thus far:

[Eskimo age hypothesis:]

All known cultural manifestations of the Eskimos are relatively recent when viewed in true perspective, 1.e. In their relationship to the total sweep of events of North American prehistory.

[Hypothesis of southern origins of riverine, maritime adaptation:]

Indications of the beginnings of a riverine-seashore orientation in the northwestern part of the continent are much older in the south than in the north [1962a:18].

Now Borden correlates his theories with those of Morris Swadesh (1954):54):

[Hypothesis that Swadesh-Borden theories coincide:] It is noteworthy, moreover, that the time depth indicated by archaeology is corroborated by glottochronology and that the implications of this time depth are likewise illuminated by the lexico-statistical data.

[Swadesh Mosan divergence time hypothesis:]

Thus the calculated time for the divergence of various languages in the Mosan phylum (Wakashan-Chimakuan-Salishan) suggest that the ancestors of the ethnic groups belonging to this language phylum were present in the Pacific Northwest in the seventh or eighth millennium B.C., that Wakashan existed as a separate stock by at least the fifth millennium, and that Wakashan separated into its two main divisions, Nootkan and Kwakiut1, at approximately 1000 B.C. (Swadesh et al., 1954, p.362, Table I). 
[Borden Wakashan distribution-time hypothesis:]

The extended, but continuous and purely coastal, distribution of Wakashan-speaking groups suggests that their forebears had been present on the seashore long before the divergence of the Wakashan stock began.

[Ethnographic confirmatory evidence:]

It is probably no coincidence [since maritime, or any environmental adaption develops through time] that it is precisely these groups, the Kwakiutl and especially the Nootka-Makah, who are the most maritime of all Northwest Coast peoples.

[Archaeological confirmatory evidence:]

The Nootka, it seems, were the originators of some of the more typical and basic Northwest Coast elements, such as the Dshaped adze and the Important ocean-going canoe (01son, 1927, p.16, 22),

[Ethnographic confirmatory evidence:] and only they hunted all the important sea mammals: the sea otter, hair seal, fur seal, sea lion, various species of porpoises, as well as the larger whales (Swan, 1870, pp.19-22, 30; Drucker, 1950, pp.171-3) [Borden 1962a:18].

This argument is expanded in Borden's unpublished 1970 paper.

Now what of the linguistic groups that are found ethnographical-

ly between these culturaliy similar maritime people?

[Hypothesis of later arrival of Haida, Tlingit, and Tsimshian speakers:]

If, as these close correspondences suggest, sustained cultural contacts between Wakashan speakers and Eskimos occurred, they must subsequently have been interrupted by the emergence on the Pacific seaboard of the Haida, the Tlingit, and the Tsimsh1an (Borden, 1951, pp.37-9).

[Hypothes is of causes of northern Northwest Coast distinctiveness: ]

The distinctive aspect of the northern Northwest Coast probably resulted from the blending of the maritime culture pattern previously evolved on the coast with newly introduced features such as the hafted maul, the grooved adze, rod and slat armor, slate mirrors, matrilineal social organization, and memorial columns [1962a:18-19].

[Hypothes is of subsequent trait diffusion:]

Some of these items in turn were passed on to neighboring Eskimo and Wakashan peoples [1962a:19]. 
(I recognize that Borden's list of the northern Northwest Coast characteristics is a trait-1 ist summary. As such, "matrilineal social organization" is an element of culture just as "rad and slat armor" is an element of culture. If Borden were to discuss these elements at length, these vastly diverse kinds of cultural elements would be more adequately distinguished.)

Borden continues with a series of hypotheses of population movements resulting from the hypothesized Haida, Tlingit and Tsimshian intrusions. It is based on the presupposition that at least some culture change was a result of one group "crowding out" another group.

[General population shift hypothesis:]

The appearance of these intrusive groups on the seaboard probably led to extensive population shifts,

[Nootka population shift hypothesis:]

perhaps forcing the Nootka to occupy the rugged western coast of Vancouver Island

[Eskimo population shift hypothesis:] and perhaps also compelling Eskimo groups to look for new homes farther north and west.

[Ethnographic confirmatory instances:]

Probably we may discern the last ripples of such dislocations in the recent intrusion of Tlingit, Eyak, and Tanaina into territory formerly held by Eskimos (Krause, 1885, p.99;

Swanton, 1908, pp.396, 414; de Laguna, 1934, pp.11, 156) [1962a:19].

\section{Archaeological Testing}

If the linguistic and ethnographic evidence above is correctly interpreted, Borden hopes to be able to find confirmatory evidence or tests for the archaeologist:

[Hypothesis that population shifts are archaeologically detectable:]

Similar population shifts at earlier periods should be de- 
tectable archaeologically,

[Instances of type of evidence to be found:] and they may account in part for some of the puzzling disrupted distributions along the western shores of North America [1962a:19].

Note here that Borden's words "in part" and "some of the" are evidence that this theory is not a simple migration theory. This will be reinforced in the $1969 d$ paper in which Borden as discussant reviews this complex linguistic and artifact distribution pattern with a variety of explanations. Other factors that Borden has stated for similar culture shifts have been climatic changes, glacial action or sea level changes.

Work to be Done

Borden summarizes the work still to be done to solve many of these puzzles:

The answers to these and many other problems still lie buried in countless sites along the more than 1,000 miles of the once populous and archaeologically almost unknown coast between the Gulf of Georgia and the Pacific Eskimo region. Obviously, at the present stage of research, historic reconstructions can be of the most tentative sort only and are likely to be subject to drastic revision as new data accumulate. Nevertheless, progress is being made. The historic perspective in the Pacific Northwest has been extended back some 9,000 years.

[Hypothesis of Gulf of Georgia a center of overlapping influence from multiple culture sources:]

Moreover, it is becoming increasingly apparent that during the last millennia B.C. the Gulf of Georgia region was a center of intense cultural elaboration where influences from Asia overlapped with those coming up the Pacific slope from the south.

[Re-statement of disconfirmation of Drucker test hypothesis:] The thesis that this growth was contingent on the prior development of maritime subsistence patterns in the Arctic and Sub-arctic is no longer tenable.

[Re-statement of south to north influence movement hypothesis:] 
On the other hand, it will not be surprising if future excavations should confirm and add to present indications that the Northwest Coast exerted a significant influence on the incipient stages and subsequent development of Eskimo-Aleut culture [1962a:19].

Borden's middle period papers begin this radiocarbon date-based chronology which corrects the early period theories based on typological similarities. In his recent papers, the quality and amount of interdependent data increases tremendous $7 y$, and the implications can be more finely drawn. 
CHAPTER XXVII

1961b FRASER RIVER ARCHAEOLOGICAL PROJECT, PROGRESS REPORT

Since the 1957 Notes and News, Borden has been publishing summaries of the evidence from $D j R i 3$. In this short report, published in the first number of the National Museum of Canada Anthropology Papers, he organizes the occupation and geologic levels into zones. In his 1965 paper, the first of my division of recent papers, Borden will re-group these archaeological zones into cultural phases.

The text of this Progress Report is summarized in a table of the "Stratigraphy and Chronology" of the site, a schematic drawing and photograph of the site, and photographs of chipped stone artifacts from zones $I, G$ and $E$.

The zones are alphabetical, beginning from the surface. The top cultural horizon ( $A$ and $C$ ) is interrupted in one portion of the excavation by an unsorted gravel layer (Zone $B$ ). The materials in zones $C$ and $A$ are still culturally undifferentiated. $A$ and $C$, six feet of sandy loam, yielded these artifacts:

[Sample size:]

The top horizon...yielded around 4,500 artifacts,

[Types of upper horizon artifacts:] including choppers, chipped knives, scrapers, small profectile points of various types, drills, ground slate knives, mortars and pestles, stone saws, adze blades, hammerstones, handmauls, microblades and polyhedral cores, beads, stone pendants, labrets, effigy pipes, as well as carved animal and human figurines. 
[Dating evidence:]

Charcoal obtalned from a sandy loam stratum (zone $C$ ) In the 1959 trench has just been dated by radiocarbon analysis at

2360 B.P. \pm 60 years $(S-112)$.

[Evidence to be examined:]

Other samples from different levels of the topsoil horizon are awaiting measurement.

[Hypothesis of earliest date of top horizon:]

The earliest cultural remains from this zone may go back about 3000 years (c. 1000 B.C.) $[1967 b: 1]$.

Zones $D$ to $F$ are "...some fourteen feet of gravels and coarse sands..." $(p .4)$.

[Hypothesis, repeated from Mathews in Borden 1960a, on deposition of sands and gravels:]

[The]...gravels and coarse sands [are] the fan deposits

of a small stream which is now extinct...[1961b:4].

This sterile zone D "... Is traversed by a seam of volcanic ash originating from period of last major activity of Glacier Peak" (p.6).

Borden gives the radiocarbon dates of this eruption, with an average age of about 6300 years. The pumice from the eruption is several feet below the top of $D$ zone.

[Dated evidence of zone E:]

A few feet deeper [than the pumice], the sterfle gravel is traversed by a dark culture-bearing stratum (zone E) which has a C14 date of $7350 \pm 150$ B.P. (S-61).

[Evidence of artifacts of zone E:] The inventory [no sample size] from this horizon consists of cobble choppers, scrapers, hammerstones, one abrader, chipped knives, and lanceolate profectile points...[1961b:4].

Below zone E, $F$ is another zone of "...sterile stream-lald gravels and coarse sands..." $[P, 6)$. Zones $G$ and $H$ are culture bearing deposits. $G$ is a sand deposit, H, stream-laid gravels. Borden's account of zone $G$ is a summary of the hypotheses and evidence presented in his DjRi 3 paper (1960a): 
[Description of zone $G:$ ]

At a depth of nearly twenty feet, the massive gravels are, in turn, underlaid by a thick deposit of sand (zone G),

[Mathews-Borden formation hypothesis:]

a sand-bar laid down by the Fraser when the annual highwater level of the river was some 60 feet higher than the mean high-water mark at present.

[Seasona] occupation hypothesis, repeated:]

These sands contain evidence of repeated seasonal occupation

[Evidence of dating:]

which, according to radiocarbon measurement, occurred 8150 \pm 310 years ago $(S-47)$.

[Artifact sample size, zone $G:]$

The sample of around 500 artifacts from this zone

[Evidence of artifact types from zone G:]

includes cobble choppers, crude scrapers, carefully shaped scrapers, a series of chipped leaf-shaped projectile-and knife-points, hammer-and anvi1-stones...[1961b:4].

Zone $H$ is described as "...stream-laid gravels traversed by thin culture-bearing silty strata" (p.6).

Zones $I, J$ and $K$ are the lowest levels of the site. Zone $I$ is the earliest culture-bearing level. This is what Borden writes:

Perhaps the most significant development of the 1960 season was the uncovering of another occupation level at a depth of $25 \mathrm{ft}$. and $5 \mathrm{ft}$. below the one dated at $8150 \mathrm{B.P}$.

[Cultural evidence:]

The cultural remains from this earliest level (zone I) consist of black ash, charcoal, stakeholes, scrapers, a small chopper, and one chipped projectile point...

[Evidence of plant remains:]

All three of the early horizons have produced charred pits of a wild cherry, among the oldest plant food remains in the Americas.

[New radiocarbon evidence, confirming "Westcoast Crossties..." time hypothesis:]

Dr. K. J. McCallum of the Radiocarbon Dating Laboratory, University of Saskatchewan, where all our C14 samples are being 
analysed, has just reported an age of $9000 \pm 150$ years for charcoal from the earliest occupational horizon at Fraser Canyon Site DJRi 3.

[Comparative statement:]

The finds from this level are the earliest securely dated cultural remains from western Canada [1961b:4].

This culture bearing stratum is on top of fine silty sands, zone

J. Borden's description includes an hypothes is of age:

[Evidence of stratum composition of zone $\mathrm{J}:$ ]

Massive ( $7 \mathrm{ft.}$ ) deposit of very fine silty sand

[Hypothesis of general time of deposition:] probably laid down during terminal cold sub-stage of last glaciation.

[Specific correlation hypothesis:]

May correlate in time with dates on wood samples obtained by

J. Armstrong from glacial deposits farther down river:

$\overline{\mathrm{L}} 321-\mathrm{C}: \quad 10,950 \pm 200$ years;

L 321-A: 11,450 \pm 150 years [1961b:6].

Beneath this is zone $K$,

Stream-laid (?) subangular gravel,

[Hypothesis of general time of deposition of zone $\mathrm{K}:$ ] perhaps dating from a warm interval preceding the last cold sub-stage $[1967 b: 6]$.

Borden concludes his progress report with an outline of the work to be done:

It is hoped that sufficient funds for the 1961 season will be forthcoming in order to make substantial progress in the following objectives:

(a) To expose more of the occupational zone, dated at 9000 \pm 150 years ago;

(b) To examine the sedimentary deposits underlying the 9000year-old level for evidence of even earlier occupation;

(c) To start excavations at the pit-house village located 100 yards down-river from $D f R i 3$. The remains at this settlement, which was inhabited until late in the nineteenth century, represent the last phase in 9,000 years of local cultural development [1961b:4]. 
CHAPTER XXVIII

1961C NOTES AND NEWS, NORTHWEST

These three consecutive issues of American Antiquity, and the 1963 book review, conclude what I have classified as Borden's middle period. The Notes and News issues are reports with new information and interpretation from his Fraser Canyon work. The 1962 book review elaborates a number of points he has already made about the five Mile Rapids area on the Columbia, with several sections of theoretical interest.

The two radiocarbon dates reported here were presented in the progress report, (1961b). I regarded the following paragraph as one of the most important in any Notes and News:

Robert J. Drake, Department of Zoology, U.B.C., is making a study of a large body of faunal remains which were excavated by Borden at a series of archaeological sites on the coast and in the interior of British Columbia over a period of 12 years. This study is supported by a grant from the National Science Foundation [1967c:274].

Because I found no later trace of this research, I asked Dr. Borden of its outcome. He reported that the results were incomplete and disappointing. They never reached the stage which would have permitted their meaningful correlation with the rest of the archaeological material. He was uncertain whether the condition of the material would allow a second analysis to be made (personal communication, 1973). If it is not possible, Borden's reports covering these first twelve years will be missing a most significant dimension. Without a statistical 
analysis of the remains from hunting, fishing, and food processing as they vary in these sites, many questions will go unanswered. 
CHAPTER XXIX

1962b REVIEW OF L. S. CRESSMAN...: CULTURAL

SEQUENCES AT THE DALLES, OREGON

Cressman's book is written in collaboration with David L. Cole, Wilbur A. Davis, Thomas M. Newman, and Daniel J. Scheans.

Borden's review relates to the subject matter of this thesis in two respects:

\section{EVIDENCE FROM THE REPORT}

First, the evidence and interpretations presented by Cressman and his associates constitute evidence for Borden's interpretation of his own archaeological evidence. Two passages are examples. This is the first:

Early parts of the monograph deal with the theoretical basis of the research and the development of research theory in the Northwest. In his usual masterful fashion, Cressman then describes and discusses the geographic and ecological background, the complex geological stratigraphy, and the ethnohistorical setting....Geological and cultural stratigraphy and a series of radiocarbon dates formed the basis for dividing the archaeological record into three main stages: Early, Transitional, and Late.... Radiocarbon measurements on a composite sample of charcoal, collected from throughout Stratum I, gave an age of $9785 \pm 220$ B.P. Cressman presents convincing reasons for suggesting that the earliest occupation started not less than 11,000 years ago [1962b: 437].

In the second passage, Borden comments on "...the importance of Cressman's major contribution" (p.438);

We are indebted to him for providing us with this unique 
cultural record of western North America, though much detail remains to be filled in. Already in his study on Klamath prehistory, but particularly in the present monograph, he has demonstrated that shortly after the termination of the Pleistocene, while hunters in most other parts of the continent were still stalking big game, people in the Northwest had developed efficient utilization patterns for the exploitation of riverine resources. The salmon area as one of the major food areas of North America, it seems, began to take shape at a much earlier time than anyone had anticipated. The possible implications of this early ecological adaptation both for the subsequent cultural development of the Northwest Coast and of areas even farther north are immense. In the concluding sections of the monograph, Cressman summarizes some of the hard archaeological facts that are beginning to emerge as the result of recent research and that no one with an interest in the prehistory and cultural development of North America can afford to ignore [1962b:438].

\section{IMPORTANCE TO BORDEN OF REPORT'S}

\section{CLASSIFICATION SYSTEM}

This broad sweep of Cressman's work is of vast usefulness to Borden. The second aspect of this review illustrates Borden's detailed attention to artifact attributes and classification. This attention is related to Borden's central theoretical concerns. Two of Borden's earlier hypotheses (1960a:116-117), predicted that the early assemblages at DJRi 3 would resemble the early assemblages from the FiveMile Rapids site, and would differ from the early Lind Coulee assemblages. Borden reads this publication by Cressman and his associates, relying on it for evidence to test and either confirm or disconfirm his hypothesis of similarity. It is not surprising then, to find that Borden's only critical comments reflect this interest.

Regarding the bone and antier artifacts, he has a number of questions: 
[Problem of identity of antler "beveled faces":]

The possibility that at least some of the so-called "beveled faces" were used as splitting wedges is perhaps too readily dismissed....

[Statement of problem of two bone artifacts:] The identification of two bone artifacts requires clarification. One is termed "Harpoon or Harpoon prong" (F1gs. 20 $\mathrm{C}, 40 \mathrm{a}, \mathrm{b}, \mathrm{C})$, and the other a "Composite Harpoon Prong fragment" (Figs. $20 \mathrm{~A}, 40 \mathrm{a}, \mathrm{b}, \mathrm{F}$ ).

[Borden's definitions of "harpoon" and "prong": ]

A true harpoon head is a detachable point usually provided with some visible means for the attachment of a retrieving line. A prong is fixed, such as the prongs of a leister.

[Borden's conclusion from definitions:]

The combination "Harpoon Prong" is contradictory.

[Borden's alternative identification of the second object:] If the latter of the above devices were somewhat larger, it could conceivably be the base of a lateral prong of a leister spear. The enlarged illustration of the fragment is misleading. Its actual size, particularly its narrow width, would seem to preclude such use. On the other hand, it could well be the base of the inward pointing barb that was lashed to the lateral prong of a leister [1962b:437].

[Problem of identification of the first object:]

Similar reservations may be raised regarding the identification of the small $(5 \mathrm{~cm}$.) barbed point as a "harpoon". It is suggested that the point in question was used like a Northwest Coast barbed harpoon head 1llustrated (greatly reduced) by Drucker. Such harpoon heads, however, were generally larger and much sturdier than the delicate little early point from The Dalles.

[Borden al ternate identification:]

Just what function this particular point may have had it is difficult to say. Perhaps it served as the barb on a composite fish-hook.

[Statement of significance of these two artifacts:] The precise use of these devices is less important than the fact that the early occupants of The Long Narrows knew how to carve multiple barbs on bone points [1962b:438].

Borden's criticisms of the classification of stone artifacts also reflects his desire to compare these assemblages with his Fraser Canyon material. In each case, he begins by clarifying the definition of 
terms as he uses or understands them.

[Cressman's definitions of "primary flaking" and "secondary flaking":]

The shaping of stone artifacts by percussion is consistently referred to as "primary flaking," while retouching by pressure is called "secondary flaking."

[Borden's definitions of these terms:]

As far as I know, the dressing of a "primary flake," whether by percussion or pressure is "secondary flaking" [1962b:438].

Now Borden discussed knives, blades and scrapers:

[Borden's statement of problem:]

No clear distinction is made between knives and scrapers.

[Consequence of problem:]

Unnecessary confusion arises from lumping together under the heading "Blades" both "bifacially worked blades" (normally called knives) and "blades" that are "flaked only on one face" (normally called scrapers).

[Basis of Cressman's distinction between knives and blades:] "This distinction," as explained here, "between knives and blades is primarily one of size, with the term knife being applied to small cutting tools."

[Question about this basis:]

Is such a distinction really desirable,

[Internal inconsistency:]

particularly since it is not consistently adhered to in this work?

[Evidence of inconsistency:]

Some "blades", for instance, are only $35 \mathrm{~mm}$. long (p. 48, type B 2), while "knives" may be up to $40 \mathrm{~mm}$. long (p. 50).

[Absence of evidence needed for cultural comparisons:] "Knives" and numerous other chipped artifacts of potential importance in establishing cultural relationships lack illustrations. Many drawings and photographs are excellent but others lack sufficient detail [1962b:438].

Borden deals with projectile point classification in a way that is reminiscent of his comments when he introduced the classification that he chose in reporting his survey of the Kootenay area (1956:86). [Projectile point variability and classification consequences:] 
The exuberant stone industries in the Northwest with their wide range of projectile point forms are a challenge to workers to develop their own classificatory system. Some have done so repeatedly.

[Consequences of multiple typologies:]

The resulting proliferation in point typologies makes it increasingly difficult to carry out comparative studies [1962b:438].

Borden does not deny the merit of the Cressman system, but the two statements expressing his reservations are central to the characteristics of sound classification. First Borden describes the system:

The present classification has considerable merit. Seven main types are discerned on the basis of the general outline of the edges of the point. Subdivisions of the main types in turn are made according to the form of the stem and the form of the juncture between the side and the stem.

[Borden's reservation concerning relative cultural significance of types and sub-types:]

The question arises as to whether some of the subtypes do not have greater cultural affinity and hence greater cultural-historical significance than some of the main types.

[Borden's reservation that types are grouped meaningfully:] It is certainly a misleading overslmplification to indicate without qualification that Type I points, which include forms ranging from simple bi-pointed leaf shapes to shouldered and barbed forms with varying stems, occur throughout the long occupation of the Five-Mile Rapids area (Fig. 21) [1962b: 438]. 
CHAPTER XXX

1962C NOTES AND NEWS, NORTHWEST

\section{EARLY HORIZON ARTIFACTS}

Borden reports that work during the 1961 season at $\mathrm{DjRi} 3$ added

a few artifacts to the small sample from the earliest horizon, "... several chipped artifacts, scrapers and one lanceolate point..." (1962c:

613). They excavated below this level:

The underlying deposits of silts, sands, and gravels are not cemented, but a test shaft excavated to a depth of 46 feet produced no indubitable cultural remains of greater age.

[Hypothesis that older cultural material is a possibility:] Since the Fraser valley was probably free of ice more than 10,000 years ago, the possibility of finding evidence of earlier occupation in this vicinity still exists [1962c:613].

\section{FOSSILIZED SALMON BONES}

Borden reports next his only direct evidence of salmon fishing in the canyon:

\section{Evidence}

Support for the assumption that these anadromous fish were the main attraction to the site even 7000 to 9000 years ago was provided by the discovery, in 1961 at a nearby locality, of fossilized midden deposits

[Hypothesis of age of deposits:] presumably of similar age, containing an abundance of salmon bones.

[Test of age hypothesis:]

The presence of charcoal in the same deposits will make it possible to check the age estimate [1962c:613]. 
Subsequent Developments

This midden is not mentioned in more recent works, so I asked Dr. Borden about the evidence. He handed me a chunk of the material and told me about the problem. All chemical processes that had been used to isolate charcoal from the matrix had dissolved the charcoal as we11. In a more recent communication (1974), he reported that a chemist from the University of British Columbia was using a new process, with hope of success. A small sample for possible dating is now available for dating (July 1974). "It's all black matter, but the chemist is not certain whether it is all charcoal. He could burn it and find out and then it would be gone!" (pers. com.) Borden will submit it for dating.

Borden's next hypothesis is an instance of his view that cultur-

al elaboration depends on a sound economic base:

Salmon apparently were the main food staple throughout the long occupation of the locality

[Hypothes is of economic base necessary for cultural elaboration:]

and provided the economic basis for a rich efflorescence of culture in later periods [1962c:673].

\section{RECENT CULTURAL ZONE}

\section{Evidence}

He gives us new information from the most recent cultural zone:

[General statement of culture change:]

Preliminary analysis of last sumer's finds from the topsoll zone revealed significant indications of culture change.

[Stratigraphic evidence of artistic objects:] Thus, disc beads, as well as pendants and zoomorphic carving in steatite, apparently antedate the advent of ground slate knives, which, according to available radiocarbon dates were appearing in this part of the valley around $400 \mathrm{~B} . \mathrm{C}$. 
[Hypothesis of early date of Northwest Coast art:]

The findings from the Fraser Canyon and evidence from sites at the mouth of the river suggest that the beginnings of Northwest Coast art go back at least to the early centuries of the first millennium B.C. [1962c:613].

Another objective of the season had been to work at the pithouse site, called Esile'u (DjRi 5). A few early contact goods show this to date to the early 19th century.

\section{Subsequent Developments}

The 400 B.C. date above comes from a site at Hope Flat. Subsequent work showed that ground slate goes back to the early Eayem phase (Borden pers. com., 1974). 
CHAPTER XXXI

1963 REVIEW OF RUTH GRUHN: THE ARCHAEOLOGY

OF WILSON BUTTE CAVE...

Borden's review for American Antiquity illumines his analysis of environmental archaeology. He calls it a "...methodological approach..." (Borden 1965:124), not a theory nor an hypothes is. Borden states the environmental approach as follows:

...since prehistoric cultures can be fully understood only in their ecological context, it is necessary to study in detail the relationships of each culture with its environment by making Inferences from both the cultural and natural remains [p.124].

Borden's critique is based on the evidence of Gruhn's study, which he examines within her own terms, her own "methodological approach". On the basis of Gruhn's data leading to evidence of climatic variations and faunal and vegetal changes, Borden suggests an alternative interpretation of the dating of the various strata to one of Gruhn's. Both alternatives are tentative since this is a pioneering study in the area.

A seeming paradox in evidence indicates an increase in waterfowl at the time when the climate was increasingly dry and hot. Borden suggests that concentrations of formerly dispersed waterfowl might have found refuge at "...Star Lake near Wilson Butte Cave..." (p. 125).

Borden's summary evaluation shows his own interest in establishing interlocking chronologies of the various areas, and an appreciation of the environmental archaeologist's approach, though I do not 
believe he sees himself primarily within that tradition:

On the whole, the colorful pageant of changing climate, biota, and cultures unfolds with fascinating clarity and fullness. Local events are astutely linked to developments elsewhere and thus shed fresh light on the prehistory of three major, adjacent culture areas: the Great Basin, the Plateau, and the Plains. Prior to the Wilson Butte Cave project, our knowledge of Idaho culture history was slender indeed. Thanks to Gruhn's meticulous and thorough research, Idaho suddenly assumes a prominent and important place in the archaeo1ogy of western North America [p.125]. 
PART III

RECENT PERIOD

Reproduced with permission of the copyright owner. Further reproduction prohibited without permission. 
CHAPTER XXXII

RECENT PERIOD PAPERS

The Skagit River At7atl paper (1969b, Chapter XXXVII), was originally written in 1959, and revised for publication during this time. It is an analysis of Northwest Coast artistic motifs, mythology and archaeological traditions. It is unique, and could belong to any time period of Borden's career. The 01d Musqueam report (1969a, Chapter $X X X V I)$ is similar to earlier reports.

\section{CHARACTERISTICS}

All of the other recent papers share new characteristics. First, early questions, answered in the middle period with the new radiocarbon technology suggest even more complex questions and problems. This complexity is the hallmark of the recent papers. Clifford Geertz cites Levi-Strauss in a discussion of complexity in scientific explanation:

...Levi-Strauss remarks that scientific explanation does not consist, as we have been led to imagine, in the reduction of the complex to the simple. Rather, it consists, he says, in a substitution of a complexity more intelligible for one which is less... [Geertz continues to discuss social sciences specifical1y:] Scientific advancement commonly consists in a progressive complication of what once seemed a beautifully simple set of notions but now seems an unbearably simplistic one [Geertz 1974: 19-20].

Because the process of retroduction proceeds from the phenomena to the hypothesis, it is not surprising that the recent period is the most complex. Borden now uses vastly more complex evidence from many more discipines. Analyses of glaciers, volcanoes, pollen, peat, and lake 
sediments, deltaic formation, terrace cutting, sedimentation, ice dam ponding, sea level changes, and isostatic rebound all become evidence which Borden must synthesize and accommodate within one coherent framework.

Second, these many disciplines can correct one another. Radiocarbon techniques led to a rapid expansion of all branches of Quaternary research. Borden found some of the answers given him by geologists to be quite unsatisfactory as explanations of the archaeological data. Chapters XXXIII-XXXV, XXXVIII and XLII (1965, 1968a, 1968b, 1969c, and 1972) are a sequence of papers in which Borden tries to develop a reasonable explanation for the presence of a pebble tool complex within five deep terraces 2.5 miles downriver from the Milliken site DjRi3. Less than a gram of carbon was collected in these terraces, so radiocarbon dating was not possible. Borden "wrote his own geology" in these chapters, with the consequence (1972, Chapter XLII), that geologists are now re-writing their geology to fit with Borden's evidence and theory. This one sequence of papers illustrates the interdependence of different disciplines in this recent period. This series shows that there are no impermeable boundaries in archaeology and archaeologi.cal theory.

The third characteristic of the recent papers is the definition and use of "phase", the basic archaeological unit described in the summary papers of 1968a, Prehistory of the Lower Mainland (Chapter XXXIV), and 1970, Culture History of the Fraser Delta Region (Chapter XL). Enough evidence is available to distinguish a commonality among slightly varied assemblages, and enough dates to assure that they share a common 
time-span. Some of Borden's phases are quite extended in time, lasting as long as 1500 and 2000 years (for the Milliken, Mazama and Eayem phases). Others are shorter, lasting as long as 1000 and 400 years (for the Marpole, Emery, Esilao, and Whalen II phases). Both cultural anthropologists and archaeologists continue to discuss "...social equivalents..." (Willey and Phillips, 1958:48) of a "phase" (see Abbott, 1972). Some of the work of environmental archaeologists leads to changing the designations of some "phases" to "activity-specific sites". Borden, in 1974, thought it possible that Whalen I and Locarno Beach may have been such "activity specific sites" (see the discussion of the Locarno Beach phase in 1970, Chapter XL). Thus, designation of a phase is an hypothesis for further testing. Until regular patterns in culture change can be observed ethnographically, and operational rules formulated, designation of phases will still be arguable in terms of anthropological theory.

A fourth aspect of this period is Borden's use of the term "tradition" to indicate a few (three, in 1969c, Chapter XXXVIII) general patterns of similarity among a 11 western New World sites. Borden's Crossties paper in his middle period was his first publication using extensive evidence outside his immediate area.

After Borden assembled the "Notes and News, Northwest" for American Antiquity, he served four years as its Associate Editor. From sixteen assistant editors, he received archaeological information from all of the Western Hemisphere. It seemed to me that it was precisely because Borden had this new source of information, that he could see phenomena that required new and broader explanation. I asked Borden if this was the case. He responded: 
Oh, yes. It gave me a very comprehensive notion; I was right at the leading edge. I was aware of some of the results before they appeared in print,--in fact some never appeared in print [pers. comm., July 20, 1975].

(At Borden's suggestion, the name "Notes and News" was changed to "Current Research", indicating the emphasis that he preferred.)

Because of this scope of evidence, he asked other questions, still centered on the chronology of prehistory in the New World. His paper on "Early Population Movements from Asia into Western North America" (1969c, Chapter XXXVIII) involved evidence from Siberia, as does his unpublished paper read in Siberia in 1973. (see Chapter XLII). Borden's hypotheses about traditions embrace evidence from scholars on both sides of the Pacific.

Fifth, and characteristically, he asks questiors about the languages spoken by those whose cultural remains he studies. His 1970 unpublished paper (Chapter XLII) was a "trial balloon", a re-integration of evidence from archaeology, glottochronology and glaciology, similar in scope to the early paper (1954b, Chapter XIV). The archaeological evidence available in the 1970's makes a big difference in the explanations, however. When Borden was discussant at a symposium on Northwest Coast archaeology (1969d, Chapter XXXIX), he stated one aspect of the linguistic, and archaeological problem this way, "Somenow, someday, we will have to account for the isolated presence of the Tsimshian so far to the north, so remote from their nearest linguistic kin..." This is an anomaly that Borden feels needs an explanation. To do an adequate prehistoric chronology, Borden holds that all of the aspects of culture must be considered.

$$
\text { Sixth, and explicitly in the 1969d discussant paper (Chapter }
$$


XXXIX), is Borden's insistence that the evidence is primary, and the theory is derived from it. This is the only paper with the give and take of a live argument. I have labelled it a "tour de force". Borden takes the evidence from the papers he is discussing, and sets that evidence in a context as wide as his knowledge. But in addition to this, he discusses the use of "models" as a theoretical tool of archaeology. He correctly states that a model is not properly used as a chosen point of view, but should be used to fit or illustrate the complex circumstance or evidence that has been noted. Borden's statements about the "evidence speaking for itself" tend to over-simplify the relationship of evidence and theory, but his critique of the use of models is an accurate one, even though this is not a concept that Borden uses in his own work. (See the Summary and Conclusion of this thesis, Chapter XLIII, for an extended evaluation of the function of models in Borden's discussion of the concept.) 


\section{OUTLINES OF PAPERS}

1965 Radiocarbon and Geological Dating of the Lower Fraser Canyon Archaeological Sequence (Chapter XXXIII)

A. Evidence:

1. Material culture (radiocarbon dated), from Milliken and Esilao sites.

2. Evidence of changes in Fraser River, glaciers, ocean level and land elevations (in part based upon radiocarbon dating).

3. Specific, local, geological formations at Milliken and Pasika sites.

4. Culture changes from Milliken and Esilao, now in named phases.

5. Mazama ash identified (not Glacier Peak, former hypothes is disconfirmed).

B. Purpose: to present to a Radiocarbon and Tritium Dating Conference the evidence of an archaeological sequence from three Fraser Canyon sites. (A companion paper, 1968b, Chapter XXXIV, is based on much the same evidence, and provides an easier introduction to this material.)

C. Steps in Retroduction and testing:

1. Explain simple Pasika technology (compared with dated components at Milliken, 2.5 miles away).

2. Establish relative dating of Pasika, Milliken phases.

3. Formulate hypotheses of earliest ice-free time for habitation, and of conditions suitable for 350 feet of deltaic deposits, from evidence of terrace formation and cutting, and glacial intervals. 
4. Correlate these, perhaps in Everson Interstade, with Sumas Stade, postulated ice dam below the sites, in time of terrace cutting.

5. Correlate river profile at Milliken (also with deltaic or ponded deposits).

6. Uetermine the time and rate of terrace cutting from Methods 15.

7. Correlate the terrace cutting with deposition of artifacts, their distribution and wear.

8. Suggest time of occupation, with tests for future work.

9. Suggest extra-areal origin of Milliken phase. 


\section{8a Prehistory of the Lower Mainland (Chapter XXXIV)}

A. Evidence: (summarized at the most general level)

1. Geological and climatic conditions over the last 18,000 years.

2. Ethnographic studies.

3. Geological description of South Yale terraces, of Milliken and other canyon and delta sites; changes in stream flow.

4. Artifacts by phases.

5. Archaeological evidence from sites in other areas.

6. Radiocarbon dates.

7. Obsidian or other raw material sources.

8. Vegetal remains where available, also faunal where found.

B. Purpose: A general interpretation of all known excavated remains from Fraser Canyon to the delta, for a general audience, therefore a good introduction to the preceding paper.

C. Steps in Retroduction and testing:

1. Correlate radiocarbon samples and assemblages in Fraser area to get phases (defined in this paper).

2. Explain South Yale artifact deposition to fit evidence 2-5 above.

3. Show how these artifacts relate to other phases.

4. Explain \#: 5, 6, and 8 as instances of trade or influence.

5. Suggest relation of general climate shifts to culture.

6. Suggest local drying or renewal of streams in relation to phases.

7. Reason from cherry pit seasonality to fishing economy.

8. Describe similarities and differences of all phases, assemblages. 
1968b A Late Pleistocene Pebble Tool Industry... (Chapter XXXV)

A. Evidence:

1. Geological evidence: (a) from geologists, and (b) from Borden.

2. New geological interpretations, 1966, contrary to Borden's 1965 hypotheses .

3. Anomalous evidence from (a) dated Milliken sites, (b) river levels at South Yale and Milliken, and (c) terrace levels.

4. Two newly discovered, higher terraces.

5. 1218 specimens of tools, illustrated, counted, broken tools.

6. Study of tools for used edges, classification.

7. Milliken technology.

8. Peat bog dates, and dates on maritime shells in Georgia Strait, and Puget lowland.

9. Evidence of deposition and wear of artifacts in and on terraces.

B. Purpose: to present to a conference on early man in western North America, hypotheses to explain the evidence from the Pasika phase.

C. Steps in Retroduction and testing:

1. Develop a new geological theory on the basis of archaeological evidence.

2. Analyze and classify tools from Pasika.

3. Explain the uses of tools, and the uses of the Pasika site.

4. Test pebble tool use by checking correlation between adze blade appearance and pebble tool disappearance.

5. Contrast Miliiken technology with Pasika technology.

6. Argue by analogy from nearby dated Puget Sound sites.

7. Present two distinct and complex arguments for artifact deposition. 


\section{9a Excavations at 01d Musqueam 1967-68 (Chapter XXXVI)}

A. Evidence:

1. Sample size: 1554 artifacts.

2. New radiocarbon date: $2350 \pm 80$ B.P.; earliest reliable date for Marpole.

3. Hearths and house floor deposits.

4. Information on burial practices, raw materials, food remains, settlement patterns, structural details of houses.

5. Antler comb.

6. Dentalium shell necklace in burial (other dentalia too).

7. Pebble tool industry under Musqueam Village deposit.

8. Geological evidence of underlying raised beach.

B. Purpose: to inform Archaeological Society of results of salvage in which they played an important part.

C. Steps in Retroduction and testing:

1. Classify this as a Marpole phase from Evidence \#1.

2. Emphasize, from \#2, that this is a reliable date (unlike another one).

3. Interpret, from \#3, that this is a winter village site.

4. Correlate evidence \#5 and \#2 with unnamed data to show comb as earliest on the coast.

5. Explain from evidence \#7 and \#8, that deposit could be 8000 or 9000 years old. 


\section{9b The Skagit River Atlat1: A Reappraisal (Chapter XXXVII)}

A. Evidence:

1. Description of atlati artifact, with illustrations.

2. Photographs and descriptions of other Northwest Coast sculptured or painted figures.

3. Raw material of atlatl and its other uses in the area.

4. Form/function of the Atlatl.

5. Evidence of age of artifact.

6. Ethnographically described myths concerning similar figures.

7. Significance of sisuit?.

8. Radiocarbon dated atlatis on Northivest Coast.

B. Purpose: to analyze the style and meaning of the carving, determine its probable provenience, and the importance of the carving to its use.

C. Steps in Retroduction and testing:

1. Disprove earlier position held by Taylor and Caldwell that this is not Northwest Coast in origin.

2. Compare Evidence \#1 and \#2 by elements or motifs.

3. Correlate \#3, \#4, \#6 and \#7 to suggest form, function, and significance.

4. Suggest dates from the style, and evidence \#2, \#5, and \#8. 
1969c Early Population Movements from Asia into Western North America (Chapter XXVIII)

A. Evidence:

1. Geological, glaciological, crimatic limits of population movement (Beringia dates, for instance).

2. Geographic features allowing population passage (intermontane corridor).

3. Dated microblade sites, west of Rockies in the New World, and in Siberia.

4. Spatial distribution and linguistic relationships of indigenous groups.

5. Distribution of earliest sites (west of Rockies).

6. Milliken assemblage, Five Mile Rapids, one Wilson Butte Cave component.

7. Pasika Assemblage.

B. Purpose: To integrate or explain archaeological evidence from 01d and New World sites to show possible times and routes of people from the 01d to the New World, and within the New World, for anthropologists.

C. Steps in Retroduction and testing:

1. Organize or combine assemblages and phases by similarities rather than by diversity, to show broad traditions.

2. Place these similar traditions on a space/time continuum to show population movement.

a. Microblade users=Early Boreal, with rate, route and time of movement. 
b. Protowestern tradition, with Milliken, Five Mile Rapids and Wilson Butte Cave as illustrations, and San Diguito as test.

c. Pebble Tool tradition, with Pasika as illustration.

3. Correlate with language groups (different from 1954b, and 1974).

4. Suggest places to look for confirming tests. 


\section{9d Discussion of Papers Presented During the Symposium... (Chapter} $X X X I X)$

A. Evidence:

1. Mitchell's paper.

a. Cites Borden's work as an illustration of dislocation model.

b. Statement of intent to favor continuity model.

2. MacDonald's paper.

a. Use of co-tradition mode1.

b. Evidence of change through time in Tsimshian assemblages.

c. Evidence showing Tsimshians did not come from the Interior.

3. Borden's additional evidence (as discussant).

a. Uses both continuity and discontinuity, from differing evidence.

b. Drucker's sub-areas on Northwest Coast.

c. Discontinuities in Fraser delta sites.

d. Marpole and Locarno Beach assemblages.

e. Glacial limits to population.

f. Foods available on the coast and the interior.

g. Changes in population growth (slow early, rapid later).

h. Language distribution on the coast.

B. Purpose: to discuss hypotheses of continuity of development on the Northwest Coast, the use of models in archaeological research, and to present alternative view.

c. Steps in Retroduction and testing:

1. Disclaim holding to a particular model \#1a, \#3a, above. 
2. Caution against using model as an "oath of allegiance", (\#lb).

3. Compare co-tradition model with Drucker's sub-areas.

4. Interpret some Tsimshian assemblages as similar to Marpole, perhaps a northward diffusion; nothing like Locarno Beach.

5. Propose southern origin of Tsimshian from \#4 above, Evidence $\# 3 h$.

6. Explain evidence \#e, $f, g$ as process of coastal adaptation. 
1970 Culture History of the Fraser-Delta Region: An Outline (Chapter XL)

A. Evidence:

1. Early radiocarbon dates from Glenrose Cannery Site.

2. 15 other radiocarbon dates from delta sites.

3. Ethnographic evidence.

4. Assemblages, organized into phases with diagnostic traits, with some photographs and descriptions.

5. Spore analysis.

B. Purpose: To present an expanded presentation of the Fraser deita phases (most known since 1950), with illustrations and charts to document the hypotheses (In this chapter I have included some new evidence and hypotheses added by Borden up to June 1974).

C. Steps in Retroduction and testing:

1. Divide culture history into five phases by radiocarbon dates and diagnostic traits.

2. Correlate tool types with ethnographically known tool uses.

3. Suggest hypothes is of weal th and stratified society at Marpole time to explain artifacts (bead caches and skull deformation), and ethnographic information.

4. Extrapolate pre-Stselax phase to fill a time-gap, characterized by the introduction of traits found frequently in Stselax phase, but not known earlier (since confirmed).

5. Suggest the weaving of mountain goat wool to explain evidence of pollen from mountain vegetation in lowland site. 
1972 New Radiocarbon Dates From the Yale Area of the Lower Fraser River Canyon, British Columbia (Chapter XLI)

A. Evidence:

1. Three lake bottom cores.

2. Three radiocarbon dates from these cores.

3. Pollen samples from cores.

B. Purpose:

1. To date earliest possible habitation in Fraser Canyon near South Yale terraces and Milliken sites.

2. To confirm Borden's hypotheses of Pasika phase as much earlier than Mathews' and Armstrong's geological hypotheses allowed.

C. Steps in Retroduction and testing:

1. Use standard core sampling methods.

2. Interpret radiocarbon dates to mean that this area was ice-free since before 11430 B.P.

3. Disconfirm Mathews' hypotheses (the canyon itself may not have been habitable, but for a reason other than glaciers).

4. Suggest that the ice Mathews' postulated was probably Cordi1leran ice, not Sumas ice. 


\section{0 and 1973 Unpublished Papers (Chapter XLII)}

A. Evidence:

1. 1970 unpublished paper.

a. Glottochronology of Swadesh.

b. Archaeological evidence both from the coast and the interior.

c. Glaciological evidence from Southwestern Yukon Territory.

2. 1973 unpublished paper.

a. All early sites in New World.

b. Other relevant evidence from glaciology, etc., except linguistics.

c. Siberian data little used.

B. Purposes:

1. 1970 paper: a trial balloon to suggest new linguistic affiliations to archaeological traditions.

2. 1973 paper: a new account of peopling of the Hew World, for the Soviet Academy of Sciences Conference on the Bering Land Bridge.

C. Retroduction and testing:

1. For 1970 paper: Correlate all hypotheses that fit all of the evidence above (similar to 1954b) with glottochronology added. (My account of this paper adds information up to 1974 as Borden would revise this paper.)

2. For 1973 paper: explain in a summary retroduction, all the new evidence as in 1969c, but with expressed need for caution in use of siberian data. 
CHAPTER XXXIII

\section{RADIOCARBON AND GEOLOGICAL DATING \\ OF THE LOWER FRASER CANYON \\ ARCHAEOLOGICAL SEQUENCE}

\section{BACKGROUND}

This paper was presented at the Sixth International Conference on Radiocarbon and Tritium Dating, and is published in its Proceedings. One of Borden's footnotes cites another paper of his in a National Museum of Canada Bulletin in press, called "Lower Fraser Canyon Prehistory". This was expanded, and appeared later, as the next paper in my sequence, "Prehistory of the Lower Mainiand (Borden, personal communication, 1974).

This paper tells us of a new site, DjRi 7 , the South Yale or Pasika site. It also treats the Fraser Canyon site, DjRi 3, now cal.. led the Milliken site, and DjRi 5, the Esilao Village site, as a sequence of named phases. A number of older hypotheses are disconfirmed, and new ones proposed.

\section{I1lustrations}

In the paper is a topographic map of the Fraser area in which the sites are located. Correlated with a photograph showing the stratigraph$y$ of site DjRi 3 is a chart with zones, dates, and phases. Another chart of the "Geoarchaeological Chronology of the Lower Fraser Canyon" gives dates, climatic conditions, and cultural phases of the South Yale ter- 
ing the geological evidence to the evidence from the artifacts and or other cultural material at the sites. He concludes with alternative possibilities about the "eventual fate of the cobble tool folk" (p.177) from the South Yale terraces, and their relationship with the earliest occupants of the Milliken site.

\section{Basic Argument}

The broad scheme of his argument is this: The assemblage in the South Yale terraces is very different from, and more 1 imited technologically than any at the Milliken site. Borden concludes that the technologies just $2 \frac{1}{2}$ miles apart could not have been co-existent without technological borrowing. Thus, from the radiocarbon dated evidence at Milliken and Esilao Village and the geological formations in which they are found, we may be able to infer the minimum date that the South Yale Terraces were occupied, and from geological information we may be able to infer the maximum occupation time. The variables, which include changes in the Fraser River, in glaciers, in ocean level, and land elevations form a termendously complex picture.

Borden begins by stating the subject of the paper:

Radiocarbon age determinations are greatly facilitating the establishment of local and regional archaeological chronologies in the Pacific Northwest. This paper will deal with the dating of a cultural sequence in southwestern British Columbia $[1965: 165]$.

He describes the site locations and their general descriptions:

The Lower Fraser Canyon Archaeological Project...concentrated for flve years (1959-63) on three sites on the left bank of the Fraser River in the vicinity of Yale.... Two sites, Milliken (code:DjRi 3) and Esilao Village (DjRi 5), are 10cated in the narrow gorge of the canyon proper while the third, the South Yale site (DjRi 7), is situated 2.5 miles 
races and of the Fraser River between and including the South Yale and Milliken sites. More recent versions of these illustrations accompany Chapter XXXV of this thesis, 1968b.

\section{Amount of Evidence}

This paper is characteristic of the recent period of Borden's work because of the vast amount of evidence from a variety of disciplines that must be reconciled by his theories. The amount of evidence available by 1965 is in contrast with the early 1950's when there was minimal evidence. In the middle period of Borden's writings there was a manageable amount of evidence. However, the wealth of evidence does not result in a tidier or more final picture, because that evidence is not easily reconciled. Borden will try various approaches as he formulates his hypotheses. In the face of conflicting evidence, Borden's characteristic response, explicitly stated in this paper, is to formulate hypotheses anyway. Only when the consequences of the evidence are clarified can new evidence correct old errors.

\section{The Sites}

After an introductory description of the site areas, Borden reports on the Milliken site. Some of the material is familiar; some is new. Since artifacts have been found in all the South Yale terraces where no radiocarbon evidence has been found, the next step in his presentation is to examine the geological evidence relating to the age of the terrace formation at the South Yale site. Less than a gram of carbon was collected there, too little for testing (Borden, personal communication, 1973). Borden proposes a long series of hypotheses relat- 


\begin{abstract}
downstream on river terraces in a somewhat wider part of the valley.... In this restricted region a long and nearly continuous archaeological sequence is being developed. Nine millennia of this sequence are dated by radiocarbon. An additional cultural phase,
\end{abstract}

[Hypothesis of time sequence:]

probably antedating the others, may have to be added on the basis of cultural and geological evidence indirectly supported by C14 dates [1965:165].

\title{
II. MILLIKEN AND ESILAO VILLAGE SITES
}

The underlying geological trough formation at the Milliken site is described essentially as Mathews does in Borden, 1960a. Borden tells about the deepest level of the excavation:

Excavations at the Milliken site...were carried down to a maximum depth of 46 feet when further penetration was halted by underground water. The lower 20 feet were purely fluvial deposits,

[Hypothesis of cause of variation in sediment consistency:] the different consistency of successive beds of sediment apparently reflecting varying rates of flow of the river [1965: $165]$.

\section{Milliken Phase}

Zones $I, H$ and $G$, described in the progress report, $(1961 \mathrm{~b}: 4,6)$ earlier, are now grouped together as the Milliken phase. The site and the phase are named for August Milliken who discovered the site and called it to Borden's attention.

This phase, as indicated on the accompanying geoarchaeological chart..., began during the cool humid conditions of the Early Postglacial and continued to the beginning of the Hypsithermal when the climate was becoming considerably warmer and drier (Heusser, 1960) [Borden 1965:168].

I regard each phase as an hypothesis, since designating a phase groups a collection of assemblages and says in effect, "These are sim- 
ilar enough to represent one culture or life-way and its variations, rather than many cultures or life-ways".

Two radiocarbon dates have been determined from these zones.

Zone I has been dated $9000 \pm 150$, and Zone $G$ at $8150 \pm 310$.

Zone I is covered by about three feet of cemented angular gravels traversed by thin layers of Silt (Zone $\mathrm{H}$ ). The gravels represent small slides of talus, while the silt strata are fluvial. The presence of cultural material in the silt

[Hypothesis of seasonal occupation:]

suggests a periodic lowering of the water level permitting seasonal occupation.

[Stratigraphic evidence and interpretation:]

This zone of alternating gravel and silt is overlain by a substantial bed of fluvial sand (Zone $G$ ) which attains a thickness of over three feet in places. Numerous artifacts, an abundance of lithic detritus and several hearths again

[Hypothesis of seasonal occupation:] suggests that this sand bar was seasonally occupied... The presence in Zones $I$ and $G$ of numerous charred pits of a wild cherry (Prunus demissa), a fruit which ripens in late summer, indicates

[Hypothesis of specific time of seasonal occupation:]

that seasonal camping at the site occurred after the flood crest had subsided $[1965: 165,168]$.

The similarity in site usage tends to confirm Borden's estimate that this is one culture. At least it is not disconfirmatory. Later publications discuss the similarities of the artifacts in the various zones.

Borden next gives one of the key time-river elevation correlations that he will use in dating the South Yale terraces:

The fluvial sands of Zone $G$ mark the last transgressions of the river at the site. In the ensuing eight millennia the mean flood stage at this locality has dropped about 70 feet...[T] he elevation of the surface of Zone $G$ is ca. 260 feet above sea level [1965:168]. 
Mazama Phase

Borden continues with evidence about the newer deposits at the Milliken and Esilao Village sites. Cultural Zones D and E are grouped into one phase, with new geological evidence and interpretation.

[Evidence of matrix of Zones $D$ and $F:$ ]

Overlying Zone $G$ is a massive bed of poorly sorted subangular gravels and coarse sands, the fan deposits of a small stream that once flowed down the hillside to the east. The exposed part of the fan has a maximum thickness of 12 feet.

[Stratigraphy of cultural Zone E:]

A charcoal stained cultural stratum (Zone E) traverses the fan deposit about midway and divides it into an upper (D) and a lower zone (F).

[Dating of Zone $E:]$

Zone $\mathrm{E}$, the cultural layer, has a C14 date of $5400 \pm 150 \mathrm{~B} . \mathrm{C}$.

[Mazama hypothesis, imp]icitly disconfirming Glacier Peak hypothesis:]

Also present in the fan gravels, in the upper part of Zone $D$, is a seam of volcanic ash originating from the explosive eruption of Mt. Mazama (Crater Lake), Oregon.

[Dating of Mazama ash:]

C14 dates on organic materials associated with Mazama ash at various sites in the Pacific Northwest average around 4750 B.C. [1965:168].

[Footnoted reservation about this date:]

This date may be too recent since in a number of instances the ash associated with analyzed C14 samples was no longer in primary position. L. S. Cressman, Univ, of Oregon. Personal communication, June 1965 [Borden 1965:178].

[Hypothesis dating end of gravel deposition:]

The depth of the ash seam relative to the surface of Zone $D$ at the Milliken site suggests that the build-up of the gravel fan ceased prior to 4000 B.C.

[Hypothes is of immediate cause of deposition end:]

The implication is that the small stream which once watered the site failed at about the same time,

[Hypothesis of general climatic cause of stream failure:] possibly because of continuing aridity and progressive desiccation during the Hypsithermal period [1965:168]. 
Borden groups two cultural levels into one phase. The upper level is not directly dated, but indirectly, through the hypotheses above, since it is on top of the fan gravels.

Cultural materials from Zone $E$ and from the surface of the gravel fan have been assigned to a cultural phase designated Mt. Mazama, because they appear to straddle the time of this volcano's eruption [1965:168].

Radiocarbon dating shows a long period of relative disuse of this site after the Mazama phase:

C14 dates on charcoal from strata immediately overlying Zone $D$ indicate that no appreciable amount of geological sediment was deposited on the gravel fan and the Mazama phase artifacts resting on its surface for some 3000 years, that is to around 1000 B.C. In this protracted interval, the site was apparently visited only rarely $[1965: 168,170]$.

\section{Eayem Phase}

From Esilao Village is evidence of occupation during this time.

Borden had quoted the next phase name from Duff in his 1960a paper.

The long gap in the archaeology is filled in large part by finds at the nearby Esilao Village site, where the earliest exposed cultural remains are those of the Eayem phase which has a series of radiocarbon dates ranging from about 3600 to 2400 B.C. The thickness of Eayem phase deposits overlying the dated strata suggests that the phase may have continued until the early centuries of the second millennium B.C. [1965: 170].

Borden's chronology chart gives the three dates of the Eayem phase:

$5490 \pm 500$
$4880 \pm 180$
$4420 \pm 160$

[1965:169].

\section{Baldwin Phase}

The next phase in the sequence, the Baldwin phase, is represented at the Milliken site. Borden's description shows the inter-relation of 
archaeological and geological-climatic evidence. Jim Baldwin, a student of Borden's, was killed in a mountain-climbing accident (Wayne Suttles, pers. com., 1973).

For data on the Baldwin phase, the next in the sequence, we must return to the Milliken site.

[Evidence of type of deposition:]

Here the $f$ an gravels of Zone $D$ are overlain by wind-blown sandy loam and boulders from the talus slope.

[Correlation with climatic periods:]

Deposition of the aeolian sediment apparently began with the onset of modern climatic conditions at the end of the Hypsithermal around 1000 B.C.

[Stratigraphic and radiocarbon correlations:]

Two charcoal samples from near the bottom of the sandy loam were dated to the ninth century B.C., thus providing a check on the time of the climatic shift and on the time when the small stream which had failed during the Hypsithermal began to flow again.

[Dating near the top of the Baldwin deposit:]

A C14 date of $410 \pm 60$ B.C. on charcoal from the same deposit may only slightly predate the end of the Baldwin phase, which is one of the richest in the sequence [1965:170].

\section{More Recent Phases: Skamel, Emery, and Esilao}

Borden's text generalizes about the phases after the Baldwin phase, but the chart names them and correlates the radiocarbon dates and the sites. where these materials are found. This section illustrates the problem of dating pit house sites, where the mechanical mixing of different time and culture periods has to be carefully evaluated. An intrusive burial at the top of the Milliken site probably indicates that this site was last used as the burial ground for Esilao Village. This is how Borden summarizes the later material:

Following Baldwin are at least three additional phases, bringing the culture history right up to the nineteenth cen- 
tury. Only two radiocarbon dates at 40 B.C. and A.D. 1390 respectively are presently on hand for these later stages. Further C14 dates are needed before chronological detalls for the remainder of the sequence can be worked out [1965: $170]$.

From the chart (page 169), there is this information:

\begin{tabular}{|c|c|c|}
\hline Skamel phase & at Esilao Village & dated $2000 \pm 120$ B.P. \\
\hline Emery phase & $\begin{array}{l}\text { at Milliken and } \\
\text { at Esilao Village }\end{array}$ & \\
\hline Esilao phase & $\begin{array}{l}\text { at Milliken and } \\
\text { at Esilao Village }\end{array}$ & dated $540 \pm 100$ \\
\hline
\end{tabular}

The date for the Esilao phase appears to be the beginning of the phase as Borden charts it. That date appears again, as A.D. $1380 \pm 100$ on the photograph showing the intrusive burial at the Milliken site ( $p$. 167). The cultural remains of these phases are described in some detail in Borden's 1968 a paper.

\section{SOUTH YALE SITE}

\section{Background}

Now Borden turns his attention down river to the South Yale site. He begins with the hypothesis that this site represents an earlier occupation than the Milliken phases. He then interprets the relationship of Carbon 14 information to his study:

We must now go back in time and examine data from the South Yale site [Hypothes is of earlier occupation:]

indicative of human occupation which appears to antedate the earliest phase of the radiocarbon dated sequence.

[Negative evidence:]

Since materials suitable for $\mathrm{Cl} 4$ analysis are not available

[Evidence available:]

it is necessary to rely mainly on cultural and geological evidence. 
[Regional radiocarbon correlations:]

although even here C14 dates on geological events which affected the entire region are of great assistance.

[Local river level, radiocarbon correlation:]

Moreover, it is possible to make pertinent correlations pertaining to river levels in the canyon gorge and at South Yale on the basis of $\mathrm{Cl} 4$ dates for the two earliest dated cultural horizons at the Milliken site [1965:170].

Even though little is known of the "...surficial geology of this part of the valley..." (p.171), Borden will hypothesize with the evidence at hand. In a footnote about this, he writes:

I am grateful to Dr. W. H. Mathews, Dept. of Geology, Univ. of British Columbia, and to Dr. J. E. Armstrong, Geological Survey of Canada, for visiting the South Yale locality with me on different occasions and for the enlightening discussions I had with them. They can, however, not be held responsible for the data and interpretations presented here [1965:178].

\section{Terrace Description}

This is his description of the terraces:

At South Yale, partly obscured by forest, are three river terraces..... Terrace I, the lowest, is about 200 feet above mean sea level. Terraces II and III have elevations of approximately 250 and 350 feet. While the lower two terraces parallel the river for about one third and three fourths of a mile respectively, only a relatively small remnant is left of the third. Another remnant with an elevation similar to the last is preserved about one half mile distant on the opposite bank, suggesting the probability that at one time the entire valley was filled with sediments up to the 350 foot elevation [1965:171].

(The 350 foot elevation is the height of Terrace III. Evidence of two additional, higher terraces will be added in Borden 1968b.)

\section{Artifact Distribution}

He next discusses the artifacts and their distribution in relation to the terraces: 
Archaeological interest in the South Yale terraces derives from the fact that

[Tool type and deposition:]

quantities of very crude stone tools occur on each of them.

[Evidence of deposition from excavation:]

Many have been recovered from the disturbed surface, but

test excavations carried out in 1963 (Mitchell, in press)

have demonstrated that similar artifacts and the detritus of their manufacture are imbedded in and covered by undisturbed fluvial sands and silts, sometimes to a depth of over three feet

[Evidence of water-wear, my emphasis:]

It is significant, moreover, that some of the artifacts on each of the terraces are strongly water-worn.

[A1 ternative hypotheses relating age of terraces and age of tools:]

These facts suggest that the implements were made and left by groups who occupied the terraces successively either

[1] at the time of their formation or

[2] in a subsequent period during a resubmergence or reemergence of the land [1965:171].

\section{Artifact Description}

Borden gives us his first description of the crude tools of this complex:

[Hypothesis that this is a tool complex:]

The tool assemblage occurring on the South Yale terraces has been designated the Pasika Complex.

[General description of tool and raw material:]

It is composed mainly of heavy tools based on whole or occasionally on artificially split river cobbles.

[Sample size:]

Over 700 cobble tools,

[Description of manufacture technique:]

most of them choppers, unifacially percussion flaked on one end or on one side, have been recovered to date.

[Evidence to support hypothesis that these are artifacts:] In order to head off suspicion that these artifacts could have 
been created by natural agents it is important to stress the following points: (a) the cobble tools do not occur in the river gravel but in fine sand and silt, (b) they are made according to definite patterns, (c) flaking is exclusively unifacial, (d) hammerstones and manufacturing waste are found in the same sands and silts [1965:171].

\section{Cobble Tool and Pebble Tool Designation}

Borden's use of the phrase "cobble tools" is clarified in the draft of a chapter of an unpublished book that he kindly supplied to me:

The Pasika Complex consists predominantly of pebble tools, that is, core tools made on well-rounded river pebbles. Because we originally referred to these artifacts as "cobble tools" (Borden 1965:171) some explanation for this change in term is in order. To this author, and many of his acquaintances, a pebble is a rather small stone, perhaps up to three inches in size $(7.5 \mathrm{~cm}$.$) . Because nearly all Pasika arti-$ facts are based on larger and heavier stones the term cobble tool seemed more appropriate. However, a check of definitions, revealed that intuitive notions concerning pebbles and cobbles were faulty. According to Webster's New Collegiate Dictionary, a pebble is a "small roundish stone, smaller than a cobblestone..., especially one worn and rounded by the action of water," whereas a cobble is defined as a "naturally rounded stone larger than a pebble, especially orie from six inches to a foot in diameter" $(15-30 \mathrm{~cm}$; author's italics). On the basis of these definitions, less than $4 \%$ of the pasika core tools are made on cobbles and more than $96 \%$ on pebbles. Obviously then, the Pasika Complex is predominantly a "pebbletool industry." [Borden n.d.c.].

\section{Manufacture Technique}

Borden stresses the characteristics of the tools of this complex, and the skills that are and are not exhibited in their mainfacture.

This has to do with the patterns he mentioned in (b) above.

A considerable variety of chopper types can be distinguished dependirg on the form and position of the cutting edge, the angle of retouch and other criteria. 
[Example of a type:]

Some large globular cobbles were made into steeply flaked scraper planes.

[Evidence of types of detritus:]

The associated detritus consists of cobble fragments and chunky flakes.

[Use marks on some of these flakes:]

Several of these pieces show differential wear along one or several edges.

[Evidence of retouch on flakes:]

A few exhibit rough unifacial retouch.

[Hypothesis of lack of additional manufacturing technique:] The artifacts as well as the detritus of this complex appear to reflect an inability on the part of the stone workers to detach thin flakes.

[Negative evidence:]

Bifaclally worked knives and projectile points apparently are lacking [1965:171,173].

\section{Contrast with Earliest, Milliken Phase, at Milliken Site}

The next step in the argument is to establish the evidence of the technology in use at the earliest 9000 B.P. level at the Milliken site. Borden begins with the hypothes is of contrast:

[Hypothesis of technological contrast:]

The simple stone technology of the Pasika Complex contrasts strikingly with that of the Milliken phase, the earliest in the C14 dated sequence [1965:173].

In the next sentence, the word "still" appears to beg the question of time relationship that Borden is seeking to establish in this argument. If the word is omitted, the argument is clear.

[Evidence of cobble tools in Milliken phase:]

Though a few cobble tools are still present

[Evidence of varied technologies:]

the Milliken phase assemblage features numerous carefully fashioned scrapers and perforators, thin bifacially flaked knives and projectile points, a few burins, and many thou- 
sands of thin flakes. Most of the thin flakes have small facetted striking platforms, and slender, blade-like flakes are fairly common [1965:173].

Since these two sites are so close together making almost certain that two co-existing groups would have an effect on each other's ways, and since no later phase at the Milliken and Esilao sites have assemblages solely made up of cobble tools, the third alternative time relationship can be concluded:

The brief summaries of these two early Fraser Canyon assemblages are sufficient to indicate the remarkable contrast between them.

[Hypothesis, re-stated, that the Pasika Complex is the older:] The differences clearly suggest that the Pasika Complex represents a simpler and very likely an earlier cultural assemblage [1965:173].

Hypotheses Determining Earl iest Time the Terraces Could Be Inhabited

The first step in bracketing the age of the Pasika Complex is complete. It is older than 9000 B.P. The next hypotheses will form an argument leading to an hypothes is suggesting the earliest period in which the makers of these cobble tools could have inhabited the South Yale terraces. Borden turns to all the complexities of the geological variables in search of an hypothes is consistent with geological and artifactual evidence.

Borden is aware of the low prior probability of his hypotheses:

[Problem of any current hypotheses on dating Pasika Complex:] The attempt to determine when the bearers of the cobble tool culture inhabited the Fraser Canyon region is still fraught with difficulties at the present state of research,

[Revisions in evidence and hypotheses are a consequence:] and revisions in the following data and interpretations are to be expected. 
[Importance of making hypotheses of low prior probability:] Nevertheless, the attempt is considered worthwhile because it will help to bring the problem into sharper focus [1965: $173]$.

This, in Borden's own words, describes what I think is one of his great contributions. He makes explicit the consequences of the theories of this time. Any change in evidence can then be applied to that part of the theory that it affects, so that the theory may be re-examined and revised, or regarded as more probable. In respect to the dating of this complex, Borden's subsequent papers continue to revise both the evidence (especially 1972), and the theories.

\section{Glaciation Evidence and Hypotheses}

Borden begins with evidence from a current study on the final periods of glaciation in the general area:

[Statement that this is best evidence:]

Geologists specializing in the Pacific Northwest have recentIy reached a general consensus regarding the sequence and duration of late Pleistocene events in northwestern Washington and southwestern British Columbia. The sequence is supported by a long series of $\mathrm{C} 14$ dates (Armstrong et al., 1965) [Borden 1965: 173].

The time of the disappearance of the cordilleran ice sheet is the early limit of the South Yale occupation. Borden seeks to establish the time when this part of the Fraser was ice-free:

[Geological evidence of beginning of ice retreat:] The Everson Interstade, in the course of which most of the Cordilleran ice sheet of the last major glaciation disappeared from this area, began about 12,000 B.C.

[Hypothesis on ice-free date for the lower Fraser:]

Very likely, most of the lower Fraser region was ice free by around 11,000 B.C. or short1y thereafter.

[Hypothesis of period of lowered land elevation:] 
In the early part of the Interstade while the ice sheet was wasting and for a period after its disappearance,

[Hypothesis of correlation with period of beginning of isostatic rebound:]

before isostatic adjustment had progressed far,

[Hypothes is of correlation to Strait of Georgia inlet:] the lower Fraser region was occupied by an inlet of the Stralt of Georgia, which extended up to the vicinity of Yale and beyond

[Hypothes is of correlation with Fraser mouth location:] so that the mouth of the river at that time was some 110 miles or more from its present position.

[Hypothes is that South Yale sands are deltaic deposits and are from this period:]

It must have been in this period that the deltaic deposits which filled the valley near Yale up to the present 350 foot elevation were laid down [1965:173].

Borden now has hypotheses that do two things. First they approximately date the deltaic deposit of which the terraces are composed, and second, they indicate other events all of which must have been present to form this deep sand deposits at South Yale.

\section{Terrace Cutting Hypotheses:}

Now he will discuss how the terraces were cut from this deep deposit. Evidence for the beginning of the terrace cutting is from general geological theory of the period; the later levels of terrace formation will be correlated with the water levels from the dated Milliken site. Within this "given" framework, Borden will try to account for the varied water-worn characteristics of artifacts in all of the terraces

Borden begins with the geological evidence and theory for the original terrace-cutting. 
[General geological hypothesis of isostatic rebound, land elevation correlation:]

Later in the Everson Interstade, in response to the disappearance of the ice load, rapid isostatic adjustment occurred which raised the land to within 100 feet or less of present level (Armstrong 1961)

[Hypothesis correlating hypothesis above with initial terrace cutting:]

It was probably during this interval of rapid uplift, when the 1 and was emerging and the mouth of the Fraser was migrating down the valley, that the river began eroding its bed into the valley fill, thus initiating the process of terrace cutting at South Yale.

[Negative evidence of extent of terrace cut in this period:] At the present state of research it is impossible to state with certainty how much of the sediment the river removed before the end of the Interstade.

[Pre] iminary statement of hypothesis of early rapid-erosion rate:]

However, as will become evident later, the rate of erosion must have been exceedingly rapid in this early period [1965: $174]$.

The evidence that Borden will present for this early rapid erosion hypothesis later in this paper, correlates terrace data from South Yale with the water level from the dated Milliken site. Here he states

a summary-conclusion from that evidence:

[Hypothesis of time of initial terrace cutting:]

It seems a fair estimate that from around 10,500 B.C., when the process of downcutting very likely began,

[Hypothesis of terrace formation at end of Interstade:] to about 9000 B.C. when the Interstade ended, the 350 foot terrace had been cut and that most of the broad sloping expanse of the second terrace was periodically exposed.

[Hypothesis of time of renewed glaciation:] But then [about 9000 B.C.] the erosional process was interrupted by the onset of renewed glaciation [1965:174].

The contrasting conditions before and after about 9000 B.C. add complicating factors that Borden must consider in his hypotheses about 
the South Yale terraces:

[Evidence of late Everson climatic conditions:]

In the latter part of the Everson Interstade a relatively warm climate with moderate humidity had prevalled (Heusser 1960:181).

[Evidence of glaciation in this area:]

Around 9000 B.C., with the beginning of the Sumas Stade, the climate worsened again, and a glacier which appears to have been centered in the southern Cascades of British Columbia (J. E. Armstrong, Personal Communication, May 1965) advanced westward into the Fraser Lowland.

[Geological evidence of the Sumas advance:]

Evidence for this Sumas advance abounds in the lowland region in the form of drift and outwash. In the Fraser valley between Hope and Yale such massive evidence is lacking, but the kame gravels exposed along the second terrace just downriver from South Yale may indicate that a branch of the Sumas glacier once extended for a considerable distance into the valley north of Hope. Farther south, the main body of the glacier probably constituted a barrier of sufficient bulk to dam the river.

[Hypothesis correlating silt on Terrace II with time of ice dam:]

The silt bed of Zone $J$ at the Milliken site, and the silt and fine sand deposit which still mantles much of the second terrace at South Yale may both have been laid down in the quiescent water resulting from the ponding of the river [1965:174].

How long did this cold stage last, and how did this affect the

ice dam and the South Yale terraces?

[General geological hypothesis of short and local Sumas stade:] Evidently the glaciation of the Sumas Stade was a rather 10calized phenomenon and of relatively short duration.

[Hypothesis on end of Sumas maximum in spite of inconclusive evidence:]

Though no conclusive evidence exists it is assumed to have passed 1ts maximal thrust by $85 \mathrm{CO}$ B.C.

[Heusser classification based on this maximum:]

This presumed turning point has been taken by Heusser (1960:

181, 183; Table 6,p.179) as marking the transition from late glacial to early postglacial times in southwestern British

Columbia and northwestern Washington.

[Borden's hypothesis correlating beginning of Sumas de-gla- 
ciation and ice dam:]

Although the Sumas glacier may have ceased its advance by 8500 B.C. the postulated ice dam could have continued to exist for some considerable period.

[Sedimentary evidence for previous hypothesis:]

The silt bed which overlies the kame gravels near South Yale perhaps tends to support this assumption.

[Hypothesis of time of end of ponding:]

Possibly the final disintegration of the ice barrier and release of the ponded water in the valley did not occur until we11 into the eighth millennium B.C. [1965:174].

Borden interprets Zone $\mathrm{J}$ and Zone I from the Milliken site as confirmatory evidence to the end of the ponding:

It is perhaps significant [may be confirmatory evidence] that the first Milliken phase camp (Zone I) atop Zone J (the deep silt bed at the Milliken site which is tentatively attributed to have resulted from the ponding of the river) apparently was established very shortly after the water level had dropped sufficiently to expose the surface and to permit occupation. This event, as we have seen, has a C14 date of 7050 B.C. $[1965: 174-175]$.

\section{Correlations of Water Levels at South Yale and Milliken Sites}

Now Borden correlates the water levels of Milliken with South

Yale to establish within general limits the levels of terrace cutting from 7000 B.C. to 6000 B.C. First he reviews time and river elevation evidence at Milliken.

[Evidence of time of Fraser flooding the Milliken site:] We must also recall at this point that from 7050 B.C. until near the end of the ensuing millennium, that is from about 7000 to 6000 B.C., the site was seasonally occupied after inundation during the annual flood stage. The last transgressions of the river appear to have occurred at about the latter date.

[Evidence of river elevation at this time:] Pertinent in this connection is the fact that the elevation of the Zone $G$ surface is about 260 feet above sea level. We may thus assume that the water surface at flood stage around 
6000 B.C. had an elevation of roughly 265 feet in the vicinity of the Milliken site.

[Statement that we can use this to infer the conditions of the Fraser at South Yale:]

These are useful data because combined with data pertaining to the present characteristics and behavior of the Fraser they permit us to infer approximately the condition and activities of the river at South Yale in the period 7000 to 6000 B.C. [1965:175].

Borden gives the present data on the river profile between these two sites:

[Evidence of present elevation differences:]

The profile of the present mean surface of the river between the Milliken site and Yale shows a drop in elevation of about 35 feet..., that is from an elevation of 175 to 140 feet above mean sea level (Data supplied through the generous cooperation of Professor E. S. Pretious, Department of Civil Engineering, and formerly Director of Fraser River Model, Univ. of British Columbia).

[Conciusion from substitution of present day figure to earlier elevations:]

On subtracting a similar amount from the presumed high water of 265 feet at the Milliken site 8000 years ago we obtain a value of some 230 feet for South Yale.

[Correction to account for differences in variation in canyon and at South Yale:]

Actually, the latter figure should probably be somewhat less since the difference between the high and low values is more marked in the narrow gorge above Yale than at Yale itself. The present low at Yale is about 42 feet below the high water mark. A corresponding difference would bring the low mark 8000 yeurs ago to about 188 feet above sea leve1 [1965:175].

Border stresses the general range within which these elevations

must be interpreted. He then spells out how this water level corre-

Tates with the terrace cutting:

[Hypothes is of consequences with a general caution:]

Although these values of 230 and 188 feet are only approximations they are sufficiently accurate to warrant the following inferences...:

[Conditions during the 7000 B.C. to 6000 B.C. span:] 
(a) the river was eroding its bed into the second or 250

foot terrace in the 7000 to 6000 B.C. period; and

[Conditions prior to 5000 B.C.:]

(b) the low water level of 188 feet indicates that downcutting from the edge of the first or 200 foot terrace had begun prior to 6000 B.C. The elevation of the present boitom of the river at Yale is about 100 feet above sea level [1965: 175].

\section{Rate of Terrace Cutting}

Now Borden can support the hypothesis that he proposed earlier, that the earlier terrace cutting was much more rapid than the later erosion. He can compare the later 1000 year span of erosion with the elevation of the higher terraces and the time span that geological hypotheses allow for the earlier terrace erosion. Borden suggests a reason in addition to the isostatic rebound which he had mentioned previous?y:

It is instructive to note the sharp contrast between the relatively slow erosion in the post Sumas millennia compared with the vigorous erosion which occurred in the late interval of the Everson Interstade,

[One condition causing vigorous erosion:] when the river was enormously swollen by the melt water from the rapidly wasting Cordilleran ice sheet [1965:175].

\section{Summary of Time of Terrace Cutting}

Borden summarizes his terrace-cutting-time hypotheses in order to correlate the geological consequences that he has been examining with the cultural evidence. Thus he can ask when and how the occupants of the South Yale terraces came and when they left this area.

This is Borden's summary, in four time segments, of the hypotheses relating geological evidence to the local problem of South Yale 
terrace cutting. In the next section of this analysis I will refer to the time segments by the numbers I have inserted in his summary:

[Borden's explicit statement that this is an hypothesis:] Stressing again the tentative nature of these reconstructions, we may summarize briefly as follows:

[1] The 350 foot terrace was cut and subsequently much if not most of the surface of the second terrace was exposed periodically in the late interval of the Everson Interstade, that is, from 10,500 to 9,000 B.C. [1965:175-176].

[2] From around 9000 B.C. to probably some time in the eighth millennium B.C., the river was ponded and the sites inundated as a result of the Sumas ice dam.

[3] From before 7000 to about 6000 B.C., the 200 foot terrace was cut into the margin of the second terrace.

[4] Erosion from the edge of the first terrace to the present bottom of the river occurred in the last 8000 years [1965:176].

Correlation of Artifact Evidence with Previous Hypotheses

Borden has completed the time-bracketing of the Pasika Complex with this early time sequence. It is important to note that Borden's next reconstruction logicaliy presumes the accuracy of the geological interpretations. He says, in effect, then,

1) how would this "stage setting" affect the makers of the cobble tools and

2) does the evidence of artifact distribution and wear fit this "stage setting".

Everson Interstade. The first group of hypotheses deals with the time segment numbered [1], the Everson Interstade:

[Hypothesis of time of local deglaciation correlated with "migration" of plants and animals to the area:] 
During the warm, moderately humid latter part of the Everson Interstade, that is between ca. 10,500 and 9000 B.C., plants and animals migrated from Washington into the newly deglaciated region of southwestern British Columbia.

[Hypothesis of subsequent early migration of cobble tool makers:]

These apparently were soon followed by early Indian groups possessing a simple, relatively crude stone technology.

[Stratigraphic evidence for preceding hypothesis:]

We may infer this from the cobbie tools of the Pasika Complex which are imbedded in the fluvial silt and sand of the 350 and 250 foot terraces which originated during this geological interval.

[Confirmatory evidence from wear marks of artifacts:] Especially convincing evidence for the contemporaneity of this complex with the geological events is the strongly water-worn condition of some specimens from both terraces.

[Expanded argument on wearing mechanism:]

Since the terraces, as they were forming, were subject to both tidal action and seasonal fluctuations of the river level, artifacts and detritus left on the surface of the river beach were exposed to the abrasive action of moving water and sand.

[Hypothesis that this is a necessary as well as sufficient condition for wearing at this elevation:]

The strongly water-worn condition of certain specimens from these two terraces can be accounted for only in this way [1965:176].

Borden says that these artifacts could be in this condition if and only if they were present at a time when such abrasive action was taking place.

Sumas Stade. The next time segment, numbered [2] above, is the Sumas Stade:

[Geological presupposition based on silt layers on Terrace II and water elevations at Milliken:]

During the Sumas Stade, when presumably the river was ponded by an Ice dam, the surface of the second terrace must have been inundated.

[Hypothes is of gradual change:] 
However, the level of the pool probably rose only slowly

[Hypothesis of variability of water level correlated to ice dam: ]

and depended, moreover, on the height of the ice barrier, which may have been variable.

[Hypothesis of variability of water level correlated to seasonal run-offs:]

Furthermore, the water level would have still been subject to seasonal fluctuations [1965:176].

Therefore, the second terrace is not necessarily proved to be uninhabitable:

[Hypothesis of early, or seasonal utilization of second terrace:]

Human utilization of the second terrace beach, therefore, could have continued for some considerable time as long as the occupying groups were able to cope with the worsening climate.

[Hypothesis of the consequence of previous hypothesis:] Thus, some of the Pasika Complex artifacts on the second terrace could be Sumas Stade in age.

[Hypothesis to account for non-water worn artifacts on Terrace III:]

The same may apply to some specimens without water-wear on the third terrace [1965:176].

To find confirmatory evidence for the last hypothesis, Borden now examines evidence for the maximum height of the pool behind the ice dam.

[Tentative nature of evidence:]

It is not certain whether the pool rose above the elevation of this 350 foot terrace,

[Confirmatory evidence:]

though the presence of some fine silt on the terrace surface suggests this possibility [1965:176].

If the third terrace was silt covered, the second terrace might have had a very deep bed of silt at the same time. Borden illustrates this possibility from the Milliken site prior to 7000 B.C.:

The bed of silt and sand on the second terrace may have been 
quite massive at one time corresponding to the seven foot depth of Zone $\mathrm{J}$ at the Milliken site.

[Hypothesis of rapid erosion of silt from South Yale:] Much of this fine deposit at South Yale was probably flushed away subsequently when the ponded water rushed out of the valley upon disintegration of the ice dam.

[Hypothesis that distribution of artifacts is confirmatory evidence of preceding hypothesis:]

The force of this rushing water must have been strong enough to move even heavy cobble tools, which are widely scattered over the terrace and occur at various depths of the remaining silt and sand [1965:176-177].

Post Sumas Stade. Now Borden examines the time segment previous-

Ty numbered [3], the post Sumas period.

[Negative evidence:]

Unfortunately, all evidence of fires which may have existed at one time seems also to have been swept away.

[Hypothesis that post Sumas occupants would have left fire remains:]

If the second terrace had been inhabited by cobble tool folk in post Sumas times, that is after the draining of the pool, one might reasonably expect to find the remains of fires associated with artifacts of the Pasika Complex [1965:177].

The preceding argument is of the valid logical form called modus tollens, or denying the consequent. Borden said, reversing his order: If the second terrace had been occupied by Pasika Complex makers in post sumas times, then reasonably we would expect to find remains of fires associated with their artifacts. The other statements denies the consequent of this conditional statement: We did not find any fire remains associated with their artifacts. The valid conclusion is: It is not the case that the second terrace was occupied in post sumas times by the makers of the Pasika Complex. Borden concludes this implicitly when he chooses another alternative rather than the presence "... of the cobble tool folk" below. His argument continues with an examination 
of the consequences if the fire remains are found at the South Yale

site. He begins with a statement that such a possibility exists:

[Hypothes is that fire remains may be found:]

Perhaps future work will yet produce such evidence.

[Evidence of time correlation of post Sumas occupation:]

However, the time when reoccupation of the terrace became possible was probably very close to the period when groups of Milliken phase culture made their appearance in the valley.

[Hypothesis of probable artifact association with post Sumas fire remains at South Yale:]

Thus, at so late a date one might expect to find evidence of their presence rather than of the cobble tool folk [1965:177].

In the event fire remains are found, Borden has given this double series of hypotheses which will be testable.

\section{Problem of Terrace I Artifacts}

Before Borden can say that the Pasika Complex makers were not present in the post Sumas period, he must account for the large number of artifacts from the first terrace that was being cut during that time.

This is the evidence and his argument:

[Evidence of artifact presence:]

Large numbers of cobble tools have been recovered from the 200 foot terrace.

[Evidence of terrace formation age:]

This terrace, as we have seen, originated in the seventh millennium B.C.

[Evidence of co-existence of Milliken phase:]

In this period, however, the Milliken phase culture with its quite sophisticated stone technology was in full flower,

[Negative evidence at South Yale site:]

and it is certainly significant that not a single item which could be regarded as diagnostic for the Milliken phase is among the first terrace finds [1965:177].

Borden leaves out the conclusion: no post Sumas artifacts from 
the Milliken culture, and thus from any contemporary, South Yale culture, are in the first terrace. Instead, he answers the next question: if the artifacts are not contemporary with the terrace formation, how did earlier artifacts become deposited in terraces that formed later?

[Hypothesis that the explanation is reasonaible:] The explanation for this situation is not too difficult.

[Hypothesis of original place and time of artifact deposition: ]

The cobble tools as well as other artifacts and detritus of the Pasika Complex were originally left on the second terrace-- probably during the Everson Interstade.

[Hypothesis of mechanism of deposition:]

When the river eventually eroded away the fine sediments from the marginal area of the second terrace the current was not of sufficlent strength to carry away the stone artifacts. These came to rest finally on and in the sand of the first terrace, especially near the downriver portion of the feature.

[Evidence tending to confirm previous hypothesis:]

The highly water-worn condition of a high percentage of the Pasika artifacts from this terrace tends to confirm this explanation [1965:177].

The problem of Terrace I artifacts is discussed in more detail in Chapter XXXV, Borden's 1968b paper.

Hypotheses on Pasika-Milliken Relationships

Borden concludes the paper with alternative hypotheses "of the eventual fate of the cobble tool folk":

Nothing is known as yet of the eventual fate of the cobble tool folk, [First al ternative hypothesis:]

whether they remained in the valley throughout the Sumas Stade

[Second a]ternative hypothesis:]

or whether they finally wandered off to seek a more favorable environment when ecological conditions in southernBritish Columbia became intolerable. 
[Absence of two sorts of evidence to support the first a]ternative: ]

[1] We have no conclusive proof for their presence in the canyon region in post Sumas times,

[2] nor as yet any indication that the development from the Pasika Complex stage to the culture of the Milliken phase occurred locally [1965:177].

Thus, either later sites solely of Pasika tools, or intermediate stages of manufacturing techniques leading to Milliken phase techniques would tend to confirm the first hypothesis. In the absence of this evidence, Borden examines the Milliken phase as an intrusive culture:

[Firm evidence of Milliken phase presence:]

The first $\mathrm{C} 14$ dated evidence for the presence of Milliken phase groups in the Fraser valley is the 9000 year old camp atop Zone $\mathrm{J}$ at the Milliken site.

[Hypothes is of possible earlier occupation:]

Possibly Milliken phase groups had been present in the region prior to the 7050 B.C. date,

[Hypothesis of full development at early date:]

but by the end of the eighth millennium B.C., the Milliken phase culture seems fully developed [1965:177].

With glacial conditions setting time limits for development, and with no local evidence, Borden re-states the second alternative as more probable:

[Hypothesis that Milliken phase developed elsewhere:]

on the basis of present evidence then it seems more likely

that this development occurred elsewhere

[Hypothesis of Sumas Stade abandonment of Canyon:] and that the archaeological data should be interpreted as indicating an abandonment of the region during the Sumas Stade

[Hypothes is of post Sumas reoccupation:] and a reoccupation of the valley in post sumas times [1965: 177-178].

These hypotheses will have confirmatory evidence; see particularly 
in Borden $1968 \mathrm{~b}$ and 1969c. Borden notes that even this tentative reconstruction, based on evidence so recently available, would have been "utterly impossible" without radiocarbon dating (p.178). 
CHAPTER XXXIV

1968a PREHISTORY OF THE LOWER MAINLAND

I. BACKGROUND

This paper is the first chapter in 'Lower Fraser Valley: Evolution of a Cultural Landscape' B.C. Geographical Series, edited by A. H. Siemans.

Borden's contribution to this volume begins with a clear definition of "prehistory", and defines its limits in the "Lower Mainland", which is the Fraser valley from the Milliken site to the delta sites. His definitions of two other terms, "phase" and "culture" are in the second chapter of this thesis. I put them in context here; both definitions are logical links in his presentation. Since this is a summary of thousands of years of prehistory, much evidence is missing. The interpretations are founded on selected instances from Borden's evidence. This selection process is not part of this paper, nor the appropriate ground for evaluating it.

After the definition of prehistory, Borden gives its recent lim$i t s$, and then summarizes the geological and climatic conditions preceding and during the span of this study. Then he proceeds with the description of the culture phase by phase, beginning with the Pasika Complex, then the early levels at the Milliken and Esilao Village sites. He then summarizes the delta geological conditions and cultures, and finishes with the most recent canyon phases. 
With this paper we have our first glimpse of the assemblages that characterize the later canyon phases. The Fraser Canyon Progress Report (1961b) gave geological zones and dates; the Radiocarbon paper (1965) added the phase names, but only in their chronological and geological setting, not with cultural evidence.

Although much concrete evidence to support his hypotheses is not available in this paper for study, the hypotheses themselves are presented. These are linked into the network of Borden's thought and are part of the chronology of his search for the intercultural connections between these peoples and those of other places and other times.

\section{RECENT LIMITS OF PREHISTORY}

This is how Borden explains the meaning and recent limits of prehistory in this region:

The prehistory of the Americas is the history of the Indian peoples prior to the advent of the Europeans. It is believed that the first whites to visit the Stalo, the native inhabitants of the Lower Mainland region, where Spaniards, probably companions of Juan de Fuca, who explored this part of the coast in 1592 (Swanton, 1953:600). Two centuries later, in 1792, Captain George Vancouver charted the shores of Burrard Inlet. But the first white men to travel the full length of the lower mainland and to come in intimate contact with the Indian peoples along their route were Simon Fraser and his crew. Fraser's journey down the river which now bears his name marks the dividing line between prehistoric and historic times in these parts. The year was 1808 (Lamb, 1960). While the end of prehistory here is thus incisively clear, the beginnings are remote and less certain [1968a:9].

(The reader not familiar with an ethnography of the canyon people may want to read the final pages of this analysis before continuing with the prehistory.) He summarizes the archaeological evidence from which such prehistory can be derived: 
and continued to waste away in the ensuing three millennia. Before the end of this warm interval, now referred to as the Everson Interstade, the Ice had vanished from Puget Sound and Georgia Strait and from most of the lower mainland. During this interval, plants and animals migrated from unglaciated areas in Washington into the newly deglaciated regions of British Columbia close on the heels of the retreating ice (Borden, n.d. a) [Borden 1968a:9,11].

[Hypothesis of early occupation by man:] Over the last few years, evidence has been accumulating to indicate that also some Indian bands crossed the 49 th parallel northward into southwestern British Columbia during this late interval of the Glacial Age [1968a:11].

\section{Sumas Evidence}

Borden then summarizes the geological evidence of the Sumas period:

Around 11,000 years ago, the climate deteriorated once more, and a glacier, centred in the Cascades of southern British Columbia, advanced westward into the Fraser lowland to within 25 miles of Vancouver (Armstrong, 1957, 1960a, 1960b). This socalled Sunas advance was of relatively short duration and the onset of the retreat of this glacier roughly 10,500 years ago to recognized as indicating the dividing line between the Late Glacial and Early Postglacial periods (Heusser, 1960: 179, Table 6) [Borden 1968a:11].

\section{Postglacial Period}

During the Postglacial age, there is evidence of three climatic periods:

Paleobotanical data combined with radiocarbon dates ind1cate three main periods in the climatic history of the Postglacial Age (Heusser 1960:179, Table 6):

8500-6500 B. C. - Early Postglacial

The climate was cool and moist, shifting to warmer and drier conditions late in this period.

6500-1000 B.C. - The Hypsithermal

In this perfod of ca. 5000 years, the climate was warmer and drier and the mean annual temperature higher than today. 
Archaeological investigations carried out by the Department of Anthropology and Sociology, University of British Columbia, on the lower mainland have been concentrated in the western and eastern extremities of the region, with work in the interventing parts confined to site surveys (Borden, 1950, 1951, 1954, 1955, 1960, 1961, n.d. b; Mitchel1, 1965). In order to utilize the results of our work in the eastern portion it will be necessary to expand the "Lower Mainland" or "Lower Fraser Valley" concept somewhat to include the southern-most part of the Fraser Canyon....[1968a:9].

He begins with the canyon history, which goes back "...probably to late glacial times" (p.9), before presenting the delta history that goes back about 3000 years.

\section{GEOLOGICAL AND CLIMATIC CONDITIONS}

His summary of geological evidence is important in establishing an absolute limit to continuous occupation of this area.

Over the last twenty-five millennia, the lower mainland has undergone vast environmental changes (Armstrong et al, 1965; Borden, n.d. a; Crande1, 1965; Easterbrook, 1966; Heusser, 1960). Around 18,000 years ago, during the Vashon Stade of the Fraser Glaciation, the Cordilleran ice sheet covered all of British Columbia. Over the Hope area the ice stood 6000 feet high and 5500 feet over Vancouver. Westward the ice blanketed Vancouver Island and the Straits of Georgia and Juan de Fuca. Southward a long lobe of the glacier extended down the Puget lowland to the vicinity of the Chehalis River in Washington, but twenty miles due south of Hope the advance of the Cordilleran ice sheet was blocked by the Cascade Range. Here it coalesced with local glaciers centred on high peaks of this massif. Most of the interior of Washington east of the Cascades was never glaciated [1968a:9].

\section{Earliest Possible Post Cordilleran 0ccupation}

This is his evidence of the earliest possible post Cordilleran occupation of this area:

Paleobotanical studies and radiocarbon dates indicate an amelioration of the climate beginning probably more than 14,000 years ago. The continental glacier was in retreat 
1000 B. C. to the present - Late Postglacial

The cool humid conditions which characterize the present climate of southern coastal British Columbia have prevailed with relatively little change for the past 3000 years [1968a:11].

\section{Deposition of South Yale Terraces}

Borden repeats his 1965 evidence for the deposition of the deltaic deposits at South Yale that eroded to form the terraces there. However, he speaks of the terraces as "...mainly drift left by the Cordilleran glacier as the ice wasted during the Everson Interstade" (p.11). There is also a difference in the way in which he refers to the three terraces. He says, my emphasis, "...the three lowest terraces (I, II, and III) have elevations of 200, 260, and 370 feet respectively" (p.12). We may infer that there is at least preliminary evidence of additional, higher terraces. These are mapped in 1968b, his next publication.

IV. PASIKA PHASE ca. $10,500,-9000$ B.C.

Definition of "Phase"

Borden now calls the Pasika Complex the Pasika phase, and footnotes the definition of phase:

The concept "phase," as employed by archaeologists, denotes "an archaeological unit possessing traits sufficiently characteristic to distinguish it from all other units similarly conceived, whether of the same or other cultures or civilizations spatially limited to the order of magnitude of a localtty or region and chronologically limited to a relatively brief interval of time" (Willey and Phillips, 1958:22) [Borden 1968a:25].

\section{Artifacts and their Distribution}

Borden describes the artifacts and their distribution, and then 
presents a series of hypotheses about their deposition similar to his 1965 interpretation. They seem more guarded and tentative, but this may be the result of the abbreviated presentation. The terraces are not described as composed entirely of sand and silt, but are gravels and boulders mantled by sands and silts:

[Distribution of artifact evidence:] On all three terraces quantities of very crude artifacts have been found. These occur not only on or near the surface, but also deeply embedded in the fluvial silts and sands that mantle the gravels and boulders of the terraces proper (Mitchell, 1965).

[Evidence of differentia] water wearing:]

Moreover, all three terraces have yielded specimens whtch are strongly worn by water action,

[Hypothesis of general cause of water-wearing:] an effect which could have been produced only at times when the respective terrace was periodically covered by flowing water.

[Alternate hypotheses of water-flow:] These fluctuations in water level

[1] may have been seasonal in nature

[2] or due to tidal action.

[3] Perhaps they were a combination of both [1968a:12].

From these interpretations, Borden rules out the possibility that the artifacts are more recent than the time that the terraces were being cut:

\section{Artifact Deposition}

[Hypotheses of possible age range of artifacts, correlated to terrace cutting:]

At any rate, there is clear evidence here that the artifacts were used and left at this locality

[1] during or

[2] before the periods when the terraces were being successively formed,

[Hypothesis that the terrace formation was successive:] the terraces were... successively formed, the highest first and the lowest last. 
[Hypothesis of time span of terrace-cutting:]

The most likely period for the formation of Terraces II and III was the warm interval between 10,500 and $9000 \mathrm{~B}$. C., the time when presumably the land, upon retreat of the ice, was rising rapidly. Erosion of the lowest terrace probably did not begin until ca. 7000 B. C. after the disappearance of an ice dam farther down the valley which is believed to have blocked the river flow for a time during the Sumas Stade (Borden, 1965) [Borden 1968a:12].

This series of hypotheses tends to support the time range that Borden assigns to the Pasika phase.

\section{Types of Artifacts}

Borden describes the tools, how they may have been used, and similar tool assemilages elsewhere. He speculates on what he calls their "conservatism".

[Hypothesis that complex-type is confirmatory of the hypothesis of great age of complex:]

The nature of the archaeological complex recovered at the site supports the assumption of great antiquity for these results.

[Evidence of artifact formation:]

The vast majority of the artifacts are fashioned from wellworn river pebbles and cobbles through the removal by percussion of large flakes from one end or one side of the stone. The retouch is invariably confined to only one face and generally to the area near the edge of the specimen. Some specialization was achieved through selecting pebbles of different size and shape, by varying the angle of retouch from very acute to $90^{\circ}$, and varying the form of the cutting edge: straight, convex, concave, converging to a point, etc.

[Hypotheses grouping these into use-types:]

Among the types that can be recognized are various kinds of choppers, cleavers, picks, scrapers, and scraper-planes.

[Hypotheses interpreting some as multi-purpose tools:] Many are obviously multipurpose tools, equally serviceable for chopping down a sapling and fashioning a pointed staff, for piercing and cutting the tough hide of large game animals, for severing a joint or splitting skulls and long bones to get at succulent brain and marrow.

[Evidence of utilized flakes:] 
Sometimes the sharp edges of flakes removed in the manufacture of pebble tools were utilized,

[Evidence of infrequent retouching of flakes:] but only a very few such flakes are rudely retouched.

[Negative evidence of other stone technologies stated as a simpler stage:]

The stone technology of these early groups that camped on the banks of the Fraser in late glacial times apparently had not reached the stage which would have enabled them to manufacture thin, bifacially worked knives and projectile points.

[Hypothesis of subsistence pattern:]

Presumably they were hunters, subsisting on the fauna characteristic of a periglacial environment.

[Hypothesis confirmatory of hypothesis above, that this culture's hunting is analagous to east Asian chopper culture hunting:]

Not only in their stone technology but also in their hunting methods they appear to have persisted in continuing traditions resembling those of the very ancient chopper and chopping-tool cultures of eastern Asia (Movius, 1949; Chard, 1959) [Borden 1968a: 12].

\section{Discussion}

It would be interesting to follow the reasons by which Borden argues to the final hypothes is above. Is it "in the absence of evidence to the contrary", that from similar tools we may argue similar techniques in hunting? Rather than environmental similarities, perhaps wear patterns or statistical type clusters of the artifacts in the two regions are similar. Borden does not say whether the analys is of these tools had progressed enough to warrant making this sort of statement, or whether there is another sort of evidence. Perhaps he is only saying that both cultures lack bows and arrows, or at least stone projectile points, and other lance or spear heads of stone, so in the absence of these forms, we may deduce that there is one and only one hunting pattern that lacks all other stone tools than these. 
Relation to Other Cultures

With these questions in mind, we continue with Borden's analysis. How is it possible that these people could lack a more sophisticated stone technology at the same time that others in the northern New World were using "elegantly fluted points"?

[Hypothesis that evidence of Pasika phase relates to antiquity of man in the New World:]

The conservatism of these early pebble tool folk of southern British Columbia is a problem fraught with far-reaching implications bearing on the antiquity of man in the New World.

[Hypothesis of isolation, implicitly after early arrival in New World:]

Perhaps the conservatism was due to long isolation.

[Evidence of contrasting culture at 10,500-9000 B. C.:] Certainly the simple stone technology of these ancient residents of the Northwest contrasts sharply with the progressiveness of the contemporary Paleo-Indians east of the Rocky Mountains who by this time were slaying mammoths by hurling darts armed with elegantly fashioned fluted points at the huge beasts (Willey, 1966:38-9) [Borden 1968a:12,13].

\section{Eventual Fate of the Makers of Pebble Tools}

Borden's hypotheses about the makers of the pebble tools are almost identical to those in 1965 , except that there he implicitly hypothesizes an earlier southern habitat for the Pasika people, while in this paper he is more definite about the influences from other places that were brought to the Milliken site:

[Hypothesis of southern "return" of Pasika peoples:] The eventual fate of the pebble tool folk 1 s not known. Perhaps they managed to return south to Washington before the worsening ecological conditions during the Sumas Stade made life in the canyon difficult or impossible.

[Hypothesis of migration of new peoples north to Milliken site:]

Meanwhile, some of the cultural advances which had been made in other parts of the continent were also spreading to the 
Pacific Northwest, and when during the early postglacial perlod improving conditions on the lower mainland invited settlement once more, new immigrants brought these innovations to the Fraser Valley [1968a:73].

Borden expands on this material in his next paper (1968b). Now he moves his attention to evidence from sites 2.5 miles up the Fraser in the narrow canyon, from which he now has seventeen dated charcoal samples.

V. MILLIKEN PHASE-Ca. 7500-6000 B. C.

Note that each heading for a phase-section in this paper is a short summary of two hypotheses: the first is the hypothesis that each of these groups of assemblages is a phase, and second, that the dates relate accurately to that group of assemblages.

In Borden's highly condensed treatment of the Milliken phase, I have supplied, in brackets, possible interpretations which might appear in a more expanded argument. These are my own interpretations as I follow Borden's argument.

Possible Pasika/Milliken Relationships

The first statement contains phrases that implicitly suggest two alternatives to Borden's hypotheses that the Pasika pebble tool makers left the area to go to the south. I have underlined those phrases, and added the implicit hypotheses:

[Statement comparing Milliken and Pasika assemblages:]

Compared with the materials of the Pasika phase, the cultural assemblage of the Milliken phase is highly sophisticated,

[Hypothesis of generic relationship of two phases:] although the continued presence of some pebble tools hints at a gener1c relationship with the earlier culture. (Borden 1960: 
Plate 1, Figure 1) [1968a:13].

[Implicit alternative hypotheses:]

[such that the knowledge of pebble tool manufacture and use may have been passed on

1. either to the descendants of the early people or to the "new immigrants",

2. in the south if one (or both) groups were there, or in the canyon, if the Pasika descendants remained.]

[Evidence of comparative frequency:]

However, these tools constitute only a minor part of the total artifact assemblage.

[Evidence of types which were more numerous:]

More important [i.e. more numerous in proportion,] are numerous scrapers of different types based on thin flakes... Many scrapers are carefully shaped.... and some are provided with a tang for hafting.

[Evidence of other types:]

Poinied implements, possible perforators, and burins are also present.

[Implications of burins:]

The latter are specialized tools for working organic materials such as bone and antler [so that from the presence of burins we may infer their use, and the former presence of bone and antler materials] [Borden 1968a:13].

\section{Milliken Technology}

In the next section I have suggested possible reasons for Borden's comment "Most significantly..." that introduces the next characteristic of the Milliken phase.

[Hypothesis that new manufacturing technique is important:] Most significantly, the Indians of the Milliken phase fashioned large but thin ovate and semilunar stone knives as well as projectile points of a generalized laurel-leaf form by skillfully controlled bifacial flaking (Borden 1961: Plate II, a-f; 1962: P1ate 1, e-h) [Borden 1968a:13].

[Possible presuppositions for interpretation of importance above:]

[1. A new manufacturing technique, well done, indicates a change greater in significance than new artifacts, listed previousiy. 
2. The significance may lie in evidence of invention, migration, diffusion, and/or in possibilities for ensuing culture change as a result of the new technique.

3. These particular artifacts may be specific to a particular activity for which this is the only, or a confirming instance.]

I have noted that the next evidence, new to this paper, seems also very significant when seen in relation to a new manufacturing technique.

Red ochre was crushed and ground for use as pigment, and grinding and polishing techniques were beginning to be applied to stone [1968a:13].

Borden then repeats the evidence given in 1965, of transparent obsidian, occurring in Oregon 400 miles away. This is his trade hypothesis based on this evidence:

Very likely, therefore, these early occupants of the Fraser Canyon had trade connections in that direction [1968a:13].

Salmon-Based Economy

Borden then repeats his hypothes is on a salmon-based economy from the cherry pit evidence, and the salmon vertebrae at Five Mile Rapids on the Columbia.

\section{Climatic Correlations}

He concludes his description of this phase by correlating the salmon hypothesis with the climatic characteristics of the extended time of the phase:

[Hypothesis correlating genera] climatic evidence with radiocarbon evidence at the site:]

The dates for the Milliken phase indicate that it lasted from the cool and humid climate of the early Postglacial well into the warmer and drier conditions of the Hypsithermal.

[Negative evidence:] 
No marked change in the way of life seems to have been effected by the climatic shift at this time.

[Hypothesis of salmon continuity:]

No doubt the salmon runs continued to ascend the river as before, a dependable crop for those who knew how to harvest it [1968a:14].

VI. THE MAZAMA PHASE -ca. $6000-4500$ B. C.

The dates of this phase fall within the Hypsithermal period. Borden's dates, including the date he gave tentatively for the Mazama eruption in 1965, are repeated here wi thout qualification.

Three main lines of evidence and hypotheses are presented.

1. The artifact sample size is smal1, interpreted to mean that the site was rarely visited during this long time span.

2. "...in general no marked change from the preceding phase is indicated.... Only a few new types of artifacts make their appearance" (p.14).

3. Correlated with the Hypsithermal, there is local evidence that the stream at the site "...apparently ceased to flow..." (p.14), which caused the rare use of the site.

Although Borden does not mention it, burins appear in this assemblage just as they did in the Milliken and Baldwin phases (pers. com., 1973).

I wonder if Borden has designated Mazama as a phase because a phase is defined as of limited duration. Otherwise the Milliken span of 1500 years would be doubled.

VII. EAYEM PHASE - Ca. 3500-1500 B. C. 
This is another very long culture phase, with a number of changes within the 2000 years. It is found at the Esilao Village site, where the creek "...evidently continued to flow--at least for awhile--..." (p.14) during this dry climatic period. Borden introduces his discussion of the Eayem assemblage with an hypothesis about the extent and duration of the site's occupation by the bearers of this culture:

[Regular, prolonged habitation hypothesis:]

For the approximate1y 2000 years of this phase, the Esilao site was inhabited regularly, at least during the fishing season.

[Hypothesis that this assemblage reflects technological advances:]

Certain important technological advances occurred in this period

[Evidence of new types of artifacts to support hypothesis above:]

[1] Projectiles provided with stems to facilitate hafting make their appearance.

[2] Drills of various types are added to the tool kit

[Hypothesis of use:]

and hint at the manufacture of perforated beads and pendants of bone and antler though such perishable materials unfortunately have not been preserved.

[3] A small fragment of a thin siltstone plaque decorated with incised cross-hatching was recovered, as well as two small spindle-shaped steatite objects with encircling lines.

[Hypothes is of identity of above:]

Possibly the latter are gaming pieces used in slahal, a guessing game still passionately played by the Indians of today.

[4] Among the most striking developments of this phase was the beginning of the ground slate industry [the material used in grinding in the Milliken phase was not slate], which in later periods was to assume great importance on the lower mainland and in some adjacent regions for the manufacture of projectile points, daggers, harpoon cutting blades, fish knives and so forth.

[5] The Eayem deposits at Esilao have yielded a sertes of chipped and partially ground slate points and fragments of exceedingly well-made ground and polished knives [1968a:14]. 
Borden's hypothes is of the cause of abandonment of this site is also connected with the Hypsithermal:

[Interpretation of stratigraphic evidence:]

Stratigraphic evidence at Esilao suggest that the cultural deposits of the Eayem phase ceased to accumulate around $1500 \mathrm{~B}$. C.

[Hypothesis of cause of abandonment:]

Possibly abandonment of the site at this time was necessitated by the failure of the nearby creek [1968a:14-15].

VIII. BALDWIN PHASE -ca. 1000-350 B. C.

From a general climatic change, Borden concludes that the Milliken site is an instance of a general pattern of reoccupation:

[General climatic-archaeological correlation hypothesis:] With the beginning of the cool and humid climate of the Late Postglacial. around $1000 \mathrm{~B}$. C. the streams that had gone dry during the Hypsthermal began to flow again, inviting renewed occupation of once abandoned sites.

[Hypothesis of specific instance at Milliken:]

It is probably no coincidence that after a lapse of more than 3500 years intensive reoccupation of the Milliken site coincides with the onset of modern climatic conditions [1968a:15].

Hypotheses on Cultural Richness

Borden proposes a series of hypotheses to account for the abundance of material in the Baldwin assemblage. In analyzing this assemblage, he finds some instances of continuity, and some instances of resemblance to other areas. He attributes this culture change to a variety of causes:

[General statement of kind of evidence in this assemblage:] The Baldwin phase is one of the richest and most interesting in the long culture history of the Fraser Canyon.

[Hypothesis of change by growth in local tradition:] Aside from evidence of vigorous local cultural growth 
[Hypothesis of change by stimuli from distant areas:] there are indications of cultural stimuli that emanated in far distant areas.

[First hypothesis on mechanism of cultural stimuli, by influence:]

Some of these influences may be the result of cultural diffussion,

[Second hypothesis on mechanism of cultural stimuli, by migration:]

others may have been migration borne.

[Cressman hypothesis on Hypsithermal population shifts:]

The long drought which accompanied the Hypsithermal in large parts of this continent is believed to have induced extensive population shifts, compelling for instance groups that used to live in once lush areas of the Great Basin to move into adjacent regions, west into California and northward into Oregon, Washington, and perhaps British Columbia (Cressman, et al, 1960)

[Borden hypothesis that Baldwin phase may be an instance of the Cressman hypothes is:]

Certain manifestations of the Baldwin phase may have reached the Fraser Canyon as the result of such dislocations [1968a: 15].

Borden analyzes some of the types of artifacts according to their origin, use, and significance.

[Hypothesis that chipped stone industry is an instance of change by local development:]

Continuing development of local traditions is evident in the chipped stone industry.

[Evidence of the type of change:]

Projectile point forms of the preceding phase continue but are generally smaller [1968a:75].

\section{Artifacts and their Use}

Now Borden views the same artifacts in a different way. The small projectile point is an instance of a stone-working technique used in this locality at earlier times, but modified in some characteristics. But the use of these points is an instance of a hunting technique that 
is new to the area:

[Evidence of common new artifact form:]

Particularly abundant are small stemmed points that might have armed arrows.

[Hypothes is of time of introduction from elsewhere of new hunting technique:]

Very likely, the bow and arrow was introduced in the Fraser Canyon region in this period [1968a:15].

Another new complex is found in the Baldwin assemblage. This

is how Borden introduces the hypotheses:

[Hypothesis of first utilization of a vegetal resource:]

While the small projectile points suggest new hunting techniques, the appearance of mortars and pestles in this phase may indicate utilization of certain resources in vegetal foods that were neglected in earlier periods.

[Hypothesis of source of this complex:]

The mortar and pestle complex evidences affinities with regions to the south, the Columbia River valley and the Great Basin where such utensils and associated economic activities have great time depth [1968a:15].

\section{Discussion}

As I was analyzing this section of Borden's paper, I noted additional hypotheses to explain uses of the mortar and pestle. I also questioned the presupposition that I interpreted to be underlying Borden's statement, "...such utensils and associated economic activities (my emphasis) have great time depth" (p.15). It seems to me that this implies that mortar and pestles have a group of associated economic activities. As Borden implies when he discusses the composite nature of culture (1968a:22), old tools are often put to new uses, in new combinations. It may therefore be important to look for the variation in economic or other activities associated with these utensils.

One of my hypotheses for their use was that dried salmon may 
have been processed with these implements. When I mentioned my alternatives to Borden, he went over them, supplying the additional evidence that in each case tended to disconfirm my hypotheses and to support his hypothesis.

Mortars and pestles are not found in the phase before or after this one, so he was looking for evidence of some use that also varied in this time, perhaps connected to the climatic conditions. Borden's exact meaning in the preceding hypothesis was this:

The appearance of mortars and pestles may indicate utilization of acorns from the Garry 0ak, which had been neglected in earlier periods.

The present distribution of this species of oak, and the climate in which it flourishes, suggest that it was available and especially plentiful at this time and place. Thus Borden's hypothes is of conditions that vary with the variation in artifact presence is more probable than hypotheses suggesting temporary use of a resource which is continuous during a long span of time.

\section{Stone Abrading}

Borden turns to evidence of abrading in stone manufacture:

Abrasive techniques are now applied to tough stone as shown by the presence of numerous ground nephrite chisels and a few larger sawn and ground blades

[Hypothesis of blade use:]

that probably were hafted and used as adzes.

[Hypothesis of method and source of culture change:]

These innovations may have diffused upriver from the coast.

[Evidence for hypothes is above:]

As we shall see, neatly made chisels and adzes are important 
In Fraser delta sites dating to the first millennium B. C. [1968a:15].

\section{Discussion of Woodworking Complex}

Here is an hypothesis which is contrary to one in Borden's ear$7 y$ papers, which said that this part of the woodworking complex was derived from the interior. I was puzzled about his choice on the basis of the evidence in this paper. The delta sites that are contemporary with the Baldwin phase are Locarno Beach, the earlier, and Marpole, the later. He does not have evidence from the coast that is earlier than the Baldwin phase itself. On the other hand, in the preceding Eayem canyon phase, was the beginning of the ground slate industry. Other kinds of stone were ground in the earliest, Milliken, phase. From the time depth of the grinding technique in the canyon, I would have expected Borden to maintain his earlier position of inland to coastal diffusion of the ground adze, and to treat it here as a step in local cultural development. Perhaps this is no longer an either/ or relationship, so that Borden really treats the delta and canyon as one local area, called in this paper the "Lower Mainland", with such close relationships that innovations will be immediately known within it.

Borden responded to my comments in this section with his current viewpoint (1974) viewpoint on the woodworking complex:

1. The mauls, a local specialization of a pestle, and

2. The wedges, are common in early interior sites, probably of Asiatic origin.

3. Earliest evidence of adze blades, however, is found on 
the coast.

There is no evidence that adze blades passed through the intermontane corridor. All three came together on the coast at a relatively late time [Borden, pers. com., 1974].

\section{Microblades}

Borden now discusses the microblades and cores in the Baldwin phase. Since Borden uses this complex as diagnostic in distinguishing various cultures (1962a), he writes of its special significance.

[Summary of evidence of source and first New World occurrences of microblades:]

The technique of detaching very small parallel-sided prismatic flakes with very keen edges, so-called "microblades," from specially prepared polyhedral cores of cryptocrystalline stone was introduced into the New World from Asia probably in late glacial or early in postglacial times.

[MuTtipurpose use of this tool:]

The microblades produced by this highly specialized technique could be put to many different uses.

[Summary of area and route of trait dispersal:] Subsequently, this technology and associated practices became an important part of numerous arctic and subarctic cultures, some of which appear to have passed southward through the intermontane interior of British Columbia (Borden, 1962; Sanger, 1963, 1966) [Borden 1968a:15].

[Hypothesis of significance of microblade evidence in Baldwin phase:]

It is of extreme interest that this boreal complex of ultimate Asiatic origin is also present in the culture of the Baldwin phase [1968a:15-16].

In later papers (1969c; 1973), the reason for Borden's "extreme interest" is clarified. In these same papers his use of the phrase "this early boreal complex" will be expanded into general theories of early population movements in the New World. Burins are also present in this assemblage (Borden, pers. com., 1973).

Ornaments 
Borden now discusses the ornamental and decorative artifacts in the Baldwin assemblage:

[Hypothesis of varied cultural-interaction as cause of cultura] efflorescence:]

The interaction of local cultural tradition with widely varfed alien influences during this period appears to have generated a cultural efflorescence

[Evidence of cultural efflorescence:] which is reflected in many remarkable non-utiliterian artifacts.

[Hypothesis of artifacts missing due to poor preservation:] Fortunately, the Indians of this phase used in addition to bone, antler and other perishables which have not been preserved,

[Evidence of ornamental objects:] varlous non-perishable soft stones, such as clay shale, phyllite, steatite, lignite, and graphite, which could be worked with techniques similar to those applied to bone and antler. Here for the first time are ornaments galore, many hundreds of disc beads, oval and cylindrical beads, pendants, grooved or perforated for suspension, delicately formed rings, earspools and labrets.

[Hypothesis of labret significance:]

Probably status symbols, these latter ornaments were worn in a perforation of the lower lip [1968a:16].

If "utilitarian" can have meaning at two levels of abstraction, it is possible that these objects could be instances of basic or general economic utility. A useful artifact might be a stick to dig with, or an implement for hunting. A more general use could be assigned to those artifacts which are part of the mechanism for maintaining the economic system of an area. If differential status and wealth provided such a mechanism (Suttles 1968:esp. 66-68), then these ornamental objects may be of the most basic utility in the survival of a population. In responding to these comments, Borden notes his agreement. His usage of "non-utilitarian" is a convention. He does regard the origin 
of art as utilitarian (Borden pers. com., 1974).

\section{Sculpture}

The Baldwin assemblage also includes sculpture:

Present also in the Baldwin phase are the earliest known sculptures of the Pacific Northwest, small animal figurines: fish, birds, bear, and other creatures that cannot be readily identified. There is even a small effigy of a human head with a mask-11ke face.

[Hypothesis of similarity with, and therefore origins of Tater Northwest Coast art:]

Though simple and rudimentary, there is manifest in some of this sculpture the dawning of the famous Northwest Coast art [1968a:16].

Borden's summary hypothesis expresses his estimation of the culture change represented in this phase:

Space limitations make it impossible to do justice to the Baldwin phase,

[Summary Baldwin hypothesis:]

but enough has been presented to indicate the quantum leap which separated this phase from all that had gone before in the culture history of this region [1968a:16].

IX. SKAMEL PHASE - Ca. 350 B. C. -200 A. D.

\section{Evidence}

Now there is a change in the archaeological evidence. This is

Borden's evidence and the hypotheses for interpreting that evidence:

[General hypothesis of cause of ending of Baldwin phase:] The cultural efflorescence of the Baldwin phase seems to have come to an abrupt end in the canyon some time in the fourth century B. C. with the appearance of an alien group on the river.

[Summary of negative archaeological evidence for preceding hypothesis:]

Virtually everything that was characteristic of the Baldwin phase vanishes. 
[Four types of archaeological evidence characteristic of this phase, also confirming the preceding hypothesis:]

[1] Hall marks of the newcomers were diagonally corner-notched triangular profectile points, that is, barbed arrow heads with expanding stems.

[2] These people utilized many fine cryptocrystalline stones that seem to have been unknown to their predecessors

[3] and they employed a great variety of small specialized tools: drills, gravers, etc.

[4] They also seem to have introduced the pithouse, the circular semisubterranean habitation which was to become the characteristic winter dwelling of the groups in this region until the nineteenth century.

[Evidence for dating the phase:]

Our main trench at Esilao sliced through such a house which had been destroyed by fire. Carbon 14 analysis of two charcoal samples from charred timbers of this house indicates a date of about 80 B. C. for this event.

[Evidence of artifacts from this house:]

Among the charred remains of the dwelling were fragments of cordage, matting, wooden artifacts, and portions of a wooden box embellished with deeply engraved curvilinear designs [1968a:16].

\section{Discussion}

This completes Borden's discussion of the Skamel phase. I note two questions that are not raised. Do the designs on the box also represent one of the origins of Northwest Coast art? Does Borden interpret this pit house, which in 1956 he regarded as perhaps diagnostic of Salish people in the Kootenay region, to be evidence that these intrusive people were ancestors of the Salish people in the canyon, particularly since the projectile points with expanding stem are new characteristics at the same time?

In response to the first question, Borden said that the Skemel box could be one early origin of Northwest Coast art. In response to 
the second, he referred to his discussion (1969d) of this period, and then added this statement about the current state of archaeological theory:

We are not yet ready to answer this question. We are approachIng a threshold where we will have a clarification of these relationships. Phases are very complex, and it is very difficult to detect population movements in the archaeological record [Borden pers. com., 1974].

\section{DELTA SITES AND GEOLOGICAL CONDITIONS}

Borden now writes about the delta sites, the earliest known of which begin at about the same time as the Baldwin phase. (By 1974, excavations at St. Mungo Cannery and Glenrose Cannery sites have revealed early components that are about the same time as the Milliken phase, Borden, pers. com.) After he has followed the delta cultures to historic times, he wi]l return to the canyon and the final two phases there.

Borden begins with a list and location of the delta sites, and geological information about the delta formation. These are the sites:

1. Point Grey

2. Locarno Beach

3. Marpole

4. Whalen Farm

5. Beach Grove

6. Stselax Village
In the

city of

Vancouver.

On the Canada U.S.A. border, on the shore of Boundary Bay, Point Roberts Peninsula

"...base of the Point Roberts upland on the southern margin of the delta alluvium" (p.17) Musqueam Reserve, mouth of the north arm of the Fraser

[Summary of phases and extent of radiocarbon data:]

On the basis of available data (H. I. Smith, 1903; Borden, $1950 ; 1951 ; 1954 ; 1955 ; 1962)$ and twelve radiocarbon dates the known prehistory of the delta region can be divided into five phases. 
[Statement implying hypothesis of earlier local coastal phases yet to be found:]

It is necessary to stress the known prehistory, because none of the delta sites investigated to date has yielded evidence earlier than the first millennium B. $C$. By that time the Northwest Coast culture patterns are well blocked out.

[Hypothesis predicting important early local sites:]

The Strait of Georgia is recognized as a potentially important area for the initial stages in the development of Northwest Coast culture, and the mouth of the Fraser is viewed as the most logical and ideal locality for the early transition from a riverine economy to utilization patterns aciapted to a coastal environment (Kroeber, 1947:30; Borden, 1960:117-118; 1962:11-12).

[Hypothes is of location of sites to test preceding hypothesis:] If this thesis has any validity then the data on the stages which preceded the earliest known phases of our delta sequence must still lie buried in the ground, probably in sites farther upstream from those investigated to date.

[Geological evidence to support preceding hypothesis:]

The Fraser is constantly building its delta westward at a rate of roughly 1000 feet in one century.

[Consequence of evidence above:]

As a result, a site like Marpole which 2000 years ago faced salt-water now is more than three and a half miles from the river mouth [1968a:17].

XI. LOCARNO BEACH PHASE - Ca. 1000-100 B. C.

Most of this account is similar to Borden's earliest papers. This

phase has two components,

...one being Locarno Beach in the extreme northwestern part of the delta region and the other, Whalen $I$, that is, the earlier horizon at the Whalen Farm site, in the southwestern part of the delta [1968a:17].

Dating

His dating evidence is stated this way:

Three radiocarbon dates suggest that this culture was in operation several centuries before and after 500 B. C. [1968a: 17]. 
Assemblage

Borden repeats these main characteristics of this assemblage: toggling harpoons, slate grinding of "...large faceted projectile points and thick-backed knives..." (p.17), a stone chipping industry of relatively minor importance, and bone points ground in the same way as stone points. "Very long dagger-like bone points with small barbs were also in use..." (p.17). Giant mussel shell was used to make chisels and adzes.

Adze blades were also ground of bone, cherty slate and nephrite (Borden, 1962:Plate VI, $j-k$ ). Adzes are $f e w$ in number and small with narrow bit suitable for working bones, antler, and wood on a small scale. Some nephrite adzes bear evidence of sawing. Cobbles and pebbles were used as hammerstones. Wedges of wapiti antler are rare and of small size. Eyed needles were made of mammal and bird bone [1968a:17-18].

The atlatl, part of which is mentioned below, is "a throwing device which gives extra leverage to the arm...was used to propel darts and harpoons..." (p.17). This is Borden's first published identification of this object, the atlatl hook, but in 1958 it was the subject of a paper, which he subsequently revised and published in 1969.

Ornaments include perforated graphite and tooth pendants, earspools, and labrets (Borden, 1962:Plate V, $j-k$ ). An atlatl hook is carved realistically in the form of a human head wearing a cone-shaped hat and a medial labret [1968a:18].

\section{Food Quest}

This is Borden's summary of the food quest of the Locarno Beach occupants:

Although the people of the Locarno Beach phase did not neglect land game: toggling harpoons and faunal remains indicate that sea mammals, including seal, sea lion, and porpoise, were frequently hunted. The main midden fill,--like that of all delta sites investigated--consists of the discarded shells of 
mussels, cockles, and clams, Indicating the importance of molluscan fauna in the diet of these coast dwellers [p.18].

\section{Preservation of Artifacts}

Borden adds a note about bone and antler preservation:

The calcium carbonate of the shells, incidentally, contributed to the excellent preservation of bone and antler objects, which because of the acidity of the soil have completely disintegratad and hence are absent in the cultural deposits of the canyon sites [p.18].

The only artifact of bone or antler recovered in the canyon was one ant-

ler wedge. This underlines the importance of proper faunal analysis

from Borden's coastal excavations.

Woodworking

Borden repeats his early hypotheses about the absence of heavy duty woodworking at Locarno Beach:

[Hypothesis of improbabi]ity of large plank houses and dugout canoes:]

...it is difficult to envisage large-scale woodworking, such as produced the large plank houses and dugouts of later periods, with the type of tools that have been recovered to date.

[Hypothesis of types of boats and habitations:]

Perhaps these groups used skincovered boats and habitations different from those of later periods [1968a:18].

(These hypotheses may be testable in the waterlogged site being excavated at the Musqueam Reserve, 1972-1974).

\section{Seasonal Occupation of a More Northerly or Island Culture}

Borden concludes with hypotheses on seasonal occupation of the del ta sites, with an island or northern center for this culture. In this paper, he does not amplify his reasons for not suggesting an early southern coastal center, as he had done for early interior influences, 
but in conversation he has given one reason. Ground slate, so important at Locarno Beach, fades out of assemblages south of the Fraser delta, but is important in sites to the north (pers. com., 1974).

[Hypothesis of island center, seasonal delta occupation:] The people of the Locarno Beach phase may have had their main centres on the islands in the Strait of Georgia and visited the delta sites only seasonally.

[Hypothes is of contemporary and earlier center to the north:] Other contemporary centres as well as antecedent stages of this early maritime culture, however, may yet be found farther north on the coast [1968a:18].

XII. MARPOLE PHASE- ca. 450 B. C. -500 A. D.

This phase has components at Marpole, Point Grey, and Beach Grove, which have been excavated, and is represented "...through surface finds from at least three other delta sites" (p.18).

[Hypothesis of time relation to Marpole; revised since 1962a:] Indications are that the initial manifestations of the Marpole culture in the Fraser delta region overlapped in time with the terminal stages of the Locarno Beach phase [p.18].

\section{Typical Northwest Coast Culture}

Borden elaborates on a theme from all of his works about Marpole, saying that this is a typical Northwest Coast culture:

[Hypothesis of Marpole as typical of Northwest Coast:] While important aspects of later coastal culture are anticipated in the Locarno Beach phase, in the Marpole phase the typical Northwest Coast patterns are already well blocked out maritime orientation, highly developed woodworking, large villages with commodious houses along the shore, impressive achievements in the plastic arts, and evidence hinting at wealth emphasis and stratified society [1968a:18].

This clause "...and evidence hinting at wealth emphasis and stratified society" is new with this publication. 
Salmon Base

Again Borden emphasizes the similar salmon basis of this society:

Salmon, was the basic staple, as it was of all other phases of the lower mainland, with the possible exception of the Pasika phase [1968a: 18].

Comparisons with Locarno Beach and Eayem Phases

The Marpole phase differs from Locarno Beach in the gear used in hunting and fishing:

[Evidence of differing gear:]

Whereas, for instance, in the Locarno Beach phase reliance for taking sea mammals and large fish was on toggling harpoons, in the Marpole phase, almost exclusive use was made of barbed harpoons of wapiti antler (Borden, 1962:Plate II, a-f; Willey, 1966:390, Fig.6-52, a-h).

[General statement of variety of gear at Marpole:]

In the brief space available it is impossible to convey a notion of the wide variety of hunting and fishing gear and auxiliary equipment employed in the Marpole phase. The chipped stone industry was relatively more important than in the Locarno Beach phase, especially for projectile points, although large numbers of knives for butchering fish were ground of slate (Borden, 1962:Plate IV, c-d, g-j; Willey, 1966:389, Fig.6-48, d).

[Comparison of Marpole and Eayem knives:]

These knives, interestingly, are very similar to those occurring 2000 years earlier in the Eayem phase in the Fraser Canyon. They are very thin, of even thickness, and ground over the entire surface [1968a:19].

Borden usually means that these similarities are interesting clues to culture influence or population movements.

Woodworking, Canoes, and Habitations

He now reviews the abundant evidence of the three heavy-duty tools for woodworking. From the evidence of these tools and faunal remains he suggests this hypothesis, my emphasis: 
From the presence of such tools and the remains of marine fauna we may reasonably infer the use of dugouts in fishing, sea mammal hunting, and for travel to nearby localities (p.19].

When this hypothesis is compared to the quotation from Wilson Duff's ethnography of The Upper Stalo Indians, which forms the conclusion of this paper, we may conclude that Borden traces back at least as far as this Marpole culture the significant, close connection known in historic times between all the Indian groups on the Fraser and in the Gulf of Georgia region.

Borden again reports the evidence of post hole and hearth remains which show that Marpole residents lived in large plank houses that were Tike those of recent times.

\section{Artistic Endeavors}

When he discusses sculptured objects, Borden's hypothesis presumes that skills for "useful" tasks precede skills for "decorative" tasks:

[Hypothesis that sculptures are impressive feature of Marpole phase:]

Among the most impressive cultural features of the Marpole phase are sculptures in antler and stone (Borden, 1962: Plate V, a-c, i-o, 9: Willey, 1966:390, Figs. 6-50 and 6-51, p.392, Fig. 6-55).

[Hypothesis of primacy of skills in useful endeavors:] The mastery of working antler acquired in the manufacture of wedges, harpoons and other devices, was put to skillful and imaginative use in the creation of exquisite realistic and semiabstract carvings and engravings of birds, frogs, fish, sea-monsters, and human figures.

[Evidence of stone scuipture objects:] Soft stones, such as steatite and siltstone were treated in much the same way in the carving of fish effigies and small seated human figures embracing a bowl-like container. Characteristic of the Marpole phase, moreover, are numerous stone vessels, some of these perhaps mortars, of lava, granitic 
rock, and sandstone [1968a:19].

The ornaments in this phase add to the contrast with Locarno Beach:

[Evidence of ornaments:]

An abundance and great diversity of beads and pendants of many different materials add luster to the Marpole phase. Gorgets and labrets are also present [p.19].

[Evidence of Locarno Beach burials:]

The dead were buried (sometimes with grave additions) on the inland slope of the midden mound [p.18].

[Evidence of Marpole burials:]

The dead were buried on the inland slope of the village midden. Most burials are rather simple affairs, a few are lavishly furnished [p.19].

Borden summarizes Marpole in relation to other coast phases:

[Long cultural development c] imax hypothesis:]

It is difficult to do justice to the rich Marpole culture in a brief summary, but obviously this phase represents a climax of long cultural development.

[Hypothesis of nature and length of climax:]

A cultural intensity and complexity was attained here at that time, which on this southern part of the coast was neither maintained nor reached again in later periods [1968a:19].

\section{Comparison with Baldwin Phase}

In addition to the similarity of Marpole knives to those from the Eayem phase, Borden points out "broad affinities" to the Baldwin phase:

[Hypothesis of affinity of Marpole and Baldwin phases:] Mention should be made of the obviously broad affinities that exist between the culture of the Marpole phase and that of the somewhat earlier Baldwin phase in the Fraser Canyon. Many of the upriver traditions and practices were continued and further developed in the delta region during the liarpole phase [p.20].

Among these common characteristics are mortars, abrasive techniques, stone sawing, beads, pendants, labrets, ear spools, and sculpture. Microblades, mentioned in 1962a for recent Marpole deposits are 
not mentioned in this summary. It is possible that Borden has re-assigned them to the time of the whalen II phase.

[Hypothesis that time relation of Baldwin phase conclusion and Marpole beginning is significant:]

Intriguing also is the fact that the climax at the mouth of the river occurred in the centuries after the arrival of the people of the Skamel phase had brought an end to the Baldwin phase in the canyon region.

[Test area and time for the type of relationship of preceding hypothes is:]

Future work in the intervening areas of the lower mainland will no doubt illuminate the events and developments which occurred during this interesting period [1968a:20].

XIII. WHALEN II PHASE - Ca. A. D. 350-750

\section{Discussion}

From his earliest description of Whalen II, Borden has interpreted the assemblage as evidence of a new people from the interior at the delta of the Fraser (1950a:24). In this section Borden now can show a similar assemblage up the canyon at an appropriately earlier date, also of an "alien people". He does not mention this canyon Skamel phase by name, but only refers to the appearance of side-notched and cornernotched points with expanding stem coinciding "...with the end of the Baldwin phase" (p.20). In his earlier works, Borden has hypothesized that Whalen II marks the arrival of the proto-Salish on the coast (1950b:245). In another early work (1956:97), he grouped side- and corner-notched points with expanding stem, and pit houses, as characteristic of Salish assemblages in the Kootenay area of the interior of British Columbia. He does not say in the Skamel section of this paper that these were proto-Salish people. He does not say that those protoSalish people displaced the Marpole people in the delta just as they 
displaced the same or similar Baldwin people in the canyon. However, I think these are implicit in the arguments of this 1968 a paper if he is following the same logic as he did in his earlier writings.

\section{Distinctive Features}

This is how he introduces the Whalen II phase:

[Evidence in recent Marpole deposits:]

The appearance in late deposits of the Marpole phase of traits that are new to the delta

[Hypothesis of new population in the delta:]

heralds the arrival at the mouth of the Fraser of an alien people

[Hypothesis of cause of Marpole decline:]

and probably related decline of the Marpole phase culture.

[Whalen II components:]

Information on this new development comes mainly from the upper cultural horizon of the Whalen Farm site.

[Dating of phase:]

The Whalen II phase has a radiocarbon date of A. D. 396 but its beginnings are probably somewhat earlier.

[Characteristics unique to Whalen II assemblage or absent from it:]

[1] A striking feature of the Whalen II assemblage is the absence of certain complexes and traditions, such as [a] the ground slate industry and [b] stonecarving, which were prominent in earlier local phases.

[2] Moreover, elements hitherto unknown in the delta suddenly appear [i.e. not a few in one leve1, more in the next, but many in this level with none beneath].

[Examples of new traits:]

Among such traits are microblades..., olivella beads, and new types of chipped projectile points, particularly side-notched and corner-notched forms with expanding stem.

[Hypothesis of similarity with Skamel artifacts:]

The appearance of similar points in the Fraser Canyon several centurles earlier, we may recall, coincided with the end of the Baldwin phase [1968a:20]. 


\section{Fusion of Traits}

In addition to these distinctive features, or absences, in the Whalen II phase, Borden interprets other aspects of the assemblage as "a fusion" of traits from one or the other of the two earlier assemblages. This is an hypothesis from his earliest paper (1950a:25). This assemblage contains toggling harpoons like those of Locarno Beach and heavy woodworking tools and large plank houses like those of Marpole. Borden adds an hypothesis similar to the travel-by-canoe hypothes is in his Marpole division:

[Hypothesis on dugout canoes in Whalen II culture:] We may reasonably infer moreover, that they used dugout canoes capable of navigating the waters of the Strait of Georgia [1968a:20].

On the basis of one artifact, Borden proposes another hypothesis:

[Hypothesis of master carver at Whalen II:]

Evidence that the Whalen II people had master carvers among them

[Evidence for hypothes is above:]

is provided by a handsomely sculptured human figure on the haft of a beaver tooth carving tool found with a midden burial at the Whalen Farm site (Duff, 1956[C]: P1ate I,b)

[1968a:20].

\section{INTERVENING PERIOD}

There are no sites to provide evidence for the next interval.

This is Borden's hypothesis for a period of synthesis:

Unfortunately, we have as yet few data for the centuries immediately following the Whalen II phase, that is, approximately the time between A. D. 750 to 1250 .

[Hypothesis that some surface finds represent this period:]

But surface finds from a site, probably dating to this period, 
[Evidence from Stselax:]

and the altural materials of the last major phase in the Fraser delta

[Hypothesis of period of synthes is from the sites above:] suggest that this intervening period was one of continuing synthesis. The amalgamation of old and new elements eventually led to the final prehistoric phase in the delta region: the Stselax phase [1968a:20].

XV. STSELAX PHASE -Ca. A. D. 1250-1808

This is clearly labeled a Coast Salish phase, from a long-studied site whose assemblage has provided Borden with evidence for hypotheses since his early papers. Borden sometimes refers to the inhabitants of this site using the term "Salish" and sometimes the term "Stalo", which means "River" in the Salish language of that area. The Salish people along the river are thus referred to as Stalo Indians. Borden gives additional ethnographic information about them in the concluding section of this paper.

\section{Cultural Stability}

[Evidence of culture stability:]

Culture during the Stselax phase appears to have been remarkably stable. No obvious changes are archaeologically discernable until the advent of historic times [1968a:21].

Because of this stability, Borden can rely on ethnographic evidence since 1808 as well as the archaeological evidence.

\section{Fusion of Traits}

The assemblage at Stselax is like Whalen II in containing both toggling (composite), harpoons and the heavy duty woodworking tools and adds ground slate tools, "...another ancient delta tradition" $(p .21)$ 
[Evidence of stone tools in assemblage:]

Rectangular ground slate knives, used in butchering fish resemble Marpole phase specimens of similar shape. They are thin, of even thickness and ground over the entire surface. The chipped stone industry is reduced to a minor role, but a few side-notched and corner-notched projectile points, or arrow heads, are present $[p .21]$.

Borden describes the Coast Salish houses, built with this triad of woodworking tools:

These relatively simple implements enabled the Coast Salish Indians to ready the materials for the construction of huge rectangular houses, 500 to 600 feet or more in length by 60 feet deep and from 12 to 15 feet high. The walls, consisting of long, hand-split cedar planks, suspended between rows of paired uprights, were not connected structurally with the massive framework which supported the single-pitched cedar plank roof. Large sea-worthy canoes were made with the same basic tools [1968a:21].

\section{Changes in Artistic Expression and Burial Customs}

Artifacts of two earlier complexes are missing or rare:

[Negative evidence of stone carving:]

No evidence was found to indicate that the Stalo Indians of the Stselax phase used stone vessels or practised stone carving.

[Rare ornamenta] objects:]

Striking, moreover, is the paucity of personal ornaments in the Stselax assemblage. This is in marked contract with earlier phases, especially with Marpole [1968a:21].

[Evidence of new traits, connected with weaving of blankets and their method of use:]

There are, however, new traits. Thus, archaeological evidence from Stselax supplements ethnographic data on the spinning and weaving of mountain goat and dog wool. Decoratively carved spindle whorls of whalebone testify that these textile arts were practised centuries ago. Gracefully formed and embellished pins of wapiti antler served for pinning together woollen blankets worn over the shoulders.

[Evidence of combs:]

Also present are antler combs with zoomorphic, anthropomorphic, or other decoration $[1968 \mathrm{a}: 21]$. 
Burial customs have changed in this phase.

[Hypothesis of date of new custom:]

By contrast with earlier groups in the delta region, who practised inhumation, the inhabitants of Stselax apparently, from the beginning of the settlement, disposed of their dead by wrapping them in mats or blankets and placing them in mortuary

houses a hosrt distance from the village [1968a:21].

It is deep under such a mortuary house site that excavations at Musqueam in the 1970's reveal evidence of Marpole and Locarno Beach cultures.

XVI. EMERY PHASE ca. A. D. 200-1200

This phase is named for the late Chief Emery of the Thompson Indians who, with his wife, fished at this site during the time that these archaeological investigations were being carried (Borden pers. com., 1974).

Borden's evidence of prehistoric cultures at the Esilao Village site in the canyon has been organized and interpreted with great difficulty. In the course of his ensuing description of these last two canyon phases he explains the working conditions that have led to hypotheses of a particularly tentative nature.

\section{Definition of Culture}

Borden's introduction to the Emery phase is a definition of "culture" which is the logical basis of his grouping this material into a phase:

Numerous anthropological studies have shown that a culture "is a very composite phenomenon, in which elements from widely different sources and of greatly different ages gather together, not into an accidental and incoherent conglomerate, but into a harmonious, working organism" (Birket-Smith, 1929, 222). 
[Hypothes is that earlier (probably Baldwin, Marpole, Whalen II, and Stselax), phases on the Fraser have been instances of such "cultures":]

We have seen repeated evidence of this culture building process in the preceding pages.

[Hypothesis that the Emery phase is an instance of the BirketSmith definition:]

It is apparent again in the Emery phase which in the Lower

Fraser Canyon follows upon the Skamel phase [1968a:22].

\section{Assemblage and Hypotheses}

These are the data and hypotheses that Borden presents:

[Tentative nature of hypothesis partly due to small sample size:]

Information on this culture phase is still sparse,

[Hypothes is of fusion of Skame] and Marpole/Baldwin characteristics:]

but available data suggest a fusion in this period of Skamel phase culture with traditions characteristic of the Baldwin and Marpole phases.

[Evidence of artifacts similar to Marpole/Ba]dwin:]

Among such. latter traditions is work in steatite and phyllite. During the Emery phase, vessels, both plain and zoomorphic were fashioned of these soft stones as well as seated human figures, very much like those of the Marpole phase.

[Possible evidence of both carving and weaving:] Moreover, a large, impressively embellished spindle whorl of black steatite from disturbed deposits at the Milliken site has been tentatively assigned to a late stage in this phase.

[Hypothesis of outside influence:]

Indicative of strong outside influences during the Emery phase

[Evidence for hypothesis above:]

is the first evidence of pipe smoking. Some effigy pipes are magnificently carved.

[Additional evidence of Marpole type of influence:] One specimen represents a seated human figure strongly resembling in posture and details of execution the larger seated figurines which first appear in the Marpole phase at the mouth of the river [1968a:22].

Discussion 
It had seemed to me that the unwritten but implicit part of the argument of the influence of these "non-utiliterian" objects might be as follows:

Since details in the style and workmanship of such "nonutilitarian" artifacts are highly unlikely to be similar by chance.

Whereas workmanship on objects for use may be similar because the use dictates or demands similarities within more strict limits.

Non-utilitarian similarities are more probably diagnostic of influence, and utilitarian similarities less positively so.

Borden states that this is too broad a generalization, which would result in some great errors. For instance, carvings of seated human figures shaped as bowls are found all over the world, but he and other archaeologists would not postulate cultural connections because of this (Borden pers. com., 1974).

[Hypothesis that richness of phase is the consequence of synthesis of many influences (similar to a Baldwin hypothesis):] The merging of varlous traditions and influences during the Emery phase appears to have produced a cultural synthesis which made this phase one of the richest in the long culture history of the lower Fraser Canyon [1968a:22].

XVIII. ESILAO PHASE -Ca. A. D. 1200-1808

\section{Components}

Borden estimates that this phase is the exact contemporary of the Stselax phase on the delta. It is known from two components, the vil- 
lage site and what was probably its burial ground, the Milliken site. Because

...small neatly made side-notched points, a type which is believed to have been in use in the canyon at least by $A . D$. 1200 [are found in one Milliken burial dated at A. D. 1380, this]...date is assumed to represent the approximate beginning of this final phase $[p .22]$.

\section{Village Site and Pit House Description}

It is important to picture the village site, and imagine the mechanical mixture in which the artifacts are found, in order to appreciate the steps in formulating any hypotheses about the final three phases in the canyon. First Borden gives the dimensions of the site in relation to the dimensions of the pit houses:

The four pit houses that comprise Esilao Village occupy virtually all of the available flat ground at the site, an area measuring barely 100 by 200 feet [p.22].

Borden then describes a typical pit house. We can imagine the earlier artifacts being moved from their original positions, some being placed on top of the roof of the new structures with the sod and soi1. He then indicates that he does not have evidence as yet that these pit houses are of typical form. This is his description of an ethnographically typical pit house of this area:

A typical pit house is circular in plan, from 20 to 35 feet in diameter and often up to 5 feet deep. The framework of the roof consisted of four main rafters, each supported by one upright post and braced by two side rafters. The butts of the rafters were enbedded in the ground around the edge of the house-pit, while the butts of the upright supports were sunk in the house floor. The superstructure was completed by covering the open spaces with cross-pieces and bark, and then plling sod and soil on top of these. An opening at the apex of the conical roof served as doorway, window, and chimney, and a notched log ladder reaching from the house floor to the aperture in the roof was used to enter and leave the dwelling. The main advantage of these semi-subterrnean habitations was 
that they afforded warmth and protection against the rigors of winter. With the onset of warmer weather, the Indians moved into mat lodges of light construction [1968a:22-23].

The Esilao houses may vary from this general pattern:

[Tentative hypothesis of general similarity:]

While the dwellings at Esilao may have conformed in general to the usual plan of pit houses,

[Evidence of one variation in shape:] at least one partially excavated structure at the village appears to have deviated from this design in that it is subrectangular rather than circular in outline [1968a:23].

\section{Problem}

Borden states the problem of interpretation:

Efforts to assemble artifacts which can be assigned with confidence to the Esilao phase are complicated by the scrambled state of a major portion of the later deposits at Esilao Village and the Milliken site. The disturbed condition resulted from the earth moving activities of the Indian occupants in late periods of canyon history. Much additional work is required before it will be possible to detail the composition of a typical Esilao phase assemblage [p.23].

\section{Discussion}

Borden must rely on the types of artifacts from other, dated, sites. His reasoning then assumes that artifacts from such nearby sites for the period after 1200 A. D. can most safely be assumed to be diagnostic of this period. The Esilao Village site cannot be used for evidence of the unusual or unique. He must assume that its assemblage is similar to those of nearby contemporary sites.

\section{Assemblage}

In beginning to define the Esilao assemblage, this is what Borden writes: 
[Hypothesis of evidence with highest prior probability:] We are on relatively safe ground with projectile points which are distinctly different from earlier types. The projectiles of the Esilao phase are generally smaller and lighter than those of earlier periods. This miniaturization trend continued even during the Esilao phase itself until finally some points are only $1.4 \mathrm{~cm}$. long

[Evidence of three types of Esilao projectile points:]

[1] As mentioned above, at the Milliken site small triangular side-notched points are associated with burials of the Esilao phase. In addition to several variations that were developed on this basic theme, [2] there are also small triangular stemmed points with square shoulders and some with sloping shoulders.

[3] Another distinctive type is a small delicate barbed point with markedly concave edges [1968a:22].

Other artifact types that Borden interprets as belonging to this

phase are a variety of specialized forms, and many of ground slate:

[Evidence of specialized stone artifact types:]

The assemblage of the Esilao phase also includes endscrapers, drills, small endblades for knives, and considerable numbers of abraders.

[General statement that there is increase in proportion of ground slate from earlier assemblages:]

Ground slate artifacts have increased tremendously [1968a:23].

\section{Ground Slate and Fish Processing}

Borden moves from the artifacts of ground slate to ethnographic

evidence in this passage:

[Evidence of large proportion of fish knives:]

Most of these are fish knives, generally rectangular in outline and similar to those of earlier phases.

[Hypothesis that evidence above is instance of continuity of salmon catching and processing:]

These implements point up the continuing importance of salmon fishing and processing.

[Ethnographic evidence confirmatory of preceding hypothesis:] Evidence from the historic period indicates that great quantities of salmon were butchered, filleted and prepared for winter storage by drying them in large open racks, exposed to the 
warm breeze which flows almost continuously through the canyon (Duff, 1952:18) [Borden 1968a:23].

Woodworking

When Borden compares canyon and delta assemblages, he notes a difference for which he suggests an hypothesis:

[Evidence of scarcity of woodworking tools in canyon:] Conspicuous by their paucity in the canyon sites are heavy duty woodworking tools which are so common in Fraser delta deposits of the last 2000 years.

[Hypothesis to explain evidence above:]

The contrast in the incidence of such tools may reflect the difference in house types in the two regions. The large planks for the coastal houses were split from cedar logs with wedges and stone handmauls, tools which were not required in readying the timbers and other structural materials for semisubterranean lodges [1968a:23].

After puzzling over the order in the reasoning, which seems to be of this form: contrast in tool types may reflect contrast in house types, I conclude that Borden means that these aspects of the culture, tool and habitation, fit with each other. Because of instances like these, we can move confidently when we infer from tool to habitation form. (The variable of easily split cedar varieties is not mentioned.)

Weaving

There is almost no archaeological evidence for the weaving of dog and goat wool blankets, which is known ethnographically. Borden assumes that this weaving took place at the Esilao Village "as in the Coast Salish area generally..." (p.23).

[Negative evidence:]

Even in the most recent deposits of the Esilao phase, artifacts of bone and antler are virtually absent.

[Smal1 amount of evidence:] 
Among the few faunal remains recovered are the vestiges of horn cores of mountain goats.

[Ethnographic evidence:]

These animals were hunted not only for their meat, but especlally for their fleeces. As in the Coast Salish area general$1 y$, the woolly hair of the mountain goat was combined with the hair of a spectal breed of woolly dog and spun and woven into heavy blankets $[1968 a: 23]$.

\section{Smoking and Ornaments}

There is archaeological evidence for smoking, although in this case there is no ethnographic confirmation:

[Negative ethnographic evidence:]

Although ethnographic evidence is lacking,

[Hypothesis of time span of smoking:]

archaeological data suggest that the custom of smoking continued at least for some time into the Esilao phase. Effigy pipes, apparently, were no longer made. The pipe in common use was straight and tubular with either a plain or expanded mouthpiece and a trumpet shaped bow1 [1968a:23-24].

Ornaments were rare unti] late deposits which contained many

European beads or ornaments, some of copper foil.

Objects of iron are rare. Only two small slender points of sheet iron were recovered $[p .24]$.

Borden's conclusion includes important ethnographic information and additional hypotheses relating to prehistory. He contrasts the 120 centuries of prehistory with $1 \frac{1}{2}$ centuries of history in this region.

This is the culture at the beginning of the historic period:

The people whom Simon Fraser encountered in these parts were the Stalo ("river") Indians, a branch of the Coast Salish. The Stalo were divided into eighteen local groups occupying land along or near the Fraser River. Stalo territory is virtually co-extensive with the somewhat expanded lower mainland concept employed in this outline prehistory of the region.... The Stalo spoke Halkomelem, a language which exhibited only slight dialectical differences between the groups living east and west of the vicinity of Chilliwack. Surrounding the stalo 
to the north, south, and east were uther Salish peoples whose languages, however, were unintelligible to them. The vicinity of Chilliwack was also the approximate dividing line for certain cultural differences. Groups living up-river from Chilliwack showed marked cultural affinities with the interior of British Columbia and Washington, while the downriver groups aligned culturally with peoples on the shores of the strait of Georgia. One of the more striking differences was the use by the Upper Stalo mainly of pit houses, while the Lower Stalo lived in plank houses [1968a:24].

\section{Length of Stalo Occupation: A Problem}

Borden summarizes the pit house evidence for the Fraser Canyon

in this sentence:

As we have seen, archaeological data suggest that this subregtonal cultural difference appears to go back at least 2000 years $[p .24]$.

Now Borden proposes three hypotheses based on the limited archaeological knowledge of this area:

[1. Hypothesis denying that the conclusion of continuous Stalo occupation is a necessary one:]

This observation does not necessarily imply that ancestors of the Stalo have occupied the entire or even part of the lower mainland region for the past two millennia.

[2. Hypothesis of possible population shifts in the last 2000 years:]

Population shifts may have occurred within this period,

[3. Hypothesis that archaeological evidence may test the preceding hypothesis:]

which perhaps will become evident when the archaeological record is more complete [1968a:24].

The first hypothesis shows that Borden is cautious in equating instances of pit houses and side-notched points with a continuity of a particular linguistic or cultural occupation. In the third hypothesis is Borden's explicit goal, that archaeological data and interpretation may be sensitive enough to detect population movements as distinct from other causes of culture change. 
As Borden says,

Population shifts are very difficult to detect. Even clusters of traits can be introduced and accepted by diffusion. But in a very contrasting situation with site intrusions, there is a strong suggestion of population shifts [Pers. com., 1974).

\section{Ethnographic Conclusion}

Borden concludes this summary of prehistory with a recommendation that his readers also study Wilson Duff's ethnography, The Upper Stalo Indians (1952). Borden's summary and a final quotation from Duff might we11 have begun this prehistory, because it expresses the important place of the river in the lives of all these peoples. The references to woodworking and canoe making in early delta cultures are best understood after reading this section about the Fraser. For those on the delta, similar importance applies to the Gulf or Strait of Georgia as we11:

Despite differences in language and culture, individual Stalo groups were aware of their close relationship with the others. Certain factors tended to soften regional differences and to create a certain sense of unity. One was the fact that the best salmon fishery was located in the lower canyon, a circumstance which every summer drew many downriver people to this easternmost part of Stalo territory. Another was the river itself combined with the mobility afforded by well-made canoes. The importance of this stream in the lives of the Stalo Indians is well summarized by Duff (1952:16):

The river was their main source of food the year round. It was their highway, which invited travel in the two dominant directions of their lives, up-river and down-river, and which brought to their villages visitors, new ideas, sometimes raiding parties. More than a highway, the river was their main street, and they came to know its floods and shallows, its winter ice, its deep pools, rapids, beaches, snags, and rocks as intimately as a child in a large city knows his own block [1968a:24-25]. 
CHAPTER XXXV

1968b A LATE PLEISTOCENE PEBBLE TOOL INDUSTRY...

This paper, published in Early Man in Western North America, Eastern New Mexico University Contributions in Anthropology, begins with the following footnote:

The National Museum of Canada has kindly granted permission for the publication of the present paper in the symposium volume. The article is based in part on a more comprehensive report to be published by the National Museum [1968b:55].

I quoted earlier (analysis of 1965:344) from the unpublished chapter on which this 1968b paper was based (Borden, pers. com., 1973), about his change in terminology from "cobble tools" to "pebble tools".

In another footnote to the present paper, Borden notes the $f i-$ nancial support for the research, and local residents who helped. Among the individuals he mentions "...especially Messrs. August Milliken, Alex Miller, Manuel Soares and Roman Pasika, [who] rendered invaluable assistance" (p.55).

\section{BACKGROUND MATERIAL FOR THIS PAPER}

\section{Publication}

This paper is the second detailed examination of the evidence from the South Yale site known as the Pasika phase. The first was Borden's 1965 Radiocarbon paper. At that time Borden used information from radiocarbon dating, both indirectly in geological evidence, and directly in relation to his nearby archaeological site at Milliken. 
When acknowledging the advice of geologists Dr. W. H. Mathews and Dr. J. E. Armstrong who visited the site, Borden wrote, "They can, however, not be held responsible for the data and interpretations presented here" (1965:342). In the present paper, Borden stresses that in the absence of a consensus on lower Fraser Canyon geological events, "The interpretations and conclusions presented here are essentially my own" (1968b:64).

As in the 1965 paper, Borden here attempts to bracket the age range of the Pasika phase. He reviews the evidence to support his hypothesis that it is older than the Milliken phase. The problem he faces is with the geological evidence limiting the earliest possible habitation of this immediate region.

\section{Geologist's Analysis}

This was stated clearly in the interval since Borden's 1965 paper, constituting new evidence or theory which Borden must accommodate in this work. On August 4, 1966, Dr. W. H. Mathews wrote to Dr. L. S. Cressman about these limiting factors, and sent a copy of his letter to Borden. Cressman had asked Mathews for his interpretation of the Everson-Sumas relationship.

According to Mathews, the retreat of the Cordilleran ice sheet proceeded more slowly than Borden infers. Moreover, Mathews and other geologists viewed the Sumas Stadial as a re-advance of the Cordilleran ice down the Fraser Valley into the Fraser lowland. Mathews' analys is was based on studies at Greendrop Lake in the Skagit Range. Measuring from the ice levels at Greendrop Lake, Mathews calculated that the ice 
covered the Fraser Valley from Hope northward (i.e. the Milliken and South Yale sites), substantially above the 3,400 foot contour line in late Sumas time, that is at about 8,500 B. C. or less.

\section{Consequences of Mathews' Position for Borden's Analysis}

Since 3,400 feet of ice would have had to melt, and suitable ecological conditions would have had to be established before man could have inhabited the area, Borden's analysis of the Pasika complex would have had to be drastically altered. Borden's Pasika dates would either have been almost co-existent with the Milliken phase, or of very short duration, since Borden would have had to telescope the terracecutting of all the levels above the Milliken high-water level in a very foreshortened Everson Interstade.

\section{Borden's Interpretation}

In other chapters of the unpublished report from which the present $1968 b$ paper was written, Borden wrote his re-interpretation of the Mathews evidence. On the basis of his own evidence from the Pasika artifacts as they relate to the terraces at South Yaie, Borden's hypothesis is this: The evidence at Greendrop Lake, and thus at Hope, related not to Late Sumas time 8,000 years B. C., but 2,500 years earlier, or 10,500 B. C. Borden wrote, "Thus it represents not Sumas ice, but the end of the Vashon Stade of the Cordilleran ice, and the beginning of the Everson Interstade".

This is the background for his statement in this 1968b paper

that "the interpretations and conclusions presented here are essentially my own". As another archaeologist put it, "Borden was writing his 
own geology of the area" (T. M. Newman, pers. com., 1973). The next body of evidence related to this series of hypotheses will be presented in Borden's 1972 publication.

This paper is in two main sections. One deals with the artifacts from the Pasika phase, the other with the dating of the phase.

\section{General Chart and Illustration}

There are illustration, maps, and charts. I am including a number of them in this paper. On the following page, my Fig. 6, (Borden 1968b:56 Fig. 1), is Borden's contour map of the "Lower Fraser Car1yon Region". It is identical to the one in the Radiocarbon paper (1965) except that Terraces IV and $V$ are marked at the South Yale site, downriver (south) from the lower terraces.

Borden illustrates the relationship of the South Yale and Milliken sites with a chart, my Fig. 7 (Borden 1968b:57 Fig. 2). This is a revised version of a similar chart from the Radiocarbon paper (1965: 6 Fig. 3).

\section{PASIKA ASSEMBLAGE}

\section{New Terraces}

After a resume of the location of the South Yale site, relating to its delta formation and the Milliken site with its dated sequence, Borden discusses the artifacts of the Pasika Complex.

Among the more significant recent developments has been the discovery of Pasika materials on two higher terraces a short distance downstream from the lower benches [1958b:55].

\section{Summary Hypotheses}




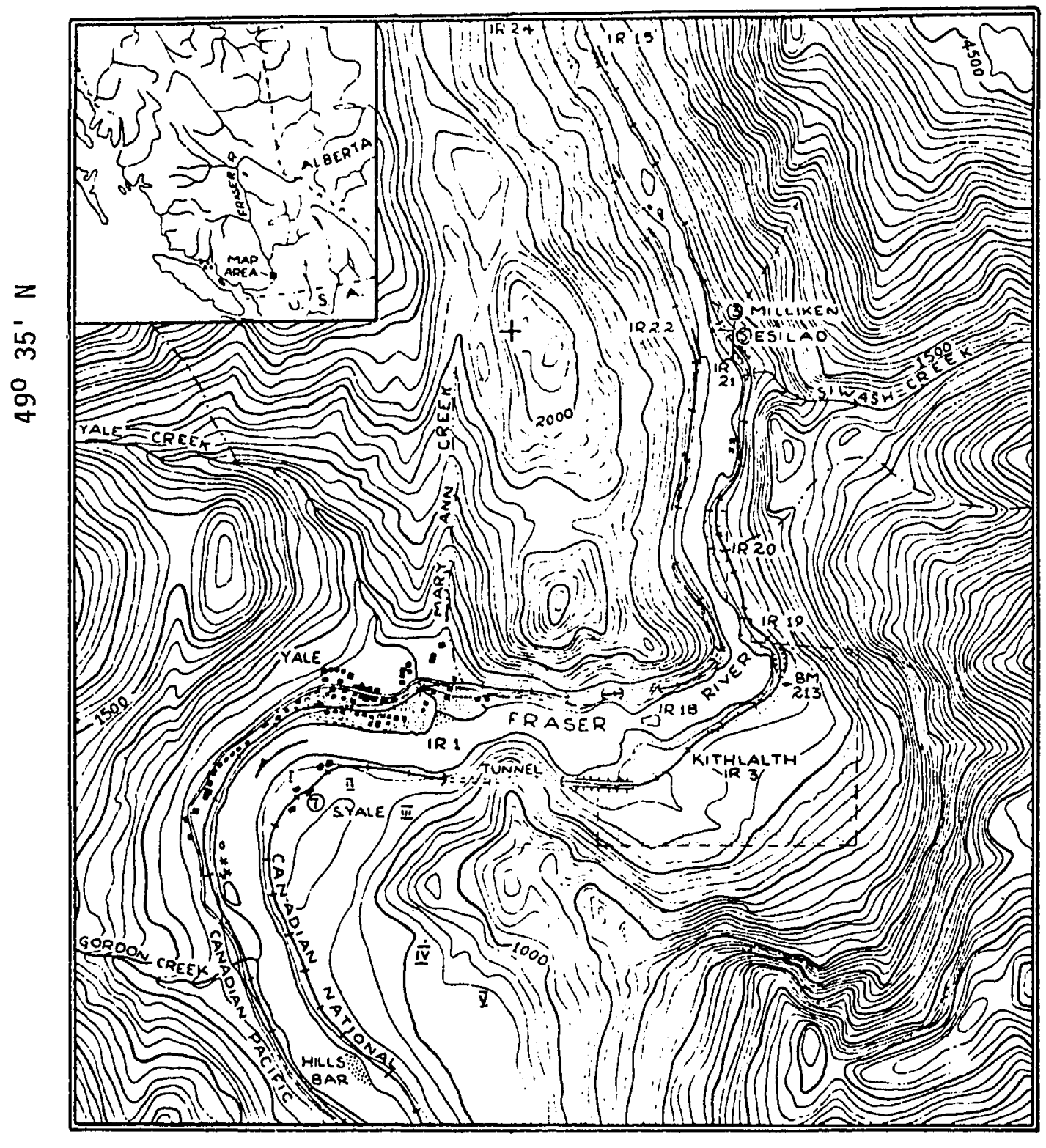

$121^{\circ} 25^{\circ} \mathrm{W}$

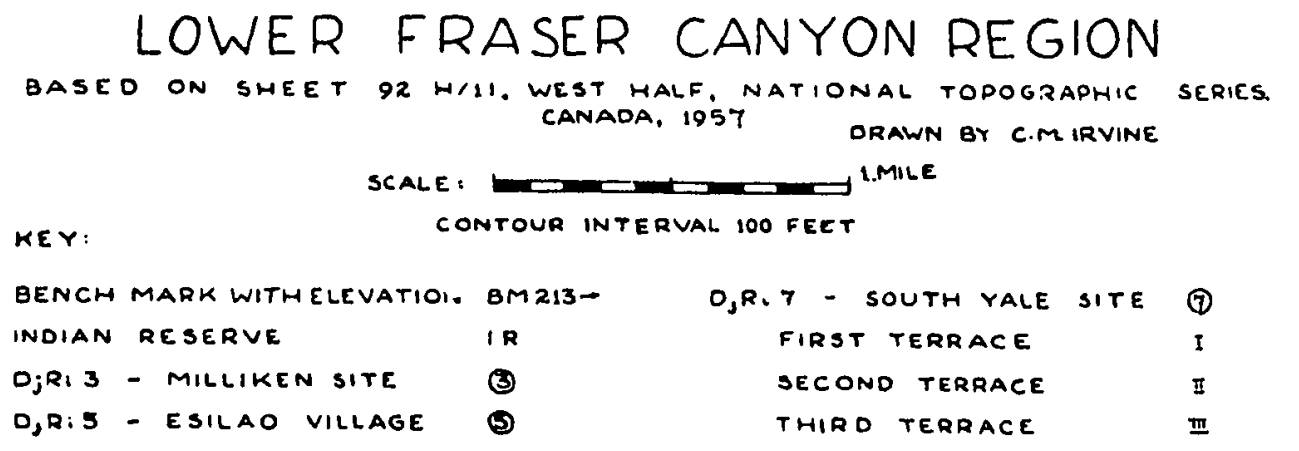

Figure 6. Lower Fraser Canyon region (1968b:56 Figure 1). 


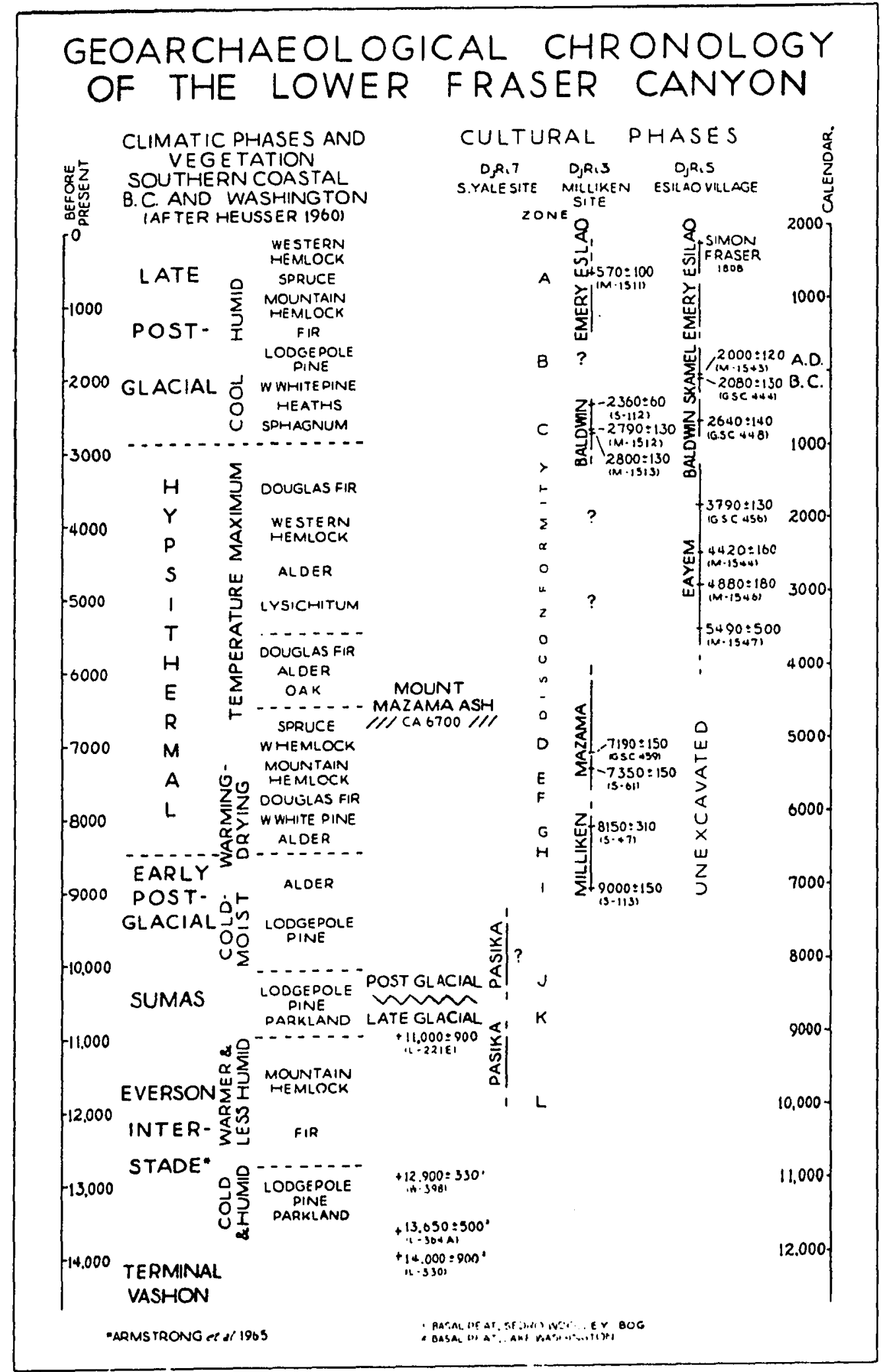

Figure 7. Geoarchaeological Chronology of the Lower Fraser Canyor region (1968b:57 Figure 2). 
Borden's introduction to this complex can be viewed as summary hypotheses within his classification system, to which he will add both evidence and supporting hypotheses:

[Hypothesis summarizing predominant tool type:]

The Pasika Complex consists predominantly of core tools made on well-rounded river pebbles.

[Hypothesis summarizing the repeated presence of sub-types within the complex:]

These pebble tools comprise a wide range of specialized types of readily recognizable form and pattern, each of which can be documented by multiple, indeed, in most instances by numerous examples.

[Evidence of sample size:]

To date, the collection consists of 1218 specimens, not counting waste flakes and other detritus.

[Evidence of sample size of basic classification types:] of this number, 1053 or $86.5 \%$ are core tools while the remaining 165 artifacts or $13.5 \%$ can be classed as flake tools [1968b:55].

\section{Slate Tools}

Borden completes his description of these tools before writing about the other artifacts of the Pasika Complex. In order to show the total Pasika assemblage, I have reversed this order.

[Hypothesis, imp]icit, that the following data are instances of artifacts:]

Finally, among the materials occurring on the terraces in association with Pasika materials are some slabs of raw slate, unmodified except for splitting along a cleavage plane.

[Sample size, and evidence of two instances with out]ine similar to Pasika tool type to support hypothesis above:]

Two of the six in the collection resemble cortex spall tools in outline.

[Evidence of use, supporting hypothesis that these are artifacts:]

The edge of these [not clear whether "these" are the two, or the six, above] specimens shows signs of use [1968b:61]. 
The size of this collection of slate confirms Borden's initial hypothesis that the Pasika Complex is predominantly a pebble tool industry.

\section{Pebble Core Tools}

Borden now discusses the pebble tools as distinguished from the flake tools.

Manufacturing Site. He begins with his interpretation of the kind of site that is found at South Yale:

[Hypothesis that South Yale is a manufacturing site:] Indicative of extensive manufactures that were carried on at the locality

[Evidence of hypothesis above:]

is the fact that among the 1053 pebble tools there are 245 unclassifiable rejects and broken items. The latter are unbroken, but so battered and worn as to be of uncertain type.

[Hypothesis, restatement of second summary hypothesis:] The remaining 743 artifacts are suitable for classificatory studies,... [1968b:55].

In the first of these three statements above, Borden is saying more than that the tools themselves were made here, or that it is a workshop. For this he has the evidence of waste flakes that he is not mentioning here. He is saying that at this place these tools were put to all or many of their various uses, because they were worn out and discarded here. In the second of these three statements, Borden presupposes that his classification of artifacts is the same as that of the people who made and used them. He will state why he thinks this is so in the course of this paper, but for now it is just important to note that unless Borden can accurately recognize an artifact as the maker and user meant it to be, he cannot accurately recognize a reject, 
or one that is broken and worn. Thus in his third statement above, Borden hypothesizes that the 743 remaining pebble tools are, and were, artifact types of distinct and distinguishable varieties.

Characteristics of Most Tools. Before dividing them into these types, Borden notes "...some characteristics that most of these tools have in common" (p.55). He qualifies these statements either with statistics or with such phrases as "with few exceptions" or "as a rule". These are the usual characteristics:

[1 Type of raw material:]

With few exceptions, the implements are based on entire, wellrounded oval river pebbles.

[2 Shape of pebble:]

The two pebble faces are, as a rule, somewhat flattened, that is, they are only slightly or moderately convex.

[3 size of artifact:]

Most of the finished artifacts have a maximum dimension of less than 6 in. $(15 \mathrm{~cm})$ and more than $3.5 \mathrm{in} .(9 \mathrm{~cm})$. Only $4 \%$ are larger than 6 inches.

[4 Method of manufacture:]

All the artifacts are flaked by percussion, and flaking is confined to one face only [1968b:55].

In this fourth characteristic, Borden speaks of all the artifacts, and then in the next hypothesis underlines how important he thinks this fact is:

[Hypothesis that unifacial flaking is important:]

This unifacial treatment is an outstanding characteristic of the Pasika Complex.

[5 Limited extent of flaked edge:]

Moreover, in nearly all instances flaking is restricted to areas along the side or ends of the pebble and only rarely extends far over one face of the implement [1968b:59].

Exceptions. The only exceptions to this seem to be six artifacts from class VIII, and five from class IX. Borden details the usual way 
the working edge is formed:

[6 Usual edge formation:]

In the majority of artifacts the working edge is formed through the Intersection of the bevel plane of the flake scars on the worked face with the smooth cortex face of the pebble.

[7 Frequency of retouch:]

Evidence of edge retouching and/or resharpening is found on many specimens [1968b:59].

\section{Basis of Classification}

Borden now explains his preliminary system of classification. He wants to use "prominent attributes" and justifies this primarily on the ground that it will reflect not just his judgment, but that of the original makers and users of these tools as well:

[Hypothesis that this classification will show diversity according to the most prominent attributes:]

The preliminary classification presented here intends to convey a notion on the remarkable diversification among these artifacts by simply grouping them according to the most prominent attributes.

[Hypothesis that there is one criterion which is of paramount significance:]

Among the criteria suitable for classifying pebble tools one seems of paramount significance;

[Hypothesis that working edge form is most significant criterion:]

that is the form given by the maker of the implement to the business end or the working edge

[Hypothesis of form-function correlation:]

because in doing so he must have had in.mind the specialized function the tool was intended to perform [1968b:59].

The consequence of this is as follows:

Implicit consequence of Borden's classification system:

Thus classification made on the basis of the working edge will approximate the classification of the tool maker and/ or tool user. 
On the basis of this classification system, we can fill in the basis

for Borden's previous statement:

...there are 245 unclassifiable rejects and broken items, and

65 worn-out and discarded implements. The latter are unbroken, but so battered and worn as to be of uncertain type [p.55].

These either have a working edge that is broken in such a way that it cannot be typed, or the working edge is battered and worn so that its former, useful shape has disappeared.

Borden's edge-classification method has been useful even in ordering the unusually shaped artifacts:

[Hypothesis of applicability of classification method:] This criterion is applicable to the majority of pebble tools, even to those in which the basic shape of the stone on which the tool is made deviates from the norm [p.59].

\section{Classification of Core Tools}

Borden then introduces the table of core tool types, my Table II (Borden 1968b:58 Table I), and the drawings, my Fig. 8 (Borden 1968b: $60 \mathrm{Fig.} \mathrm{3),} \mathrm{and} \mathrm{photographs} \mathrm{which} \mathrm{illustrate} \mathrm{each} \mathrm{of} \mathrm{the} \mathrm{eleven} \mathrm{types.}$ In his comments about Class IX, Borden notes the five distinctive artifacts:

For the most part, the specimens in this last class are crude amorphous affairs, but 5 in the total of 67 show well-controlled peripheral flaking extending over one entire face. In this respect these 5 deviate from all other Pasika artifacts [p.59].

This is his description of Class $X$ artifacts:

Class $X$, finally, includes 30 battered pebbles and cobbles which were evidently used as hammerstones [p.59].

This last sentence is the only one in which Borden's words are intended to ascribe use. In all other comments, he repeats the shape just as in the table. The phrases "pick-like", "scraper-plane-like" 

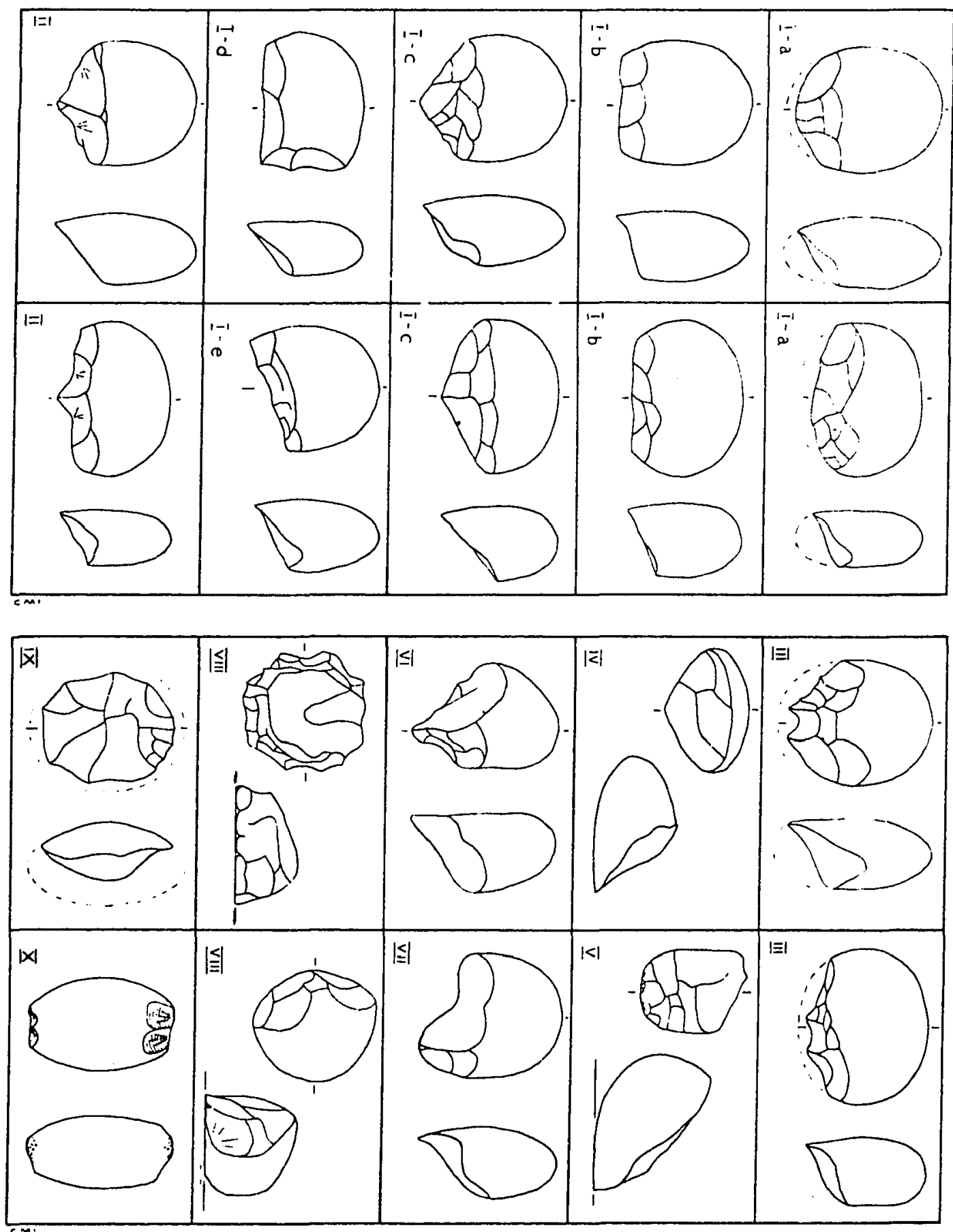

Class I, Edged tools: I.a, convex edge; I-b, straight edgc; I.c, symmetrically converging edges; I-d, asymmetrically converging edges; I.e, oblique edge. Class II, III, double pointed tools. Class IV, tool with $V$-shaped cross scction; end-on view on left. Class V, tools with U-shaped cross section; end.on view on left. Class VI, Pick.like tools.
Class VII, Spokeshave-like tools. Class VIII, Scraper-plane-like tools; on left, flaked all around; on right, partly around. Class IX, Peh. ble remnant tools; overall unifacial flaking. Class X, Hanuncrstones. Classes I-a to I-c, II, and III show end tool on left, side tool on right.

Figure 8. Classification of core tools (1968b:60 Figure 3). 
TABLE II

\section{CIAASSIFICATION OF CORE TOOLS}

I Edged tools:

a) Convex....................:204

side.....6 61

isometric.. $27 \ldots 192$

b) Straight............end......8 80

side...... 28... 108

c) Symmetrically converging...end......48 48

side...... 16... 64

d) Asymmetrically converging............ 23

e) Oblique......................... 34...421

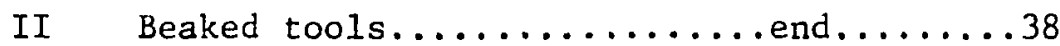

side................ 58

III Double-pointed tools.........end....... 7

side................ 24

IV Tools with triangular or 'V'-shaped cross section:

end.......25

side...... $7 \ldots \ldots \ldots . .32$

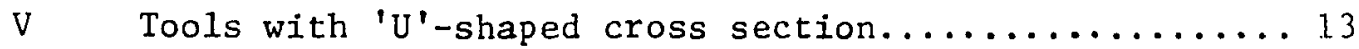

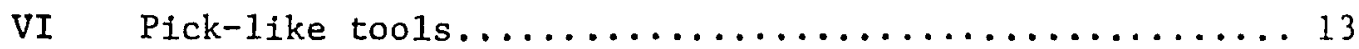

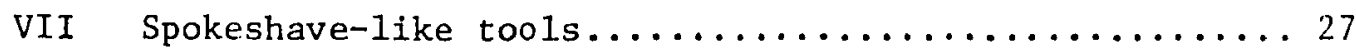

VIII Scraper-plane-like tools:

trimmed all round, domed...........6 6

trimmed partly around -- domed ........19

- flat top .........13

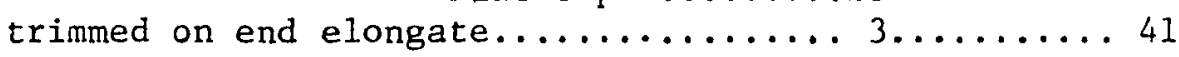

IX Pebble remnant tools .....................67 67

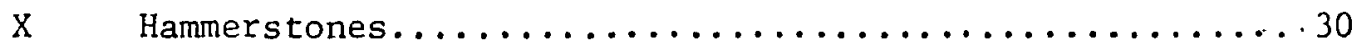

XI Combination tools:

Hammerstones and other tools........ 17

Anvil stones and other tools ........ 8... 25

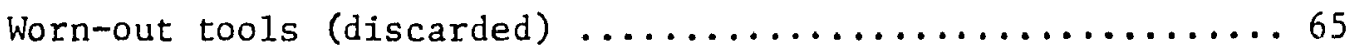

Rejects, broken, and unclassifiable ................245

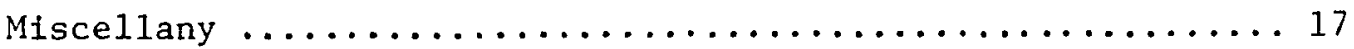

TOTAL

1053

[Borden 1968b:58]. 
and "spokeshave-1ike" are intended, as he will specify presently, to point to a shape-type rather than a use-type. With these shapes in mind, we can follow Borden's distinctions between these classes, and use them as titles to aid in cross-checking between the table and the various illustrations.

\section{Flake Tools}

The flake tools and slate slab tools are considered next in my Table III (Borden 1968b:59 Table II)

TABLE III

CLASSIFICATION OF FLAKE TOOLS

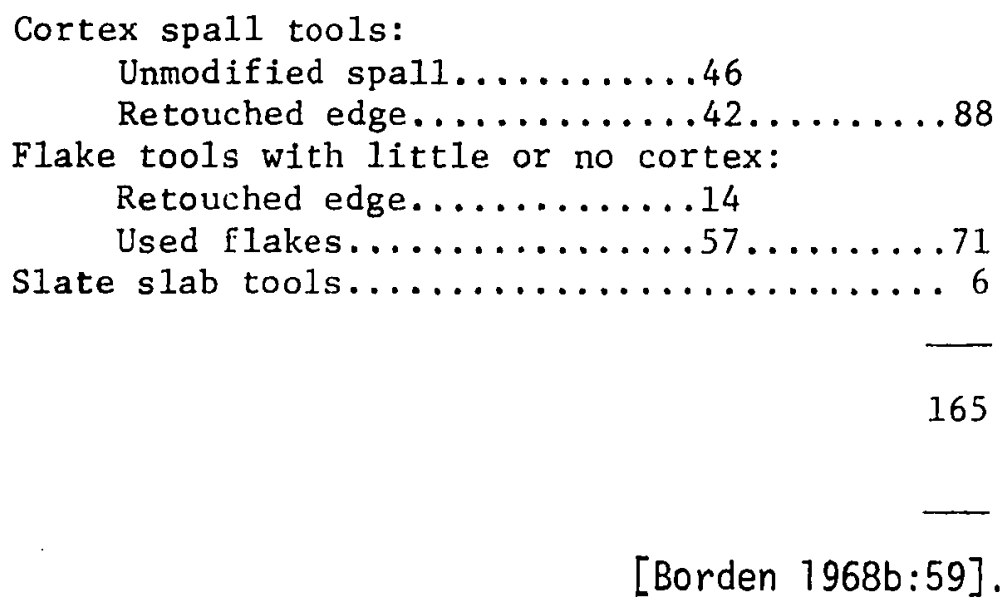

Cortex Spal1 Tools. Borden describes the first division: cortex spal1 tools:

[Definition/description of cortex spal1 tool:] "Cortex spalls", as the term is employed here, are strong, handsized or larger, generally oval flakes, struck from pebbles or cobbles. When struck off properly, cortex spalls resemble large ulu-like implements, the long sharp cutting edge resulting from the intersecting at an acute angle of the bulbar and cortex faces. The opposite edge near the point of impact is usually blunt so that the implement can be gripped firmly here [1968b: 59]. 
The phrase in this definition "when struck off properly..." is not seen to be circular, or begging the question, when it is seen as part of the earlier argument of classification. If Borden's classification approximates the classification of the maker of these tools, then he can appropriately speak of flakes being "struck off properly." They have too thick an edge to be usable (Borden pers. com., 1974).

It is interesting to note that in 1956 Borden wrote about nineteen artifacts "...somewhat difficult to classify as to type and function..." (Borden 1956:92) and listed them as "Large scraper-knives". His description in that publication of some tools of that group is clear and detailed enough to recognize them as what he here calls "Cortex spa17s".

Borden's table divides the cortex spalls according to whether they were used with or without retouching.

Flake Tools with Little or No Cortex. Since this is a condensation of a larger chapter from a projected book, one further statistic which would clarify Borden's discussion of the second group of flake tools has been omitted. The total used flakes, with and without retouch is 71 , as the chart shows, but Borden does not supply the total waste flake number with which he compares them:

[Hypothesis that cortex spalls are the only major flake tools made intentionally in the Pasika Complex:]

Except for the cortex spalls, it appears on present evidence that the production of flakes either for immediate use or as the starting point for formed artifacts was not a primary objective of the Pasika stone workers.

[Description of virtually all waste flakes:] Virtually all the flakes that have been recovered are quite obviously waste from the manufacture of pebble tools. Most flakes are chunky, with broad striking platforms, and por- 
tions of pebble cortex are present on practically every flake [1968b:59].

On the basis of wear, Borden suggests the use to which the unretouched flakes were put:

[Hypothesis of use of flakes:]

Use retouch or differential blunting along one or more edges of 57 otherwise unmodified flake suggests they were employed in some scraping or cutting operation.

[Hypothesis that retouch was not correlated to specialized use:] Only 14 flakes show evidence of deliberate retouching, not to achieve a particular form, but merely to straighten or sharpen an edge.

[Evidence of flaking style and method:]

Flaking is consistently unifacial and by percussion [1968b:59, 61].

At this point in the paper Borden discusses the slate artifacts, which I presented above.

\section{Uses of Artifacts}

Borden now writes generally about assigning uses to these classes of artifacts.

[Statement that only hammerstone class is to be regarded as a functional category:]

Except in the case of the rather obvious hammerstones an effort has been made here to avoid assigning functional terms to the various categories of Pasika artifacts.

[Hypothesis that wear pattern analysis is essential to functional classification:]

Attempts to assess the function of implements should be supported, if possible, by careful studies of the kind of wear perceptible on the working edge and on other parts of the tools.

[Lack of evidence at this time:]

Such studies are yet to be made.

[Statement that some hypotheses, general (or tentative) are possible:] 
Certain general conclusions, however, can be reached here [7968b:61].

General Range of Uses. These general conclusions or hypotheses have to do with a possible range and variation in use, but Borden does not mention any of the specific classes of tools in this section.

[Hypothesis, implicitly based on absence of hafting-wear evidence: ]

The pebble artifacts are hand tools not meant for hafting.

[Evidence of hand-fit:]

The round smooth butt of most specimens fits snugly into the palm of one hand, making contract with wide areas of the skin,

[Hypothesis of functional advantage of evidence above:]

a feature which helps to distribute the shock of heavy blows.

[Hypothesis and uses of larger tools, based on weight and form:]

The weight and form of many of the larger tools suggests their employment in heavy-duty work; cutting, chopping, crushing, cracking, shredding, pulping, scraping, smoothing.

[Hypothesis that more than one classification may have more than one, overlapping function:]

A considerable number of the more generalized forms would be serviceable in a variety of such operations [1968b:61].

Possible Specialized Uses. Still without specifying which class he refers to, Borden states hypotheses of specialized use of some of the tools:

[Hypothesis that some classes of tools are specialized in function:]

However not all pebble tools are so generalized.

[Hypothesis repeated, of variation related to working edge:] The range in variation of the working edges and business ends suggests a corresponding range in specialized functions [1968b: $61]$.

This is almost identical to Borden's thought in discussing side scrapers in 1956:

The business edge, which may vary between 2 and $6 \mathrm{~cm}$. In length, is usually slightly convex, sometimes straight and in a few in- 
stances concave. These and other variations suggest a variety of specialized uses for these tools and may eventually make further subdivisions necessary [1956:95].

Returning to the consideration of the Pasika Complex, the next statement suggests that further subdivisions will be necessary in classification here:

[Hypothesis of still undocumented specialization:] Moreover, the differentiation goes much further than it has been possible to indicate here.

[Hypothesis of wood, bone, and antler industries:] Some of the specialized tools and matiy broken and worn-out implements hint at extensive manufactures in wood and possibly in bone and antler.

[Absence of confirmatory evidence:]

Unfortunately, none of these perishables has been preserved [1968b:61].

Possible Tests. The hypothes is on wood, bone and antler manufactures still has to be tested experimentally. Another potentially productive correlation that Borden suggests is this:

Pebble tools tend to be phased out as soon as good adze blades come in [Borden pers. com., 1974].

Uniformity of Pasika Technology

Now Borden reiterates what he considers to be of basic significance: the uniformity of technique which produced this diverse tool kit. I have altered his order and added an implicit step in his argument:

[Restatement of uniform technique:]

Despite the diversification in stone artifacts there is discernible throughout a consistent modus operandi, a uniformity of technique.

[Evidence of uniform size and shape of raw material:] Starting point for all artifacts was the river pebble, or more rarely, the somewhat larger cobble, 
[Evidence of rock types selected:]

Even the most refractory rock types were tackled.

[Imp]icit hypothesis:

The apparently random mixture of rock material and the nonrandom, limited variation in size and shape would indicate that it was not on the basis of chance, but probably on the basis of choice and purposive selection that the raw material was picked up.]

[Hypothes is from previous evidence that selection was on size and shape but not rock type:]

selected on the basis of size and shape rather than for the type of rock [1968b:61].

Starting from this selection of pebbles, the tool makers used a very limited technology. Borden gives additional details on how the tools were made:

[Hypothes is that this description of tool-making techniques is the general pattern:]

Stone working methods employed at the site were limited. They appear to have been confined to a form of bi-polar technique for the detaching of large cortex spalls and to percussion flaking with elongate stone hammers, held so that the long axis was in line with the direction of the blow. Deliberate flaking [as distinguished from wear retouch] was invariably unifacial and usually restricted to the sides or ends of the artifacts.

[Negative evidence stated as hypothesis of lack of technique on part of tool maker:]

Apparently it never occurred to Pasika stone workers to create a cutting edge by alternate flaking from two opposite faces.

[Implicit and necessary hypothes is on tool-skill relationship: Since the absence of a tool form (i.e. bifacially flaked artifacts) in the presence of the raw material (i.e. stone) may be generally attributed to the lack of the idea or skill,]

[Hypothesis, consequence or specific instance of hypotheses above: ]

According to present evidence, therefore, they seem to have lacked the techniques required for flattening and thinning stone projectile points and knives of thin biface form (see Kr1eger 1964:42) [Borden 1968b:61].

Contrast with Milliken Technology 
Borden's comparison of the Pasika and Milliken phase artifacts is more extended and detajled than in his 1965 paper. He begins with the basic principle of contrast and then summarizes the different tools of the Milliken phase:

[Hypothesis of basic Pasika and Milliken phase difference:] In this absence of artifacts made by more advanced stone working techniques the Pasika Complex contrasts sharply with the assemblage of the Milliken phase, the earliest of the radiocarbon dated post-Pleistocene cultures in the Fraser Canyon region... [See Fig. 7].

[Evidence of age and tool types of Milliken phase:]

This culture, which was in operation before the end of the 8 th millennium B.C., features thin bifacially flaked knives and leaf-shaped projectile points in a wide size range, carefully formed endscrapers, sidescrapers and pointed tools, numerous thin flake scrapers, an occasional burin, and many thousands of thin flakes, detached not with a hammerstone, but with a resilient striker of some organic material. Most of these flakes have small facetted striking platforms with a sharp edge projecting conspicuously on the side of the bulbar face. Moreover, common among the debitage are slender elongated prismatic flakes which can be termed crude blades [1968b:61].

As in 1965, Borden's use of the phrase "still present" in the statement below, is dependent on his later analysis of the South Yale terrace dates, or else must be seen as begging the question when presented this early in the discussion. The statement is more clear without the phrase.

[Evidence of proportion of pebble tools in Milliken assembTage:]

Although some pebble tools are still present they constitute less than $5 \%$ of the assemblage.

[Hypothesis of contrast, re-stated:]

Obviously, this stone industry represents a striking contrast

to the limited stone technology of the Pasika Complex [1968b:61].

\section{Examples and Problems of Other Pebble Tool Assemblages}

Now Borden re-examines pebble tool industries, and the range of their antiquity. He states the problem: 
[Complications of establishing a particular complex as a pebble tool industry:]

The difficulties of establishing whether a complex is a true pebble tool industry or not are compounded by the fact that some types of pebble tools continue in various parts of the Americas, including the Pacific Northwest, into much later periods and thus do occur when in association with stone artifacts of much more sophisticated manufacture (Bird 1965, Butler 1961; Cressman and others 1960; Jennings 1968:68) [Borden 1968b:67,64].

Borden suggests that one of two relationships can usually be established for mixed assemblages. They can be correctly assigned to an early or recent date by geological or cultural association:

[Hypothesis on methods by which assemblages with some pebble tools can be differentiated:]

The point which should be stressed, however, is that when pebble tools are present in late assemblages or in early complexes containing also stone artifacts of more refined technology, the geological and cultural context is usually such as to leave no doubt about their lateness or about the technological stage a particular culture has achieved.

[Hypothesis that on both geological and cultural evidence, the Pasika Complex is confirmed as a pebble tool industry:] Both the geological context at South Yale and the fact that Pasika materials recovered from undisturbed deposits are not associated with artifacts or other manifestations of any of the dated post-Pleistocene cultures in the Fraser Canyon region suggests that we are dealing here with the remains of a culture which is different and discrete from other prehistorIc cultures in these parts, and probably more ancient than the oldest of them [1968b:64].

\section{Discussion}

After reading this passage concerning "...the technological stage a particular culture has achieved", I noted down a series of questions which Borden answered (pers. com., 1974):

1. How is "technological stage" meant?

It is a way of doing things with tools that you have available. It appears that the Pasika folk did not know how to thin their thick flakes to make a biface tool. 
2. With any one people, is movement from one stage to another unilinear?

Oh my no. You can go back and look at the Greeks...

3. How flexible is such movement, and in what way do stages chance?

One group may be lacking a more advanced technology. Two different cultures come in contact with each other. They do learn from each other. They do borrow, and adopt traits from each other.

\section{DATING THE PASIKA COMPLEX}

Now Borden summarizes the evidence for dating the Pasika Complex. The peat bog dates added in the chart are repeated here. All of this is with Mathews' contrary opinion in mind. The quotation about his re-interpretation of Mathews' data which is in the opening of my analysis of this paper, is taken from the chapters of the unpublished work to which Borden refers in the following passage:

I have dealt with the problems of dating the Pasika Complex in considerable detail elsewhere (Borden 1965; n.d., Chapters IIIVI) and can only summarize the results here.

[Statement that in the absence of consensus among geologists, the hypotheses are Borden's:]

Before proceeding, I must stress that a consensus on the course of late Plefstocene and early Holocene events in the lower Fraser Canyon region has not yet been reached and that further investigations are required to clarify the situation. The interpretations and conclusions presented here are essentially my own $[1968 \mathrm{~b}: 64]$.

\section{Arguments by Ana logy}

In the absence of dated peat bogs from the immediate vicinity of the South Yale or Milliken sites, Borden bases his hypotheses on dates to the south, with an hypothesis that the Fraser Canyon sites were 
similar:

[Evidence from dated peat bogs and maritime shells:] Radiocarbon dates on marine shells from various parts of Puget Sound and Georgia Strait and on Iimnic peat from recessional lakes and ponds in the southern and norther Puget Lowland

[Hypothesis based on evidence generally indicated above:] indicate that the Cordilleran ice sheet had vanished from these parts more than 13,000 years ago (11,000 B.C.), that is, before the recognized date for the end of the Vashon Stadial and prior to the ensuing Everson Interstadial (see Fig. 2; Armstrong and others, 1965; Easterbrook 1966; Rigg and Gould 1957).

[Evidence of Chilliwack River deposits:]

In the Chilliwack River valley of southern British Columbia, immediately to the north of the Puget Lowland, floodplain deposits exceeding 350 feet in thickness are overlain by drift from the Sumas ice advance of 11,000 years ago (Armstrong 1960),

[Hypothesis based on evidence above:]

indicating that this last cold oscillation, the Sumas Stadial, was preceded by a thermal interval which can be none other than the Everson Interstadia1, which thus had a duration here of some 2000 years.

[Evidence of close Chilliwack-Fraser relationship:]

The South Yale locality lies a mere 30 miles to the north of the Chilliwack River, separated from it by the Skagit Range.

[Evidence of Fraser Lowland distance to sea:]

During the Interstadial, the Fraser Lowland region was occupied by the sea, and South Yale was a bare 15 miles (or less) from salt water.

[Hypothesis that Fraser sites were in a more coastal area:] The lower Fraser Canyon region was thus much more a part of the coast at that time than it is now.

[Hypothes is of Fraser/Chilliwack paralle]:]

There is every reason to believe that climatic and environmental developments in the two neighboring river valleys were closely paralle1 [1968b:64].

Borden's new evidence from a nearby area supports his position when he infers that the warm period occurred earlier than had been believed. If Borden can prove this for his local area, he can disconfirm the Mathews position. He cites Armstrong on the Sumas glaciation. 
[Hypothesis of Sumas glaciation in Fraser area:]

The glacier which at the time of the Sumas Stadial moved westward into the Fraser Lowland area apparently was centered in the western Skagit Range of the Cascades (Armstrong 1960) and seems to have affected only immediately adjacent parts of the Chilliwack and Fraser River valleys. Areas farther up the Fraser valley, at least to the lower portion of the Canyon region, were never again glaciated after the disappearance of the Cordilleran ice sheet before the end of the Vashon Stadial [1968b:64].

Argument from Milliken Correlation

Milliken Deposition. Borden briefly describes the deposits un-

derlying the lowest dated (9000 B. P.) occupation level at Milliken:

[General description of deposits underlying ear]iest cultural zone: ]

...more than 20 feet of fluvial sediments subdivided into three specialized zones,

[Hypothesis of time lowest exposed layer was deposited:] of which the lowest exposed sediments (well-rounded fine gravel and coarse sand) appear to date to a relatively warm phase of the Everson Interstadial, when the Fraser was flowing freely,

[Hypothesis of time of uppermost (Zone J) deposition:]

whereas the 7 feet of silt and fine sand in the uppermost zone seem to correlate with the Sumas Stadial and early post-Sumas times, when the river was in a quiescent state.

[Evidence of Zone J, cultural zone relationship:]

The earliest camp of the Milliken phase was established on top of this bed (Zone J) [1968b:64].

River Levels at Milliken. Borden then reviews the water levels

for the 1000 year period of the Milliken phase, from 7000 to $6000 \mathrm{~B}$. C. as he had done in 1965, with this summary hypothesis:

[Hypothesis of midsummer river level during Milliken phase:] It is thus possible to state that midsummer river levels in that part of the valley during the 7 th millennium $B$. C. remained relatively constant at about 260 feet above sea level [1968b:66].

South Yale Terrace Elevations. Then he relates this to the South 
Yale terraces. This is his new information on the five terraces and their elevations:

$\begin{array}{cc}\text { TERRACE } & \text { Elevations Above Sea Leve1 } \\ \text { V } & 565 \text { feet } \\ \text { IV } & 470 \\ \text { III } & 375 \\ \text { II } & 265 \\ \text { I } & 200\end{array}$

$[1968 b: 66]$.

Terrace Temporal Significance. Borden's presentation is a straightforward logical sequence:

[Hypothesis, taken to be of high probability, of temporal significance of terraces:]

These South Yale terraces unquestionably have temporal significance.

[Hypothesis, also taken to have high probability, that the sequence is a simple chronological one:]

From the highest to the lowest they represent a chronology of decreasing age.

[Hypothesis of consequent information which may be derived:] If it should be possible to determine the time when one of them was being formed then we could conclude that higher terraces were formed earlier [1968b:66].

Discussion. It is important to note that the strength of the following argument depends on the accuracy of these first two hypotheses. Borden does not just say that the highest and lowest terraces are earliest and latest, but he specifies that each of the intermediate terraces are in a simple chronological order. As it becomes possible to date these independently, it will be important to test this hypothesis to make sure that in the complex situation at the close of the Pleistocene, a more complex series may not be evidenced in these terraces. Until such time, it is sufficient to note that the next argument depends on the truth of Borden's chronological hypothesis. 
River Profile. Now Borden will establish the conditions specified in the antecedent of the last conditional statement: "If it should be possible to determine the time when one of them was being formed...". This he does by means of the river profile and stream gradient to calculate the level at South Yale from the dated level at Milliken throughout the 7 th millennium B. C. Then he will conclude, as the last hypothesis in the sequence above says, "...then we could conclude that higher terraces were formed earlier", having used the valid deductive argument, affirming the antecedent, or modus ponens. In his argument he refers to the river profile chart, my Fig. 9 (Borden 1968b:65 Fig. 6).

[Evidence of present river levels at the two sites:] Partly because of the river gradient, but mainly because the width of the valley and of the river channel is greater at South Yale than at the Milliken site there is at present a drop of some 35 feet in mean river level from the upriver site to South Yale.

[Hypothesis that similar relationship existed from 9000-8000 B. P.:] The river level indicated on Fig. 6 assumes that a comparable difference between the two localities existed 8-9000 years ago.

[Hypothesis that range of error is not sufficient to change the conclusions regarding terrace formation for that time:] Even if the margin of error in these calculations should be considerable it cannot be large enough to escape the conclusion

[Hypothesis of terrace formation at $8000-9000$ B. P.:]

that the lowest terrace was not yet in being, and that the Fraser was still engaged in eroding away the former downriver portion of the Second Terrace, a process which eventually led to the formation of Terrace I [1968b:66].

Periods of Terrace Erosion. With an elevation and Terrace level at South Yale identified, Borden discusses the evidence which might relate to the rate that erosion was taking place immediately before that 


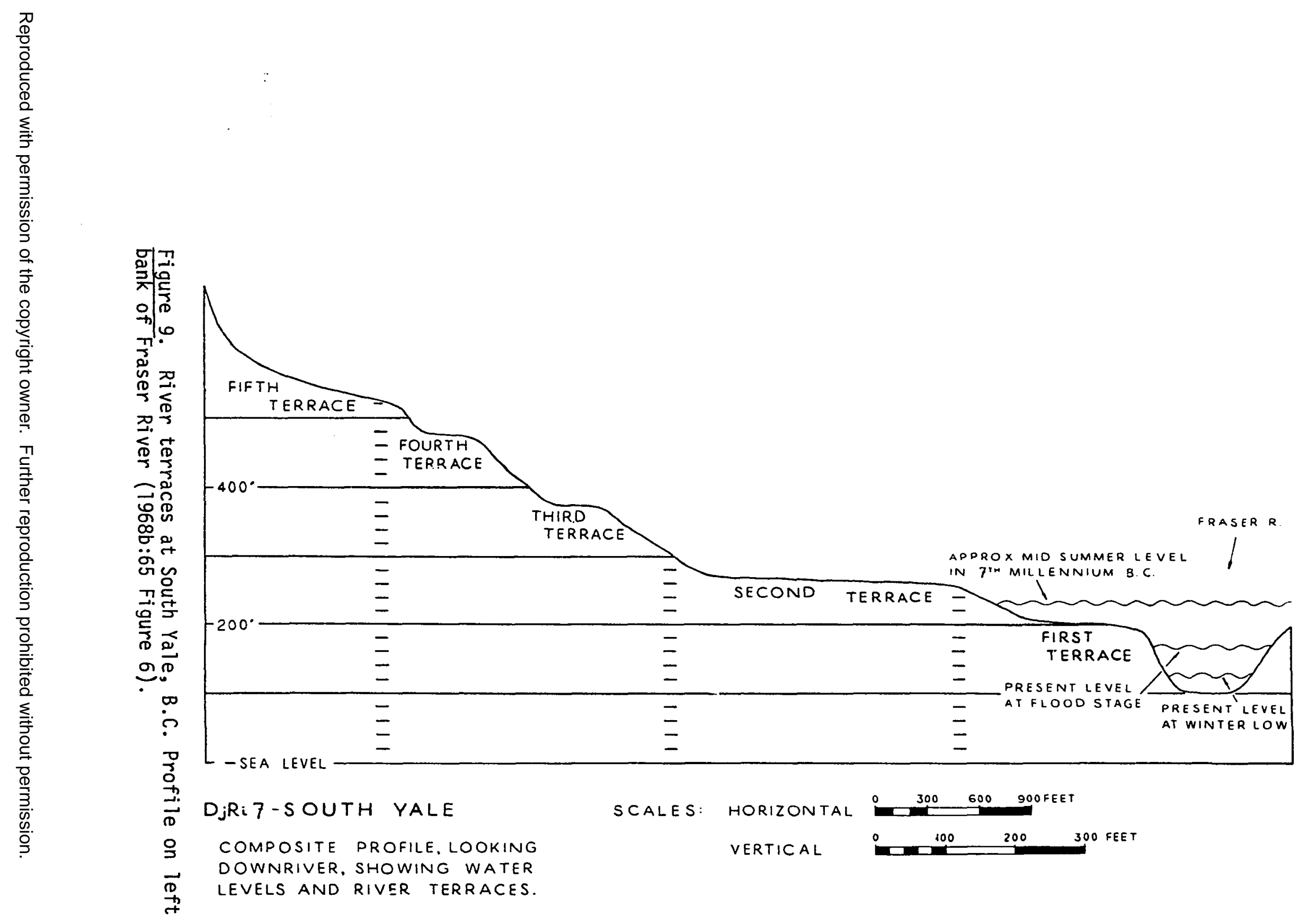


period:

[Hypothesis of time interval for this part of erosion:] Very likely, some phase of the erosion, which involved the removal of some 60 feet of sediment, from the 260-foot elevation of Terrace II to the 200-foot level of the First Terrace had started much earlier.

[Evidence to support the preceding genera] hypothesis and the following specific hypothesis:]

The fact that in the vicinity of the Milliken site the river during the entire 7 th millennium B. C. rose and fell annually above and below the 260-foot elevation

[Hypothesis of rate of erosion during this thousand years:] suggests that the river was incising its bed relatively slowly in that period [1968b:66].

[Hypothesis of earlier, post-Sumas downcutting rate, presumably from general climatic information:]

In the preceding cool and humid post-Sumas centuries downcutting progressed probably even more slowly,

[Hypothesis of possible sedimentation during the Sumas: while during the Sumas Stadial itself ponding of the river further downstream by alpine glaciers descending to the bottom of the Fraser valley from sumits in the Skagit Range may actually have led to deposition of sediments [1968b:66].

From all of these pieces of theory, Borden summarizes the erosion that occurred during the Holocene times, to complete the information needed for his first part of the argument for the dated terraces so that he can deduce that the higher terraces are earlier.

[Hypothesis, summary of the datable terrace cutting:] There arises, therefore, the distinct impression that the erosional activity of the Fraser in the vicinity of the South Yale locality during the entire Holocene has been confined to completing the creation of Terrace $I$ and to incising its bed down to its present 100-foot elevation above sea level [1968b:66].

Everson Interstadial Corollary. Borden completes his earlier argument, with the presupposition that such terrace cutting happened only during warm intervals:

[Hypothesis of consequent of dating of higher terraces:] 
The obvious corollary to this conclusion is that the formation of the higher South Yale terraces must have occurred in a more remote thermal interval, which can only be the Everson Interstadial [p.66].

Borden has completed his argument about the time span during which the South Yale terraces were cut. The next hypothesis states that this argument also supports his view on the longer Everson Interstadial, contrary to the Mathews view:

[Hypothes is that previous evidence and hypotheses support Borden interpretation of early disappearance of Cordilleran ice:] Moreover, these data, as well as the considerations and conclusions arising from them, lend further support to the view, expressed earlier on the basis of data on deglaciation from nearby areas, that the Cordilleran ice sheet had vanished from the lower Fraser Canyon region before the end of the Vashon Stadial [1968b:66].

Hypotheses Correlating Time of Terrace Cutting and Age of Artifacts

How do the artifacts relate to the time of terrace cutting? (I

find this one of the most difficult sections to analyze.) Borden answers with evidence and hypotheses in three sections: first relating to the upper two terraces, then the next two, and finally the lowest terrace. This is how he begins:

We must now examine the evidence which links the Pasika occupations with periods of terrace formation.

Terraces IV and $V$.

[Statement that in absence of sufficient research, hypotheses will not be offered yet for upper terraces:]

Although the presence of pebble tools on Terraces IV and $V$ has been established recently the implications of these potentialIy important discoveries are not yet clear [1968b:66,68].

[Statement of provenience of most evidence:]

Most of our information to date comes from the three lower terraces.

[Hypothesis of silt and sand deposition on lower terraces:] 
The basal gravels of the lower terraces are mantled with silts and fine sands laid down by the river at flood stage.

[Hypothes is of cause for the deposition to remain:] When, in the course of deepening its channel, the river eventually abandoned a terrace these fine sediments remained behind [1968b:68].

Terraces II and III. Borden presents an hypothesis and evidence that the Pasika Complex is contemporaneous with the formation of the Second and Third Terraces:

[Preliminary statement of hypothesis:]

The presumed contemporaneity of the Pasika Complex occupations with periods of terrace formation

[Evidence, including subsidiary hypotheses, for hypothesis above and below:]

is suggested by three points of evidence:

1. Pebble tools, detritus, and other materials of the complex are found not only on and near the surface but also deeply embedded in fluvial sediments which have not been disturbed since the time of their deposition on the terrace (Figure $7 \mathrm{a}$ ).

2. The patina acquired by the Pasika materials [Hypothesis:] suggests that they weathered in situ along with the soil zones in which they occur.

3. Each of the three terraces has yielded strongly waterworn specimens. This condition of water-wear could have developed [Hypothesis:] only through prolonged exposure to the abrasive action of water and sand at times when the river at flood stage still rose above the surface of the terrace.

[Hypothesis, restated:]

The above evidence applies in full to the Second and Third Terraces [1968b:68].

Discussion of Argument. Borden has identical evidence for Terrace One, but he will show that from this same evidence he must draw an opposite conclusion. He has said that evidence 1,2, and 3 above show that the terraces were formed and the artifacts were made at the same time, or

If $1,2,3$, then the terraces and artifacts are contemporary. 
Now he will conclude about the lowest terrace,

Even if 1,2 , and 3 , then the lowest terrace and its artifacts are not contemporary.

In deductive logic, this form of argument,

$$
\text { If } x \text { then } y
$$

is false under just one condition, if " $x$ " is true and " $y$ " is false. At first glance, Borden's argument appears to be of this form.

When speaking of Terrace II and III, he says

$$
\text { If } x \text { then } y \text {. }
$$

When speaking of Terrace I, he will say,

If $x$ then not $y$.

The second statement would seem to prove the first one false.

Such an analysis would overlook two important aspects of Borden's argument. The most basic is that this is an inductive argument, rather than a deductive one. Borden is saying in effect,

In these instances, we may generalize in one way, in other instances, we may generalize in another way. He is dealing with a probable conclusion from specific instances, not with an absolutely certain conclusions from universally applicable instances.

The other aspect that would be overlooked in this analys is is that there are other conditions, not included in those laid out in neatly numbered form, that make these two terrace theories different, and not contradictory. The differences can be symbolized this way:

Argument concerning Terraces II and III:

If $1,2,3,4$, and $5, \ldots$ then the artifacts are contemporary with the terrace formation. 
Argument concerning Terrace I:

If $1,2,3,6$, and $7, \ldots$ then the artifacts are not contemporary with the terrace formation.

What are the conditions symbolized by the last numbers in these statements? Borden writes about the evidence that I have numbered 6 and 7 in the second argument. After examining this evidence, we can supply the evidence that is symbolized by 4 and 5 in the first argument.

Terrace I. This is Borden's argument about the lowest terrace:

[Preliminary statement of the problem:]

The presence of great quantities of Pasika artifacts also on the surface and deep in the sands of Terrace I (Figure $7 \mathrm{~b}$ ) requires explanation.

[Evidence, symbolized by 6 above, relating to the time of terrace cutting:]

The lowest bench, it will be recalled, is post-Sumas in age and was still in the process of formation during the 7 th millennium B. C., the period when the culture of the Milliken phase with its advanced stone technology was in full flower.

[Negative evidence, symbolized by 7 above, relating to the absence of Milliken artifacts at South Yale:]

Significantly, the distinctive artifacts of this relatively sophisticated culture are not found on the First Terrace.

[Hypothesis which could be symbolized by \#8, repeated from above, that cultures so close together would, if coeval, share technologies:]

On the other hand, it seems obvious that the Pasika materials

on the lowest bench cannot possibly be coeval with the period

of its formation [1968b:68].

Now, if Borden's time-table on the cutting of Terrace I is correct, and it seems to be the elevation most certainly tied to the dated Milliken evidence, he finds only one alternative hypothes is to explain the evidence:

[Hypothesis to account for artifact evidence on and in Terrace 
I, first a negative then an affirmative statement:]

The only plausible explanation would seem to be that these materials are not in their original position but that they were derived from camps on the former surface of the Second Terrace, camps which had been occupied by Pasika Complex groups during the Everson Interstadial.

[Hypothes is on mechanics of artifact removal and redeposition:] As the Fraser in the early post-Pleistocene millennia cut into the massive sand beds at the downriver end of the Second Terrace the current swept away the fine sand, but it was not strong enough to carry of $f$ the heavy materials of the Pasika Complex that had been left on the surface of the old river bank. These artifacts drifted and were rolled over varying distances until eventually they came to rest on and were buried at various depths in the surface sands of the 200 foot terrace.

[Hypothesis, which could be symbolized by \#9, that water-wearing evidence is strongly confirmatory on the re-deposition hypothesis: ]

The explanation presented here receives strong support from the heavily water-worn condition which a great many Pasika specimens from this terrace exhibit [1968b:68].

Discussion of Argument. The hypothes is that Milliken and Pasika are not coeval could have been numbered 8 , and evidence that the artifacts on Terrace I are heavily water-worn could be numbered 9 , and so on. In short, Borden states an extended series of conditions which relate to the lowest terrace which make it necessary to argue that the tools and terraces are not contemporary.

If the evidence that Borden and I have numbered 1,2, and 3 are necessary but not sufficient conditions to argue that the tools and terraces are contemporary, a further question must be posed: What kinds of evidence can be brought forth, symbolized by 4 and $5 .$. above, to strengthen Borden's argument that the Terrace II and III tools and terraces are contemporary? Borden has suggested one pertinent fact, which is the spatial relationship of the five terraces. Only Terrace I is directly below another one, Terrace II. All of the 
other terraces are strung out from each other (pers. com., 1974).

It is possible that Borden will devise a more complex theory, adding evidence from Terraces IV and $V$. He may, for instance, conclude that the artifacts with little or no water wearing on the upper four terraces are coeval with the terrace in which it is found, whereas heavily water worn specimens have been redeposited from higher terraces, as he supposes with the artifacts on the lowest terrace.

Another sort of evidence that might strengthen Borden's Terrace II and III argument, and be symbolized by 4 and $5 \ldots$ would be dating, such as charcoal samples from these terraces, which, correlated with terrace stratigraphy could shed light on times when the terraces were habitable.

We hay conclude that Borden is not self-contradictory in these two sorts of terrace-tool theories, and we can begin to see the kinds of evidence that could lead to confirmation of both of them.

\section{Other Cultural Relationships}

Borden completes this paper with a discussion of the Pasika Com-

plex as it may relate to other cultures:

[Hypothesis of early relationship to Asiatic chopping tool tradition:]

The apparent presence in the Pacific Northwest of a late Pleistocene pebble tool culture lacking artifacts of more advanced stone technology raises intriguing questions regarding its origins and possibly remote relationships with early chopper tool cultures of eastern Asia (Chard 1959; 1963).

[Evidence of pebble tool complexes in the New World:] Pebble tool or, as they are also called, "chopper-scraper" complexes have been reported from widely separated areas in the Western Hemisphere. What was known about these mani- 
festations a few years ago was well summarized by Krieger (1964).

[Statement of status of these complexes:]

Unfortunately, the status of nearly all such complexes is under a cloud; many are surface finds, others were recovered without adequate controls. As a result, American archaeologists generally maintain a sceptical attitude toward pebble tools and are reluctant to become involved with the problems posed by them.

[Jennings', and Borden's, hypothes is of importance of this problem: ]

Yet, as Jennings (1968:69) forcefully pointed out recently, these problems are among the most pressing that face New World archaeologists today.

[Hypothesis that South Yale Complex may be instance in solution of the problem:]

Much work remains to be done at South Yale, It is hoped that future investigations at this locality and other sites in the Fraser Canyon region will contribute to their eventual solution [1968b:68]. 
CHAPTER XXXVI

1969a EXCAVATIONS AT OLD MUSQUEAM 1967-68

Borden's brief report to the Archaeological Society of British Columbia in its Newsletter has details of the work at this site, and of the urgency of the excavation. Because the site was about to be destroyed in a real estate development, the Musqueam Band gave permission for the excavation. The Archaeological Society members played an important part in the salvage project.

This is an instance of the cooperation that Borden seeks and uses outside of the regular academic community.

The total sample size from the work is 1554 artifacts. The excavations confirmed what surface collections had suggested, namely that this was a Marpole phase site.

[Evidence of village site:]

House floor deposits, from three to four feet deep, and numerous hearths were exposed along the trench faces, suggesting that the site had been a winter village with permanent dwellings.

[Radiocarbon evidence:]

One of the hearths yielded a good charcoal sample which was subsequently radiocarbon dated under the Paleochronology Program of the National Museum of Canada, Ottawa. The determined date of 400 B. C. $[2350 \pm 80$ (Borden pers. com., $1974]$ is the earliest reliable date so far obtained on a Marpole phase component of the Fraser delta region [1969a: 2].

[Types of evidence obtained:]

The work produced much valuable information on faod remains, raw mateiials used, manufacturing processes, burial practices, settlement pattern and structural details [p.2]. 
The basic Marpole complex was represented at this site. Borden singles out two special finds:

Among the more spectacular finds of the summer were two exquisite antler carvings, so characteristic for the Marpole phase, an antler comb (the earliest comb from the Northwest Coast:), and the burial of a youth with copper stains around the mouth (probably the remains of an ornament) and wearing a composite necklace made up of more than 180 large dentalium shells and uncounted segmented dentalia [1969a:3-4].

Finally, Borden tells of evidence together with his hypotheses

relating to a pebble tool complex underlying the village deposits:

[Evidence of pebble tools and hypothesis of significance:] Potentially of great significance finally was the discovery of a pebble tool industry in the orange sand underlying the old Musqueam village deposits.

[Genera] geological hypothesis/evidence:] According to geological evidence, the locality is part of a raised beach dating to early post-glacial time.

[Hypothesis from evidence of water wearing:] Since most of the pebble tools are strongly water worn (from wave action?) it is possible they date to an early occupation some 8 to 9,000 years ago when the beach was still active [1969a:3]. 
CHAPTER XXXVII

1969b THE SKAGIT RIVER ATLATL:

A REAPPRAISAL

This paper was published in the first issue of B. C. Studies.

"An earlier version of this paper was presented at the Twelfth Annual Meeting of the Northwest Anthropological Conference, Portland, Oregon, 1959" (1969b:13). With this footnoted comment, Borden begins an analysis of this useful artifact, together with its possible artistic and mythical symbolism. When Borden and I were discussing all of his pubtications, I remarked that this was one of my favorites. He said, "I had great fun doing it, and would enjoy writing other papers of this kind". It is independent of the close-woven fabric of his other papers. Borden's delight in the artistry of this artifact is apparent. He describes this object from various viewpoints in this relaxed yet wide-ranging paper.

\section{PROBLEM}

He sets himself this problem: can we tell whether this broken atlatl dredged from the Skagit River originated somewhere else, or whether it belongs within the Northwest Coast culture area? This is his background presentation:

Some years ago, H. C. Taylor and W. Caldwell (1954) published a brief note on a remarkable wooden artifact which was dredged from the northwest distributary of the Skagit River, a short 
distance from where it empties into the Strait of Georgia. The artifact, readily identified as an atlat1, a device for hurling spears and similar projectiles, is embellished with a striking and skillfully executed carving (Figs. 1 and 2) [Borden 1969b: $13]$.

Position of Taylor and Caldwell

Borden states the problem and repeats some comments by Taylor and Caldwe11:

[Statement of first problem of this paper:]

Pertinent to the prehistory of the Northwest Coast is the question of whether the piece is a local product or a cultural intrusive.

[Taylor and Caldwel]'s position as interpreted by Borden:] Taylor and Caldwell leave the question open although the burden of their comments appears to argue against the possibility of local origin.

[Borden's supporting evidence for preceding interpretation:]

[1] The atlat1, they point out, "is unknown from the Northwest Coast."

[2] Besides, none of the authorities that were consulted

"thought the carvings to be at all typical of the Northwest Coast,"

[3] nor do the authors themselves discern any "clear-cut similarity in design and/or design elements" [1969b:13].

\section{Borden's Position}

Borden will examine these three arguments, that the atlatl was not known on the Northwest Coast, that the carving is not typically Northwest Coast in style, at least in a clear cut manner in design or in elements of design. This is how he presents his position:

[Negative ethnographic evidence:]

The artifact, it is true, does not fit readily into the cultura1 context of the Northwest Coast--at least not into that of the recent ethnographic coast.

[General statement of two areas of correlation:]

However, when certain archaeological finds from the Georgia

Strait region are viewed alongside various ethnographic data 
from the Northwest Coast

[Preliminary statement of hypothesis:]

the possibility arises that the piece may date from an earlier period.

[Method of procedure in examining this hypothesis:]

Because of this possibility a fuller description and analysis of this unique artifact is warranted

[Re-statement of hypothesis:]

to determine more definitely its significance and possible position in the culture history of the Northwest Coast [1969b: 13].

\section{DESCRIPTION OF THE ATLATL}

\section{Illustrations}

The artifact was acquired by the Museum of Anthropology, University of British Columbia, but this paper is illustrated by photographs that Borden took before that acquisition.

Prior to its acquisition, the original appearance of the object had been altered through cleaning, buffing, and the application of preservative. Incredibly, moreover, the original length had been shortened through the removal of about $1.5 \mathrm{~cm}$ from the distal end of the implement [p.13].

The illustrations, my Fig. 10 (Borden 1969b:Figs. 1 and 2), show the left and right side views of the atlatl, and the top view. For purposes of comparison, there are photographs of a Nootka whalebone club, of a petroglyph near Nanaimo, B. C., a Nootkà painted screen, two views of figures from a totem pole carved by Mungo Martin, two views of the atlati hook from Locarno Beach, and two bone knife handles, also from Locarno Beach, my Fig. 11 (Borden 1969b: Figs. 7,8,9, and 10$)$.

\section{Raw Material}




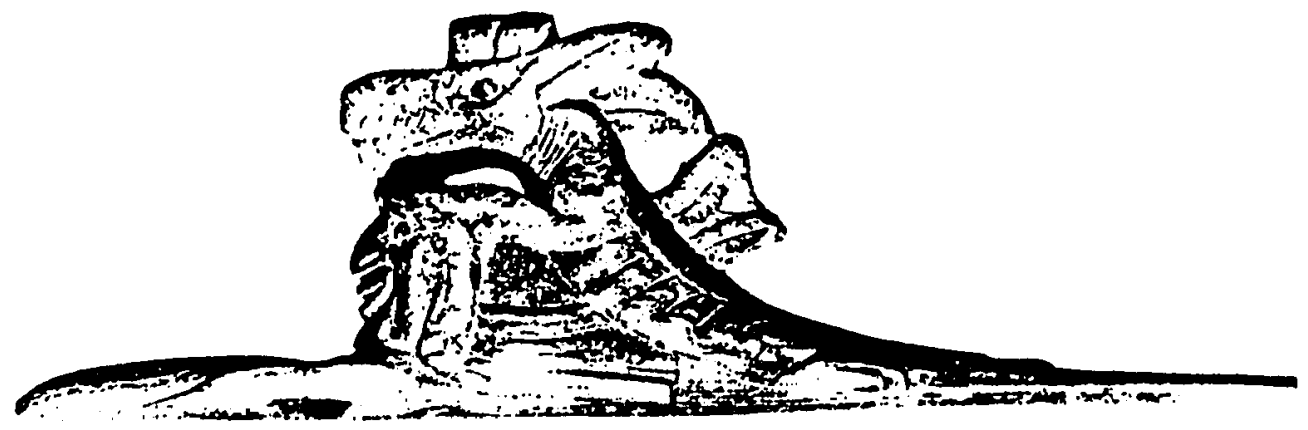

FIG. 1.

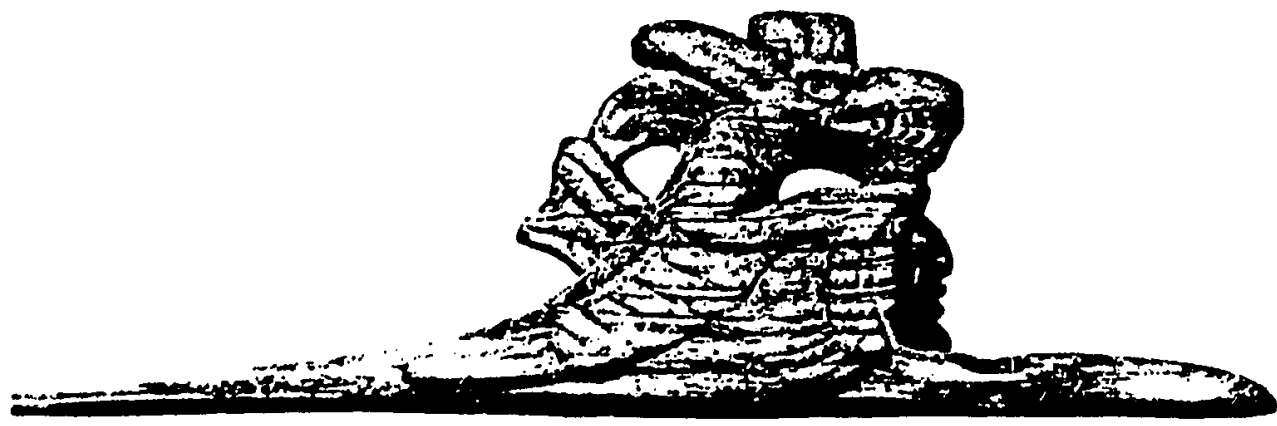

FIG. 2.

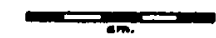

Figure 10. Skagit River atlat1, left and right views (1969b:14ff. Figures 1 and 2 ). 


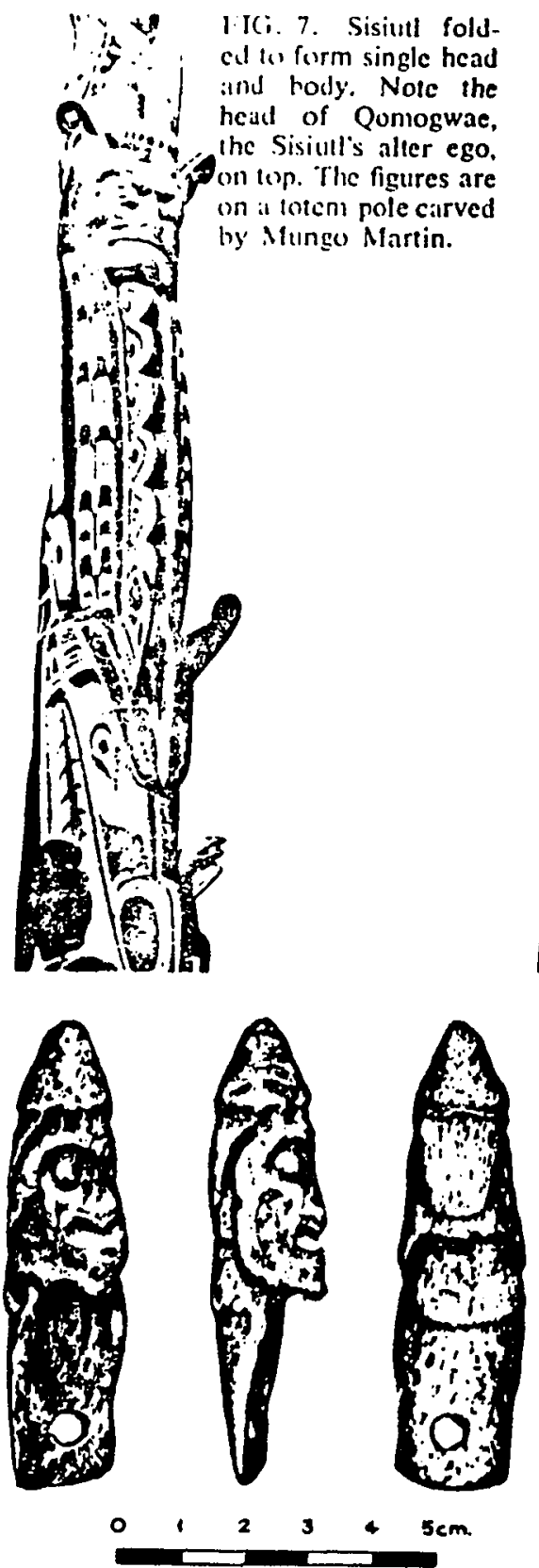

FIG. 9. Anthropomorphic atlatl hook from Locarno Beach site, Vancouver, BC. The figure, carved from in intler tyne tip. wears a conical basketry (?) hat and a medial labret in the lower lip. The projecting chin served as the hook which engaged the depression at the bult end of the projectile shaft. The artifact dates to about 500 BC.

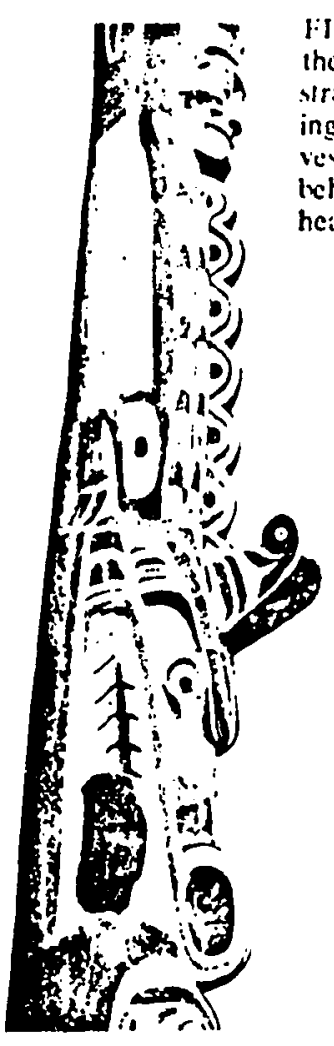

FIG. 8. Side view of the folded Sisiutl illusrated in fig. 7 , show. ing "joint-eye" and vesticiial forelimb just trehind the serpent's heid.

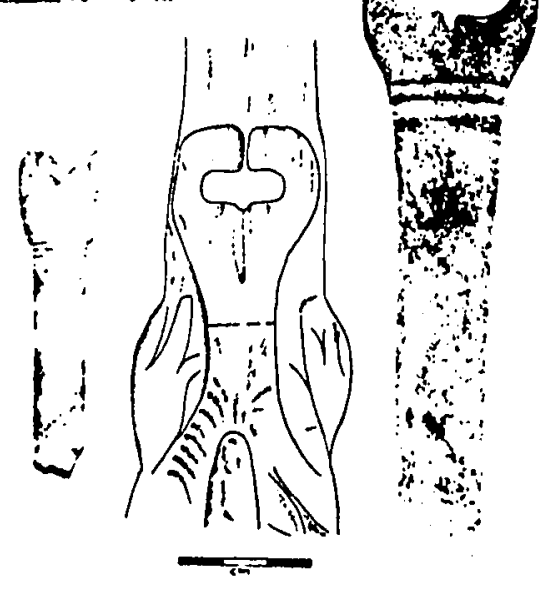

FIG. 10. Two bone knives from the Locarno Beach phase of the Fraser delta sequence cmbellished with a decorative motif suggesting the bifurcate tail of a whitle with the elongated tips of the flukes turned inward. Note resemblance of this motif with the tail on the Skagit River atlatl. Sce also fig. 3.

Figure 11. Totem figure, atlatl hook, and bone knives (1969b: $14 \mathrm{ff}$. Figures $7,8,9$, and 10). 
The Skagit River atlatl is made from Western Yew (Taxus brevifolia, Nutt.).

This tough elastic wood is especially suited to withstand the great stresses an atlatl is subjected to when propelling a dart, a spear, or a harpoon [p.14].

Borden describes how this fragment, with its finger holes, fitted into the total atlatl and hurled shaft unit. He compares and describes the placing of the finger holes which are

...side by side at right angles to the main axis, in a fashion reminiscent of those on atlatls in Central America, Florida, and during the Basketmaker period in the Southwest (fig. 3) (Mason 1928) [Borden 1969b: 14].

\section{Form and Function}

The next section details the form and function of the atlat in use:

In throwing position, the elaborate carving immediately behind the hand-grip would hang in an inverted position from the underside of the device. Like the atlatl weights of stone, which are both widespread and ancient in the New World (Butler and Osborne 1959; Neuman 1967; Ritchie 1965), and the magnificent animal carvings on spear throwers from the Magdalenian period in France, the sculpture on the Skagit River atlatl had a mechanical function. When a spear or harpoon is held in throwing position, the anterior portion of the shaft projecting in front of the supporting hand is considerably longer and thus heavier than the short posterior part which rests on the atlatl. Because of this imbalance the front end of the shaft will dip downward unless it is supported by the other hand until the hunter is ready to hurl the projectile. However, a weight attached to the atlatl behind the casting hand tends to correct this imbalance so that the weapon can be held in one hand until the critical moment, thus freeing the opposite hand for other tasks. This important function of atlatl weights is not commonly understood [1969b:14].

\section{Importance of Meaning of Carving}

Now Borden moves from considering the sculpture as a mechanical 
weight, and in a prel iminary hypothesis, states that even more important to the owner of this atlatl was the meaning of the sculptured form:

[Hypothesis that meaning is primary va]ue, both to Borden and to original owner of atlat $1:]$

However, of greater import to our inquiry (and probably also to the original owner) than the mechanical function is the carving itself and its significance [1969b:14].

\section{Description of Carved Sea-Monster}

The next step is to describe this carving, then compare these

formal elements with other instances in Northwest coast art, and finally to examine its significance. In this description, we see the atlatl through Borden's eyes and feelings:

The sculpture depicts a rampant animal, evidently a seamonster of some sort, surmounting a human head (figs. 1 and 2). Awesome and majestic in appearance, the beast bares a menacing array of teeth. Oval eyes, inlaid with precisely fitting insets made of a whitish stone, seem to scan a distant horizon. A series of closely spaced wrinkles on each side of the neck adds a touch of realism. Prominent are plumelike appendages which rise from the head, neck, and back. The paws of the short forelimbs rest on top of the human head, while the flipper-like rear limbs are extended backward from the body on each side of the tail [p.14]. Extending from the flanks to the belly of the animal, in the area between the fore and hind limbs, are incised lines which might be interpreted as ribs, but which may also be intended to suggest the large ventral scales of a serpent [p.14-15].

The tail of the beast is of more than passing interest (fig. 3). It resembles the horizontally oriented bifurcate tail of a whale, and as in the latter there is an indentation in the centre between the flukes. Curiously, the exaggeratedly long tips of the flukes are turned inward so that they nearly touch. A transversely incised line separates the caudal appendage from the rest of the body [1969b:15].

Borden completes this portion of the description with the comment that, "The significance of these peculiar design elements will become apparent later" (p.15). By finding these elements in Northwest Coast 
art, and finding ethnographic mythical motifs to give them meaning, Borden will outline this significance, and will seek to confirm his hypothesis that the meaning of the carving on the atlatl was more important than the mechanism of its function.

\section{Description of Caried Human Head}

Borden returns to the figure on the atlatl, describing the carved human head:

The human head beneath the sea-monster rises directly from the wooden base as if to suggest that it had just emerged from the sea. In profile, the face shows a prominent, boldly aquiline nose, thick lips, and a strong chin. The eyes, like those of the sea-monster, are inlaid with insets of the same whitish stone. Suggestive of rapid forward motion are incised lines, perhaps meant to indicate hair or seaweed, extending backward from the rear margin of a ribbon-like band which is draped over the head [1969b:15].

Workmanship and Age

The next data and interpretations concern general items of workmanship and age:

[Hypothesis-valuation of high workmanship:]

All parts of this splendid and powerful composition are executed with consummate skill and careful attention to fine detail.

[Evidence of size:]

The main figure rises to a height of $10 \mathrm{~cm}$, while the overall length of the sculpture is nearly $18 \mathrm{~cm}$.

[Evidence of method of manufacture:]

The entire object--atlatl and the decorative carving--is fashioned from a single piece of wood.

[Evidence of preservation and condition of wood:] The raised grain and long deep checks in the wood, which are particularly in evidence on the right side of the figures,

[Hypothesis of long submersion after carving:] suggest prolonged submersion after the artifact had been completed (fig. 2). 
[Hypothesis that carving is esoteric:]

This condition of the wood along with the esoteric nature of the carving

[Hypothesis of age and authenticity of atlat], from preceding evidence:]

may be regarded as evidence that the piece is not of recent manufacture, and the possibility of intended fraud can be dismissed $[1969 \mathrm{~b}: 15]$.

\section{Comparison with Northwest Coast Art. Forms}

Now Borden will consider whether this body of evidence fits with other evidence from the Northwest Coast. He begins with a caution against a simplistic view of Northwest Coast art that ignores its history and development.

[Hypothesis of profound change through time:]

In considering whether the artifact could have originated in the general area where 1 t was discovered, several points must be kept in mind. The recent art forms in the various subareas of the Northwest Coast are the end products of long evolution, and we must expect profound conceptual, stylistic, and other changes to have occurred in the course of such development.

[General hypothesis of change through space:] Moreover, the main centre of [material?] cultural activity did not necessarily always remain in the same area.

[Specific hypothesis by Kroeber, affirmed by Borden, of northward spacial shift through time:]

All our archaeological findings to date tend to confirm the inference made some considerable time ago by Kroeber (1939:30) on the slender evidence then available that a marked northward shift in cultural intensity had occurred from an earlier centre in the Strait of Georgia to later centres located farther north on the Northwest Coast [1969b:15].

Borden's view of cultural complexity and simplicity is illuminated again in the following passage:

[Hypothesis of early complexity, late simplicity in Fraser delta:]

A cultural climax, manifested in, among other things, elaborate carving in stone, antler, bone, and, by inference, in wood, had been reached in the Fraser Delta region during the 
last millennium B. C., while later culture phases are by comparison simpler and less complex (Borden 1962 and 1968; Willey 1966:387-96) [Borden 1969b:15].

Ethnographic Salish Art. Borden sums up two kinds of negative evidence to contrast ethnographic Salish cultures with the evidence of this at1atl:

[Evidence of contrast in atlat] use:]

Thus, apart from the fact that atlatls are absent in the latest culture phase of the Georgia Strait area,

[Evidence of contrast in artistic expression:]

it is difficult to envisage a recent Coast Salish artist as the author of the intricate carving on the Skagit River atlat 1 [1969b:15-16].

Although the viewpoint of recent Coast Salish of the Fraser Delta region, stressing private meaning of artistic expression, precludes expression in sculptures with explicit significance, earlier delta phases had such sculptured items.

Archaeological Similarities. [Hypothesis of similarity to Marpole or Locarno Beach artifacts:]

On the other hand, the sculpture would not seem out of place in the context of the Marpole or Locarno Beach phases of the Fraser Delta cultural sequence (Borden 1962: plate 5; Willey 1966: 390-3) [1969b:16].

\section{NORTHWEST COAST MOTIFS}

Borden turns to the motifs in Northwest Coast mythical literature and plastic art for instances similar to characteristics of the atlatl carving. This is his first statement:

[Hypothesis of similarity to recent motifs:]

Surprisingly, despite the probable antiquity of the artifact, the sculpture embellishing it exhibits marked affinitles with recent Northwest Coast motifs $[p .16]$.

This may be surprising in light of the changes he said could be expect- 
ed, but it is very possible that myths might change at a slower rate than the forms by which they are represented. These motifs from myths are examined in turn, first the sea monster theme, second the whale theme, then serpents and snakes. He concludes this section with an extended description of the Sisiutl, a double headed serpent.

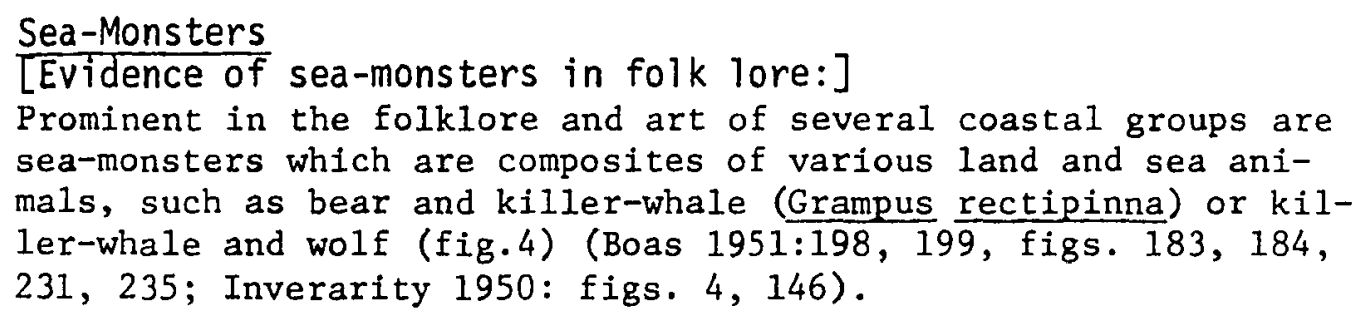

[Evidence of recent art representing these monsters:]

Representations of such composite creatures in recent graphic and plastic art ordinarily show the front half as that of the land mammal complete with the forelimbs and a fearsome mouthful of bared teeth, while the rear half including the tail are those of tine whale. Often present also is the prominent dorsal fin of the killer-whale.

[Hypothesis, concluded to be of high probability, of similarity of ethnographic instances to atlatl figure:]

The similarity of such composite sea-monsters both conceptual$1 y$ and in detail with the main figure on the skagit atlat 1 is evident and need not be belaboured [1969b:16].

Whales

Now Borden elaborates on designs on the atlatl similar to the whale motif but also present in representations of other mythical creatures:

[Hypothesis that appendage on back could be a whale feature:] Since, as was shown above, the tail of the Skagit monster is clearly modelled after that of a cetacean the erect bi-lobed appendage on the beast's back could conceivably have likewise been inspired by the dorsal fin of the killer-whale, although it differs from the latter in form [1969b:16].

\section{Serpents and Snakes}

If the form was not meant to represent part of a whale, it can 
be compared to other Northwest Coast forms:

[A]ternate implicit hypothesis, with three instances, to the one above:]

Fut appendages, plume-like or of other shape, are not at all rare on the Northwest Coast.

[First instance to support alternate hypothesis above:]

They appear on varfous mythical creatures in the Nanaimo petroglyphs (fig. 5), which date to an as yet undetermined period of the prehistoric past,

[Second instance to support alternate hypothes is above:] and they are regularly found on Kwakiutl representations of the Sisiut1, the double-headed serpent (Inverarity 1950: figs. 13, 78; Hawthorn 1967: figs. 126-9),

[Third instance to support a]ternate hypothesis above:] and on the lightning snake, Hahektoak, which the thunderbird hurls down upon the earth (Swan 1898: fig. 1; Inverarity 1950: figs. 10,11) [Borden 1969b:16].

\section{"Lightning Snakes" and the Sisiutl}

If Borden can link details of such creatures to other features on the atlatl, he will further confirm his position that this is a Northwest Coast artifact. Both lightning snakes and the Sisiutl sometimes have forelimbs like the atlatl figure, and in one instance a decoration like a whale's tail:

[Evidence, implicitly of similarity, of forelimbs on 2 creatures:]

Interestingly [for comparison with the atlat1], "lightning snakes" and the Sisiutl are sometimes shown with forelimbs (fig. 6) (Hawthorn 1967: fig. 128, second from bottom). These serpents should, therefore, not be understood necessarily as reptiles without limbs in the strict blological sense.

[Evidence, implicitly of similarity, of whale tail motif:] In some instances, lightning snakes on Nootka painted screens have a design near the end of their tail resembling the conventionalized tail of a whale (fig. 6) [Borden 1969b:16].

Description of the Sisiut] 
Now Borden describes the form of the Sisiutl, in order to support an hypothesis that the figure on the atlatl is a Sisiutl. His first statement would be more accurate if he had substituted the word "basically" or "generally" for the word "invariably", since he proceeds to describe one important variation on the basis sisiutl theme, a variation which he uses and needs, to support his identification of the atlatl figure as the Sisiutl.

[Evidence of "invariable" Sisiutl form:]

Invariably depicted in the centre of Sisiutl representations is a human head with one-half of the double-headed monster extending from it on either side.

[General statement that there are variations:] However, the dual nature of the Sisiutl is not always shown so explicitly.

[Instance of this variation:]

This was brought home to me when I asked the late Mungo Martin, the noted Kwakiutl artist, about the figures on one of his totem poles on display at the University of British Columbia. Among the mythological beings carved on this pole is a seamonster with a long body extending vertically upward and at the forward part a pair of vestigal forelimbs and a single large head with bared teeth and appendages like those of the Sisiut1 (figs. 7-8). According to Mungo Martin, this was indeed the Sisiutl. He had folded the beast and combined the two halves into one [1969b:16].

[Specific human head relationship:]

The human head, which is always associated with the Sisiutl, appears on the pole directly above the beast, that is, at its tail end [pp.16-17].

[Hypothesis that instance of Mungo Martin's totem conceptually approximates the atlati:]

This representation of the Sisiutl is of extreme interest since conceptually it approximates the group on the Skagit River atlatl: the sea-monster or sea-serpent in intimate association with the bodyless head.

[Hypothesis that atlat] represents the Sisiut]:]

Despite peculiarities in representational details the carving on the atlatl very likely represents an early version of the two aspects of the Sisiutl that are still found invariably 
associated in recent representations of this mythological being [1969b: 17].

Now Borden re-states the basic thesis of this paper, first negatively, then positively:

[Hypothesis, re-stated, of atlat?'s position in Northwest Coast culture:]

There is, therefore, really nothing in the skagit River sculpture that is alien to the Northwest Coast. On the contrary, conceptually and artistically it fits completely into the cultural context of the area $[p .17]$.

Significance of the Sisiutl in Mythology

Borden adds further support to this identification of the atlatl carving in his description of the meaning or significance of this serpent figure. It will also support his hypothes is that the meaning of the atlatl carving was more important to its owner than the mechanics of its weight in use. This is what the Sisiutl represents:

[Evidence of Sisiutl in mythology:]

The Sisiutl occupies a central position in the complex mythology of Northwest Coast peoples, especially among the Wakashan speakers, the Kwakiutl and Nootka. One Kwakiut1 myth relates how Qatenats, in his quest for supernatural power, descends to the bottom of the ocean to the house of Qomogwae, god of the underworld and of the sea. Qomogwae is described as a "stout man." Presently, however, Qatenats recognizes that Qomogwae is the Sisiutl, the double-headed serpent (Boas and Hunt 1904:22-7). It is this man-serpent duality of the Sisiutl that is reflected in recent Kwakiutl representations and evidently also in the Skagit River carving. However, the Sisiutl had the power to assume other shapes. It could appear in the form of a whale, a composite sea-monster, such as bear and killer-whale, or even as a self-propelled canoe. As ruler of the sea and of the underworld the dual divinity had the power to work both good and evil, to give and to take life. The god also controlled wealth, for that is the meaning of the name Qomogwae (Locher 1932).

[Statement of economic base of Northwest Coast people:] Food and wealth of the Northwest Coast peoples came from the sea.

[Hypothesis of significance of the Sisiutl to its owner:] 
What was more appropriate for a sea-mammal hunter than to enlist the aid of the powerful god, who controlled the resources of the sea, by having the divinity represented on the atlat 1 that was to propel the hunter's projectiles? [1969b:17].

Borden thus completes the artistic and mythological section of the paper, having used evidence of artistic details and cultural-mythological significance to link this artifact into the context of Northwest Coast life.

\section{POSSIBLE AGE OF THE ATLATL}

This paper concludes with evidence and hypotheses attempting to place this artifact into the most probable time frame.

\section{Evidence That It Is Not Recent}

First he reviews the evidence leading to the hypothes is that it is not recent:

[Re-statement of dissimilarity from ethnographic Coast Salish:] As mentioned in the beginning of this paper, one would not ordinarily associate an intricate carving such as on the Skagit River atlat 1 with recent Coast Salish culture.

[Negative evidence of recent use of atlat]:] This, and the fact that atlatls were not used in historic times in the Strait of Georgia or elsewhere on the Northwest Coast,

[Evidence of northern use of atlatl:] except far to the north among the Tlingit,

[Hypothesis, re-stated, of antiquity of atlatl:] suggests some considerable antiquity for the Skagit River specimen $[1969 \mathrm{~b}: 17]$.

\section{Other Northwest Coast Atlatls}

Now Borden will review archaeological evidence in the Fraser Delta for the use of the atlatl, and in other Northwest areas: 
[Negative evidence for 2000 years in Fraser Delta:]

Our investigations in the Fraser Delta region have produced no convincing evidence for the use of atlatls in culture phases of the last two millennia.

[Evidence in other Northwest sites:]

Yet researches in Oregon and Washington indicate that atlatls had a long history in the Pacific Northwest (Cressman and Krieger 1932; Cressman et al. 1960: 43; Osborne and Butler 1959).

[Evidence from Locarno Beach:]

Moreover, clear-cut evidence demonstrating that spear throwers were employed in the Georgia Strait area at least during the Locarno Beach phase of the last millennium B. C. comes from the Locarno Beach site in Vancouver, which only minutes before its destruction by a bulldozer yielded an anthropomorphic atlatl hook (fig. 9) [1969b:17].

\section{Comparison of Skagit River and Locarno Beach Atlat7s}

The Locarno Beach and Skagit River atlatls are compared to each other and to additional specimens from the area:

[Evidence of differences between Locarno Beach and Cressman's specimens:]

This hook is unlike those recovered by Cressman and his associates in very ancient horizons in Oregon [pp.17-18],

[Evidence comparing Locarno Beach atlat] with eastern Archaic specimens:]

but resembles rather the hooks of the eastern Archaic which are fashioned from the tip ends of antler tynes (DeJarnette 1952: fig. 147). However, while the eastern specimens are invariably plain and undecorated, the Locarno Beach hook is carved in the form of a small human figurine wearing a conical basketry(?) hat and a medial labret.

[Evidence further describing Locarno Beach artifact:]

The jutting chin of the figure served as the hook that engaged the pit at the butt of the projectile shaft. A perforation in the basal portion for the insertion of a peg and a broad lashing area on the back of the tyne indicate how the hook was fastened to the distal end of the atlatl.

[Evidence of simi]arity between Skagit River and Locarno Beach atlatls:]

Significantly [for our comparison], the $1.9 \mathrm{~cm}$ width of the lashing area corresponds closely to what the width of the business end of the Skagit River atlatl would have been before 
breakage [1969b:18].

[Implicit step in the argument:

A Though only this single specimen of an atlatl was found at Locarno Beach, there is abundant evidence of harpoons, and spears or darts with which atlatls are often used.]

[Evidence of points from thrown projectiles:]

The harpoons of the sea-mammal hunters who occupied the Locarno Beach site were armed with toggle heads and their spears or darts with ground slate points of which many were recovered (Borden 1950: 15-16; 1951:plate 1,2,4; plate II, 1-4; 1962: plate $2,1, m$, plate $3, a-h)$.

[Hypothes is that the evidence to be presented next, represents close affinity between Skagit River atlatl and the Locarno Beach culture:]

The Locarno Beach site produced further evidence hinting at contemporaneity and close affinity between the culture of the Locarno Beach phase and that which produced the Skagit River atlatl.

[Evidence of detail of bone knives from Locarno Beach:] Present in the assemblage are well-made bone knives decorated at the handle end with a distinctive ornamentation which despite its stylized form suggests the bifurcate tail of a whale with the tips of the flukes turned inward.

[Hypothesis/evidence of closest similarity between knife handle and Skagit River atlati:]

To my knowledge, there is nothing in Northwest Coast art which duplicates this motif more closely than the tail of the seamonster on the Skagit River atlatl with its similarly shaped flukes (fig. 10).

[Evidence of details supporting preceding hypothesis:] [As further evidence of that similarity,] Three parallel lines, placed transversely below the decoration on each of the bone knives, correspond to the single transverse line across the tail of the Skagit River sea-monster [1969b:18].

Can such a wooden object be as oid as the Locarno Beach phase?

Borden replies that such preservation is possible:

[Evidence of age of Locarno Beach phase:]

According to radiocarbon dates, the culture of the Locarno Beach phase was in operation in the Strait of Georgia during most of the 1ast millennium BC (Borden 1968: 17-18). 
[Hypothesis that preservation is possible:]

The question as to whether it is likely that a wooden artifact could be so well preserved over such a long period need not trouble us.

[General statement of similar instances:]

objects more delicate than this and dating back to even earlier periods have been recovered from the silt of lake bottoms and streams and the estuaries of rivers in many parts of the world [1969b:18].

\section{CONCLUSION}

Borden re-states his hypotheses from this paper, clearly saying

that they are still hypotheses, and not demonstrated facts:

[Statement that the paper's conclusions are hypotheses:] Although it is not possible to terminate this paper with a quod erat demonstrandum, the evidence presented suggests the probability that

[Hypotheses of the paper, re-stated:] the Skagit River atlatl is a genuine product of the Northwest Coast and that this masterpiece of wood sculpture originated somewhere in the Georgia Strait area most likely during the Locarno Beach culture phase [1969b:18]. 
CHAPTER XXXVIII

\section{C EARLY POPULATION MOVEMENTS FROM ASIA INTO WESTERN NORTH AMERICA}

This paper published in Syesis by the British Columbia Provincial Museum, was sent to me by $\mathrm{Dr}$. Borden in response to my reques.t for several papers that I had been unable to secure. I had asked for a copy of the following paper:

New Evidence of Early Cultural Relations Between Eurasia and Western North America. Paper presented 8th International Congress of Anthropological and Ethnographic Sciences, Tokyo, Japan, 1968.

Borden wrote:

Instead of this publication,.... I have given... you a reprint of a closely related and only slightly modified paper which was published in Syesis... [pers. com., July, 1973].

Another, shorter version of this paper was printed in The Britannica Book of the Year, 1969, entitled "New Evidence on the Early Peopling of the New World" (pp.101-104). In the 1967 Britannica Book of the Year, Borden's article summarizing archaeological work of that year in the Western Hemisphere presents material which is repeated in this present work. One of these pieces of evidence is Ackerman's date for the Ground Hog Bay site, at Icy Strait, Glacier Bay, Alaska, which Borden refers to as "surprisingly early" (1969c:2). This site, its assemblage and dates are regarded as important evidence in this 1969c paper, and will be used as key data in papers 1969d, and 1973.

One further preliminary comment may help in studying this paper. 
I have already quoted some of Borden's ideas on the changes in his theoretical stance over the twenty-three year span of his publications to date. This is a longer section from one of his letters about these changes:

... when new data seemed to make it necessary I have been ready to abandon previously held views and even to reverse myself (cf. 1962 West Coast Crossties...). This is an ongoing process. For instance, on reading my syesis (1969) paper you will find that I hypothesized that Athapascans were responsible for spreading the Early Boreal Tradition southward through intermontane interior British Columbia. But I have since learned from linguists that the time depth for the divergence of Athapascan languages is far too shallow for them to have done so. I was probably already on the right track in my $1954 \mathrm{~b}$ paper. Eventually I will elaborate this further for you [pers. com., 1973).

With Borden's caution in mind, the reader may note that the Athapascan theory is independent of the Early Boreal theory and evidence. Thus, by substituting the phrase "Early Boreal" for the word "Athapascan" in all except the purely linguistic sections of this paper, the essential argument which Borden derives from archaeological evidence is preserved. In some instances, I have inserted "Early Boreal" after "Athapascan" to illustrate this.

Borden's paper is in these sections:

1. Geological and geographic background for population movements.

2. Microblade sites as evidence of population movements, designated as the Early Boreal cultural tradition.

3. Linguistic evidence and hypotheses that proto-Athapascans may have been the Early Boreal peoples.

4. Evidence of an earlier tradition in the western New World, 
designated as the Protowestern cultural tradition.

5. Evidence for another earlier tradition, called the PebbleTool cultural tradition.

6. Conclusions correlating these traditions.

\section{GEOLOGICAL AND CLIMATIC BACKGROUND}

\section{Bering Landbridge and Southern Dispersion Routes}

Beginning from the data on periods when the Bering landbridge formed a united 01d and New World continent, Borden examines the evidence for passage into the New World "...from permanently unglaciated areas of central Alaska..." (p.1) into other parts of the New World.

[General statement of consensus on Bering landbridge:] Thanks to recent research on the late Cenozoic history of the Chukch1-Bering region, it is now fairly well known at what times in the past animals and men could range freely over the landbridge which during periods of low sea level linked Asia with America (Hopkins, 1967).

[General statement of problem of subsequent migration routes:] What needs to be determined more precisely is when and where game animals and hunters could and did pass from permanently unglaciated areas of central Alaska to and through parts of North America which were repeatedly buried under continental glaciers.

[Hypothesis of migration corridor east of the Rockies:]

In past discussions and speculations concerning the early peopling of the New World, the postulated migration corridor between the Cordilleran and Keewatin ice sheets which periodically opened and closed has figured prominently.

[Hypothes is of Borden intermontane corridor route, preliminary statement:]

By contrast with this much-mooted route east of the Rocky Mountains, little consideration has been given to possible early population movements through the intermontane corridor of British Columbia. The present paper will :ompensate in part for such past neglect [1969c:1].

\section{Description of the Intermontane Corridor}


Borden gives another description of this route, which has figured in his theories since 1954 (Borden and Duff):

Flanked by the towering Coast Mountains in the west and by the Rockies in the east, the high plateaus of British Columbia's intermontane interior form part of a continuous belt of similar plateau country in southwestern Yukon Territory and central Alaska. Moreover, from central Alaska, natural pathways lead via Tanana River valley and Teslin River directly toward and deeply into the interior of Canada's westernmost province [1969c: $1-2]$.

\section{Glaciation}

Superimposed upon this landscape are the recurring glaciers:

[Evidence of tota] glaciation over British Columbia:]

During the Fraser (Wisconsin) Glaciation, British Columbia was completely blanketed by Cordilleran ice which attained a thickness of more than 2,000 metres over wide areas.

[Evidence of beginning time and duration of Wisconsin Glaciation:]

Beginning around 23,000 B. C., the glaciation lasted for more than 14,000 years (Armstrong et al., 1965).

[Evidence of end of glaciation in southern Interior British CoTumbia:]

Carbon-14 dates on peat from bogs in the southern Interior indicate that ice had vanished from the area and vegetation had been established by around 8000 B. C. (Lowdon et al., 1967, p. 27; Fulton, 1968, p.1079).

[Hypothesis of end of glaciation in northern Interior:]

In the northern Interior deglaciation probably occurred somewhat later [1969c:2].

This section harks back to papers in 1952, 1954, 1956, and 1962, and anticipates peat bog dates in 1972, and new theories in 1973. Now Borden states explicitly the background against which he will examine the microblade-bearing cultures. He will be writing about migration of peoples into an unoccupied territory:

The Province thus represents an ideal natural laboratory for 
the tracing of population movements during early Holocene

time. We start with a clean slate, as it were [1969c:2].

\section{EARLY BOREAL CULTURAL TRADITION}

Borden summarizes the contents of this section of the paper in the abstract:

Newly available data indicate that in terminal Plefstoceneearly Holocene time people with an essentially Mesolithic culture spread from Siberia across Beringia into unglaciated interior Alaska and thence through the newly deglaciated corridor between the Rockies and the Coast Mountains into the Pacific Northwest. To date, this is the only major archaeologically detectable movement of people and culture into America in early postglacial time. It is distinct from the somewhat later arrival of ancestral Aleut and Eskimo [1969c:1].

\section{Review of Earlier Writings}

Borden reviews his earlier writings about microblade cultures:

In an earlier paper (Borden, 1962), I utilized the then rather sparse data on the distribution of microblades in space and time to demonstrate that cultural influences emanating in Asia could reach the Northwest Coast of North America by traveling interior routes through Alaska, Yukon Territory, and British Columbia. Since then, thanks to the researches of many scholars, the data have proliferated enormously (Fig. 1)

[Hypothesis of new implications:]

and they now carry implications far beyond those envisaged in 1960 [1969c:2].

Presently Known and Dated Microblade Sites, 1969

Northern New World Sites. Borden now gives dates, evidence, authorities, and hypotheses about the distribution and relationships of microblade sites. A map (figure 1, page 2), shows dated and undated microblade sites. On the map is a list of the dates for the sites ranging generally from Northwest to the south and east. The ages are given 
in B. C. dates, with no range of probable error:

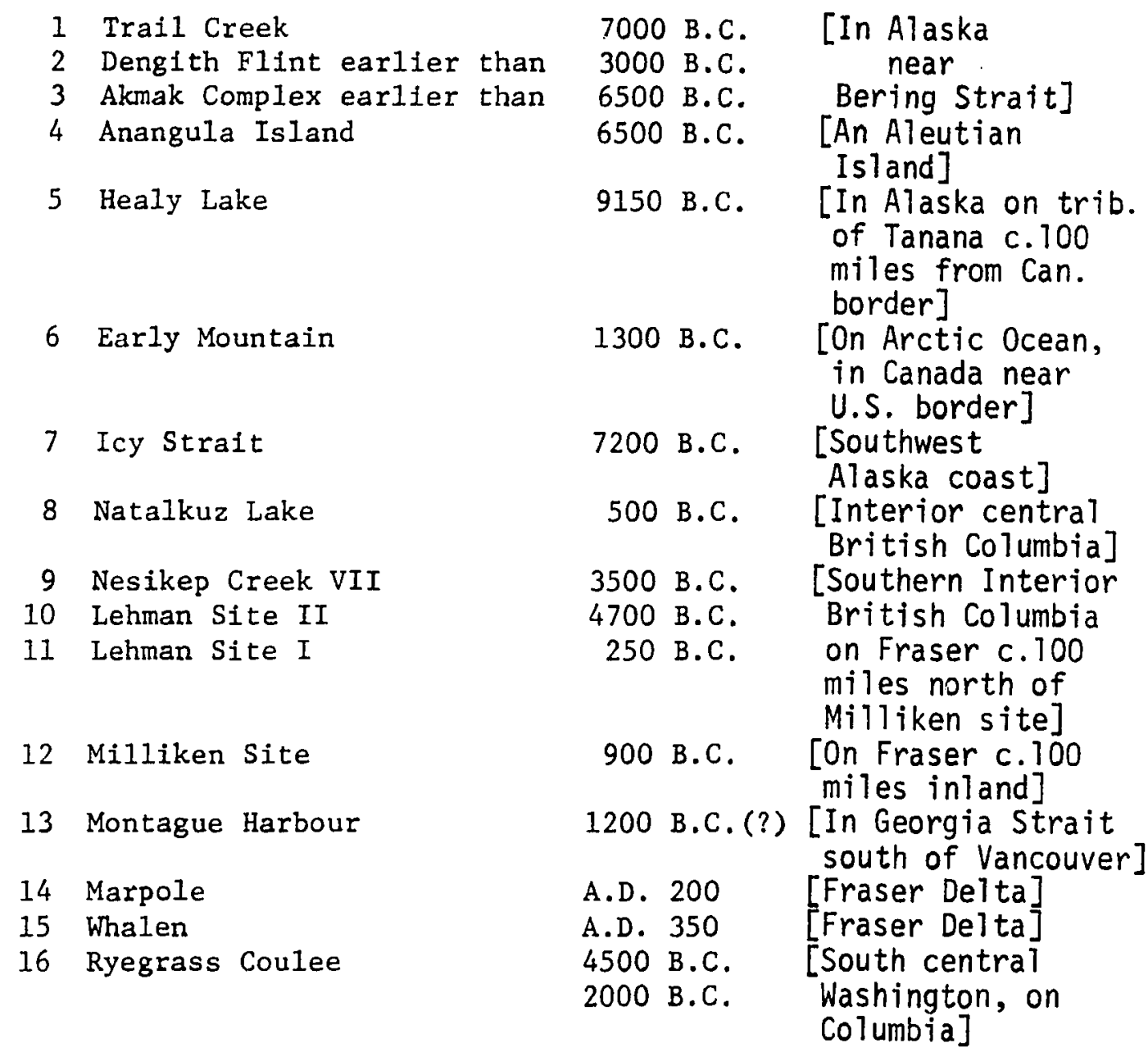

[1969c:3]

The legend accompanying the map contains hypotheses and additiona) evidence:

[Summary hypothes is interpreting data:]

Distribution in space and time of microblade sites, documenting the migration-borne spread of the Early Boreal Cultural Tradition from Asia and Bering Strait to the Pacific Northwest of North America via interior Alaska, southwestern Yukon, and the intermontane corridor of British Columbia.

[Statement that apparent negative evidence results from no research:]

Blank area in northern half of British Columbia reflects lack of archaeological investigations. 
[Negative evidence in Tsimshian and Haida territories:] Extensive recent excavations carried out by G. MacDonald, National Museum of Man, Ottawa, in Tsimshian territory, both in the Interior and on the Coast, as well as on Queen Charlotte Islands, occupied by the Haida, have produced no microblades.

[Evidence on coast with early date; hypothesized or interpreted as surprising:]

Aside from Ackerman's (1968) surprisingly early site on Icy Strait far north on the Northwest Coast (No. 7 on figure),

[Statement of other coastal sites and time range:]

the only other part of the coast where microblade sites have been discovered to date is the Puget Sound-Georgia Strait area. As C14 dates indicate, microblade technology was introduced relatively late to the southern coast.

[Hypothesis relating to del ta microblade users:]

The groups responsible were almost certainly non-Athapascan.

[Hypothesis/evidence from Sanger, with Borden concurring, of different manufacturing technique in the delta:]

As Sanger (1968) has shown, the production of these late coastal microblades differed significantly from the technique employed by Early Boreal groups in the intermontane interior of Washington and southern British Columbia [1969c:2].

Some of the evidence new since Borden's 1962 paper comes from

two sites in Alaska on or inland from the Bering Sea, Trail Creek Cave and Onion Portage.

[Evidence from sites with significant proportion of microblades:] of particular significance is a new series of early C14 dates on archaeological complexes, all of which evince a strong reliance on microblade technology.

[Evidence from Trail Creek Cave:]

A sample associated with microblades and side-slotted projectlle points of antler from the 1mportant Trail Creek Cave site in western Alaska was recently dated at 7000 B. C. (Larsen, 1968).

[Evidence from Onion Portage:]

Farther north, at the deeply stratified Onion Portage site in western interior Alaska, Anderson (1968) uncovered beneath the Kobuk complex horizon, dated at 6500 B. C., the probably much older Akmak complex.

[Anderson hypothesis of age and relationships of Akmak complex:] 
Anderson surmises that the bearers of the Akmak complex may have been using the locality from as far back as 13,000 B.C., and he recognizes relationships between this complex and Siberian cultures [1969c:2].

Siberian Sites. Relationships with Siberia rest partiy on new

Soviet data. (In 1973, Borden will re-evaluate the weight he gives to the Soviet evidence.)

[Evidence on Kamchatka, with Dikov hypotheses of relationship with Siberian and Alaskan sites:]

Recent Soviet discoveries are of importance in this context, especially the late Paleolithic culture uncovered by Dikov (1968) at Ushki sites I,II, and IV on Kamchatka. Rejecting an age determination of $19,150 \pm 900$ B.C., Dikov accepts as more reasonable the results of another $\mathrm{Cl} 4$ analysis which places this culture at 8500 B.C. According to Dikov, this Ushki culture is related to late Pleistocene complexes at south Siberian sites on Angara River and Yeniesel River west of Lake Baikal. But Dikov also discerns affinities with the microcore and blade technology of the Denali complex, recently defined by Hadleigh-West (1967) at Donnelly Ridge and other sites in the lower Tanana River drainage area of central Alaska [1969c:2].

The next hypotheses lead to a possible period for movement from

Siberia to Alaska of these microblade making people:

[Evidence from dates bracketing Afontova Gora II:]

The main or lower horizon at Afontova Gora II, one of the components west of Lake Balkal, is bracketed by C14 dates of 9400 B.C. and 18,950 B.C. on samples taken from just above and below the main deposit (Chard and Workman, 1965, p.150; Chard, $1969 \mathrm{c}, \mathrm{p} .778$ ), suggesting a possible mean age for Afontova Gora II of around 15,000 B.C.

[Hadleigh-West hypothesis of Denali complex age:]

In view of the similarities with the distant Stberian sites Hadleigh-West surmises that the Denali complex of central Alaska must be at least as old as the aforementioned Ushk1 culture, dated at 8500 B.C.

[Hypothesis of time before which microblades came to Alaska:] The bearers of the Denali culture should, therefore, have crossed the Bering landbridge prior to that [8,500 B.C.] time [Borden 1969c:2,4].

Hypotheses for Time and Route of New World Microblade Introduction 
If microblades came from Siberia, this seems to be confirmed by dates of microblade sites in Alaska, some from before 8,500 B.C.:

[General statement of confirmatory instances to Hadleigh-West hypothesis:]

This assumption receives strong support from new finds in southeastern interior Alaska.

[Evidence of dates from Healey Lake:]

Early components with microblades dated at 7000 B.C. and 9150 B.C. have recently been uncovered by R. A. McKennan and J. P. Cook (1968) farther up the Tanana River at Healy Lake, some 125 miles southeast of Fairbanks.

[MacNeish hypothesis from southwestern Yukon Territory sites:] Still farther to the southeast, in southwestern Yukon Territory, MacNeish (1964) tested numerous sites whose microblade components he arranged chronologically into three phases, estimated to span the period from the sixth millennium B.C. to shortly before A.D. 300 .

[Borden hypothes is to revise MacNeish:]

The initial estimate may be too conservative.

[Evidence from Icy Strait tending to confirm Borden hypothes is above: ]

A date of $8230 \pm 800$ B.C. on microblade-bearing level III at the Ground Hog Bay 2 site on Icy Stralt on the northern Northwest Coast of southeastern Alaska (Ackerman, 1968, p.60),

[Borden dating hypothesis, an al ternative to MacNeish:] suggests the presence of microblade-using groups in the adjacent Yukon interior by at least 7400 B.C.,

[Borden hypothesis supporting preceding hypothesis:]

because the only possible route to the site locality at that time was one that passed through southwesternmost Yukon Territory.

[Statement that dates from Healey Lake (as related to dates from Icy Strait) corroborate this hypothesis:]

The early dates at Healy Lake lend credence to this interpretation [1969c:4].

\section{Correlation with Deglaciation}

Borden now correlates the 7400 B.C. date for microblade groups in the Yukon interior derived through this last body of evidence and 
theory, with the geological evidence which began this paper. If there is evidence for deglaciation in the southern Interior of British Columbia by around 8000 B.C., and the northern Interior was presumed to be glaciated longer, then the people in the central Yukon must have been moving south exactly with the deglaciation:

[Hypothes is correlating migration and deglaciation:]

While Asian immigrants could move into the permanently unglaciated areas of central Alaska before the end of the Wisconsin Glaciation, the apparent presence of microblade groups in the southern Yukon prior to 7000 B.C. suggests that these groups were advancing into newly deglaciated territory hard upon the retreating Cordilleran ice [p.4].

\section{Intermontane Route}

Borden extrapolates from southern Interior British Columbia sites to suppose that this movement with the ice melt was a continuing one:

[Hypothesis of continuing population movement- ice melt correlation:]

That microblade-using continued to press onward into newly opened territory.

[Evidence from Drynoch Slide:]

is revealed by Sanger's (1967a,b:1968) findings in the southcentral interior of British Columbia. The date of 5500 B.C. on the Drynoch Slide site on Thompson River

[Preceding hypothesis, re-stated:]

shows that by then microblade bands had passed through virtually the full length of British Columbia's Intermontane corridor.

[Hypothesis of movement extrapolated from Rygrass Coulee site:] The southernmost penetration of early microblade groups, according to present evidence, is the Vantage region of western interior Washington,

[Evidence for preceding hypothesis:]

where Munsell's (1967) earliest date at the Ryegrass Coulee site indicates their presence by about 4500 B.C. [1969c:4].

Now Borden sets this microblade tradition, with its local variations and histories into a world-wide context: 
[Upper Paleolithic tradition hypothesis:]

Various technological specializations in the production and use of microblades, combined with persisting peculiarities in the composition of associated assemblages, have been identified as traditions. However, all these local or regional traditions are clearly manifestations of the great Upper Paleolithic cultural tradition which was belatedly carried from Asia to the New World at the very end of the Pleistocene [1969c:4].

\section{Early Boreal Cultural Tradition}

Borden expands on this tradition, the habitat of its people, their economic base and additional artifacts in their technology. The basic hypothesis of this section of the paper is in grouping them into one tradition, which he did above, and now assigning that tradition a general name:

[Hypothesis of contrasting later coastal cultures:] By contrast with the later and ethnically and culturally probably distinct bearers of the Anangula culture (6500 B.C.), who seem to have favoured the southern coastal region of Beringia (Laughlin, 1967),

[Statement of name designation and hypothesis that bearers of Early Boreal tradition were inland tundra, and distinctively riverine peoples:]

the bearers of the more northerly tradition, which we propose to call the Early Boreal cultural tradition, were inland hunters adapted to the Siberian tundra. However, like all late Paleolithic peoples of southern Siberia, and unlike the PaleoIndian hunters of the American Plains, they also exploited the fish resources of lakes and rivers (Dikov, 1968).

[Summary statement of additional technologies of these people:] These immigrants to the New World brought with them not only core and blade technology and refined techniques for fashioning a multitude of artifacts from bone and antler with the aid of burins, but many other Upper Paleolithic refinements and innovations [1969c:4].

In 1973, Borden amplifies this description of the "cultural baggage" of these Early Boreal people.

\section{Summary Hypotheses}


Borden concludes this section with a summary, re-emphasizing the migration character of this portion of the culture history of this region, and generalizing a time gradient for its movement through space:

[Hypothesis of migration, re-stated:]

It is important to emphasize that we are not concerned here with diffusion but with a migration-borne spread of a cultural tradition,

[General statement of type of evidence supporting the hypothesis:]

as is demonstrated by the fact that at least in southwestern interior Alaska, in southwestern Yukon, and in the interior of northern British Columbia [whereas perhaps deglaciation progressed more rapidly or earlier in southern British Columbia, so that it may have been inhabited from the south before the northern population arrived; Borden pers. com., 1974] these groups were moving into newly deglaciated, still uninhabited regions.

[Hypothesis generalizing the time-space correlation of this population movement:]

As suggested by the newly available C14 dates, the time gradient of this population movement may have been approximately as follows (Fig. 2):

Lake Baikal

Beringia

Central Alaska

11,000 B.C.

Southwest Yukon

9500 B.C.

Northern Interior British Columbia

9000 B.C.

7500 B.C.

South Central British Columbia

6500 B.C.

Western Interior Washington

5500 B.C. 4500 B.C.

$[1969 c: 4]$.

\section{Discussion}

The figure to which Borden refers is a map (1969c:5) of the northern New World, with a series of arrows showing the direction and time that this tradition spread, as well as the other traditions discussed in this paper. (A 1973 version of this map accompanies Chapter XLII of this thesis). T.ie basis of this 1969 map's scheme, which summarizes a long series of hypotheses, is stated in the legend: 
... as inferred from the distribution in space and time of the manifestations of important early cultural traditions [1969c: 5].

The soundness of this scheme rests not only on the evidence available to the archaeologist, but also on his accuracy in identifying, as traditions from that evidence, those characteristics important to the early inhabitants of these areas. The hazards of classification increase with the generality of hypotheses derived from the data.

\section{HYPOTHESES CONCERNING PROTO-ATHAPASCANS}

\section{Discussion}

The hypotheses linking the Early Boreal with the proto-Athapascans are not summarized in the abstract at the beginning of the paper. This omission underlines the incidental part that this section plays in the argument of the paper.

While it is not logically integrated into the paper, it is not unimportant. From his early period (1954b) Borden has consistently attempted to integrate evidence of linguistic distribution and change into his archaeological theory. He will reiterate this explicitly in his discussion of the papers in the 1969d section of this thesis.

\section{General Hypotheses}

As I was analyzing this section of the present paper, I noted Borden's shift from the use of the term "fact" to the term "hypothesis". Sometimes the shift is in meaning, from expressions which convey certainty, to expressions which convey probability or doubt. Sometimes Borden labels the same idea as fact, in one passage, and as hypothesis, 
in another. I have designated these as hypotheses, and noted Borden's various labelling.

[Hypothes is that Athapascans were the Early Boreal people, stated as an hypothesis:]

There is no more likely ethno-linguistic stock that could have been involved in this population movement and the spread of the Early Boreal tradition than the Athapascans (Nadene) [pp.4,6].

[Ethnographic evidence to confirm previous hypothesis:] Athapascans still inhabit much of the same area,

[Evidence from distribution and glottochronology suggesting changing pattern, not disconfirmatory of previous hypothesis:] although both their present distribution and glottochronological data on Athapascan languages suggest that they lost and gained, and perhaps in part regained, territory in later periods.

[Hypothesis of fluid boundaries:]

Ethnic boundaries in the interior of the Pacific Northwest appear to have been in a fluid state during much of the prehistoric past (Borden 1952, p.39) [Borden 1969c:6].

Not only in the 1952 paper that Borden cites, but in the 1954b paper, he gave explicit examples of instances of the complexities that he generalizes here as "ethnic boundaries". In the 1954 publication his examples showed that language and culture varied independently of one another in the Northwest Coast culture area, and he acknowledged that grouping race with language and with culture was therefore only a rough approximation of the reality. In the absence of a better criterion, Borden will try to accommodate all the variables when he has evidence to do so.

In the rest of this section, we may translate three designations as equivalent:

$$
\begin{gathered}
\text { burin, microblades } \\
\text { assemblages }
\end{gathered}=\begin{gathered}
\text { Early Boreal } \\
\text { Tradition }
\end{gathered}=\begin{gathered}
\text { proto-Athapascan } \\
\text { speakers }
\end{gathered}
$$

Relationships with Early New World Populations 
This Borden's account of the interactions of the Early Boreal people with the earlier inhabitants of the New World:

[Hypothesis of early contact with Paleo-Indians from the Plains:]

Already [Even] during their early Holocene expansion in the New World, the proto-Athapascans must have occasionally encountered Paleo-Indian hunters from the Plains (MacNeish, 1964) who, upon the northward shift of biotic zones in the postglacial period, were following game herds into the western Canadian provinces east of the Rockies, the Northwest Territories, and into the Yukon and Alaska. Some of the early hunters from the Plains also found their way into British Columbia (Borden, ‥ . . .).

[Borden's basic hypothesis of inevitability of culture exchange:]

Cultural exchange with such groups of Plano tradition was inevitable [1969c:6].

Here again is a basic hypothesis of inevitable cultural exchange, at a very high level of abstraction. In most cases the type of exchange would be difficult to prove. This hypothesis was a basic and necessary working tool in pre-radiocarbon dating times. If assemblages were different, yet close in space, the sort of exchange would be part of the process in determining age relationships. With radiocarbon dating, limits or limiting instances of this basic Borden (and general archaeological) hypothesis could be found if assemblages from two sideby-side phases were found to be extended, contemporary, but without significant borrowing. In the concluding section of the thesis, this problem will again be discussed in relation to comments by Richard $G$. Klein.

Borden discusses intercultural relationships from a later time:

[Hypothesis of later, southern British Columbia and Washington Athapascan relationships:]

When, somewhat later in their expansion, Athapascans (perhaps by then mixed with other ethnic stock) spread into the plateaux 
of southern British Columbia and adjacent Washington, they may have come in contact with yet other ethnic groups

[Hypotries is of southerly origin of other groups:]

who, according to still tenuous archaeological evidence, were moving into these areas from the south [p.6].

These other groups will be discussed in the next section, as Proto-western people.

[Hypothes is of interaction:]

Thus the stage was set for further interaction.

[General statement of instance of this last hypothesis:]

The results of such commingling are clearly evident in later culture phases of south-central British Columbia, where microblade technology and associated practices persisted for over 5,500 years to the early centuries of the Christian era (Sanger, 1967b) [Borden 1969c:6].

\section{Discussion of Milliken Site}

In trying to identify these movements in terms of the Milliken site, for instance, I found here an answer to a question that I had noted concerning Borden's statement in 1968 that the microblades occurring in the Baldwin phase were "of extreme interest".

It is of extreme interest that this boreal complex of ultimate Asiatic origin is also present in the culture of the Baldwin phase [Borden 1968a:15-16].

In that same 1968 paper, Borden had hypothesized that a variety of influences contributed to the cultural richness and complexity of the Baldwin phase, some migration borne, some diffused from distant centers of influence, some from "vigorous local cultural growth..." (p.15). Borden had judged the presence of microblades in the Baldwin phase to be a clue to the subsequent history of the early Boreal tradition, a clue now understood to be of great interest in the context of the discussion in the present paper. 


\section{Diffusion of Early Boreal Tradition}

Borden continues with a description of other instances showing the influences of this Early Boreal tradition. His distinction between assemblages showing evidence of migration and those that show evidences of diffusion are probably based in this way:

Migration is indicated when the total technological assemblage is found in successively neighboring areas.

Diffusion is indicated when only part of the technology is present (borrowed).

Rapid diffusion is evidenced by artifact assemblage similarities, but not necessarily identities, and with dates that are very close to each other.

This is Borden's hypothesis:

[Hypothesis of subsequent rapid diffusion:]

Some of the Early Boreal elements acquired by southern groups evidently diffused rapidly far beyond the areas actually occupied by the proto-Athapascans.

[Evidence of an instance hypothesized to support the preceding hypothesis:]

This is suggested, for instance, by Cressman's (1960) Early II assemblage at the Fivemile Rapids site on the Columbia, dated at 5700 B.C. Although devoid of microblades, this assemblage includes burins, sectioned bone and antler, barbed antler points, atlatl hooks, components of fish hooks (?) and leister spears, cylinders and splitting wedges of antler, and many thousands of salmon bones. The work in bone and antier reveals the use of techniques virtually identical to those employed throughout northern Eurasia in early Mesolithic time (e.g. Clark et al., 1954; Larsen, 1968) [Borden 1969c:6].

Summary Hypotheses

Borden's summary of the Early Boreal, proto-Athapascan section of the paper includes shifts from the concept of "fact" to the concept 
of "hypothesis":

[Summary hypothesis, regarded as highly probable, or "facts":] In concluding this section on the advent and spread of the Ear1y Boreal culture in western North America, we may note the following significant facts:

[Hypothesis of intermontane migration route:]

(1) While there are rare occurrences of microblades east of the Rocky Mountains, none of these has been shown to have an antiquity comparable to that of the early complexes in the west. There seems no doubt that the early thrust of the bearers of the Early Boreal culture passed west of the Rockies through the intermontane corridor of British Columbia.

[Hypothesis that with one exception, the proto-Athapascans, or Early Boreal people were the only tradition to come to the New World in this geological time span:]

(2) Aside from the arrival of the ancestral Eskimo-Aleut, presumably documented by the Anangula culture, and the advent and early spread of the proto-Athapascans, traceable in space and time through the remains of the Early Boreal culture, there is no convincing evidence for the passage from Asia to the New World of any other major cultural tradition or ethnic stock in terminal Pleistocene or early Holocene time.

[Hypothesis, corollary to previous hypothesis, that all other traditions came at an earlier geological period:]

Indications are that all other late Pleistocene and early Holocene cultures in the Americas are derivatives of cultures brought to the New World during a much earlier period [1969c:6].

\section{PROTOWESTERN CULTURAL TRADITION}

Borden summarizes the conclusions he will derive from the evidence

of the Protowestern tradition in the abstract introducing this paper:

Other new evidence, supported by radiocarbon dates, reveals that long before the above events, when the classical Wisconsin Glaciation was at its height, the vast areas south of British Columbia and west of the Rocky Mountains were already inhabited by hunting and gathering groups. Bringing a culture which combined late Mousteroid with some Upper Paleolithic elements, the ancestors of these groups had moved from Siberia into Alaska and southward into the American West before the ice sheets of the last glaciation blocked the routes of travel. They survived the long glacial interval south of the ice front [1969c:1]. 
Early Remains West of the Rockies

This is the introduction to the evidence of early remains in

the intermontane, Great Basin, and coastal areas:

[General statement of evidence with early dates:]

South of British Columbia, in the vast intermontane and Great

Basin areas as well as on the coast, are found some of the earliest dated human remains in America $[p p .6,8]$.

[Evidence from Marmes Rockshelter, Washington:]

These include human skeletal material and artifacts recently uncovered at Marmes Rockshelter in southeastern Washington, well beneath occupational levels radiocarbon dated at 9000

B.C. (Fryxe11 et a1., 1968),

[Evidence from Tule Springs, Nevada:]

the bone tools from the Tule Springs phase, Nevada, dating from 11,000 to 9000 B.C. (Shutler, 1967a, p.302; 1967b, p. 305),

[Evidence from Laguna Beach, California:]

and the skull from Laguna Beach, California, which has a C14

date of about 15,000 B.C. (D. T. Stewart, pers. com., 1968)

[Borden 1969c:8].

\section{Western Assemblage}

Borden's next argument does not say that the assemblage which he

will call Protowestern is associated with these three instances. He

says something more tenuous, namely that in this same area these assem-

blages occur:

[Hypothesis that a distinctive assemblage is found in the same area: ]

Widely spread in the same areas are lithic assemblages which are distinct both from those of the Early Boreal tradition to the north and from Paleo-Indian traditions on the Great Plains east of the Rocky Mountains.

[Hypothesis that Butler's assemblages are instances of above:] Among such assemblages are some described by Butler (1961) for the area from Puget Sound southward to the northern Great Bas in and eastward to southeastern Idaho.

[Hypothesis that southern assemblages, including San Dieguito complex are other instances:] 
Also included must be various assemblages farther south in Nevada, California, and Mexico, especially those subsumed under the name San Dieguito complex, which was recently clarified by Warren (1967) [Borden 1969c:8].

Before giving other instances, Borden describes the tools of this tradition:

[Hypothesis that this combination represents an actual tradition:]

Though regional and local specializations are often apparent, such assemblages commonly feature large biface knives and leafshaped points, scrapers in a wide range of size and type, occasionally crude or even well-made blades, but never microblades. Varying quantities of pebble tools are usually present $[1969 c: 8]$.

\section{Milliken Phase Assemblage}

Borden's illustrations of a Protowestern assemblage come from the Milliken phase in the Fraser canyon (Fig. 3, page 7). He introduces the Milliken hypothesis in this way:

[Hypothesis that Milliken phase is an instance of Protowestern tradition:]

One example of such an assemblage is that of the Milliken phase in southwestern British Columbia, dated at 7100 to 6200 B.C. (Fig. 3) (Borden, 1960; 1962; 1965; 1968a, p.13).

[Hypothesis of more specific relationship of Milliken phase to the tradition:]

Undoubtedly of earlier more southerly origin, the Milliken culture is at present the northern-most exponent of these cultural manifestations [1969c:8].

Here we have Borden's most complete hypothesis about the Milliken phase, relating the earliest dated phase in the Fraser Canyon to the Protowestern tradition. In 1965 he had hypothesized that it represented a fully developed culture, intrusive in the newly deglaciated region (1965:10). As early as 1952, he had discussed the possibility of present ethnic groups in the interior of British Columbia coming from the south (1952a:14). If we accept Borden's classification, then in 
the Baldwin phase, "local cultural development" may include elements from this earlier southern tradition.

\section{Other Protowestern Sites}

Borden continues with instances from Fivemile Rapids, and other earlier southern sites.

[Hypothes is that the early Fivemi]e Rapids component and the lower Fort Rock Cave level are instances of this tradition:] Farther south, Cressman's (1960) Early I component at Fivemile Rapids, dated at 7800 B.C. and material from the lower levels of Fort Rock Cave (south-central Oregon), which have a C14 date of 11,200 B.C. (Cressman and Bedwe11, 1968), probably represent earlier manifestations of this tradition.

[Hypothesis that early component at Wi]son Butte Cave is an instance of this tradition:]

Highly significant also is Gruhn's $(1961 ; 1965)$ small, but important early component at Wilson Butte Cave, Idaho, dated at 12,600 B.C. Included in this assemblage is a biface foliate. An underlying occupation level in the same cave has a C14 date of 13,150 B.C.

[Information about dates of San Dieguito complex, previous]y suggested as an instance of this tradition:]

The antiquity of the San Dieguito complex is still in dispute, but Warren (1967) cites C14 dates and geological evidence indicating that the San Dieguito occupations date from earlier than 9000 to 7000 B.C. [Borden 1969c:8].

\section{San Dieguito Test Hypotheses}

Borden's next section may be viewed as a test hypothesis: If further work substantiates the date given below, and fills in the artifacts of the assemblage tradition, then Borden will be correct in connecting it with this tradition. This is implicit in his phrase, "Of potentially great importance..." below:

[Evidence from Puebla and implicit hypothesis that Valsequillo cultures may be connected with this tradition:]

of potentially great importance are Irwin-Williams' (1967; $1968 \mathrm{a}, \mathrm{b})$ discoveries of chipping detritus and edge-retouched 
blade and flake tools in association with extinct fauna at Valsequillo and other localities in Puebla, Mexico. Age determinations on carbon samples associated with these finds vary greatly, though a date earlier than 20,000 B.C. is like1y. The relation of these early manifestations to later cultures in the region and to others farther to the north is not yet clear. No bifacially flaked knives and projectile points have been found, but the artifacts recovered to date are still few in number, and the possibility of their presence cannot yet be ruled out [p.8].

[Hypothesis naming this general tradition:]

The San Dieguito complex and the similar, in part seemingly earlier complexes in Oregon, Idaho, Washington, and southwestern British Columbia appear to be manifestations of a widespread distinctive tradition in western North America which can be aptly termed the Protowestern cultural tradition.

[Evidence correlating glacial maximum:]

In assessing the significance of this tradition to New World prehistory, one should note that it was in existence in areas south of British Columbia and west of the Rocky Mountains at a time when Canada was still buried under coalesced continental glaciers.

[Hypothesis of minimum date of population movements of bearers of this tradition:]

We must conclude, therefore, that the population movement which brought the parent culture across Beringia to Alaska and then to areas south of the ice front occurred prior to the Fraser (Wisconsin) Glaciation, probably toward the end of the preceding interstadial, around 24,000 B.C. [1969c:8].

\section{Mul ler-Beck Migration Route Hypotheses}

Now Borden reviews Muller-Beck's theory of the migration route

followed by peoples in this pre-Wisconsin period, and then gives evidence and his hypothesis to the contrary.

[Muller-Beck hypothesis on time and route of migration:] Muller-Beck $(1966 ; 1967)$ has postulated recently that hunters bearing triangular bifacially-flaked and basally-thinned projectile points, of a type found in level 5 of Kostyenki site I on the lower Don of southern Russia, moved around 28,000 to 26,000 years ago in a continuous migration across Beringia through Alaska and Yukon Territory and thence southward through the still open corridor between the Cordilleran and Keewatin ice sheets to the Plains of central North America. 
[Muller-Beck hypothesis that these people were ancestors of Paleo-Indians of the 01der Liano culture:]

Having survived here the Wisconsin maximum south of the continental ice masses, the descendants of these early immigrants are sald to have emerged at the end of the Pleistocene as the Paleo-Indians of Llano culture, famed for their distinctive Clovis-fluted points. Muller-Beck believes to discern close affinities between this "01der Llano" and the aforementioned Kostyenki complex of southern Russia [Borden 1969c:8-9].

\section{Borden Migration Route Hypotheses}

This is Borden's argument to the contrary:

[Borden hypothes is that much Muller-Beck evidence is relevant:] While many of the data assembled by Muller-Beck do have a significant bearing on the early peopling of the Americas,

[Borden's summary of negative evidence:] there is at present no evidence of a southward migration such as the one envisaged by him, nor for the presence of human groups in the Plains throughout the last glacial maximum.

[Borden hypothesis that the negative evidence is significant evidence of a contrary interpretation:]

On the contrary, the absence in the Great Plains of archaeological remains from periods earlier than the tenth millennium B.C. (Haynes, 1967)

[Borden's summary of early more westerly evidence:] and accumulating indications for man's much earlier presence in areas west of the Rocky Mountains

[Borden hypothesis on early migration through intermontane corridor:]

hint that the early population movement which brought bifacial knives, leaf-shaped projectiles, and the various Mousteroid scrapers of the Protowestern tradition to..western North America passed through the intermontane corridor of British Columbia like that of the Athapascans many millennia later [1969c:9].

Now Borden counters the Muller-Beck reconstruction of the develop-

ment leading to the Clovis points:

[Hypothesis denying Muller-Beck's Clovis-development thesis:] Furthermore, there is no suggestion in the currently available archaeological materials either in Asia or America that projectiles like these from level 5 at Kostyenki I were carried to the New World and that they were the prototypes from which fluted 
points evolved [1969c:9].

This is Borden's counter-hypothesis:

[Borden hypothesis that leaf-shaped points were the forerunners of basic New World forms:]

A1though space and time limitations make it impossible to do so here, a strong case can be built in support of the proposition that the simple percussion-flaked leaf-shaped points were the progenftors not only of the fluted points, but also of the Plano and virtually all other early stone projectile point traditions in both North and South America (Wormington, 1962; Bryan, 1965, p.72) [Borden 1969c:9].

Borden underlines the work necessary to test this hypothes is:

[Statement of tests for this hypothesis, and their importance:]

This probability enhances the importance of the simple foliate form as well as the need to learn more of its earlier history and cultural associations both in Asia and in North America.

[Specific case of this test in Siberia:]

Rudenko's findings at Ust'-Kanskaia Cave in the western foothills of the Altai Mountains do indicate the occurrence of biface leaf-shaped points in late Mousterian contexts of Siberia (Rudenko, 1961; Wormington, 1962)

[Additiona] instances of test expected:] and raise expectations that Soviet archaeologists will discover comparable assemblages of the right age at Siberian sites nearer Bering Strait [1969c:9].

\section{PEBBLE TOOL TRADITION}

This is Borden's introduction to the Pebble Tool tradition in the abstract of the paper:

The widely scattered occurrence in the Americas of crude chopper and scraper complexes lacking thin bifacially flaked artifacts suggests a separate early migration from the Pacific coastal zone of northeast Asla of folk who brought to the New World the tenaciously persisting Pebble Tool tradition [1969c:1].

\section{Widespread Occurrences}


In the body of the paper, he states it this way:

[Hypotheses of early Pebble Tool tradition:]

Finally, it is necessary to mention, at least briefly, the Pebble Tool tradition as a probable additional basic cultural tradition that may have been brought to America in pre-Classical Wisconsin time and which may have contributed substantially to early cultural development in the New World.

[Evidence of occurrences of these tools:]

As most American archaeologists know, virtually all early lithic assemblages in North and South America contain quantities of rather heavy, crudely percussion-flaked core tools, commonly based on whole or split pebbles and cobbles.

[Statement that origins of these implements is unknown:] At present we do not know when or where the bearers of these early cultures acquired such implements.

[Hypothesis that long persistence of this artifact type is evidence of its utility:]

The great usefulness of these tools is demonstrated by the fact that they persist in many areas until very recent periods.

[Hypothes is that utility-persistence has caused misinterpretation of early occurrences:]

Ironically, it is perhaps because of this very fact that when pebble tools do turn up, they are of ten dismissed as unimportant, as "probably recent," even when they occur in great numbers and unaccompanied by artifacts of thin biface form [1969c: 9].

\section{Pasika Complex}

Borden uses the Pasika Complex as an instance of this last hypothesis, and for the first time places it in a New World tradition hypothesis. Artifacts from South Yale appear in an illustration (Fig. 4, p. 11), of pebble tools.

[Hypotheses that Pasika Complex is an instance of this tradition:]

Pure pebble tool sites, evidently dating to the Everson Interstadial (=Two Creeks) occur in southwestern British Columbia (Fig. 4) (Borden, 1965; 1968a,p.9; 1968a [s'nould read 1968b]; Mitchel1, 1965).

[Hypothesis of southerly origin of these people:] 
The bearers of this "Pasika complex," like those of the later Milliken culture, appear to have moved into British Columbia from the south.

[Hypothesis of time minimum of these peoples' occupation:] Indications are that they too were present in the Pacific Northwest prior to the Fraser (Wisconsin) Glaciation.

[General statement of similar evidence:]

Pebble-tool complexes are widely distributed in the Americas (Krieger, 1964), and some are demonstrably old.

[Hypothesis that Venezuelan assemblage is an instance of this tradition:]

Pebble tools associated with Plelstocene faunal remains, at Taima-taima, Venezuela, have been dated at 12,500 B.C. (Haynes, 1967, p.273) [Borden 1969c:9].

\section{Hypotheses of Early Connections}

Borden refers to Krieger's similar hypothesis:

[Krieger's pebble-tool hypothesis:]

Krieger has broken many a lance in defence of his conviction that there exists in the Americas an ancient stone-working tradition which lacked biface projectile points and knives.

[Borden hypothesis of early migration from coastal northeast Asia:]

The problem is far from settled, and we still cannot discount the possibility of a separate movement from the Pacific coastal zone of northeast Asia of folk who brought with them the tenaciously persisting Pebble Tool tradition and contributed it as a significant component to early American lithic technology [1969c:9-10].

[Evidence of tentatively dated eastern Siberian occurrences:] Pebble tools, including spectalized types identical to some in the Pasika complex of British Columbia... [Borden notes in particular a beaked specimen in the illustrations], have recently been discovered on ancient stream terraces along the lower Amur River of eastern U.S.S.R. StIll of uncertain age, these artifacts, according to A. P. Okladnikov (pers. comm., 1968), may date to the late Middle Paleolithic.

[Hypothesis based on evidence above, stated to be of low prior probability:]

If this very tentative estimate should prove correct, this East Asiatic industry would probably have been available for export to the New World during the stadial which preceded the warm 
interval prior to the last glacial maximum [1969c:10].

\section{CONCLUSIONS}

\section{Early Boreal/Proto-Athapascan Summary}

Borden's conclusion sums up the previous material, and introduces some additional ideas.

[Hypothesis that Borden's Early Borea]=Athapascan theory is in line with Sapir's theories:]

The evidence presented in this study seems in accord with Edward Sapir's (1916) view of more than half a century ago that the Athapascans (Nadene) and Eskimo-Aleut were the latest linguistic arrivals in North America [1969c:10].

Borden now states clearly that this Athapascan argument is hypothesis, not fact, as he had seemed to indicate in one place on page 6 of this paper :

[Proto-Athapascan hypothesis, re-stated:] However, much work needs to be done to fill in existing gaps, and it remains to be seen whether future research will reinforce the present conclusion that the spread of the Early Boreal cultural tradition, as it has been traced here, reflects the coming of the proto-Athapascans to Alaska and their gradual expansion into the Pacific Northwest of North America or whether some other group was involved. The problem is complex and will be further examined elsewhere (Borden, n.d.) [Borden 1969c: $10]$.

Borden's terminology above reflects a change in words, and perhaps also a change in ideas. He begins in this paper to use the word "expansion" instead of, or along with, the word "migration", a practice that he continues in later works, rarely using "migration" in his 1973 paper.

[Further hypothesis of Athapascan influence, stated as dependend on previous hypothesis:]

If the interpretation which is favoured here is correct, then the Athapascans must probably be credited with transmitting to other peoples already. present in America much of the nonmaterial culture and technological know-how that had evolved in the 01d World during the Upper Paleolithic and early Mesolithic periods. 
Probably this early western population was ancestral to most of the native peoples in the Americas not descended from the Athapascans, the Eskimo-Aleut, and perhaps the Pebble Tool Folk [1969c:12].

\section{Summary of Migration Route Hypotheses}

Borden ends with a discussion of early migration routes:

The data presented here also shed some significant light on the problem of carly migration routes into the North American continent.

[Hypothesis of intermontane migration of Early Boreal peoples, from space-time correlation, repeated:]

The distribution of the Early Boreal remains in space and time seems to demonstrate convincingly that the proto-Athapascans [Early Boreal people] followed the western route through the intermontane corridor of British Columbia rather than the postulated pathway east of the Rocky Mountains.

[Hypothesis of deeply buried evidence of earlier remains in the north:]

Evidence for the path taken by the early bearers of the Mousteroid culture is probably largely burled under great masses of sediments left by the Fraser (Wisconsin) Glaciation,

[Hypothes is of Protowestern intermontane migration, based on evidence from the south:]

but the distribution of early Protowestern remains south of the ice front exclusively in areas west of the Rockies hints that the movements of these much earlier immigrants were also channelled along the same route as that taken by the Athapascans.

[General statement of possible eastern route:]

of course, we cannot yet rule out the possibility that some early groups travelled southward along the eastern flanks of the Rocky Mountains.

[Genera] re-statement of lack of evidence presently at hand:] However, to date, there is no firm evidence for such an assumption.

[Evidence of northward Paleo-Indian tradition:] On the other hand, many early finds in the Plains of northern United States and Canada suggest a northward movement in postglacial time of Paleo-Indian hunters of Fluted Point and Plano tradition.

[Hypothesis, re-stated, of Protowestern origin of Paleo-Indian 
[General statement of problem of proto-Eskimo-Aleut influence:] What part the ancestors of the Eskfmo-Aleut may have played in this process is still unclear.

[Hypothesis of Anangula complex as instance of this tradition:] Their seemingly later arrival and different ecological orientation are perhaps documented by the Anangula complex at the southern margin of Beringia. We do not really know.

[Hypothesis corre]ating time of Anangula culture and Early Boreal tradition:]

In any case, even by 6500 B.C., the earliest C14 date obtained on the Anangula complex, the Athapascans [Early Boreal peoples] had been in Alaska for some 3,000 years and were spreading into British Columbia.

[Hypothesis of time of Early Boreal, Paleo-Indian contact:] During much of this time $[9,500$ B.C. $-6,500$ B.C.] they probably had been in contact with far-ranging Paleo-Indian bands from the Plains.

[Hypothesis of later contact with Protowestern tradition:] Very likely, somewhat later, they also met groups that were moving northward from the Columbia River and Great Basin areas to the south [1969c:10].

\section{Protowestern Summary}

Now Borden summarizes his Protowestern hypotheses:

[Sapir hypothesis on early date of man in the New World:] Because Sapir (1916) comprehended the slowness at which languages differentiate, he regarded 10,000 years as a hopelessly inadequate span of time for the development from a homogeneous origin of such linguistic differentiation as is actually

found in the New World.

[Borden hypothesis, generally stated, that archaeological evidence is confirmatory of the Sapir hypothesis:]

Rapidly mounting evidence again tends to confirm Sapir's conclustion.

[Protowestern hypothesis, restated:]

The now accumulating data relating to the Protowestern tradition and the growing series of impressively early dates clearly indicate that the bearers of this cultural tradition were present in the American West south of the continental ice sheets while the Fraser (Wisconsin) Glaciation was at its height and hence that their southward passage must antedate the onset of this climatic phase [1969c:10]. 
Problem of Archaeological Testing

Borden speculates on the numbers of these earliest peoples, and the slim probability that the evidence that archaeologists have discovered so far is related to them. I have inserted an implicit step in his argument:

[Hypoties is of small initial population:]

Probably initially few in number,

[Hypothes is of few remains, corollary to above:] these early imnigrants from Siberia left only few and widely scattered traces of the Mousteroid culture they had brought with them.

[Implied hypothesis of statistical sampling:

If the preceding hypothes is is true, then it is not statistically probable that we would have in our limited archaeological sample to date, those few and widely scattered traces.]

[Hypothes is that our evidence is of later descendants:] It seems likely, therefore, that up to now we have uncovered merely some of the more abundant leavings of their more numerous late descendants

[Hypothes is of nature of future discoveries based on larger archaeological sample:]

and that coming years will bring the discovery of much earlier manifestations of the Protowestern tradition which evolved from the parent culture [1969c:10].

Borden suggests the development that may have taken place while the Wisconsin Glaciation isolated this population from further 01d World influence:

[Hypothesis of population increase:]

The probably more than 14,000 year duration of the Fraser (Wisconsin) Glaciation provided ample time for population increase $[1969 \mathrm{c}: 10,12]$.

[Hypothes is of Tinguistic and cultural diversification:] and for the development of the degree of linguistic and cultural differentiation that seems to have existed in the American West by the end of the Pleistocene.

[Hypothesis of genetic relationships:] 
tradition:]

Future research may determine whether these early hunting cultures of the Plains were derived from the more ancient Protowestern tradition in the great and once lush intermontane areas to the west [1969c:12].

In 1973, Borden adds evidence from deep sites of the sort he suggests would mantle evidence of population movements in glaciated areas, and revises portions of theories presented in this paper. 
CHAPTER XXXIX

1969d A DISCUSSION OF PAPERS...

Northwest Anthropological Research Notes published the Symposium on Current Archaeological Research on the Northwest Coast, including the discussion by Borden. The symposium was presented at the 22nd Annual Northwest Anthropological Conference. Participants were as follows:

Chairman, George F. MacDonald, National Museum of Man Discussant, Charles E. Borden, University of British Columbia

Presenting papers or having papers read and discussing them:

Donald H. Mitchell, University of Victoria

William J. Folan, Historic Sites Branch, National Museum

George F. MacDonald

James Hester, University of Colorado

\section{BACKGROUND}

This paper is our only example of Borden in face to face dialogue with other archaeologists and their ideas. It is good reading, with passages of humor, poignancy, and careful reasoning. In these pages, we find Borden's own statement of his use of hypotheses and models, so it is of central importance to the subject of this thesis.

The effect of reading only Borden's thoughts as discussant would be much the same as the effect of reading Plato's dialogue Apology, 
which presents what Socrates said at his trial before the Athenians. In both cases we wonder what the other people said. By summarizing those portions of the papers to which Borden refers, I hope to suggest the context for his remarks, al though the richness of the background provided by the papers and the extended dialogue in the question period is lost. I have selected only those ideas from the other participants which serve to clarify Borden's ideas.

Borden spoke from notes taken after reading the papers on the night before the symposium. He confines his remarks to papers by Mitche11, "Site Survey in the Johnstone Strait region", and by MacDonald, "Preliminary Cultural Sequence from the Coast Tsimshian areas, British Columbia". Hester's work at Namu, a site which has since proved to be as important as Icy Strait in Borden's theories, was onty beginning, as Borden's remark indicates:

My main comments will be concerned with the papers by Mitchell and MacDonald, the contributions which have real meat in them. I do not wish to slight Jim Hester's report but it reminds me somewhat of the skunk cabbage which pushes its bloom above the ground before the actual arrival of spring. You cherish it more for what it heralds than for what it is [Borden 1969d:255].

Borden opens his discussion with a review of the rapidly accumulating evidence from work on the coast that indicates a greater time depth than ever before. In addition to the Mitchell and MacDonald material from the symposium papers, he refers to Folan's Yuquot site and to Gay Calvert's St. Mungo Cannery site on the Fraser near New Westminster:

[General statement of rapid increase in knowledge about ancient sites:] 
It is impressive really what has been going on in the last few years of this decade. Sequences are developing that extend back far beyond what we had originally imagined they would. Of course, there were a few scholars like BirketSmith, who long ago suspected that the Northwest Coast might have been a center of cultural elaboration and diffusion for a much longer time than others were ready to accept.

[Instances of the above:]

[1] Bill Folan's excavations at Yuquot on the west coast of Vancouver Island, yielded an early date of 2400 B.C., [2] and recently Gay Calvert from the Centennial Museum of Vancouver, excavating an ancient site in the Fraser Delta, obtained an equally early date, extending the Fraser Delta sequence back more than a millennium and a half beyond what we had previously.

[3] Don Mitchell has conducted site surveys in Johnson [Johnstone] Strait, collecting shell samples from the top of the middens. The long series of dates obtained on these shells ranges from the 14 th century A.D. back to the 5 th millennium B.C.

[4] Excavating on the northern Northwest Coast, George MacDonald is beginning to develop a similarly long sequence.

[General statement, repeated:]

This is very impressive indeed, and it all happened so very rapidly [1969d:255].

\section{PORTIONS OF MITCHELL'S PAPER}

Mitchell's paper, which Borden discusses first, is in two parts.

This is Mitche11's introduction to the paper:

The start of systematic archaeological work in a virtually untouched territory presents the investigator with unusual opportunity and responsibility. The opportunity is because you are not burdened by already established regional archaeological schema to which your attention must be addressed; and the responsibility derives from realization that your organization of data is going to influence what will initial$7 y$ be perceived as significant problems centering on the area. It is with this responsibility in mind that I turn, after a report on survey activity in the Johnstone Strait region, to consideration of two models of cultural development. The argument advanced is that selection of one or the other will give distinctly different direction to the course of future archaeological investigations in the surveyed area (Mitchell 1969: 193]. 
Under the heading of "Models of Cultural Development and Investigation Strategy", Mitchell describes and illustrates two contrasting models that he finds in archaeological literature. First he explains the relationship of interpretation of archaeological data. to these models. From the model selected, appropriate questions and problems arise. These are different in the two cases.

Characteristically, as excavations begin and time depth is gained, the data acquired before long permit delineation of phases. Interpretation of the relationship of these culture units is critical, particularly in the case of temporally distinct phases, for the nature of many of the "problems" apparently offered by the region will be established by selection of one or another model of phase relationship. It follows that careful consideration should be given to the alternate bases for organizing phase data (Mitchell 1969: 208].

\section{Two Models}

Mitchell introduces the two models and then describes the first:

The alternatives can be seen most clearly if we contrast two models found, implicitly in one case, explicitiy, in the other, in North American archaeological literature. I have termed these opposing interpretations of phase relationship, the continuity model and the dislocation model. If my reading of recent archaeological theoretical orientation is correct, the former is "in" and the latter, "out". So let us turn to the dislocation model first.

Dislocation Model. The dislocation model is perhaps more commonly referred to as a migration model but that is an oversimplification of its interpretive position. It has tended to attribute major culture change in a region (as represented by phase differentiation) to two possible sources: (1). Migration, or the dislocation of population and culture. (2). Diffusion of whole culture complexes or groups of culture complexes, with often so large a segment of culture involved that what is being transferred cannot be far short of a total way of 7 ife. This represents dislocation of culture, despite stability of population. Indications of stability in culture are equated with an absence of migration, or simply a low, absorbable, level of cultural diffusion [Mitchel1 1969:208]. 
Instances of Dislocation Model

Mitchell gives four instances of "...classic statements of the 'dislocation' approach to culture change" (p.208). The first is an extended quotation from Borden's second publication in which he interprets the Whalen II culture as migration borne, related to Athapascan and Salish population movements (Borden 1950b:245).

His second example is from Borden's first publication interpreting the Locarno Beach culture as showing

...the impact of the vigorous cultural current which at one time flowed from the Far North south along the coast until it was choked off by intrusive tribes from the northern interior [Borden 1950a:26 as quoted in Mitchel1 1969:209].

Mitchell's second and third examples are from publications in 1956 by Marian Smith, and in 1965 by Wilson Duff.

Mitchell describes the continuity model:

Continuity Model. In contrast with the preceding, a continuity model emphasises in situ development. Rather than look to migration or "massive" diffusion for explanation of observed culture change, it assumes the transformation took place within the area under study. Examples of interpretations of phase relationships using this kind of model are fairly common in recent archaeological writings. I need cite only three instances to indicate the difference between the "continuity" and "dislocation" approaches (Mitchel1 1969d: 210].

\section{Instances of Continuity Model}

His three instances here are more general, being within themselves arguments against migration and for continuity, first by several authors with respect to Iroquois-Algonquin relationships in a Northeast region. The second, from Giddings, is introduced as follows:

The western arctic has also been a region where population movement frequently was advanced to explain marked differ- 
ences between culture phases. However, in recent years, a different $v$ iew has come to the fore:

The fabric of Bering Strait archaeology, it appears to me, has its warp in the patterns of behavior handed down by parents to their children in a single locality, and a weft made up of the continuous interchange of thoughts outward through space. The passage of ideas by contemporaries may be lightning swift. It need not be conceived as a result of either migration or slow, directional drift. While I do not wish to doubt the occasional migration of groups, or the retardation of drift, I am drawn to the probability that cultures also come to look alike across similar spans of a similar environment because they are constantly receiving impulses-accepting ideas--on the same time Tevel (Giddings 1961:157) [Mitche11 1969:210-211].

His third example is from Taylor's rejection of the migration hypothesis to explain the source of the Dorset culture (Taylor 1968).

Rules of the Models

To clarify these models, Mitchell gives them as "opposing rules" (emphasis added):

1. From the dislocation model, we get the rule: In the absence of evidence to the contrary, assume major cuiture change has resulted from population or cultural dislocation.

2. From the continuity model, we get the rule: In the absence of evidence to the contrary, assume major cultural change can be explained Targely by local development [Mitchel1 1969:211].

\section{Questions Asked by Each Model}

The questions asked, or the problems raised, would vary with these models. Mitchell poses these contrasting questions. In the dislocation model, answers come from outside the area under consideration.

...the main "problem" offered by the phase difference is: Where did the new population and/or culture items come from? If more than one investigator is playing the game by these rules, the problem can easily be expanded into a different sort of debate, with arguments centering on the relative 
suitability of different cultures or areas as sources of innovations.

Further work within the region tends to concentrate on problems of phase delineation and distribution, but for explanation of phase differences, you turn outwards and seek historical reasons for the assumed dislocation [Mitchell 1969:211-212].

From the continuity model a different set of problems is perceived:

If the assumption is one of in situ development, then for explanation of phase differences you turn first to the question of what local circumstances have brought about the observed change. With diffusion from other areas always a possibility, attention is directed to such questions as: Why is offered (or available) variation accepted or rejected: How are new cultural features incorporated into the local cultural tradition? And what effect do the new features have on evolution of the regional culture type? Continuity models also tend to move outside the cultural system to changes in the natural setting for some explanation of phase differences [Mitche11 1969:212].

\section{Statement of Intent}

Now Mitchell makes an explicit choice:

Turning, finally, to the application of these alternate models to future work in the Johnstone Strait region, I will conclude with what amounts to a statement of intent. You may have noted that each of the continuity model examples represented a departure from an earlier dislocation explanation of phase difference. The recent history of archaeological investigation shows repeatedly that as the volume of data expands for a region, there is a shift from a formerly espoused dislocation model towards a phase structure emphasizing continuity.

It would seem, in light of the investigation history of these other areas, and in order to avoid raising what experience suggests are likely to be spurious problems, the best strategy to follow in any new region is to lean strongly towards a continuity model. The possibility of dislocation is not to be ruled out, of course, but instead of being viewed as the explanatory norm, population spread and culture complex diffusion will be used only under certain, constrained circumstances [Mitchel1 1969:212]. 
Acceptable Evidence

Since the rule for this model states that it will be followed "in the absence of evidence to the contrary", Mitchell defines what he considers to be acceptable evidence to the contrary:

The circumstances can be specified:

A. For the dislocation by migration:

1. Historically documented movement of people, or of a second order of confidence, traditions of migration.

2. A demonstrated change of physical types with a new type known to exist in the area of postulated migration origin.

3. Historical linguistic support for the movement, recognizing, however, that languages can spread without a corresponding movement of people.

4. Sufficient control over the time dimension of archaeological data to state with reasonable certainty that a major cultural dislocation has taken place in a very short period of time. There must also be virtual identity of the replacement culture with the postulated "donor" culture, and this latter culture must have clear temporal priority over the other.

B. For dislocation by diffusion:

1. Historically documented diffusion.

2. Entrance of culture complex characteristics as a complex, traceable to a specific culture which has priority in development of the complex [Mitche11 1969: 212-213].

Mitchell concludes with a re-statement of his intent:

This paper has distinguished between two approaches to the interpretation of phase differences and has indicated the writer's intention to emphasize the continuity model in further investigation of the Johnstone Strait Region. It is hoped that this discussion of the model and reasons underlying its selection will make more understandable the direction to be taken by research on this particular part of the coast [Mitchell 1969:213].

\section{BORDEN'S DISCUSSION OF MITCHELL'S PAPER}

\section{Survey Results}

Borden addresses both aspects of Mitchell's paper, the first part briefly, the second, with an extended discussion of Borden's own view 
of the relation between theory and evidence. He introduces the discussion of the survey results in this way:

Mitchell's paper readily divides into two parts--one, the survey of Johnstone Strait, and two, what might be called 'Mitchel1's Midden Manifesto."

[Borden hypothesis that Mitchell's survey results is a confirmatory instance of Boas' ethnographic information:]

The results of the survey more than confirm Boas' early findings that this part of the coast, inhabited by the southern Kwakiut1, was one of the most densely settled areas in the New Wor $1 \mathrm{~d}$,

[Borden hypothesis that the survey result is a confirmatory instance of Drucker's Wakashan theories:]

and the impressive series of early radiocarbon dates reminds us of Drucker who regarded the Wakashan speakers as probably the longest established on the coast and as possessing Northwest Coast culture of purest strain.

[Genera] statement of importance of the data potentially available:]

Intensive investigations in this region will no doubt yield fascinating results [Borden 1969d:255].

Borden discusses Mitchell's theoretical presentation and calls the continuity model Mitchell's "operational guidelines".

\section{Defense of Dislocation Illustration}

In response to the quotations from his early works, used to i1lustrate Mitchell's "dislocation model", Borden presents what I think is his own manifesto.

[Borden's implicit definition of equivalence between model and "operational guidel ine":]

In elaborating operational guidelines for himself,

[Statement that Mitchell evidence was before radiocarbon dating technique:]

Mitchell quotes from some of my papers written some 20 years ago in those ancient B.C. -14 days.

[Borden defense:] 
I shall not defend what I wrote then beyond stating that interpretations were based on then available data [pp.255-256].

[Borden's general statement of continuity of some early interpretations:]

I still think that some of the interpretations were correct,

[Statement that disconfirming evidence has led to new interpretations:]

although new data have made new interpretations necessary in other instances.

[Borden's theoretical position, negative statement:]

A reading of my publication will reveal that $I$ am neither a

'dislocationist' nor committed to a 'continuity model.'

[Borden's theoretical position, positive statement:]

I prefer to let the evidence speak for itself [1969d:256].

\section{Evidence for Continuity and Dislocation}

Borden begins his elaboration of his meaning with examples from his Lower Mainland paper (1968a). He will show the instances of continuity and instances of dislocation.

[Instance of evidence and hypothesis of continuity in the Fraser Canyon:]

In a recently published paper on the prehistory of the lower mainland of British Columbia, I was able to trace cultural development in the Fraser Canyon through five phases, from late in the 8th millennium B.C. to the second century B.C. without any marked break, only gradual changes in the style of artifacts, and cultural accretion attributable to vigorous local growth, at times stimulated by outside influences.

[Instance of evidence and hypothesis of dislocation in the Fraser Canyon:]

But eventually, there was a break--the discontinuity between the Baldwin phase on the one hand and the ensuing Skamel phase on the other--is sudden and complete, and I cannot account for it in any other way than by inferring that the Skamel phase assemblage marks the appearance of a new population in the canyon region.

[Instance of similar break in continuity of the Delta:] A few centuries later, a similarly sharp break is discernible in the Fraser Delta, and I believe probably for similar reasons. At least that is what the data seem to tell me and cer- 
tainly not because I am an adherent of this or that operational mode1 [Borden 1969d:256].

Dâiiger of Choosing a Model

The next step in Borden's "manifesto" is an examination of possible consequences of choosing any model in the absence of evidence:

[General statement of disagreement with Mitche11:]

I find the last paragraph of Mitchell's paper somewhat perturbing.

[Specific area of disagreement:]

His stated "intention to emphasize the continuity model in further investigation" sounds like an oath of allegiance to a particular faith.

[Borden hypothesis that a pre-evidence intent is contrary to the scientific method:]

Such a commitment seems to me scientifically unsound.

[Borden hypothesis of basic scientific position:]

We must endeavor to approach our problem without any bias whatever.

[Possible consequence, in data collection or recognition, of Mitchel1 method:]

Emphasis on a particular model raises the danger of glossing over evidence that does not fit the model

[Possible consequences, in interpretation, of Mitchel1 method:] and thus of making seriously skewed interpretations.

[Borden's operational guidelines, re-stated:]

We should, as much as possible, let the hard archaeological

facts speak for themselves [1969d:256].

Borden turns to MacDonald's paper next. In discussing it, Borden presents other instances illustrating his own guidelines. During the question period, he adds other instances, so I will defer my summation until the end of this paper's analysis.

\section{PORTIONS OF MACDONALD'S PAPER}

\section{Previous Evidence and Theories on Coast Tsimshian Prehistory}


MacDonald's paper (1969:240-254), begins with five pages of theoretical background for the evidence from his survey. He presents previous archaeological, linguistic and ethnographic theories regarding the prehistory of the present Coast Tsimshian area. Then he relates the most recent linguistic data (Rigsby 1968) to the results of his survey data and proposes an alternative model to former hypotheses interpreting Coast Tsimshian data. It is a paper worth careful analys is for his use of data from mythology and other ethnographic materials, and linguistics, as well as archaeological material. The following portions indicate only a few of his ideas, but do not cover his material except to put Borden's comments in context. The Tsimshian language family has a coastal and an interior division, not mutually intelligible:

[Linguistic evidence of prehistoric divergence:]

Historical linguists agree that the time depth of the divergence of proto-Tsimshian is probably about 2,000 years, even though the degree of relationship of the coast and upriver languages appears to be much closer due to constant and heavy lexical borrowing (Rigsby 1968).

[Ethnographic evidence of coastal distribution:]

The establishment of a Hudson Bay Post at Port Simpson on the coast mid-way between the Nass and Skeena estuaries in 1834 disrupted the aboriginal settlement pattern by encouraging resettlement at the Port. Prior to that, there were at least fifteen named tribes of Coast Tsimshian, the majority of whom inhabited winter villages in the Prince Rupert Harbour, and who also held fishing villages and hunting territories on the lower Skeena and oolachon fishing grounds on the Nass with many camping grounds on the coast and islands between.

Most tribes followed a seasonal cycle of resource exploitation that took them from their winter villages early in April to the oolachon fishing on the Nass; in late spring they moved to the lower Skeena villages for the salmon runs lasting through most of the summer. The men left for the hunting grounds in the fall and in November they returned, with their families, to the villages in the protected Rupert Harbour, where shellfish were a main item of the diet. 
[Problem of origin:]

Ethnologists, beginning with Boas (1916), searched through

the traditional histories and mythological accounts and

found a baffling array of directions of origin indicated

for the Tsimshian [MacDonald 1969:240].

MacDonald gives details of these complex traditions, and inter-

prets Boas to mean that

...only small portions of each phratry may have originated among another linguistic group but in time the emphasis put on multiple origins stressed exotic derivation at the expense of local traditions until the latter were submerged....

[Subsequent scholarly hypotheses:]

Where Boas stressed the complexity and various interpretations of the traditional histories, many subsequent scholars have become more pedantic about the inland origin of the Tsimshian on the upper Skeena and their recent coastal occupation....

[Review of ethnohistory and previous archaeology based on it:]

The broiled-down [sic] version of the ethnohistory that provided the early archaeological models of Tsimshian prehistory favored their inland origin and subsequent movement down river and out onto salt water. In terms of artifact markers for this migration, it was suggested that Tsimshian occupation would be indicated by such traits from the interior as grooved adzes, grooved mauls, and barbed points. Harlan I. Smith spent much time searching in vain for the interior town of Temleham. The Gitksan were, of course, considered to be descendants of the original upper Skeena population, who had remained when other groups moved down river [MacDonald 1969:242].

\section{MacDonald's Evidence to the Contrary}

[MacDonald survey evidence to the contrary:]

The archaeological evidence from Prince Rupert Harbour indicates that winter villages were by no means a recent phenomena. There are almost 50 sizeable shell middens in the harbor that show continuous occupation for more than 4,000 years according to the radio-carbon age determinations. About half of these are large winter villages. At present three horizons have been distinguished in the midden deposits divided simply into upper (A.D. 1800-A.D. 500), middle (A.D. 500 - 500 B.C.) and lower (500 B.C. - 2000 B.C.). 
In brief, all of the artifacts relating to economic activities and manufacturing which form the vast majority of the collections show continuity from the lower to upper horizons and with ethnographic Tsimshian specimens (these include fish hook components, line weights and net gauges, barbed points, hunting gear, bark peelers and shredders, shell knives, planing adzes, beaver teeth carving tools, etc.) [MacDonald 1969:242-243].

[MacDonald evidence of variation in the continuity:] Certain industries such as ground slate or pecked stone implements show tendencies to peak in certain horizons, but are generally present in the others.

[MacDonald evidence of new forms:]

Zoomorphic pecked forms, grooved adzes, hafted mauls and bone pendants, pins, and combs with classic Northwest Coast motifs begin in the upper horizon about 500 A.D. Geometric decorations are found in all three horizons (cross-hatching, neucleated circles, triangular motifs, etc.) [MacDonald 1969: 243].

MacDonald states that in the Queen Charlotte Islands, evidence

seems to be almost identical for the Haida area:

Most artifact forms, in fact, are undistinguishable in comparable horizons between the Haida, Tlingit, and Tsimshian [p.243].

Co-Tradition Model

On the basis of time depth and similarities between these three linguistic group areas, MacDonald proposes an alternative model to the previously held position:

[MacDonald co-tradition model:]

Now let us consider an alternative prehistoric model from that suggesting interior origins of the Tsimshian. In fact, the model I would propose is almost a mirror image of the former one. That is, I see the Tsimshian occupying the lower Skeena from just above the Kitselas Canyon and the Prince Rupert Harbour area for a minimum of 3,000 years. A11 three horizons of the Prince Rupert middens then represent continuous Tsimshian cultural development. This development is not an isolated one, however, for similar changes in economy, settlement pattern, and technology are taking place on the Queen Charlotte Islands and undoubtedly in the Tlingit area 
as well. What I am suggesting is an application of the area co-tradition concept [MacDonald 1969:243-244].

The area of this co-tradition is the same as the area of Drucker's Northern Aspect of the Northwest coast. MacDonald elaborates the mechanisms for cultural interchange. He first gives ethnographic evidence for specialized manufacture and trade between these peoples, then he gives other relationships:

[Hypothesis of co-tradition mechanisms:] Contacts between the triad were not always peaceful and the myths contain more details of wars and raids than of peaceful exchange. Raids served the same function as trade, nevertheless, in supplying needed commodities to the rank systemspecifically slaves and booty. Captives of the other groups were found in every village, and marriage alliances between the three tribes encouraged further cultural convergences.

[Co-tradition hypothes is, re-stated as disconfirming earlier interior origin hypothesis:]

Al1 historically oriented comparisons between the three tribes, no matter what aspect of culture is involved, indicate that the interrelations have very deep roots in time. It is al most inconceivable that the Tsimshian could have been restricted to an interior riverine base until only a few hundred years before contact and then to have articulated their cultural forms on many levels so closely with those of the Haida and Tlingit [MacDonald 1969:244].

MacDonald completes his presentation with this caution:

[Tentative but useful nature of co-tradition model:] obviously much more archaeology is required on the Skeena and in the Rupert area before this model can be proved or disposed of, but it is a logical al ternative to the previous one and warrants consideration from archaeologists, linguists, and ethnohistorians [p.246].

\section{BORDEN'S DISCUSSION OF MACDONALD'S PAPER}

\section{Co-Tradition Model}

Borden's discussion of MacDonald's paper develops into a Borden position statement. First Borden discusses the co-tradition model: 
Let us now turn to MacDonald's paper. As I mentioned earlier, MacDonald is developing the first long culture sequence on the northern Northwest Coast and I was intrigued by his introduction into this region of the area co-tradition concept.

[Borden hypothesis that co-tradition model is a prehistoric instance of ethnographic subarea hypothesis:]

I see nothing wrong with this; the concept is implicit in our recognition of a general Northwest Coast culture pattern, and when applied to various subareas, the concept seems even more fitting.

[Review of evidence for co-tradition:]

It is evident that in the Prince Rupert region, innovations were rapidly diffused from one group to another. MacDonald has some evidence suggesting considerable time depth for this situation, at least as far as the Tsimshian and Haida are concerned. More work, however, is needed to establish this on a firm basis [Borden 1969d:256].

Borden suggests some finer details that may emerge:

[Borden hypothesis that innovators may be identifiable:] Future results may yet reveal that one or the other group was the prime innovator.

[Evidence that may distinguish Tlingit assemblages:]

Some hint that this may be so is evident when one compares the results of de Laguna's work in northern Tlingit territory with MacDonald's findings in the Tsimshian coastal sites. There is much that the northern Tlingit shared with groups farther south --the basic elements of grooved mauls and adzes, slate mirrors, etc. These were part of the northern Northwest Coast culture pattern. But much of what gives glamour to the Upper Horizon in Tsimshian territory appears to be absent or attenuated farther to the north.

[Test hypotheses of culture-center south of Tlingit area:] Thus, future work may reveal that the center of cultural intensity during the Upper Horizon period lay in the south, and to be sure, not with the Tlingit, but

[1] either jointly with the Tsimshian and Haida, [2] or with one of them [Borden 1969d:256].

\section{Comparison of Tsimshian/Marpole Assemblages}

The next series of hypotheses relates Tsimshian assemblages with the Marpole phase on the Fraser Delta. 
[General statement of similarities:]

It is intriguing also to compare the Upper Horizon assemblage with the assemblages of the lower Fraser-Georgia Strait area.

[Hypothesis of negligible similarity with recent Coast Salish:] It is immediately clear that, except in a general sort of way, the assemblage of the latest phase in Coast Salish territory has little in common with the Upper Horizon assemblage of the Tsimshian.

[Hypothesis of Upper Horizon Tsimshian assemblage resemblance to Marpole phase assemblage:]

However, on comparing the assemblage of the Marpole phase as defined in the Fraser Delta with the recent period of the north, we note significant parallels.

[Evidence confirmatory of hypothes is above, of artifacts new to Upper Horizon also found in Marpole phase:]

MacDonald lists among the elements occurring only in the Upper Horizon, combs, she11-disc beads, gorgets of purple-hinged scallop shells, dentalium beads, jet beads, ornaments of native copper, canine tooth pendants with root faces ground flat before perforation, bird bone whistles, barbed harpoons with laterally projecting lineholes, stone clubs with perforated handles, zoomorphic pins. Significantly, all of these are present already in the Marpole phase.

[Evidence confirmatory of hypothes is above, of artifacts new to Middle Horizon, usually also in Upper Horizon assemblage, also found in Marpole phase:]

In addition, there is a series of elements which first appear in the Middle Horizon and which, with few exceptions, continue into the recent period. Again, all of these are also present already in the Marpole phase. These traits include certain types of bone, stone, coal, and shell labrets. Bark peelers of similar type are made of Wapiti antler tines in the south and in the north, where there were no Wapiti, of whale bone, but the shape of these artifacts is quite similar. Perforated net sinkers, bird bone beads, bird bone drinking tubes, brow bands, concretions with incised skeletal structure of fish, plain stone bowls, and bird bone awls are other Middle Horizon traits that are also in use in the Fraser Delta already during the Marpole phase.

[Evidence of time relationship of Coast Tsimshian horizons and Marpole phase, to confirm hypotheses above and below:] The Marpole phase, as suggested by radiocarbon age determinations, lasted from about 400 B.C. to the fourth century A.D. so that this latter series [Middle Horizon] of traits is roughly contemporary with those in the north, but all those elements 
that appear first in the Upper Horizon series are definitely earlier in the Lower Fraser-Georgia Strait area than in Tsimshian sites. Most of them are operational in the south during the latter half of the last millennium B.C. so that they predate the north by at least more than 500 years. This includes the practice of carving cult objects and artifacts of daily use in the shape of animals. It is these zoomorphic carvings predominantly which give glamour to the Marpole phase on the one hand and to the Upper Horizon in Tsimshian territory on the other.

[Borden hypothesis of south to north diffusion:]

Now, I do not know what Mitchell thinks of all this, but to me at least there is a strong suggestion here of south to north diffusion.

[Test for previous hypothesis (as Namu site has proved to be):] Future investigations in the intervening regions may either confirm or disprove this. We will have to see [Borden 1969d: 257].

Borden's quite ordinary statement is an instance of his operational method. From similarities and differences in assemblages, he proposes hypotheses that can be tested by future investigations, not as "my" hypothesis, but as an hypothesis based on specific evidence.

\section{Relationship with Fraser Delta Discontinuity}

Having suggested south to north diffusion, Borden now proposes that additional evidence relating to the same problem may suggest an alternative hypothesis to be even more probable:

[Borden implicit hypothesis for displacement or migration of people:]

Perhaps there is even more here than is at first apparent.

[Evidence of close time-relationships between end of Marpole phase in south with new traits appearing in north:]

I am intrigued for instance, by the circumstance that the end of the Marpole phase in the Fraser Delta nearly coincides with the time when a significant series of new traits of possible southern origin begin to appear in the north; traits that contribute importantly to giving Tsimshian culture its distinctive cast [Borden 1969d:257].

Note that the ornamental, or "non-utiliterian" artifacts are important 
as Borden distinguishes between cultures.

[Evidence that this end of Marpole phase is a "clear break" in a continuity:]

The end of the Marpole phase in the Delta also coincides with the appearance there of a distinctive new assemblage, the Whalen II assemblage.

[Hypothes is of continuity from Whalen II to recent Salish culture, repeated from 1950b:]

From here on, cultural development seems to proceed in a straight line to that of the recent Coast Salish [Borden 1969d: 257].

This continuity, first hypothesized in Borden's first account of the excavation at Whalen Farm (1950b), remains one of Borden's views, which he feels has not been disconfirmed in the intervening years.

Borden suggests alternate hypotheses to interpret the break in the sequences in the south, and the subsequent appearance of similar forms in the north. Although he states that he is not choosing between them, he presents the additional, and to him, crucial, evidence that an adequate hypothes is must accommodate. It is linguistic evidence. Borden's argument, which, with the hypotheses and evidence leading up to it, further illustrates the scope of his meaning when he urges that the evidence speak to the theorist.

Hypotheses Relating to Ethnographic Linguistic Distribution

Borden introduces the alternative hypotheses, asking for possible explanations of the Marpole/Whaten II break:

Thus, in the fourth century, there is a clear break in the cultural sequence. What does it mean?

[First alternative, continuity hypothesis:]

Does it mean that Marpole groups merged with an intrusive population, perhaps the ancestors of the Coast Salish,

[Second alternative, discontinuity, hypothesis:] 
or did this event trigger a series of population shifts?

[Statement that this second hypothesis is being treated as tentative: ]

I am not saying yet that it did, I am only asking a question;

[Statement that more evidence must be accounted for:]

but there is another aspect to this problem.

[Statement that Tsimshian language is evidence for the archaeologist:]

Somehow, someday, we will have to account for the isolated presence of the Tsimshian so far to the north, so remote from their nearest linguistic kin, assuming, of course, that the Tsimshian language, as some linguists maintain, is a branch of the Penutian language family.

[Borden hypothesis accepting MacDonald's disproof of Tsimshian interior origin:]

MacDonald has disposed rather convincingly of the formerly postulated interior origin for the Tsimshian.

[Borden's new hypothesis of ecologica] orientation and area of Tsimshian origin:]

Perhaps they were a coastal people of long standing whose earlier home lay farther to the south [Borden 1969d:257-258].

\section{Hypotheses on Coast Tsimshian Homeland}

Borden was one of the scholars who had supposed the Tsimshian to have come from up the Skeena, so this MacDonald presentation is the paper which marks the evidence and the theory to disconfirm that portion of Borden's earlier thought. In 1954 Borden discussed alternate homelands for the Tsimshians before they came to the upper Skeena:

They may be late arrivals from Asia, but it is also possible that they migrated northward from an earlier southern habitat [Borden 1954b:194].

He based the southern hypothesis on a possible Penutian connection, only tentatively worked out in 1954. By 1969, the Tsimshian piece of the ethnographic-linguistic jig-saw puzzle is re-examined, and clearly, though tentatively, set in a place. The evidence for this present paper comes 
from wide geographic areas, and many disciplines are interrelated in its formulation. No later Borden publication has proposed a different hypothesis.

\section{Locarno Beach Relationships}

The next relationship is still a mystery. Since the time of his first putlication, Borden has hypothesized about and searched for, antecedents to the Locarno Beach phase. He had first thought that the influences came from northern, Eskimoid cultures, then in 1962, published hypotheses reversing the direction of this influence movement. Research at Prince Rupert, between these areas, could confirm or disconfirm these opposing possibilities, or suggest others. With these questions in mind,

Borden considers the Coast Tsimshian assemblages:

[Hypothes is that there is only slight evidence for relationship between Locarno Beach and Coast Tsimshian assemblages:]

Curiously, there is little evidence as yet in the sites investigated to date by MacDonald for the other ancient and quite different coastal cultural tradition manifest on the one hand in the Pacific Eskimo area in the north and the culture of the Locarno Beach phase in the Fraser Delta and Georgia Strait area on the other,

[Evidence that may reflect influence:] except that the ground slate points which are present in Tsimshian sites could indicate early contact with such groups.

[Negative evidence of toggling (composite) harpoons:] However, toggling harpoon heads, which are so characteristic of this other maritime tradition, were evidently rejected by the Tsimshian as well as by the Haida and Tlingit.

[Evidence of parallel negative evidence in Marpole phase:] Interestingly, they did not become established either among Marpole phase groups.

[Evidence of parallel harpoon use between Wakashan groups and Locarno Beach phase:]

On the other hand, toggle heads are the harpoon heads that the Wakashan speakers, the Kwakiutl and Nootka, employed for sea 
mammal hunting and harpooning fish, attesting to the long persistence also of this tradition [Borden 1969d:258].

Borden does not hypothesize that there is a parallel between wakashan and Salish speakers and the Locarno Beach phase, however. This

is the relationship he suggests:

[Hypothesis of Wakashan to Sal ish influence:]

Perhaps the Coast Salish, who likewise employed such harpoons, acquired them through contact with early Wakashan groups [p.258].

I have noted the question: Where were such early contacts made?

Borden concludes his formal remarks on a poignant note, but also with a word of centrally important advice from an older scientist to his former student, now a younger colleague:

It certainly is encouraging to us who for years have struggled to get archaeology moving on the coast to see it forging ahead at last. I salute those who are fortunate enough to be able to carry on this work and I wish them good luck, good digging, and an open mind [Borden 1969d:258].

\section{RESPONSE OF MITCHELL AND MACDONALD}

Before opening the symposium to questions, MacDonald as chairman, asks Mitche11 for a response to Borden's discussion, and then responds to Borden himself.

\section{Mitchell's Response}

Mitchell responds first to Borden with humor, then with a clarification of the examples that Mitchell used for his two models. Then he reiterates his intent and one reason for it:

I should, first of all, be thankful that I did not get coupled with the skunk cabbage. I have only two brief comments to make.

[Mitchell position that models, not people, are 'disjunctive' 
and 'continuity':]

First, the examples which I cited were examples of disjunc-

tive and continuity 'models' and not of disjunctive and continuity 'people.' I am aware that one of the examples I cited of a continuity model in the east was drawn from the writings of an individual who earlier had spoken in terms of, or use, a disjunctive model. I am speaking of Ritchie, and there are undoubtedly similar 'split-personalities' in the west as well. So it was of the models and not the people that I was speaking here [Mitchell 1969:258].

Since models can be constructed to be either "continuity" or "disjunctive", whereas people can hold first to one and then the other, Mitchell was not saying that Borden was a "disjunctionist", or "dislocationist", the term he used earlier. But Borden denied that Mitcheli's "split-personality" could accurately describe him, because he denied holding to either model in the absence of evidence to the contrary. Rather than choosing one hypothesis, Borden characteristically offers alternative hypotheses, and often suggests the geographic areas where tests may confirm or disconfirm these alternatives. One may be preferred, but not held, and the preferred hypothesis appears with evidence that Borden presents to support that preference. For instance, in the Radiocarbon paper (1965: esp. pages 177-178), and in the Lower Mainland paper (1968a:13), Borden 1ists the alternative possible relationships between the people of the Pasika and Milliken cultures. He examines both a continuity and a disjunction hypothesis.

Mitchell secondly discusses his intent, and tentatively accepts Borden's definition of it, but limits the intent only to the process of interpretation.

[Borden's definition of intent tentatively accepted:] Secondly, a statement of intent, which is what I labelled the latter part of the paper, is perhaps an oath of allegiance. 
[Mitchel1 intent limited to interpretation:]

I would emphasize though that data collection and description are separate from the question of interpretation, and I am only consciously biased when it comes to interpretation.

[Mitchell re-statement of his rationale:]

Biased for what I believe are good reasons. One reason, which I stated in the paper, was that the history of archaeological interpretation suggests it would, at this point, simply be good strategy to lean toward the continuity model and toward such integrative concepts as the tradition for interpretation [Mitchel] 1969:258-259].

\section{MacDonald's Response}

These are a few of MacDonald's comments in response to Borden:

[MacDona]d's statement on flexible use of models in early survey results:]

I think one of the problems that we're faced with is that most of the work that has been done on the central and northern coast is very recent and we are suddenly asked to present interpretations in terms of models that people can understand where the sequences and contents of sites have not been previously described. Undoubtedly, we are jumping to models prematurely. We have even go so far as to classify them into disruptive, continuity, and co-tradition models. This is the extreme extent of premature interpretation of survey results. I do not by any means intend to use these models rigorously and unflexibly in the archaeology I do in this area and rea I$7 y$, the problems that I am concerned with are quite removed from any pre-commitments to the particular model [MacDonald $1969: 259]$.

MacDonald expands on the usefulness of comparing technological traditions along the coast, with general instances of the slate grinding industry in the Northwest Coast area. In response to Borden's comparison of Marpole with items from the Middle and Upper Horizons in the Prince Rupert area, MacDonald speaks in terms of the evidence to support the various models:

[MacDonald hypothes is of greater discontinuity in the evidence from Fraser Delta than from Prince Rupert:]

Looking at Borden's Fraser Delta material, I can see many more discontinuities in traditions between his phases than I have 
evidence for in the northern area.

[MacDonald general response to Borden interpretation:]

At no time in the north is there ever any really great influx

of new traits, For the Prince Rupert area, Borden listed

quite a few that do come in the late period,

[MacDonald hypothesis that there is only one major change:] but the only major one in my view is the zoomorphic style applied to a long standing tradition in that area of heavy stone tools.

[Evidence of continuity:]

The basic tool forms, the harpoon types, etc., have overwhelming continuity throughout the sequence [MacDonald 1969:259].

MacDonald's emphasis is very different from Borden's in weighing the significance or meaning of new forms. This is clarified in the next

passage in which MacDonald's use of models is quite distinct from

Mitchell's, both in the hypothesis and supporting instances:

[MacDonald hypothesis on usefulness of contrasting models in clarification of ideas:]

At this stage I see some justification for kicking around models of co-tradition, continuity, or discontinuity to throw into contrast some earlier postulates.

[Instances, first general, then specific, which support cotradition or continuity models on the coast:]

[Genera]:] I think, for example, that we can definitely say now that for the entire coast of British Columbia we have good evidence of an economic system that includes harbor settlements, relying on intertidal resources, for the past 5,000 years.

[Specific:] There are a lot of factors that repeat up and down the coast; the prevalence of blue mussel in the early layers of all sites and the relatively slow build-up of the middens in the early stages [MacDonald 1969:259].

MacDonald mentions the need for studying settlement patterns, and the problems in doing this. Then he concludes with another remark about open minded use of models:

[MacDonald's operational guidelines, re-stated:]

In summary, the problems are multiple and I would think that all of us who have dealt with models have no particular commitment other than trying to communicate the tentative 
feelings we have about what our material means, but I assure [you] we will try to keep an open mind, and meanwhile, there is a tremendous amount of work to be done before models can ever be realistically proposed [p.260].

\section{RESPONSE TO QUESTIONS}

In response to the first two questions, Borden and MacDonald deal with areas of theory and evidence not mentioned earlier in the symposium. The first question suggests two alternative courses for development of Northwest Coast villages, and asks of there is evidence that might support either of them:

Question: I would like to ask if there are any suggestions of the settlement pattern from the numerous small villages collecting into larger centers through time or just the continual build-up of the middens of separate village types which can be compared to show population increase [p.260].

\section{MacDonald on Changes in Rate of Population Growth}

MacDonald answers with one hypothesis, and stresses the work needed to support it accurately:

[MacDonald hypothesis of population increase and change in rate through time:]

We11, we probably have to answer this individually. Certainiy, I think in the northern area there is evidence that the population increased through time. There were fluctuations, but the point I tried to make was the very slow build up of living materials and refuse in the lowest one foot or foot-and-a-half of each one of the shell midden sites. It represents perhaps a thousand or fifteen hundred years, whereas in the late period, particularly the last thousand years, it was an extremely rapid build up.

[MacDonald general hypothesis of cause of change:]

This shows both economic changes and indicates their range of exploitation of shellfish species in particular.

[MacDonald statement of preliminary and tentative nature of this hypothesis:] 
But this is a question that requires a fairly sophisticated answer which can only be provided after a lot of rigorous studies have been done on the material. At this stage most of us have not achieved this stage of analysis of midden contents [MacDonald 1969:260].

\section{Borden on Evidence of Early Limits of Population and on Adaptation Rate}

Borden adds evidence to supply the early limits of human occupation in the area, with hypotheses of the influx of populations from several directions into this deglaciated region. As he discusses this earIy period, he contrasts the theories of man's adaptation to his environment with evidence that he takes to disconfirm the theory. Borden begins:

[Borden statement that additional evidence must be considered:] May I make a comment? Other factors that we have to bear in mind are that

[Evidence of glaciation preventing early habitation:] during the last glacial maximum, the continent was buried under ice, in many areas 2,000 meters in thickness and more, from the Pacific to the Atlantic, and that this tremendous ice cover did not disappear in the interfor until 9 to 10,000 years ago.

[Genera] statement that there is evidence of some immediate human occupation:]

We have, however, some evidence that at least a few Indian groups came to the northern Northwest Coast virtually on the heels of this vanishing ice.

[Drucker's (and Kroeber and Borden?) slow maritime adaptation hypothesis:]

This evidence is significant in view of Drucker's opinion that Indians coming from the interior could not adjust to the rugged coastal environment.

[Drucker's hypothesis of immigrant maritime people founding Northwest Coast culture:]

He postulated that a Maritime economy introduced by people, who had already developed the technology of Maritime living elsewhere, would have to form the basis for the subsequent rise of Northwest Coast culture. 
[Evidence from Icy Strait:]

Now we have one very early radiocarbon date, which is most intriguing in this context, from the Ground Hog II site on Icy Strait, about 40 miles west of Juneau. The site dates to approximately 8,000 years B.C.

[Borden hypothesis of interior route of migration to Icy Strait:]

The only way the people could have reached the site locality at that time was by way of southwestern Yukon Territory, because all other adjacent interior areas were still completely glaciated.

[Evidence of successful adaptation at Icy Strait:]

Yet they made it to the coast and apparently succeeded in establishing themselves.

[Statement of interest in evidence of subsequent development: ] It will be interesting to see whether one can trace what developed after that [Borden 1969d:260-261].

Borden's next passage contrasts with Drucker's ideas that he just cited. Borden speaks of general success, after an initial period, in adaptation by all sorts of cultures to Northwest Coast conditions.

[Borden hypothesis of subsequent diversity of immigrants:] We have also to imagine that somewhat later, other groups came to the coast, perhaps via other valleys that led from the now deglaciated interior to the seaboard. We cannot derive all the coastal peoples from the north, although some may have spread south from there.

[Borden hypothesis of general success in adaptation:] Probably, after a period of adjustment most of these newcomers to the coast not only made a go of it, but even prospered.

[Borden statement of foods available on the coast:]

The food resources on the coast are so rich and abundant and so dependable that periods of severe starvation were probably rare. Failure of certain food resources was alleviated by the presence nearly everywhere of shell fish which could be easily obtained and which enabled people to survive even when supplies of salmon and other food staples were exhausted.

[Borden hypothesis of subsequent population growth, paralle] to Near East during incipient food production:]

It is likely that once minimal utilization patterns had been developed on the coast, population growth proceeded fairly steadily comparable perhaps to that during the period of in- 
cipient food production in the Near East.

[Borden statement of tentative nature of previous hypothesis, but based on evidence:]

Although this may be a rather daring analogy there seems some fustification for it in the archaeological record [Borden 1969d:261].

The change in the rate of midden deposition in MacDonald's response to the question would constitute such evidence, for instance.

\section{Concluding Questions}

Borden turns the next question, about evidence of early salmon use, over to MacDonald who reports:

[Earliest evidence of salmon fishing in Coast Tsimshian area:] The first assemblages that I encounter in the middens with dates as old as 4700 are highly sophisticated and well adapted to the problems of systematic exploitation of resources [MacDonald 1969:261].

Borden responds:

[Borden hypothesis of previous continuity, or development:] So some considerable period of development would have to proceed [precede] what you already have [Borden 1969d:261].

MacDonald answers in terms of the limits within which models are usefur:

[MacDonald hypothesis of time depth for salmon fishing:] And it could be that we will continue to push back the frontier of the dates, perhaps another millennia or two

[MacDonald hypothesis on time-scale of models:] so that we can not build our models in the scale of presently known time depths.

[MacDonald hypothesis of "danger of model making":] I think this is where the real danger of model making is, that your time scale becomes fixed and later you have to collapse events to fit everything into a fixed temporal span that becomes accepted.

[MacDonald hypothesis that sea-leve] changes may affect the evidence availability, and the interpretations of present evidence:] 
But the whole problem of fluctuation of sea levels in the northern area is something on which we do not have much data, but it seems to have stabilized in the last 5,000 years. Before that there is a possibility that you may have had the Hecate Strait area as dry land while there were lower water levels. But what this suggests in terms of locating sites that may now be submerged, I do not know [MacDonald 1969:262].

Folan adds the importance of ethnographic evidence in interpreting the use to which artifacts were put, and MacDonald stresses that this is especially helpful where the sites are waterlogged or have in some other manner preserved the perishable materials, such as Daugherty's Ozette site and a Bella Coola site of Hobler's. After a review of the immense amount of work needed to complete the preliminary studies presented at the symposium, MacDonald closed the meeting.

\section{Discussion}

Borden's plea for an open mind in seeing evidence and in interpreting it was illustrated with evidence from linguistics, glaciation processes, from other Northwest Coast sites, and from theories pertaining to 0ld and New World culture change. When I viewed Borden's contributions in this discussion as a total argument, I labelled them a "tour de force", primarily because they illustrate the self-correcting character of the scientific method, focused on one or two specific problems. Borden's comments functioned to fill in the larger body of evidence without which hypotheses or models concerning a small area are left isolated, and hence untestable in the broadest sense. 


\title{
CHAPTER XL
}

\section{CULTURE HISTORY OF THE FRASER-DELTA}

\author{
REGION: AN OUTLINE
}

\section{INTRODUCTION AND BACKGROUND MATERIAL}

This paper is published in B. C. Studies, Special Issue, edited by Roy L. Carlson. In the preface, Carison writes as follows:

This monograph originated from a lecture series on New Discoveries in the Archaeology of B.C. for U.B.C. Extension from October through December 1969 which I moderated. The articles are all based on the lectures presented at that time with the exception of the paper by Charles Borden. His lecture covered the early cultures in the Fraser Canyon a summary of which has recently been published in the B.C. Geographical Series, No.9, 1968 [this thes is 1968a], so he has instead prepared a paper on the Culture History of the Fraser Delta which has been included [Carlson 1970: $5]$.

At Borden's suggestion, I am correcting a number of typographical errors which appear in this publication. I have deleted commas from dates so that instead of reading (ca. $3,500-1,100$ B.C.) it will read (ca. $3500-1700$ B.C.) to conform to standard usage.

While Borden and I conferred about my analysis of his paper, he added many comments about more recent research. With his permission, I have added these comments to this chapter.

This summary paper of Fraser Delta phases begins with early evidence from the St. Mungo Cannery site:

Until recently, the known prehistory of the Fraser delta region did not extend back beyond the last millennium B.C. Important new investigations carried out by Miss Calvert at the St. Mungo Cannery site in the eastern part of the delta 
have now pushed the story back another 2000 years to the middle of the third millennium B. C. (cf. this volume) [Borden 1970:95].

In Calvert's article, she gives this more specific information:

A carbon sample collected from the base of the cultural deposit was submitted for dating. A determination of 2360 B.C. \pm 110 years (I-4053) was returned on the sample, a second sample (I-4688) also from the base of the cultural deposit gave a reading of $2290 \pm 105$ B.C. The St. Mungo site is thus the oldest dated midden in the Fraser Delta by at least 1000 years [Calvert 1970:57].

The rapidly expanding information about earlier cultures underlines Borden's emphasis on known evidence when he discusses prehistoric cultures. Theories and questions change with the increase in knowledge.

Because Calvert presents the evidence of earlier delta occupations in this issue of B.C. Studies, Borden sets this early evidence in his own theoretical context in a brief introduction, before his discussion of the more recent phases in the delta.

Borden supports his hypotheses of even earlier delta occupation with suggestions of other evidence and possible limits to confirmation:

[Borden's hypothes is of delta occupation before 3rd millennium B.C.]

Very likely, however, even this does not mark the beginning of human occupancy of the delta.

[General statement of evidence to support preceding hypothesis:]

Excavations by the University of British Columbia at several other sites have uncovered wave-worn pebble tools in the sand of raised beaches

[Hypothes is of date of evidence:] which may date to the terminal Pleistocene or early Holocene when isostatic rebound from the depression caused by the Cordilleran ice load was still continuing. 
[Hypothesis correlating Fraser delta and Fraser Canyon dates:]

It is possible, therefore, that the prehistory of the

Fraser delta was comparable in duration to that of the Fraser Canyon region (Borden 1965; 1968b).

[Hypothesis of possible limits of confirmatory evidence:] Unfortunately, the details of this prehistory will probably never be completely known because urban expansion, industrial development, farming and other human activities during the past century will have destroyed much of the evidence [Borden 1970:95].

Borden reports that as of July 1974, there is evidence of occupation extending over more than 8000 years at both the Glenrose Cannery and the adjacent St. Mungo Cannery site. The delta evidence is nearly as old as that of the Milliken sequence. The two areas show strong resemblances (Borden, pers. comm., 1974). This would be confirming evidence of the hypotheses above.

To illustrate the paper (p.96), Borden includes a chart of the "Fraser Delta Sequence" (my figure 12, Borden's fig. 29). Figures 30 to 33 are photographs of the diagnostic artifacts of the phases of the Fraser Delta Sequence: Locarno Beach, Marpole, Whalen II and Stselax.

Roy Carlson, editor of this volume, illustrates his summary of the prehistory of archaeology in British Columbia with a "Cultural Chronology of British Columbia" (Carlson 1970: Fig. 2, pp. 14-15). The Fraser Delta sequence comes from "...Borden, this volume; Calvert, this volume; ...Fraser Canyon: Borden 1965..." (Carlson 1970:15).

The basic chronology and the sites described are identical to the delta sites described in the Lower Mainland paper (1968a). The space in this paper allows Borden to give expanded descriptions and analyses, as well as to bring new evidence into his discussion. Borden's general phase-making hypothesis is based on the evidence 


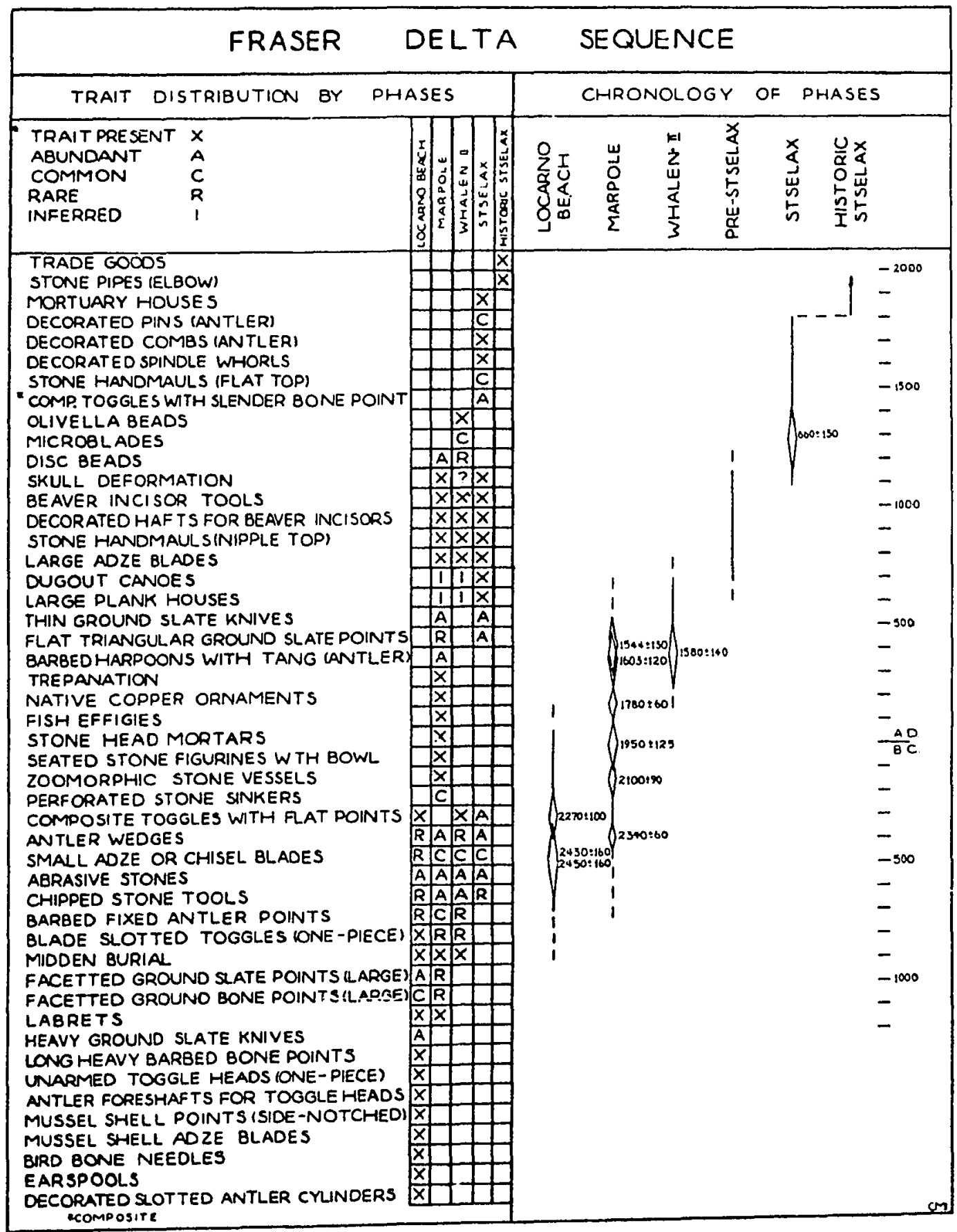

Figure 12. Fraser Delta sequence (1970:96 Figure 19). 
summarized in the chart which was my outline as I studied all of

Borden's papers:

[Types of evidence used to formulate phase hypotheses:] The recovered data, supplemented by 15 radiocarbon dates,

[Borden's phase hypotheses:]

make it possible to divide the prehistory of the western part of the delta region into five phases whose names are derived from their respective type sites: Locarno Beach, Marpole, Whalen II, Pre-Stselax, and Stselax.

[Statement about chart:]

Figure 29 shows the distribution of selected diagnostic traits in four fairly well defined phases and the accompanying chronological chart their approximate duration in time.

[Statement of relative frequency of elements:]

The relative frequency [trait present, abundant, common, rare, or inferred] is indicated where this differentiation seemed of significance and sufficient data were on hand to do so.

[Statement of correlated photographs:]

A number of the artifacts listed in the table are illustrated in Figures 30-33.

[Hypothesis that distinctivefeatures define each phase:] An examination of the trait distribution reveals that although a few elements are present in all phases, each phase has its distinctive features which sets it apart from the others [Borden 1970:97].

\section{I.I. LOCARNO BEACH PHASE Ca. 800-200 B.C.}

There were only two known components of this phase in 1970. (A third, on the Musqueam Reserve, is being excavated under Borden's direction in 1974.) As in the West Coast Crossties paper (1962a:12), Borden's description of the two locations stresses that they are on the fringe, at the extreme north and south edges of the delta area:

[Evidence of location of component sites:]

The Locarno Beach phase is known from two components, one being the type site on the north shore of Burrard Peninsula in the extreme northwest part of the delta regjon, 
and the other Whalen $I$, that is the lower or earlier horizon of the deposits at the Whalen Farm site in the southwestern part of the delta.

[Summary from radiocarbon evidence (see chart), from these components:]

Three radiocarbon dates show that this culture was in full operation around 500 B.C.

[Evidence of stratigraphy:]

Since the charcoal samples did not originate from the bottom of their respective deposits

[Hypothesis of beginning of phase:]

the beginnings of the phase must date back somewhat earlier [1970:97].

This is the evidence for Borden's estimate of 800-200 B.C. for this phase.

Now he discusses the two outstanding features of this phase, the slate grinding industry and the various toggling harpoon types.

This is Borden's most complete description of the toggling harpoons:

[Hypothesis that Locarno Beach phase is distinguished by two main features:]

Among the salient features of this culture is the reliance on toggling harpoons for fishing and sea mammal hunting, and a highly developed slate grinding industry for the manufacture of piercing and cutting implements.

[Hypothesis classifying harpoon types:]

Three types of toggling harpoon heads were used.

[Evidence describing these types, supporting hypothesis above:]

Since these particular types are not well known it is advisable to describe them in some detail:

Type A. Small one-piece toggle heads. [In figure 12: 527 , these are titled "Unarmed Toggle Heads (one-piece)"] Made from distal end of antler tine. Outline acute isosceles triangle, cross section oval, closed socket, opposed bilateral symmetric spurs, gouged line hole at right angles to spurs. Not armed with cutting blade.

Type B. One-piece toggle heads, slotted for cutting blade. [In figure 12:527, these are titled "Blade slotted toggles (one-piece)"] Made 
from distal end of antler tine. Larger and sturdier than Type A. Closed socket, short unilateral spur, deep open blade slot in same plane as spur. Cutting blade of bone, bevelled bifacially to sharp edge. No hole or groove for retrieving line. Line must have been fastened beneath the lashing which held cutting blade in place, coming away on side opposite spur to permit toggling action.

Type C. Composite (two piece) toggle heads slotted for blade. [In figure 12:527, these are titled "Composite toggles with flat points"] Made from two sections of antler cortex. These devices consist of two similar halves or "valves" which, when lashed together, form in effect a toggling harpoon head with basal socket, opposite lateral spurs and blade slot. Well defined lashing groove. Retrieving line fastened to head by same lashing that holds the two valves together, coming away on one side midway between the spreading spurs of the valves [Borden 1970:97-98].

Borden presents evidence to hypothesize that there was an additional, much larger type of toggle head:

[General statenient of harpoon foreshaft formation:] Toggle heads were used with fixed foreshafts of antler or sea mammal bone.

[Evidence of instances of foreshafts:] only fragmentary specimens are on hand from the type site, but a number of entire foreshafts were found at Whalen Farm.

[Evidence of size variation:]

Foreshafts vary considerably in size.

[Hypothesis that there are harpoon; heads of a larger type:] Some evidently were intended for substantially larger toggle heads than have been recovered [1970:98].

Borden reviews evidence of the slate grinding industry:

[Hypothesis that slate grinding is the most important industry:]

By far the most important industry of the Locarno Beach phase is slate grinding.

[Evidence with an included hypothesis, to support preceding hypothesis:]

[1] Most projectile heads are ground slate types in a 
great variety of sthall and large forms, usually hexagonal in cross section.

[Hypothesis of possible use:]

The larger specimens may have been lance heads or dagger blades.

[2] Ground slate knives are very numerous. Semilunar or rectangular in outline, the majority are heavy implements with a thick back (sometimes $10 \mathrm{~mm}$. or more), tapering

from here to a straight or curving cutting edge.

[Hypothesis of relative unimportant chipped stone industry, also confirming major slate grinding hypothesis:]

Compared with the importance of slate grinding, the chipped stone industry was of minor significance.

[Evidence of this industry:]

A few well made leaf-shaped and stemmed points are present as well as some rather heavy percussion flaked scrapers of basalt [1970:98].

Borden reviews the evidence of artifacts made of bone and antler, with information similar to his earlier accounts. These included bone projectile points (sometimes facetted like the slate points), long heavy serrated or barbed bone points, and the atlatl hook. Various sizes of needles were made of bird and mammal bone. "Ornaments include perforated graphite and tooth pendants, earspools, and labrets" (p.99), such as were shown on the anthropomorphically carved atlatl hook figure (see fig. 3, p. 54).

Borden's discussion of artifacts for woodworking and faunal remains lead to familiar hypotheses about habitation and boat forms.

[Evidence of adzes and chisels:]

The tough shell of the giant mussel (Mytilus californianus)

was ground into a variety of artifacts, even into blades for chisels and adzes. Adze blades were also ground of bone, cherty slate and nephrite. Adzes, however are few in number and rather small with narrow bit, suitable for fashioning bone, antler and wooden artifacts.

[Evidence of wedges:] Antler wedges are rare and of small to medium size. 
[Evidence of hammerstones:]

Cobbles and pebbles. were used as hammerstones.

The latest work at Musqueam N. E. and its Locarno Beach component does not change this evidence. There are still no shaped hammer stones, and no wooden mallets (Borden, pers. comm., 1974).

[General statement of evidence of land and sea game:] Al though the people of the Locarno Beach phase did not neglect land game, toggling harpoons and faunal remains indicate that sea mammals, including seal, sea lion, and porpoise were frequently hunted.

[Evidence of fish:]

Fish remains are also abundant.

[Evidence of molluscs:]

The main midden $\mathrm{fill}$, however, like that of nearly all

delta sites investigated, consists of the discarded shells of mussels, cockles, and clams, indicating the importance of marine molluscs in the diet of these coast dwellers.

[Negative evidence of specific habitation or watercraft:] We know, as yet, nothing about the habitations of the Locarno Beach phase nor of the watercraft

[Hypothesis, based on faunal remains and tools, that watercraft were used:]

that must have been in use.

[Hypothesis, stated negatively and affirmatively, of different habitation and boat types, Negative statement:]

However, it is difficult to envisage large-scale woodworking, such as produced the large plank houses and dugouts of later periods,: with the type of tools that have been recovered to date.

[Positive statement:]

Perhaps these groups used habitations and boats different from those of later times [1970:99].

In his earliest paper (1950a:24), Borden had specified the possibility of skin boats in a similar hypothesis. However, Borden now has evidence from Musqueam N. E. leading him to propose the presence of dugout canoes. Fragments of cedar bark bent up at the sides with a 
handle, may be canoe balers, which would argue for a dugout canoe, rather than one with a framework. (Borden, pers. comm., 1974).

Burials of the Locarno Beach phase, on the inland slope of the midden, sometimes with grave additions, were similar to Marpole and the subsequent Whaten II phases.

Borden suggests, as in 1962a, that the center of this culture was to the north and west. He adds that possibly these sites were seasonally used camps:

[Negative evidence to the east:]

Elements diagnostic of the Locarno Beach phase have not been found in sites east of the Fraser delta.

Three miles downriver from Hope, at the Katz site, facetted ground slate points have been found, suggesting contact with this downriver phase (Borden, pers. comm., 1974).

[Evidence of peripheral delta sites:]

Moreover, the two known sites of the phase are relatively small and located at the northern and southern extremes of the delta region.

[Hypothesis based on negative and positive evidence above, and possibly on culture center presupposition:]

Perhaps the people of this phase had their main centres on various islands in the Strait of Georgia and visited the delta sites only seasonally.

There are indications that the Musqueam N. E. site may support this seasonality hypothes is (Borden, pers. comm., 1974).

[Test hypothesis for other earlier sites or for culture center:]

Other contemporary centres as well as antecedent stages of this early maritime culture may yet be discovered farther north on the coast [1970:99].

I asked Borden why he specified a northern coastal center in this hypothesis. He replied that ground slate fades out of known assemblages south of the delta area, so he would therefore expect to 
find the center and place of origin more to the north. The third component of the Locarno Beach phase, discovered since this paper, under investigation (1972-1974), at Musqueam Northeast, DhRt 4, contains many more projectile points. than the other two sites., and microblades as we11. Borden's latest hypothesis about the Whalen I and Locarno Beach sites is this, "These are possibly activity-specific sites" (Borden, pers. comm., May, 1974). After a twenty-two year search, Borden has new evidence for the Locarno Beach hypotheses. Future publications will continue the account of the investigation of this water-logged site.

I asked Borden if there were any larger toggle heads found at Musqueam N. E., or any clues to the use of the larger foreshafts. He replied that no larger heads had been recovered. It is possible that they were fashioned of mountain goat horn, which decays very rapidly. When a driveway was cut through the old Locarno Beach site, a fragment of an even larger foreshaft was recovered. Since a skull of a sea lion was recovered from Locarno Beach, with evidence of great size of the sea lion bul1, he wonders if these harpoons may be specifically used for their hunting (Borden, pers. comm., July 6, 1974).

\section{MARPOLE PHASE Ca. 400 B. C. - A. D. 450}

\section{Marpole Assemblage Description}

Borden begins this account with a clarification of an hypothesis from his first paper $(1950 a: 15,17)$, in which he divided the Locarno Beach stratigraphical1y, with the mos.t recent layer of a different character. Now he identifies it as a Marpole component. At the same time he hypothesizes that Marpole represents a "stage in...cultural 
development":

[Hypothesis of a Marpole developmental stage component at Locarno Beach:]

On the surface and in the top layer of the Locarno Beach site were found artifacts that differ from types characteristic of the Locarno Beach phase. They are elements typical of another stage in the cultural development of the Fraser delta region: the Marpole phase [1970:99, 101].

The radiocarbon dates from the 01d Musqueam component are contemporary with Locarno Beach dates, which Borden interprets in this way:

[Hypothesis of co-existence of Locarno Beach and Marpole phases:]

Evidently the two coexisted for a period in close proximity and contacts between the two groups must have been common.

[Hypothesis correlating rise of Marpole and the end of Locarno Beach phase:]

However, even before the Marpole culture came into full

flower toward the end of the last millennium B. C.,

Locarno Beach groups had vanished from the delta region

[1970:101].

Borden had based his "West Coast Crossties..." arguments (1962a)

on the premise that Marpole represented the earliest known fully developed Northwest Coast culture. In the present paper, he adds evidence of wealth emphasis in supporting this position. This is his comparison of the Locarno Beach and Marpole phases, and his summary of Marpole culture patterns:

[Hypothesis of difference between Locarno Beach and Marpole phases: :]

While certain important aspects of later coastal culture are anticipated in the Locarno Beach phase, in the Marpole phase the typical Northwest Coast culture patterns of more recent times are already well blocked out:

[Hypotheses, as. evidence, to support preceding hypothesis:] Maritime orientation.

Highly developed woodworking.

Large villages with commodious houses along the shore.

Impressive achievements in the plastic arts. 
Evidence hinting at wealth emphasis and stratified society [1970:101].

Borden continues to compare and contrast the two early delta cultures. Both share a common economic base.

[Hypothes is of sea-based economy in both phases:]

To a considerable extent the economy of the Locarno Beach and Marpole phases is similar: the primary orientation of both is toward the sea $[1970: 101,103]$.

At the time of their occupation, all known Marpole sites had been on the Strait of Georgia. This is Borden's summary of food resources at the economic base of both phases:

[Hypothes is generalizing food resource evidence:]

Although food resources of the land were extensively utilized (deer and wapiti remains are common), the main quest was directed toward exploiting the bounties of the sea. Salmon, the basic staple, and other species of fish are supplemented by molluscs, water fowl, and sea mammals [p.103].

Borden finds the first major distinction between these phases in the gear used in this food quest:

Important differences from the Locarno Beach phase, however, are apparent in the gear employed.

[Evidence of contrast in harpoon types:]

Whereas in the Locarno Beach phase sole reliance for taking sea mammals and large fish was on toggling harpoons, in the Marpole phase almost exclusive use was made of barbed harpoon heads.

[Hypothes is that variation in Marpole harpoons suggests species-specific use:]

Fashioned of wapiti antler, they occur in a considerable variety of types and in a wide range of size, suggesting specialized use for different species of marine game.

[Evidence of variation, with subsidiary hypothesis, to support preceding hypothesis:]

[1] The dominant form of harpoon point is the unilaterally barbed head with conical tang and laterally projecting line guards.

[2] Very numerous in the Marpole phase, moreover, and represented by many different types, are fixed barbed points of antler. 
[Hypothesis of use:]

These may have tipped fish spears, darts and possibly arrows [Borden 1970:103].

Comparison of This Hypothes is With Similar Hypotheses in Borden's Writings

This passage specifically answers a question I had noted in analyzing the paper in which Borden replies to Caldwell. Borden is supporting the position that the barbed harpoon with tang and lateral line guard was an interior trait: (see fig. 4, p. 55).

Even though this Interior harpoon type was modified on the Coast to render it more suitable for sea-mammal hunting... [Borden 1954a:29].

I asked how these were modified. This was Borden's reply:

The harpoons found in interior sites are small, usually with a single barb. Some of the specimens from coastal sites are also small, with a single barb, but others are of different sizes. Some are quite large and with multiple barbs. The differences presumably reflect species-specific modifications [Borden, pers. comm., May, 1974].

This group of comments from 1954, 1970 and 1974, i17ustrates a continuity in Borden's thought. It is similar to passages in which Borden argues from a variety of stone tool forms to a variety of uses $(1956: 95 ; 1968 b: 61)$.

Marpole Assemblage Description, Continued

Borden continues with a statement of the diversity in the Marpole assemblage. From a discussion of the stone industries, he moves to the discussion of boat and habitation types.

In the brief space available it is impossible to convey an adequate notion of the diversity of hunting and fishing gear and auxiliary equipment employed in this phase.

[Statement of relative importance of chipped stone industry:] The chipped stone industry was relatively more important than in the Locarno Beach phase, especially for projectile points and broad leaf-shaped knives of basalt. 
[Evidence of ground slate knives:]

However, large numbers of knives for butchering fish were ground of slate.

[Comparisons with Eayem and Locarno Beach artifacts:] Interestingly, these slate knives are very similar to those already present by 3000 B.C. in the Eayem phase of the Fraser Canyon sequence (Borden 1968a). By contrast with the thick and heavy knives of the Locarno Beach phase, the Eayem and Marpole knives are thin (2$3 \mathrm{~mm}$.$) , of even thickness throughout, and polished over$ the entire face. Outlines range from semilunar to rectangular.

[Ethnographic evidence of canoes:]

Early explorers on the Northwest Coast were impressed by the large, seaworthy dugout canoes and the huge plank houses of the coast Indians.

[Comparison of ethnographic and Marpole woodworking tools:] The full complement of heavy-duty tools which made possible the large-scale woodworking industry of recent times is present on the southern coast for the first time in the Marpole phase.

[Evidence of woodworking complex in Marpole assemblage:] This basic tool kit includes:

Large splitting wedges of antler and wood. (Wooden wedges were recovered from the water logged basal levels of the Beach Grove site).

Pestle-shaped hand-mauls of tough fine-grained rock.

Adzes armed with finely ground and polished blades of nephrite. (Only on the northern Northwest Coast was this basic triad of tools augmented by large grooved adzes and grooved mauls.) [Borden 1970:103-104].

Borden's conclusion is explicitly derived from the above pieces of evidence. Two additional strands of the argument are implicit: one is based on ethnographic analogy and the second is based on poor preservation of wood at Marpole sites. If the recent Indians used this tool kit to make dugout canoes to travel and to hunt sea mammals, then we may infer that past Indians used the same tool kit to make similar canoes to secure the same game, of which we also have evidence 
from the past. The hypothesis is strengthened by recognizing that the only missing artifact is the perishable one. Thus, if necessary tools are present, and the results of use of sea-craft are found, the artifact which would perish under usual conditions may be inferred. This argument is indicated in the chart of elements of each phase (1970:96), by the notation "implied" in the Marpole column, by the element "dugout canoe".

[Hypothes is of dugout canoes in Marpole assemblage:] From the presence of such tools and the remains of porpoise and other sea mammals in Marpole phase deposits we may reasonably infer the use of dugouts in fishing and sea mammal huncing as well as for transport and travel [p. 104].

The importance of "transport and travel" was spelled out in the Duff quotation with which Borden concluded his Lower Mainland paper (1968a: 25). This transport and travel is essential to Borden's hypothes is that Marpole represents the full Northwest Coast culture pattern. Borden continues with evidence for large plank houses:

[Evidence, tentative, at Beach Grove site:] The former existence of large rectangular houses at the Beach Grove site was suggested by a series of oblong depressions. Unfortunately, it was not possible to explore these adequately.

[Evidence at Marpole:] However, excavations at the type site revealed a series of large widely spaced postholes capable of accommodating massive house posts. These postholes as well as extensive spreads of ash and other features associated with habitation floors

[Hypothesis of large plank houses:] indicate that Marpole phase groups lived in spacious houses, very likely comparable to the large plank houses of more recent times [1970:104].

Borden does not expand on the type or variety of coastal house. This may be because he does not have evidence which can distinguish between the ethnographically known types. 
Borden discusses the sculptural forms at length, then ornaments and burial practices. All of these add weight to the hypothesis of wealth emphasis and a stratified society. The section about sculpture is almost identical to the presentation in the Marpole discussion of the Lower Mainland paper (1968a:19).

[Hypothesis interpreting sculptures as impressive:] Among the most impressive remains of the Marpole phase are sculptures in antler and stone.

[Hypothesis that wooden sculptures probably existed:] If wood were nonperishable we would no doubt also find carvings in this medium.

[Evidence of parallel technique to support preceding hypothesis:]

Pertinent in this connection is the fact that wapiti antler was chopped, hacked, grooved, split, carved and finished with essentially the same tools and techniques that had to be used on wood [p. 104].

This last hypothesis and supporting evidence is similar to the canoe hypothesis discussed previously. In his next. description Borden includes his hypothesis that the skills for artistic endeavor originate in practical endeavors. Although it may not be a necessary nor universal condition, it can be noted as part of Borden's theory of tools and their use.

[Statement of limitation of material:]

The nature of antler put a limit on the size of the objects that could be fashioned from this material,

[Hypothesis of primary skills developed in making usefur articles:]

but the mastery of dealing with this medium, acquired in the manufacture of wedges, harpoons, barbed points and other devices,

[Evidence of artifacts with hypotheses of form and artistic value:]

was also put to skillful and imaginative use in the creation of exquisite realistic and semiabstract carvings and engravings of birds, frogs, fish, sea-monsters and human figures. 
[Evidence of other raw materials used:]

Soft stones, such as steatite and siltstone, were treated in much the same way.

[Evidence of particular artifacts of stone, described as of special interest, probabiy for inter-cultural comparisons:]

of special interest here are fish effigies and small seated human figurines holding a bowl-1ike container.

[Evidence of additional tools in assemblage:]

Beaver incisors, very small chisels of nephrite and splinters of crystalline quartz served to carve and incise fine details [1970:104-105].

In addition to these sculptures are bowl-like vessels, sometimes

plain, and sometimes carved:

[Evidence of stone vessels:]

Characteristic of the Marpole phase, moreover, are numerous stone vessels, some perhaps mortars, of lava, granite and other rock. Many are plain, some are embellished with simple geometric designs, and again others are zoomorphic or anthropomorphic.

[Evidence of manufacturing methods:]

Pecking, abrading and incising were the main techniques

employed in the creation of such utensils [1970:105].

Borden turns to evidence of ornaments in Marpole assemblages.

[Evidence of frequency and density:]

An abundance and great diversity of beads and pendants of many different materials add luster to the Marpole phase.

[Evidence of less frequent finds:]

Gorgets and labrets are occasionally encountered and even ornaments of native copper.

[General statement of evidence of imported raw materials:] Many of the materials used in ornaments and other manufactures are obviously imports.

[General hypothesis of trading in Marpole phase:] Indications are that the people of the Marpole phase were active traders [1970:105].

Borden presents new evidence, perhaps indicating wealth emphasis, in this next argument. 
[Evidence of disc beads:]

A cache of over 20,000 disc beads was discovered near

the western limits of the Marpole settlement.

[Evidence of manufacture of beads:]

Since each individual bead represents a considerable investment of effort, skill and time,

[Hypothes is of wealth represented in cache:]

such a cache must be regarded as a significant concentration of wealth [1970:105].

This hypothesis gains in prior probability in view of ethnographic emphasis on wealth. Borden examines alternative hypotheses relating these beads to the rest of his interpretation of the material remains in this assemblage. Then he adds evidence from burial remains to explore the alternatives. His use of the word "surplus" may reflect analyses in Northwest Coast ethnographic 1iterature.

[Statement of problem:]

In what manner was such surplus wealth accumulated?

[First al ternative hypothesis:]

Were the beads a medium of exchange in trading,

[Second alternative hypothesis:]

or were they intended to be displayed and distributed during potlatch-like festivals?

[Evidence of differential burials:]

The dead were buried on the inland slope of the village midden. While most burials are rather simple affairs, a few are lavishly furnished with ornaments and other grave goods.

[Evidence of differences in skull deformation practices:] Artificial deformation of the skull is fairly common, but it is of interest that not all skulls have been treated in this manner.

[Hypothesis, stated as tentative, of social status significance of differential deformation evidence:]

It is uncertain, however, whether such differences in the treatment of the dead and in skull deformation should be taken as indicating differences in social status.

[General statement of possible future testing of following hypothesis:] 
Perhaps future work will produce firm evidence indicating that

[Hypothesis of (Marpole) considerable time depth for wealth and rank emphasis:]

wealth emphasis and ranked society have considerable

time depth on the Northwest Coast [1970:105].

I asked Dr. Borden if there was additional information of this bead cache. He responded that at a site nearby, on the stream a few hundred yards to the west, a similar cache has been found. These are the same kinds of beads as those found singly in the Marpole deposit. (There have been no beads found at 01d Musqueam.) Similar caches have been found elsewhere, for instance, at Horseshoe Bay, while a path was being built, they were scooped up by the quartsfull (Borden, pers. comm., July 6, 1974).

Interrelationships of Marpole and Other Areas and Phases

Borden concludes the discussion of this culture with a series of hypotheses relating it to other phases. He does not specifically mention the Baldwin phase. I had expected to find this more explicitly brought out because of the Baldwin/Skamel relationship and the Marpole/Whalen II relationship stated in the Lower Mainland paper and in his discussion of symposium papers (1968a:20; 1969d:256). In the Whalen II discussion in the present paper, the Baldwin and Marpole similarities are not stressed.

Borden's emphasis here is on the Eayem-St. Mungo Cannery relationships as confirming instances of his local developmental hypothesis, since Calvert's evidence is from a site between the Esilao village and the Marpole sites.

[Hypothesis of Marpole as climax of development:]

The Marpole phase of the Fraser delta region appears to represent a climax of long cultural development. 
[Hypothesis of Eayem and St. Mungo cannery as earlier aspects of this local development:]

Basic affinities of the Marpole culture with both the Eayem phase (ca. 3500-1000 B.C.) in the Fraser Canyon and with the early component at the St. Mungo Cannery site (which is contemporary with the Eayem phase) in the eastern part of the delta suggest that this was essentially a local cultural development.

[Hypothesis that Marpole is climax because of diversity and ornamentation:]

However, many of the cultural features that lend diversity and glamour to the Marpole culture are not yet present in either the Eayem phase or in the early assemblage at St. Mungo.

[Hypothesis of external stimulus of climax features:] obviously, strong external cultural stimuli from diverse directions played an important role in generating the cultural efflorescence of the Marpole phase

[Hypothesis of later northerly instances:] with its many features that are generally regarded as characteristic of classic Northwest Coast culture of more northerly coastal peoples in recent times.

[Hypothesis of Marpole as southern climax:] A cultural intensity and complexity was attained in the Marpole phase which on the southern part of the coast was neither maintained nor reached again in later periods $[1970: 105,107]$.

Borden's hypothesis on external stimulus at Marpole is almost identical to his earlier hypothesis of the Baldwin phase:

The interaction of local cultural tradition with widely varied alien influences during this period appears to have generated a cultural efflorescence which is reflected in many remarkable non-utilitarian artifacts [Borden 1968a:16].

This is another facet of Borden's presuppositions of culture change, especially of its climax periods.

IV. WHALEN II PHASE ca. A. D. 350-800

Borden's basic hypotheses in this section are these: Whalen II represents an intrusive population, a significant change; the slate 
grinding industry, absent in this phase, must have had continuity elsewhere at this period; and Whalen II is a synthesis of some earlier distinct phase characteristics. No additional excavated components of Whalen II have been found. Borden has collected surface finds similar to this assemblage, and fears that sites have been destroyed which may have contained such components (Borden, pers. comm., June, 1974).

Borden begins with evidence of change in the recent deposits of the Marpole and Beach Grove sites:

[General hypothesis of significant change:]

Towards the end of the Marpole phase, there are hints of historic[important] events which were to be of great consequence for the future development of the delta and probably of other parts of the lower mainland.

[Statement of main component of Whalen II phase:] Our main source of information concerning these new developments is the upper cultural horizon at the Whalen Farm site [1970:107].

Borden's most extended account of this excavation is in his second publication (1950b; see Fig. 2, p. 34). In the present paper he correlates the radiocarbon determination for Whalen II with the most recent Marpole dates:

[Radiocarbon and stratigraphic evidence:] C-14 analysis of charcoal from well above the bottom of the Whalen II deposit gave a date of A.D. 396.

[Hypothesis of initial time of phase:]

The beginnings of the phase are therefore probably somewhat earlier.

[Correlation of Beach Grove and Whaten II dates:] As shown on the chronological chart, (Fig. 29) two C-14 dates on samples from late Marpole phase deposits at Beach Grove fall well within the time of the new phase,

[Hypothesis of interrelation of phases:] suggesting the persistence of the Marpole culture in some parts of the delta even after the appearance of Whalen II groups in the region [1970:107]. 
Borden stresses the change in assemblages with a list of absences from this assemblage, not just of artifacts, but of complexes, and traditions, and then with a list of elements that had not appeared in earlier phases that are present here. These new elements correlate with artifacts of the Skamel phase in the Fraser Canyon. This is

Borden's argument and his hypothesis derived from it.

[Hypothesis, with evidence, that Whalen II distinction is in missing complexes and traditions:]

Among the most prominent aspects of the whalen II assemblage are first of all negative traits, that is, the absence of certain complexes and traditions, such as ground slate artifacts, stone bowls and stone carving which were well established earlier at the mouth of the Fraser.

[Hypothesis that the following are distinctively new in the region:]

On the other hand, a series of elements hitherto unknown in the delta suddenly appear. Among these are microblades, Olivella beads, and new types of chipped projectile points, particularly side-notched and corner-notched arrow heads with expanding stem.

[Hypothesis correlating these traits to traits new to the Fraser Canyon earlier:]

The appearance of somewhat similar points and other new traits in the Fraser Canyon several centuries earlier, terminated the Baldwin phase in that part of the valley.

[Hypothesis of a new ethnic population as bearers of the new traits:]

Perhaps these sudden breaks in cultural developments are somehow linked with the movement of new ethnic groups into the lower Fraser region $[1970: 107,109]$.

Borden hypothesizes that Whalen II synthesizes traits not common

to both the Locarno Beach and Marpole assemblages.

[Hypothesis of fusion of earlier complexes:]

Interestingly, the break with the past was not complete. In the Whalen II assemblage one may discern the beginning of a fusion of elements and complexes that were present in either the Locarno Beach phase or the Marpole phase, but which these two earlier cultures did not share [p. 109].

These earlier traditions are the composite toggling harpoon from Lo- 
carno Beach, and the woodworking triad from Marpole. There is ev-

idence of large post holes, so that Borden repeats,

[Hypothesis of plank houses and dugout canoes:]

...the Whalen II people lived in spacious plankhouses, and we may reasonably assume that they had dugout canoes capable of navigating the waters of Georgia Strait [ $p$. 109].

Borden repeats the evidence presented in 1958a of the sculptured haft of a beaver tooth carving tool, of 01 ivella beads, and imported Oregon obsidian. He adds a new hypothesis to the discussion of the absence of slate grinding.

[Hypothesis of importance of slate grinding absence, repeated:]

Among the most striking contrasts between Whalen II and the Marpole and Locarno Beach phases is the complete absence of ground slate artifacts in the Whalen II assemblage.

[Evidence of abrasive technique in this assemblage:]

Though these people expertly employed abrasive techniques on adze blades and in other manufactures

[Presence of chipped artifacts:]

they persisted in using chipped projectiles and knives.

[Hypothesis of continuity of slate grinding tradition in other delta sites:]

But the ground slate industry must have been firmly entrenched among other groups of this region

[Evidence to support previous hypothesis:]

for among the later Coast Salish of the Strait of Georgia the grinding of slate for knives, projectiles, harpoon cutting blades, etc. had gained nearly complete ascendancy over chipping [1970:109-110].

I asked Borden if there were any newly discovered sites for this period. He referred me to a preliminary report by Charlton (1972:esp. $146,149,154)$, of excavation at the Belcarra Park site DhRr6, on Indian Arm, a northward extension of Burrard Inlet, which confirms this last hypothesis (Borden, pers. comm., 1973). Charlton's site will be 
important in testing Borden's Pre-Stselax phase hypotheses as well.

\section{PRE-STSELAX PHASE}

This is Borden's entire presentation:

[Negative evidence:]

infortunately, we have as yet no reliable data for the centuries immediately following the Whalen II phase, that is the time from about A.D. 800-1250.

[General statement of evidence from surface and from last phase:]

But surface finds from a site, probably dating to this period, and the cultural assemblage of the last major stage in the culture history of the Fraser delta

[Hypothes is of period of synthesis:] suggest that this intervening period was one of continuing synthesis. The amalgamation of old and new elements eventually led to the final prehistoric culture phase of the delta region: the Stselax phase.

[Postulated name for hypothesized stage above:]

For the time being, I am proposing the provisional term "Pre-Stselax" to denote the postulated developmental stage which intervened between whalen II and the final phase $[1970: 110]$.

Charlton's publication about the Belcarra Park site gave no radiocarbon dates, so I asked Borden if this site filled in the Pre-stselax gap. He replied that it did, with a date of about 800 A.D., and with ground slate all through this deposit, particularly ground slate knives (Borden, pers. comm., July, 1974).

\section{STSELAX PHASE ca. A.D. 1250-1808}

Although there are few new hypotheses in this section of the paper, Borden presents interesting new evidence. This evidence comes from excavations at Stselax Village, a settlement visited by Simon Fraser on July 2, 1808, and still inhabited today. It is on the 
Musqueam Reserve, near the mouth of the North Arm of the Fraser River. Only the mortuary house component at Musqueam Northeast belongs to the Stselax phase. Borden reports that the Village site is still the only excavated Stselax phase site on the mainland. However, in the Strait of Georgia and on Vancouver Island there are sites of the same age with a similar culture. Roy Carlson has designated these variant but similar culture assemblages The San Juan Phase (Borden, pers. comm., July, 1974).

Borden repeats from earlier reports his evidence for the beginning of the settlement at Stselax Village.(Fig. 13)

[Radiocarbon evidence:] Analysis of charcoal from near the bottom of the village deposits gave a C-14 date of $660 \pm 130$ B.P.,

[Hypothesis of original settlement:] suggesting that the settlement had its beginning about A.D. $1250[1970: 110]$.

Borden hypothesizes on the basis of surface collections that this is typical of recently used sites on the reserve.

Three traditions from the delta combine in this phase:

[Hypothesis of continuity from Whalen II:] Persisting in the Stselax phase are the two old Fraser delta traditions which had first merged in whalen II: (a) sea mammal hunting and fishing with composite toggling harpoons and (b) large scale woodworking.

[Hypothesis of continuity in slate grinding industry:] Added to these two complexes is now that other ancient delta tradition: the s.late grinding industry [1970:110].

A new type of toggling harpoon is added to the earlier composite type.

[Hypothesis of continuity with Locarno Beach type, with new type of blade:]

The slotted composite toggling harpoon heads with well defined lashing groove, which were first encountered in the Locarno Beach phase are now armed with triangular 


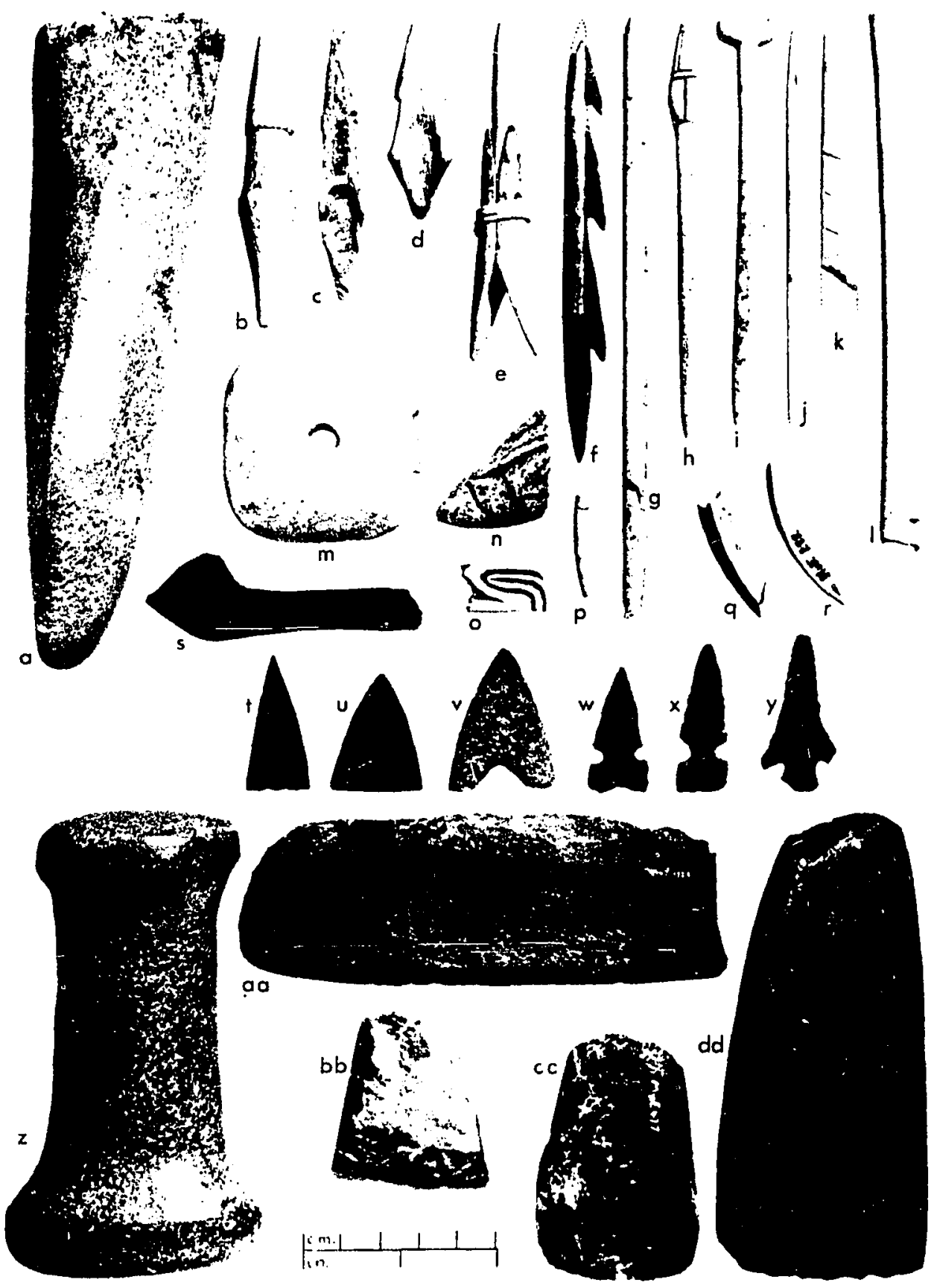

Figure 13. Artifacts typical of Stselax phase (1970:108 Figure 33). 
ground slate cutting blades.

[Evidence of great frequency:]

Valves of this type of harpoon head and triangulcir slate points are numerous at Stselax [pp. 110-111].

[Hypothesis that new type was a Pre-Stselax introduction:]

In addition, a new variant of composite toggle head occurs, which may have been introduced during the PreStselax phase [Borden 1970:111].

This new type is present at Belcarra Park, confirming this

hypothesis (Borden, pers. comm., July, 1974).

[Description of the new type:]

Generally smaller than the preceding, this new type consists of two valves without lashing grooves. The anterior portion of each valve is channeled on the ventral side so that when the two valves are fitted together a deep socket of small diameter results, into which a slender bone point is inserted.

[Ethnographic evidence for use of new type:]

According to ethnographic evidence, this new type was used primarily for taking salmon,

[Ethnographic evidence for use of older type:]

whereas the other usually larger and sturdier composite toggle head served to harpoon sea mammals and very large fish, such as sturgeon [1970:111].

These last two pieces of evidence lend weight to Borden's Marpole hypothesis that the various barbed harpoons were also speciesspecific. Borden's description of knives and other artifacts is enriched by ethnographic evidence, based on the statement appearing both in 1968a and in the present paper (1970:112), that there seems to be no archaeologically detectable change in the deposit. Therefore ethnographic evidence may be used with high probability of accuracy to interpret the use of all the artifacts of this assemblage. For instance, as he begins the discussion of stone tools, Borden says that the knives were used to butcher fish. 
[Evidence of knive formation, with ethnographic evidence of use:]

Rectangular ground slate knives, used in butchering

fish, resemble Marpole phase specimens of similar

shape. They are thin, of even thickness and usually

ground over the entire surface.

[Minor occurrence of stone chipping:]

The practice of stone flaking has declined to minor significance.

[Evidence of types that are found:]

Only a few side-notched and corner-notched points are present.

[Negative evidence of microblades:]

Completely gone are microblades.

[Evidence that microblades had been a tradition:]

The only hint of their former presence may be seen in vestigial blade-forms carved along the side of slender bone points [1970:111].

This is a rare piece of evidence, one of my favorites in Borden's work. It is an instance of the decorative use of utilitarian features toward the end of a tradition.

Borden's woodworking analysis includes a brief description of

Coast Salish house construction, and the use of canoes in recent times.

[Hypothesis of continuity of large-scale woodworking:] Large-scale woodworking continued to flourish in the Stselax phase, and it was still practised with that same complement of basic tools already attested for the Marpole phase.

[Description of Coast Salish house:]

These relatively simple implements enabled the Salish to ready the materials for the construction of large rectangular houses, often several hundred feet in length by sixty feet deep (front to back) and from twelve to fifteen feet high. The Coast Salish houses were of the shed type, that is they had a single-pitch roof, the front, which faced the water, being somewhat higher than the rear.

[Hypothesis of importance of dugout canoe:]

Another important product of the woodworking industry were dugout canoes. 
[Description of use of canoes:]

These seaworthy craft provided efficient transport

which enabled the inhabitants of the village to main-

tain contacts with distant groups in the Strait of

Georgia and farther up the river [Borden 1970:111].

Borden's account of different artistic activities among the

Coast Salish includes an important additional source of evidence.

Borden begins with artistic artifacts not found or rarely found in the

Stselax assemblage:

[Negative evidence of stone carving:]

No examples of stone carving turned up in the excavations.

[No occurrences, or rare occurrences of other decorative

items: beads, etc.: ]

Striking, moreover is the paucity of personal ornaments

in the Stselax assemblage. Lacking are not only Olivella

beads, that had made a brief appearance in the delta dur-

ing the Whalen II period, but virtually all the other types

of beads, pendants and decorations which had added lustre

to previous phases $[1970: 111]$.

There is evidence of artistic activities and products not found for

earlier delta phases:

There are, however, certain traits which have not been attested for earlier periods.

[Genera] statement of ethnographic evidence:]

Thus, ethnographic data on spinning and weaving of mountain goat and dog wool

[Confirmatory archaeological evidence and interpretation: ]

are supplemented by archaeological evidence from Stselax.

Horn cores of mountain goats, microscopic spores of a

rare alpine moss in house floor deposits

[Hypothesis:]

(the spores probably carried in on the fleeces of moun-

tain goats),

[Evidence:]

and decoratively carved spindle whorls of whale-bone tes-

tify that these textile arts were practised centuries ago.

[Evidence of frequency, and hypothes is of pin use:]

Fairly common, moreover, are gracefully formed and 
embellished pins of wapiti antler which probably served for pinning together woven woolen blankets worn over the shoulders [1970:112].

I asked Borden about the moss spores. A student analyzed them, and Borden had suggested the interpretation. This glimpse at further levels of analysis suggests the richness of Borden's planned future work.

Burial practices are unlike those of earlier phases.

[Statement of earlier phase burial practice:]

While in all the preceding periods inhumation was the rule,

[Evidence of recent burial practice:]

the inhabitants of Stselax and of other Coast Salish settlements commonly disposed of their dead by wrapping them in mats or blankets and placing them in mortuary houses a short distance from the village.

[Hypothesis that negative evidence supports continuity of mortuary practices throughout this phase:]

The general absence of burials in the Stselax deposits suggest that mortuary houses were in use throughout most of the occupancy of this site [1970:112].

Borden concludes with his hypothesis of cultural stability during this phase, and a description of the relative depth of historic

and prehistoric deposits at this site.

[Hypothesis of Stselax stability:]

Coast Salish culture during the Stselax phase appears to have been remarkably stable.

[Negative evidence to support previous hypothesis:]

No obvious changes are discernible archaeologically until

the advent of historic times [p. 112].

Borden states that some decades passed after Simon Fraser's visit before the white man's culture had a profound impact.

[Evidence of midden depth of prehistoric and historic periods: ]

Archaeologically, the historic period is confined to barely more than the topmost one foot of the occupational deposit, which in places attains a depth of more than eleven feet. 
[Archaeological evidence of historic period:]

The full historic period is ushered in by the appearance of facetted and spherical trade beads of blue glass, copper foil, clay pipes, gun flints, iron files, and later by a host of other articles of Caucasian origin which increasingly replaced the artifacts of traditional Indian manuf acture [1970:112]. 
CHAPTER XLI

1972 NEW RADIOCARBON DATES FROM

THE SOUTH YALE AREA ...

\section{INTRODUCTION AND BACKGROUND}

This article's co-authors are R. W. Mathewes, Department of Botany, University of British Columbia, and G. E. Rouse, Department of Botany and Geology, University of British Columbia. It is published in the Canadian Journal of Earth Sciences. Mathewes, the botanist co-author, should be clearly distinguished from W. H. Mathews, head of the Geology Department of the University of British Columbia, with whom Borden had consulted for many years.

In 1968, Borden sought to establish, by a variety of indirect evidence, that the Fraser Canyon at the South Yale site was ice-free and not uninhabitable on account of ice, by 11,000 B.C. (Borden 1968b: exp.64-68). He was seeking to establish that time as within possible limits for the Pasika culture on the present South Yale terraces. In the introduction to my analysis of that 1968 paper, I discussed the 1966 letter from W. H. Mathews, (not the biologist but the geologist) to L. S. Cressman, Department of Anthropology, University of Oregon, in response to Cressman's request for the geologist's opinion of the ice limits, temporal and geographic, of the Sumas stade.

Mathews, geologist, wrote his opinior of the ice level both in relation to late Sumas times after the Sumas climax, and also in 
relation to the Sumas Climax. Mathews' interpretation of the data would

...place ice levels in the Fraser Canyon from Hope (15 miles north of Greendrop Lake) northward substantially above the 3400 foot contour in late Sumas time .... probably all the Fraser River, at least from Prince George or Quesnel on the north to Mission on the south, would have been under ice at the Sumas climax--not just diverted, but buried. Recognized diversions into Kamloops Lake and Okanagan occurred after the Sumas Climax, rather than in the Vashon stade [W. H. Mathews in August 4, 1966 letter to Cressman with copy to Borden].

This late Sumas time was thought by geologists in the 1960's to be about 8000 B.C. (Borden pers. corm., June, 1974).

Borden's 1968b argument was contrary to Mathews' (the geo10gist's) position. In the manuscript from which Borden prepared his 1968b paper, he had written that Mathews' data probably pertained to the Vashon stade rather than the Sumas Climax, pushing the ice-free period in the Fraser Canyon back 2,500 years to about 10,500 B.C.

In the 1968 paper, Borden's indirect evidence was of two general sorts. First, he reasoned by analogy from adjacent areas. Part of this evidence was based on:

Radiocarbon dates on marine shells from various parts of Puget Sound and Georgia Strait and on limnic peat from recessional lakes and ponds in the southern and northern Puget Lowland indicate that the Cordilleran ice sheet had vanished from these parts more than 13,000 years ago $(11,000$ B.C.), that is, before the recognized date for the end of the Vashon Stadial and prior to the ensuing Everson Interstadial... [Borden 1968b:64].

The other evidence supporting Borden's argument by analogy is in his analysis of the geological deposition of the Chilliwack floodplain. Borden hypothesized that "...climatic and environmental developments in the two neighboring river valleys were closely parallel"(p.64). 
The second line of indirect evidence was from the dated Milliken deposits, and the correlated river levels between the Fraser at the Milliken site and at the South Yale site.

In the intervening years, Borden sought to confirm either his position or Mathews' position with direct evidence from the Fraser area immediately adjacent to these two archaeological sites. As part of the South Yale archaeological project, this direct biological-radiocarbon evidence was obtained. The present paper gives the results.

\section{BORDEN'S CANYON SEQUENCE}

This is Borden's setting for the botanical research:

An archaeological sequance dating back to at least 9000 \pm 150 B.P. (S.113) was established by Borden $(1965,1968)$ from two excavations approximately $2.5 \mathrm{mi}(4 \mathrm{~km})$ upriver from South Yale in southwestern British Columbia. Using radiocarbon dates from these sites, and evidence from pebble tool collections from river terraces at South Yale, Borden (1965) suggested that Indians could have occupied the Lower Fraser Canyon region several millennia before 9000 B.P. [1972:1055].

\section{EVIDENCE FROM PINECREST AND SQUEAH LAKES}

The next section presents the evidence of three core samples from basal lake deposits at two lakes about six miles downriver from Yale, at elevations of $320 \mathrm{~m}$ and $205 \mathrm{~m}$ above sea level. The basal radiocarbon dates are among information presented in Table 1, page 1057, and are as follows: 
Sample

Radiocarbon age. Yr. B.P. error $=1$ $I=$ Teledyne Isotopes

Pinecrest L. no.1

$11000+170$

$(I-5346)$

Pinecrest L. no.2

$11430+150$

$(1-6057)$

Squeah L.

$11140+260$

$(I-6058)$

[General evidence obtained:]

As part of the South Yale archaeological project, one of us (RWM) collected sedimentary cores for pollen analysis and three basal samples for radiocarbon dating from two small lakes in the Yale area....

[Specific site of samples:]

Pinecrest L. (Lake) sample no.I was taken from the side of a floating dock approximately $10 \mathrm{~m}$ out from the shoreline.

Pinecrest L. sample no.2 and the basal Squeah L. sample were recovered from the deepest portions of the lakes as determined by prior soundings with a chain and disc....

[Hypothesis of best evidence:]

The deep water samples represent a thicker and more complete sequence of sediments than those from sloping shoreline areas. Therefore, the older date (11 $430 \pm 150$ ) for Pinecrest L. sample no. 2 is considered to be more representative of the earliest organic sediments than sample no. $1(11000 \pm 170)$.

[Limits of evidence of underlying material:]

All three cores were underlain by a blue-gray clay contalning little organic material. The total depth of clay and the time required for its formation are unknown.

[Base of sample:]

The dated samples overlying the clay are all based on a $10 \mathrm{~cm}$ section of sediment core,

[Consequence of sample range:]

and if it were practical to sample only the first formed organic material, older dates than those reported would result.

[Hypothesis relating radiocarbon dates to beginning of deposition:] 
The dates obtained therefore give the minimum age for the beginning of the accumulation of abundant organic matter in the lake basins, including spores, pollen grains, algal cysts, and heterogeneous fragmentary detritus [1972:10551056].

A11 cores contain an ash layer which is being tested to confirm the hypothesis that it is Mt. Mazama ash.

\section{INTERPRETATIONS}

The data derived from the sample from the sloping edge of Pinecrest Lake

...has already been cited by Roberts and Mark (1971, p. 1168) in connection with a discussion of problems in interpreting the Sumas Stade in the Sumas area of the Fraser Lowland (Armstrong et al. 1965).

[Basic hypothesis interpreting data for ice-free condition:] The three new dates, when considered together, now indicate that ice-free conditions existed in the region of, and at the same elevations at Pinecrest and Squeah lakes, as early as $11430 \pm 150$ and $11140 \pm 260$ years ago respectively.

[Hypothesis, based on previous hypothesis, of probable Fraser Canyon conditions:]

This allows for the possibility that the Fraser Canyon below the $205 \mathrm{~m}$ leve1 of Squeah $\mathrm{L}$. may also have been icefree at this time, and that Indians could have occupled the area as far back as 11430 B.P.

[Hypothesis of conditions which could have prevented canyon occupation:]

At the same time, however, the dates do not rule out the possibility that an ice tongue, ice-dammed lake, or an estuary controlled by a relatively high sea level occupied the bottom of the Fraser Canyon (approx. $100 \mathrm{ft}(30 \mathrm{~m})$ above sea level) below the elevation of Squeah $I_{\text {. }}$ during this interval. If this were the case, Indians would of necessity had to inhabit the areas above the canyon bottom [1972:1056].

With this firm evidence in hand, more hypotheses need to be formulated. The problems are outlined:

[Problems of South Yale terraces:] 
These new dates also point out the necessity for reevaluation of the processes summarlzed by Borden $(1965,1968)$ regarding the mode of formation and chronology of the artifact-bearing South Yale terraces.

[General problem of post-Vashon chronology:]

Their ages and origins are difficult to determine because

little is known of post-Vashon stratigraphy and chrono1ogy in tile eastern portion of the Fraser Lowland. More information is available for the central and western Fraser Lowland (Armstrong et al. 1965, Fulton 1971) and two sets of dates have recently been given for this area: (1) Post-Vashon samples that have yielded 10 dates ranging from 12625 to 11450 yr B.P., and (2) Pre- and proglacial samples for the 'Sumas Stade' that average 11400 yr B.P. (Mathews et al. 1970) [1972:1056-1057].

The evidence in this paper does not clarify the more general problem, but Borden concludes that his interpretation of the evidence in Mathews' letter to Cressman was correct, that the last ice advance in this area was not in the time range that Mathews suggested but was 2,500 years earlier:

[Present data not crucial in post-Vashon chronology:] The dates reported here from the two lakes fall on the borderline of these two sets of dates and do not help to resolve the chronology of the phases of ice advance and retreat during late and post-Vashon times.

[Summary of evidence, re-stated:]

What they do indicate, however, is that there has been continuous sedimentation of plant debris since $11430 \pm$ 150 B.P. in Pinecrest L., and $11140 \pm 260$ B.P. in Squeah L.

[Borden earlier ice-free hypothesis, re-stated as confirmed for the elevations of the Lakes examined:]

Hence at the elevation of the lakes in the Yale area, the last ice advance and subsequent retreat must have occurred prior to this time [1972:1057].

At such time in the future when Borden has dates from the terraces themselves, he will have "best" evidence. Until such time, he has disconfirmed W. H. Mathews' hypothesis of ice burying this entire region at 8000 B.C. Borden's hypoihes is to date the Pasika complex 
from as early as 10,500 B.C., published in 1965, 1968b, and 1970 is increasingly probable.

Borden reports (pers. comm., June, 1974), that when he called W. H. Mathews to tell him the three new radiocarbon dates presented in this paper, Mathews replied, "Carl, you have opened a whole new can of worms!" 
CHAPTER XLII

\section{RECENT UNPUBLISHED PAPERS}

\section{INTRODUCTION}

Included in the wealth of data in Borden's unpublished material are two papers presented in recent years which bring his thoughts up to the date of this thesis. These are as follows:

Tentative Correlations of Archaeological Evidence with Linguistic Data in Pacific Northwest North America. Paper presented in 1970 at the Annual meeting of the Canadian Archaeological Association, Ottawa, at a lecture series in Victoria, and at the Northwest Anthropological Association meeting in Corvallis.

New Evidence Concerning Late Pleistocene and Early Holocene Population Movements from Asia into the New World. Unpublished manuscript of paper presented before the International Conference on the Bering Land Bridge, Arr. by the U.S.S.R. Academy of Sciences, Khabarovsky, May, 1973.

I have seen these in full, and Borden has given me permission to use whatever I may need from them. In addition, I have seen the section on the Namu site from another work in progress:

Radiocarbon Dating and Space Time Perspectives in Pacific Northwest Archaeology. [1974].

My intent in this thesis has been to explore within Borden's published works. the evidence and the hypotheses. with which he orders that evidence. In September, 1973, Borden and I. reviewed my out]ine of the hypotheses from his published material. At that time, and subsequently, he suggested additional publications that I had not thought pertinent, or of which I had no knowledge. In addition, however, he 
suggested that perhaps. I. should read thi.s. Khabarovsk paper. It so clearly rounded-out his published work that Borden allowed me to use i.t. A few months later, I spent another few days going over his material and the first section of this thesis., specifically to discuss the 1970 paper given in Ottawa, Victoria and Corvallis. Because archaeologists have discovered much new evidence pertinent to this paper since it was presented in 1970, Borden felt that he needed to bring each section up to date before it could be useful to me. With this in mind, we decided that I should record Borden's reading of this paper and our discussion of the evidence relating to it.

Both the 1970 and 1973 papers amend the $1969 \mathrm{c}$ paper on "Early Population Movements...". The 1973 paper does not propose any corollary linguistic hypotheses, but gives new evidence of early man in the New World, presented to further substantiate the intermontane corridor route west of the Rockies. This evidence extends all the way to Mexico, and specifically west, rather than east of the Continental Divide. Borden presents evidence of early dates in South America as well. The new evidence of a coastal movement in early Holocene times south of Icy Strait appears in both the unpublished papers, so that a revised map of population movements (Fig. 14), shows arrows from the Alexander Archipelago through the Queen Charlotte's to Namu on the mainland opposite northern Vancouver Is.land.

\section{1970 PAPER}

Mosan Linguis.tic Argument

The paper that Borden read at the three 1970 meetings was "sort of a trial balloon" (pers. comm., 1974), so that other scholars might 


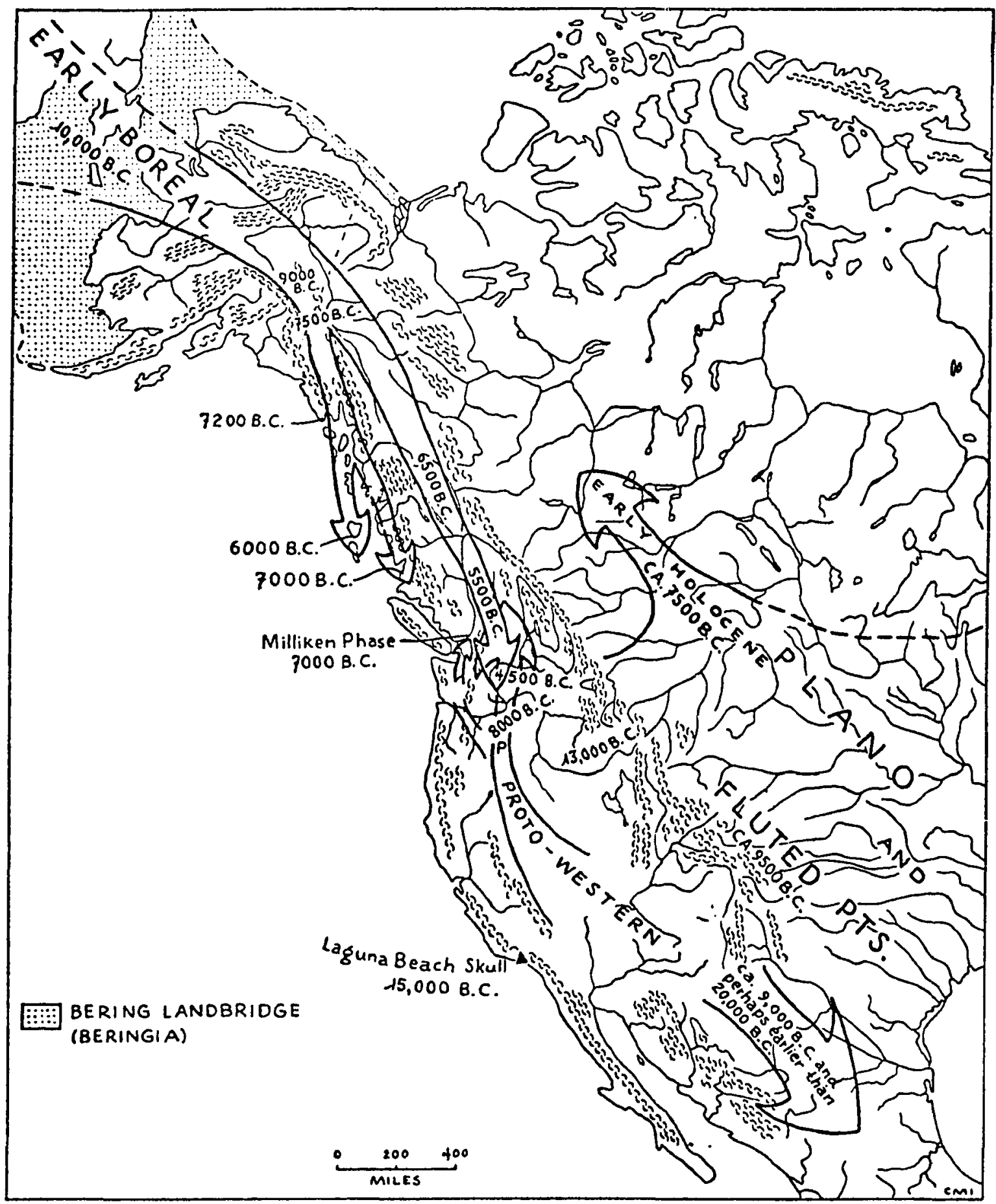

Figure 14. Major archaeological traditions in western North America (Borden 1973 ms.). 
have a chance to criticize i.t, shoot i.t down, and amend it. "Teritative Correlations...." s.tates its speculative character. This. is Borden's. first series of hypotheses relating to the major linguistic groups in the Northwest area since his 1954 paper. He had not reviewed that earlier publication until he was preparing this 1970 paper, and $w$ as amazed to find that he felt he was probably on the right track in 1954, "and on the basis of such slim evidence."

Borden reviews his 1969c "Early Population" paper in which he hypothesized that the Athapascans had brought the Early Boreal microblade culture to the Northwest Coast. After giving linguistic evidence that the Athapascan linguistic divergence was too recent for this hypothesis, he suggests another basic problem with his protoAthapascan theory. It had not accounted for the Wakashan, Chimakuan, and Salishan groups which constituted the "major population mass" in the area. If the early linguistic theories postulating a Mosan phylum encompassing these three linguistic groups is correct, and if Swadesh is even generally correct in the suggestion from glottochronology that these language families diverged about 9000 years ago, then a question of an early Mosan homeland may be raised.

Microblade Evidence and Glaciological Evidence

From two other, distinct and separate sources of evidence, Borden suggests that a people with a culture ancestral to Wakashan, Chimakuan, and Salishan cultures may have lived north of the 60th parallen before 9500 B.P. One 1 ine of dated evidence connects the microblade component at Icy Strait with dated sites in the interior, such as Healy Lake. The other is glaciological data suggesting the time of the opening of the northern part of the intermontane corridor and the 
opening of an access route to the northern Northwest Coas.t. Until about 11000 years ago, movement either west or south from the Southwestern Yukon Territory was not possible. At some time before 9500 years ago, mcreitient in both directions became possible. The people who inhabited the Healy Lake site emphasized big game hunting in the earliest, 11000 B.P. component, but by 9000 B.P., there had been a shift toward the smaller game, and fishing and fowling had become important. This is a microblade site (Cook 1969).

The next evidence of microblade sites is to the west on the coast, the Ground Hog Bay II site at Icy Strait (Ackerman 1968). Borden suggests that ancestors of the Wakashan and Chimakuan language groups may have first settled the Alexander Archipelago, then perhaps the Queen Charlottes. Fladmark had found microblades in an early component on the Graham Island site in the Queen Charlottes. This component was not yet dated, and Borden hypothesizes that these may be as early as 6000 B.P. Borden notes that by 2500 B.C., the Yuquot site about a quarter of the way down the west coast of Vancouver Island was occupied.

From the early date at Icy Strait, and from these other coastal sites, Borden most tentatively hypothesizes the southward movement of Chimakuan-Wakashan ancestors.

From the space and time distribution of the microblades in the intermontane corridor, he hypothesizes that it was the proto-Salishan people who expanded to the s.outh as. the Cordilleran glacier receded. Borden specifically discusses linguistic evidence to the contrary (Jorgensen, 1969; Suttles and Elmendorf 1962), who consider it 1ikely that the Salish homeland is to the south and west rather than to the 
north and east. Borden finds great time depth in the interior for the present Salish and their presumed antecedent culture, which seems to blend with this early microblade tradition, with its north to south time gradient. In acknowledging the lack of current linguistic evidence corroborating the classification of a Mosan phylum, Borden adds this statement, [my emphasis]:

Swadesh's evidence has been criticized, but no linguist has yet demonstrated that the Mosan hypothesis is worthless. If it appears to mesh with accumulating archaeological data, it would be irresponsible to ignore it [1970 manuscript, from tape].

Recent Research on Dated Components

Borden's 1973 paper includes the dates for Fladmark's early component. The dates are about 2000 years older than Borden's 1970 hypothesis of 6000 B.P., above. This is Borden's 1973 discussion of the population movement which in 1970 he had proposed might be related to proto-Wakashan peoples. After presenting Ackerman's Icy Strait evidence, Borden writes:

These are new discoveries, and many gaps remain to be filled in, but indications are that these Early Boreal groups readily adapted to the rugged maritime environment and spread with astonishing rapidity southward along the coast. It appears that prior to 8000 B.P., some groups had reached the Queen Charlotte Islands (Fladmark 1971). Even earlier, others had pushed still farther south to Namu, a site on the mainland coast a short distance north of the northern end of Vancouver Island. A charcoal sample obtained from the lowest cultural horizon at Namu was dated $9140 \pm$ 200 (GaK-3244). Microblades constitute a prominent part in this early component (J. Hester, pers. comm ; 1970; Luebbers 1971) [Borden 1973 manus.cript pp. 16-17].

Interpretation and Discussion

Borden interprets this evidence of early populations with microblade technologies as lending support to his. 1970 hypothes is of an early Wakashan movement down the coast. 
As. we discussed these papers., Borden described to me how he imagined this movement from the Southwestern Yukon, where cook has evidence of salmon fishing 10 000 years ago, to the Icy Strait site. I will paraphrase the conversation:

Salmon, though important, edible and nutritious, would not be in prime condition by the time they were caught far up river in the Southwestern Yukon Territory. Imagine the inland group probing in all directions, exploring the newly deglaciated territory. Imagine finding prime salmon in these short coastal streams. If these early people had boats, as they almost surely did, i.t would not take long to exploit the region of the Alexander Archipelago, and the adjacent main1and. Perhaps this is where the Wakashan's forged out their early maritime adaptation. From the southern part of this Archipelago, Graham Island in the Queen Charlotte's is visible.

In this way, Borden elaborated his hypothesis from 1969d, contrary to Drucker's view that maritime adaptation would have to have been long, difficult, and learned from maritime people of long standing. In Borden's view, this riverine people, with a very flexible Mesolithic/Upper Paleolithic culture, could adapt to all kinds of niches, and thus. could make this transition quite easily.

After Borden's. presentation of the 1970 paper in Ottawa, Cybulski, physical anthropologis.t, commented that Borden's hypothesis might help explain Cybulski.'s findings. These seemed to show that the Wakashan and Salish speakers were not physically different. There were differences, Cybulski found, between the Haida speakers on the Queen Charlottes and the adjacent Coast Tsimshian speakers. 
The Penutian Question

Borden's. 1970 paper expands on the suggestion he made in discussing MacDonald's work in the Coast Tsimshian area. Borden felt that "somehow, someday", archaeologis.ts. would have to account for the Penutian speaking Tsimshians so far north of their nearest linguistic relations. In his published papers, Borden has traced the continuity from Cressman's early Dalles site to the early Milliken phase on the Fraser Canyon, then as a continuity up to the Baldwin phase. This Baldwin phase, similar to Marpole, he has seen in ethnographic Kwakiutl and finally (in 1969d), in middle and upper horizon coast Tsimshian assemblages. This, he suggests in 1970, may be a linguistic grouping as well, and if so, would be the Penutian tradition, which is ethnographically found in the Chinook, on the Columbia River from The Dalles to the ocean.

Borden wrote in 1970 that such a change in linguistic-cultural tradition might be archaeologically detectable in the areas between the Fraser delta and Prince Rupert. In his discussion of the Namu site (Borden 1974 ms.) Borden presents what he believes to be this evidence.

\section{The Athapascans.}

The Athapascan may have quite a different position in Northwest Coast prehistory from what Borden thought to be the case in 1969. After correlating the linguistic data on this language phylum, he remarks on the irony of his new. hypothesis.: with the expansion of the Athapascans., the use of microblades very likely came to a close in this area. 


\section{1973 PAPER}

In 1973 there is a new caution in Borden's use of Siberian data. He has consistently looked to Siberian sites for relationships with the formerly connected North American Sites. He continues to use the authority of Dikov (1968), as well as Cook (1969:278-279), to support the view that early Holocene populations were fishermen and fowlers throughout this area.

In a final passage of this paper, Borden stresses the lack of reliable information from Siberia:

In writing this paper, I have in general eschewed the temptation to derive the early peoples who came to the American Continent from any particular region in Asia, or to derive New World cultures from specific cultures on the opposite side of the Pacific. We simply do not yet have sufficient data to make such attempts worthwhile. The nearest we can come is to conclude that the quite recent Early Boreal cultures of the Arctic, Subarctic and the Pacific Northwest are closely related to contemporary cultures in Siberia, and to suggest that the Early Boreal cultures were probably spread in America, in part at least, through actual population movements by peoples forced to leave their former habitat on Beringia when the land bridge that linked the two continents was being submerged at the close of the Pleistocene.

When we probe further back in the past we are very much in the dark. Recent summaries of the Pleistocene prehistory of Siberia (Chart 1971: Klein 1971) stress the continuing paucity of pre-Sartan sites in Siberia and the lack of knowledge concerning the material culture of groups dating to the Karginsky and earlier climatic phases. Further, a recently published list of radiocarbon determinations on Pleistocene archaeological sites in Siberia (Klein 1971:141, Table 1) reveals only one accepted date of $20900 \pm 300$ B.P. (GIN117) for horizon C3(?) at Afontova Gora. Virtually all the others are relatively late Sartan in age and contemporary with the long list of dates on cultural components in North and South America in the 11. 000 to 14000 B.P. range and for which these relatively late Siberian cultures could hardly have been the antecedent.....there must be still undiscovered remains in the as yet little-researched areas of Siberia or elsewhere in eastern Asia whence the progenitors of the bearers of these early American cultures may have come 
[1973 ms. pages 19-20].

In this same 1973 paper, Borden speaks of the interrelation of knowledge on which each scholar must depend. With this quotation, Borden says explicitiy that the last word in archaeological fact is not attainable. The last word will always be an hypothesis:

This paper has attempted to gather together accumulating evidence of the early presence of man in the New World and to correlate this information with geological, paleontological and geographical data in order to determine when peoples originating in Asia might have crossed Beringia and arrived in Alaska, and by what route or routes they might have dispersed from there in the New World. In such attempts the archaeologist-prehistorian is to a great extent dependent on the findings of his colleagues in ancillary sciences. Unfortunately, like those of his own, their data often lack the detail and precision required for a reasonably accurate account of local or areal events, let alone the reconstruction of prehistory on a continental or even inter-continental scale. Consequently, the results of efforts such as the present one, represent no more than tentative constructs to be exposed to the criticism of competent colleagues in various disciplines in the hope that the resulting exchange of views will produce a new synthesis that will constitute a closer approach to the truth [Borden $1973 \mathrm{~ms} . \mathrm{p}$. 19]. 
PART IV

CONCLUSION

Reproduced with permission of the copyright owner. Further reproduction prohibited without permission. 


\section{CHAPTER XLIII}

\section{SUMMARY}

For the reader interested in a particular theory relating to the Northwest Coast and to its prehistory, the chart in the pocket of the back cover, and the outlines before each period serve as guides. The chronology of Borden's evidence and theory from 1950 to 1974 is spread out in the analysis of each paper for use in identifying those hypotheses dependent on more probable evidence, or less probable evidence, as additional experience seems to show. It is an instrument of research.

In the final quotation in the previous chapter, Borden writes of the interdependence of scholarly investigations, in more closely approaching the truth. The process of analyzing Borden's work has clarified for me the areas of his strength. I hope that other scholars who rely on Borden's evidence and interpretations will find it helpful in their work.

This "Summary and Conclusion" centers on four aspects of Borden's theory that I regard as particularly important, or of particular strength.

I. The scope and variety of his evidence.

II. His view of the use of models and hypotheses.

III. Some of the presuppositions underlying his work.

IV. His writings seen as a series of retroductions. 


\section{EVIDENCE}

\section{Ancillary sciences}

Borden's stated and repeated emphas is is on evidence. In the analysis of the 1969d paper (Chapter XXXIX), I pointed out the evidence that Borden added to the material from the papers he was discussing. In the last quotation from his 1973 paper, he emphasizes the ancillary sciences on which he must depend. The sequence of papers on the Pasika terraces (1965, Chapter XXXIII; 1968a, Chapter XXXIV; 1968b, Chapter XXXV; and 1972, Chapter XLI), is evidence of the interrelation of the study of soils, glaciers, radiocarbon analys is and archaeological theory in a particular problem. It jllustrates not only the place of glacial evidence in archaeology, but also the place of archaeological theory and evidence in glaciology.

Physical Anthropology

In addition to these "ancillary sciences", Borden uses evidence from all the branches of anthropology. He rarely uses specific evidence from physical anthropology (1954b, Chapter XIV). Much of the skeletal material recovered before Borden's time is of uncertain provenience, so it has little weight (Borden, pers. comm., 1974). He eagerly awaits the results of work being done today.

\section{Ethnographic Evidence}

Ethnographic evidence shows most clearly in the paper describing life at Marpole (1955, Chapter XVI), in the plateau papers (1952a, Chapter X; 1952b, Chapter XI; 1956, Chapter XVII), in his use of Duff's Upper Stalo in papers about the Milliken and Esilao Village sites, and 
in the background for the paper on the Skagit River atlatt. Historical Linguistics

Borden's use of historical linguistics has continued from his earliest papers up to the recent papers (1950b, Chapter V; 1954t; Chapter XIV; 1956, Chapter XVII; 1969c, Chapter XXXVIII; 1969d, Chapter XXXIX, 1970 unpublished paper, Chapter XLII). When we were discussing the unpublished 1970 paper, Borden spoke informally about his use of linguistic evidence. This is a portion of the conversation:

Borden: You should have been there [at Corvallis] with your tape recorder to get Bruce Rigsby's and Wayne Suttles' attack on the Mosan hypothesis!

Robinson: How did you respond?

Borden: I stood my ground. I told them, "Don't dismiss the estimate for the Mosan languages out of hand until you've tested it archaeologically". Now in response to Bob Butler who advised that archaeologists should disregard the findings of historical linguistics,--

Robinson: Is that what Butler says?

Borden: Oh yes, he took me to task for it.

Robinson: For using heterogeneous evidence?

Borden: Yes, yes, in other words, he didn't care whether the pieces of the different disciplines fitted together or not.

Robinson: You were an archaeologist; you should use that data.

Borden: But eventually I think all the data will have to fit together somehow. They're part of the same problem.

Robinson: It's up to the linguist to help you work within that field, just as it's up to the geologists to help sort out--

Borden: I draw on all the disciplines and also the various scientific disciplines.

Robinson: I don't think Butler would think you were wrong to use geological information or botanical information. 
Borden: He uses it all the time. What is more germaine actually to anthropology (and archaeology I always consider as part of anthropology), than linguistics?

Robinson: Yes, of course. I was talking to Joe Pierce... who questioned the conclusions of historical linguistics on the basis of mathematical limits that he thinks historical linguists have sometimes disregarded...relating to the genetic relation of languages... Maybe there's something like that that Butler feels isn't-..-

Borden: No.....He thinks a cobbler should stick to his last,-but I'm no cobbler.

Robinson: Because of the confirmation from the Indo-European languages....

Borden: I don't think we can assume offhand that the rate of change would remain constant throughout time, but it may average out to something.... and actually some of his [Swadesh's] results and of the varying results he got would depend on the basic vocabulary that he chose... I'm impressed by the relatively close correlation between for instance the historical evidence and the divergence of Germanic language,--fairly close correlation. It's plus or minus a few centuries. You can't expect any more than that. If you go way back into time, with the sort of thing that we are talking about, and we have the archaeological evidence of a group of a common culture diverged more than 9000 years ago,--well, we would expect relatively little similarity, with the exception of some people who may, at a later time, say the Bella Coola, have come in contact again.---Before the divergence was so complete that there was no mutual inte1ligibility anymore,--but it could have happened that they passed through along the intermontane region and down the coast at a relatively even speed and come out at that part of the coast and come in contact there. The differences would not be so great as they would have seemed to be after so many years had elapsed since then [Borden, pers. comm., 1973].

\section{Questions}

I cannot evaluate the evidence that Borden does not use. The one area that he fails to mention is the coastal shelf which may contain evidence of sites exposed when sea levels were lower. He feels there is insufficient evidence to deal adequately with this (pers. comm., 1974). Until his full reports are prepared, many questions will 
remain. Borden has stated that his aim is to accept all the data. The result of hypotheses based on all pertinent, heterogeneous evidence will be the development of a self-correcting system. I think this is the strength of Borden's approach.

\section{MODELS}

Mitchell and MacDonald use the concept of models in archaeology in the symposium papers discussed by Borden (1969d, Chapter XXXIX), but this concept is not used by Borden elsewhere in these publications. It may be helpful to clarify this concept, to see its relation to Borden's work, and to relate it to his comments in that discussion. Meaning and Use of Models

When scientific investigation involves a large body of data with many variables, it is useful to take these variables in turn, to examine how each one or each few, would function if the others were invariable. This abstraction is a model. It is not an hypothesis. Perhaps an example from population genetics would clarify this. I am selecting portions from Levins' Evolution in Changing Environments [my emphasis throughout:]

The attempt to consider genetic, demographic, environmental, and interspecific differences simultaneously immediately runs into technical difficulties. A precise mathematical description may involve hundreds of parameters, many of which are difficult to measure, and the solution of many simultaneous non-linear partial differential equations, which are usually insoluble, to get answers that are complicated expressions of the parameters which are uninterpretable.

We are clearly in need of a different methodology for coping with systems that are intrinsically complex [Levins 1968:5].

Among Levins' steps or "propositions" in this methodology are 
descriptions of models and their use, limits, and integration. These are his steps $3,4,5,6,7,8$, and 9 .

3. The basic unit of theoretical investigation is the model, which is a reconstruction of nature for the purpose of study. The legitimacy or illegitimacy of a particular reconstruction depends on the purpose of the study, and the detailed analysis of a model for purposes other than those for which it was constructed may be as meaningless as studying a map with a microscope.

4. A model is built by a process of abstraction which defines a set of sufficient parameters on the level of study, a process of simplification which is intended to leave intact the essential aspects of reality, while removing distracting elements, and by the addition of patent 7 unreal assumptions which are needed to facilitate study.

5. A sufficient parameter is an entity defined on a high level such as a population or a community which contains the combined relevant information of many parameters at a lower leve $1 . .$.

6 . There is no single, best all-purpose model. In particular, it is not possible to maximize simultaneously generality, realism, and precision. The models which are in current use among applied ecologists usually sacrifice generality for realism and precision; models proposed by those who enter biology by way of physics often sacrifice realism to generality and precision. The strategy which is followed in this book is the sacrifice of precision for generality and realism....

7. ....A theorem which can be proved by means of different models having in common the aspect of reality under study but differing in the other details is called a robust theorem. Therefore the presentation of alternative proofs for the same result is not merely a mathematical exercise -it is a method of validation...

8. A theory is a cluster of models and their robust consequences. The constituent models fit together in several ways:

(a) as alternative schemes for testing robustness;

(b) as partially overlapping models which test the robustness of their common conclusions but also can give independent results;

(c) in a nested heirarchy,...

(d) as models differing in generality, realism, and precision....

(e) as samples spanning the universe of possible models. 
9. The role of general theoretical work is the following:

(a) the identification of the relevant sufficient parameters as new objects of study.

(b) the fairly direct generation of testable hypothesis.

(c) the posing of problems heading to lower-level theories which generate testable hypothesis....

(d) besides prediction, a theory should offer plausable explanation of what we know. It is not necessary to derive the chemical properties of all macromolecules from quantum mechanical considerations, provided we can do so in a few cases and show that in principle it can be done for the rest. [Levins 1968:6-9].

The 1969d discussion described continuity, dislocation, and cotradition models. Borden protested vigorously Mitchell's intent to emphasize one model. Levins' sixth proposition is explicit: "There is no single, best all-purpose model". The eighth proposition describes alternative, overlapping and other model relationships which could, for example, be constructed out of Borden's various hypotheses about migration, diffusion or influence. In the ninth proposition, dealing with general theory, one section describes two of the tests that Borden used in evaluating the limits of the MacDonald and Mitchell mode1s. Borden suggested testable hypotheses and explanations that were outside the scope of their particular models. Yet he found that within certain time limits, the different models had explanatory value, and corresponded to the nature of the evidence.

Mitchell chose the continuity model over the discontinuity model in the absence of evidence to the contrary. He based this choice, first, on historical considerations: pioneer work in archaeology gives the appearance of discontinuity just because of a small sample size. Differences are often more apparent at this early stage than similarities. Mitchell cites a number of archaeologists who changes their interpretations of the same evidence, when it was seen in the 
context of a more varied sample, but one that filled in the previously discerned gaps. Second, Mitchell was also seeking the most simple explanation, in the absence of evidence to the contrary (Occam's Razor). Third, Mitchell may have been expressing, in the archaeological context, a broad fashion or theory in anthropology and the social sciences: explanations for social change account for a greater variety of data when questions are asked that focus within the "community", the organization and setting of the local situation.

I have argued (with Levins), that Mitcheli's choice of one model mis-reads the function of a model. Had he presented his ideas and defended them as a theory, his usage would have been accurate.

Mitche17's three reasons for cautioning against invoking a discontinuity or dislocation explanation are important. Borden does not argue against any of them. Instead, Borden cautions against two other aspects of Mitchell's statement. The first is the importance of looking at every conceivable cxplanation, in the absence of evidence to the contrary, so that a single, chosen, explanation will not pre-pattern the perception and selection of evidence. The second is a short comment on Mitchell's use of Borden's early use of the dislocation explanation. Borden writes that he based that explanation on the best evidence available at the time.

Mitchell's Criteria for the Discontinuity Model

It seems to me that in Mitchell's own terms Borden was correct in 1950b (Chapter V), in using a "discontinuity model". This was the passage that Mitchell quoted. It concerns a quite different assemblage, Whalen II, above the Whalen I assemblage. Borden thought this 
new and different assemblage was caused by:

...repeated waves of migration of Athapascan speaking peoples sweeping from northern regions southward along the Coast and through the Interior. After the turmoil had ceased, many Indian groups occupied territory quite different from what they had held before the invasions started. Some groups held more than they possessed previously; others were squeezed in areas far smaller than they originally occupied.

Great unrest was caused among the Salish. It appears that Salish-speaking groups were jostled out of positions in the Interior of Washington and migrated toward the Coast, where they adapted themselves to a new life. They did not necessarily settle for long periods of time in one place after arrival on the Coast, but often may have been hustled along to more distant places by new groups coming from the Interior. It must have been during this time of unrest, which may have lasted for several centuries, that the Northwest Coast of Washington, the San Juan Islands, the East Coast of Vancouver Island, and the opposite Mainland were settled by the ancestors of the Salish groups inhabiting this area to-day. It must be the remains of their descendants which we find in the upper levels of many of the middens along our Southern Coast [1959b:245].

In that $1950 \mathrm{~b}$ paper (Chapter V), Borden cited the most recent

1inguistic work relating to that area (Swadesh, 1949). This is the

passage in Swadesh on which Borden based his work:

If one wished to choose a part of America where the comparative linguistic approach might quickly open fruitful insights into prehistoric currents, one could hardly choose a better field than that of the Salish and their neighbors. They are located in what must have been a main path of rigration for tribes spreading southward from the areas first reached on arrival from Asia. The last wave of prehistoric immigration was probably that of the Athabaskans, whose spread southward is evidenced on language maps. A main wedge of Carrier and Chilcotin pushes into Salish territory in the north, and there are Tenneh islands in the middle of the Salish area, eviclently marking the route of southward migration. Corroborating the indications of the map, Salish linguistic evidence suggests considerable movement of the Salish themselves that must have been motivated by the pressure of invasions from the north. The Athabaskans must also have pushed the Algonkian rribes eastward and pressed the Wakashans southward along the coast into originally Salish territory. As the Athabaskans passed through the Salish area at least once, part of the Salish, displaced eastward, pushed the Kutenai into its present territory [Swadesh 1949:161]. 
Since Mitchell explicitly states that linguistic evidence is sufficient for supporting a dislocation model, Borden's position is sound both in Mitchell's own terms, and in terms of the best evidence when it was written.

Data and Hypotheses

Borden's other comments to Mitchell about models speak to the primary importance of the Evidence in establishing an explanation. As Hanson analyzes the process of discovery, the scientist attempts to perceive or imagine a pattern "in the image of the evidence". Borden makes extended comments on the evidence that he interpreted as culture continuity, and the evidence that he interpreted as discontinuity. He strongly objects to Mitchell's use of a model (or a theory) before the fact.

I conclude that Borden does not question the use of models, nor argue against Mitchell's logic in placing rigorous requirements on the kind of evidence that can lend weight to a dislocation or discontinuity explanation. Borden correctly emphasizes the use of models to show alternate ways of dealing with evidence, or to anticipate a variety of ways that future evidence may change currently accepted explanations.

\section{PRESUPPOSITIONS}

Some presuppositions on which Borden's arguments depend are common to most archaeological work. In many cases, I noted them as they appeared in the papers. For instance, in the stratigraphic presupposition, archaeologists assume that in undisturbed sites, lower depositions 
are older than upper depositions. By "association" of one artifact with another, the archaeologist interprets the meaning of arififacts and features according to their spatial and temporal relationships. By finding the use of tools or of habitation patterns from ethnographic sources, the archaeologist assumes similar use or patterns in thic past.

Another group of presuppositions is dependent on the amount and kind of evidence that an archaeologist has in making his hypothes is. My division of Borden's papers into three general periods reflected these changes in kinds and amounts of evidence, and the dominant presuppositions of that period.

Early Period

The early papers, before radiocarbon dating and before there were many excavated sites, used the age-area hypothesis as a presupposition. In trying to order the different delta sites, Borden combined stratigraphic evidence at Whalen Farm, with typological presuppositions, that different harpoon types could be arranged in a series of developing types, from which a chronology could be derived. Until an absolute chronology is developed, this typological presupposition can accommodate accurately only typical or average situations, but not the unique or innovative one. This can occur even in present times. For instance, in discussing the recent phases at the Esilao Village site (1968a, Chapter XXXIV), Borden describes the mixed assemblages that resulted from pit house digging. His analysis of these phases was again based on types known from adjacent, dated sites. As I noted in the analysis, the late phases at the Esilao Village site must there- 
for be interpreted to be like the others of that age, not as unique or different. The typological presupposition defines this limit.

Middle Period

In what I have called Borden's middle period, thes accumulating dates put the various assemblages into phases on a common time line and often with quite definite time spans. The presuppositions of this period center around the relationships of similar assemblages as they are related in space and time. Borden's charts indicating time gradients from north to soutin of microblade assemblages, and from south to north of bifaces, are instances of this. These are variously inierpreted to mean that an idea was iearned from or brought from one place to another, perhaps with moving people, perhaps from neighbor to neighbor, and perhaps both. Rates of diffusion and diffusion 1 ag are postulated.

\section{Recent Period}

As this time period ends and the recent period begins, evidence from radiocarbon dating as it relates to biotic zones and climate and glacial changes gave rise to other presuppositions. Archaeologists who examined each site as an environment changed through time, assumed that the different biotic zones expanded and contracted with climatic changes, thus affecting the life of the inhabitants of the site. In his review of Gruhn's Wilson Butte Cave report (Borden, 1963), Borden writes:

\footnotetext{
Gruhn's metholological approach is that of the environmental archaeologist: since prehistoric cultures can be fully anderstood only in their ecologlcal context, it is necessary to study in detail the relationships of each culture with its environment by making inferences from both the cultural and
} 
natural remains $[1963: 124]$.

The presupposition is that the environment makes a significant, and archaeologically detectable difference.

\section{Presuppositions Common to All Periods}

Through all, or at least most of his work, I have noted other presuppositions which I infer from Borden's context. In some cases he has directly confirmed or denied them.

He presumes that culture is catching. "Inventions, like boats, for instance, can't be kept a secret. They spread like wildfire" (pers. comm., 1973). If the Pasika site has no bifacial flaking, then this more advanced method was not known. With more options available, a full range of tools is the mental tool kit of a stone worker. Underlying major and minor hypotheses is his presupposition that culture is adaptive. The series of papers dealing with interior, riverine, rivermouth and maritime adaptations depend on this presupposition. So is the simple statement that the usefulness of pebble tools is proved by the fact that this form has persisted for a long time (1969c: 9).

Another continuing presupposition in Borden's papers, related to this last one, is that the artistic evidence is secondary in time to the adaptive survival evidence. Skill in carving antler and wood sculptures was gained in carving harpoons, for instance.

One identification that seems to become an archaeological presupposition equates "culture" with "archaeologically discoverable material culture". Thus Marpole represents a "culture climax" (1968a: 19). The meaning is clearly preserved material culture, but our im- 
pression would be clarified if it were regularly made explicit.

Underlying the scope of data in Borden's papers is a working hypothesis which he refuses to treat as a presupposition. Although he acknowledges (1954b) that Boas was correct in treating race, language, and culture as independent variables, and supports this with evidence, Borden hypothesizes that there may be a significant correlation between them. Because of this, he insists that questions of the relationship of these variables must be asked, and proposes hypotheses presuming close identity of them so that this identity may be tested.

If evidence from anthropometry and analysis of blood alleles should indicate that a language group is a genetic population, and if skeletal evidence of such a group is found archaeologically with distinctive artifact traditions, then Borden's basic working hypotheses will have the means to be confirmed or disconfirmed.

He formulates the hypotheses in advance of such technology and evidence so that the possible relationships can be clarified (Cybuiski's comment to Borden's 1970 paper). Problems in Identifying Presuppositions

Hypotheses are most useful and most testable when their presuppositions are made explicit. I am sure that I have omitted some recent presuppositions just because I am not aware of them myself. An example may illustrate this. Wayne Suttles has prepared a map of the Northwest Coast which most students cannot initially use because it is based on a presupposition contrary to present usage. The Suttles' map is oriented so that the top of the map, "up", is upriver, and the bottom of the map is the Pacific Ocean, or downriver, the basic orienta- 
tion of the Northwest Coast Indians. Students simply do not recognize the area because of their presupposition that "up" on a map is "north". In a parallel archaeological instance, de Laguna wrote of her earlier (1946) unconscious presupposition that "Eskimo" meant "old" when she was comparing Eskimo with Indian assemblages (1962:164-169). Twenty years from now, the presuppositions of the 1970's will be painfully clear.

Some present hypotheses may become presuppositions if evidence is not available to test them. Others may be simply untenable at this time. For instance, in discussing Soviet interpretations of Pleistocene cultures in the Kostenki-Borshevo region, Klein (1969:213-215) is critical of conclusions drawn from evidence of the great diversity of their assemblages:

In addition to the diversity apparent within each stratigraphic unit, a comparison of them also shows that there are almost no assemblages in one unit which closely resemble assemblages in another. Soviet scholars have generally taken this diversity to indicate that there was virtually no cultural continuity in the Late Wurm of the Kostenki-Borshevo region, that is, that bearers of the earlier cultures were not directly ancestral to bearers of any of the later ones. This interpretation is clearly unwarranted, however, since it assumes a clear understanding of both the rate and nature of change through time in artifact assemblages. These matters are very poorly understood at present, and there is no theoretical or empirical reason to suppose that a very long time is necessary for pronounced change to take place. Indeed, the evidence from Kostenki could just as likely imply rapid cultural change as a complete lack of cultural continuity [p. 214 my emphasis].

In view of Klein's criticism, Borden's hypotheses about Northwest Coast culture take on additional significance. Borden emphasizes two sorts of evidence at two relatively clear time levels. The early time level is bracketed by glaciers that covered the central and northern Northwest Coast, leaving a "clean slate" as they receded. Popula- 
tions must have moved into the deglaciated area. The recent time $1 \mathrm{im}$ it is marked by a complex diversity of linguistic groups. Working only between these two time levels and accounting for these kinds of evidence, the archaeologist has almost a laboratory condition in which to examine the kind of problem that Klein outlined. Within this relatively short time span, it may be possible to find specific instances of culture change that fit all the available data. The Northwest Coast could provide a significant body of evidence about culture change.

\section{RETRODUCTION}

In a passing comment about Borden's hypotheses in his contribution to The Development of North American Archaeology (1973:250-285), Sprague writes:

Charles $E$. Borden began work in the Fraser Delta from the University of British Columbia in 1946, and soon (Borden 1950) was bringing the archaeological picture of British Columbia into focus. Borden, a diligent field archaeologist, also enjoys setting up straw men for his colleagues to demolish. More often than not, Borden his beaten his colleagues to the punch by demolishing his own schemes and erecting new ones (p. 263].

If a "straw man" is correctly defined as "One set up as an opponent to be easily defeated or refuted" I would question the accuracy of Sprague's usage. Instead of straw men, I see a series of retroductions. I regard the whole sweep of Borden's work as a series of retroductive inferences. They begin in 1950 with surprising phenomena in an evidence-world of five excavated sites in the Fraser delta, and Borden's suggested explanations from which these surprising phenomena would follow as a matter of course. 
Every piece of evidence and every question asked since then is a part of this series of retroductions. In 1975, Borden uses evidence from the "Current Research" of many scholars all over the Western Hemisphere, and some from the Eastern Hemisphere as we11. His explanations seek to accommodate them all.

The following series of quotations from Hanson's Patterns of Discovery, could be altered by the substitution of "archaeology" and "archaeologists" for "physics" and "physicists". Looking back over Borden's work, I find Hanson describes the search very well:

Physical theories provide patterns within which data appear intelligible. They constitute a 'conceptual Gestalt'. A theory is not pieced together from observed phenomena; it is rather what makes it possible to observe phenomena as being of a certain sort, and as related to other phenomena. Theories put phenomena into systems. They are built up 'in reverse'--retroductively. A theory is a cluster of conclusions in search of a premise. From the observed properties of phenomena the physicist reasons his way towards a keystone idea from which the properties are explicable as a matter of course. The physicist seeks not a set of possible objects, but a set of possible explanations [p. 90].

For Newton the law, as it was first retroduced, did not simply 'cap' a cluster of prior observations: it did not summarize them. Rather it was discovered as that from which the observations would become explicable as a matter of course [p. 107].

...rarely can a man observe what does not yet exist for him as a conceptual possibility [p. 175].

One of my favorite footnotes in Hanson describes how hard it is to "observe the facts". Imagine being shown an apparatus by which you can see certain lines or regularities of the spectrum:

'An object is frequently not seen from not knowing how to see $i t$, rather than from any defect in the organ of vision... [Herschel said:] "I will prepare the apparatus, and put you in such a position that [Fraunhofer's dark lines] shall be visible, and yet you shail look for them and not find them; after which, while you remain in the same position, I will instruct you how to see them, and you shall see them, and not merely 
wonder you did not see them before, but you shall find it impossible to look at the spectrum without seeing them"' (Babbage, The Decline of Science in England ( $R$. Clay, London, 1830)) [Hanson: 184].

Borden's career has been a search for those patterns that make the evidence perceivable. Bronowski, on his television series "The Ascent of Man", $(1973: 364)$, spoke of electrons that behaved like particles on Mondays, Wednesdays, and Fridays, and like waves on Tuesdays, Thursdays, and Saturdays. Borden's statements about the scientific method alternate in a similar and complementary manner. On the one hand, he sometimes writes as if the facts "speak for themselves", while on the other, he sometimes writes as if hypotheses must be devised in order to perceive these facts, as well as to provide a framework for testing them. I interpret the first as Borden's emphas is on the puzzling phenomena which limit the archaeologist's reasonable explanations. In the light of earlier explanations, new evidence appears puzzling. Thereforc ! Rnrden's second emphasis), he formulates new explanations to guide further research. This explanation shows what kind of phenomena to look for. This alternating process, retroduction and testing, has been Borden's life-work. He put it this way when I asked for his help in securing copies of his papers for this thes is:

For your sake I hope that my writings will warrant the sort of effort you are willing to devote to them. If you do discover a consistent streak running through them I trust it will be my endeavor always to search out the truth [pers. comm., July, $1973]$.

This goal is not unlike the statement attributed to Darwin, who wrote in his field notebook every piece of evidence that seemed to contradict his theory of evolution. As he said, 
If I did not, I would tend to forget the contradictory evidence, since what stays in the mind is whatever we find the most agreeable.

"Keep an open mind." This was Borden's advice to Mitche11, and it is advice that he tries to follow himself. Borden has revised his theories through all of his career. With the leisure of retirement, he hopes that his most productive period lies ahead of him. By means of these publications, he hopes to have a part in a search that will not end with his lifetime. Since the evidence will never be all in, anomalies will continue to be recognized, and thinking men will continue to suggest new hypotheses to explain man's prehistory. 


\section{BIBLIOGRAPHY}

\section{Publications by Charles E. Borden}

Borden, Charles

1950a Preliminary Report on Archaeological Investigations in the Fraser Delta Region. Anthropology in British Columbia No. 1, pp. 13-27.

1950b Notes on the Prehistory of the Southern North-west Coast. British Columbia Historical Quarterly 14(4):241-6.

1951a Facts and Problems of Northwest Coast Prehistory. Anthropology in British Columbia No. 2:35-52.

1951b Fraser River Delta Archaeological Findings. American Antiquity $16: 263$.

1957c Review of M. W. Smith: "Archaeology of the Columbia-Fraser Region". American Antiquity 16(3):278-279.

1951d Review of A. King: "Cattle Point...". American Antiquity $16(3): 279-281$.

1952a An Archaeological Reconnaissance of Tweedsmuir Park, B.C., Museum and Arts Notes, second series Vancouver, B.C. 2(2):9-15. Subtitled "July and August, 1951."

1952b Results of Archaeological Investigations in Central British Columbia, Anthropology in British Columbia No. 3:31-43, 47.

Borden, Charles and Wilson Duff

1954 A Scottsbluff-Eden Point from British Columbia. Anthropology in British Columbia, No. 4:33-34. (1953-1954).

Borden, Charles

1954a Some Aspects of Prehistoric Coastal-Interior Relations in the Pacific Northwest. Anthropology in British Columbia No. 4: 26-32.

1954b Distribution, Culture, and Origin of the Indigenous Population of British Columbia. Transactions 7th B.C. Natural Resources Conference, pp. 186-196.

1955 An Ancient Coast Indian Village in Southern British Columbia. Indian Time Vancouver 2(15):9-19. 
1956 Results of Two Archaeological Surveys in the East Kootenay Region of British Columbia. Research Studies Staie College of Washington $24: 73-104$.

1957 Notes and News, British Columbia. American Antiquity 22(3): 325.

1959a Notes and News, Northwest. American Antiquity 24(4):451-452.

1959b Notes and News, Northwest. American Antiquity 25(1):146.

n.d. The Fraser delta archaeological sequence and some of its implications. (MS. intended for publication by the Soc. Am. Archaeol.) [1958].

[cited in Borden 1960].

1960a DjRi3, An Early Site in the Fraser Canyon, British Columbia. National Museum of Canada, Bulletin, 162, Contributions to Anthropology [written in 1958] (1957), pp. 101-118.

1960b Notes and News, Northwest. American Antiquity 25(3):442.

1960c Notes and News, Northwest. American Antiquity 25(4):627-628.

1960d Notes and News, Northwest. American Antiquity 26(1):148-149.

1961a Notes and News, Northwest. American Antiquity 26(4):582-585.

1962a West Coast Crossties with Alaska, In Prehistoric Cultural Relations Between the Arctic and Temperate Zones of North America, [ed.] John M. Campbe11, Arctic Institute of North America, Technical Paper No. 11:9-19. [1960 symposium].

n.d. (a) Labrets: Eskimo or Indian? Paper presented at the 24 th Annual Meeting of the Society for American Archaeology at Salt Lake City, 1959. [cited in Borden 1962a].

n.d. (b) Ground Slate Artifacts in Asia and America. Manuscript. [cited in Borden 1962a].

1961b Fraser River Archaeological Project, Progress Report. National Museum of Canada, Anthropology Papers, No. 1:1-6.

1961c Notes and News, Northwest. American Antiquity 27(2):272-275.

1962b Review of L. S. Cressman: "Cultural Sequences at The Dalles, Oregon". American Antiquity 27(3):437-438.

1962c Notes and News, Northwest. American Antiquity 27(4):609-613. 
1963 Review of Ruth Gruhn: "The Archaeology of Wilson Butte Cave, South-Central Idaho". American Antiquity 29(1):124-125.

n.d.c. Lower Fraser Canyon Prehistory, National Museum of Canada Bulletin, in press.

[the same as n.d.b. below; as cited in 1965].

n.d.b. People of the Canyon. An Introduction to the Prehistory of the Fraser Canyon, British Columbia. Monograph to be published by the National Museum of Canada. Ottawa.

[the same as n.d.c. above; as cited in Borden 1968a].

1965 Radiocarbon and Geological Dating of the Lower Fraser Canyon Archaeological Sequence. Proceedings, 6th International Conference on Radiocarbon and Tritium Dating, Pullman, Wash., pp. $165-178$.

1968a Prehistory of the Lower Mainland. In 'Lower Fraser Valley: Evolution of a Cultural Landscape' B.C. Geographical Series, No. 9, [e.d.] A. H. Siemans, pp. 9-26, Dept. of Geography, U.B.C.

1968b A Late Pleistocene Pebble Tool Industry of Southwestern British Columbia. In Early Man in Western North America, Eastern New Mexico University Contributions in Anthropology 1(4): 55-69.

[cited in Borden 1972 as 1968].

1969a Excavations at 01d Musqueam 1967-68. Newsletter, Archaeological Society of B.C. 1(2):2-4.

1969b The Skagit River At7at1: A Reappraisa1. B.C. Studies (19681969). 1(1):13-19.

An earlier version of this paper was presented at the Twelfth Annual Meeting of the Northwest Anthropological Conference, Portland, Oregon, 1959.

n.d.a. Environmental History of the Lower Fraser and Adjacent Regions. Unpublished Manuscript.

[as cited in Borden 1968a].

[also cited in 1968b as: Unpublished Report on the Fraser Canyon Archaeological Project].

n.d. Intrusion of Paleo-Indian Hunters from the Plains into British Columbia (MS).

[as cited in Borden 1969c].

1969c Early Population Movements from Asia into Western North America. Syesis, The British Columbia Provincial Museum 2(1 \& 2): $1-13$.

A closely related version of this paper was presented at the VIIIth International Congress of Anthropological and Ethnographic Sciences, Tokyo, Japan, 1968. 
1969d Discussion of Papers Presented During the Symposium on Current Archaeological Research on the Northwest Coast. In Northwest Anthropological Research Notes, Fall 3(2):255-258, 260, 261.

1970 Culture History of the Fraser-Delta Region: An Out7ine. In Archaeology in British Columbia, New Discoveries. B.C. Studies, Special Issue, [ed.] Roy L. Carlson, Nos. 6 \& 7:95-112.

Borden, Charles, R. W. Mathewes, and G. E. Rouse

1972 New Radiocarbon Dates from the Yale Area of the Lower Fraser River Canyon, British Columbia. Canadian Journal of Earth Sciences 9(8):1055-1057.

Borden, Charles

[1970; 1974] Tentative Correlations of Archaeological Evidence with Linguistic Data in Pacific Northwest North America. Paper presented in 1970 at the Annual Meeting of the Canadian Archaeological Association, Ottawa; at a lecture series in Victoria; and at Northwest Anthropological Association meeting in Corvallis.

[1973] New Evidence Concerning Late Pleistocene and Early Holocene Population Movements from Asia into the New World. Unpublished manuscript of paper presented before the International Conference on the Bering Land Bridge, Arr. by the U.S.S.R. Academy of Sciences, Khabarovsk, May, 1973.

\section{References Cited by Charles E. Borden}

Ackerman, R. E.

1968 The Archaeology of the Glacier Bay Region, Southeastern Alaska. Wash. State Univ. Lab. Anthro. Rep. Invest. No. 44, Pul1man, Washington.

[as cited in Bordert 1969c].

Anderson, D. D.

1968 A Stone Age Campsite at the Gateway to America. Sci. Amer., 218:24-33.

[as cited in Borden 1969c].

Armstrong, J. E.

1957 Surficial Geology of New Westminster Map-Area, British Columbia. Geological Survey of Canada, paper 57-5.

[as cited in Bnrden 1968a].

1960a Surficial Geology of the Sumas Map-Area, British Columbia. Geological Survey of Canada, paper 59-9.

[as cited in Borden 1958a].

1960b Surficial Geology, Chilliwack (west half), British Columbia. Canada Geological Survey, Preliminary Series, Map 53-1959.

[as cited in Borden 1958a]. 
1961 Soils of the Coastal Area of Southwest British Columbia. In "Soils in Canada". [ed.] Robert F. Legett, Royal Society of Canada Publications, No. 3:22-23, University of Toronto Press. [a]so cited in Borden 1968a].

Armstrong, J. E. and D. R. Crande11, D. J. Easterbrook, and J. B. Noble 1965 Late Pleistocene Stratigraphy and Chronology in Southwestern British Columbia and Northwestern Washington. Geological Society of America Bulletin, 76:321-30, March. [cited in Borden 1965, 1968a, 1968b, 1969c, 1972].

Baker, Paul

1955 The Forgotten Kutenai. Mountain States Press, Boise, Idaho.

Barnes, Alfred $S$.

1947 The Production of Long Blades in Neolithic Times. American Anthropologist, n.s., 49:625-630. [as cited in Borden 1952b].

Bird, Junius

1965 The Concept of a "Pre-projectile Point" Cultural Stage in Chile and Peru. American Antiquity, $31: 262-70$ Salt Lake City. [as cited in Borden 1968b].

Birket-Smith, $K$.

1929 The Caribou Eskimos. Report Fifth Thule Expedition, 1921-24 $5(2)$. [as cited in Borden 1958a].

Boas, Franz

1951 Primitive Art. New York: Dover.

[as cited in Borden 1969b].

Boas, Franz and George Hunt

1904 KWikilit] Texts--second series The Jesup North Pacific Expeditior, $x: i$.

[as cited in Borden 1969b].

Bryan, A. L.

1965 Paleo-American Prehistory. 0ccas. Pap. Idaho State Univ.

Mus. Pocate110: No. 5.

[as cited in Borden 1969c].

Butler, B. Robert

1958 Microblades and Polyhedral Cores from a Central Washington

Site. Wash. Arch. 2(10):3-9.

[as cited in Borden 1962a].

1961 The 01d Cordilleran Culture in the Pacific Northwest. Occasional Papers of the Idaho State College Museum, Pocatello: No. 5. [as cited in Borden 1968b, 1969c]. 
Butter, B. Robert and Douglas Osborne

1959 Archaeological Evidence for the Use of Atlatl Weights in the Northwest. American Antiquity, XXV(2):215-24. [as cited in Borden 1969t].

Calvert, Gay

1970 The St. Mungo Cannery Site: A Preliminary Report In Archaeology in British Columbia, New Discoveries. [ed.] Roy L. Carlson. B.C. Studies No. $6 \&$ 7:54-76.

Carison, R. L.

n.d. Archaeological Investigations in the San Juan Islands. M.A. thesis, University of Washington, 1954.

[cited in Borden 1962a].

Chamberlain, A. F.

1893 Report on the Kootenay Indians. Report of the 62nd Meeting of the British Association for the Advancement of Science, LXII: 549-617.

[as cited in Borden 1956].

Chard, Chester 5 .

1956[a] The 01dest Sites of Northeast Siberia. American Antiquity $21(4): 405-9$.

[as cited in Borden 1962a].

1956[b] Northwest Coast-Northeast Asiatic Similarities; A New Hypothesis. Proc., Vth Int. Congr. Anthrop. and Ethn. Sci., Philadelphia, (In press).

[as cited in Borden 1960].

1958[a] An Outline of the Prehistory of Siberia, Part I, The PreMetal Periods. Southwestern J. Anthro. 14(1):1-33.

[as cited in Borden 1962a].

1959 New World Origins: A Reappraisal. Antiquity, London and Tonbridge, Great Britain: 33(129):44-49.

[as cited in Borden 1968a].

1963 The 0ld World Roots: Review and Speculations. Anthropological Papers of the University of Alaska, College, Alaska: 10(2):11521.

[as cited in Borden 1968b].

1969 Archaeology in the Soviet Union. Science, 163:774-779.

[also cited in Borden 1969c].

1971 Northeast Asia in Prehistory. Paper presented at the Annual Meeting of the Association for Asian Studies, Washington, D.C.

[as cited in Borden 1973]. 
Chard, Chester S. and W. B. Workman

1965 Soviet Radiocarbon Dates: II. Arctic Anthro., 3(1):146-150. [as cited in Borden 1969c].

Clark, J. G. D.

1952 Prehistoric Europe, The Economic Basis. London. [as cited in Borden 1962a].

Clark, J. G. D., D. Walker, H. Goodwin, F. C. Fraser, J. E. King, and J. W. Moore

1954 Excavations at Star Carr, an early Mesolithic Site at Seamer near Scarborough, Yorkshire. Cambridge: Cambridge University Press.

[as cited in Borden 1962a, 1969c].

Collier, D., A. E. Hudson and A. Ford

1942 Archaeology in the Upper Columbia Region. University of Washington Publications in Anthropology 9(1):1-178.

[as cited in Borden 1952b].

Collins, H. B.

1937 Archaeology of St. Lawrence Island, Alaska. Smithsonian Misc. Coll. 96(1).

[as cited in Borden 1962a].

1940 Outline of Eskimo Prehistory. In Essays in Historical Anthropology of North America. Smithsonian Misc. Coll. 100:533-92. [as cited in Borden 1962a].

Cook, John P.

1969 The Early Prehistory of Healy Lake, Alaska. University Micro-

films, Ann Arbour, Michigan.

[as cited in Borden 1970; unpublished 1973].

Crandel1, Dwight $R$.

1965 The Glacial History of Western Washington and Oregon. The

Quaternary of the United States. [eds.] H. E. Wright, Jr. and

D. G. Frey. Princeton: Princeton University Press.

[as cited in Borden 1968a].

Cressman, Luther S.

1956 Five Mile Rapids Site, Oregon, Progress Report. Read at the annual meeting of the Society for American Archaeology, Lincoin, Nebr., May, 1956.

[as cited in Borden 1960, 1968b].

Cressman, Luther S. and S. F. Bedwel1

1968 Report on Archaeological Research in Northern Lake County, Oregon (MS).

[as cited in Borden 1969c]. 
Cressman, Luther S., D. L. Cole, W. A. Davis, T. M. Newman and D. J. Scheans

1960 Cultural Sequences at The Dalles, Oregon. Transactions, American Philosophical Society, New Series, Philadelphia: bU(10).

[as cited in Borden 1962a, 1968, 1968a, 1969c].

Cressman, Luther S. and Alex D. Krieger

1940 Atlatls and Associated Artifacts from Southcentral Oregon.

In L. S. Cressman et al. Early Man in Oregon. Eugene, Ore:

University of Oregon Press, pp. 16-52.

[as cited in Borden 1969b].

Daugherty, Richard D.

1956 Archaeology of the Lind Coulee Site, Washington. Proc., Am.

Phi 1. Soc. 100(3):223-278.

[as cited in Borden 1960].

DeJarnette, David L.

1952 Alabama Archaeology: A Summary. In Archaeology of the Eastern

United States. [ed.] James B. Griffin. Chicago: University of

Chicago Press.

[as cited in Borden 1969b].

Dikov, N. N.

1965 The New Stone Age of Kamchatka and the Chukchi Peninsula in the Light of New Archaeological Data. Arctic Anthropology, 3(1): 10-15.

[as cited in Borden 1969c].

1968 Paleolithic Culture of Kamchatka. Moscow.

[as cited in Borden 1969c, $1973 \mathrm{~ms}$ ].

Drucker, Philip

1943 Archaeological Survey on the Northern Northwest Coast, BAE-B 133:17-132.

1950 Culture element distributions, XXVI, Northwest Coast. Anthro. Records, Univ. of Calif. 9(3):157-294.

[as cited in Borden 1962a].

1955 Sources of Northwest Coast Culture. New interpretations of aboriginal American culture history. 75th Anniv. Vol., Anthropological Society. Washington, pp. 59-81.

[as cited in Borden 1960, 1962a].

Duff, Wilson

1952 The Upper Stalo Indians of the Fraser Valley, British Columbia. Anthropology in British Columbia, Memoir No. 1, Victoria, B.C. [also cited in Borden 1968a].

1956a Prehistoric Stone Sculpture of the Fraser River and the Gulf

of Georgia. Anthropology in British Columbia, No. 5, pp. 15-151. [as cited in Borden 1962a]. 
1956b Unique Stone Artifacts from the Gulf Is]ands. Rept. Provincial Mus. Nat. Hist. and Anthro. pp. 1-i1. [as cited in Borden 1962a].

1956c An Unusual Burial at the Whalen Site. Research Studies of the State College of Washington, 24(1):67-72. [as cited in Borden 1968a as Duff 1956].

1965 Thoughts on the Nootka Canoe. Provincial Museum of Natural History and Anthropulogy, Report for the Year 1964.

[as cited in Mitchell 1969].

Easterbrook, D.J.

1966 Radiocarbon Chronology of Late Pleistocene Deposits in Northwest Washington. Science, 24(3723):764-7.

[as cited in Borden 1968a, 1968b].

Fladmark, Knut R.

1971 Early Microblade Industries on the Queen Charlotte Islands, British Columbia. Paper presented at the 4th Annual Meeting of the Canadian Archaeological Association, University of Calgary, Feb. 1971.

Forbis, Richard G. and John D. Sperry

1952 An Early Man Site in Montana. American Antiquity, XVIII: 127-133.

[as cited in Borden and Duff, 1954].

Fryxe11, R., R. D. Daugherty, T. Gielicki, C. E. Gustafson, H. I. Irwin and $B$. C. Kee?

1968 A Human Skeleton from Sediments of Mid-Pinedale Age in Southeastern Washington. Paper read at the VIIIth Internat. Cong.

Anthro. Ethno. Sci., Tokyo-Kyoto, Japar.

[as cited in Borden 1969c].

Fulton, R. J.

1968 Olympia Interglation, Purcell Trench, British Columbia. Geol. Soc. Amer. Bul1., 79:1075-1080.

[as cited in Borden 1969c].

1971 Radiocarbon Chronology of Southern British Columbia. Geol.

Surv. Can., Pap. 71-37, 28p.

[as cited in Mathewes, Borden and Rouse 1972].

Gallagher, $P$.

1959 South Cave: A Site in the Lower Grand Coulee of Central Washington. Wash. Arch. 3(5):3-26.

[as cited in Borden 1962a].

Giddings, James $L$.

1951 The Denbigh Flint Complex. American Antiquity. 16(3):193-203. [as cited in Borden 1952b, 1962a]. 
1961 Cultural Continuities of Eskimos. American Antiquity 27(2): 155-73.

[as cited in Mitchell 1969].

Gimbutas, M.

1959 Post-Paleolithic Asia in the Territories of the USSR. Encycl.

Brit. 1959 ed. Vol. 2, pp. 2590-259Q.

[ar cited in Borden 1962a].

Greenberg, Joseph $\mathrm{H}$.

1953 Historical Linguistics and Unwritten Languages. In Anthropology Today. [ed.] A. L. Kroeber, Chicago, pp. 265-286.

[as cited in Borden 1954b].

Griffin, J. B.

1960 Some Prehistoric Connections Between Siberia and America.

Science $131(3403): 801-12$.

[as cited in Borden 1962a].

Gruhn, $R$.

1961 The Archaeology of Wilson Butte Cave, South-Central Idaho.

Occas. Pap. Idaho State Coll. Mus., No. 6.

[as cited in Borden 1969c].

1965 Two Early Radiocarbon Dates from the Lower Levels of Wilson

Butte Cave, South Central Idaho. Tebiwa, 8(2):57.

[as cited in Borden 1969c].

Hadleigh-West, $F$.

1967 The Donnelly Ridge Site and the Definition of an Early Core and Blade Complex in Central Alaska. American Antiquity 32(3): 360-382.

[as cited in Borden 1969c].

Hawthorn, Audrey

1967 Art of the Kwakiut] Indians and other Northwest Coast Tribes. Seattle and London: University of Washington Press.

[as cited in Borden 1969b].

Haynes, C. V., Jr.

1967 Carbon-14 Dates and Early Man in the New World. In P.S.

Martin and H. E. Wright, Jr. [ed.], Pleistocene Extinctions: The

Search for a Cause. Proc. VIIth Congress of Internat. Assoc.

Quater. Res., pp. 267-286.

[as cited in Borden 1969c].

Heizer, Robert F.

1943 "Aconite Poison Whaling in Asia and America: An Aleutian Transfer to the New World". Bureau of American Ethnology, Bullet in No. 133, Anthropological Papers, No. 24.

[as cited in Borden 1962a]. 
1956 Archaeology of the Uyak Site Kodiak Island, Alaska. Anthro. Records, University of Calif. 17(1):1-199.

[as cited in Borden 1962a].

Heusser, C. J.

1960 Late-Pleistocene Environments of Noren-Pacific North America. American Geographical Society Special Publication No. 35, New York. [as cited in Borden 1965, 1968a, 1968b].

Hopkins, D. M. [ed.]

1967 The Bering Landbridge. Stanford: Stanford Univ. Press. [as cited in Borden 1969c].

Inverarity, Robert Bruce

1950 Art of the Northwest Coast Indians. Berkeley and Los Angeles: University of California Press.

[as cited in Borden 1969b].

Irwin-Williams, C.

1967 Associations of Early Man with Horse, Camel, and Mastodon at Hueyatlaco, Valsequillo (Puebla, Mexico). In P. S. Martin and H. E. Wright, Jr. [ed.], Pleistocene Extinctions: The Search for a Cause. Proc. VIIth Congr. Internat. Assoc. Quater. Res. Yale University Press, pp. 337-347.

[cited in Borden 1969c].

1968a Summary of Archaeological Evidence from the Valsequillo Region, Puebla, Mexico. (MS).

[as cited in Borden 1969c].

1968b Comments Concerning Radiocarbon Dates from the Valsequil10 Region and Their Relation to the Early Archaeological Localities. (MS).

[as cited in Borden 1969c].

Jenness, Diamond

1934 The Indians of Canada. Department of Mines, National Museum of Canada, Bu1. 65, Anthropological Series No. 15.

1955 Third edition [cited in Borden 1954b, 1956].

Jennings, Jesse $D$.

1968 Prehistory of North America. New York. [as cited in Borden 1968b].

Johnson, $F$.

1946a An Archaeological Survey Along the Alaska Highway, 1944. American Antiquity $11(3): 183-6$.

[cited in Borden 1962a].

Jorgensen, Joseph G.

1969 Salish Language and Culture. Indiana University Publications. Language Science Monographs v. 3. Bloomington.

[cited in Borden 1970 unpublished paper]. 
King, Arden R.

1950 Cattle Point: A Stratified Site in the Southern Northwest Coast Region. Society of American Archaeology Memoir No. 7.

Klein, Richard G.

1971 The Pleistocene Prehistory of Siberia. Quaternary Research $1(2): 133-161$.

Krause, Aure 1

1885 Die Tlinkit Indianer. Jena.

[as cited in Borden 1952b].

Krieger, Alex $D$.

1964 Early Man in the New World. In "Prehistoric Man in the New World", [ed.] J. D. Jennirgs and E. Norbeck, pp. 23-81. Chicago. [as cited in Borden 1968b, 1969c].

Kroeber, Alfred $L$.

1923 American Culture and the Northwest Coast. American Anthropologist $25: 1-20$.

[as cited in Borden 1960].

1939 Cultural and Natural Areas of Native North America. University of California Pubiications in American Archaeology and Ethn. Vol. 38.

[as cited in Borden 1960].

1947 Cultural" and Natural Areas of Native North America. University of California Press, Berkeley and Los Angeles. [as cited in Borden 1968a].

de Laguna, Frederica

1934 The Archaeology of Cook Inlet, Alaska. Philadelphia. [as cited in Borden 1962a].

1947 The Prehistory of Northern North America as Seen From the

Yukon. Society of American Archaeology Memoir No. 3 12(2):1-360. [as cited in 1952b, 1962b].

Lamb, W. K., ed.

1960 The Letters and Journals of Simon Fraser, 1806-1808. MacMillan, Toronto.

[as cited in Borden 1968a].

Lane, Robert

1952 House Types in Use Among the Chilcotin Indians. Personal communication. [as cited in Borden 1952b].

Lantis, Margaret

1938 The Alaskan Whale Cult and Its Affinities. American Anthropologist 40:438-464.

[as cited in Borden 1962a]. 
Larsen, H.

1968 Trail Creek. Final Report on the Excavation of Two Caves on Seward Peninsula, Alaska. Acta Arctica, 15. Copenhagen, $79 \mathrm{pp}$. [as cited in Borden 1969c].

Laughlin, W. S.

1951 Notes on an Aleutian Core and Blade Industry. American Antiquity 17:52-55. [as cited in Borden 1952b].

1967 Human Migration and Permanent Occupation in the Bering Sea Area. In D. M. Hopkins [ed.], The Bering Landbridge, pp. 409-450. [as cited in Borden 1969c].

Laughlin, W. S. and G. H. Marsh

1954 The Lamellar Flake Manufacturing Site on Anangula Island in the Aleutians. American Antiquity 20(1):27-39. [as cited in Borden 1962a].

Locher, G. W.

1932 The Serpent in Kwakiutl Religion: A Study in Primitive CuTture. Leyden.

[as cited in Borden 1969b].

Lowden, J. A., J. G. Fyles and W. Blake, Jr.

1967 Geological Survey of Canada Radiocarbon Dates VI. Geol. Surv. Can., Paper 67-2, Part B. [as cited in Borden 1969c].

Luebbers, Roger A.

1971 Archaeological Sampling at Namu. M.S., Department of Anthropology, University of Colorado. [as cited in Borden 1973 MS].

MacDonald, George $F$.

1969 Preliminary Culture Sequence from the Coast Tsimshian Area, British Columbia. Northwest Anthropological Research Notes 3(2):240-254 Fall.

[with discussion on pp. 255-263].

MacNeish, Richard S.

1954 The Pointed Mountain Site Near Fort Liard, Northwest Territories, Canada. American Antiquity XIX:234-253.

[as cited in Borden and Duff 1954].

1959b A Speculative Framework of Northern North American Prehistory. Anthropologica, N.S. 1(1 \& 2):7-23.

[as cited in Borden 1962a].

1960 The Callison Site in the Light of Archaeological Survey of Southwest Yukon. In Contributions to Anthropology, 1957. Nat. Mus. Can. Bul1. No. 162:1-51. 
1964 Investigations in Southwest Yukon: Archaeological Excavation, Comparisons and Speculations. Pap. Peabody Found. 6(2).

[as cited in Borden 1969c].

McKennan, R. A., and J. P. Cook

1968 Prehistory of Healy Lake, Alaska. Paper read at the VIIIth

Internat. Congr. Anthro. Ethno. Sci., Tokyo-Kyoto, Japan.

[as cited in Borden 1969c].

Mason, John Alden

1928 Some Unusual Spear Throwers of Ancient America, Museum Journal, Sept. 1928, Philadelphia. pp. 290-324.

[as cited in Borden 1969b].

Mathews, W. H., J. G. Fyles and H. W. Naismith

1970 Postglacial Crustal Movements in Southwestern British Columbia and Adjacent Washington State. Canadian Journal of Earth Sciences 7(2):690-702.

[as cited in Mathewes, Borden and Rouse 1972].

Michael, H. N.

1958 The Neolithic Age in Eastern Siberia. Trans. Amer. Phil. Soc.

N.S. $48(2): 1-108$.

[as cited in Borden 1962a].

Mitche11, Donald H.

1965 Preliminary Excavations at a Cabble Tool Site (DjRi7) in the

Fraser Canyon, British Columbia, Anthropology Papers National

Museum of Canada, No. 10, Ottawa.

[cited as n.d. in press in Borden, 1965. Cited in Borden

1968b erroneously as: Mitche11 1963].

1969 Site Survey in the Johnstone Strait Region. Northwest Anthropologicai Researci Notes Fall 3(2):193-216.

Morice, A. G.

1895 Notes Archaeological, Industrial and Sociological, on the

Western Denes. Transactions of the Canadian Institute IV:1-221.

[as cited in Borden 1952b].

1904 The History of the Northern Interior of British Columbia. Toronto.

[as cited in Borden 1952b].

Movius, Hallam L.

1949 The Lower Palaeolithic Cultures of Southern and Eastern Asia. Transactions of the American Philosophical Society, New Series $38(4): 329-420$.

[as cited in Borden 1968a]. 
Muller-Beck. H.

1966 Paleohunters in America: Origins and Diffusion. Science, 152 (3726):1191-1210. [as cited in Borden 1969c].

1967 On Migrations of Hunters Across the Bering Land Bridge in the Upper Pleistocene. In D. M. Hopkins [ed.], The Bering Land Bridge, Stanford Univ. Press, Chap. 22, pp. 373-408. [as cited in Borden 1969c].

Munse 11, D. A.

1967 The Ryegrass Coulee Site. Unpubl. M.A. thesis, Univ. of Washington, Seattle. [as cited in Borden 1969c].

Nelson, N. C.

1937 Notes on Cultural Relations Between Asia and America. American Antiquity 2(4):267-72. [as cited in Borden 1952b, 1962a].

Neuman, Robert $w$.

1967 Atlatl Weights from Certain Sites on the Northern and Central Great Plains. American Antiquity 32:36-53. [as cited in Borden 1969b].

Okladnikov, A. P.

1950 Neolithic and Bronze Age of the Baikal Area. Materialy $i$ Issledovaniya po Arkheologi i SSSR 18:412 pp. (In Russian). [as cited in Borden 1962a].

01 son, R. L.

1927 Adze, Canoe, and House Types of the Northwest Coast. Univ. Wash. Publ. in Anthro. 2(1):1-38. [as cited in Borden 1962a].

Ostorne, Douglas

1956 Early Lithic in the Pacific Northwest. Res. Stud. of the State College of Washington XXIV(1):38-44. [as cited in Borden 1960].

n.d. Archaeological Tests in the Lower Grand Coulee, Washington. [as cited in Borden 1962a].

Osborne, D., N. W. Caldwell and R. H. Crabtree

1956 The Problem of Northwest Coastal-Interior Relationships as

Seen from Seattle. American Antiquity 22(2):117-28.

[as cited in Borden 1962a].

Osborne, Douglas, Robert Crabtree and Alan Bryan

1952 Archaeological Investigations in the Chief Joseph Reservoir. American Antiquity 17:360-373.

[as cited in Borden 1952b]. 
Oswalt, $W$.

1955b Prehistoric Sea Mammal Hunters at Kaflia, Alaska. Antho.

Pap. University of Alaska 4(1):23-61.

[as cited in Borden 1962a].

Quimby, George I.

1954 Cultural and Natural Areas Before Kroeber. American Antiquity XIX:317-331.

[as cited in Borden 1956, and Borden and Duff 1954].

Rainey, Froelich, G.

1939 Archaeology in Central Alaska. American Museum of Natural

History, Anthropological Papers New York:36(4):351-405.

[as cited in Borden 1952b, 1962a].

1953 The Significance of Recent Archaeological Discoveries in Inland Alaska. Soc. for Amer. Arch. Mem. 9(3)[2]:43-6. [as cited in Borden 1962a].

Rainey, F. G. and E. RaTph

1959 Radiocarbon Dating in the Arctic. American Antiquity 24(4)

[1]:365-74.

[as cited in Borden 1962a].

Ray, Verne $F$.

1939 Cultural Relations in the Plateau of Northwestern America.

Publications of the Frederick Webb Hodge Anniversary Publication

Fund, Yol. 2, Los Angeles.

[cited in Borden 1952b and 1956].

Rigg, G. B. and N. R. Gould

1957 Age of Glacier Peak Eruption and Chronology of Post-glacial

Peat Deposits in Washington and Surrounding Areas. American Journal of Science 255:341-63.

[as cited in Borden 1968b].

Rigsby, Bruce

1968 Historical Linguistics and the Tsimshian. Paper presented at the 67th Annual Meeting of the American Anthropological Association, Seattle.

[as cited in MacDonald 1969].

Ritchie, William A.

1944 The Pre-Iroquoian Occupations of New York State. Rochester Mus. Mem. No. 1.

[as cited in Borden 1962a].

1951 a Ground Slates: Eskimo or Indian? Pennsylvania Arch. Bul1.

$21(3-4): 46-52$.

[as cited in Borden 1962a].

$1951 b$ A Current Synthesis of New York Prehistory. American Antiquity $17(2): 130-6$.

[as cited in Borden 1962a]. 
1965 The Archaeology of New York State. New York: Natural History Press. [as cited in Borden 1969b].

Roberts, M. C. and D. M. Mark

1971 Use of Trend Surfaces in Till Fabric Analysis: Reply. Canadian Journal of Earth Sciences 8(9):1167-1169.

[as cited in Mathewes, Borden and Rouse 1972].

Robinson, J. Lewis

1953 The Rocky Mountain Trench. The Beaver, A Magazine of the North, Outfit 283, March, pp. 36-39.

[as cited in Borden 1956 and Borden and Duff 1954].

Rudenko, S. I.

1967 The Ust'-Kanskaia Paleolithic Cave Site, Siberia. American Antiquity $27(2): 203-215$.

[as cited in Borden 1969c].

Sanger, David

1963 Excavations at Nesikep Creek (EdRk:4). A Stratified Site Near Lillooet, B.C.:Preliminary Report. Contributions to Anthropology, 1961-62, Part 1. National Museum of Canada, Bulletin, Ottawa 193:130-61. [as cited in Borden 1968a].

1966 Excavations in the Lochnore-Nesikep Creek Locality, B.C.:

Interim Report. Anthropology Papers, National Museum of Canada, No. 12, Ottawa.

[as cited in Borden 1968a].

1967 a Prehistory of the Pacific Northwest Plateau as Seen from the Interior of British Columbia. American Antiquity 32(2):186-197. [as cited in Borden 1969c].

1967b The Archaeology of the Lochnore-Nesikep Locality, British Columbia: Final Report. Unpubl. Ph.D thesis, Univ. of Washington, Seattie. [as cited in Borden 1969c].

1968 Prepared Core and Blade Traditions in the Pacific Northwest. Arctic Anthro. 5(1):92-120.

[as cited in Borden 1969c].

Sapir, E.

1916 Time Perspective in Âboriginal American Culture: A Study in Method. Can. Dept. of Mines, Geol. Survey, Mem. 90, Anthropol. Ser., No. 13, Ottawa.

[as cited in Borden 1969c]. 
Sellards, E. H.

1952 Early Man in America. Austin: University of Texas Press. [cited in Borden and Duff 1954].

Shiner, Joel L.

1950 Archaeological Resources in the Libby and Katka Reservoirs, Northern Idaho and Northwestern Montana. Columbia Basin Projeci, River Basin Surveys, Smithsonian Institution.

[as cited in Borden 1956].

1952 The 1950 Excavations at Site 45BN6 McNary Reservoir, Washington. American Antiquity 17:348-351. [as cited in Borden 1952b].

1953 Archaeological Reconnaissance in the Albeni Falls Reservoir. River Basin Surveys, Smithsonian Institution.

Shut]er, R., Jr.

1967a Archaeology of Tule Springs. In H. M. Wormington and D. Ellis [ed.], Pleistocene Studies in Southern Nevada. Nevada State Mus. Anthro. Pap. 13:397-303.

[as cited in Borden 1969c].

1967b Cultural Chronology in Southern Nevada. In H. M. Wormington and D. Ellis [ed.], Pleistocene Studies in Southern Nevada. Nevada State Mus. Anthro. Pap. 13:305-308.

[as cited in Borden 1969c].

Smith, Harlan I.

1899 Archaeology of Lytton, British Columbia, Memoirs of the American Museum of Natural History, Vol. 2, Pt. 3 New York. The Jt:up North Pacific Expedition pp. 129-161. May 1899. [as cited in Borden 1952b, 1954a].

1900 Archaeology of the Thompson River Region, British Columbia, Memoirs of the American Museum of ilatural History 2(6):401-454. The Jesup North Pacific Expedition. May, 1900.

1903 She11-Heaps of the Lower Fraser River, British Columbia. AMNHM Vol. 3 No. 4. The Jesup North Pacific Expedition, pp. 133191.

[as cited in Borden 1968a].

1907 Archaeology of the Gulf of Georgia and Puget Sound. American Museum of Natural History Memoirs $4(6)$. Jesup North Pacific Expedition Memoirs. New York: 2(6):302-441.

Smith, Harlan I. and Gerard Fowke

1901 Cairns of British Columbia and Washington. Memoirs of the American Museum of Natural History Vol. 4, Part 2. Jesup North Pacific Expedition. New York: 2(2):55-75. 
Smith, Marian W.

1956 The Cultural Development of the Northwest Coast. Southestern Journal of Anthropology 12(3):272-294.

[as cited in Mitchell 1969].

Strong, William Duncan

1935 An Introduction to Nebraska Archaeology. Smithsonian Misc. Coll. 93(10). [as cited in Borden 1956].

Strong, W. D., W. E. Schenck and Julian Steward

1930 Archaeology of The Dalles-Deschutes Region. University of California Publications in American Archaeology and Ethnology, Vol. 29, Berkeley. [as cited in Borden 1956].

Suttles, Wayne $P$. and William Elmendorf

1962 Linguistic Evidence for Salish Prehistory. Proceedings of the 1962 Annual Spring Meeting of the American Ethnological Society, pp. $41-52$.

[as cited in Borden 1960 unpublished paper].

Swadesh, Morris

1949 "The Linguistic Approach to Salish Pre-history." In Indians of the Urban Northwest [ed.] Marian W. Smith, New York, pp. 161173.

[as cited in Borden 1952b, 1956].

Swadesh, Morris with comments by G. I. Quimby, H. B. Collins, E. W. Haury, G. F. Ekholm, and F. Eggan

1954 Time Depths of American Linguistic Groupings. American Anthropologist $56(3): 361-77$.

[as cited in Borden 1962a].

Swan, J. G.

1870 The Indians of Cape Flattery at the Entrance to the Strait of Fuca, Washington Territory. Smithsonian Contrib. to Knowledge 16(8):1-108.

[as cited in Borden 1962a, 1969b as 1868].

Swanton, J. R.

1908 Social Condition, Beliefs, and Linguistic Relationship to the Tlingit Indians. 26th Ann. Rept. Bur. Amer. Ethn. pp. 391-485. [as cited in Borden 1962a].

1953 The Indian Tribes of North America. Bureau of American Ethnology, Bulletin 145, Washington, D.C.

[as cited in Borden 1968a].

Taylor, H. C. Jr. and W. Caldwell

1954 A Carved Atlatl from the Northwest Coast. American Antiquity $X I X: 279-80$.

[as cited in Borden 1969b]. 
Taylor, William E. Jr.

1959b Review and Assessment of the Dorset Problem. Anthropologica, N.S. $1(1 \& 2): 24-46$. [as cited in Borden 1962a].

1968 The Arnapik and Tyara Sites, An Archaeological Study of Dorset Culture Origins. Memoirs of the Society for American Archaeology, No. 22.

[as cited in Mitchell 1969].

Teit, James

1900 The Thompson Indians of British Columbia. American Museum of Natural History, Memoirs 2(4):163-392.

[as cited in Borden 1952b].

1906 The Lillooet Indians. American Museum of Natural History, Memoirs 2(5):193-300. [as cited in Borden 1952b].

1909 The Shuswap. American Museum of Natural Histcry, Memoirs $2(7)$; Leiden. [as cited in Borden 1952b, 1956].

Tolstoy, $P$.

1958a The Archaeology of the Lena Basin and its New World Relationships, Part I. American Antiquity 23(4)[1]:397-418. [as cited in Borden 1962a].

1958b The Archaeology of the Lena Basin and its New Worid Relationships, Part II. American Antiquity 24(1):63-81. [as cited in Borden 1962a].

Turney-High and Harry Holbert

1941 Ethnography of the Kutenai. Memoirs of the American Anthropological Association, No. 56. [as cited in Borden 1956].

Warren, C. N.

1967 The San Dieguito Complex: A Review and Hypothesis. American Antiquity $32: 168-185$. [as cited in Borden 1969c].

Waterman, T. T.

1921 Native Houses of Western North America. Museum Amer. Ind., Heye Foundation. [as cited in Borden 1952b].

Wilcox, R. E.

1965 Volcanic-Ash Chronology. The Quaternary of the United States. [eds.] H. E. Wright, Jr. and D. G. Frey. New Jersey: Princeton University Press. [äs cited in Borden 1968a]. 


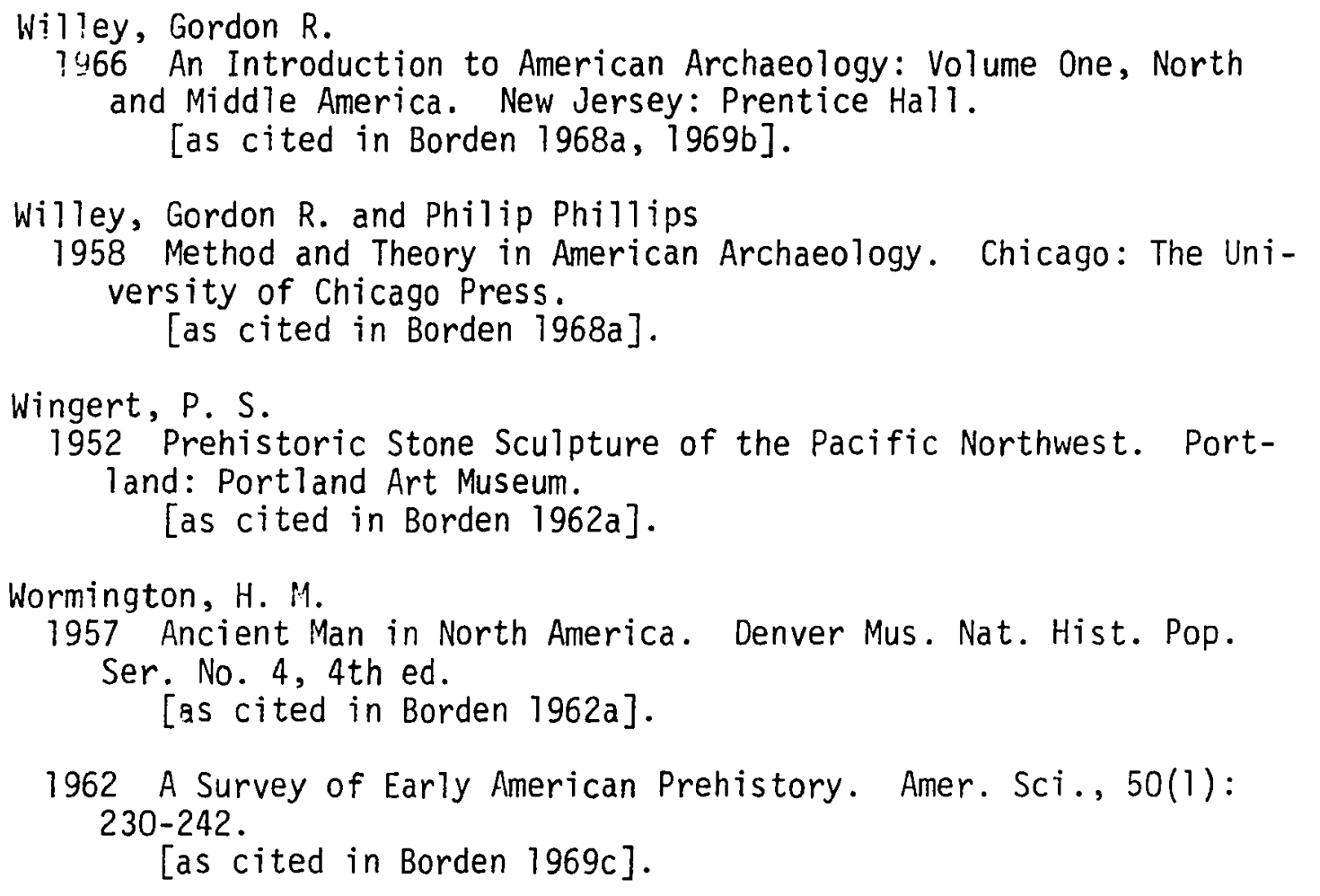

\section{References Cited by Ellen W. Robinson}

Abbott, Donald N.

1972 The Utility of the Concept of Phase in the Archaeology of the Southern Northwest Coast. Syes is 5:267-278.

Boas, Franz

1900 Conclusion, In Teit, The Thompson Indians of British Columbia: American Musaum of Natural History. Jesup North Pacific Expedition $1: 387-390$.

1912, 1913 Changes in Bodily Form of Descendents of Immigrants. American Anthropologist, N. S. 14(3) 1912, and in Zeit schrift fur Ethnologie, Vol. 45, Heft 1, 1913, In Race Language and Cu1ture, New York: MacMillan Company, 1940.

n.d. British Columbia Resources Map No. [before 1958].

[for Fig. 1].

Bronowski, J.

1973 The Ascent of Man. Boston/Toronto: Little, Brown and Company.

Canada Department of Mines and Resources

1942 British Columbia, Preliminary Revision [Map]. Ottowa, Surveys and Engineering Branch, Hydrographic and Map Service. [for Fig. 5]. 
Carlson, Roy L.

1970 Archaeology in British Columbia. In Archaeology in British Columbia, New Discoveries. [ed.] Roy L. Carlson. B.C. Studies, No. $6 \& 7: 7-17$.

Charlton, Arthur S.

1972 Noons Creek and Belcarra: A Preliminary Report on Excavations Near Port Moody. In Salvage 171: Reports on Salvage Archaeology Undertaken in British Columbia in 1971, Simon Fraser University Department of Archaeology, Publication No. 1, [ed.] Roy L. Carlson 131-155.

Cohen, Morris R. and Ernest Nagel

1934 An Introduction to Logic and Scientific Method. New York: Harcourt, Brace and World, Inc.

Evans, Bergen

1968 Dictionary of Quotations. New York: Delacorte Press.

Fitting, James E. [ed.]

1973 Development of North American Archaeology. Essays in the History of Regional Traditions. New York: Doubleday (Anchor).

Hanson, Norwood Russell

1958 Patterns of Discovery: An Inqu: ' into the Conceptual Foundations of Science. Cambridge: Cambridge University Press.

Klein, Richard G.

1969 Man and Culture in the Late Pleistocene: A Case Study. San Francisco: Chandler Publishing Company.

Kroeber, A. L.

1931 The Culture-Area and Age-Area Concepts of Clark Wissler. In Methods in Social Science, A Case Book; compiled under the direction of the Committee on Scientific Method in the Social Sciences of the Social Science Research Council. [ed.] Stuart A. Rice, pp. 248-265. Chicago: The University of Chicago Press.

Levins, R.

1968 Evolution in Changing Environments. Princeton: Princeton University Press.

Mitchel1, Donald H.

1971 Archaeology of the Gulf of Georgia Area, A Natural Region and its Cultural Types. Syesis, Vol. 4, Supp. 1. Victoria: British Columbia Provincial Museum.

Polach, H. A. and J. Golson

1966 Collection of Specimens for Radiocarbon Dating and Interpretation of Results. Australian Institute of Aboriginal Studies.

Manual No. 2. Canberra: Australian National University, pp. 1-42. 
Rice, Stuart A. [ed.]

1931 Methods in Social Science, A Case Book; compiled under the direction of the Committee on Scientific Method in the Social Sciences of the Social Science Research Council. Chicago: The University of Chicago Press.

Robinson, Ellen W. Sutherland

n.d. Harlan I. Smith, Boas, and the Salish: Unweaving Archaeological Hypotheses. Northwest Anthropological Research Notes, in press.

Salmon, Westey $C$.

1963 Logic. New Jersey: Prentice-Ha11, Inc.

Sprague, Roderick

1973 The Pacific Northwest. In The Development of North American Archaeology. Essays in the History of Regional Traditions [ed.] James E. Fitting. New York: Doubleday (Anchor) pp. 251-285.

Wissler, Clark

1922 The American Indian (1st ed., New York: McMurtrie, 1917, 2nd ed., New York: Oxford University Press, 1922).

1923 Man and Culture. New York: Thomas Y. Crowell Co.

1926 The Relation of Nature to Man in Aboriginal America. New York: Oxford University Press. 
$1950 \mathrm{a} \quad 1950 \mathrm{~b} \quad 1951 \mathrm{a} \quad 1952 \mathrm{a} \quad 1952 \mathrm{~b} \quad 1954 \mathrm{a} \quad 1954 \mathrm{~b} \quad 195$

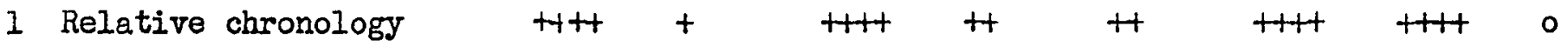

2 Absolute chronology

$\circ$

$\circ$

Htt tht 0

$++$

$+t$

$+t+$

$+H \quad 0$

4 Classification

$+\quad+$

H. H

$++$

H

5 Traditions/diffusion

t+ $\quad+$

$++$

$+$

t+

$++$

$++t+$

6 Traditions/migration

$+\quad+t+t$

$+t$

H

t+t

$++t$

7 Marpole-Locarno Beach

$t+t \quad 0 \quad t$

o

$\circ$

t+t

o

t+t

8 Ethnography

9 Ecology

10 Geology

11 Linguistics

12 Salish

$\circ$

H H H

$\circ$

tt

$\circ$

$t+t$

13 Penutian

$\circ$

0

o

o

0

$\circ$

$++$

14 Retroduction

$+4+t+4$

H+H H

$++$

$++1$

$t+t+$

\section{Testing}

$+\quad+\quad++t$

$++$

$+i \cdot$

$+1$

Reproduced with permission of the copyright owner. Further reproduction prohibited without permission. 
$\begin{array}{lllllllllllll}1954 \mathrm{~b} & 1955 & 1956 & 1960 \mathrm{a} & 1962 \mathrm{a} & 1962 \mathrm{~b} & 1963 & 1965 & 1968 \mathrm{a} & 1968 \mathrm{~b} & 1969 \mathrm{~b} & 1969 \mathrm{c}\end{array}$

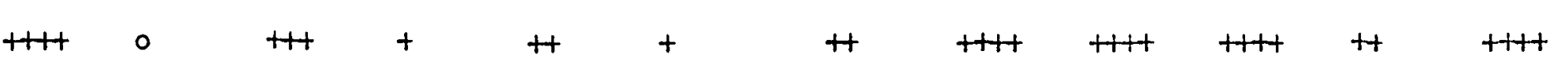

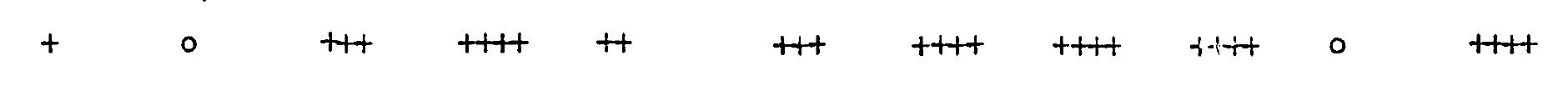

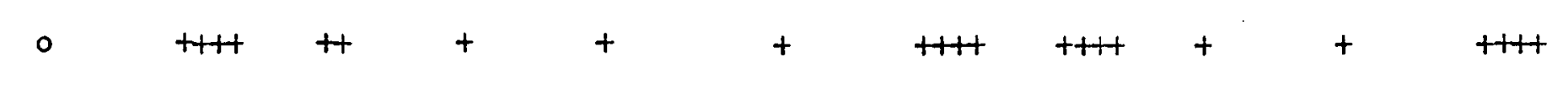

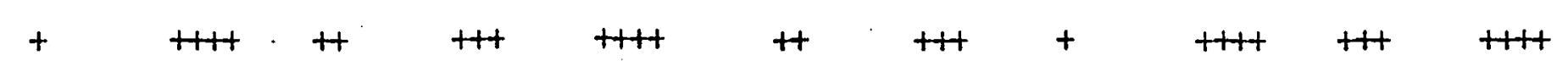

\begin{tabular}{|c|c|c|c|c|c|c|c|c|c|c|}
\hline+ & $\mathrm{HHt}$ & $+t+$ & $++t$ & $+t$ & + & t+t & $t+t+$ & + & + & t+t+ \\
\hline+ & $++t$ & $++t$ & $+t+$ & + & + & ++ & $+H$ & 0 & 0 & 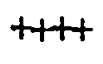 \\
\hline H+t & 0 & + & t+t & 0 & 0 & 0 & HH & 0 & + & 0 \\
\hline
\end{tabular}

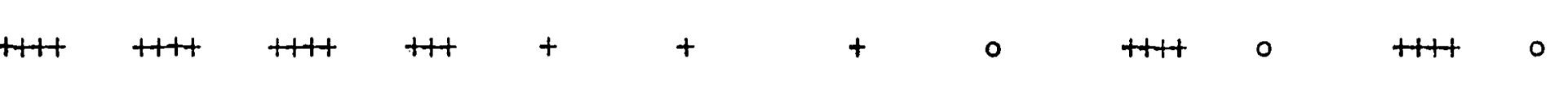

\begin{tabular}{|c|c|c|c|c|c|c|c|c|c|c|}
\hline$t+t$ & $t+t$ & $+t+$ & + & + & t+t+ & + & $t+t+$ & 0 & + & $\mathrm{HH}$ \\
\hline+ & + & $t+t$ & + & + & + & $+t+t$ & $+++t$ & $+H+H$ & $t$ & $\mathrm{HHH}$ \\
\hline
\end{tabular}

\begin{tabular}{|c|c|c|c|c|c|c|c|c|c|c|}
\hline 0 & $t+t$ & + & + & 0 & $\circ$ & 0 & + & 0 & 0 & $++t+$ \\
\hline 0 & $t+t+$ & + & + & 0 & 0 & $\circ$ & + & 0 & 0 & $\circ$ \\
\hline 0 & 0 & 0 & 0 & 0 & 0 & 0 & 0 & 0 & 0 & 0 \\
\hline t+t & $t+1+$ & $H+t$ & $+1+t$ & + & $H$ & HH & $t+t+$ & $+H+$ & $H$ & $t+t$ \\
\hline 0 & $+t+$ & $t+t+$ & $t+t+$ & + & + & $H+$ & $+H$ & $t+t+$ & $t+t$ & $+H$ \\
\hline
\end{tabular}


$1969 \mathrm{~b} \quad 1969 \mathrm{c} \quad 1969 \mathrm{~d} \quad 1970 \quad 1972 \quad$ [1970] [1973]

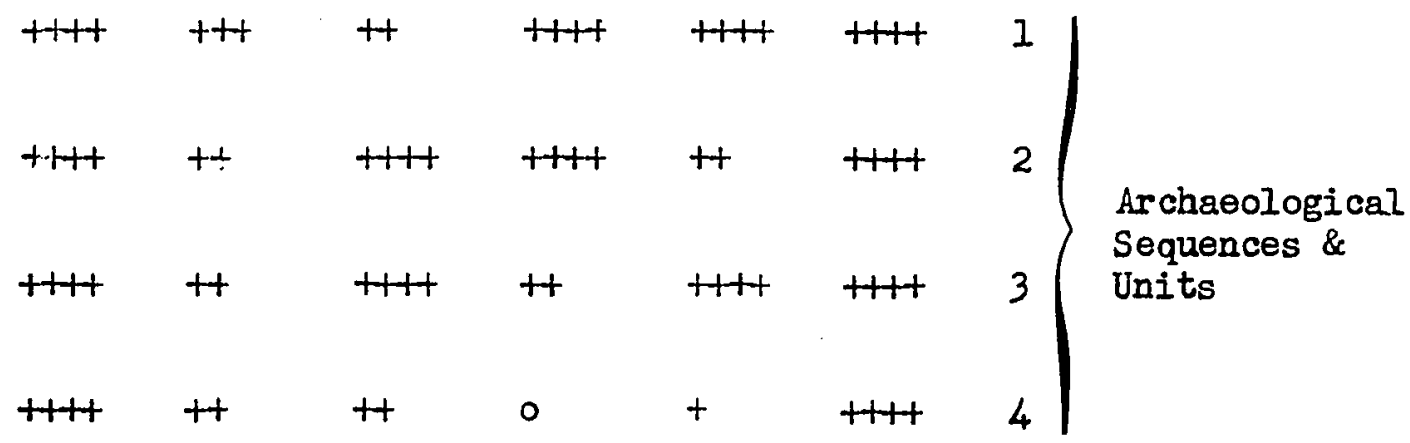

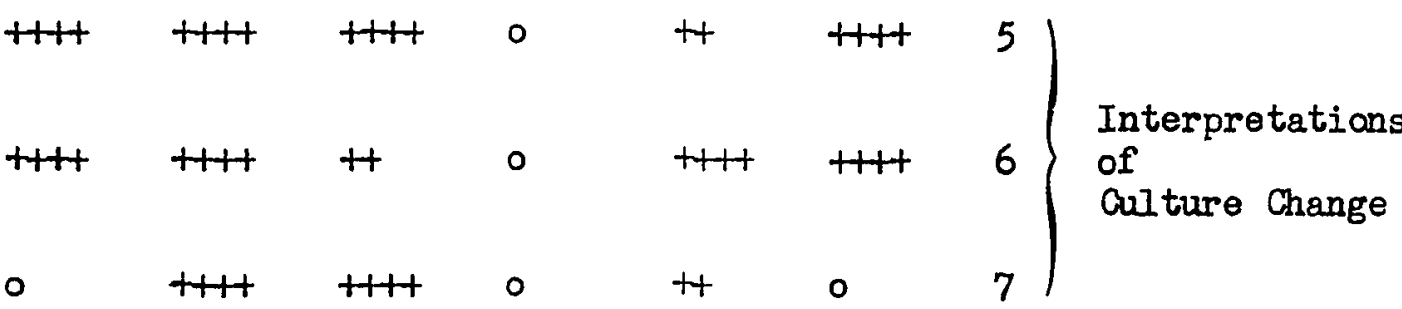

\begin{tabular}{|c|c|c|c|c|c|c|c|c|}
\hline 0 & + & H+t & 0 & $t+t+$ & + & 8. & & $\begin{array}{l}\text { Figure 15. } \\
\text { Relative empha }\end{array}$ \\
\hline$t+t$ & t+ & $H$ & $+t+$ & $t+t+$ & $H+H$ & 9 & $\begin{array}{l}\text { Other Types of } \\
\text { Evidence Used }\end{array}$ & Scale: 0 to + \\
\hline$+t+$ & t+ & t+ & $t+t+$ & H+t & H & 10 & & \\
\hline t+t & H+t & + & 0 & 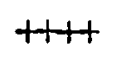 & $\circ$ & 11 & & \\
\hline
\end{tabular}

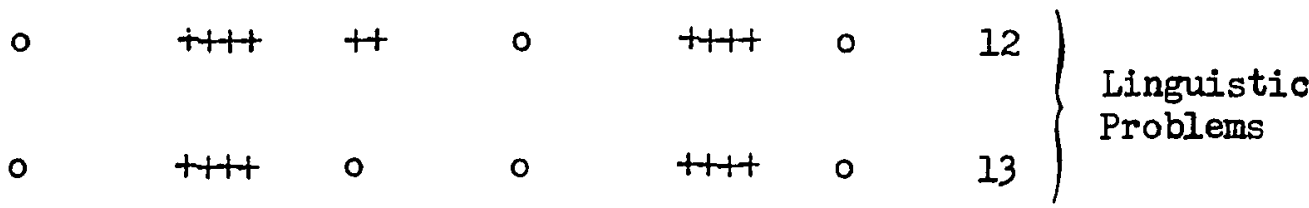

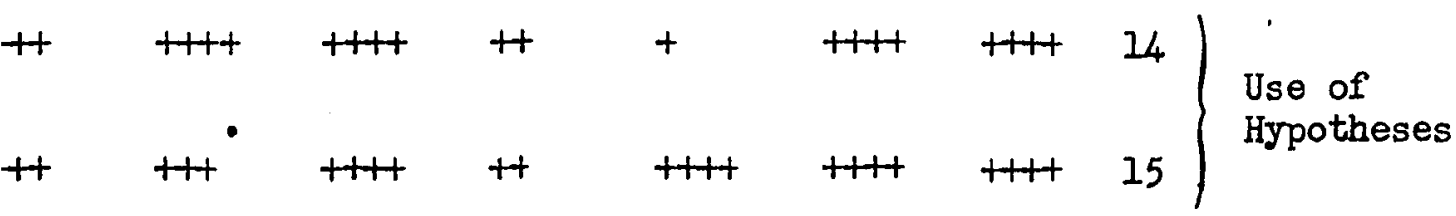


